LBL- $-28618-2 / 3$

DE9 0013808

\title{
A DATABASE FOR THE GEYSERS GEOTHERMAL FIELD
}

\section{Volume II}

\section{Appendix A: Steam Flowrates and Cumulative Mass Flows}

\author{
Gudmundur S. Bodvarsson, B. Lea Cox, Peter Fuller, Mark Ripperda, \\ Helga Tulinius, Paul A. Witherspoon, Norman Goldstein, \\ Steve Flexser, Karsten Pruess and Alfred Truesdell* \\ Earth Sciences Division \\ Lawrence Berkeley Laboratory \\ University of California \\ Berkeley, California 94720 \\ *U. S. Geological Survey \\ 345 Middlefield Road \\ Menlo Park, California 94025
}

September 1989

\section{MASTER}

This work was supported by the California State Lands Commission and by the U.S. Department of Energy under Contract No. DE-AC03-76SF00098. 


\section{DISCLAIMER}

This report was prepared as an account of work sponsored by an agency of the United States Government. Neither the United States Government nor any agency Thereof, nor any of their employees, makes any warranty, express or implied, or assumes any legal liability or responsibility for the accuracy, completeness, or usefulness of any information, apparatus, product, or process disclosed, or represents that its use would not infringe privately owned rights. Reference herein to any specific commercial product, process, or service by trade name, trademark, manufacturer, or otherwise does not necessarily constitute or imply its endorsement, recommendation, or favoring by the United States Government or any agency thereof. The views and opinions of authors expressed herein do not necessarily state or reflect those of the United States Government or any agency thereof. 


\section{DISCLAIMER}

Portions of this document may be illegible in electronic image products. Images are produced from the best available original document. 


\section{APPENDIX A}

\section{Steam Flowrates and}

Cumulative Mass Flows 

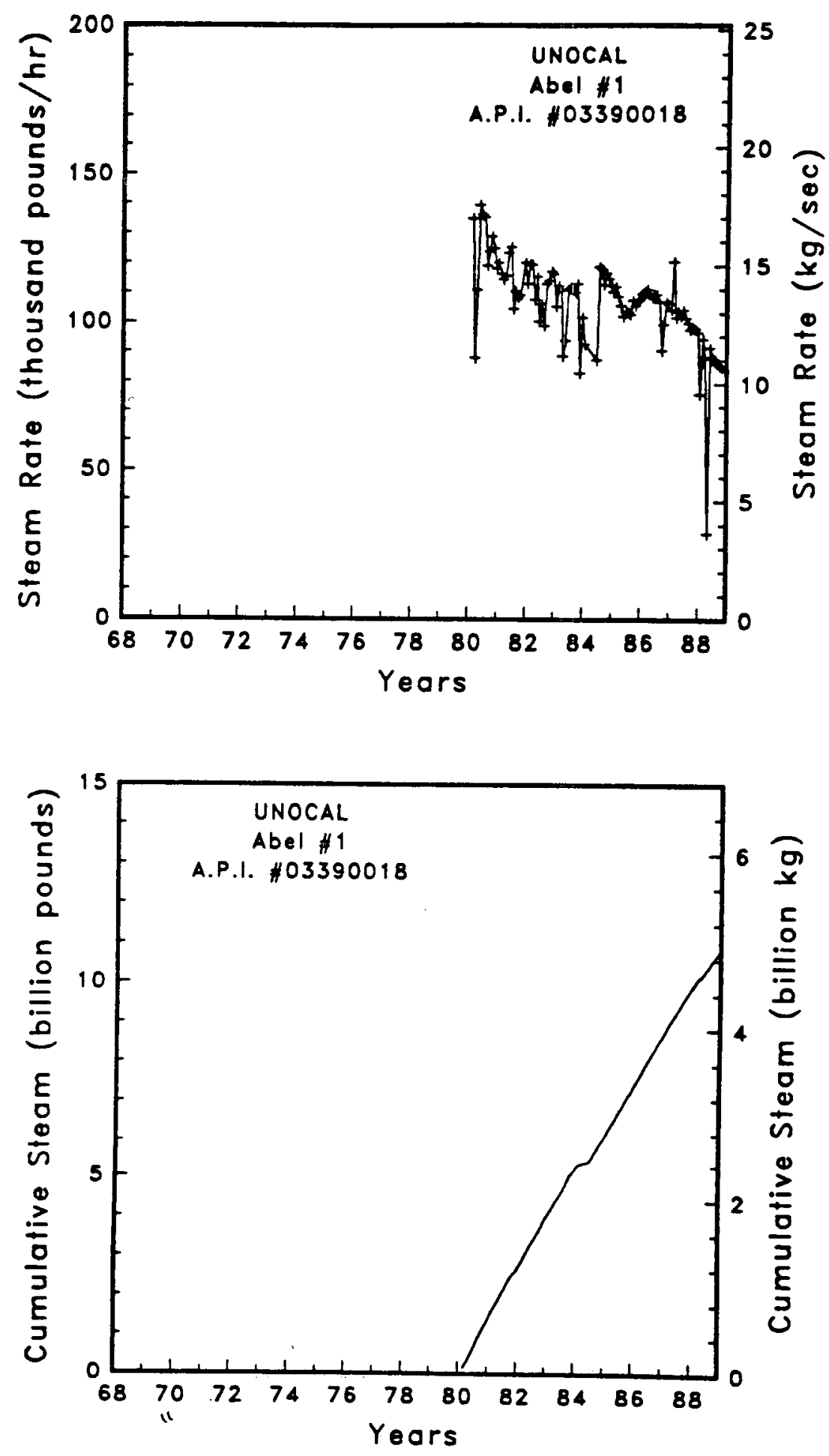

Figure A-1 Steam rate and cumulative mass flow for 

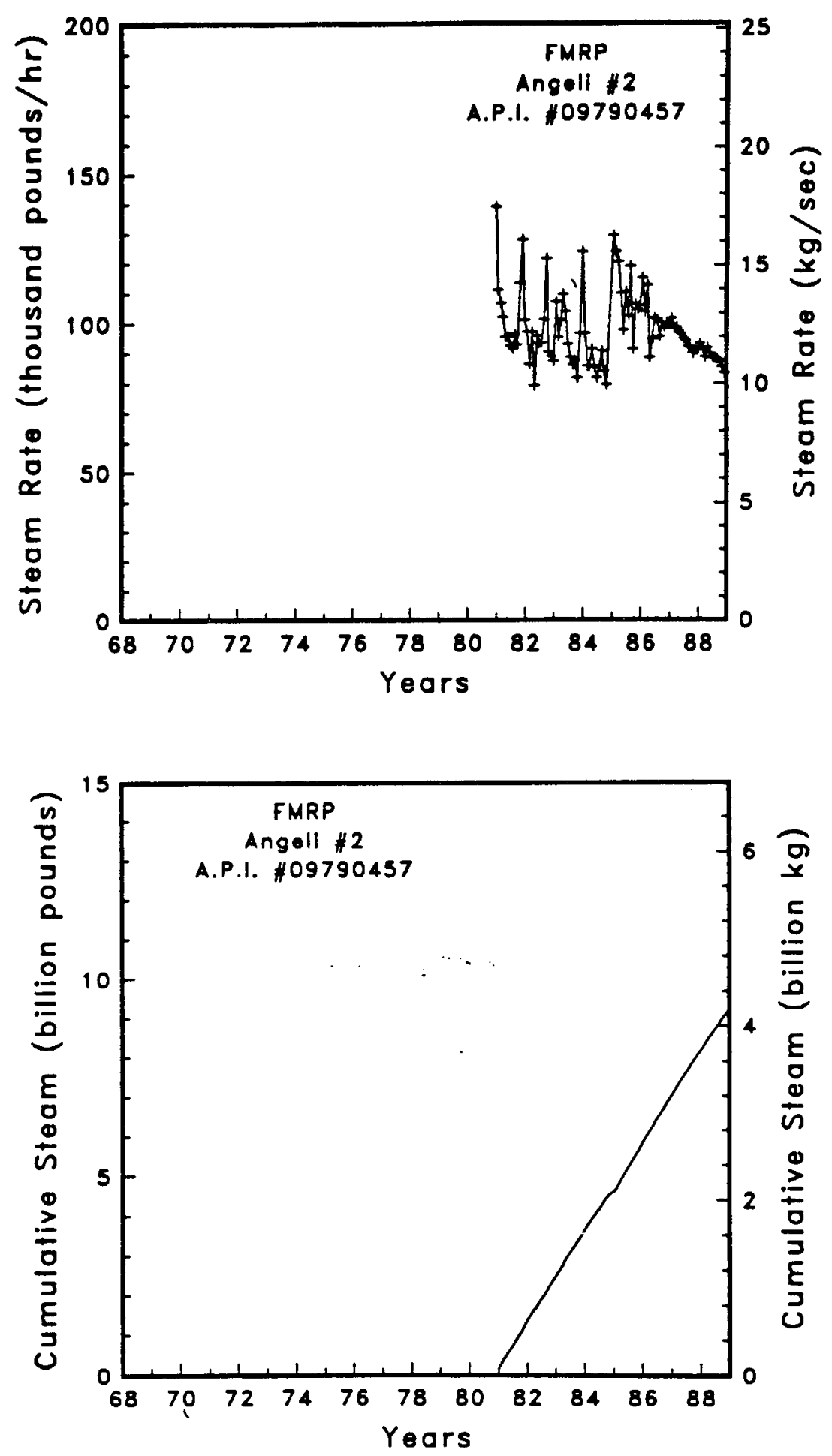

Figure A-2

Steam rate and cumulative mass flow for well Angeli \#2 

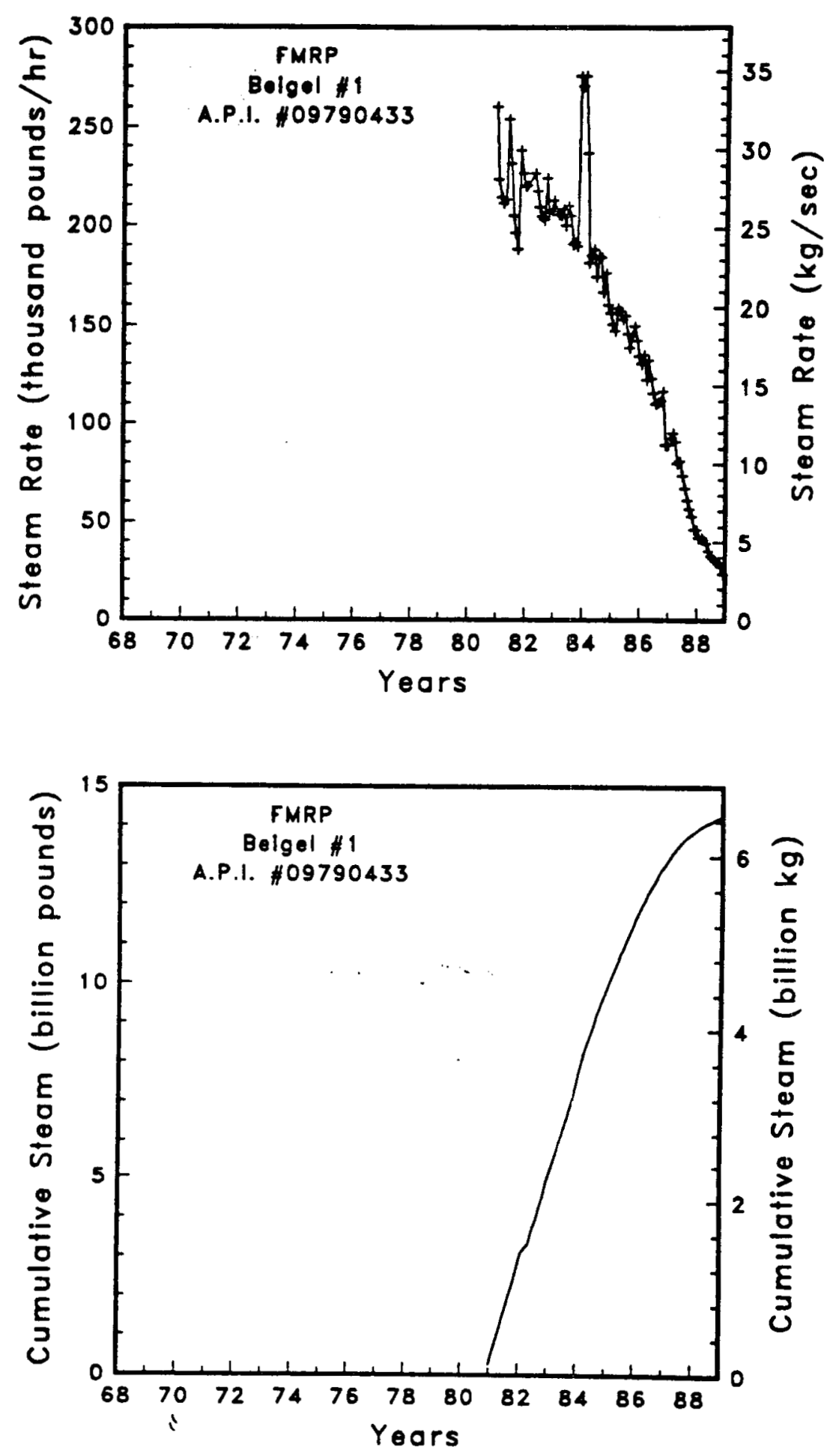

Figure A-3

Steam rate and cumulative mass flow for well Beigel \#1 

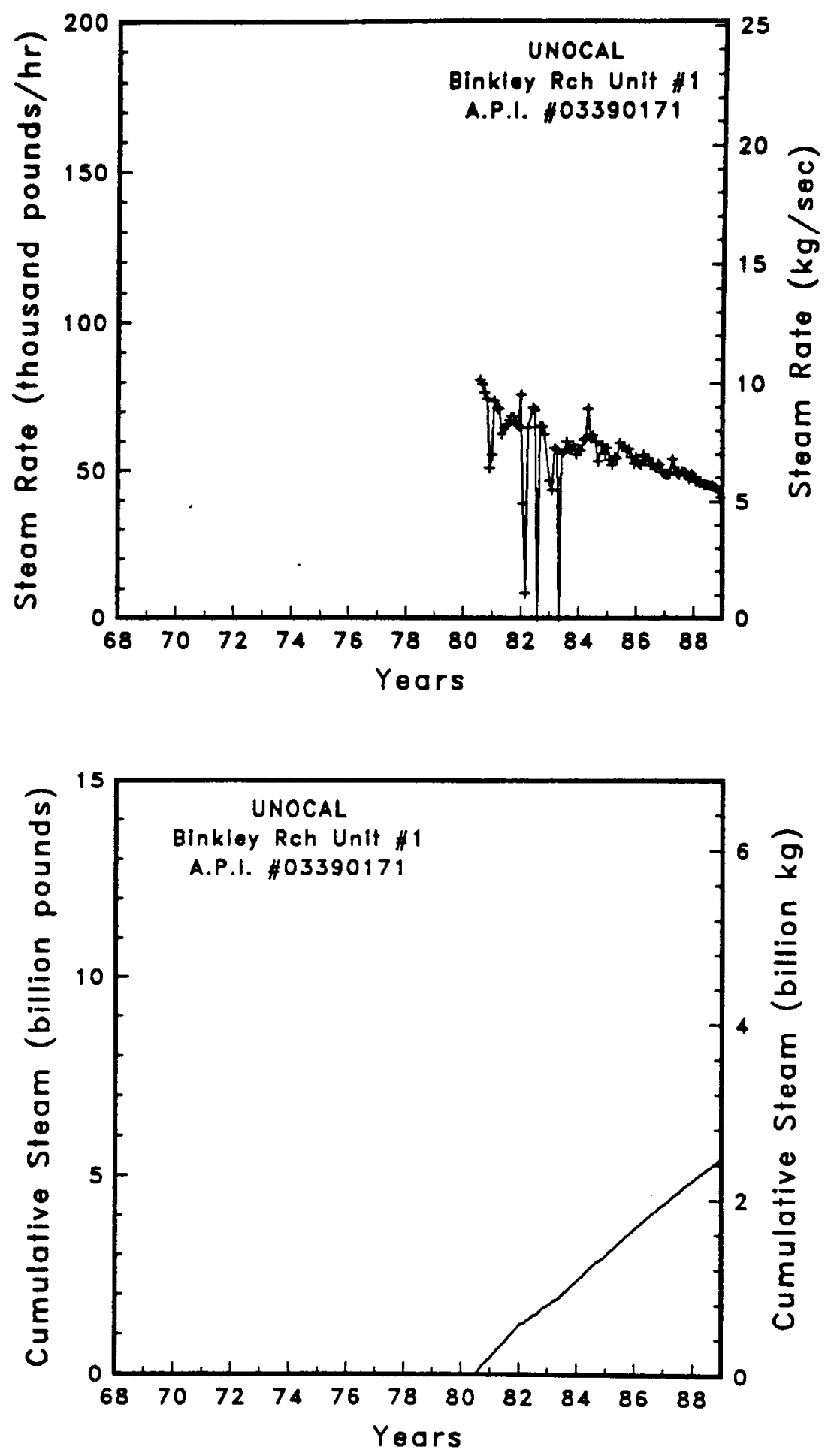

Figure A-4

Steam rate and cumulative moss flow for well Binkley Rch Unit \#1 

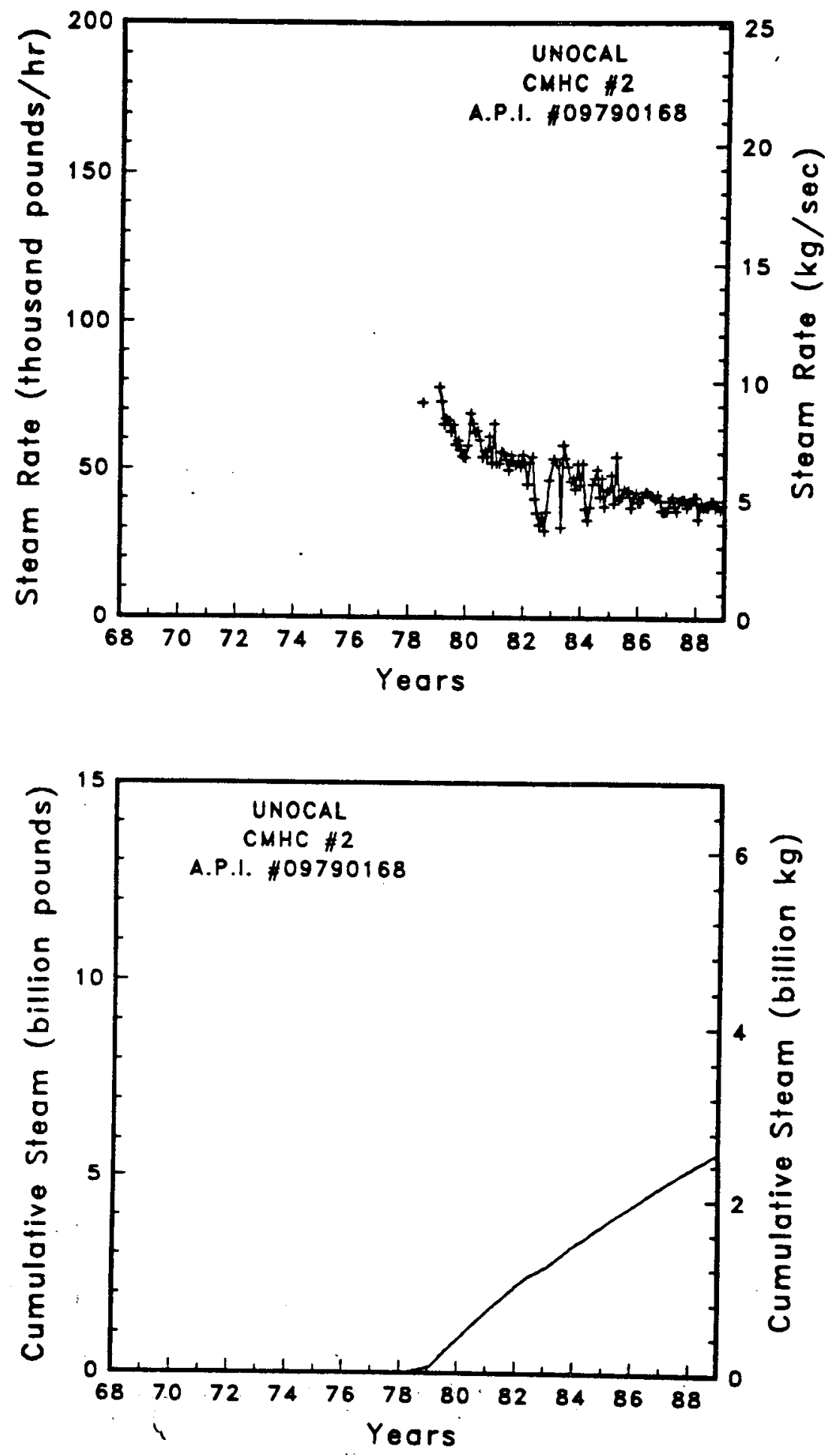

Figure A-5

Steom rate and cumulative mass flow for well CMHC \#2 

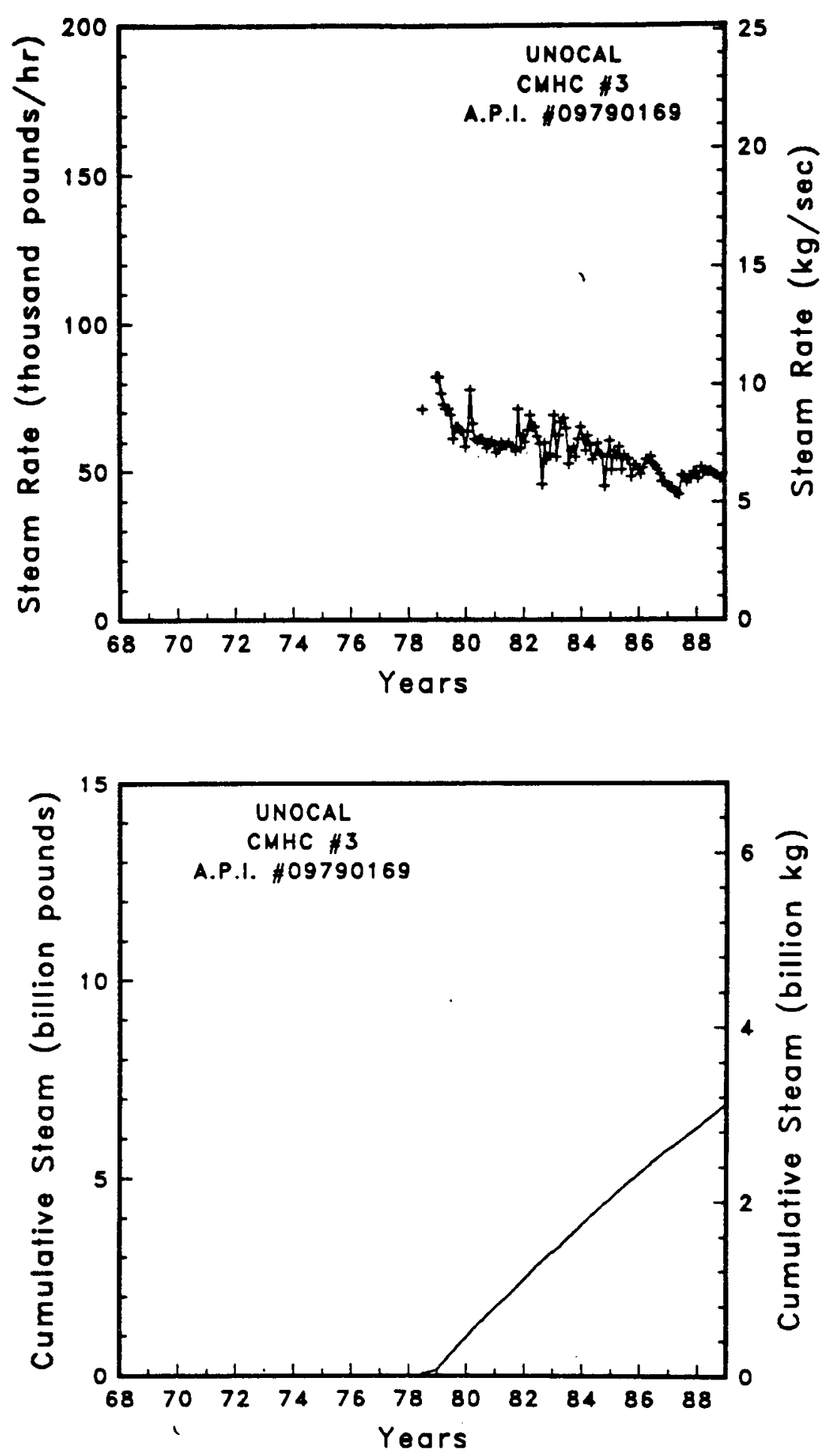

Figure A-6 Steam rate and cumulative mass flow for well CMHC \#3 

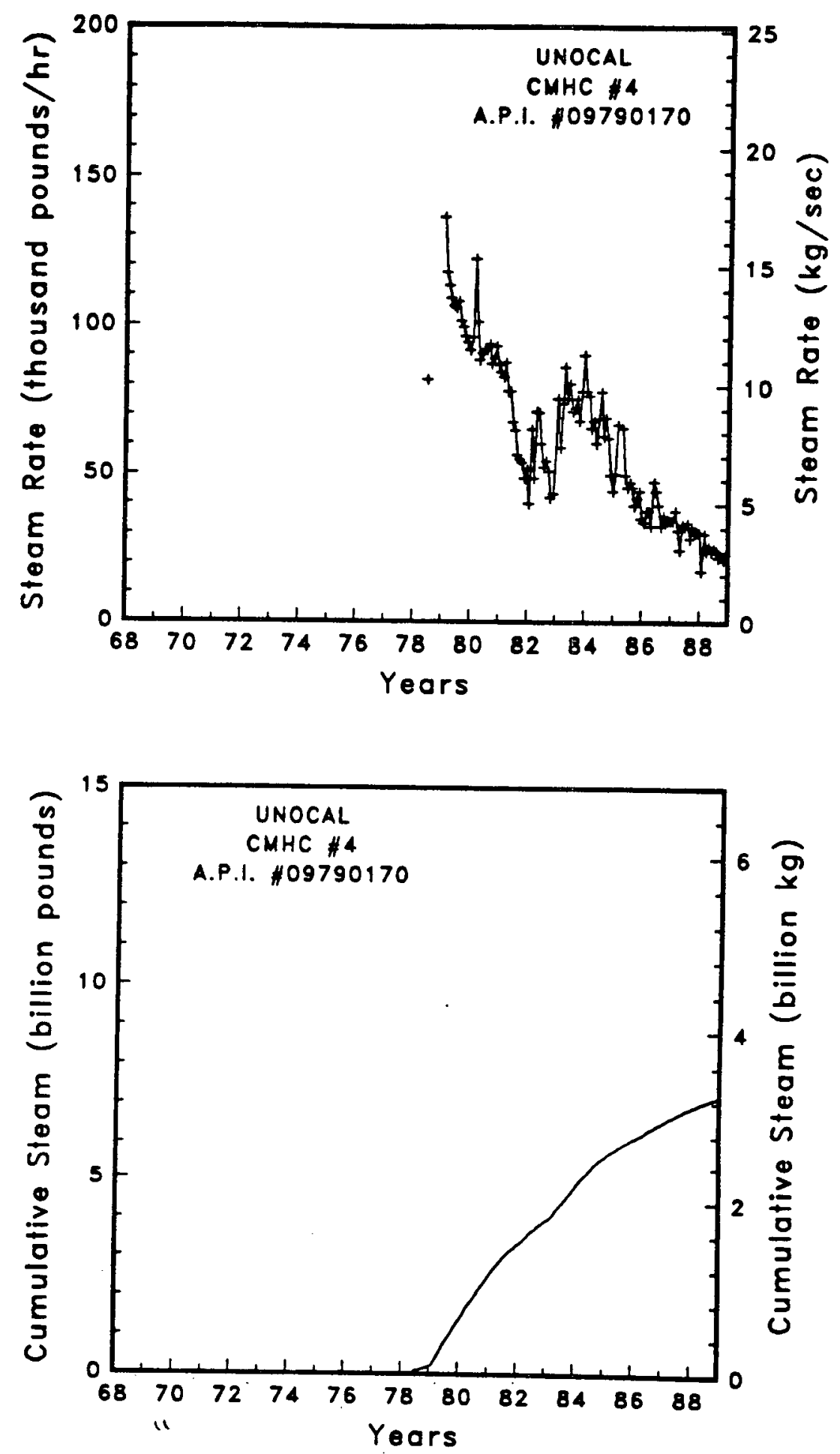

Figure A-7

Steam rate and cumulative mass flow for well CMHC \#4 

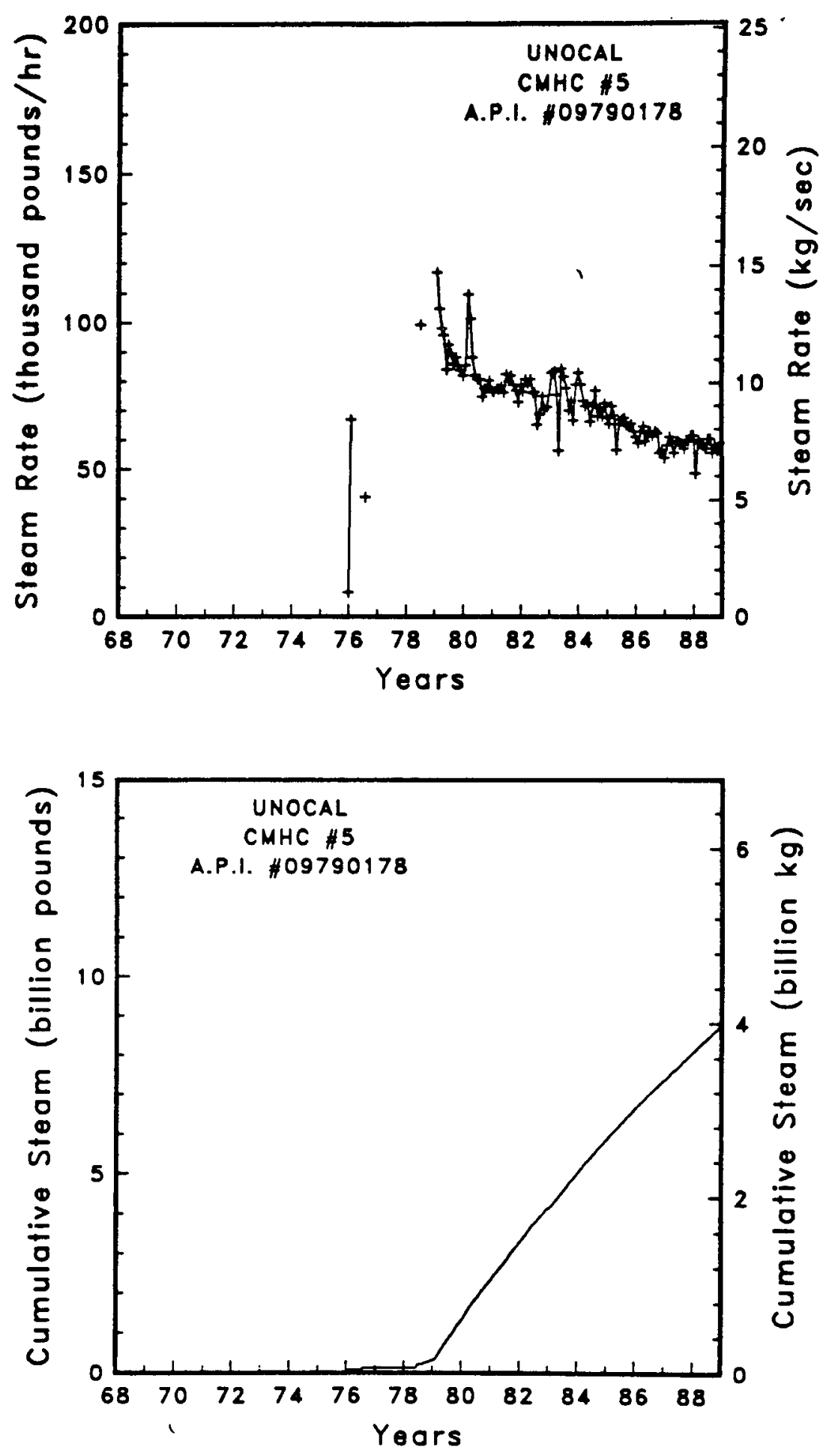

Figure A-8

Steam rate and cumulative mass flow for well CMHC \#5 

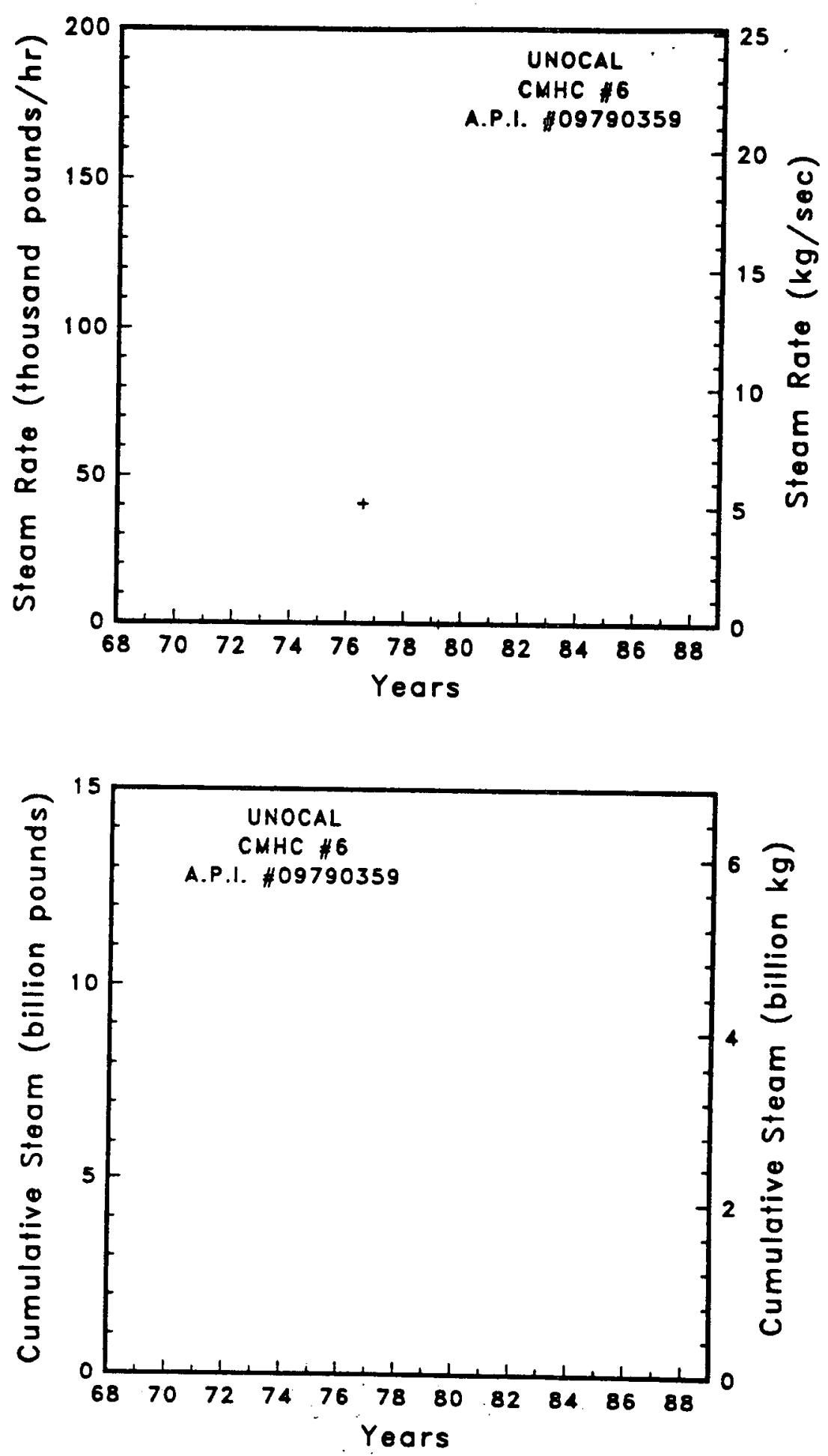

Figure A-9

Steam rate and cumulative mass flow for well CMHC \#6 

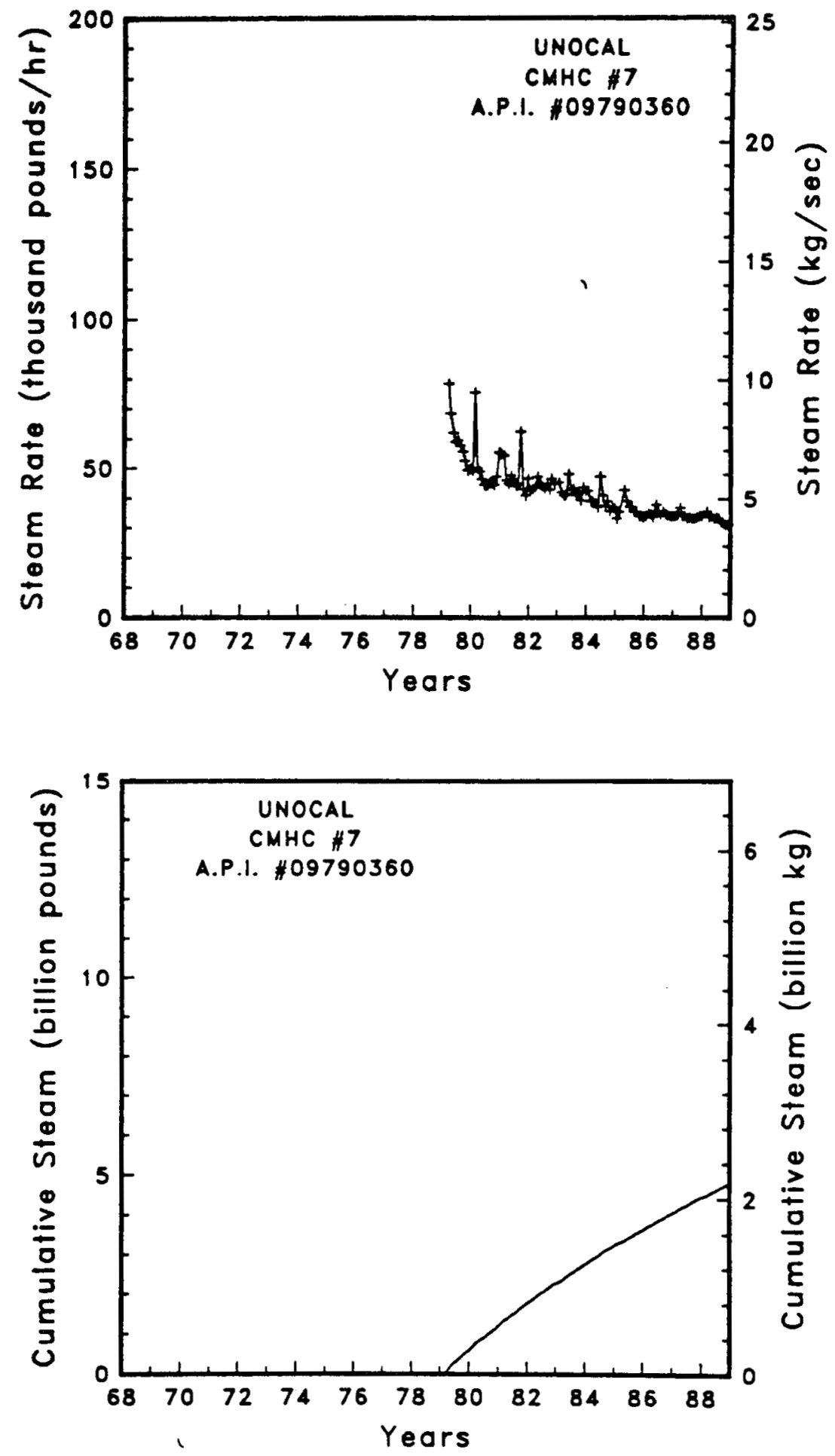

Figure A-10

Steam rate and cumulative mass flow for well CMHC \#7 

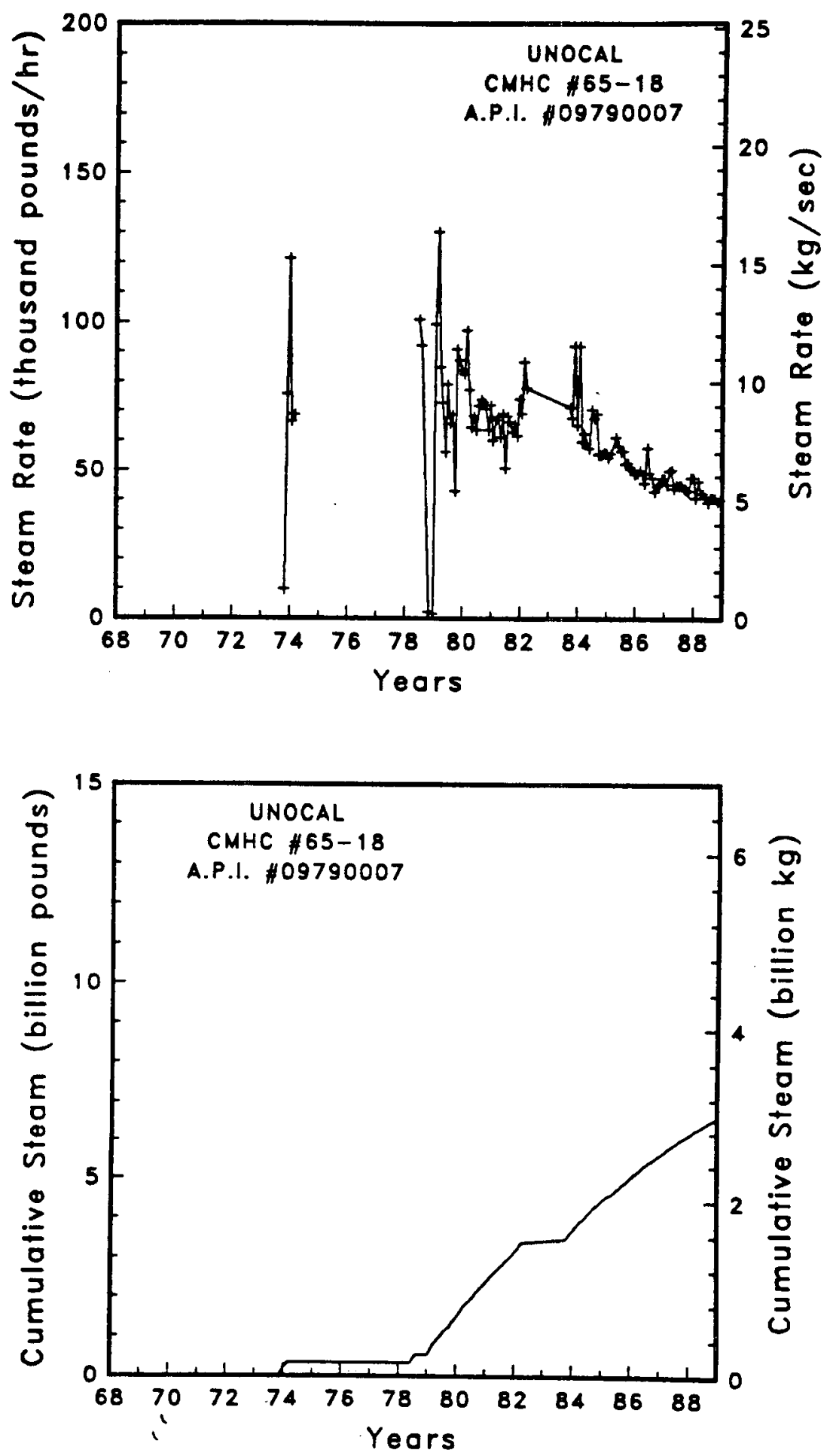

Figure A-11 Steam rate and cumulative mass flow for well CMHC \#65-18 

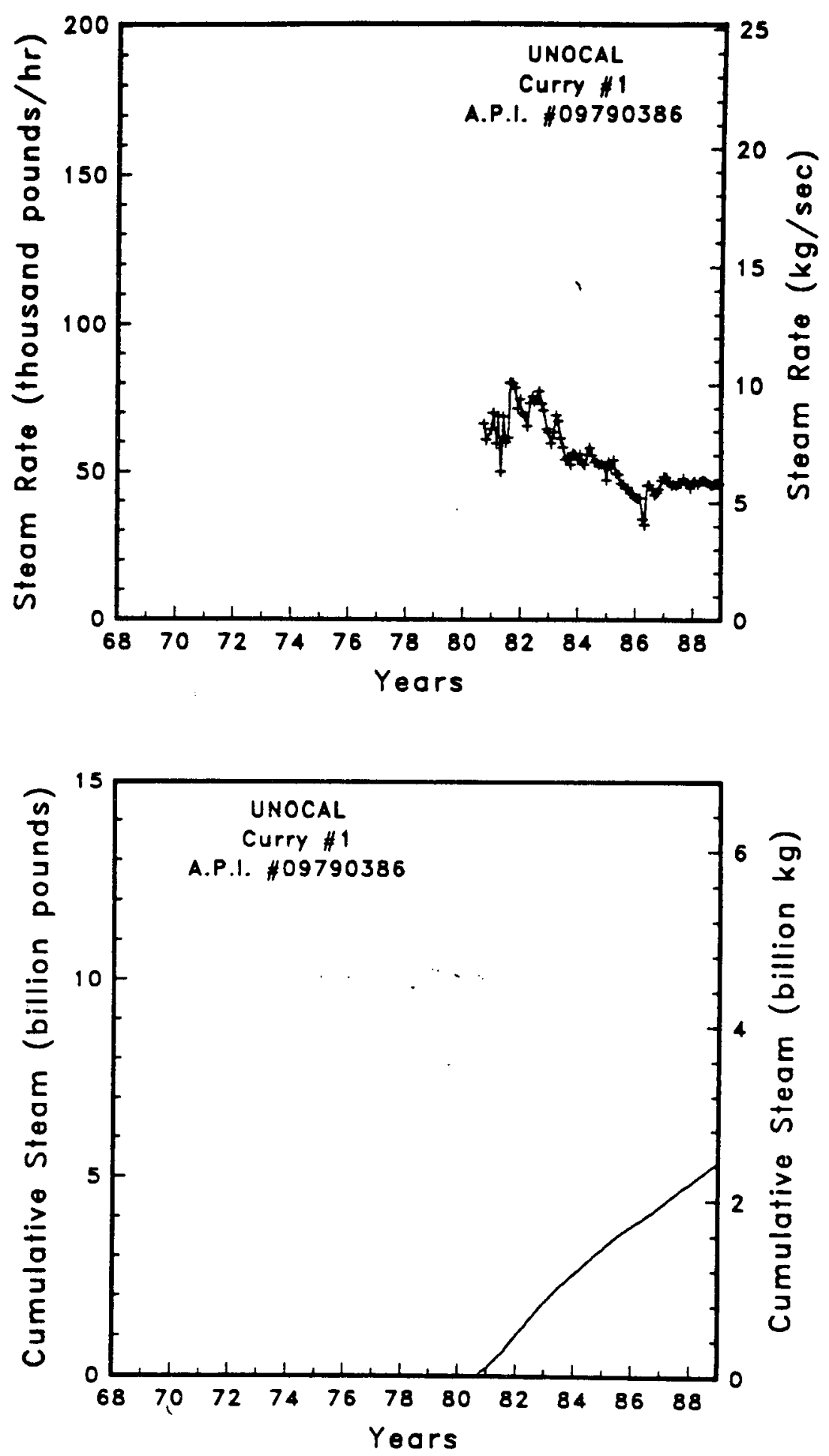

Figure A-12

Steam rate and cumulative mass flow for well Curry \#1 

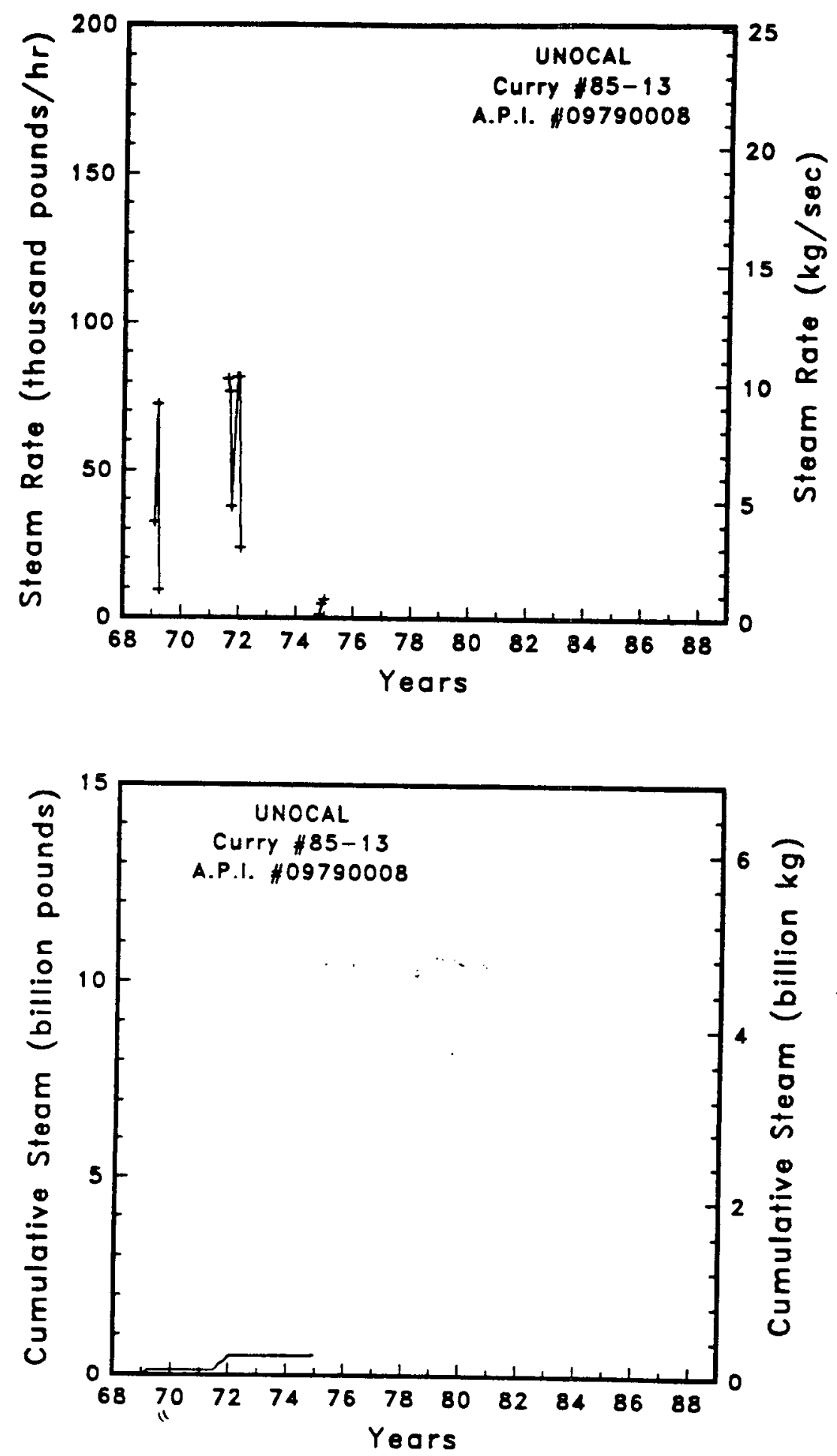

IFigure A-13 Steam rote and cumulative mass flow for well Curry \#85-13 

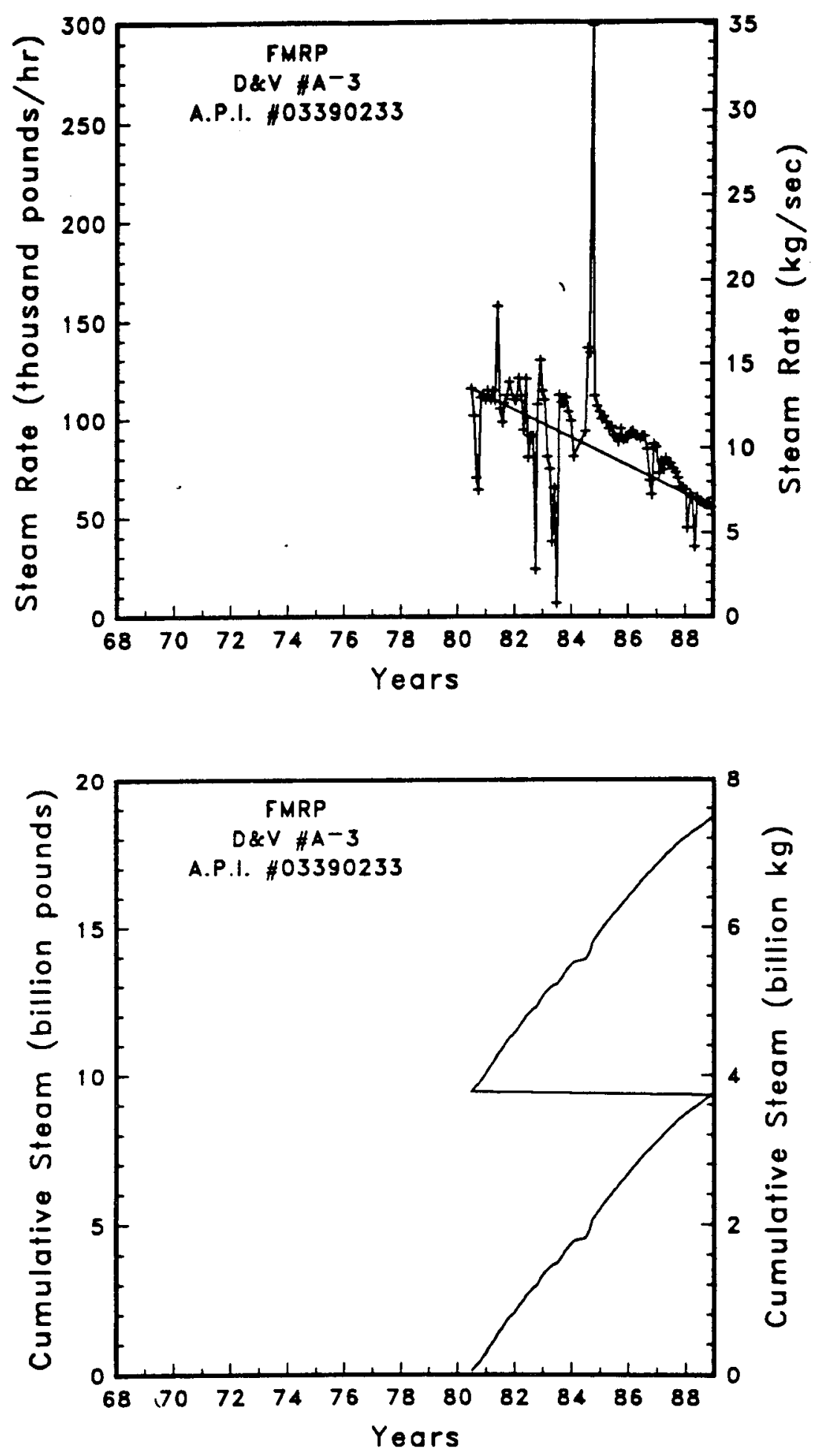

Figure A-14

Steam rate and cumulative mass flow for Well D\&V \#A-3 

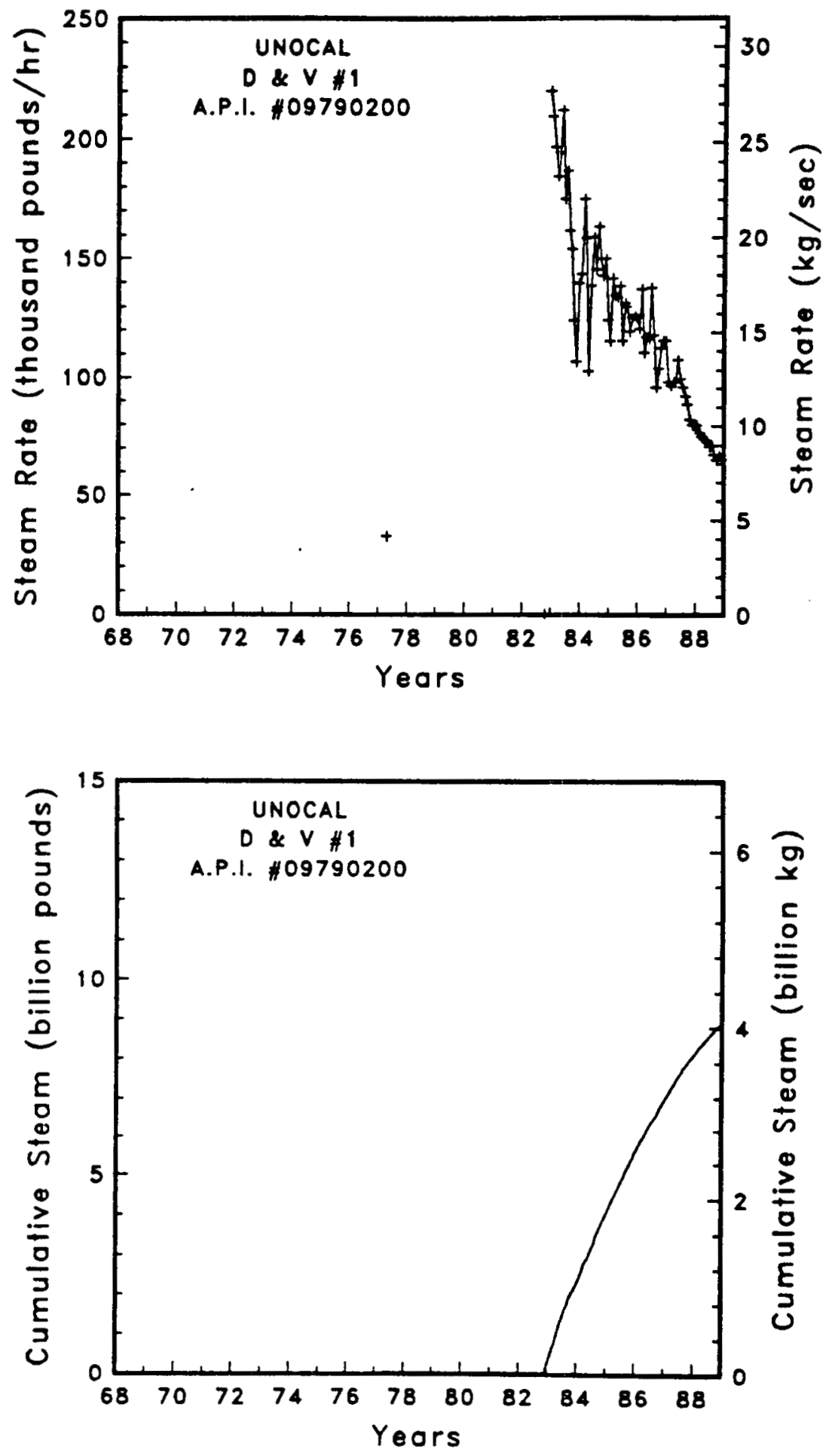

Figure A-15 Steam rate and cumulative mass flow for well $D$ \& $V \# 1$ 

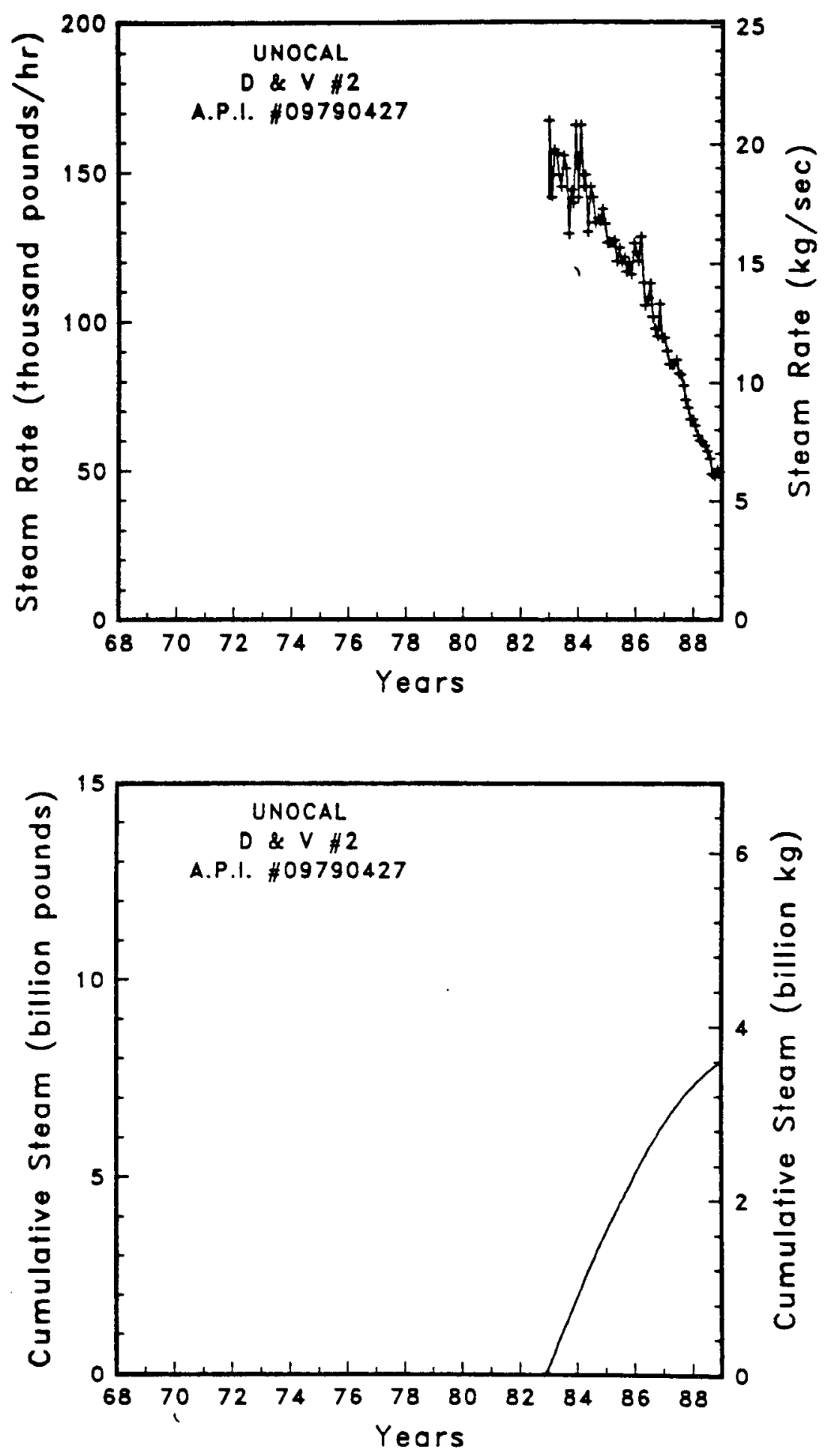

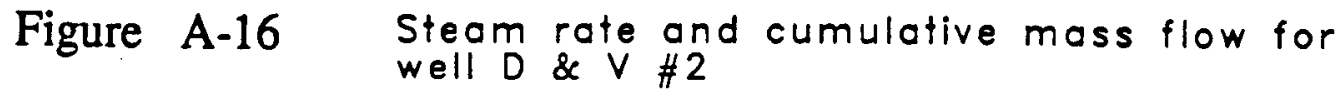



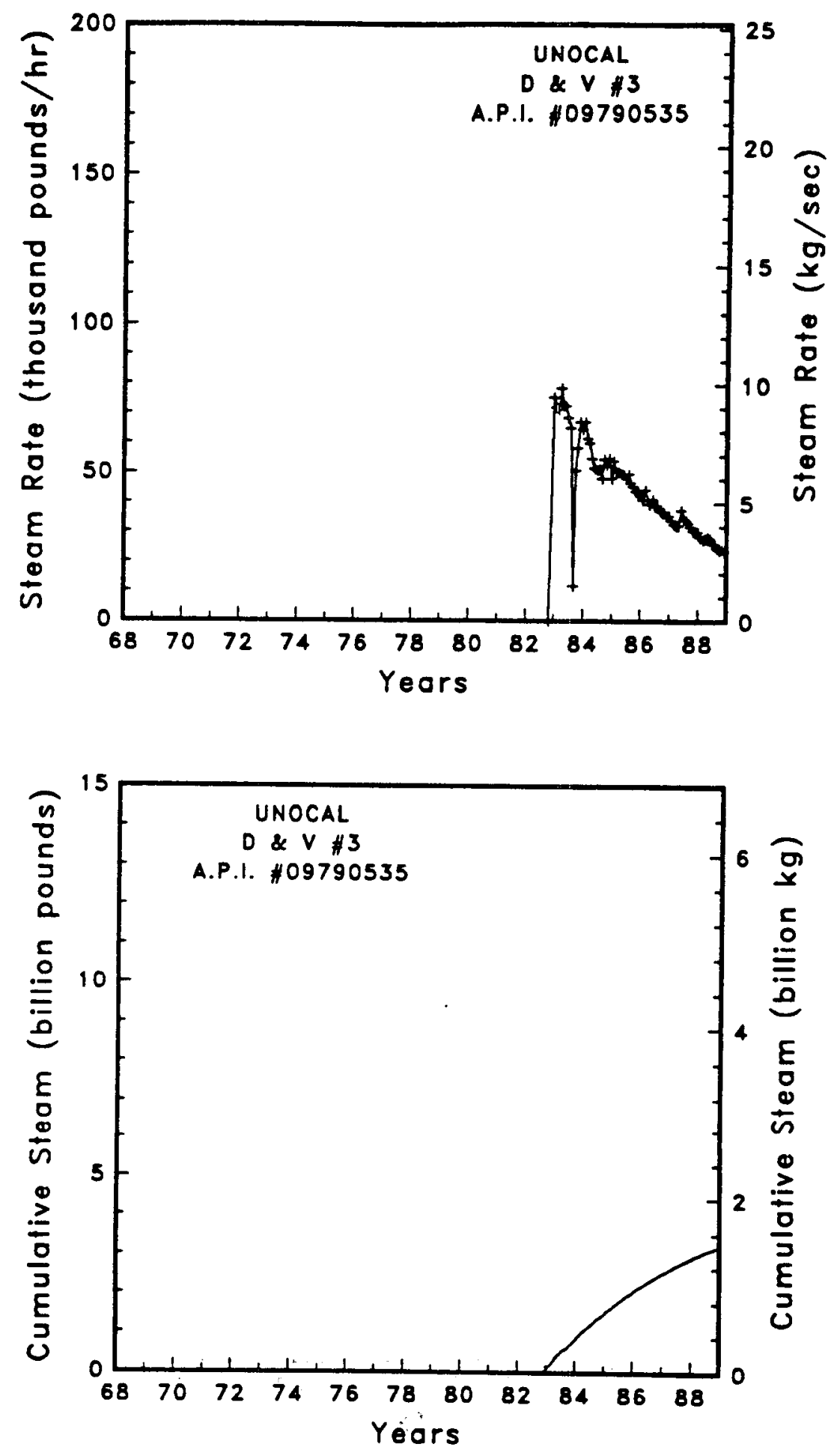

Figure A-17 Steam rate ond cumulative mass flow for
well $D$ \& $V \# 3$ 

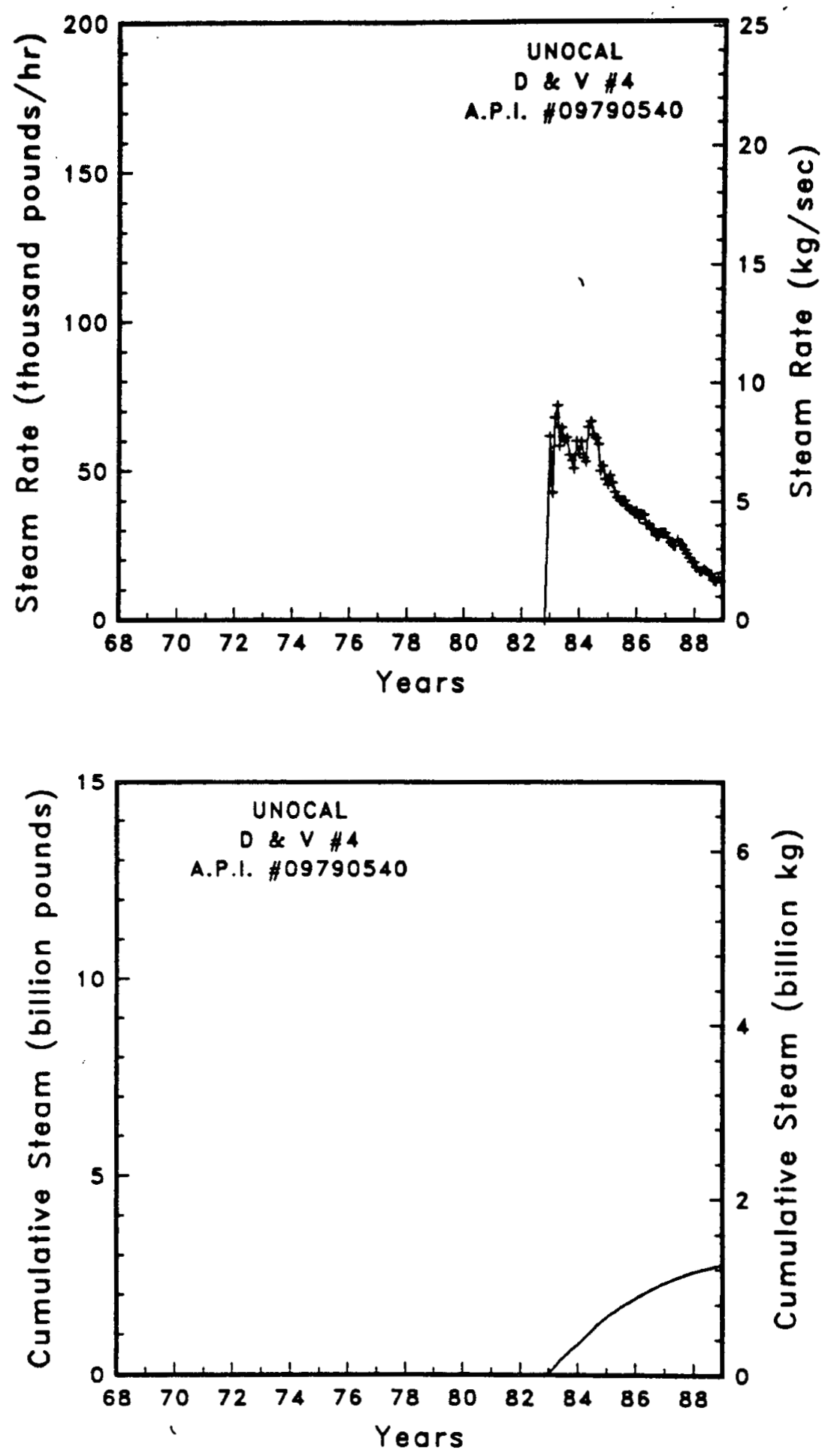

Figure A-18

Steam rate and cumulative mass flow for well $D$ \& $V$ \# 4 

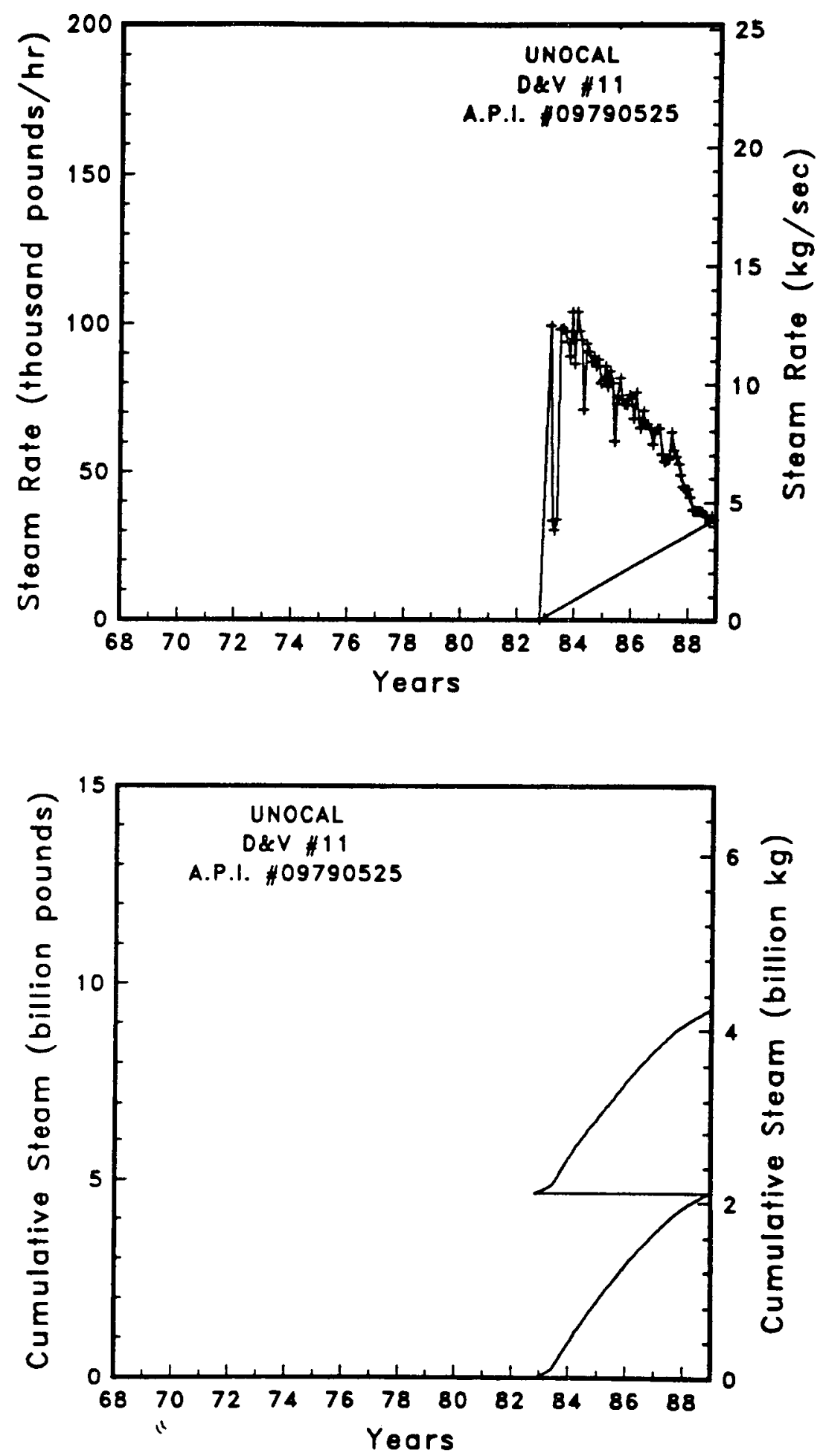

Figure A-19 Steam rate and cumulative moss flow for well D\&V \#11 

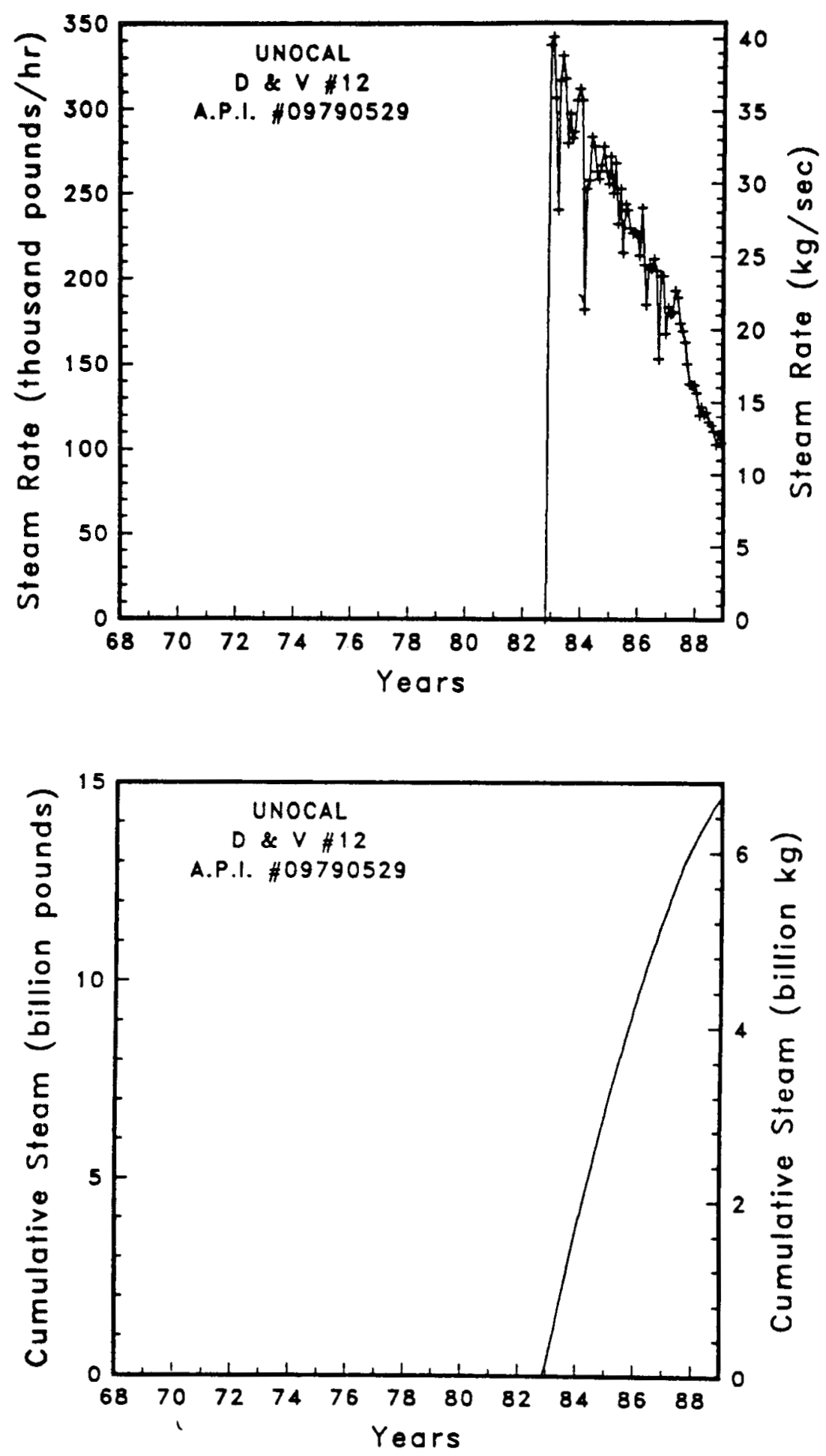

Figure A-20

Steam rate and cumulative mass flow for well $D$ \& $V \# 12$ 

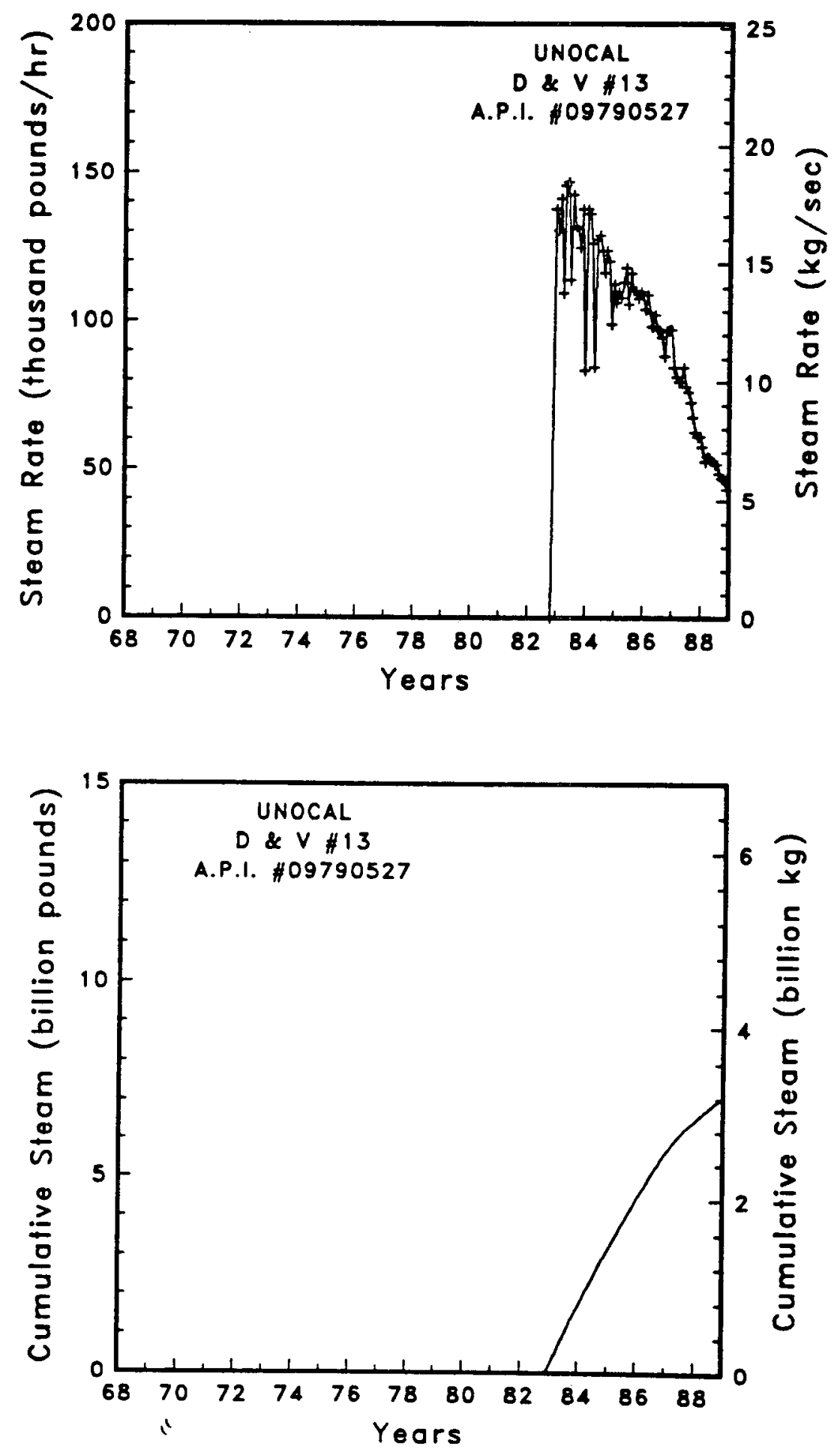

Figure A-21 Steam rate and cumulative mass flow for
well $D$ \& $V 13$ 

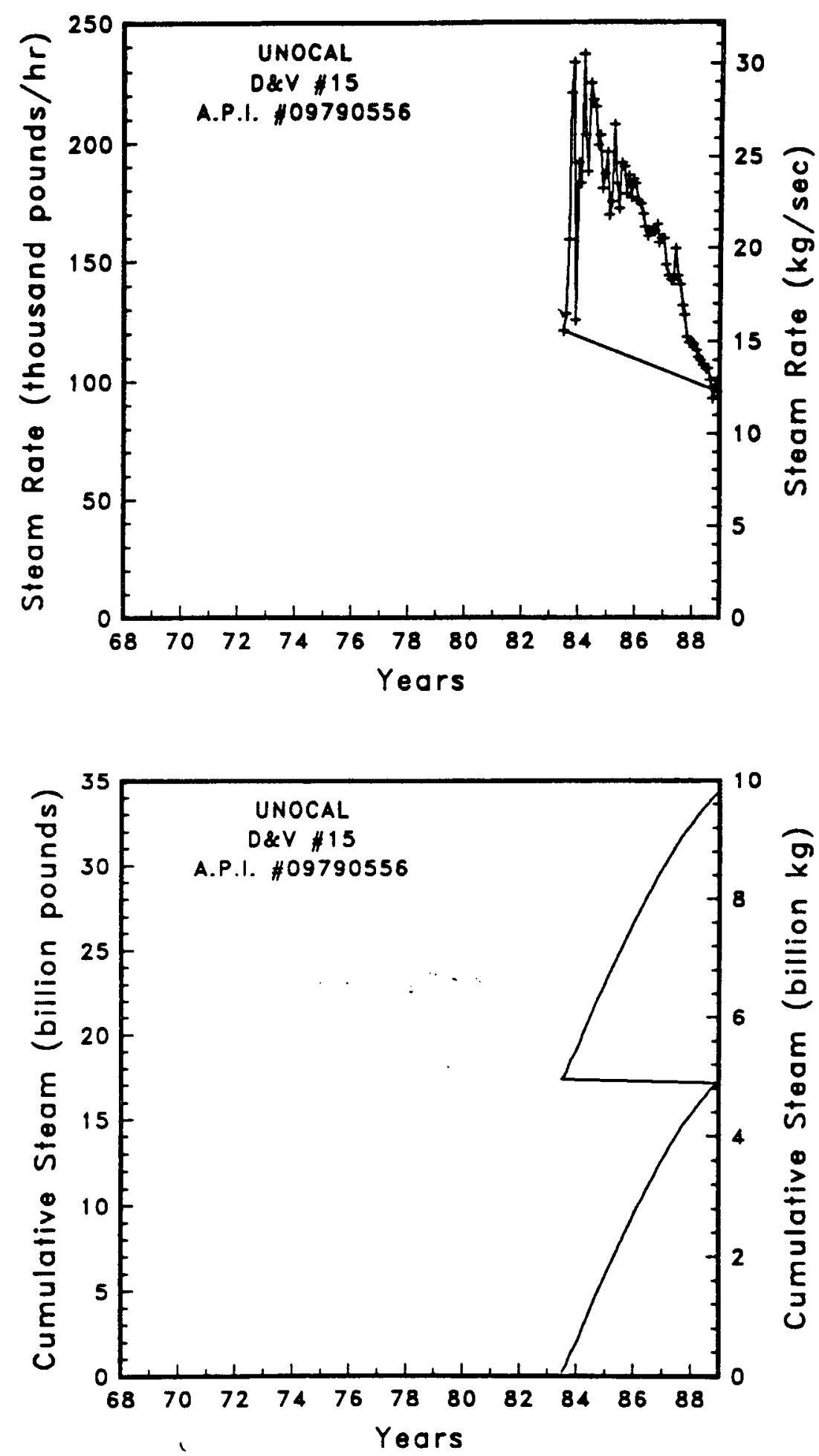

Figure A-22

Steam rate and cumulative mass flow for well D\&V \#15 

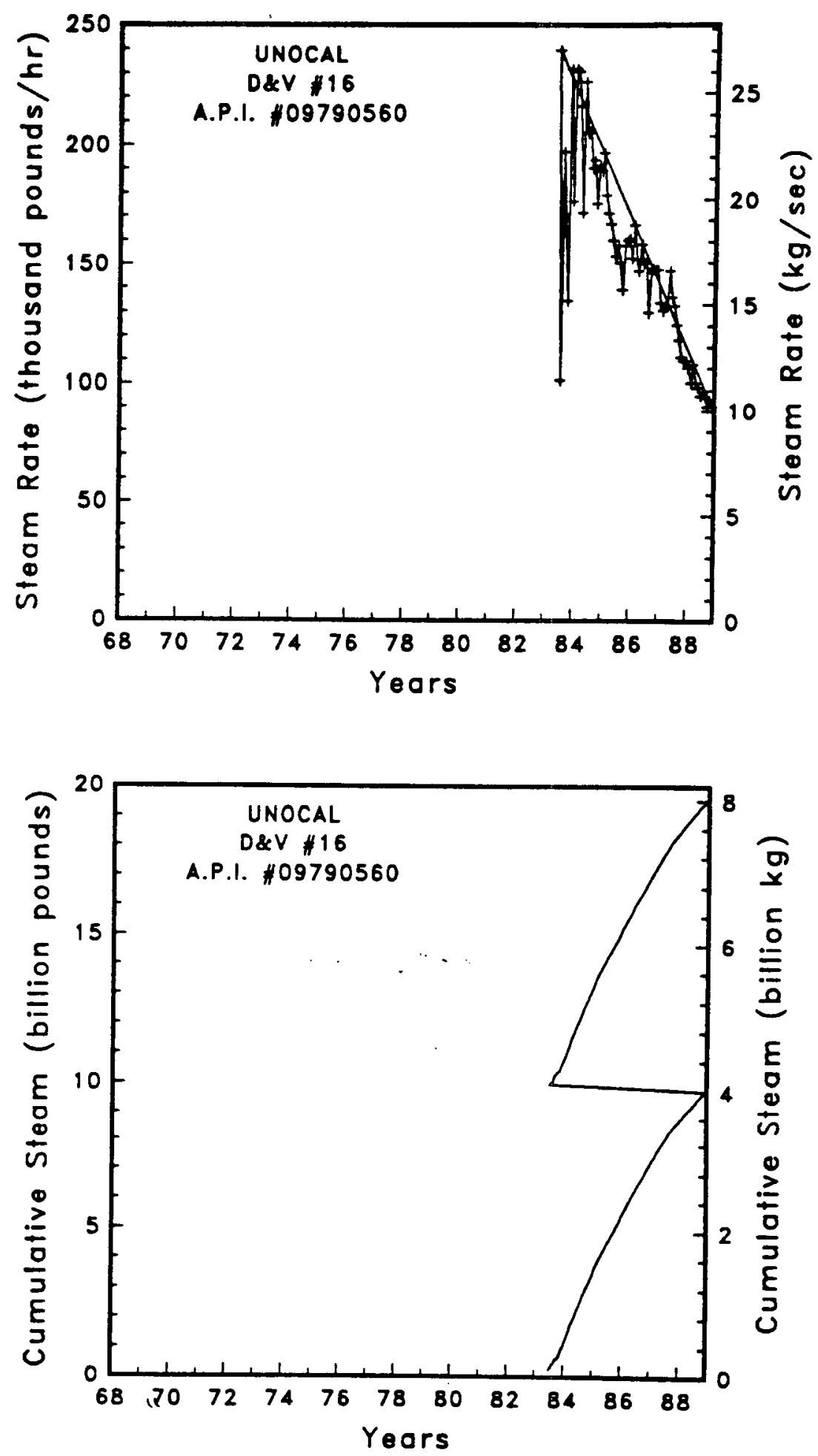

Figure A-23 Steam rate and cumulative moss flow for
well D\&V \#16 

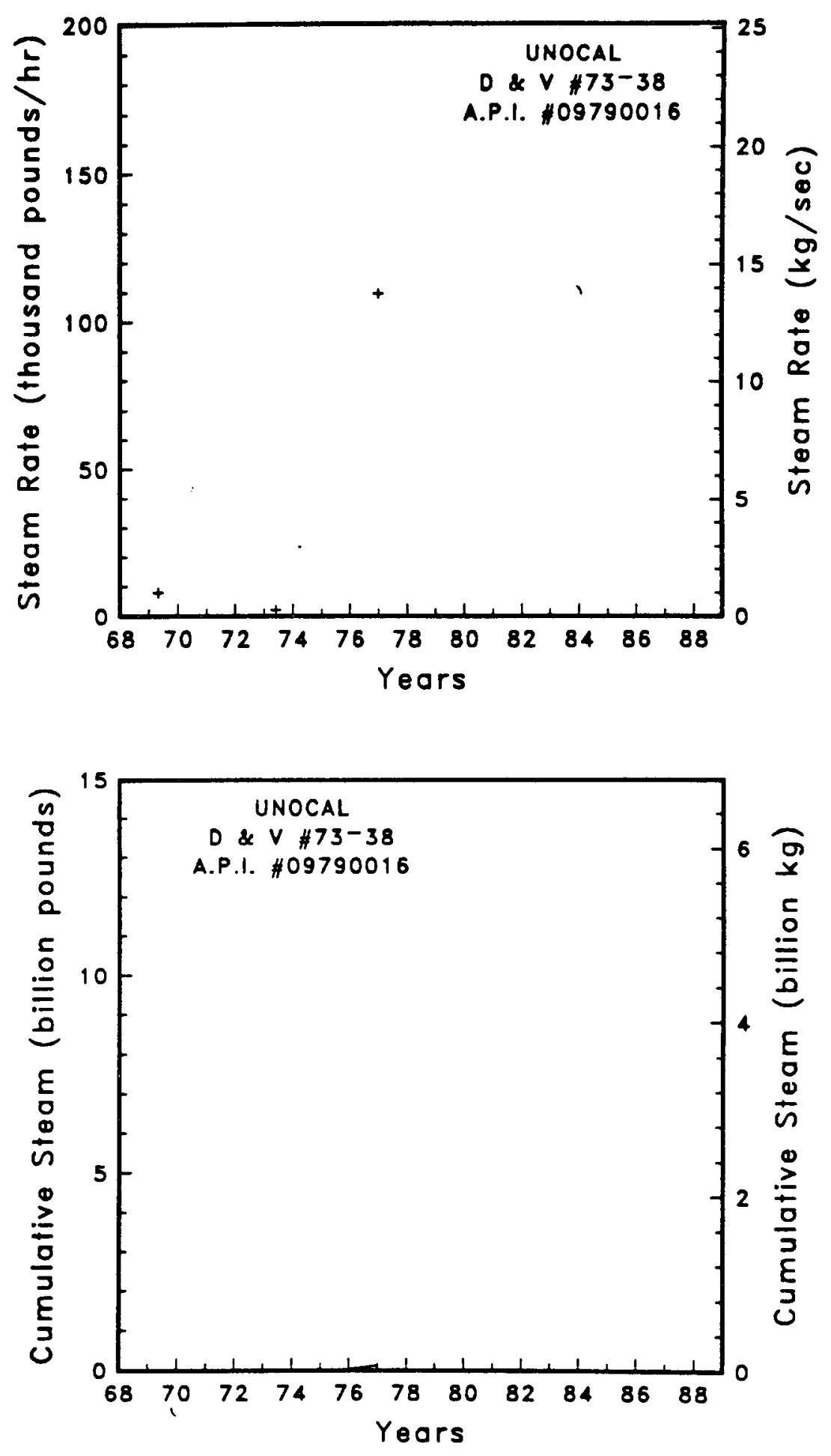

Figure A-24'

Steam rate and cumulative mass flow for well $D$ \& $V$ \#73-38 

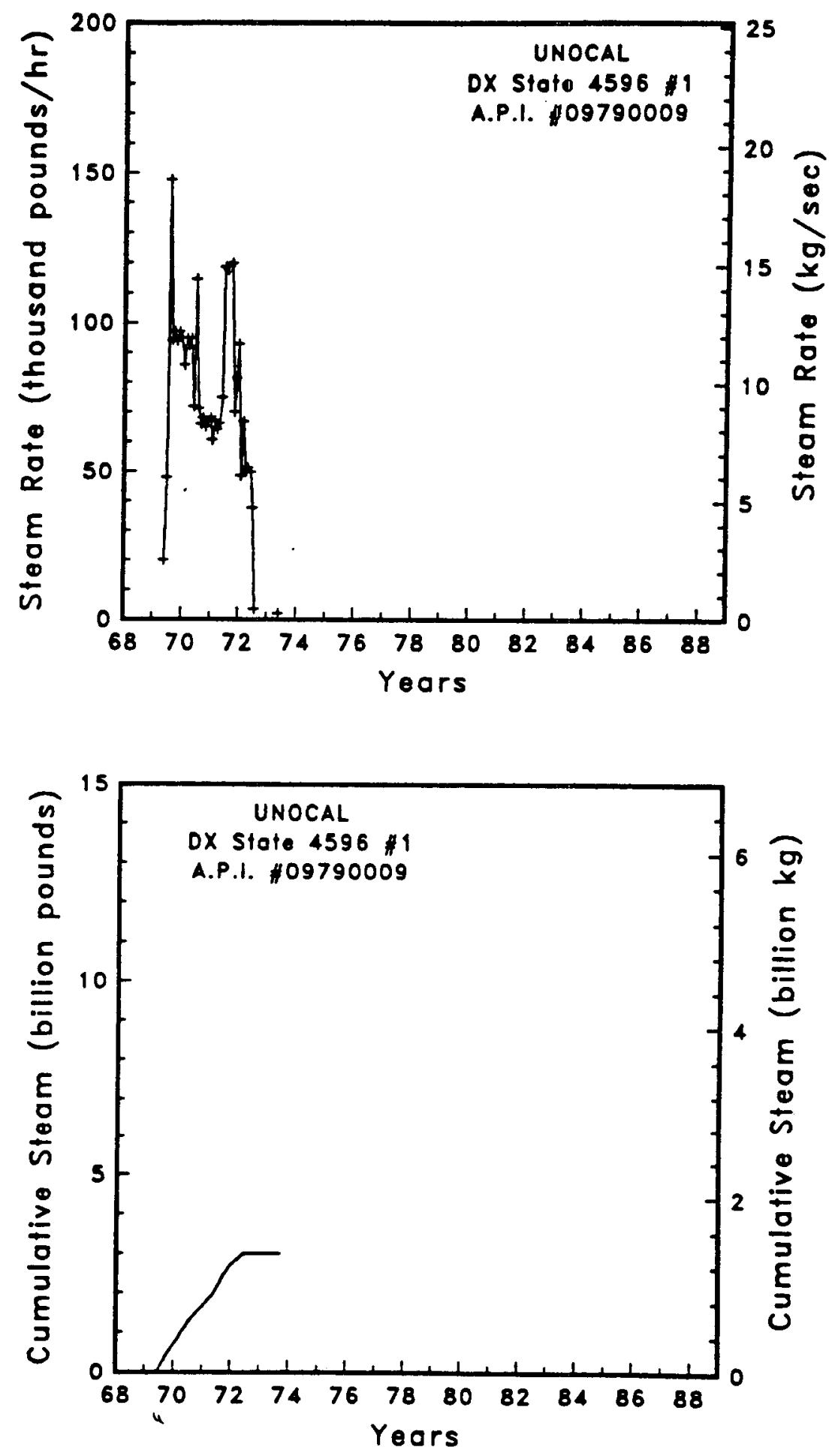

Figure A-25 Steam rate and cumulative mass flow for well DX State 4596 \#1 

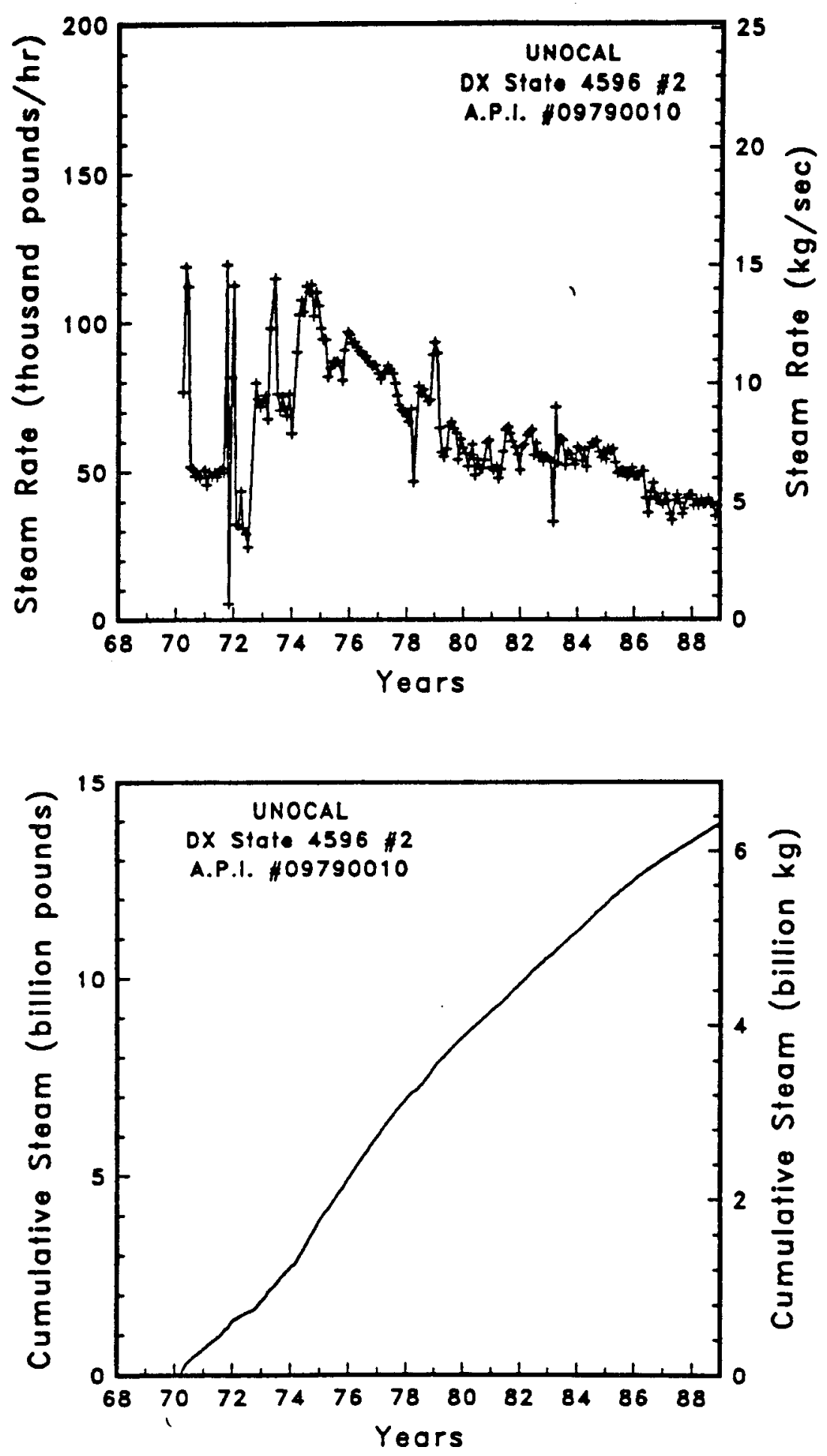

Figure A-26 Steam rate and cumulative mass flow for well DX State 4596 \#2 

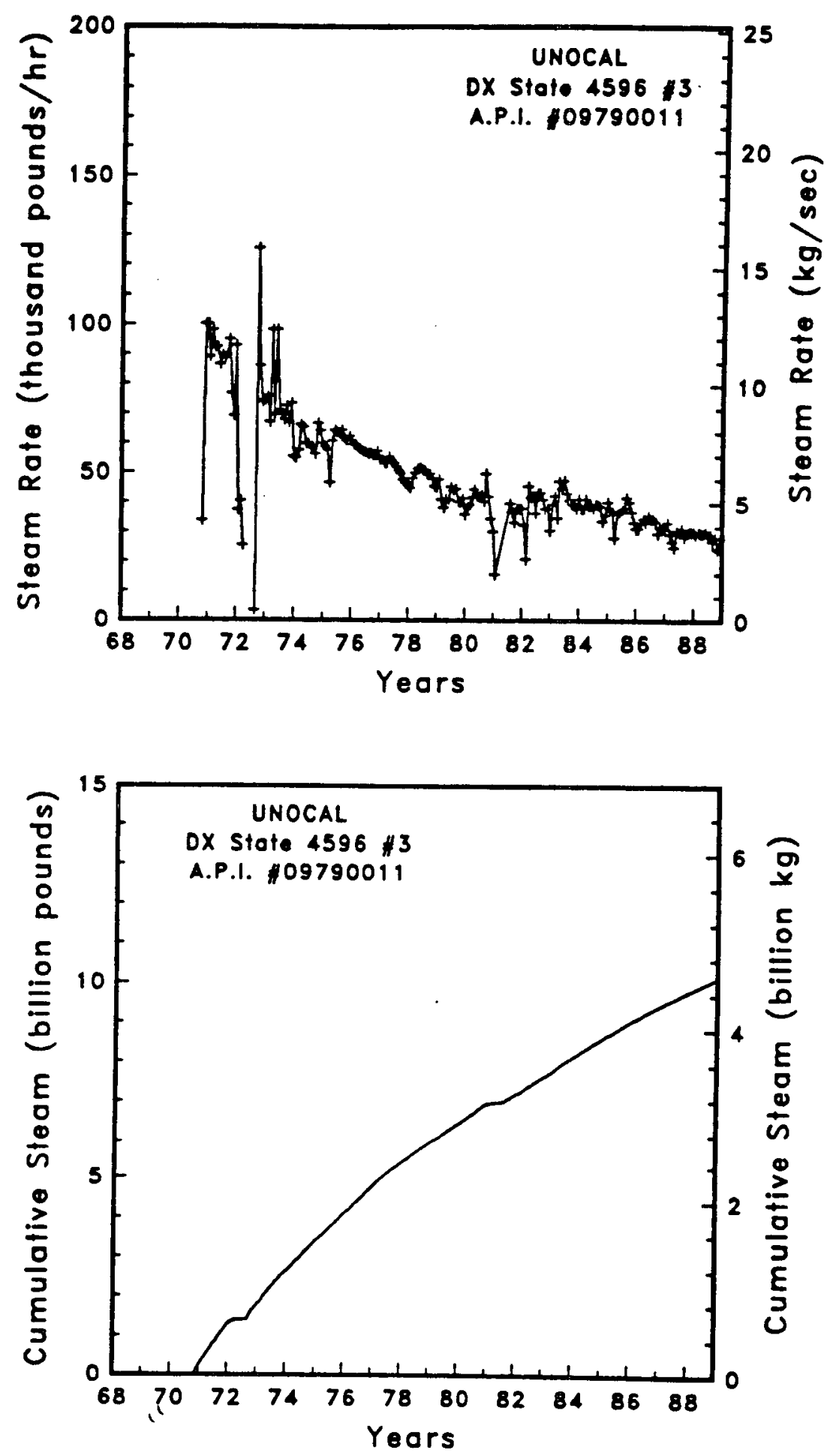

Figure A-27

Steam rate and cumulative mass flow for well DX State $4596 \# 3$ 

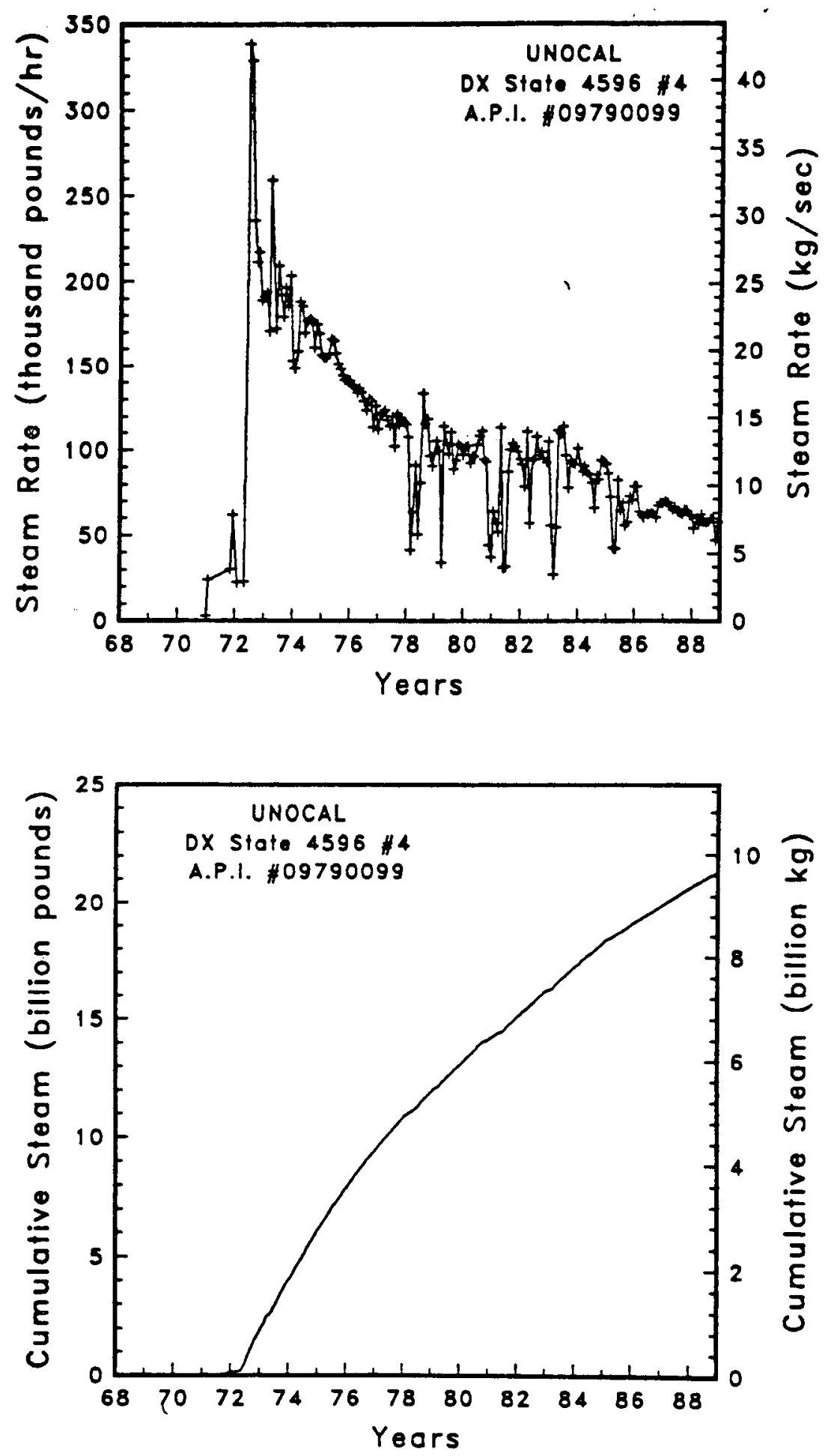

Figure A-28

Steam rate and cumulative mass flow for well DX State 4596 \# 4 

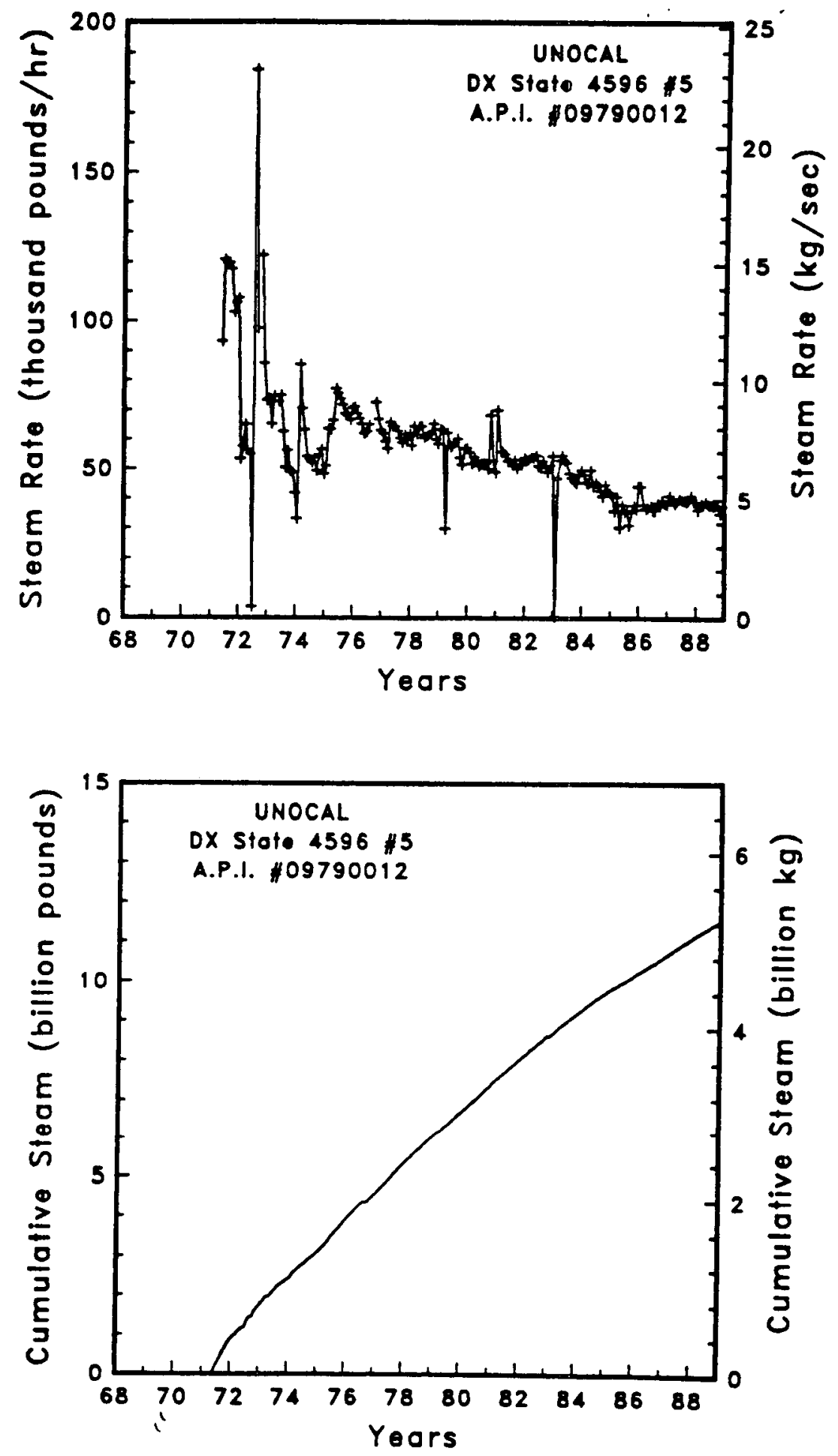

Figure A-29

Steam rate and cumulative mass flow for well DX State 4596 \#5 

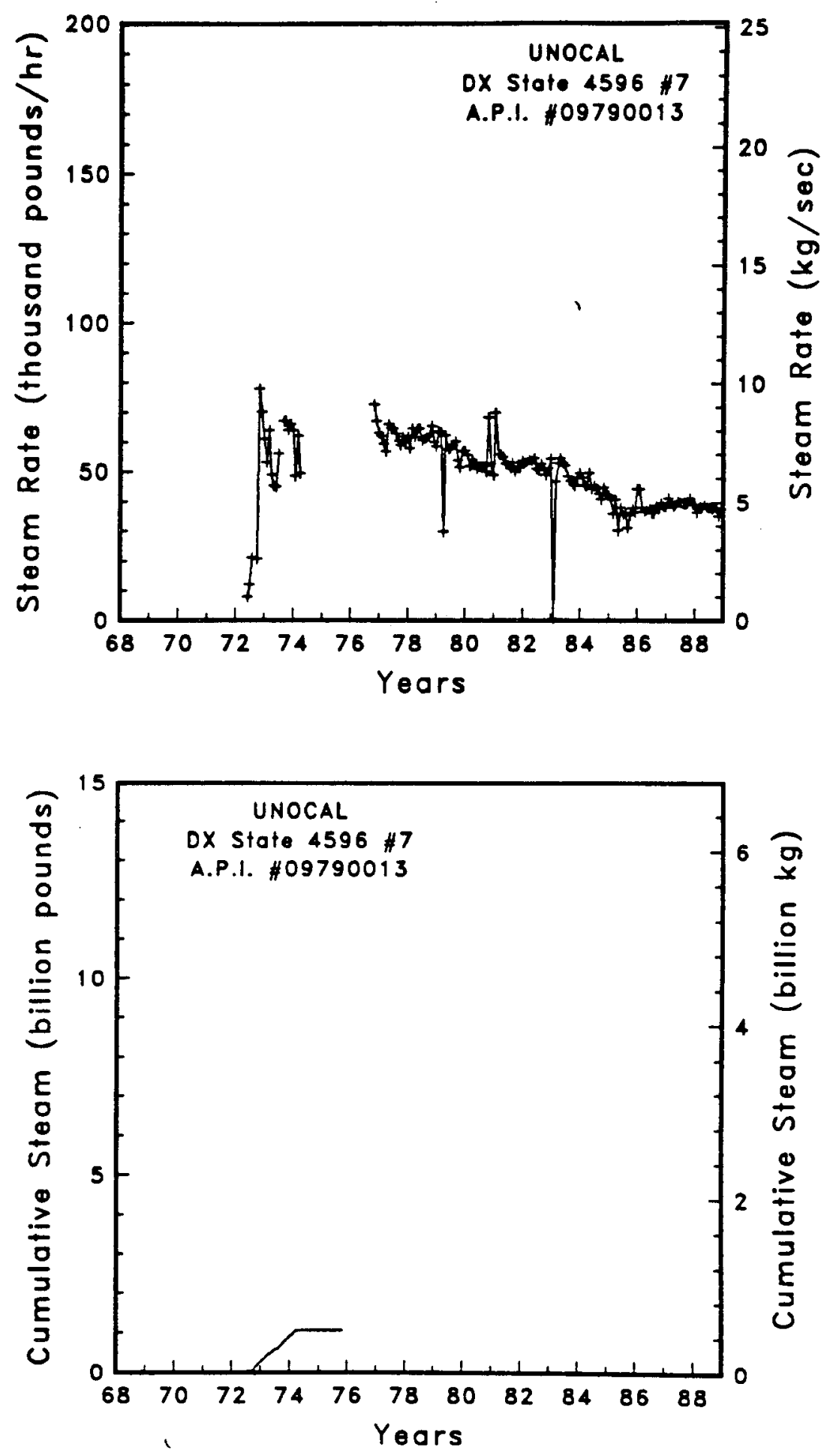

Figure A-30

Steam rate and cumulative mass flow for well DX State 4596 \#7 

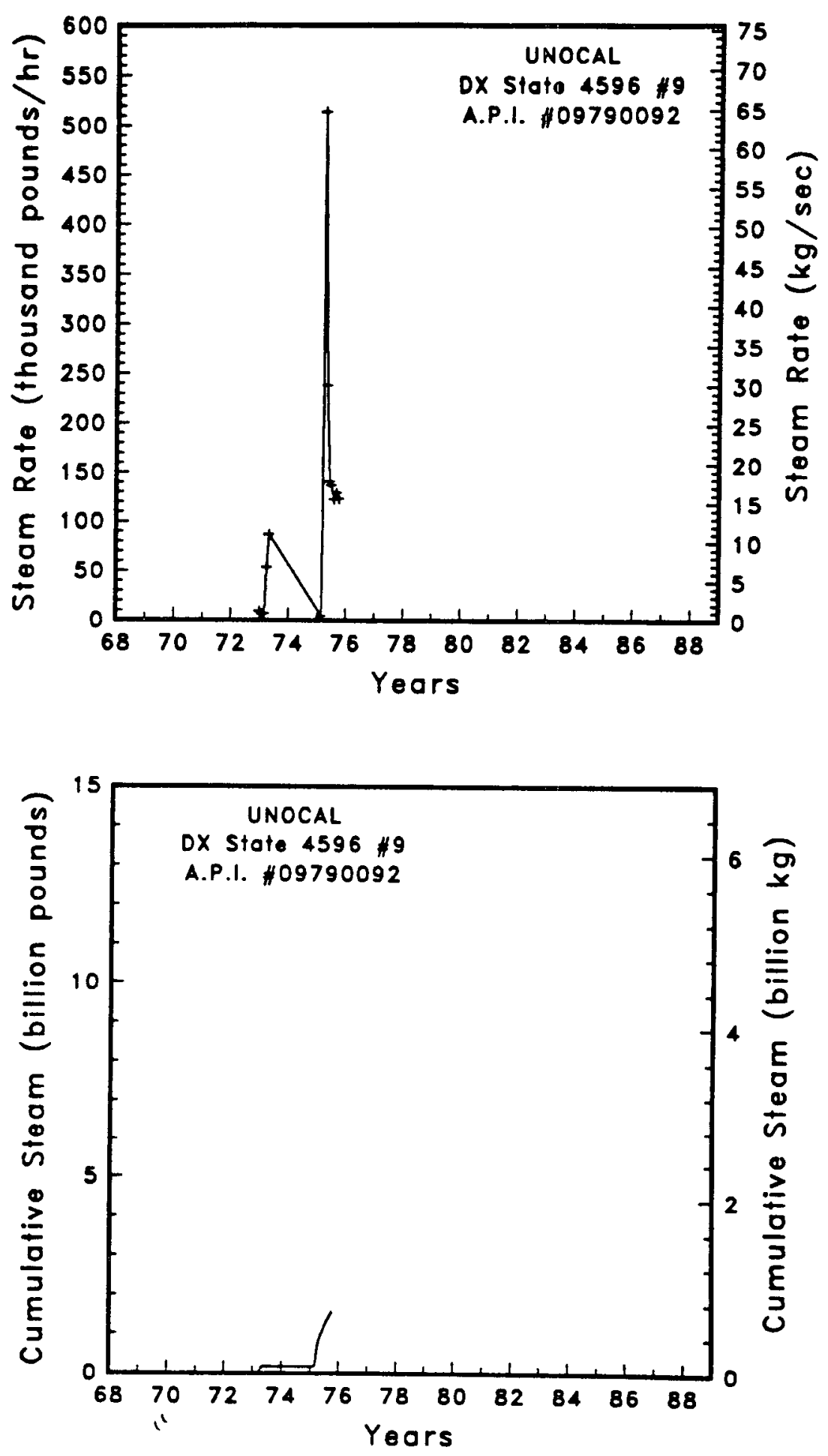

Figure A-31 Steam rate and cumulative mass flow for well DX State 4596 \#9 

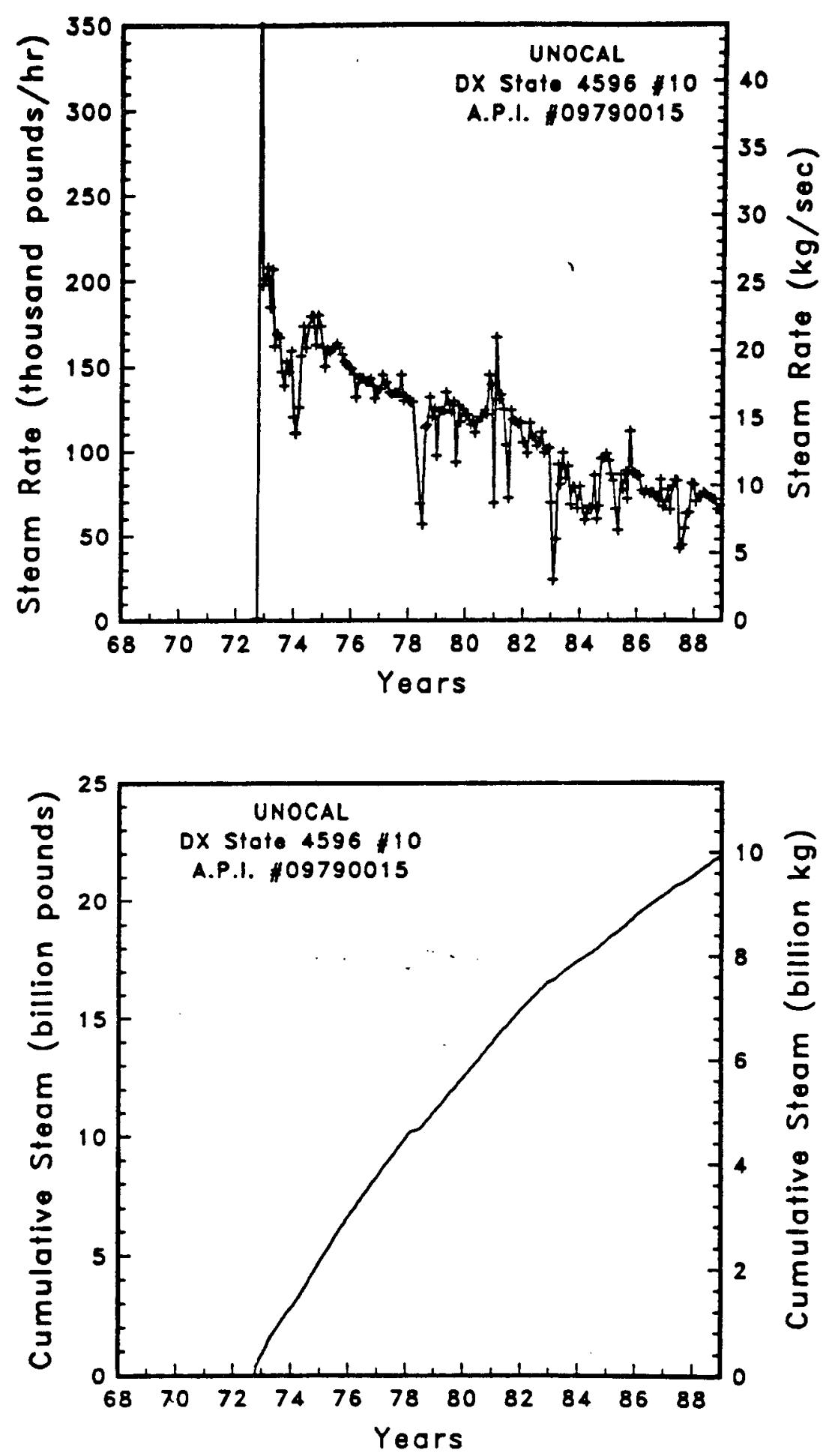

Figure A-32

Steam rate and cumulative mass flow for well DX State 4596 \#10 

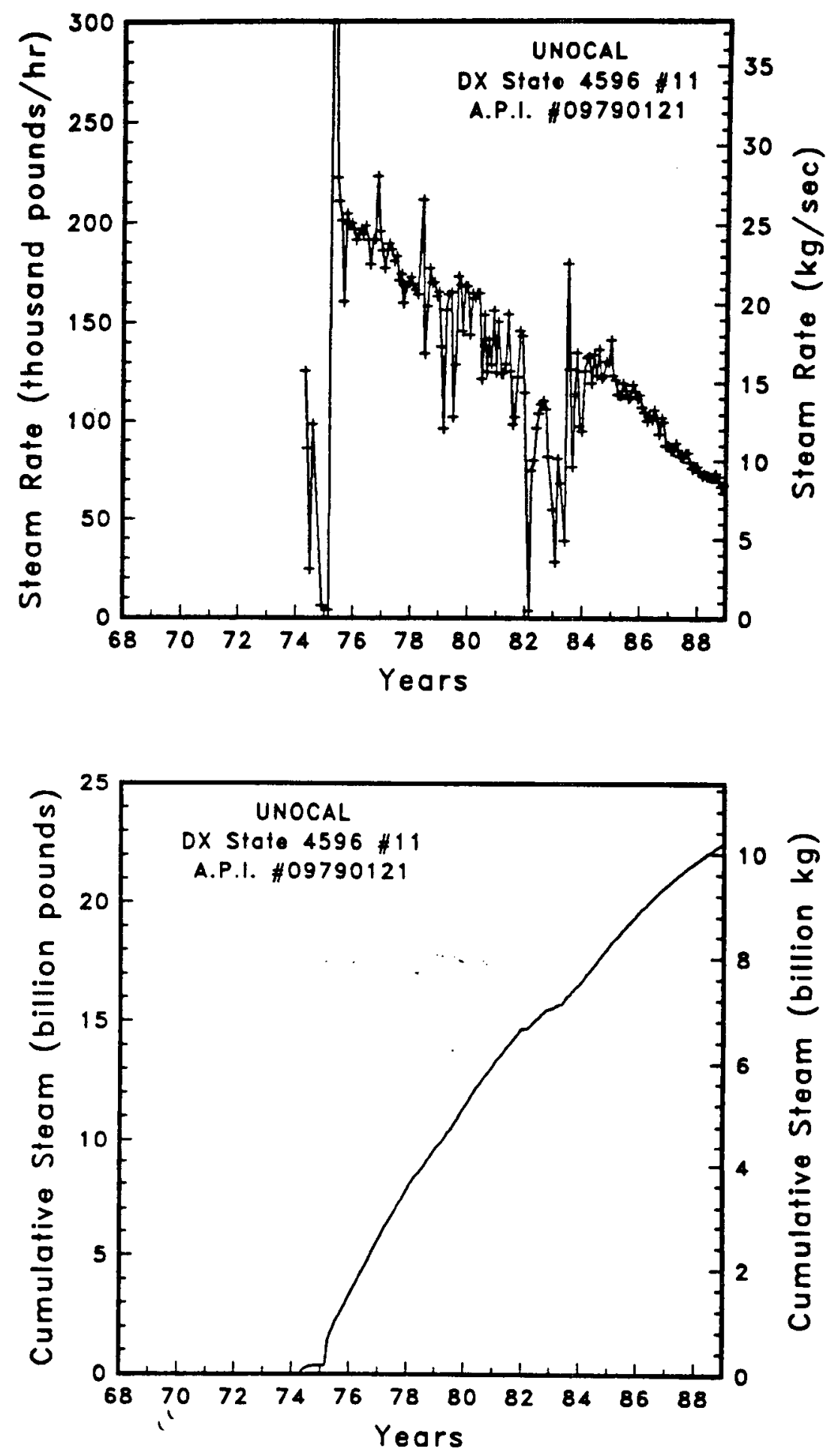

Figure A-33 Steam rate and cumulative mass flow for well DX State 4596 \#11 

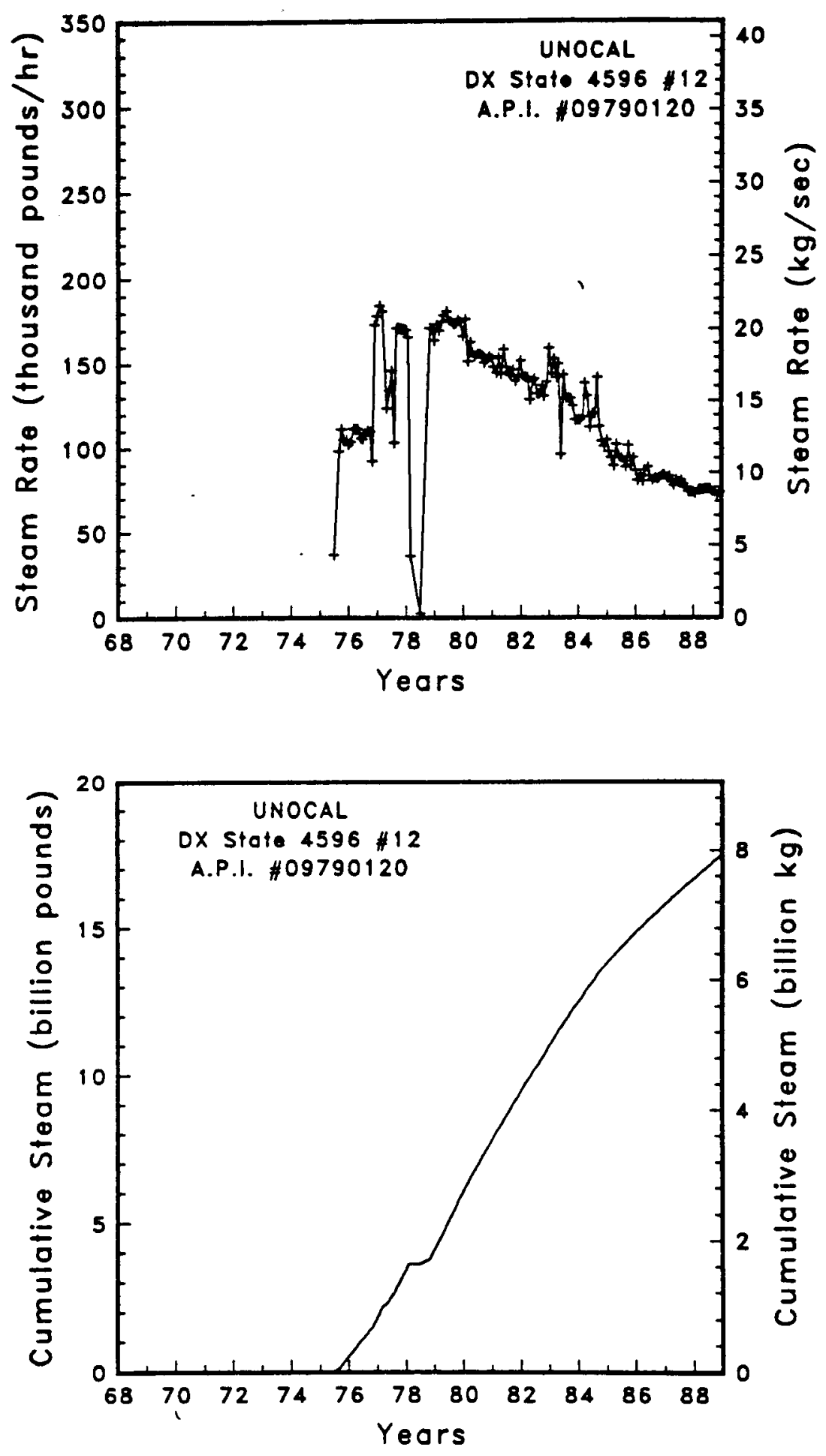

Figure A-34

Steam rate and cumulative mass flow for well DX State 4596 \#12 

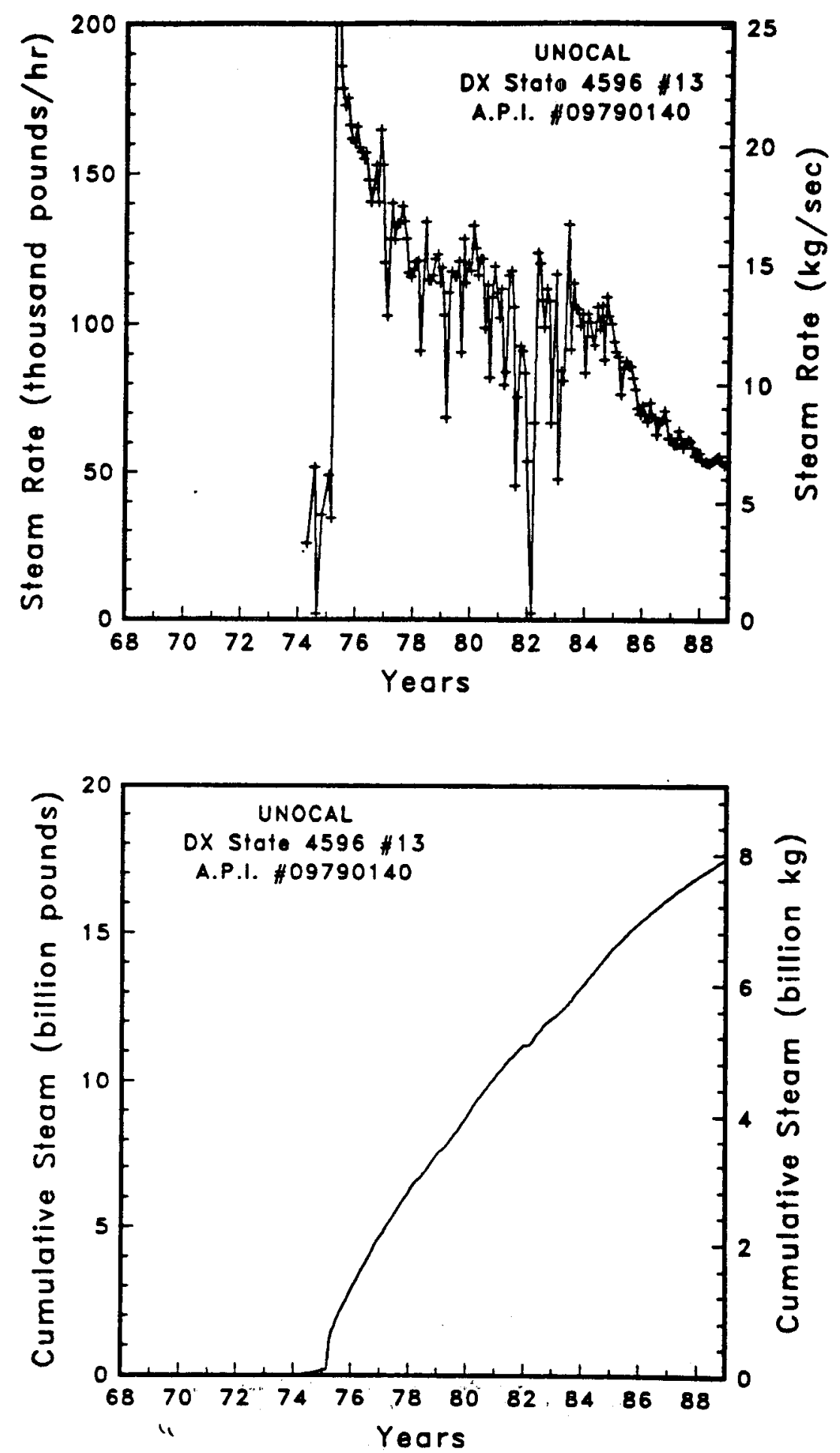

Figure A-35

Steam rate and cumulative mass flow for well DX State 4596 \#13 

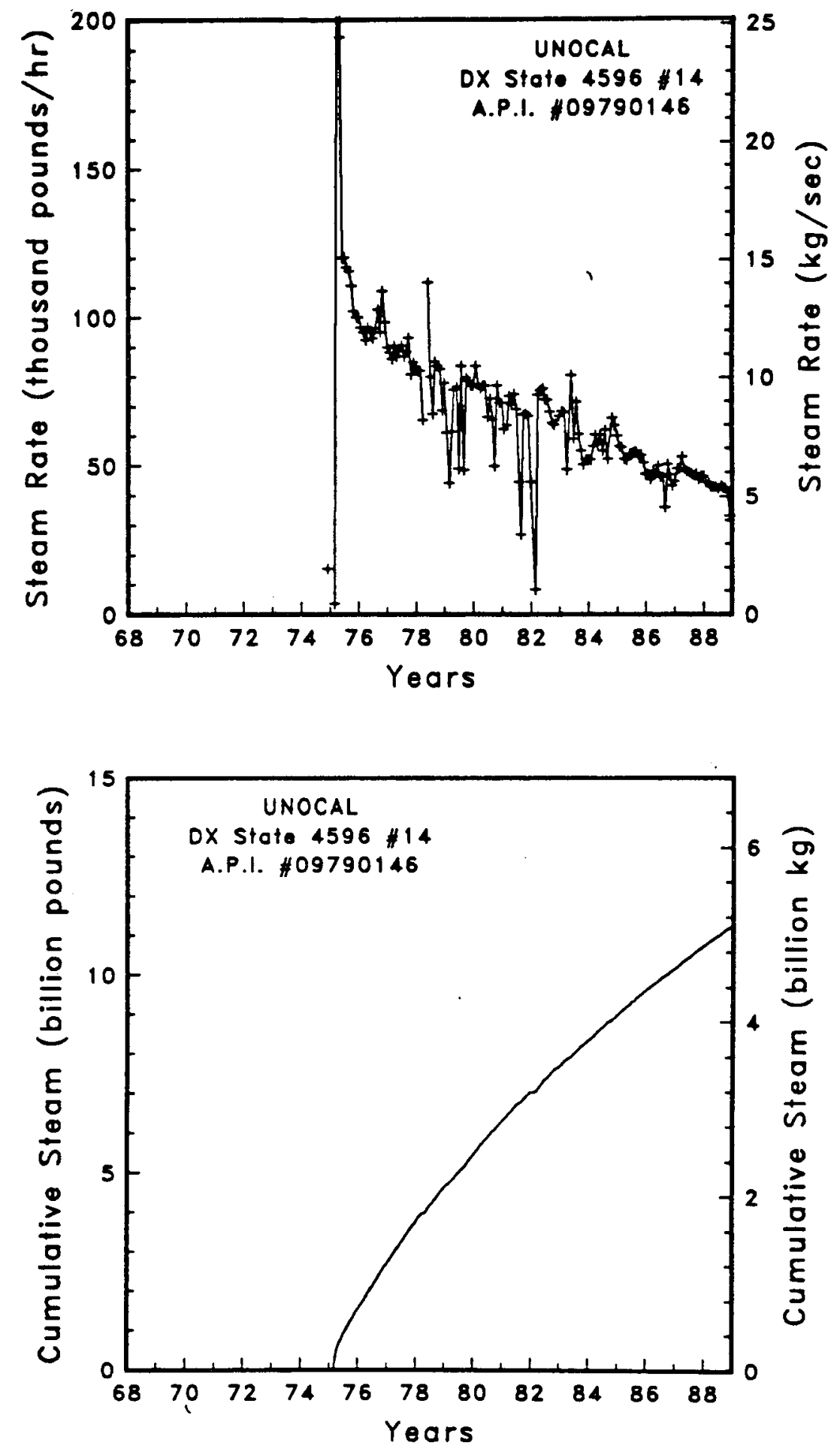

Figure A-36

Steam rate and cumulative mass flow for well DX State 4596 \#14 

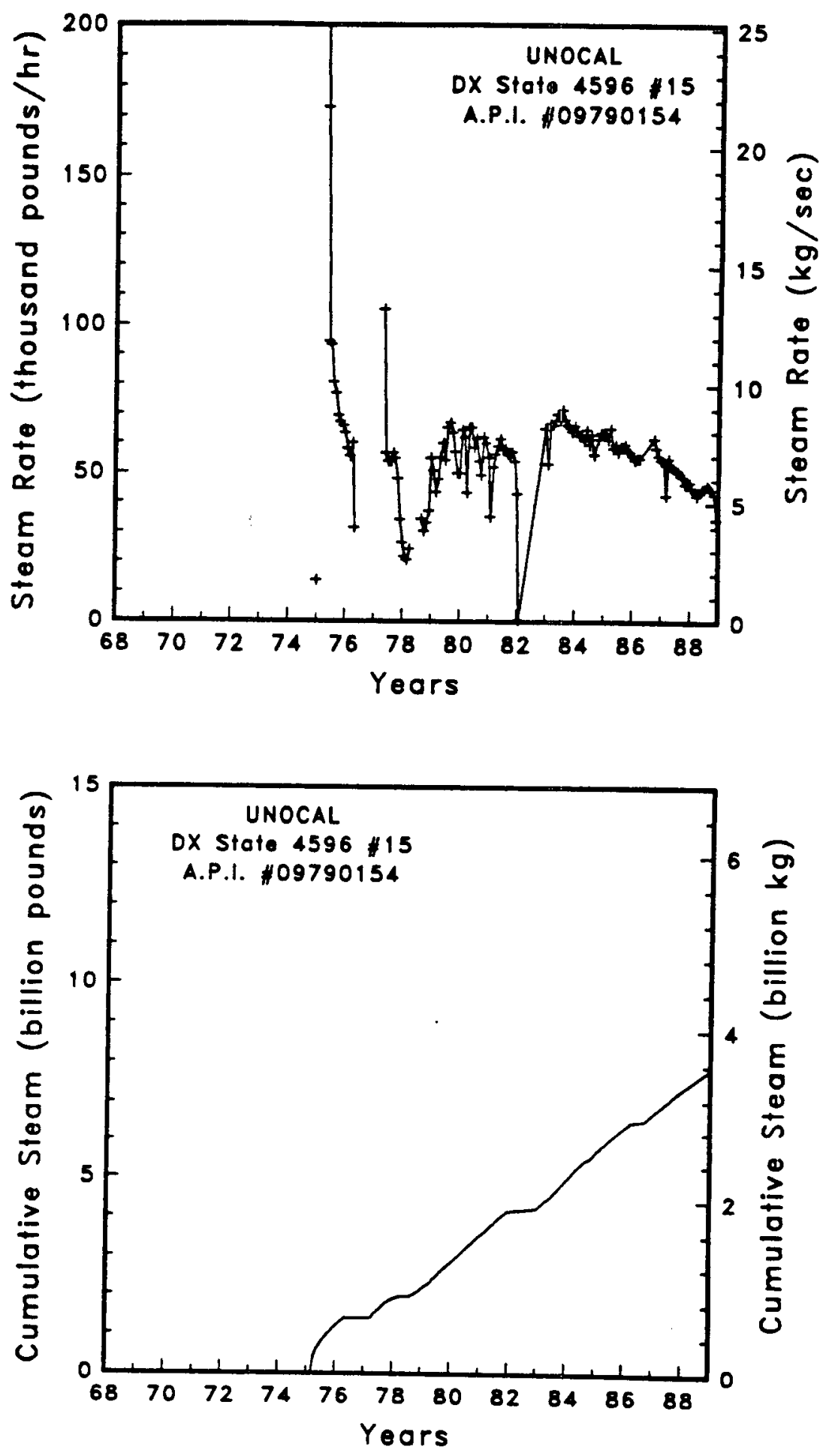

Figure A-37

Steam rate and cumulative mass flow for well Dx State $4596 \# 15$ 

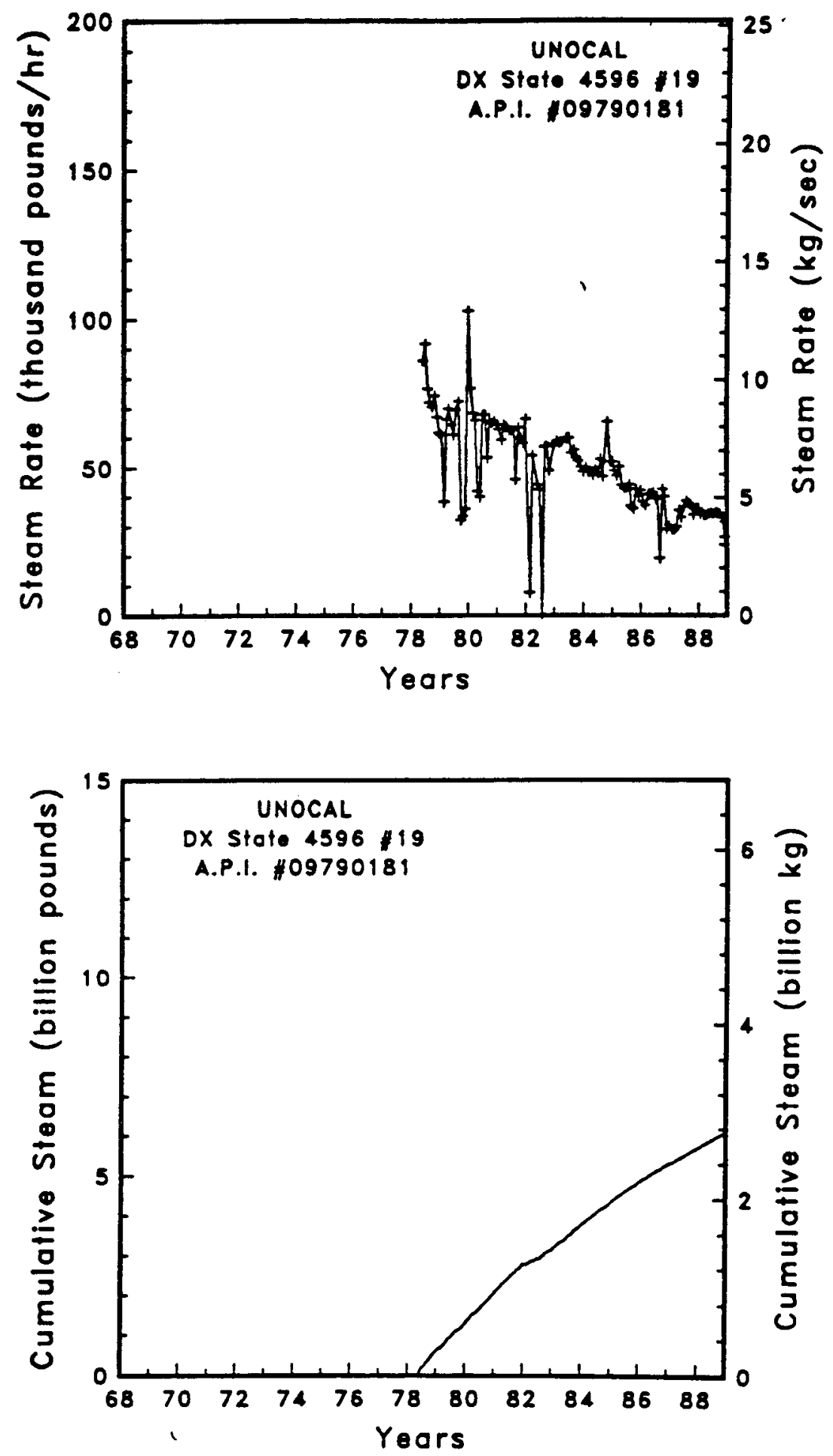

Figure A-38

Steam rote and cumulative mass flow for well DX State $4596 \# 19$ 

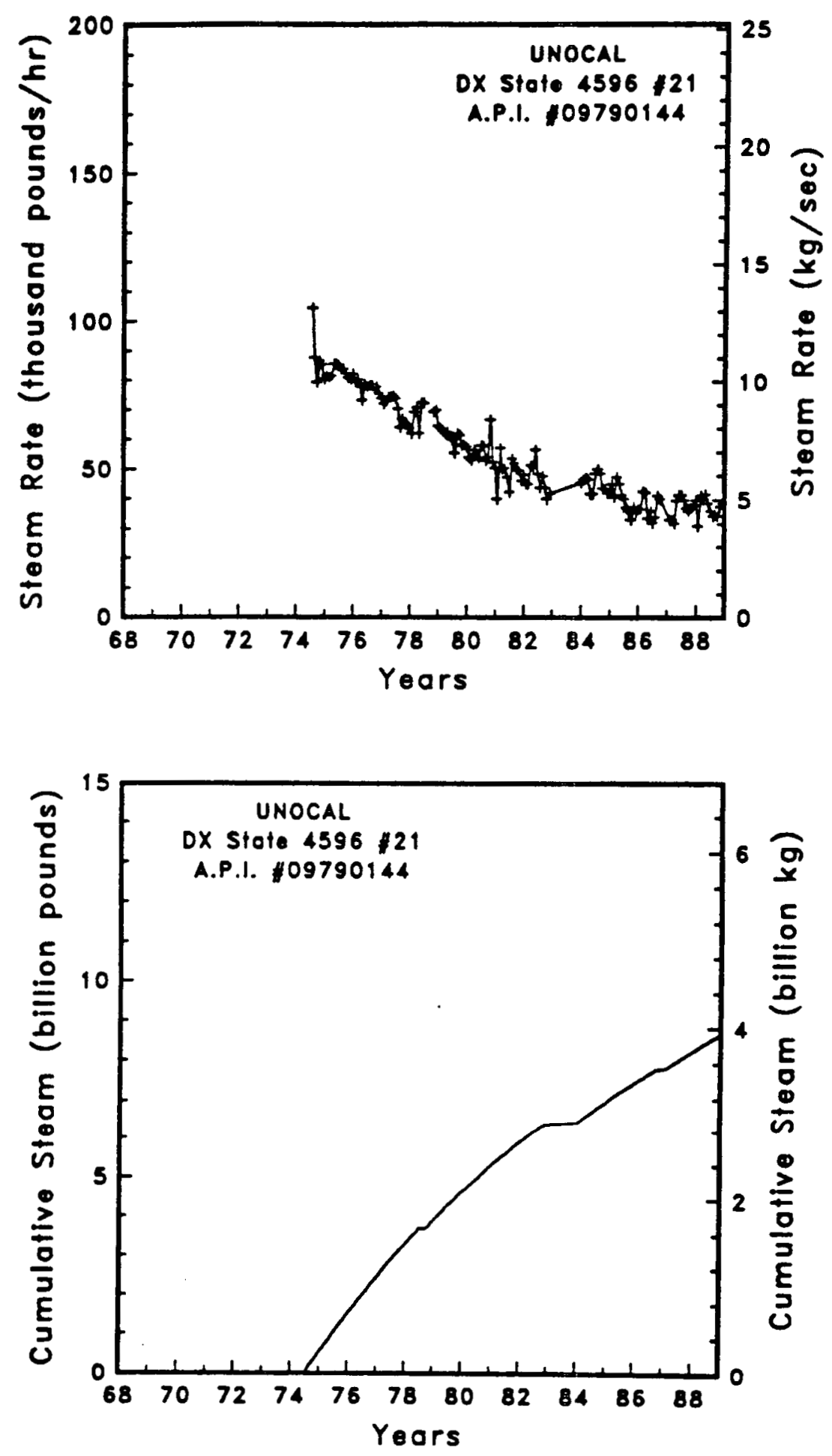

Figure A-39

Steom rote and cumulative mass flow for well DX State 4596 \#21 

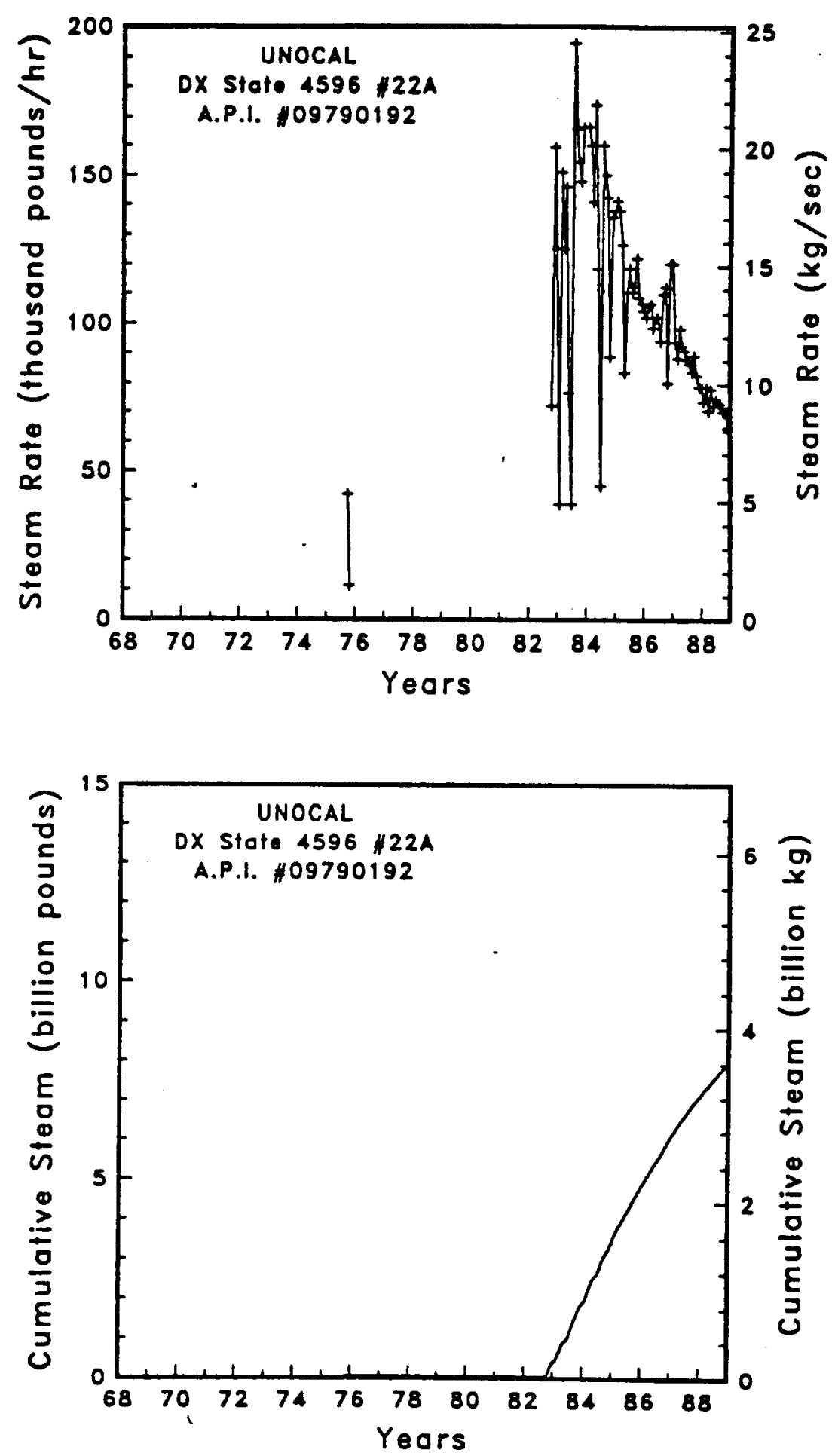

Figure A-40

Steam rate and cumulative mass flow for well DX State $4596 \# 22 A$ 

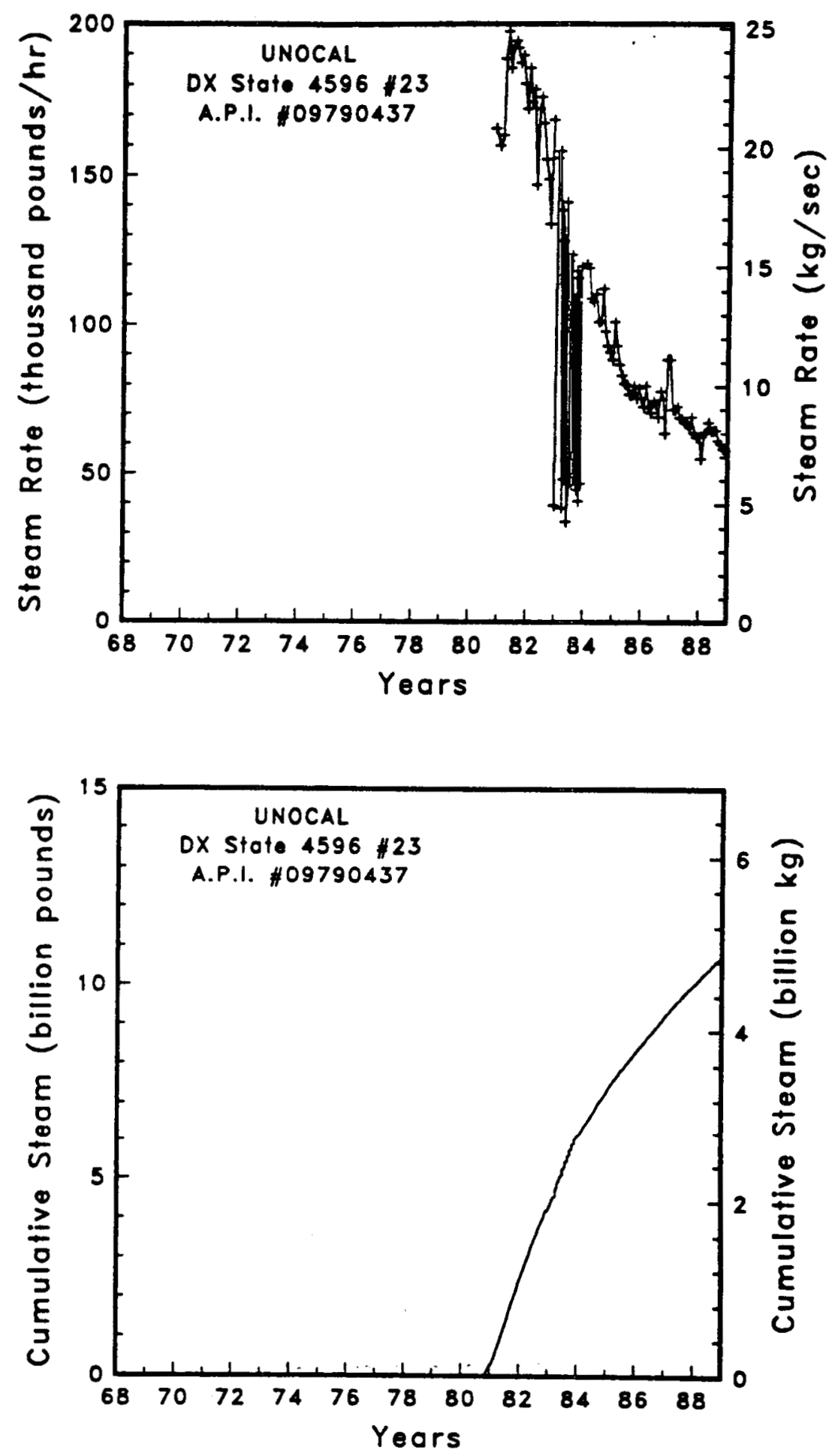

Figure A-41

Steam rate and cumulative mass flow for well DX State 4596 \#23 

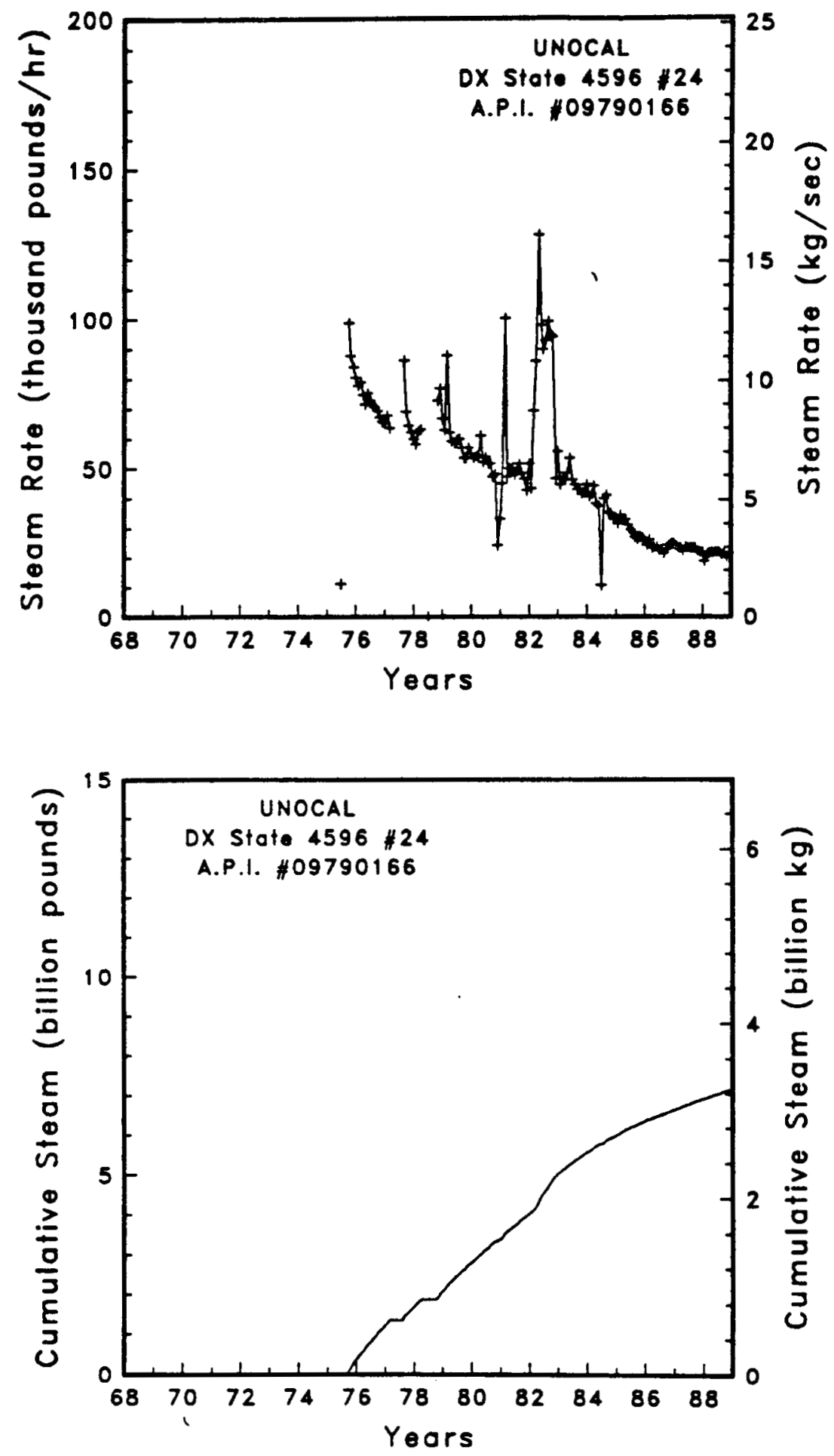

Figure A-42 Steam rate and cumulative mass flow for well DX State 4596 \#24 

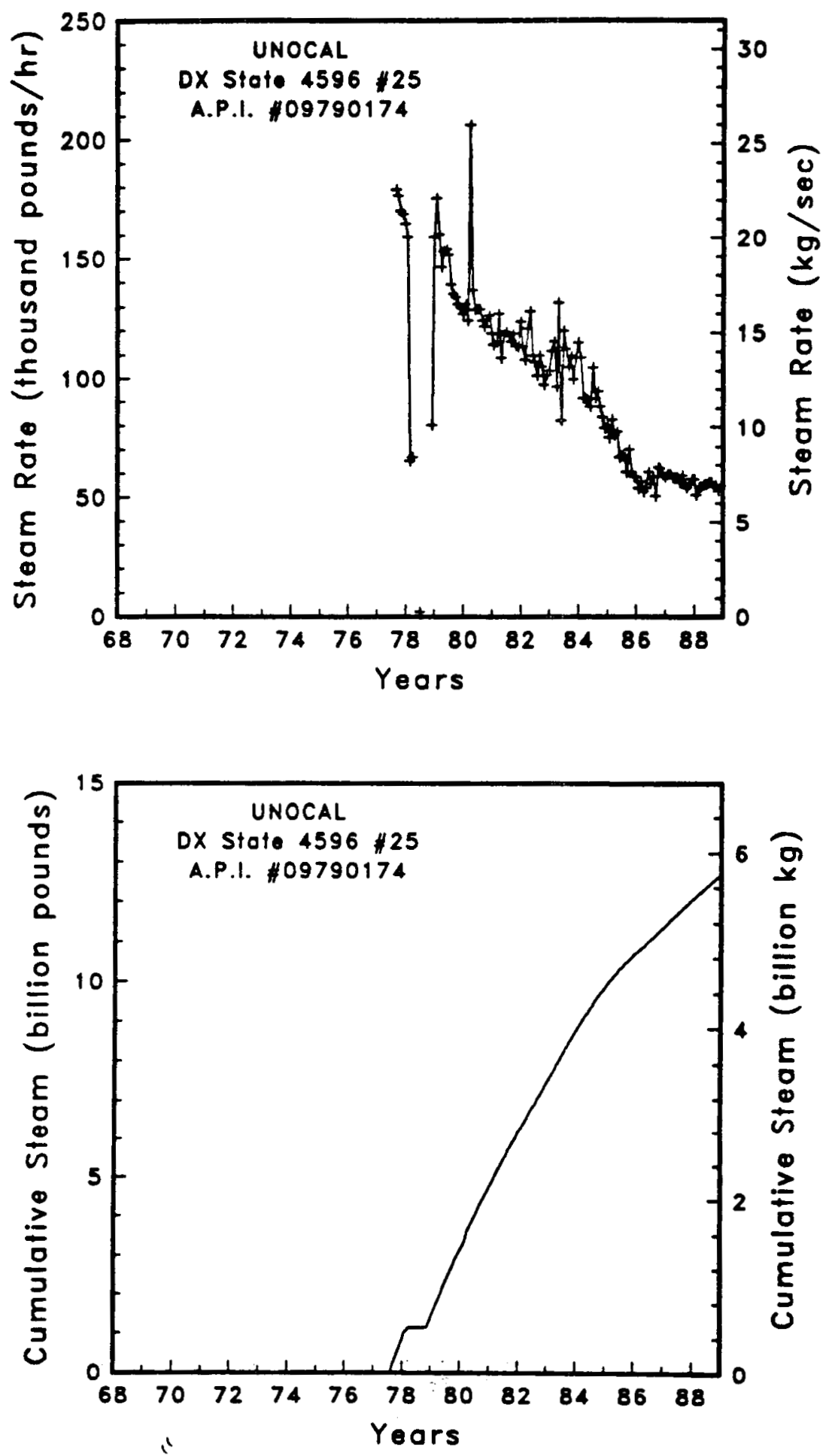

Figure A-43, Steam rate and cumulative moss flow for well DX State $4596 \# 25$ 

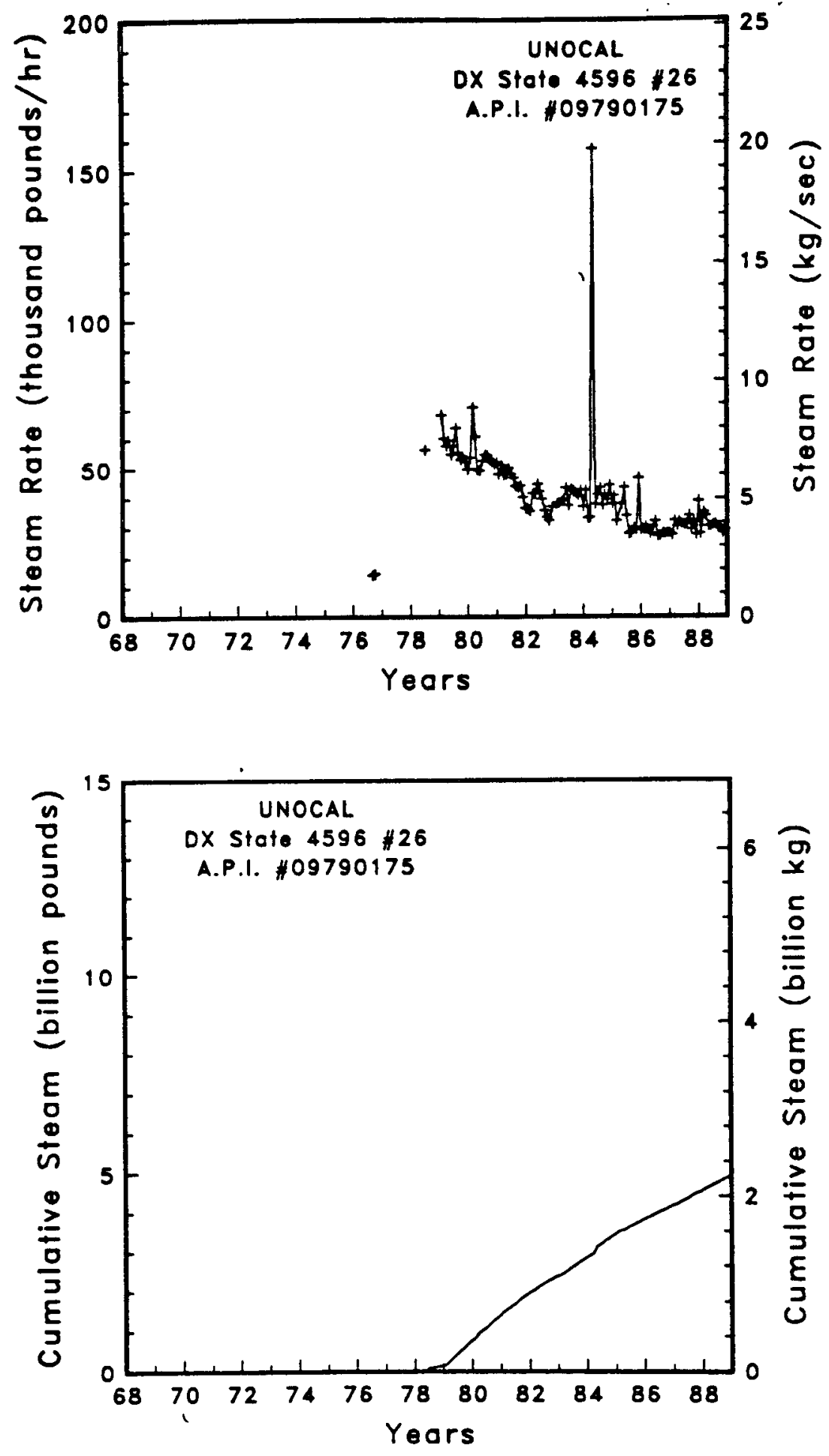

Figure A-44

Steam rate and cumulative mass flow for well DX State 4596 \#26 

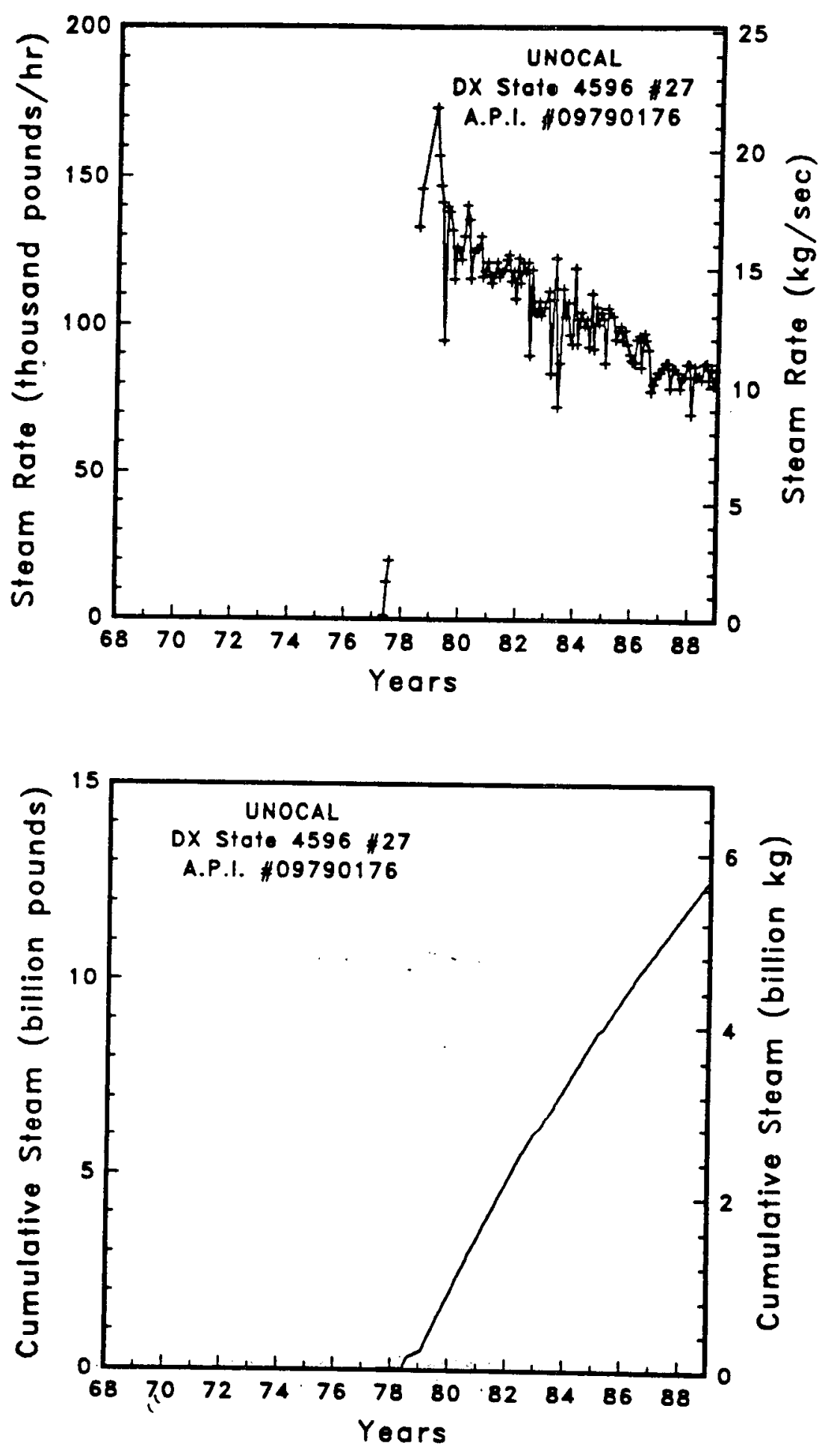

Figure A-45 Steam rate and cumulative mass flow for
well DX State 4596 \#27 

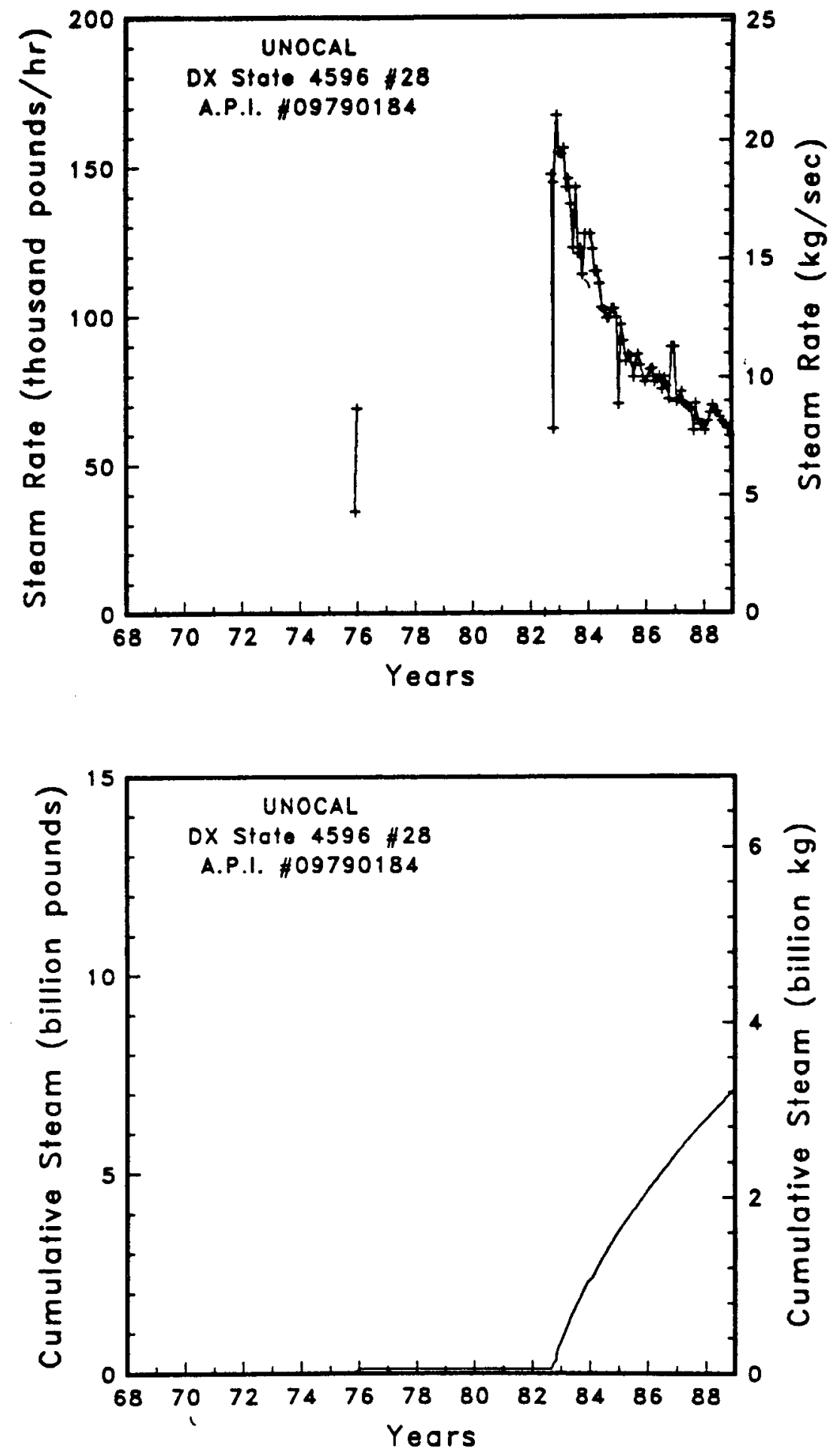

Figure A-46

Steam rate and cumulative mass flow for well DX State 4596 \#28 

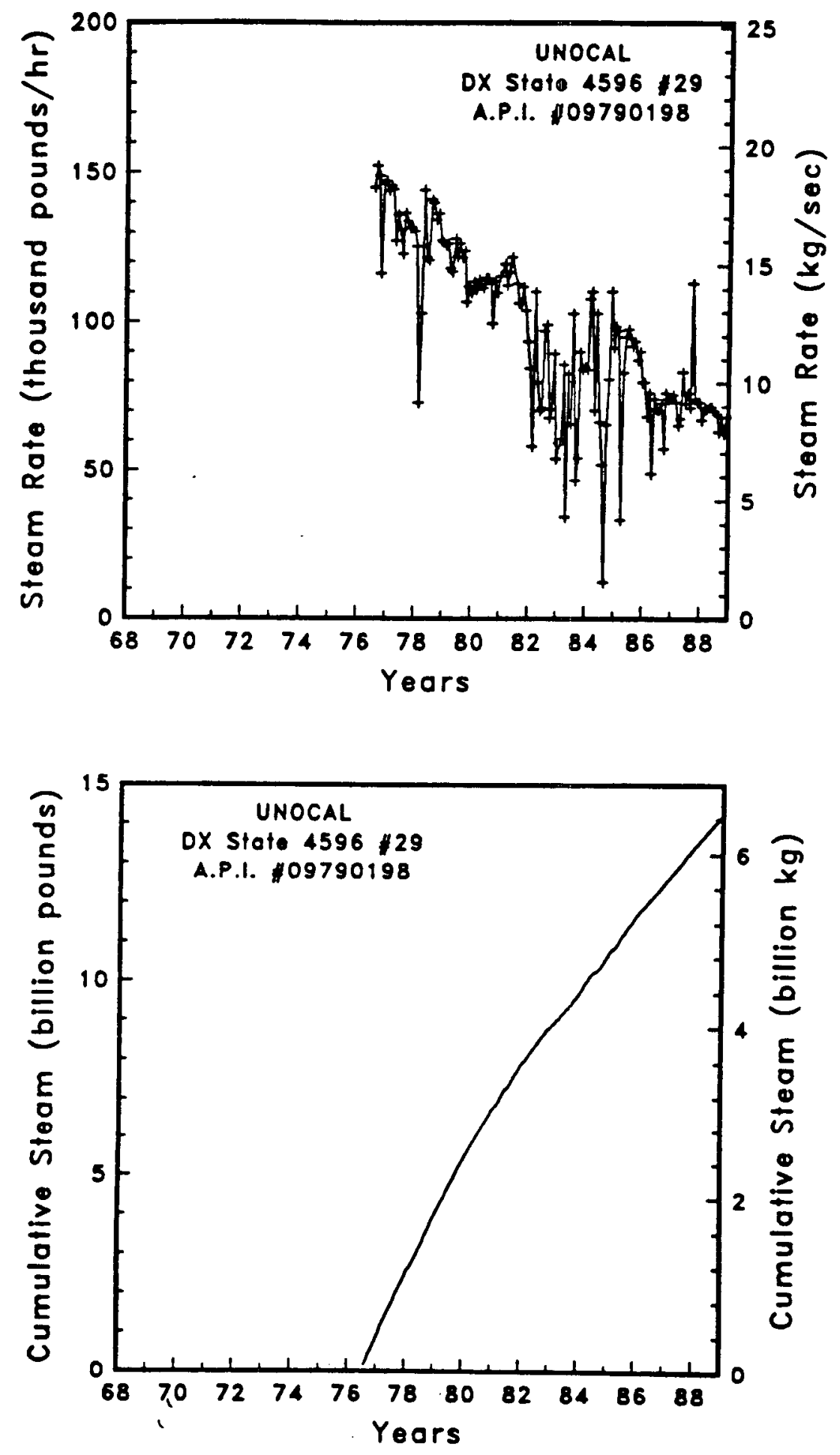

Figure A-47 Steam rate and cumulative mass flow for well DX Stote $4596 \# 29$ 

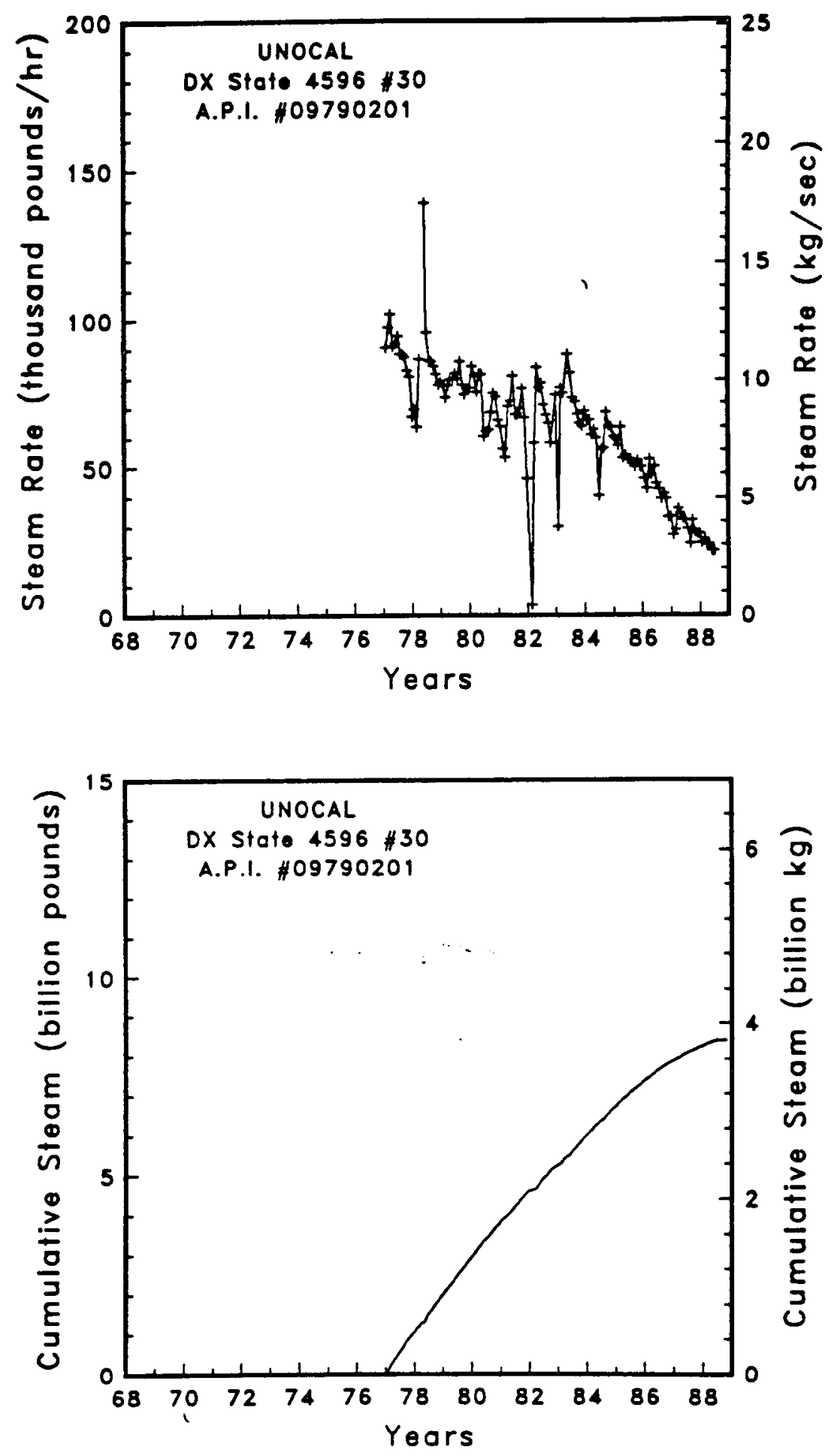

Figure A-48

Steam rate and cumulative mass flow for well DX State 4596 \#30 

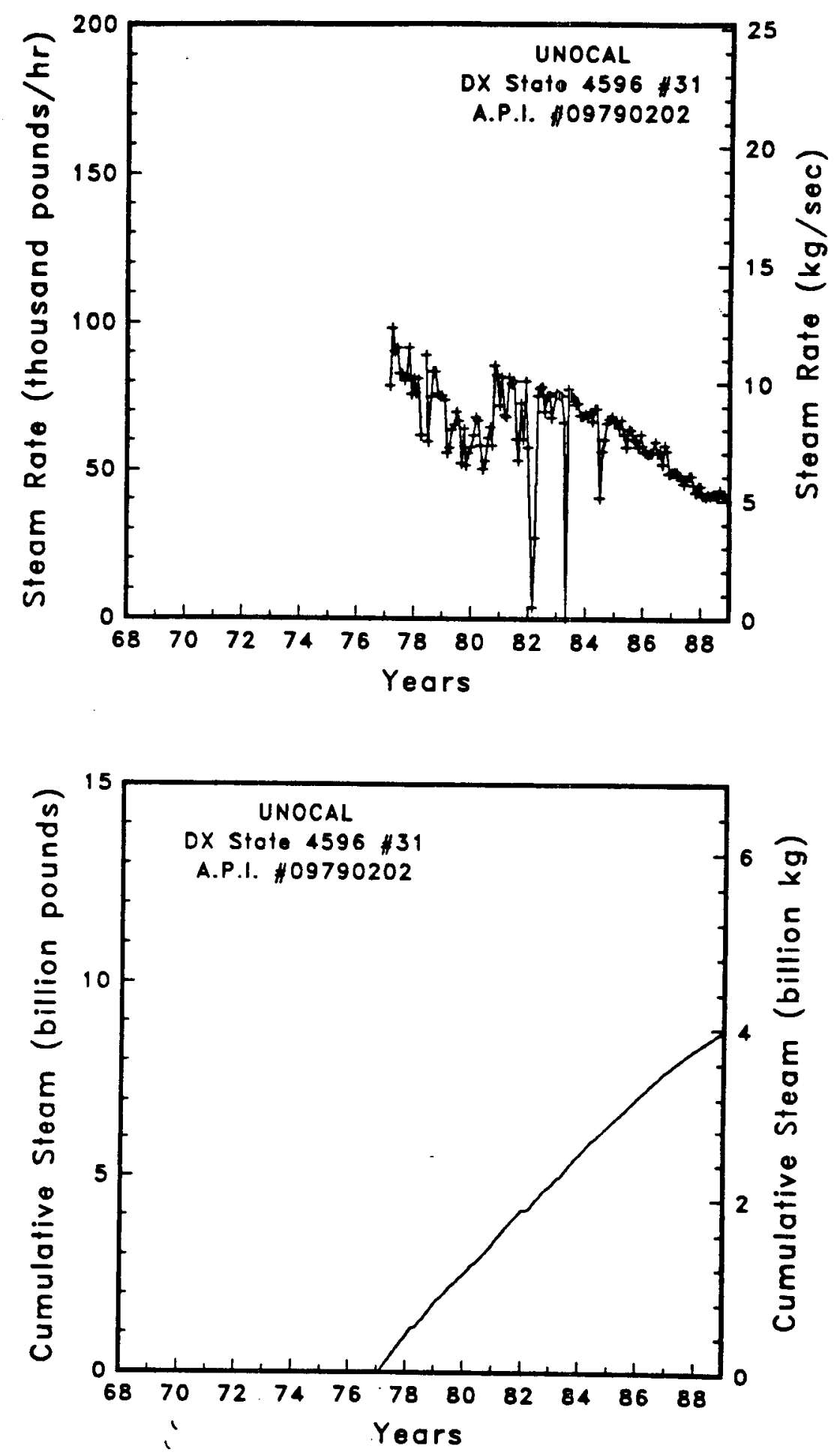

Figure A-49 Steam rate and cumulative mass flow for well DX State 4596 \#31 

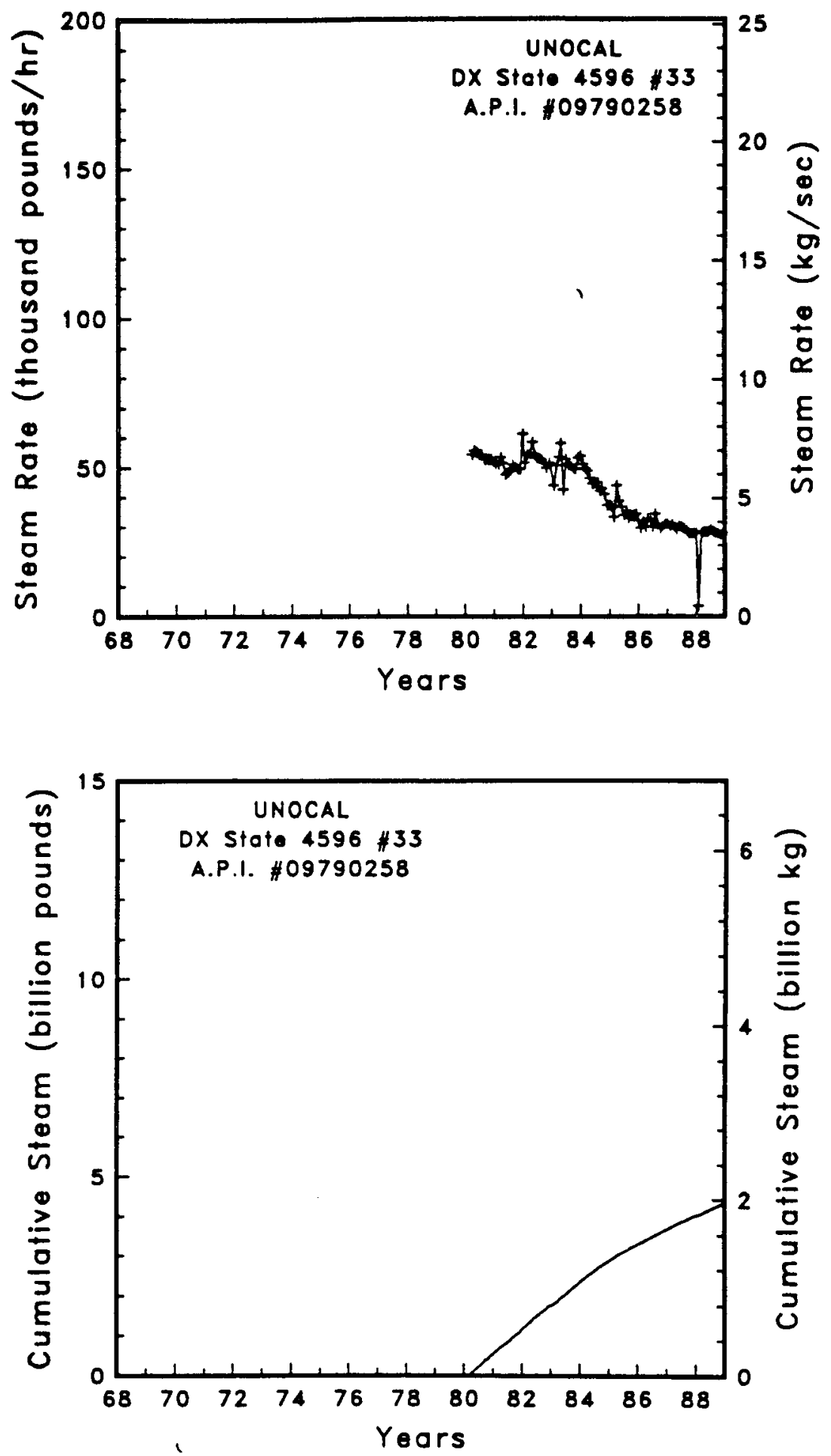

Figure A-50

Steam rate and cumulative mass flow for well DX State 4596 \#33 

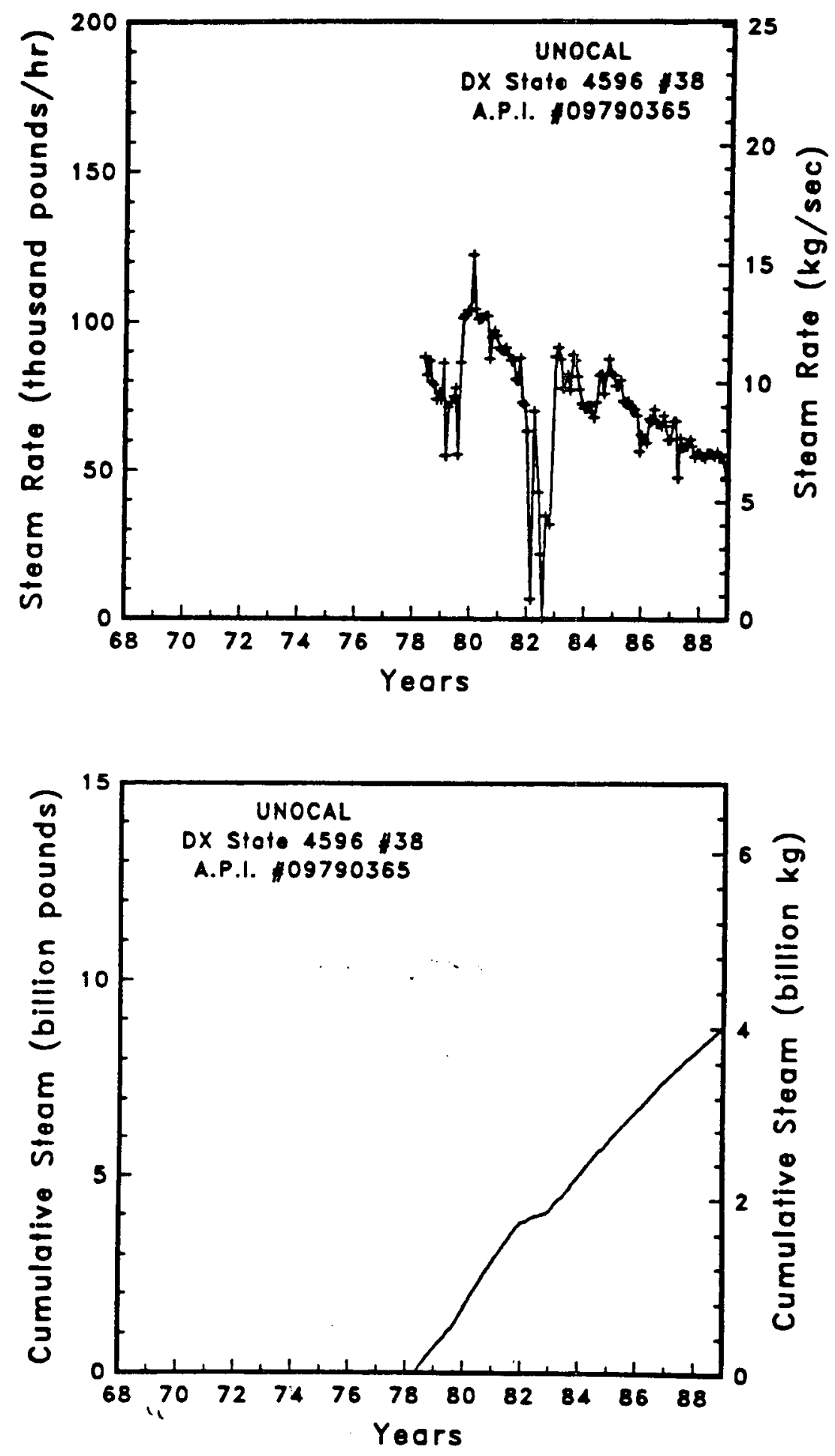

Figure A-51

Steom rate and cumulative mass flow for well DX State 4596 \#38 

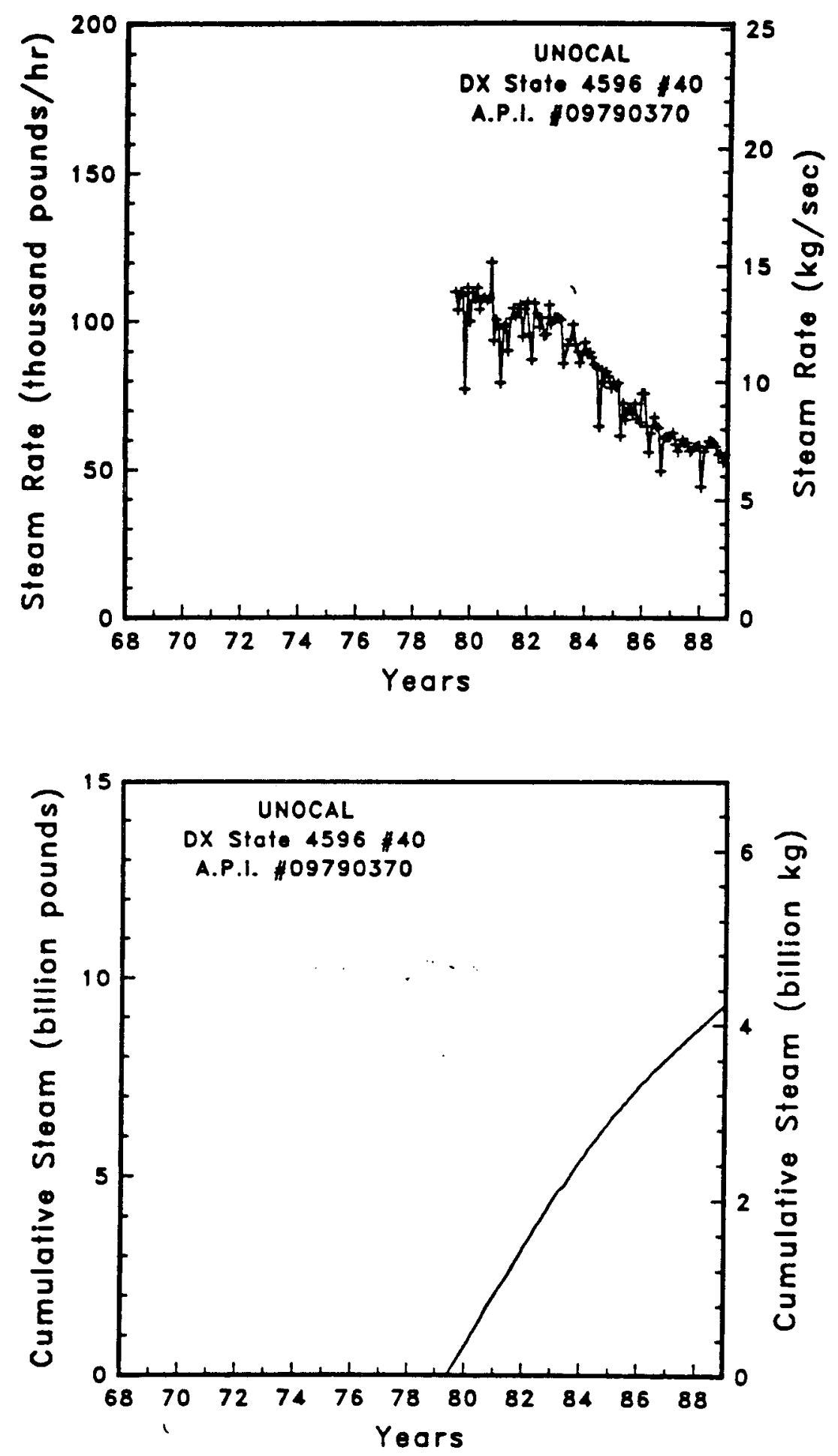

Figure A-52

Steam rate and cumulative mass flow for well DX State 4596 \#40 

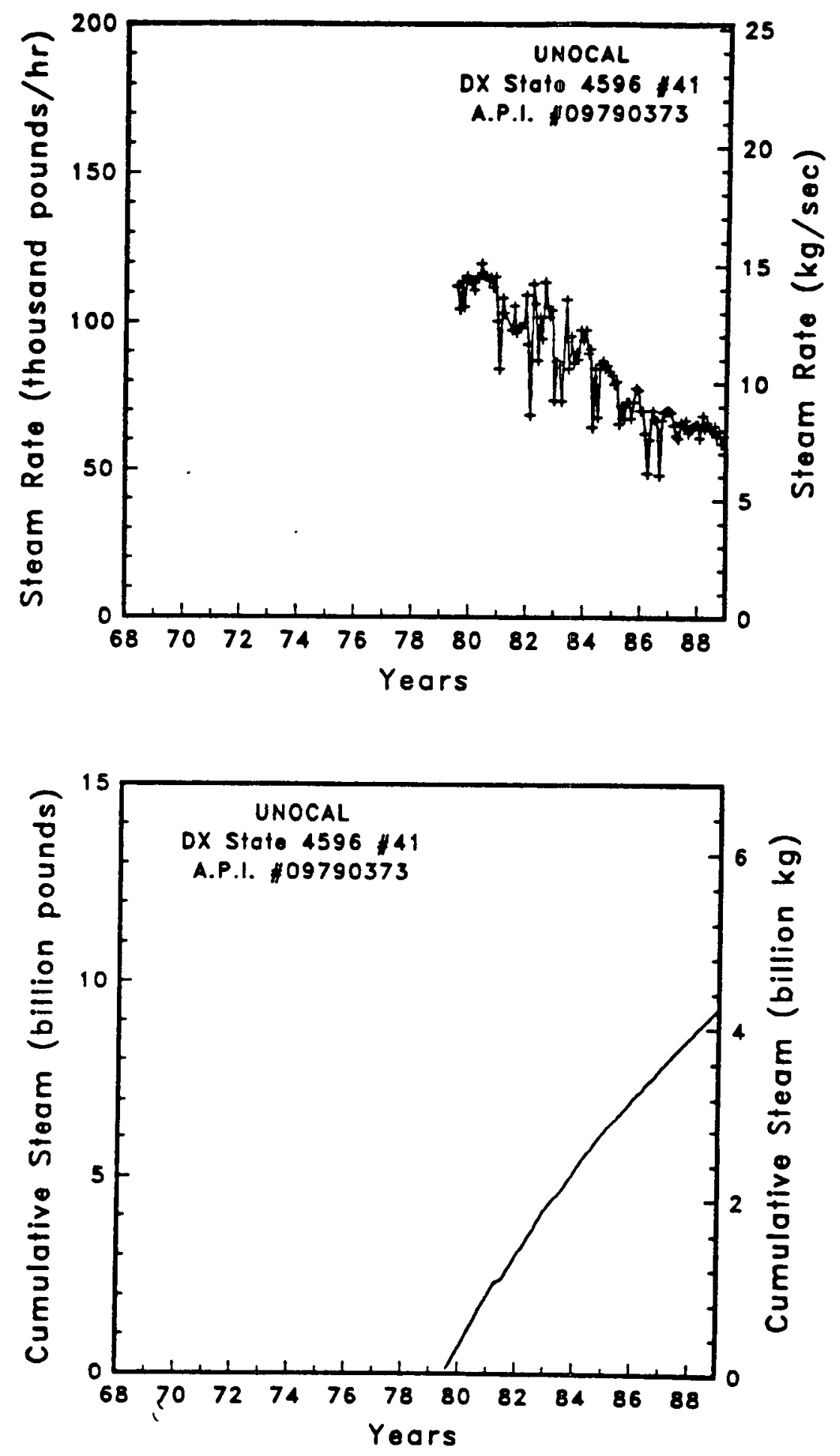

Figure A-53

Steam rate and cumulative mass flow for well DX State 4596 \#41 

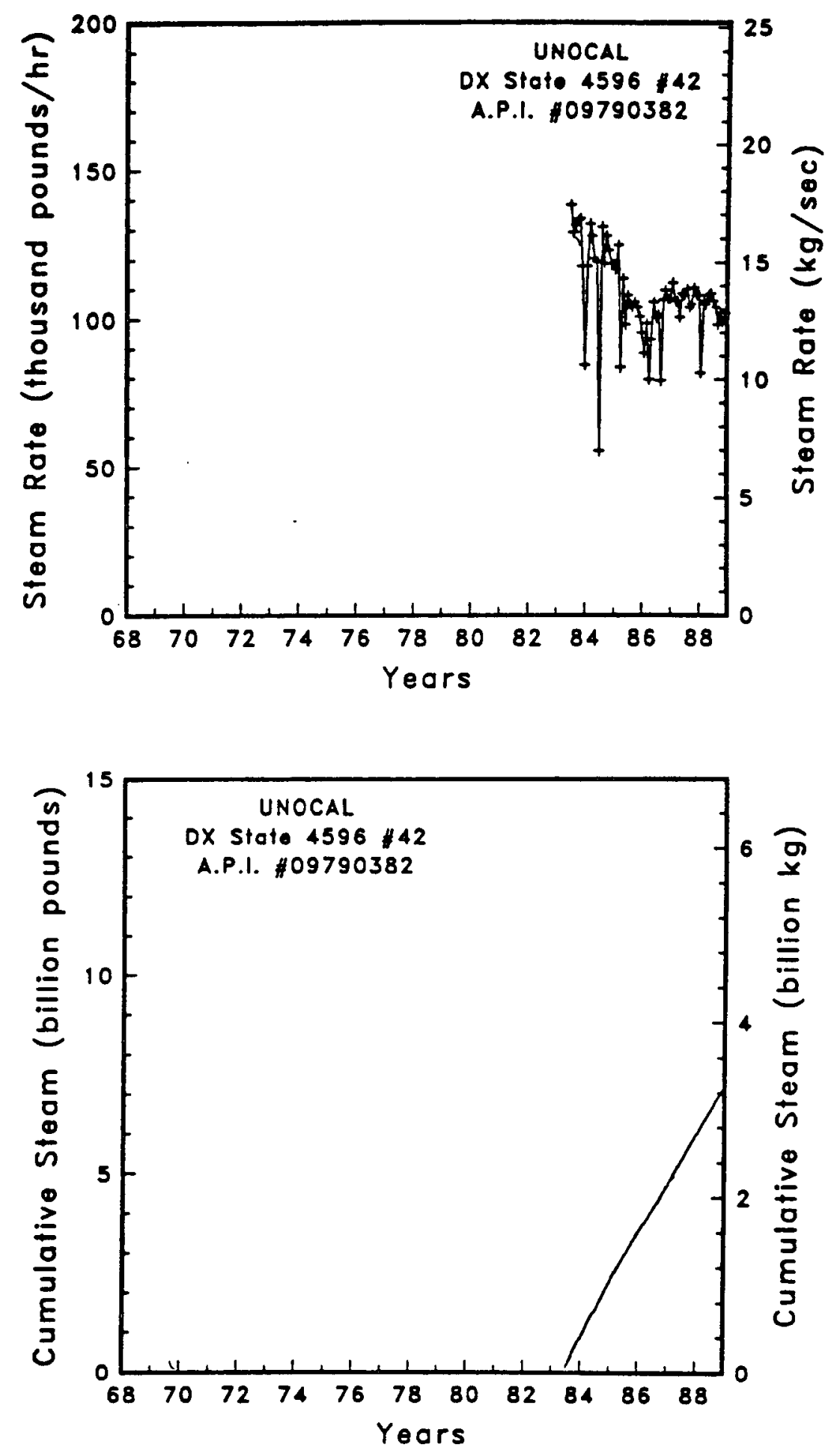

Figure A-54

Steam rate and cumulative mass flow for well DX State 4596 \#42 

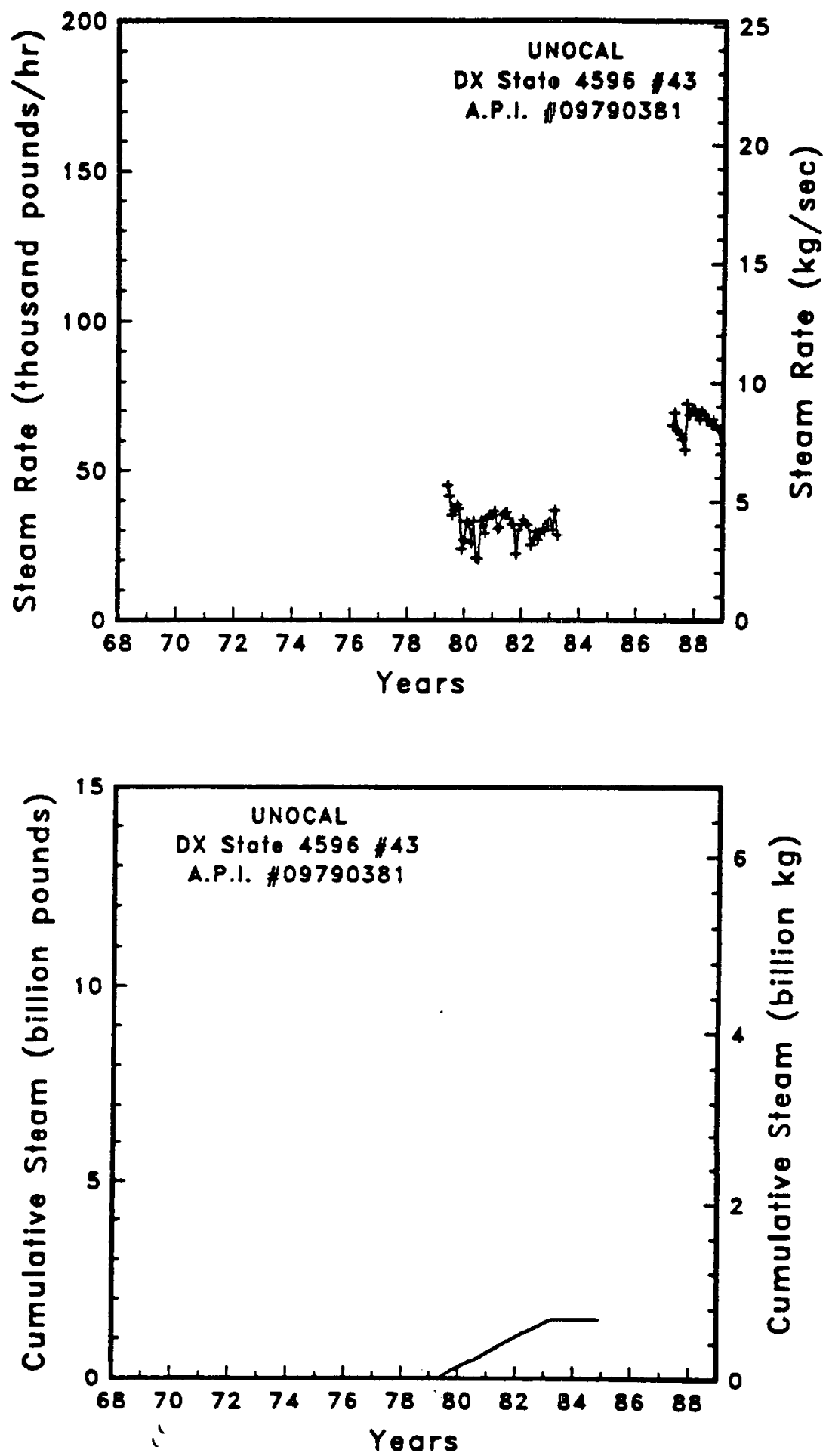

Figure A-55 Steom rote and cumulative mass flow for well DX State $4596 \# 43$ 

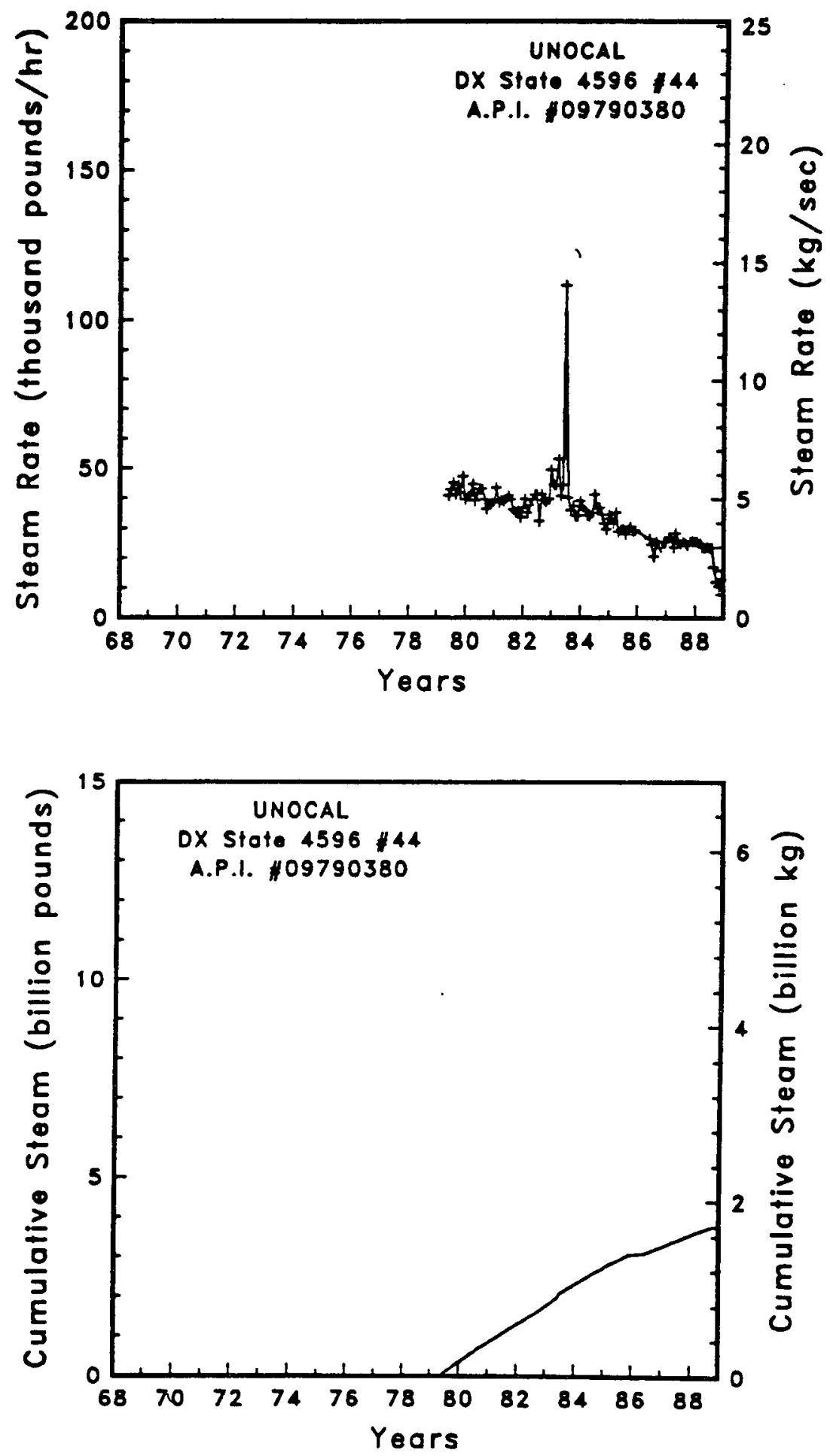

Figure A-56 Steam rate and cumulative mass flow for well DX State 4596 \#44 

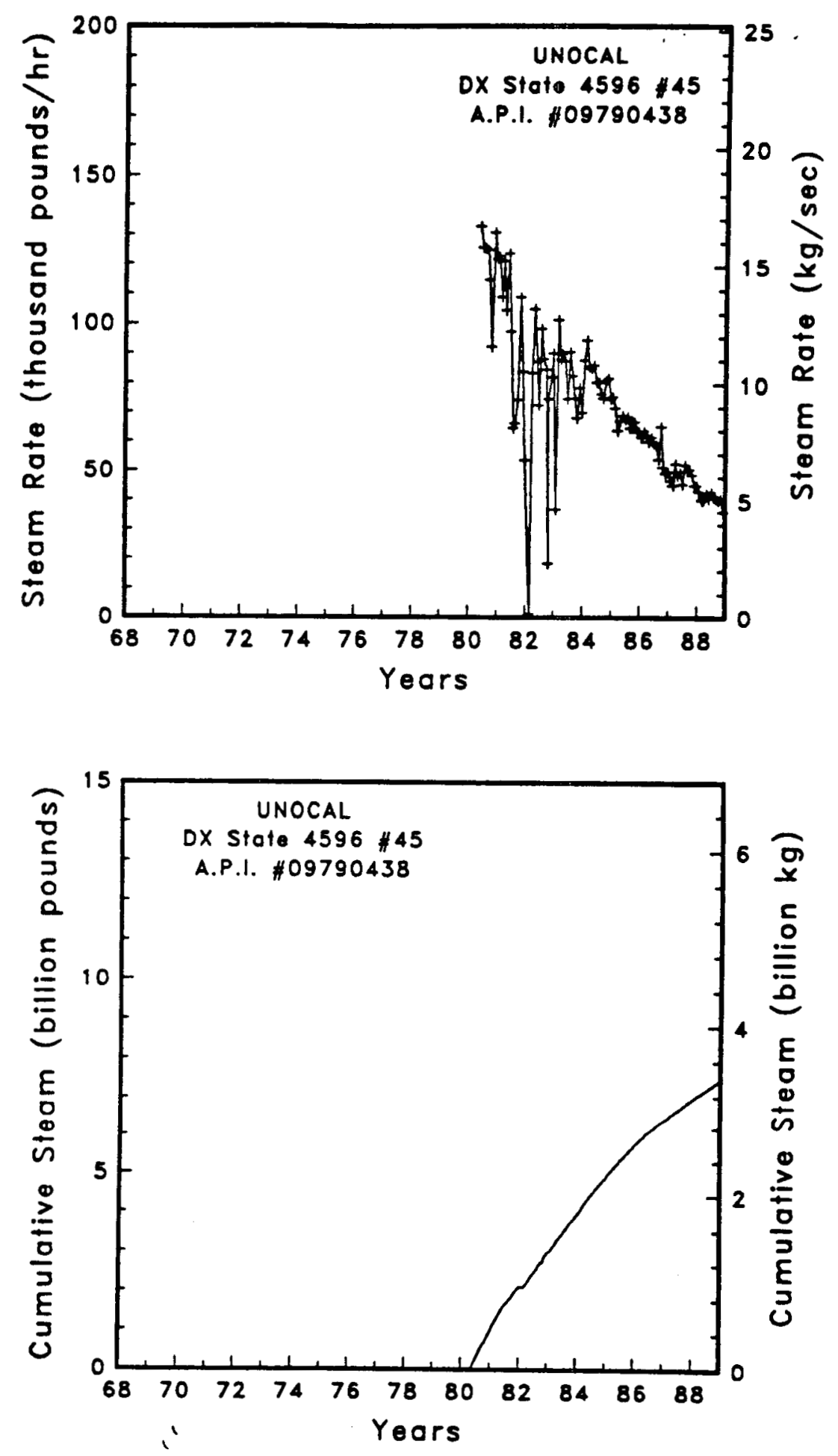

Figure A-5i Steam rate and cumulative mass flow for well DX State 4596 \#45 

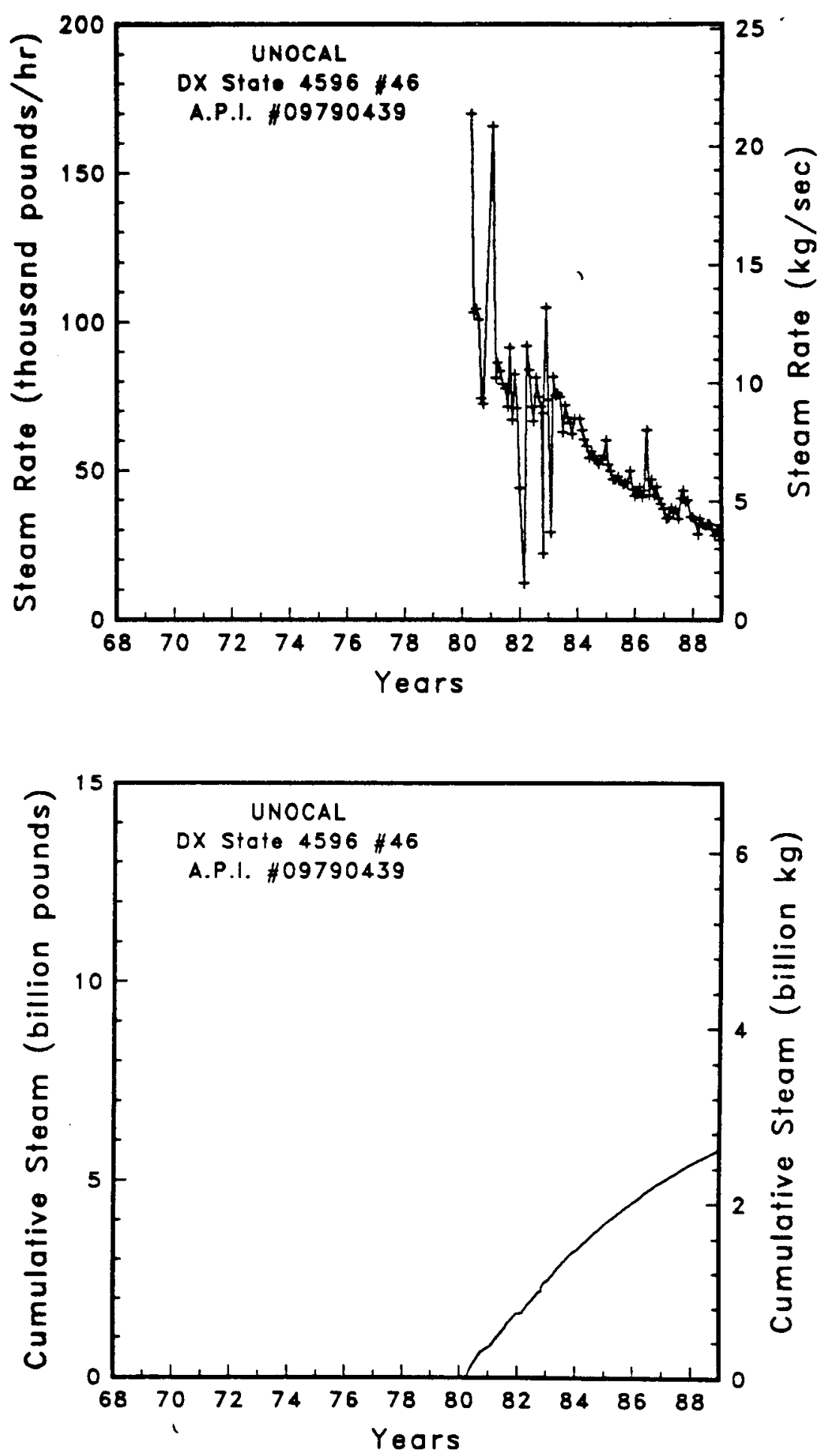

Figure A-58

Steam rate and cumulative mass flow for well DX State 4596 \#46 

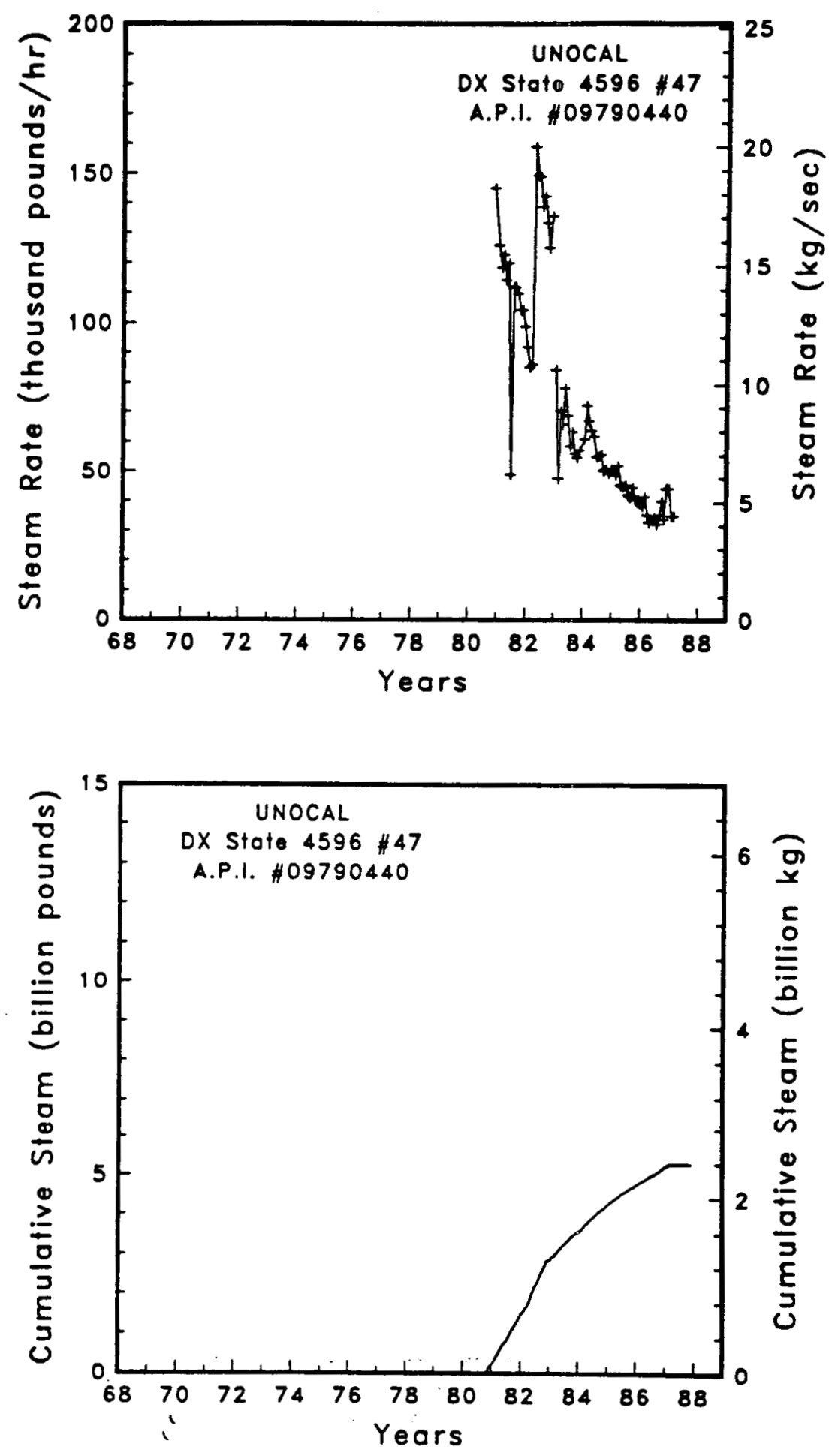

Figure A-59 well DX State 4596 \#47 

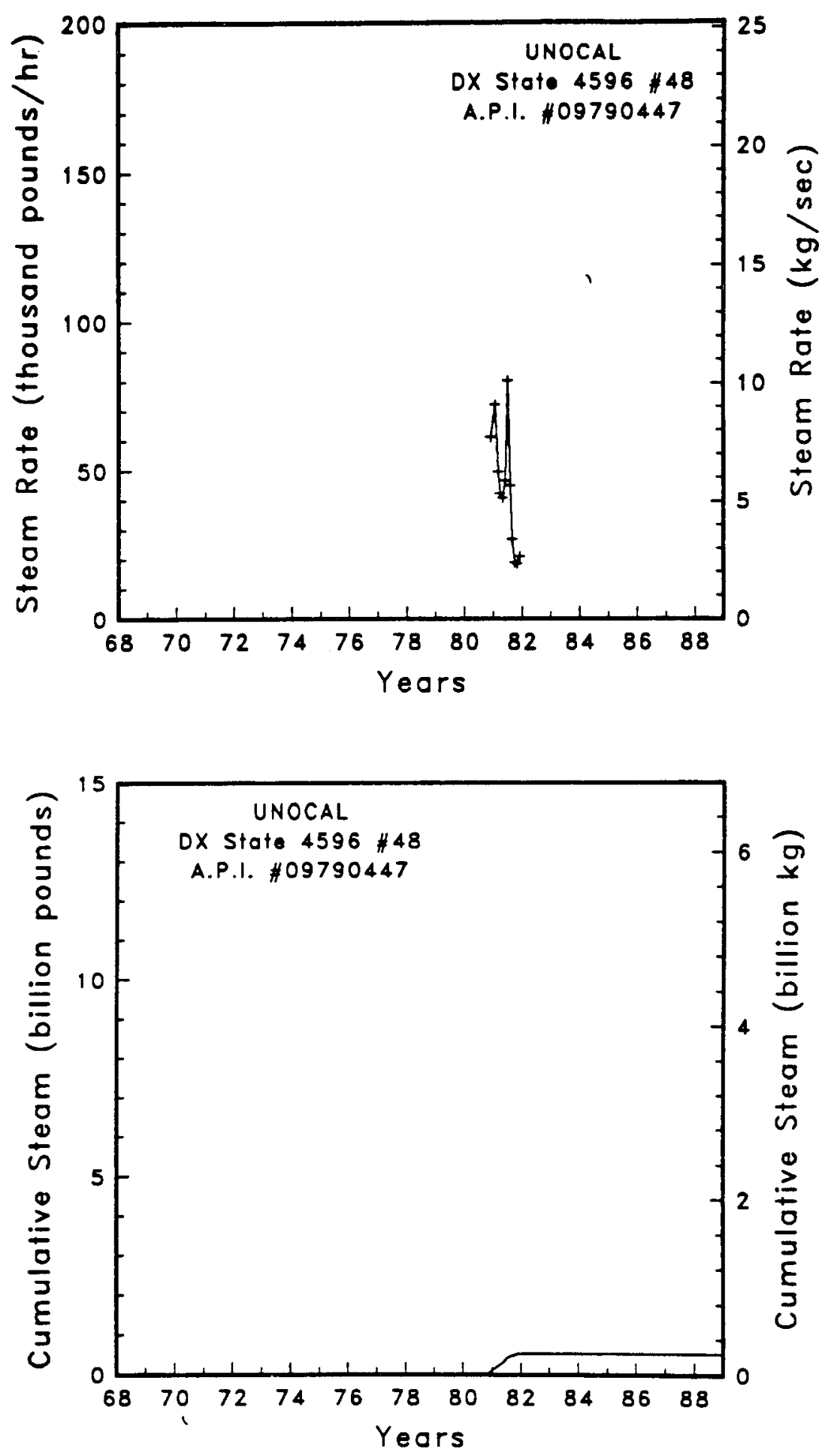

Figure A-60

Steam rate and cumulative mass flow for well DX State 4596 \#48 

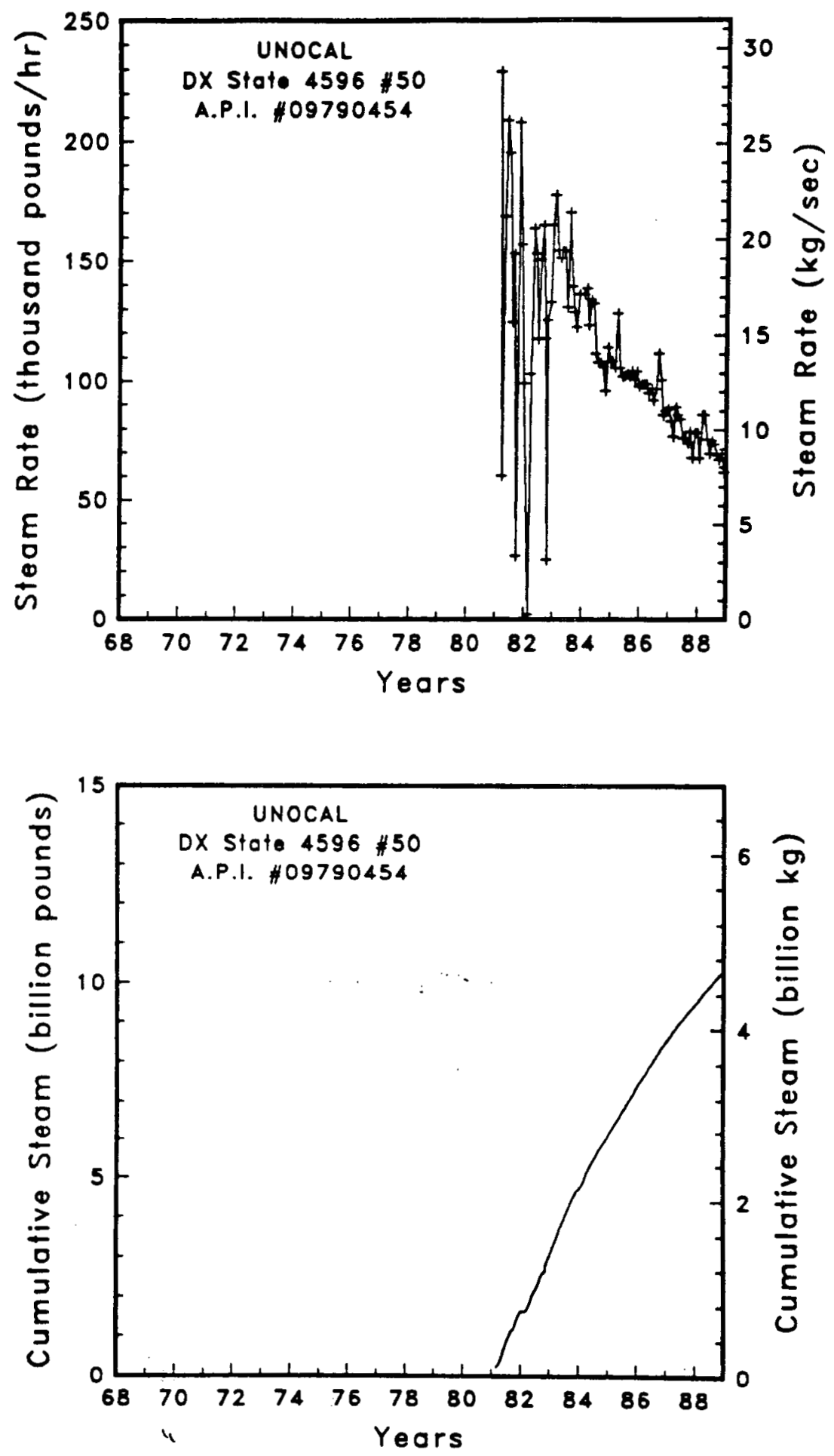

Figure A-61

Steam rate and cumulative mass flow for well DX State 4596 \#50 

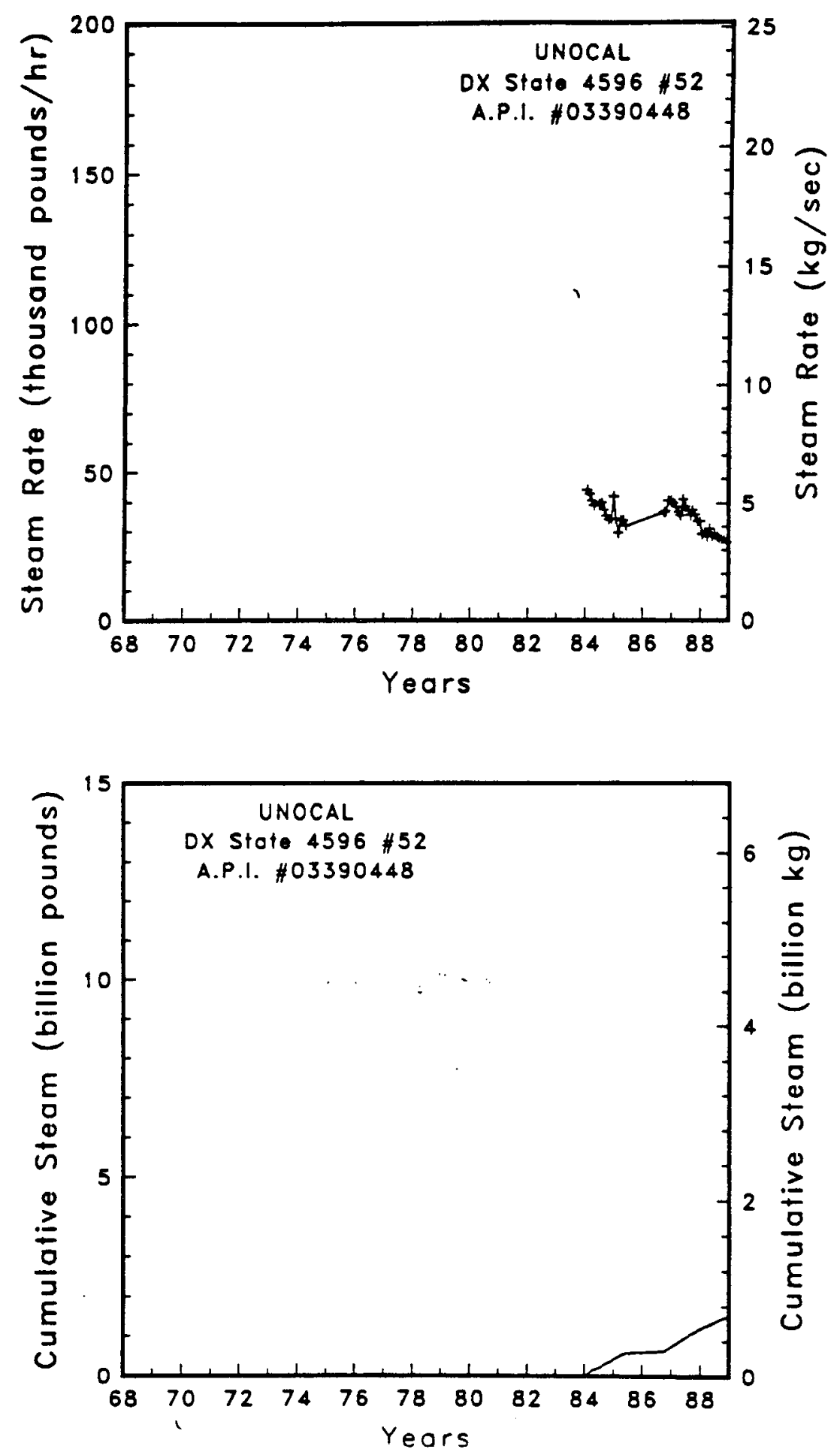

Figure A-62

Steam rate and cumulative mass flow for well DX State 4596 \#52 

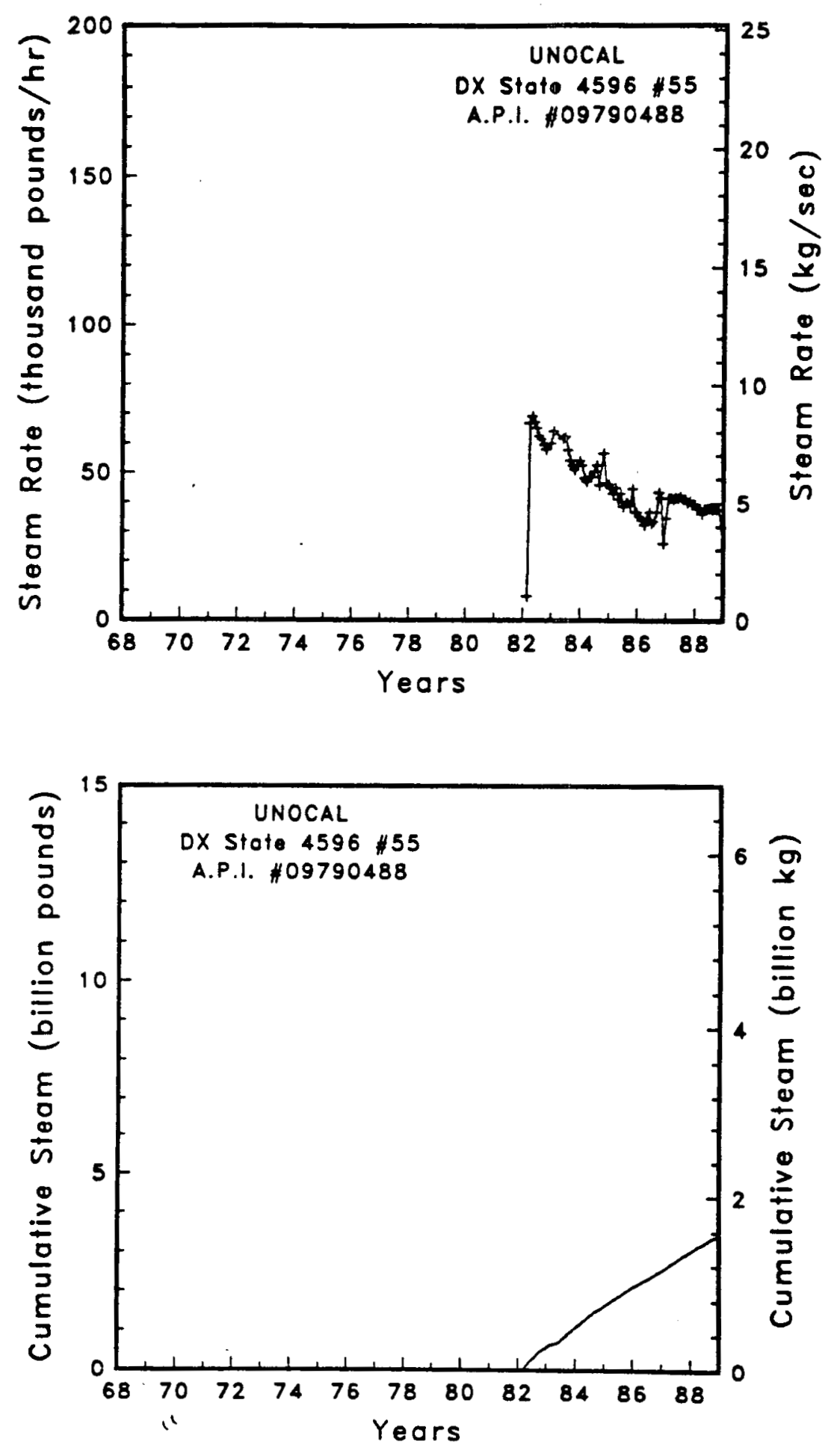

Figure A-63. Steam rate and cumulative mass flow for well DX State $4596 \# 55$ 

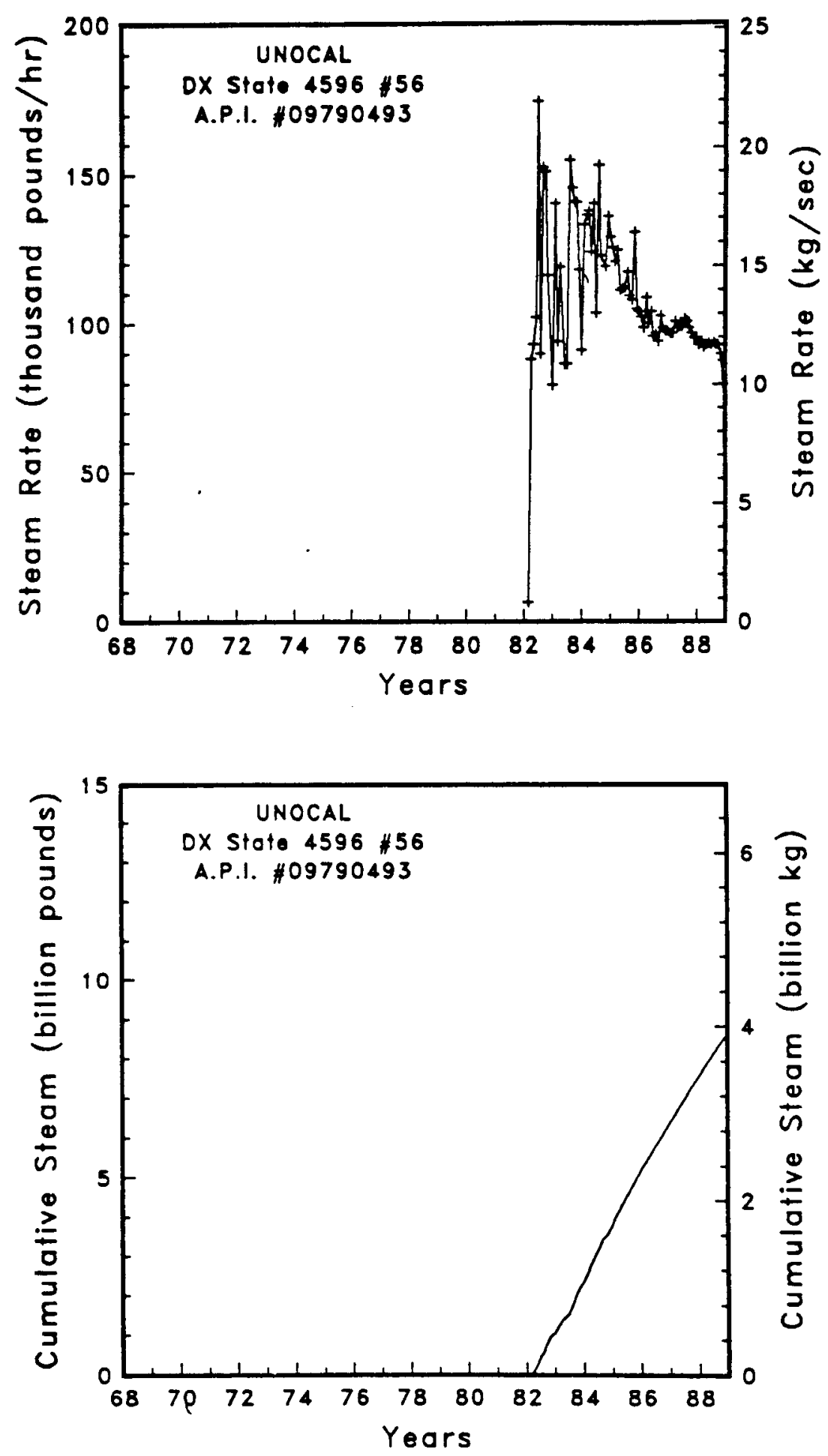

Figure A-64 Steam rate and cumulative mass flow for well DX State 4596 \#56 

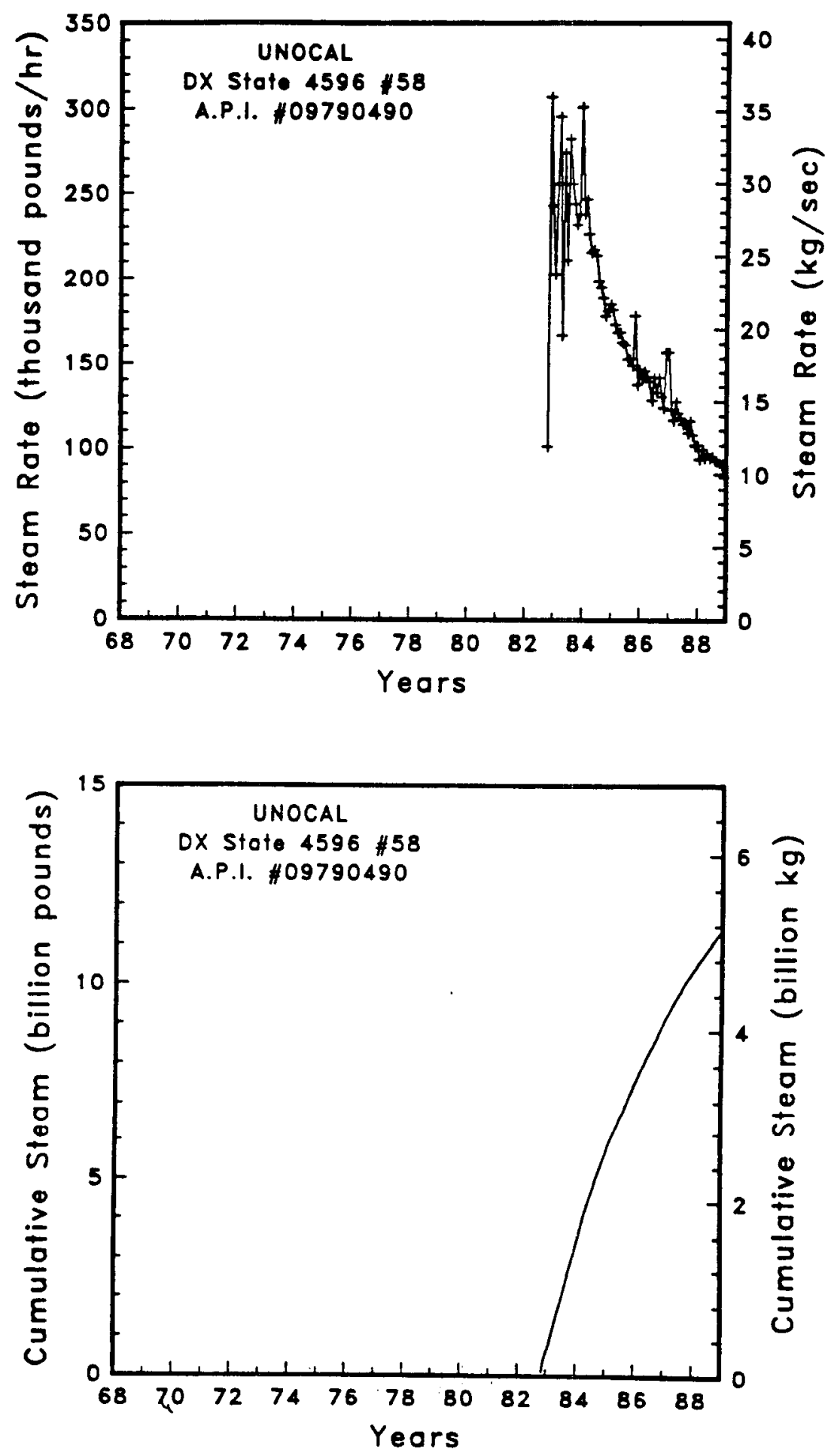

Figure A-65 Steom rate and cumulative mass flow for well DX State 4596 \#58 

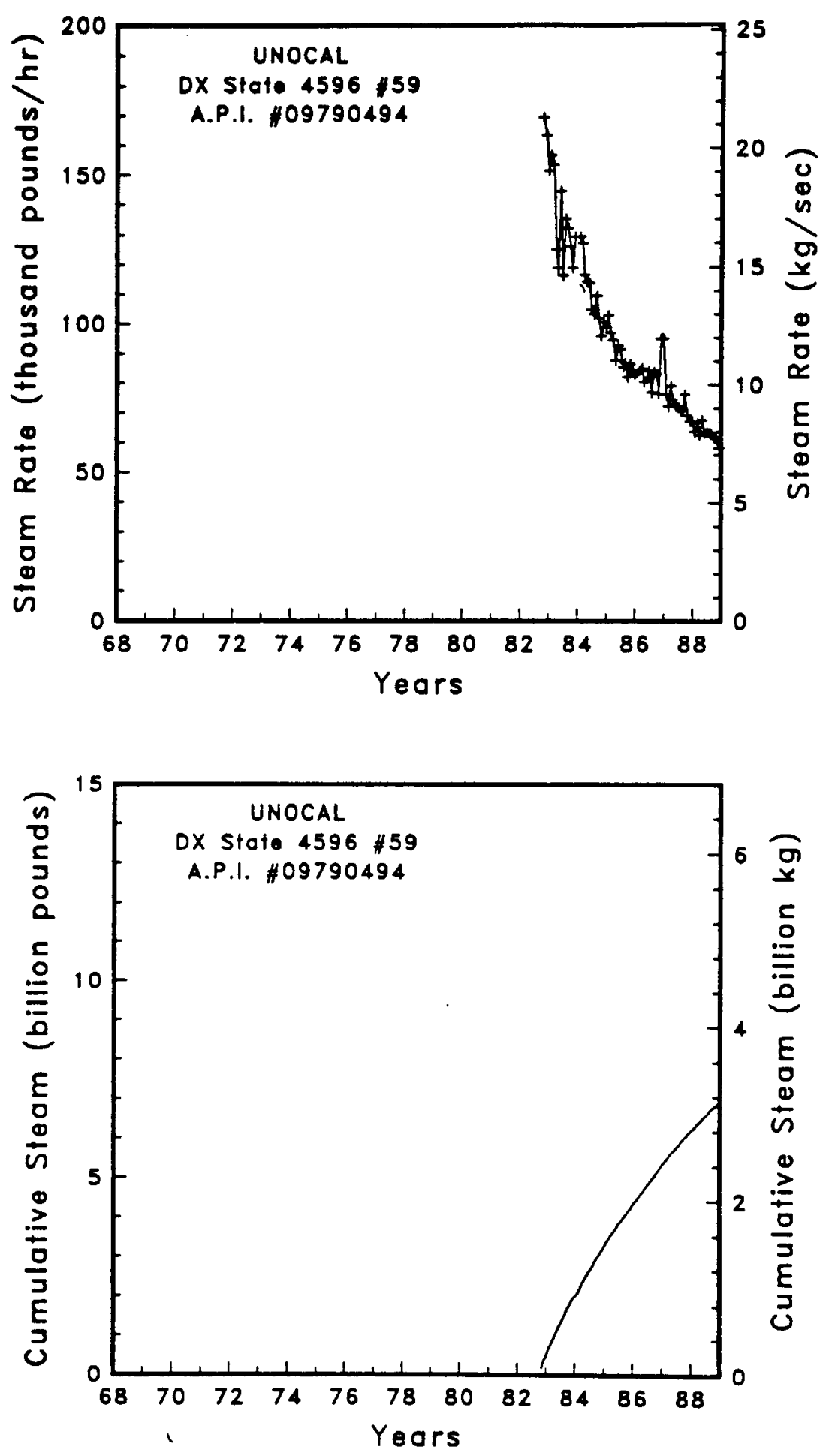

Figure A-66

Steam rate and cumulative mass flow for well DX State 4596 \#59 

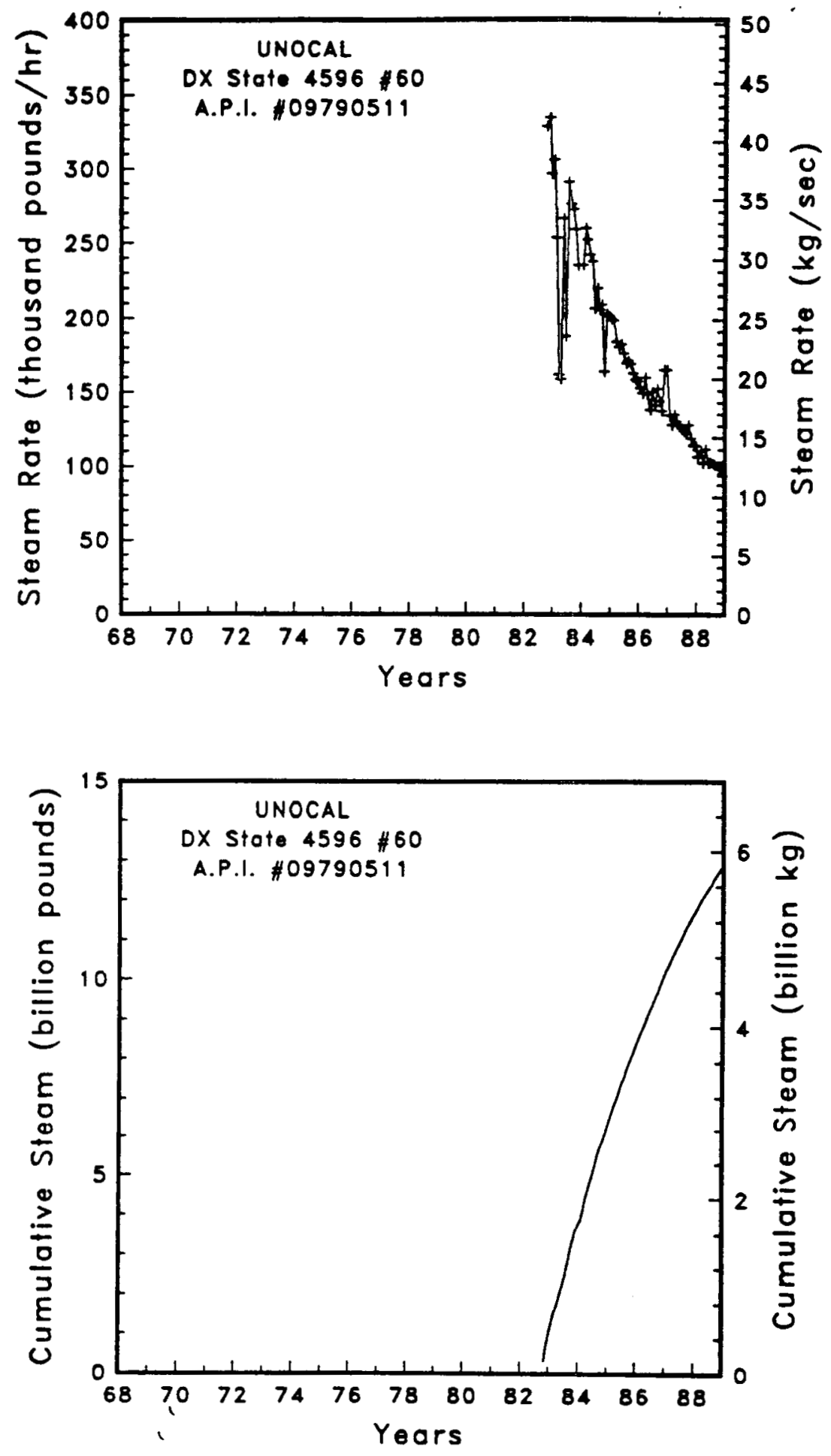

Figure A-67

Steam rote and cumulative mass flow for well DX State $4596 \# 60$ 

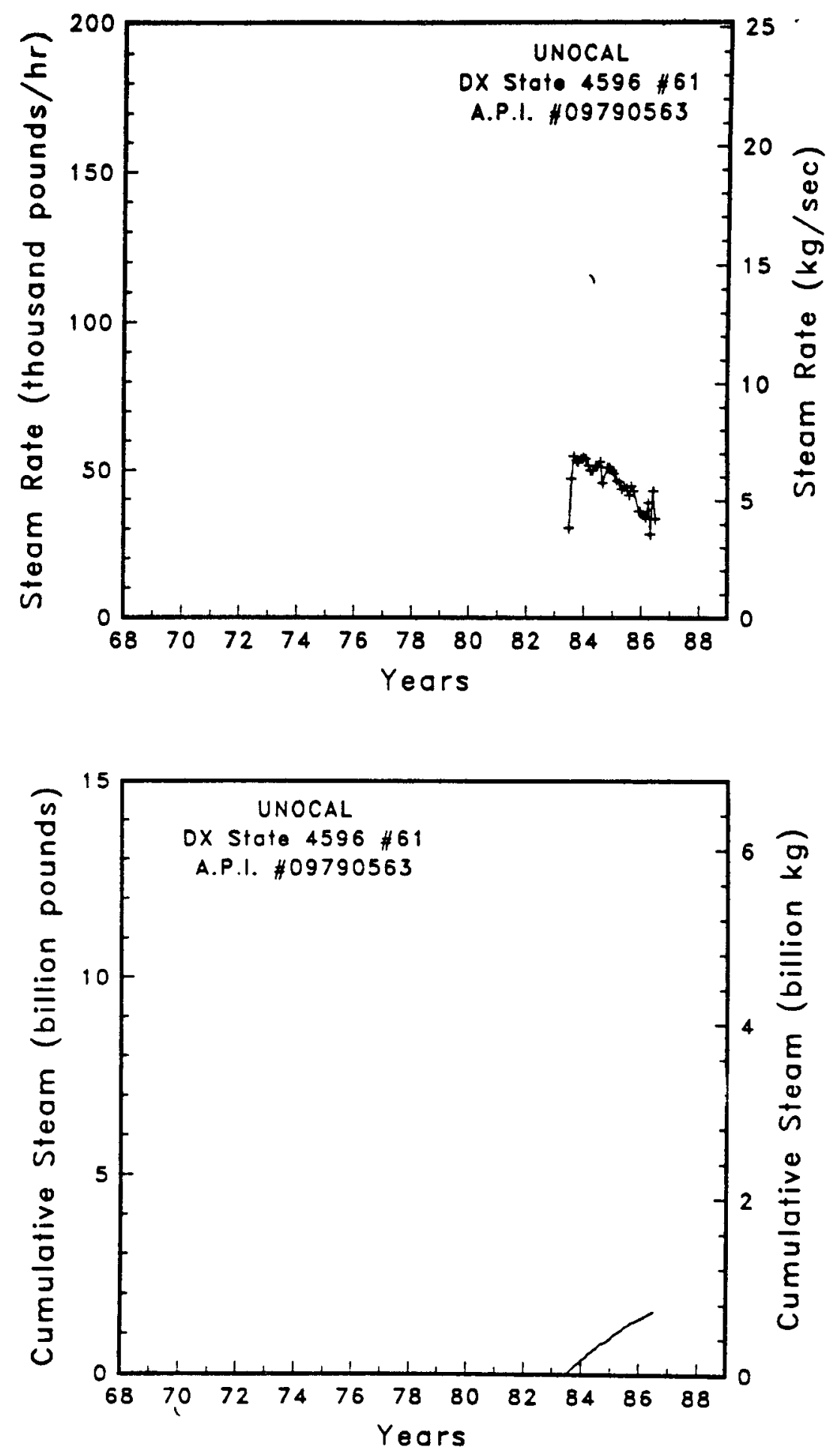

Figure A-68 Steam rate and cumulative mass flow for well DX State 4596 \#61 

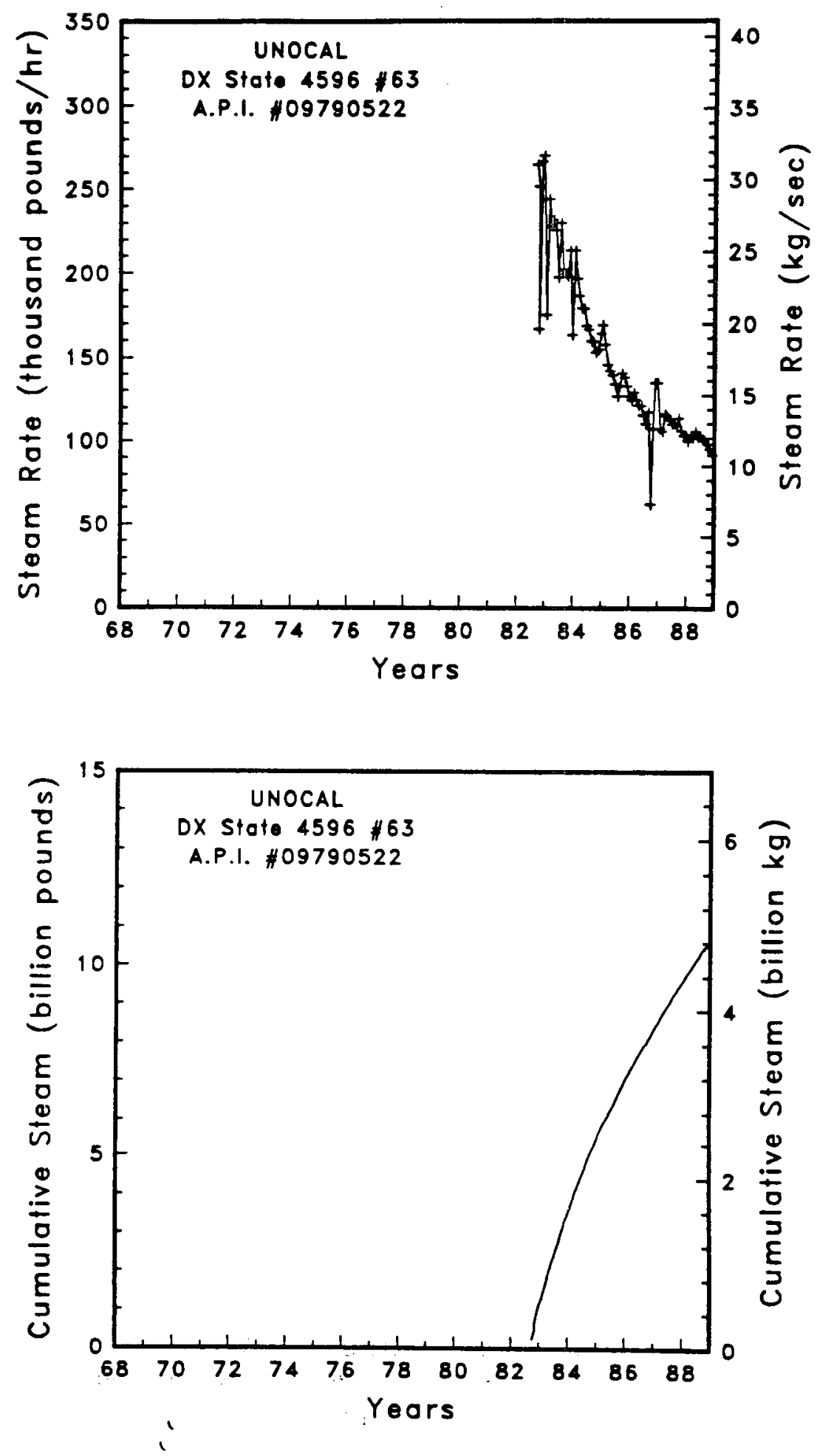

Figure A-69

Steam rote and cumulative mass flow for well DX State $4596 \# 63$ 

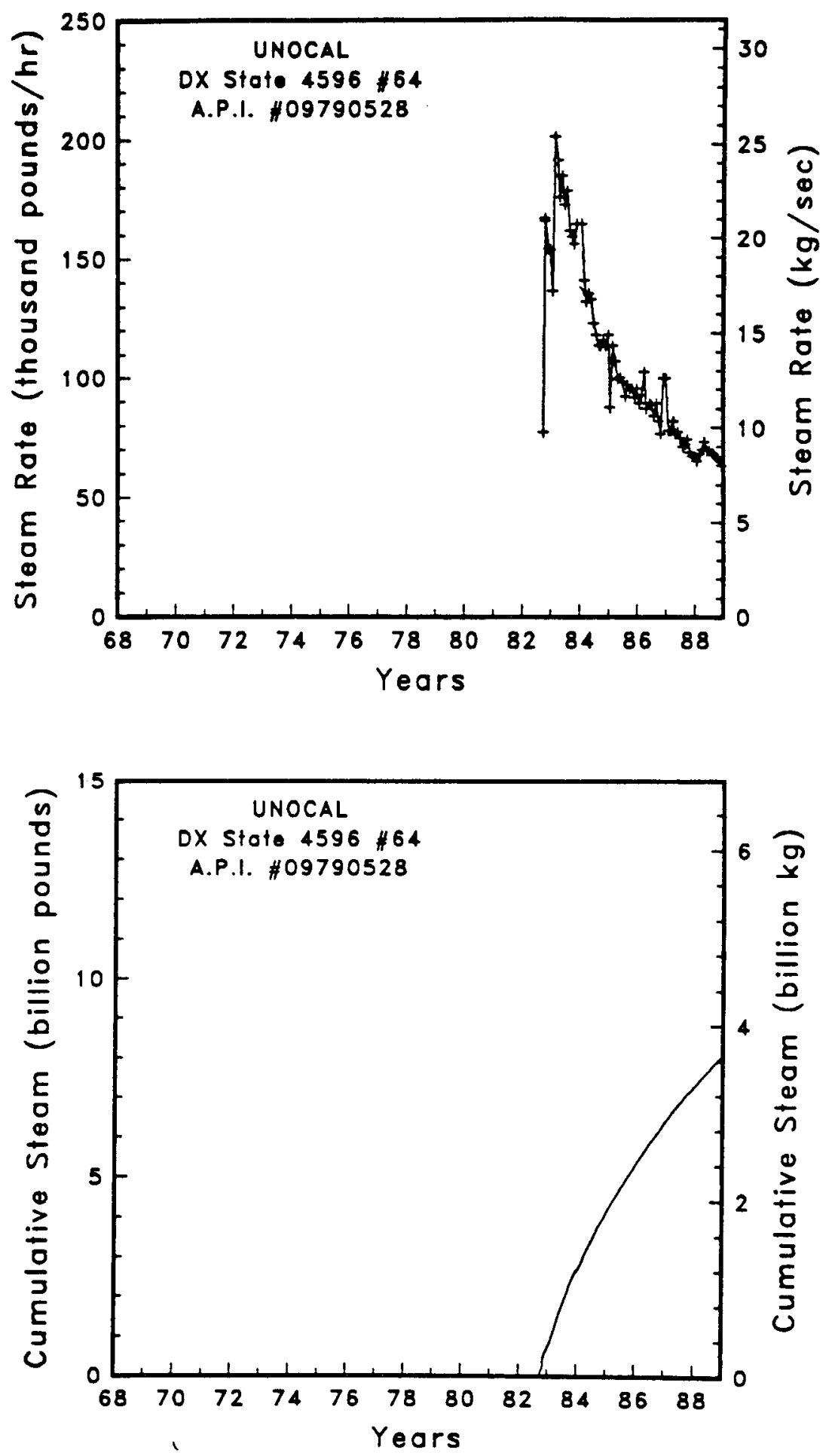

Figure A-70 Steam rate and cumulative mass flow for well DX State 4596 \#64 

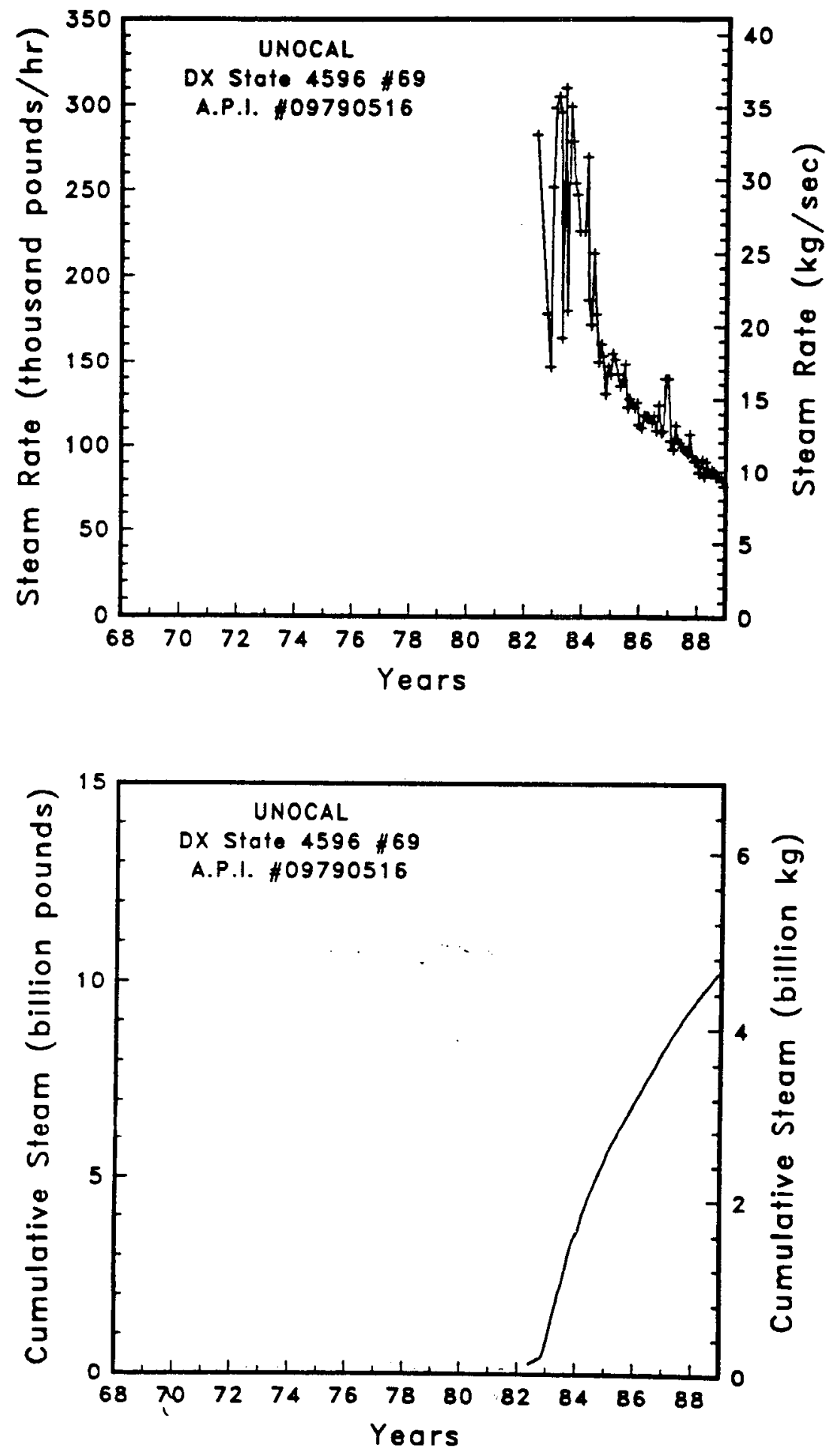

Figure A-71

Steam rate and cumulative mass flow for well DX State 4596 \#69 

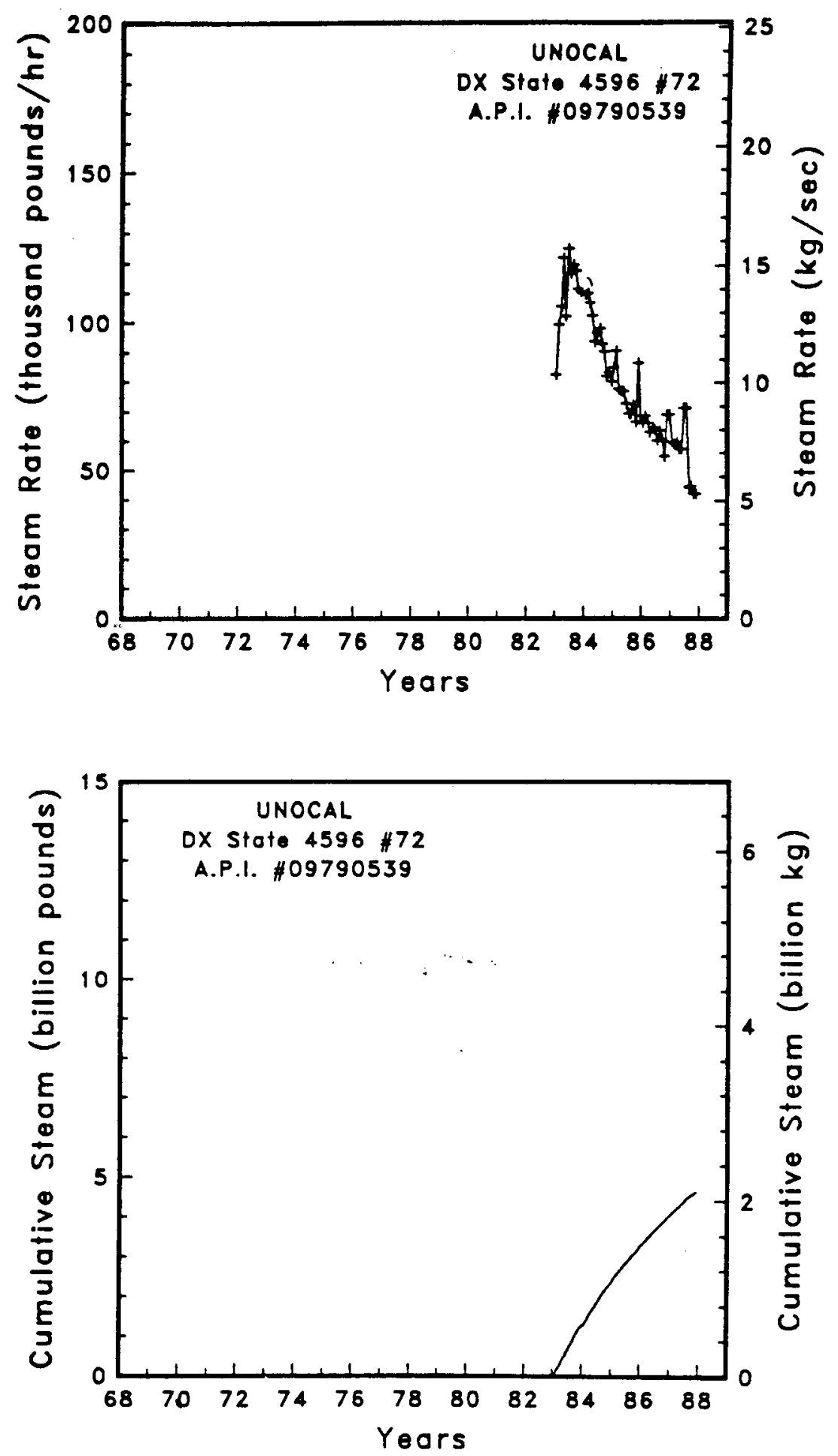

Figure A-72, Steam rate and cumulative mass flow for well DX State 4596 \#72 

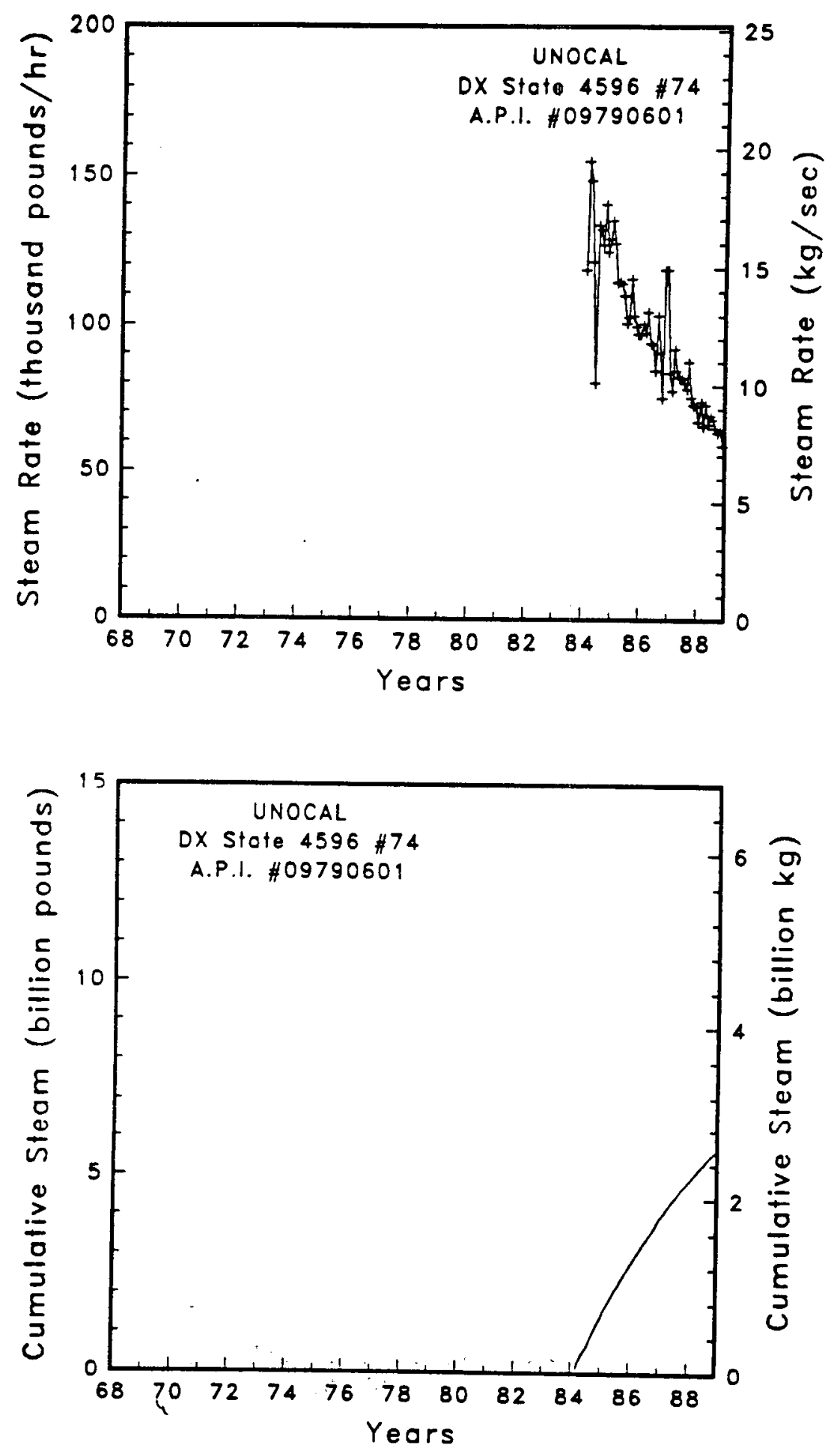

Figure A-73

Steam rate and cumulative mass flow for well DX State $4596 \# 74$ 

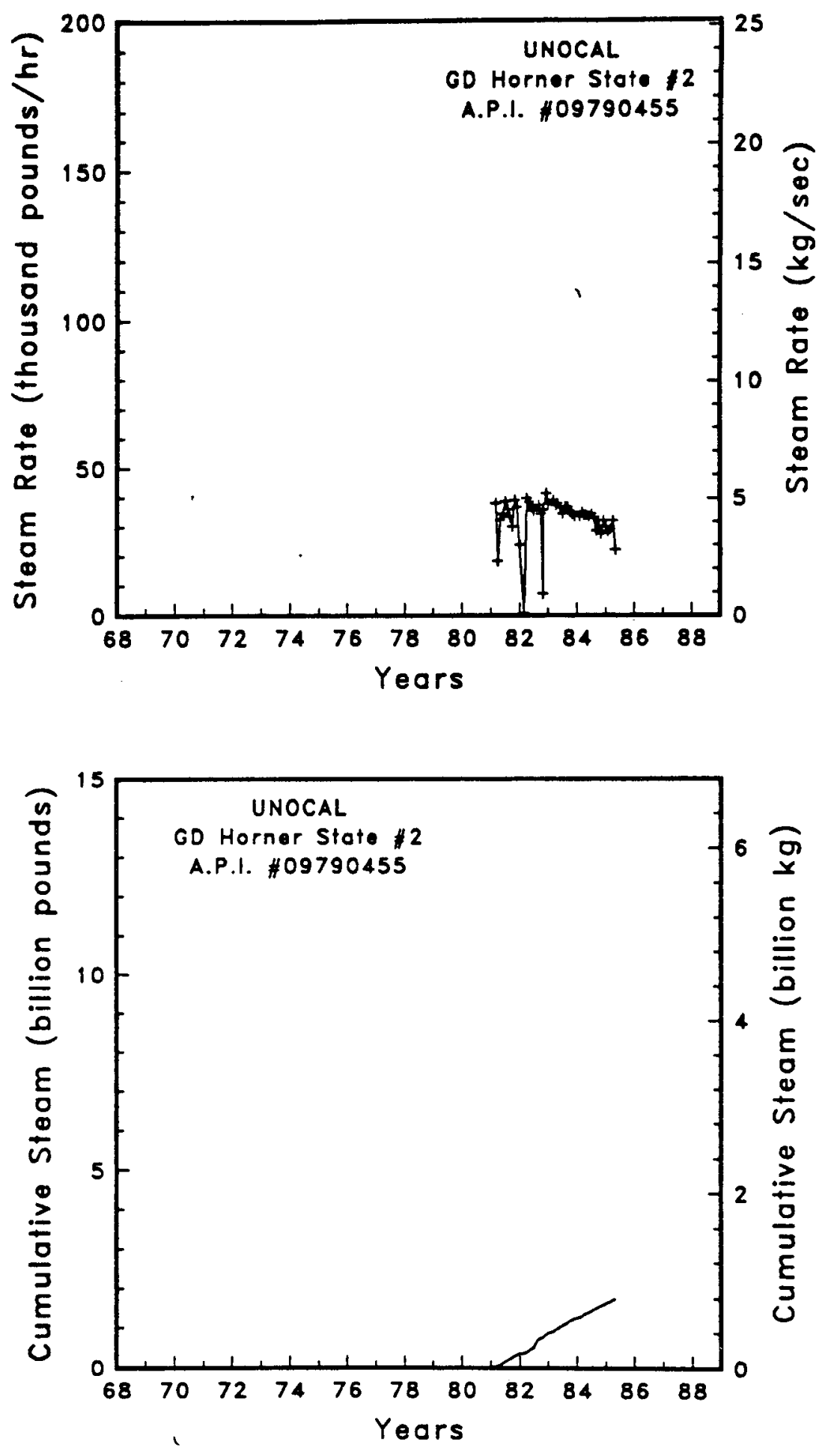

Figure A-74 Steam rate and cumulative mass flow for well GD Horner State \#2 

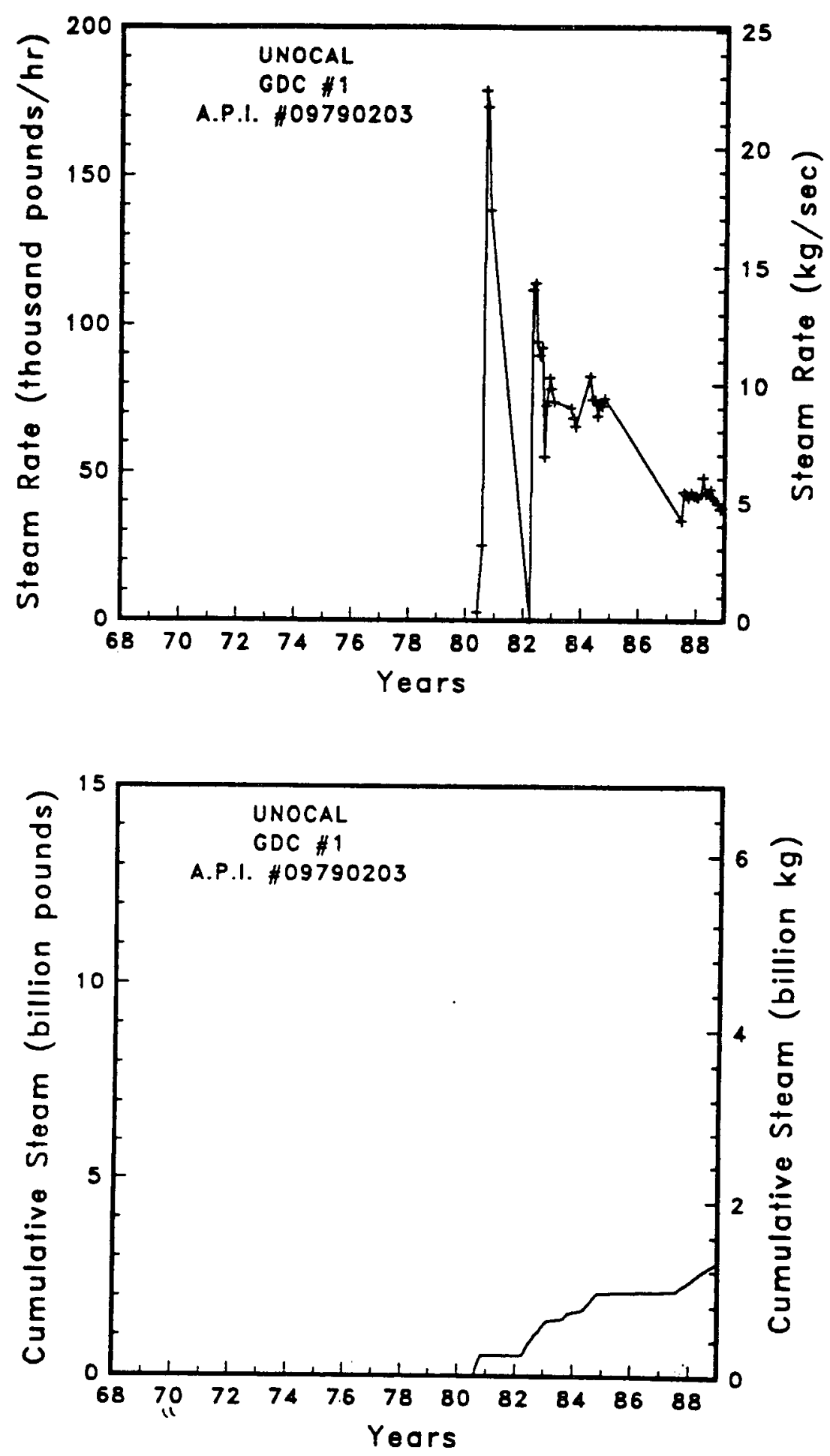

Figure A-75 Steam rate and cumulative mass flow for
well GDC \#1 

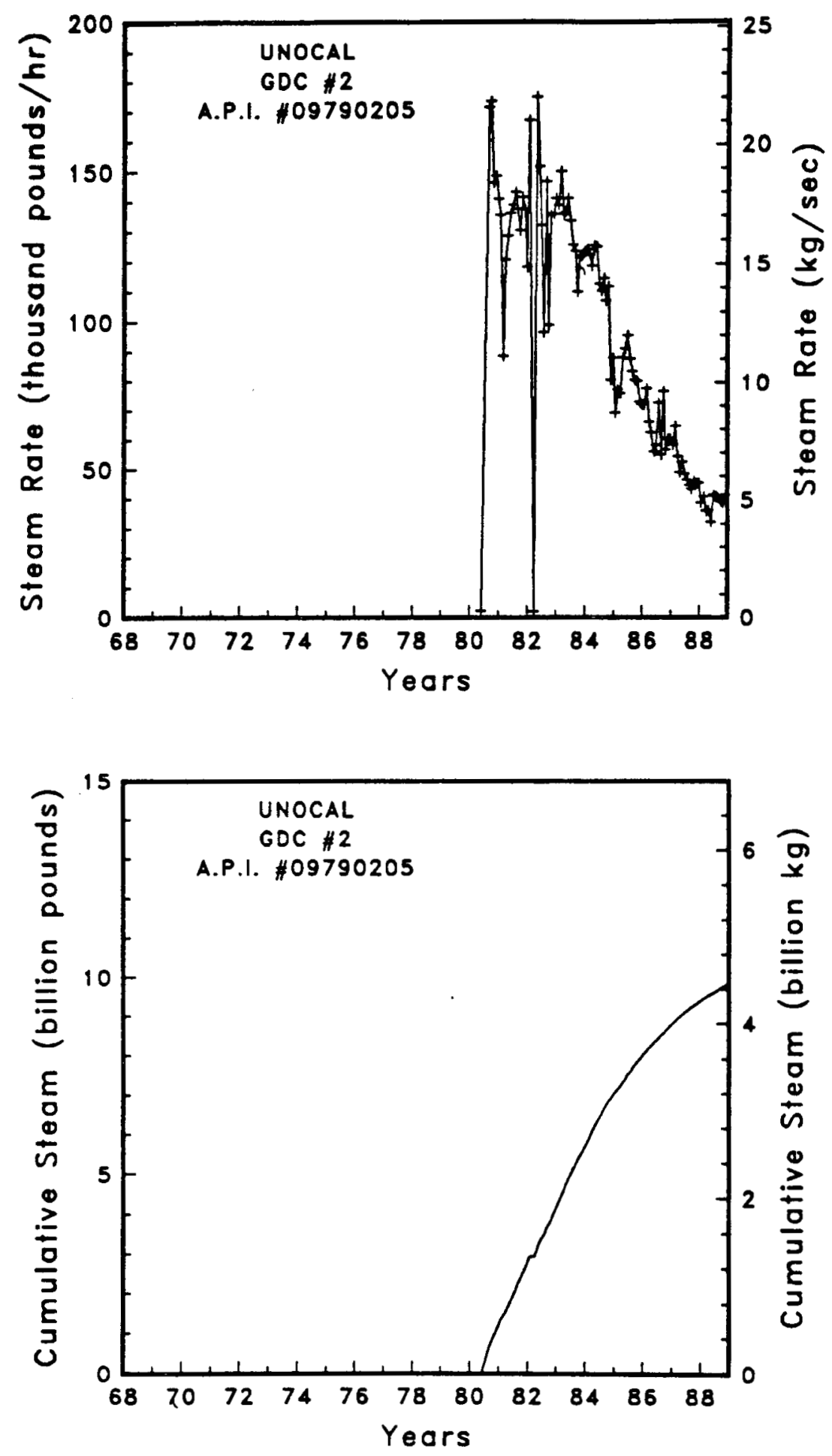

Figure A-76

Steam rate and cumulative mass flow for well GDC \#2 

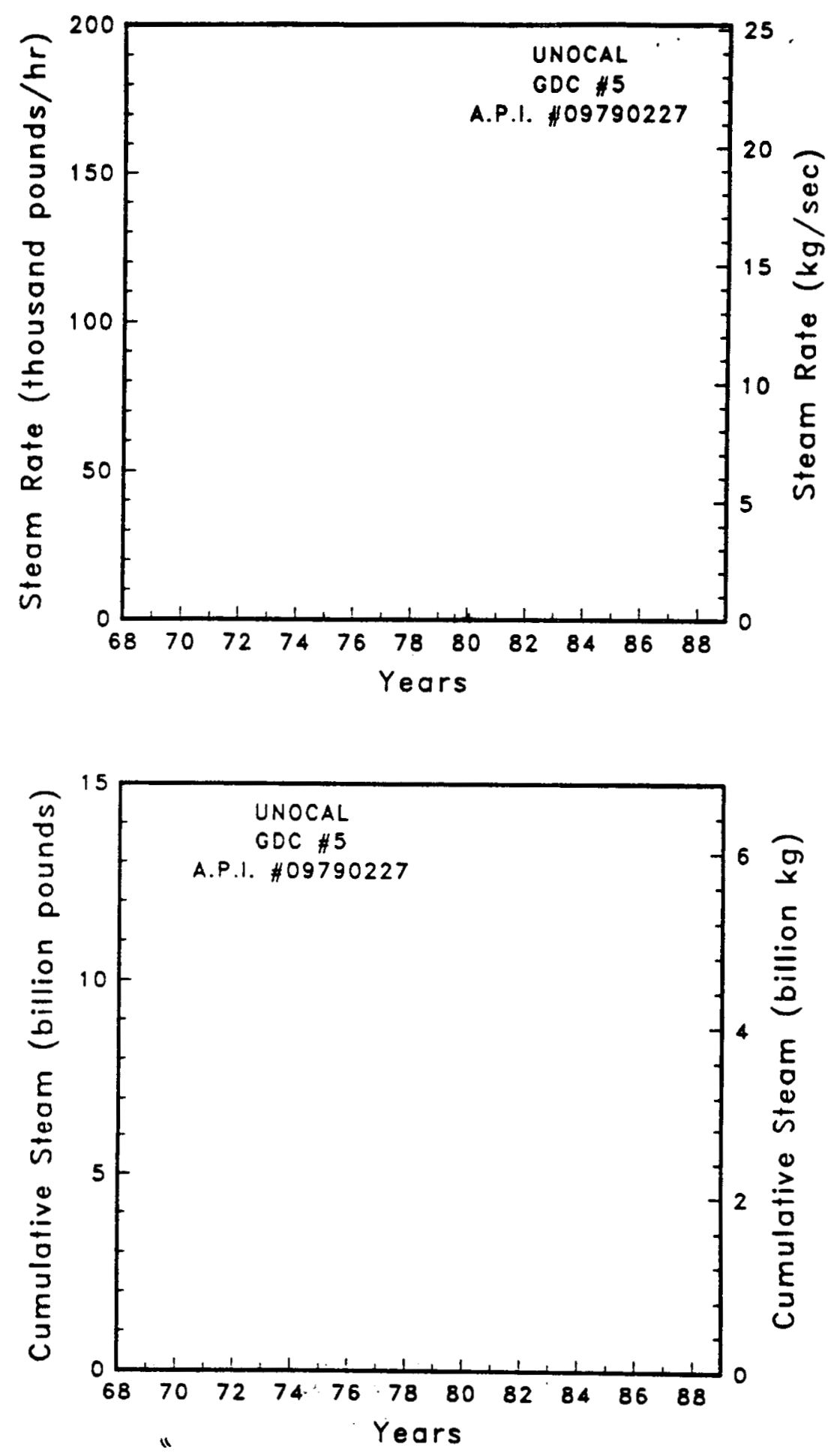

Figure A-77

Steam rate and cumulative mass flow for well GDC \#5 

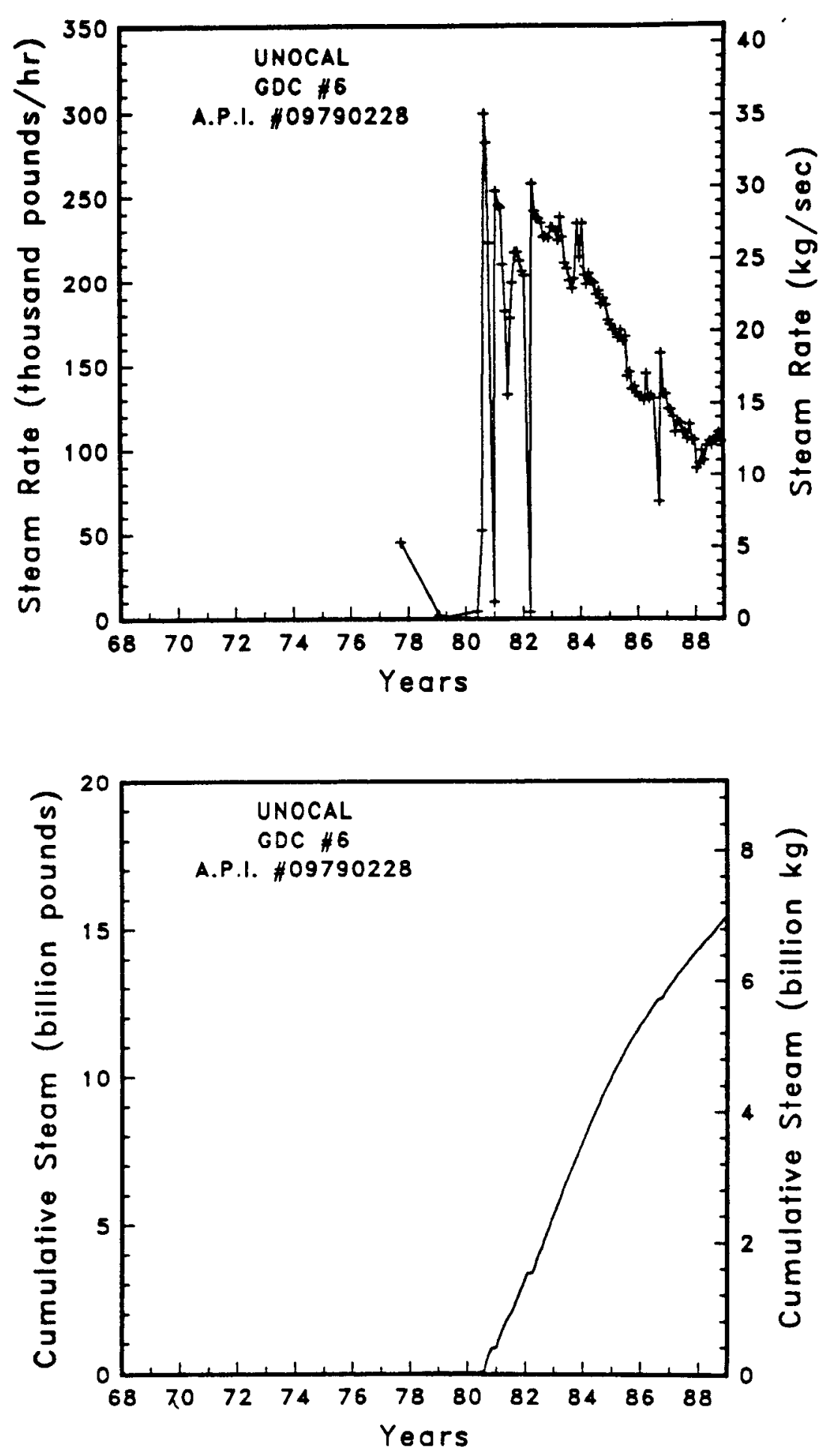

Figure A-78 Steam rate and cumulative mass flow for well GDC \#6 

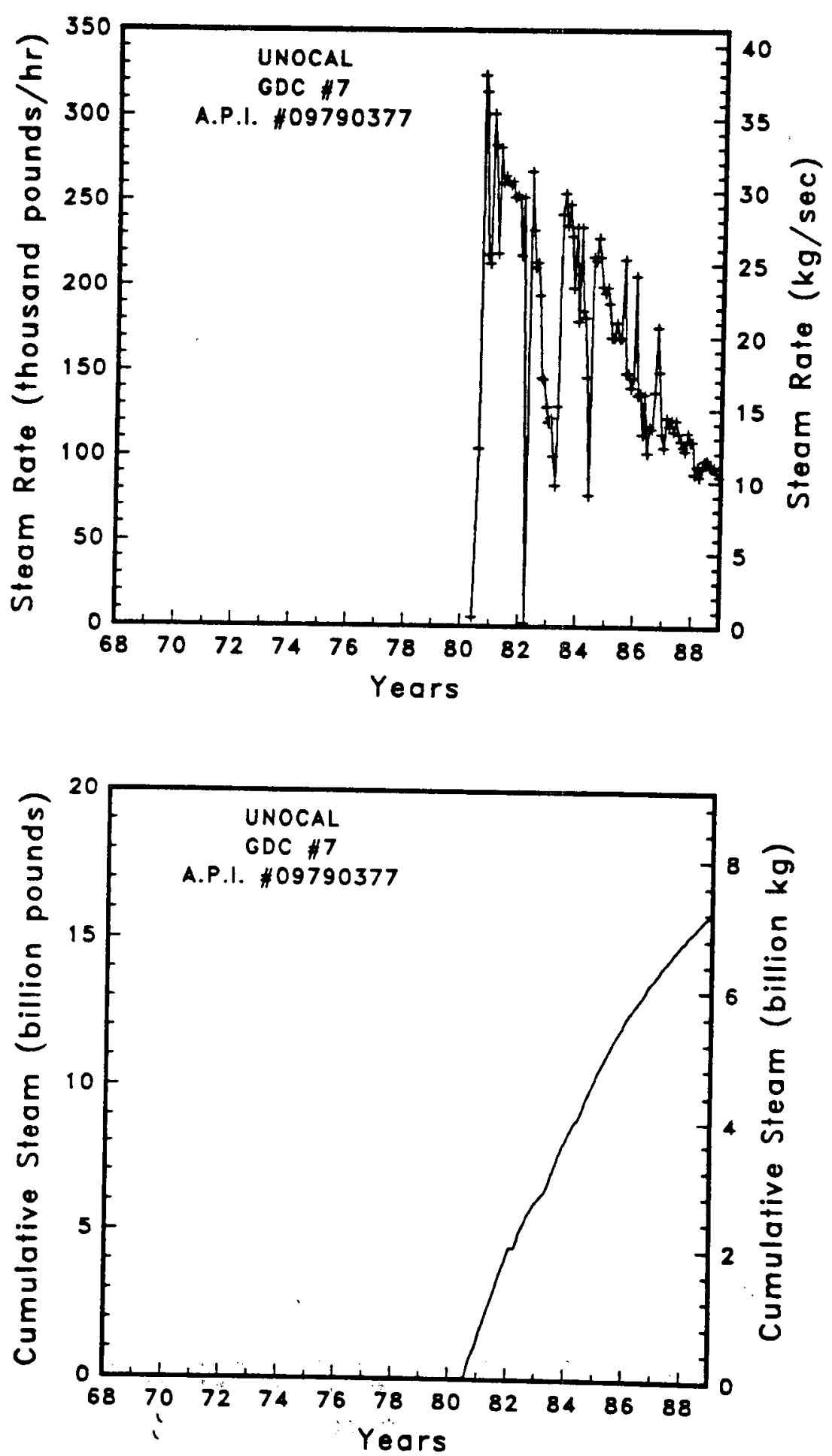

Figure A-79

Steam rate and cumulative mass flow for
well $G D C \# 7$ 

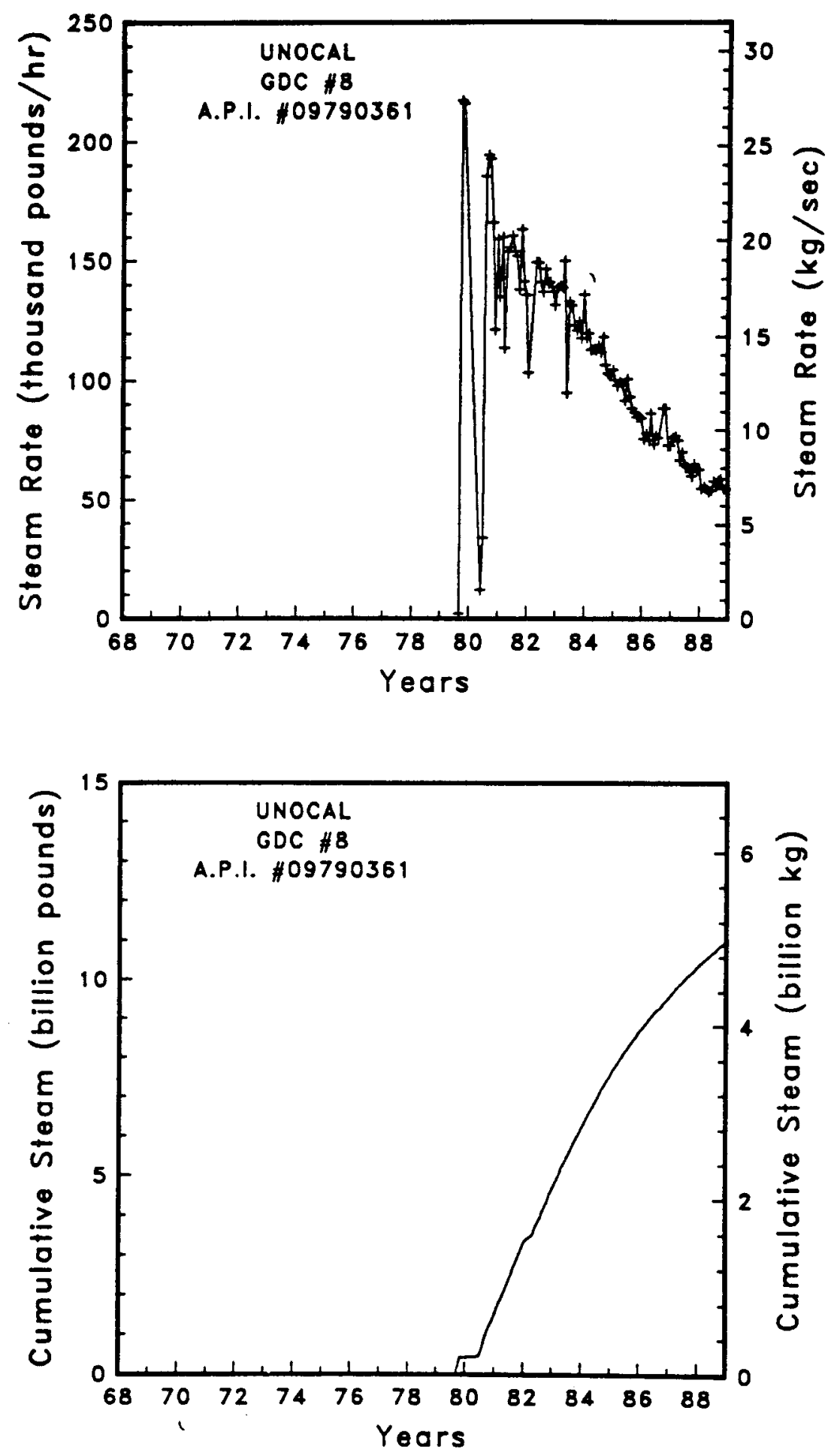

Figure A-80 Steam rate and cumulative mass flow for well GDC \#8 

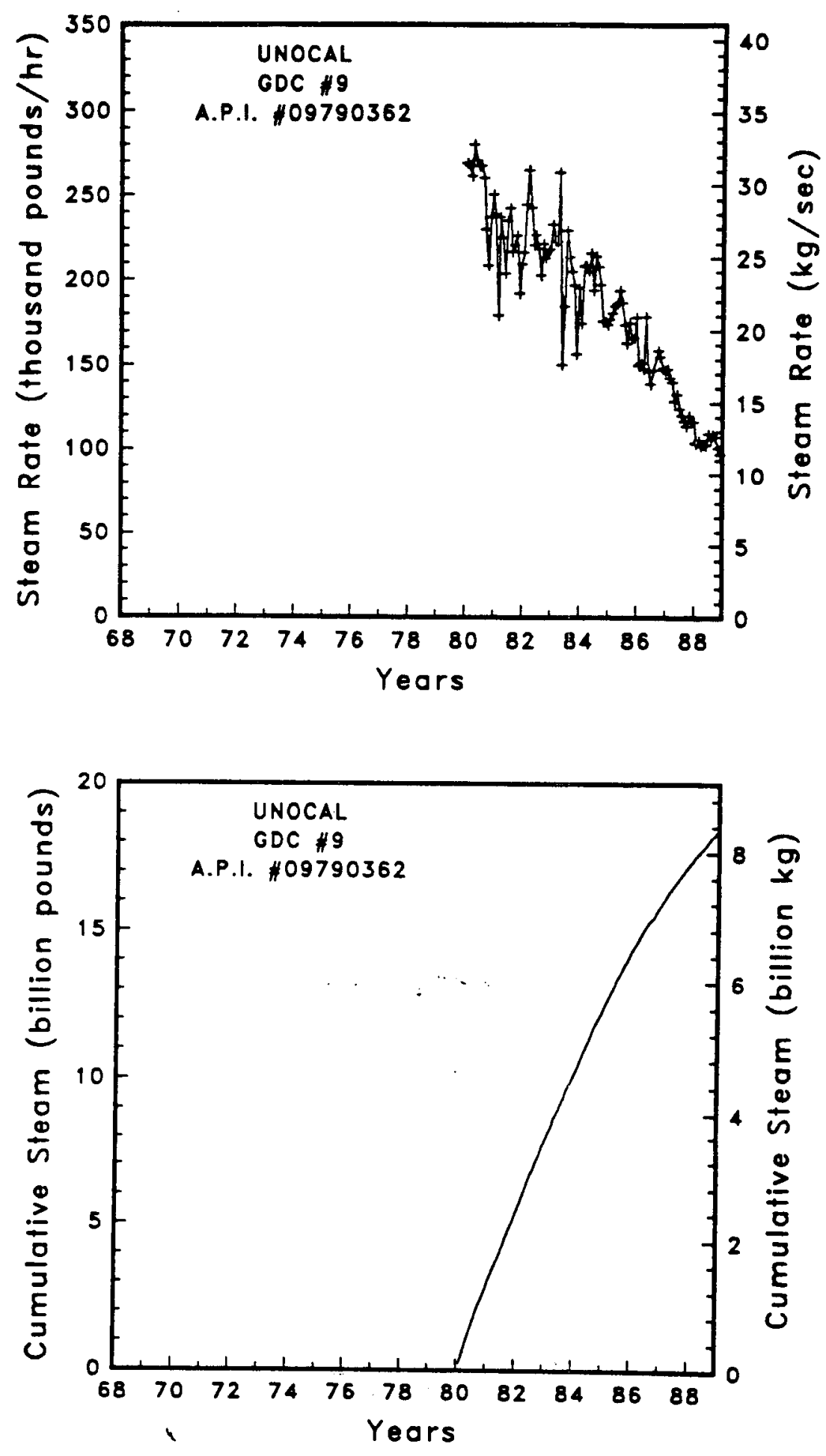

Figure A-81 Steam rate and cumulative mass flow for
well GDC \#9 

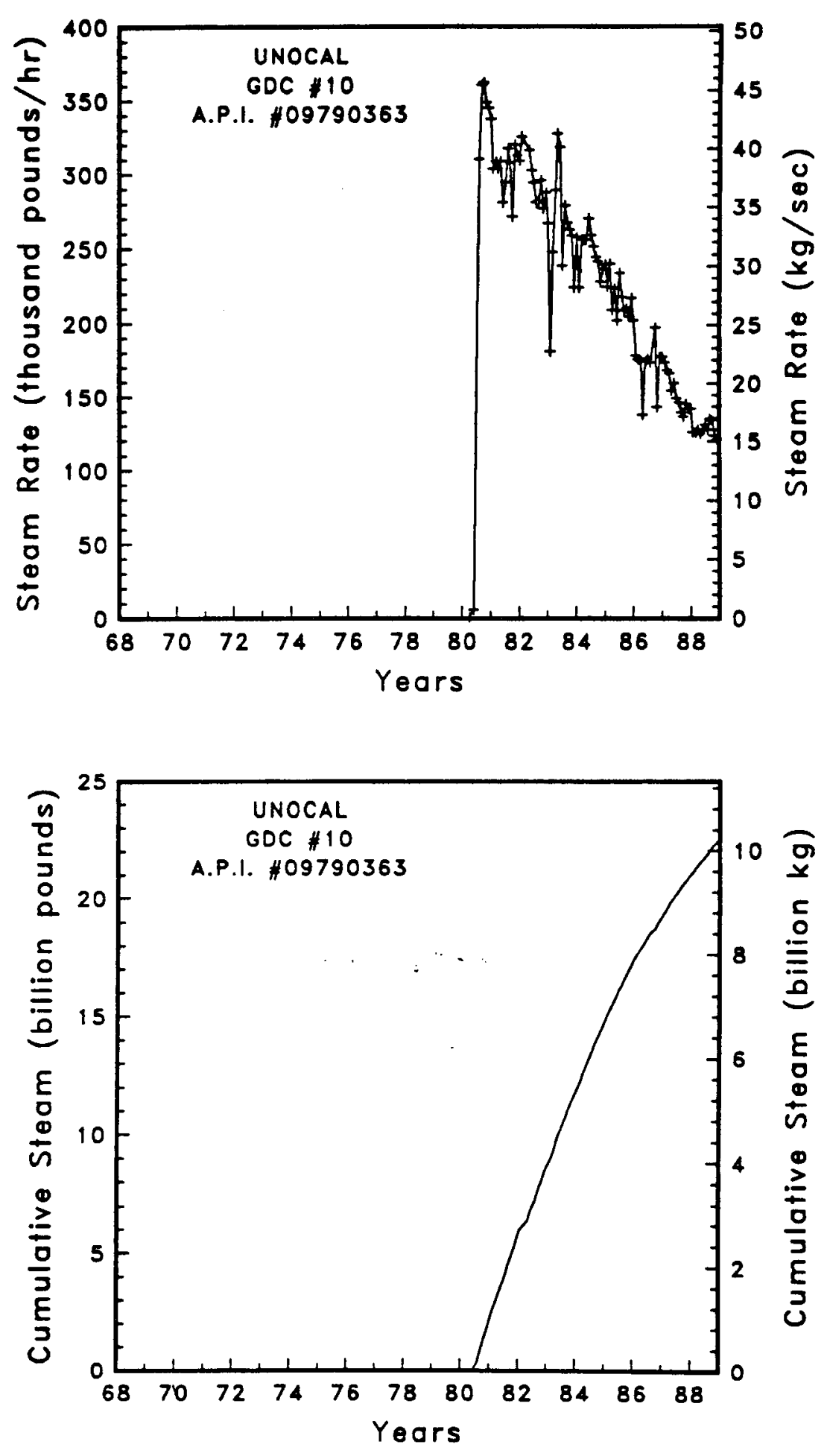

Figure A-82

Steam rate and cumulative mass flow for well GDC \#10 

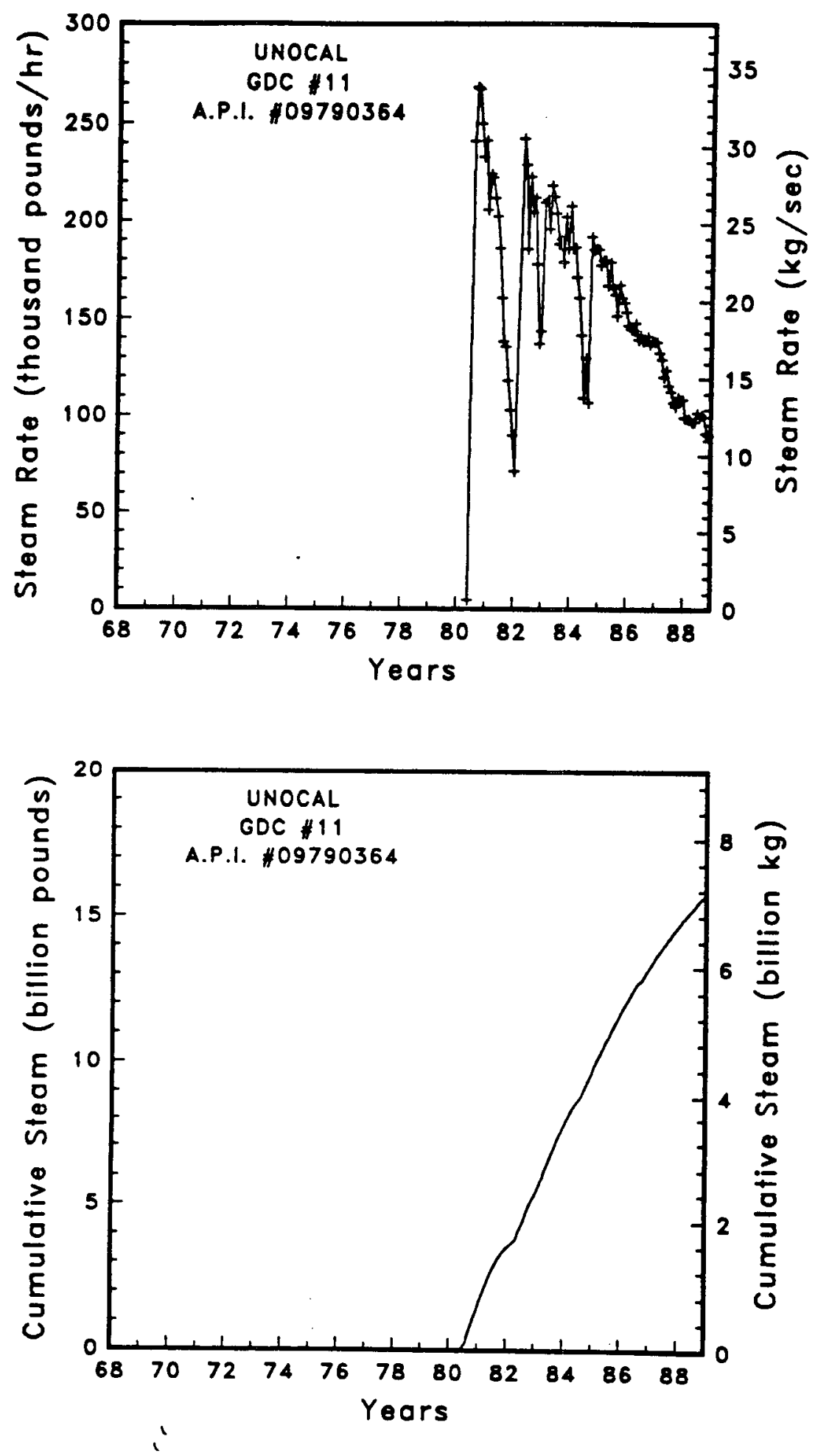

Figure A-83. Steam rate and cumulative moss flow for well GDC \#11 

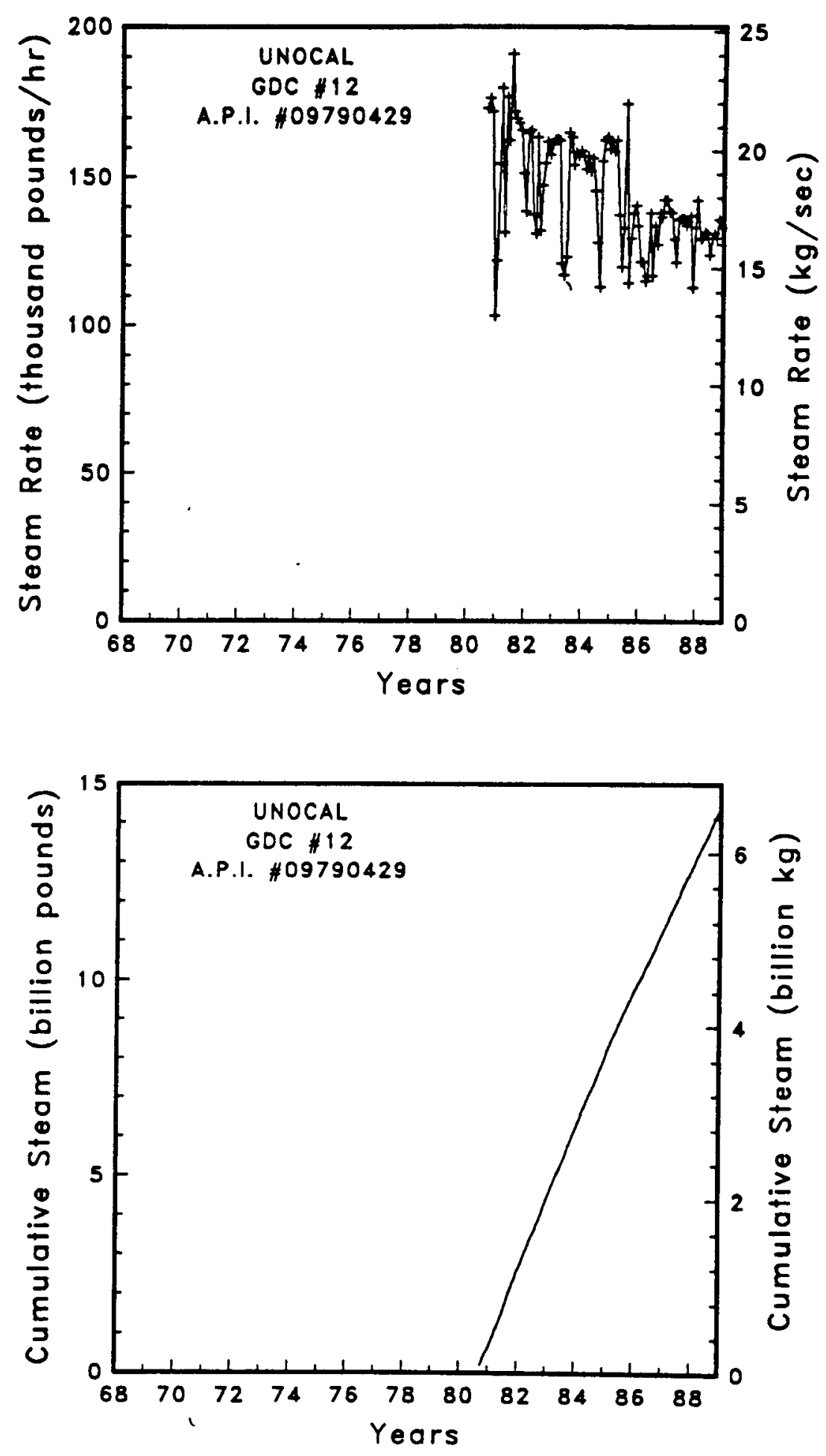

Figure A-84

Steam rate and cumulative mass flow for well GDC \#12 

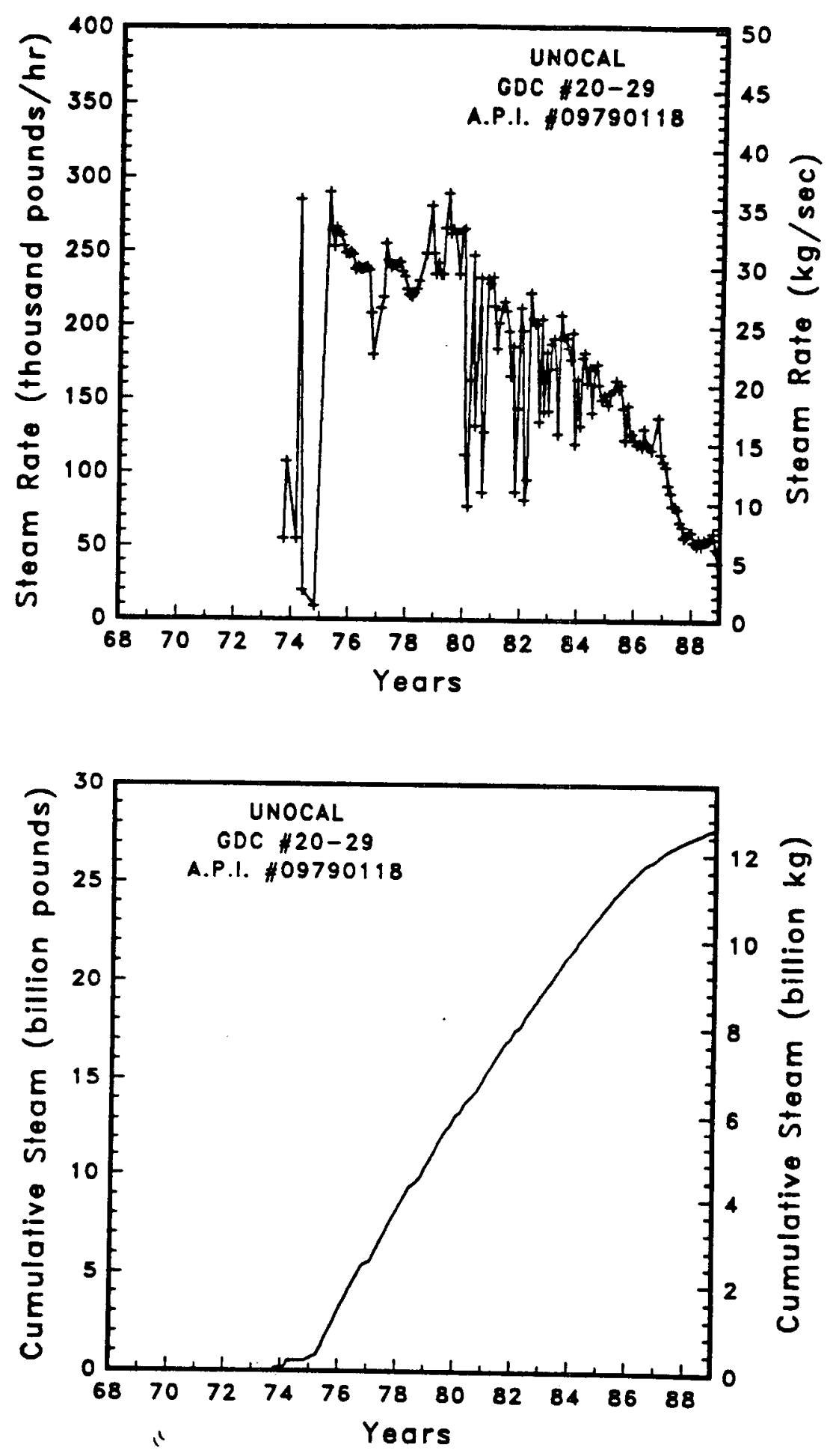

Figure A-85 Steam rote and cumulative mass flow for
well GDC $\# 20-29$ 

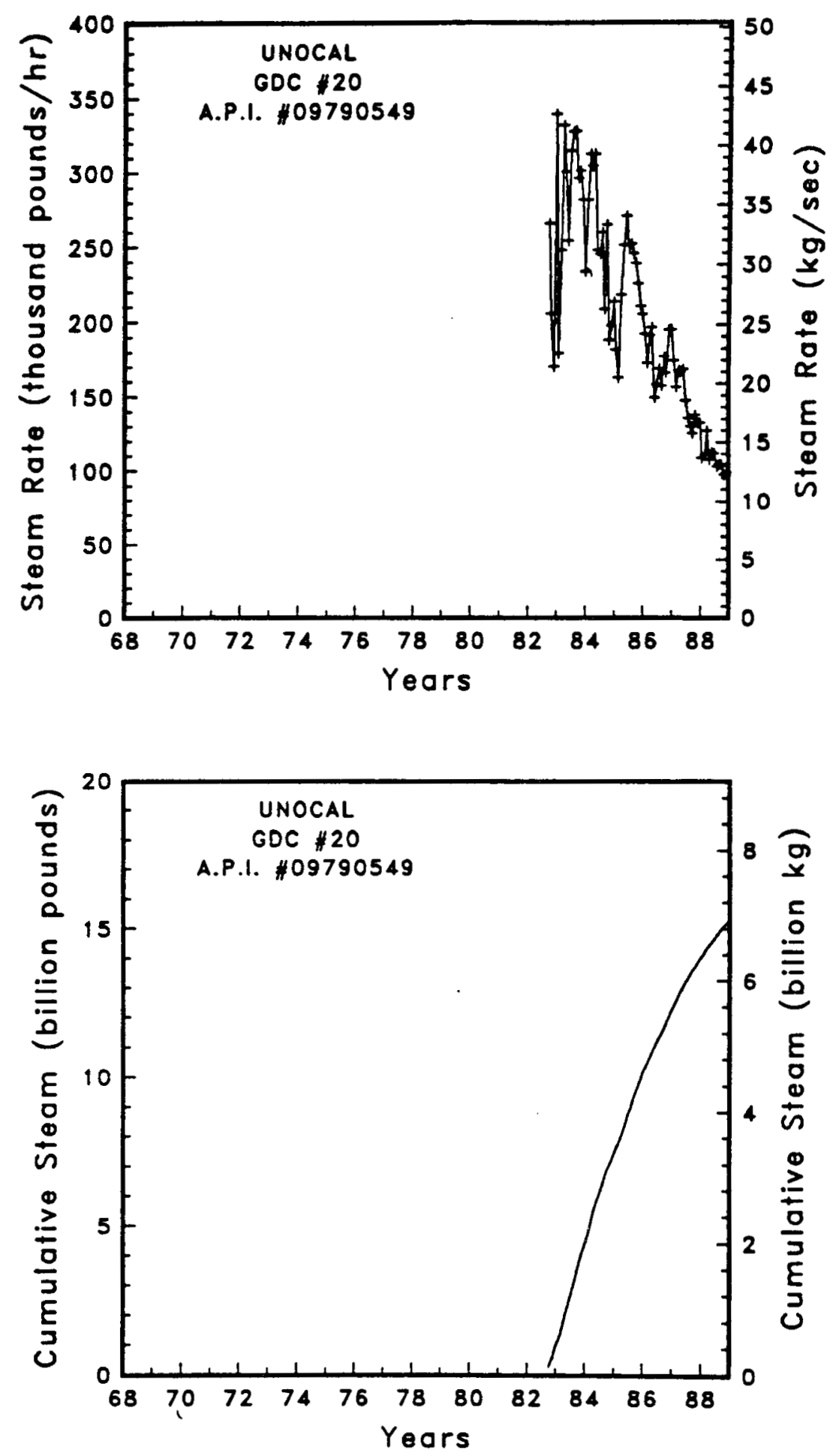

Figure A-86

Steam rate and cumulative mass flow for well GDC \#20 

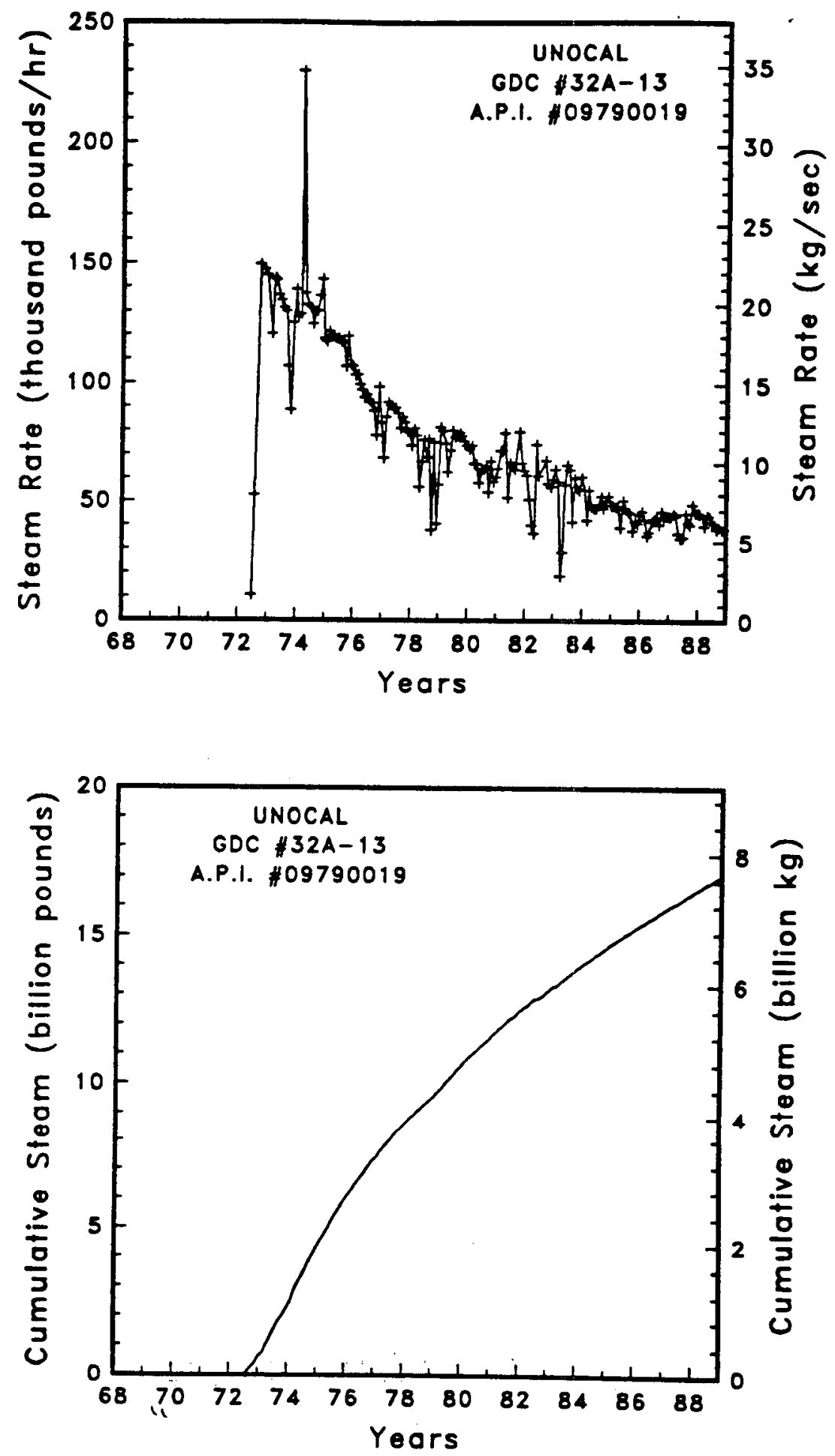

Figure A-87

Steam rate and cumulative mass flow for well GDC \#32A-13 

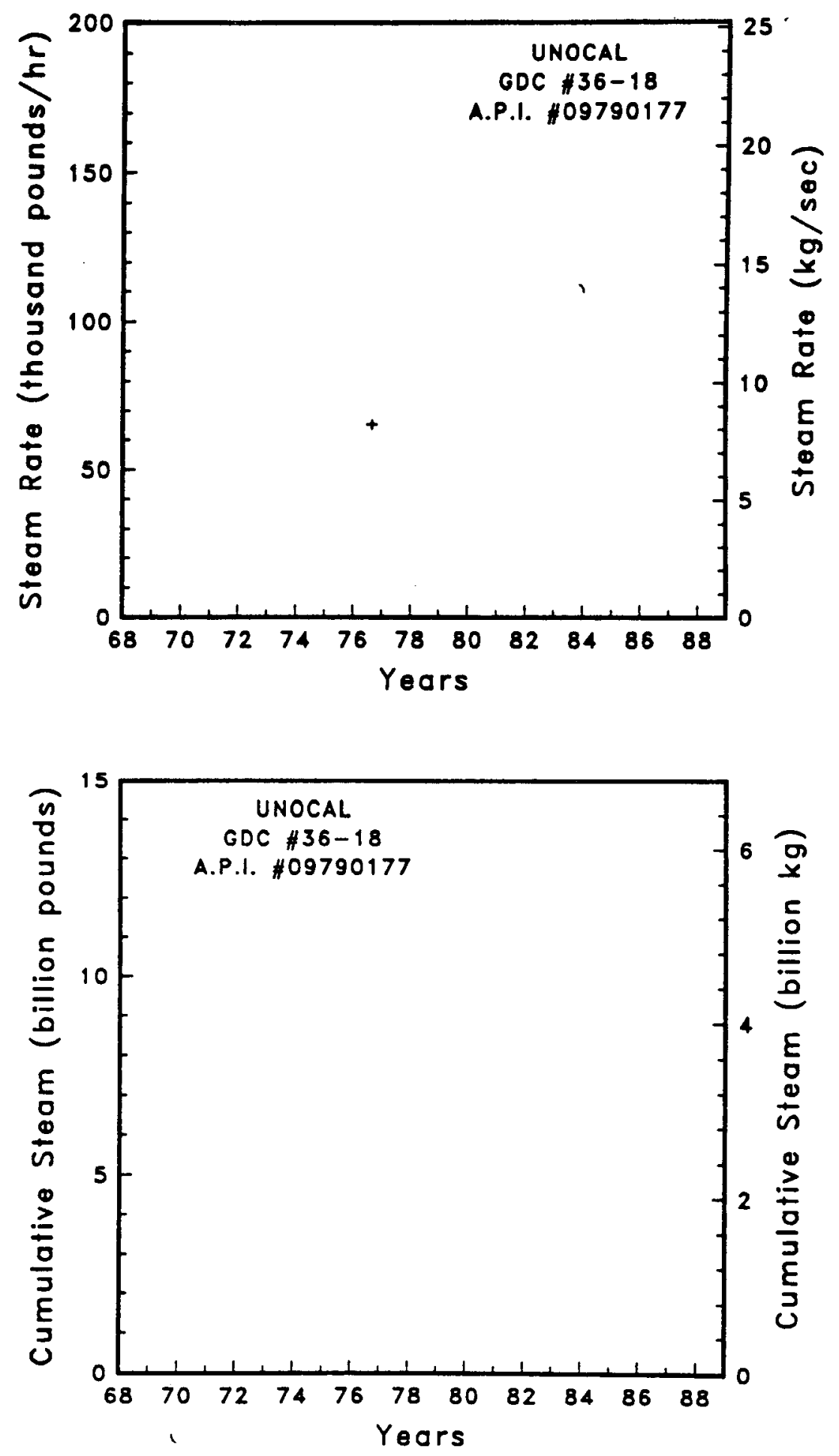

Figure A-88. Steam rate and cumulative mass flow for well GDC \#36-18 

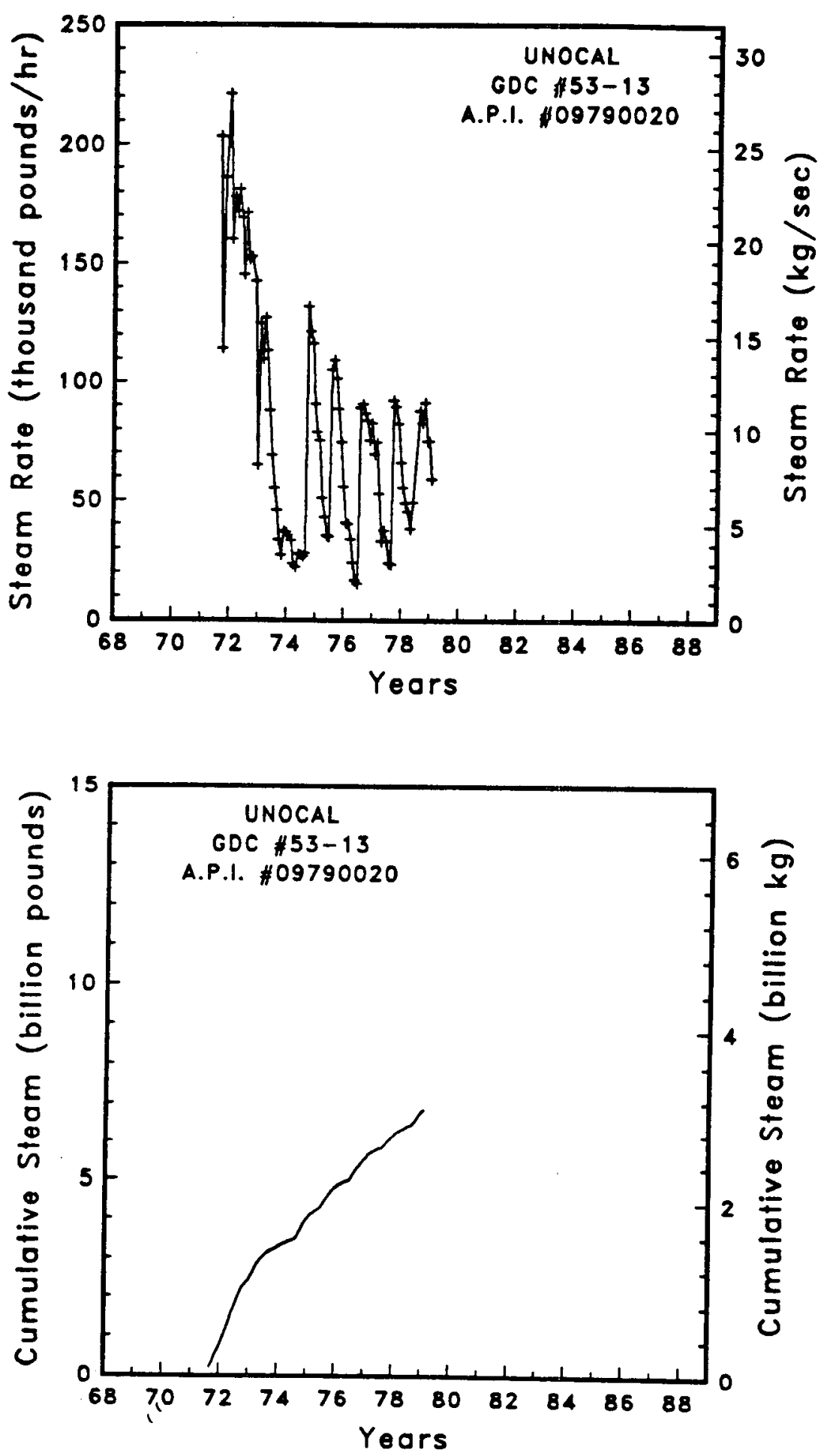

Figure A-89 Steam rate and cumulative mass flow for well GDC \#53-13 

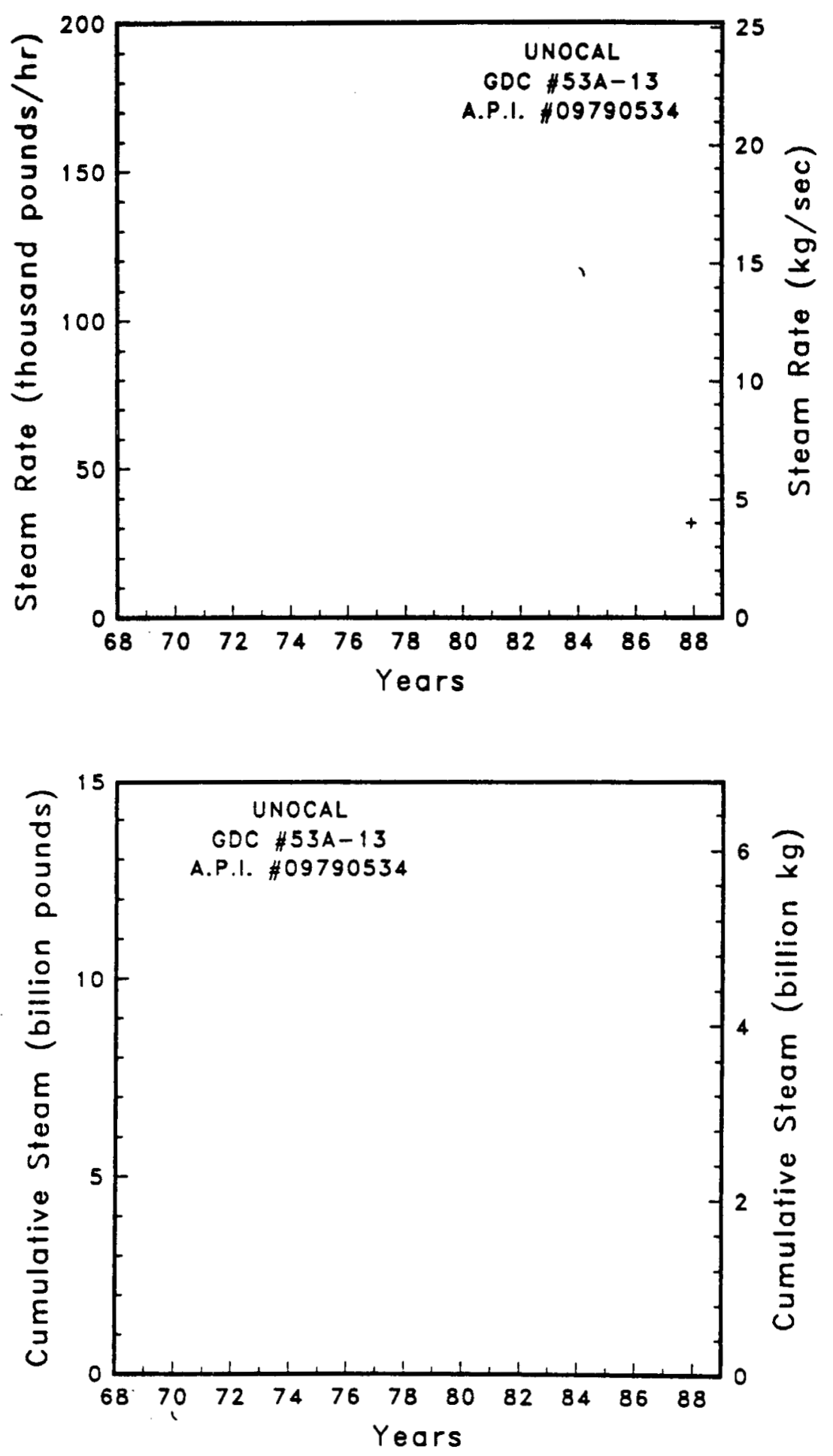

Figure A-90 Steam rate and cumulative mass flow for well GDC \#53A-13 

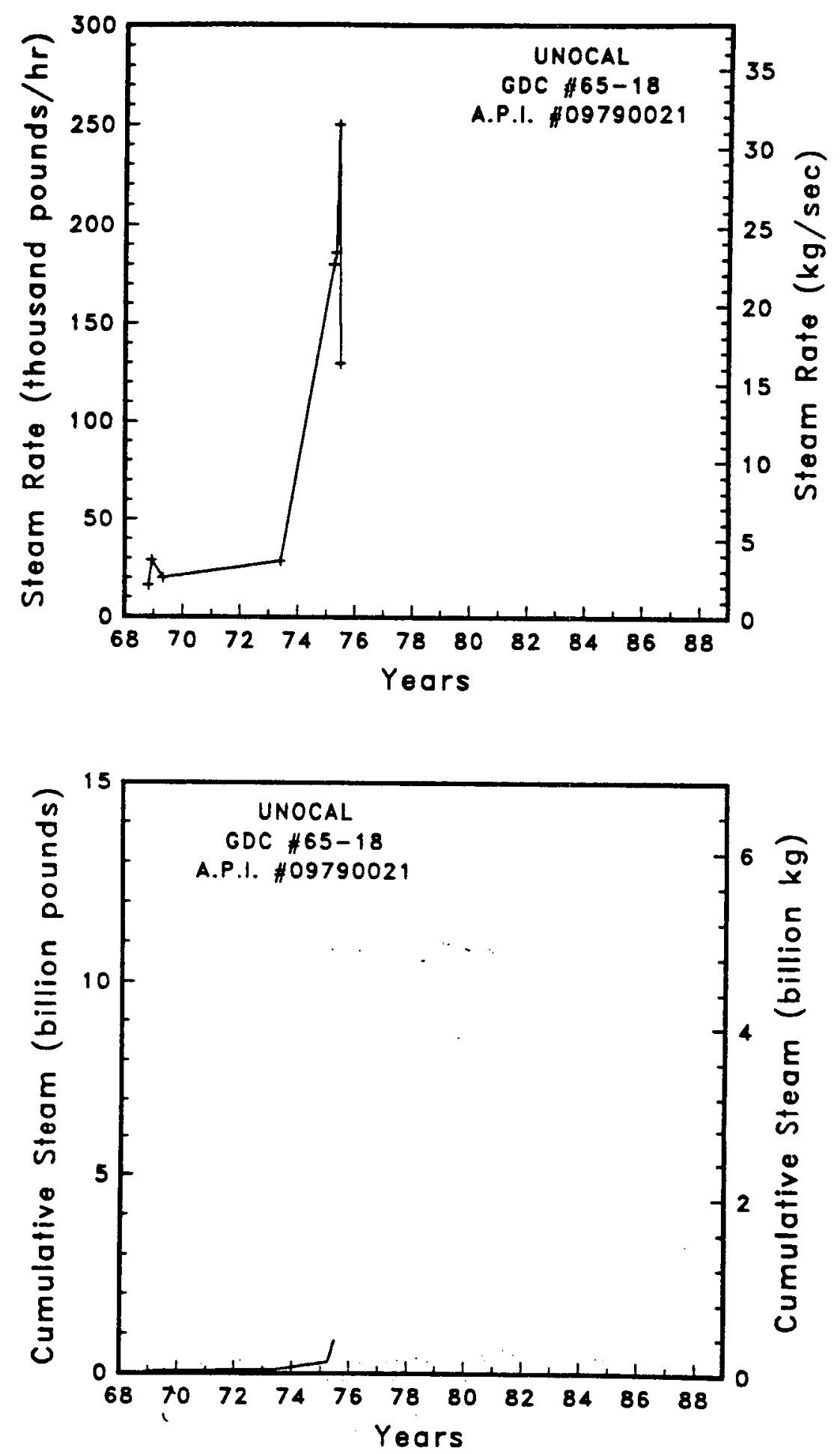

Figure A-91

Steam rate and cumulative mass flow for well GDC \#65-18 

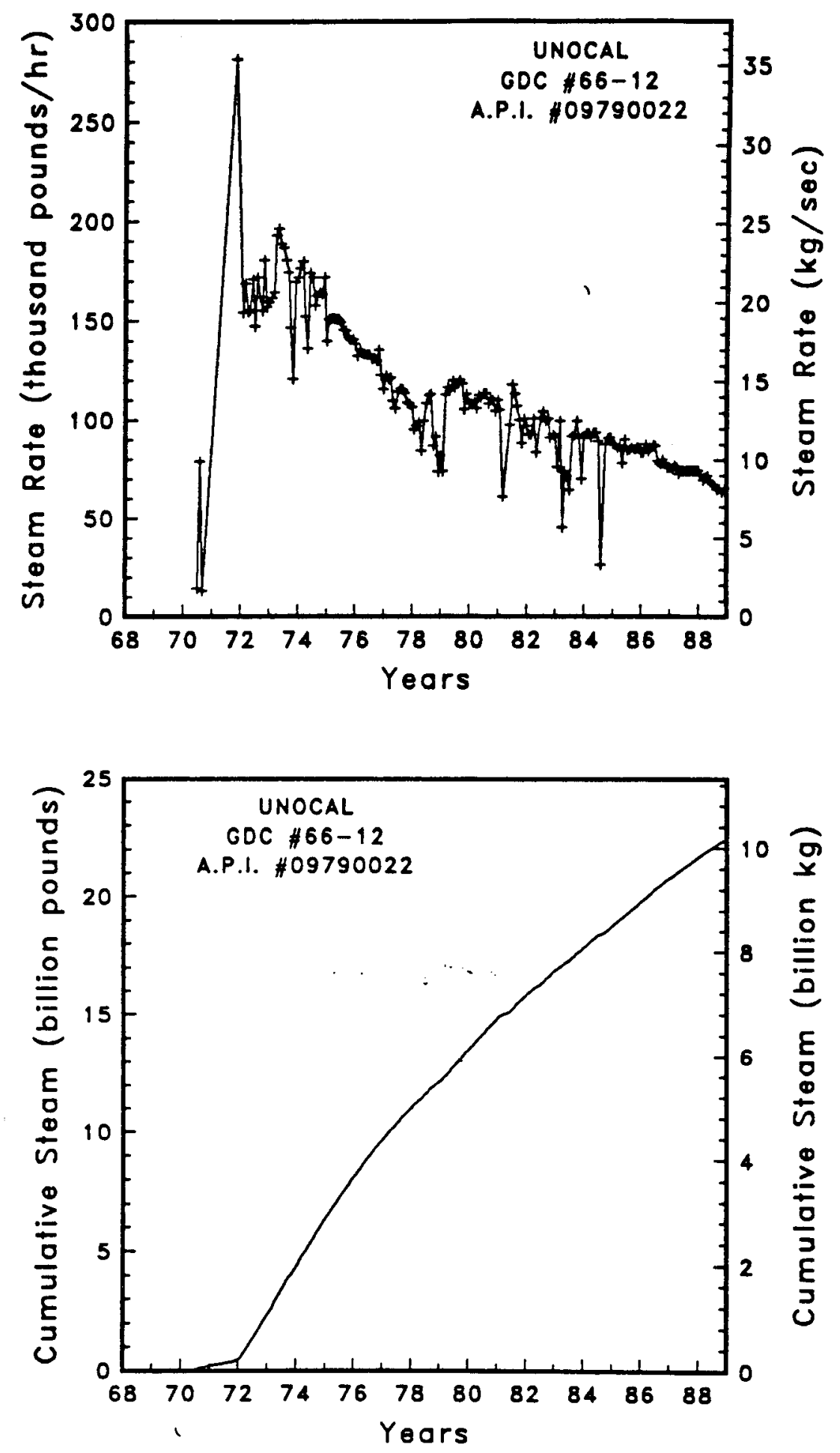

Figure A-92

Steam rate and cumulative mass flow for well GDC \#66-12 

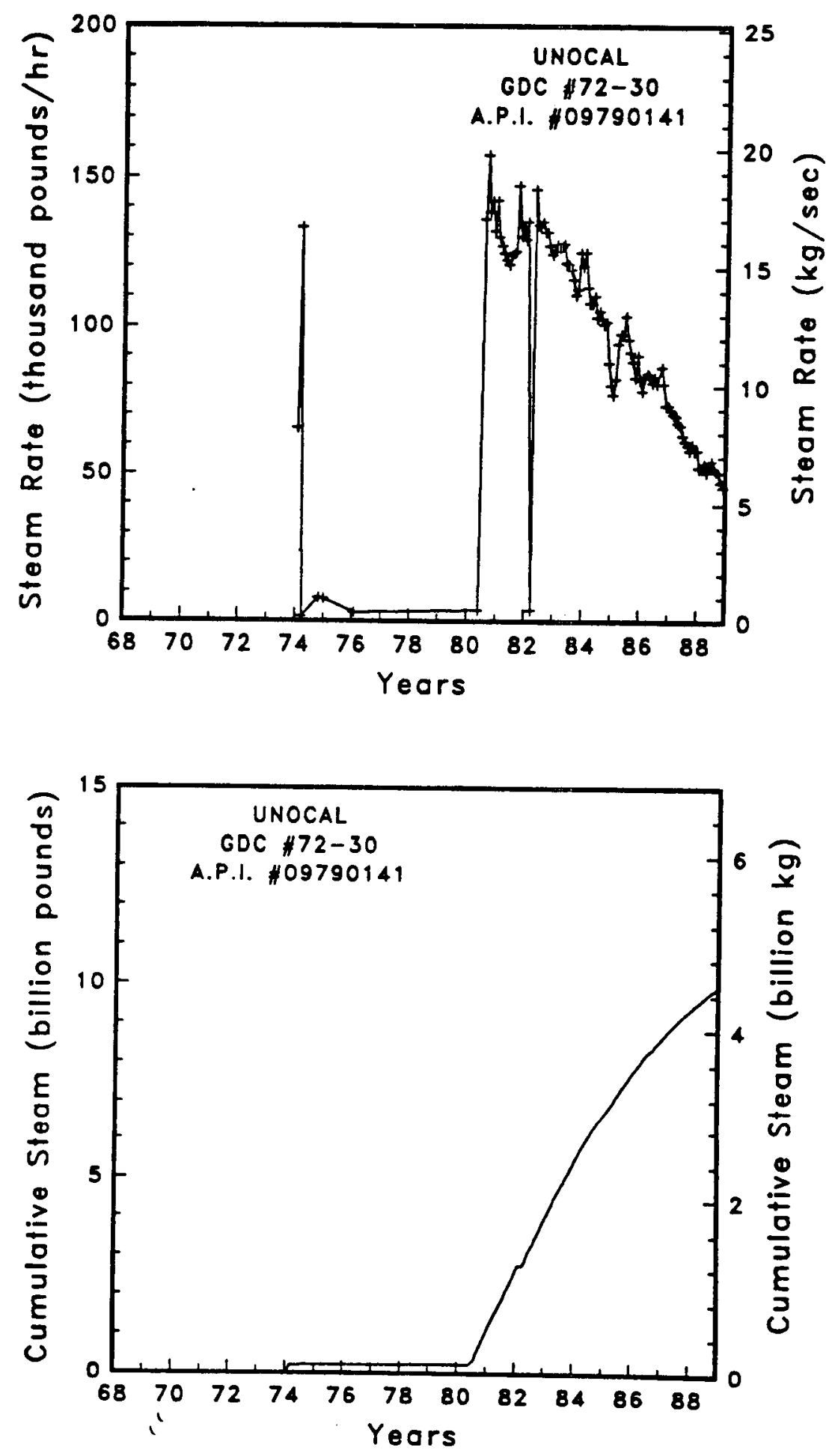

Figure A-93

Steam rate and cumulative mass flow for well GDC \#72-30 

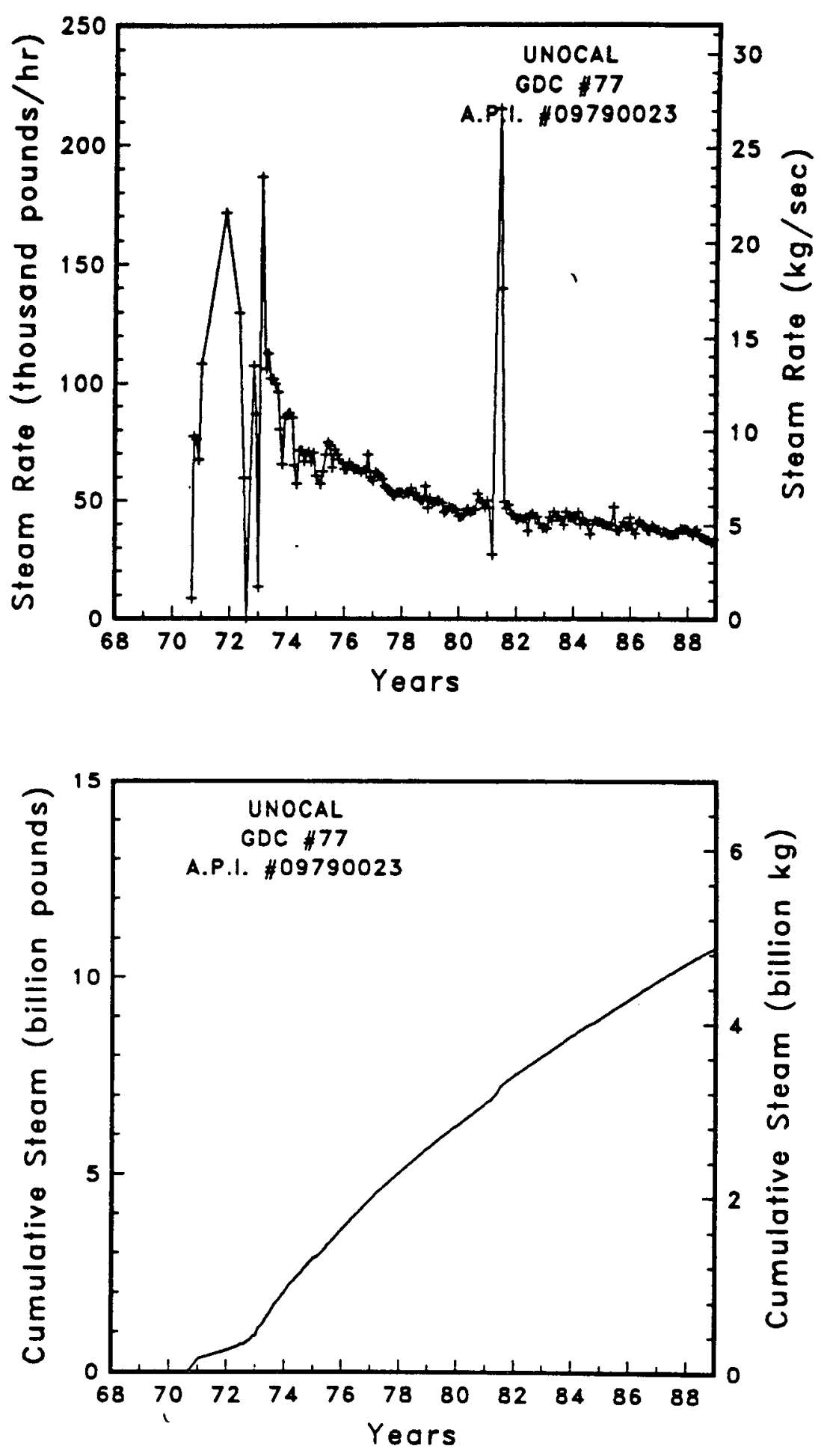

Figure A-94

Steam rate and cumulative mass flow for well GDC \#77 

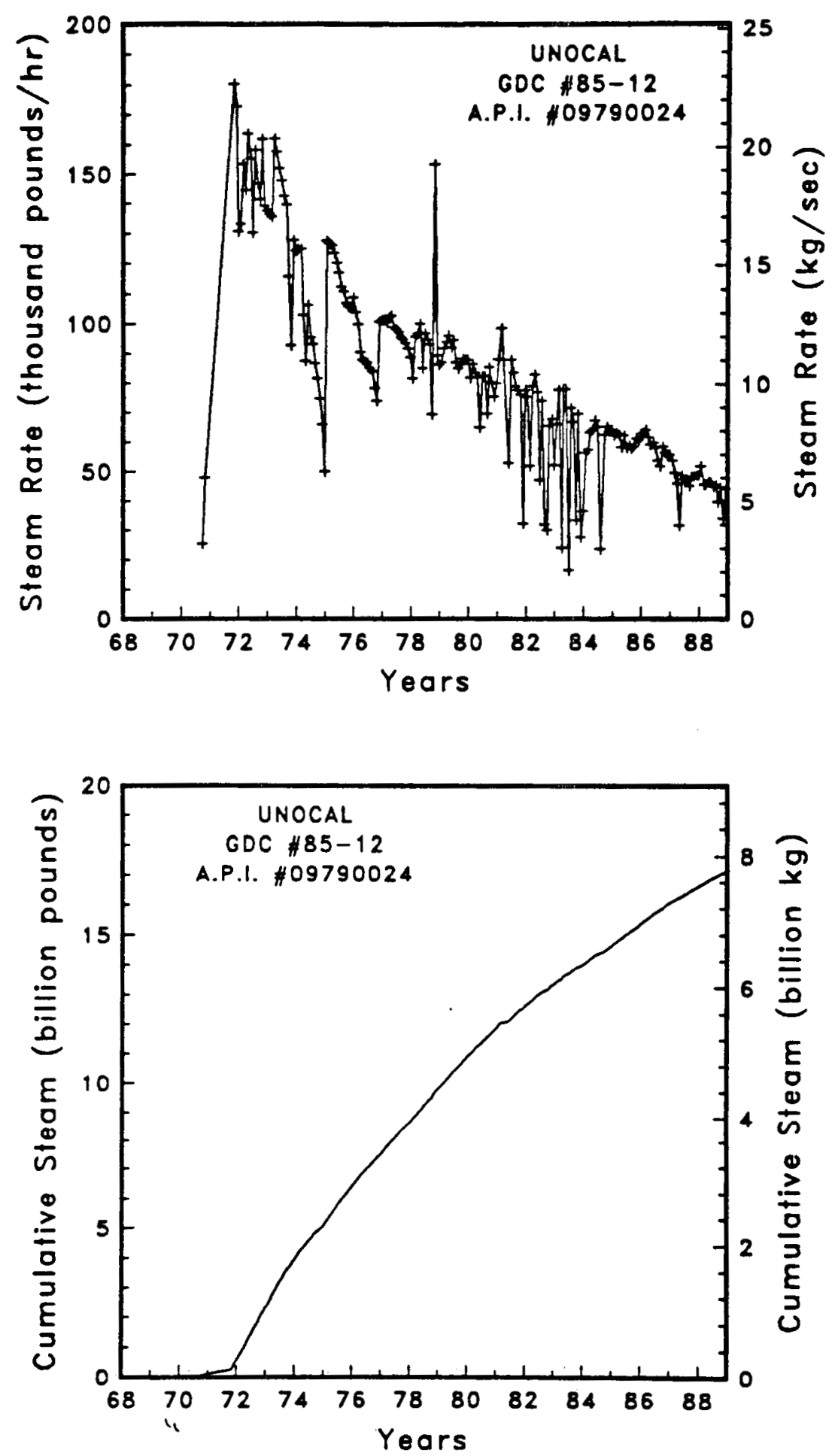

Figure A-95

Steam rate and cumulative mass flow for well GDC \#85-12 

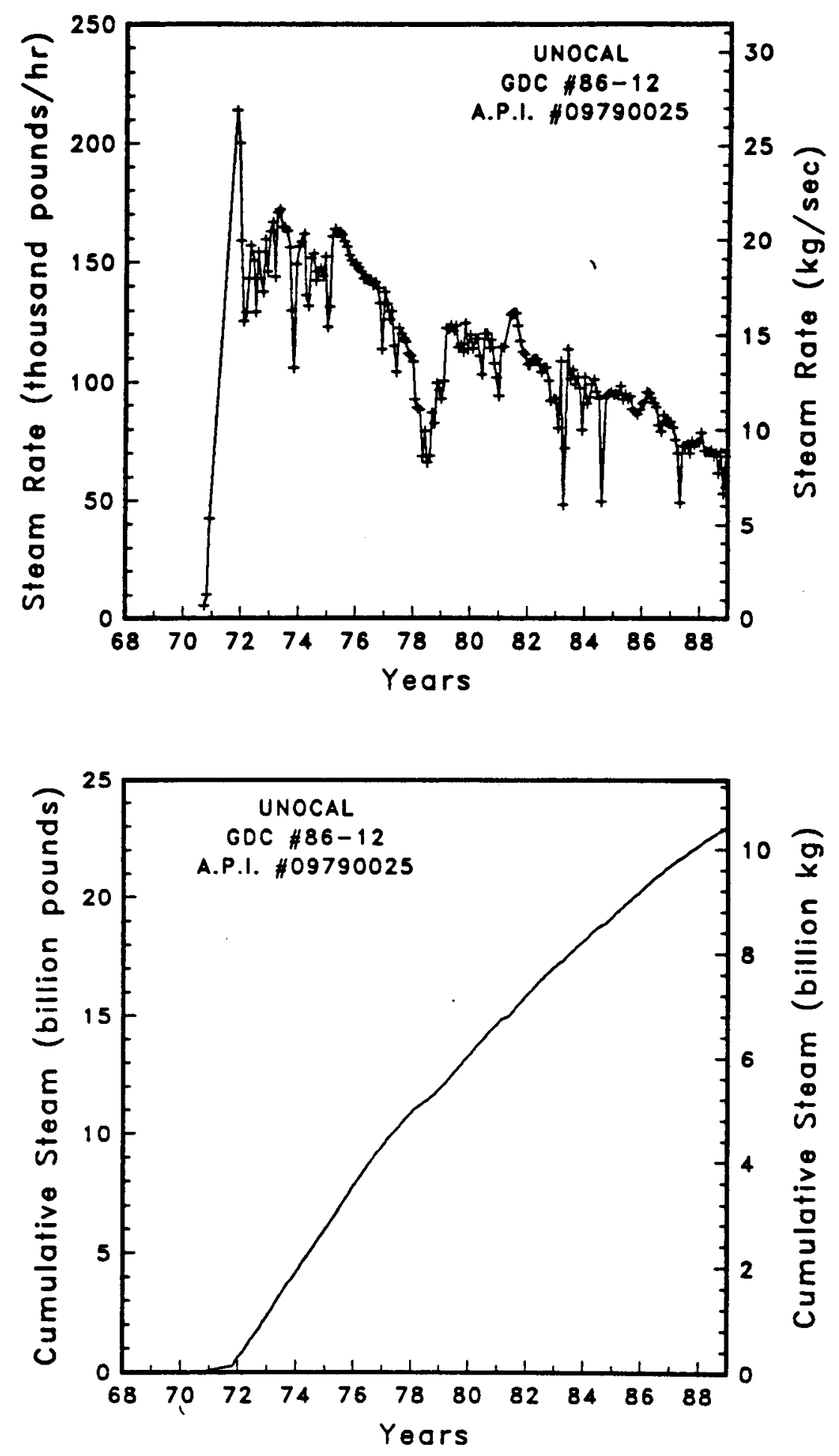

Figure A-96

Steam rate and cumulative mass flow for well GDC \#86-12 

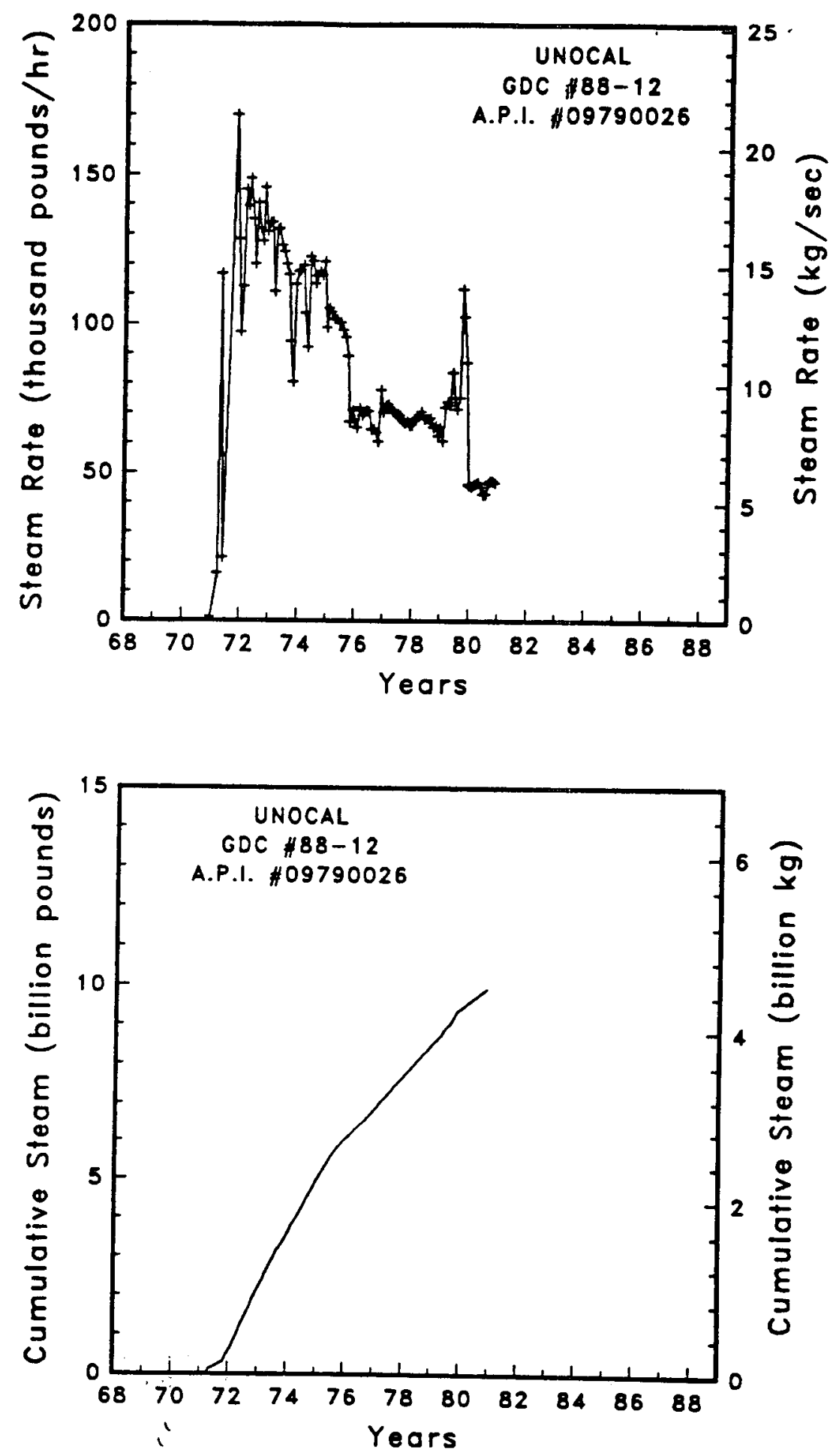

Figure A-97

Steam rate and cumulative mass flow for well GDC \#88-12 

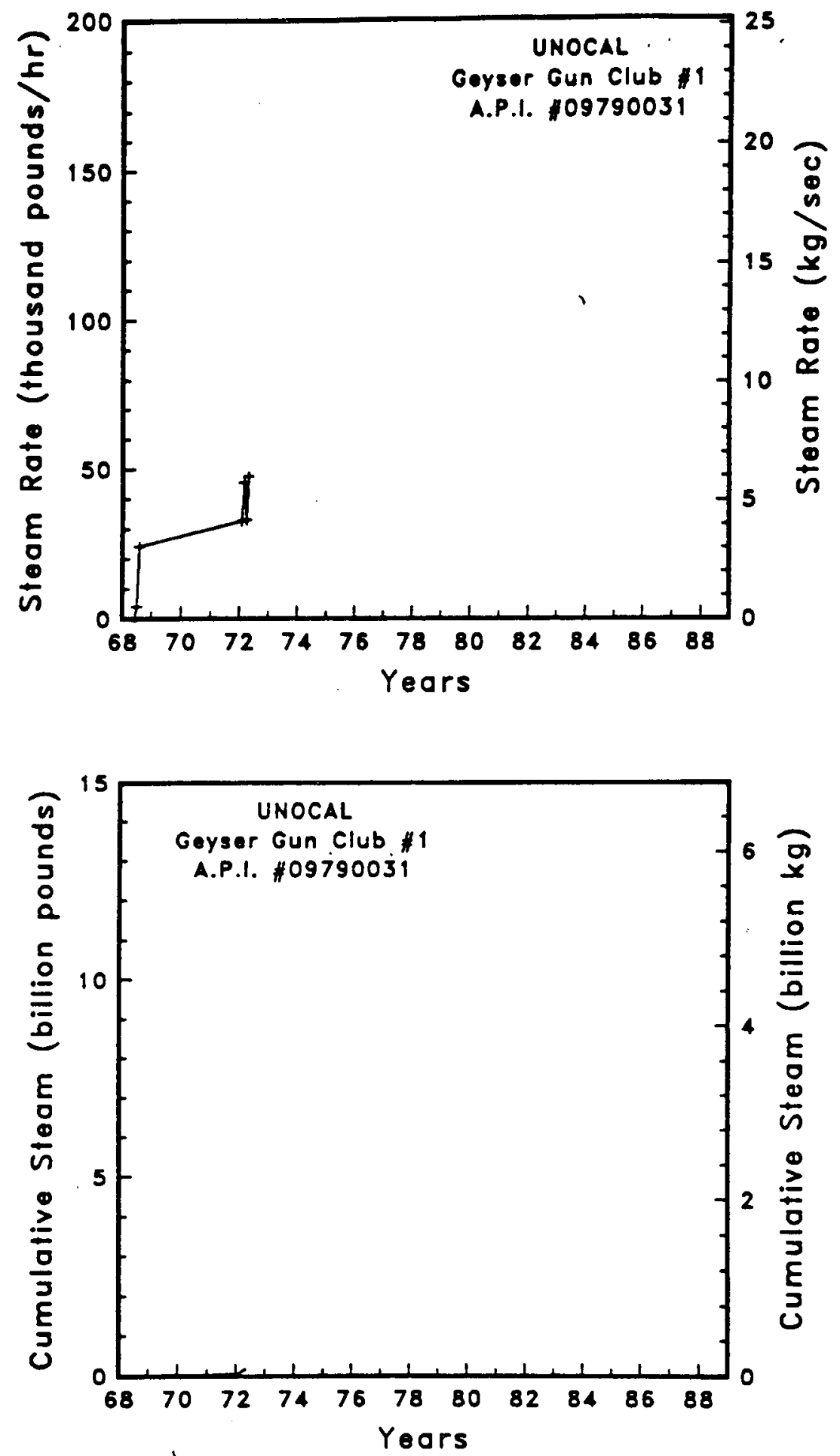

Figure A-98

Steam rate and cumulative mass flow for well Geyser Gun Club \#1 

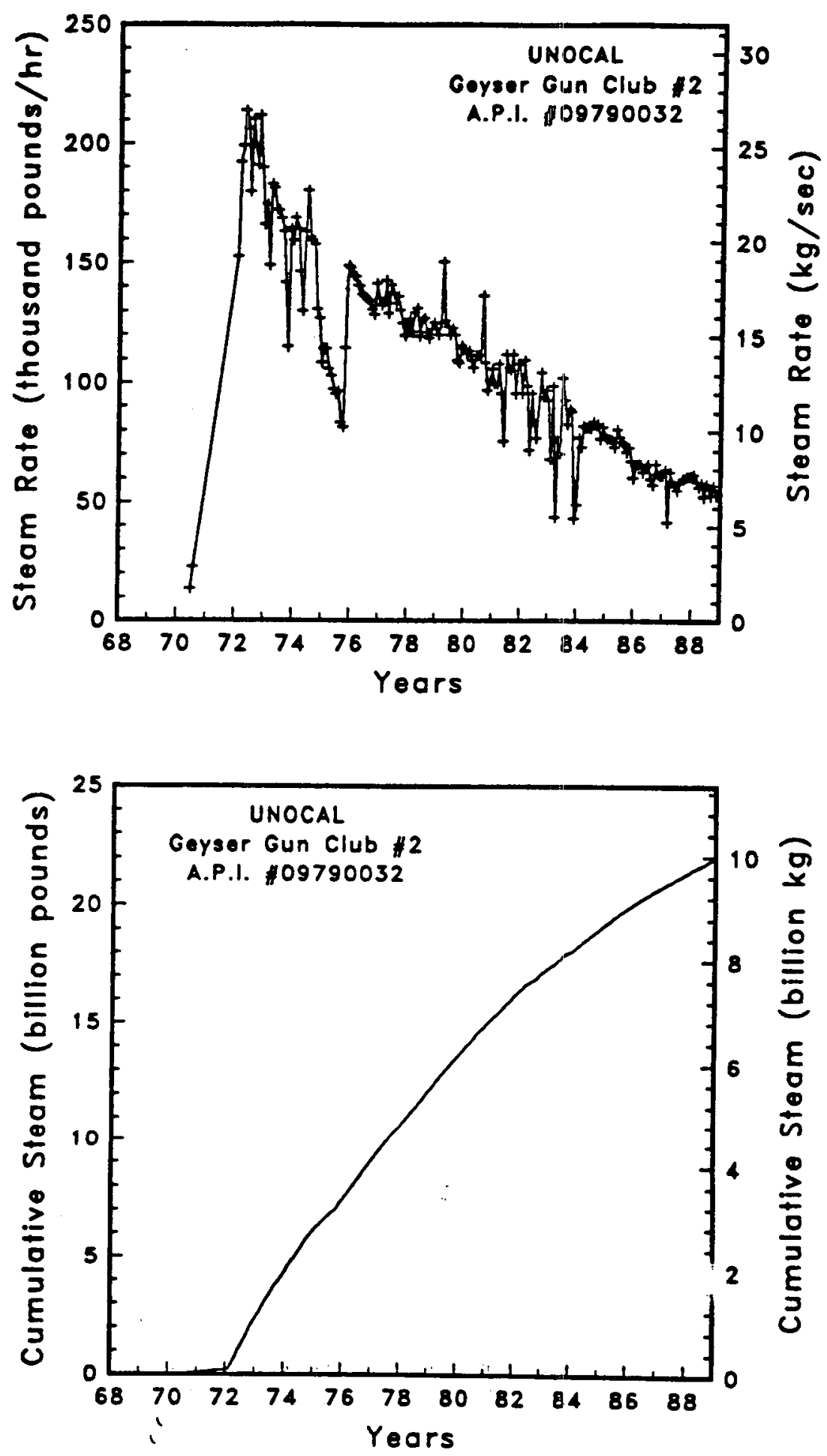

Figure A-99 Steam rate and cumulative mass flow for well Geyser Gun Club \#2 

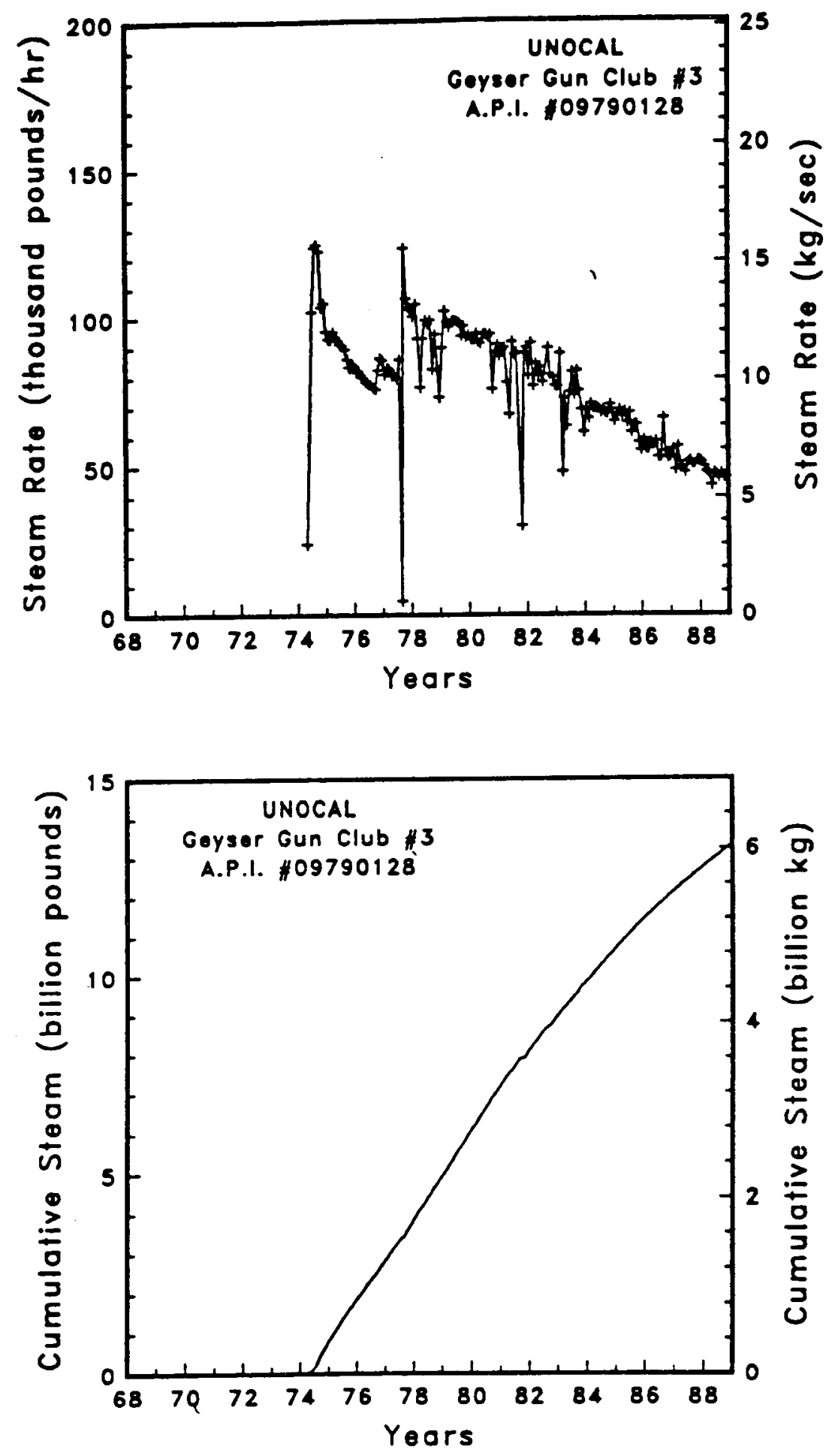

Figure A-100

Steam rate and cumulative mass flow for well Geyser Gun Club \#3 

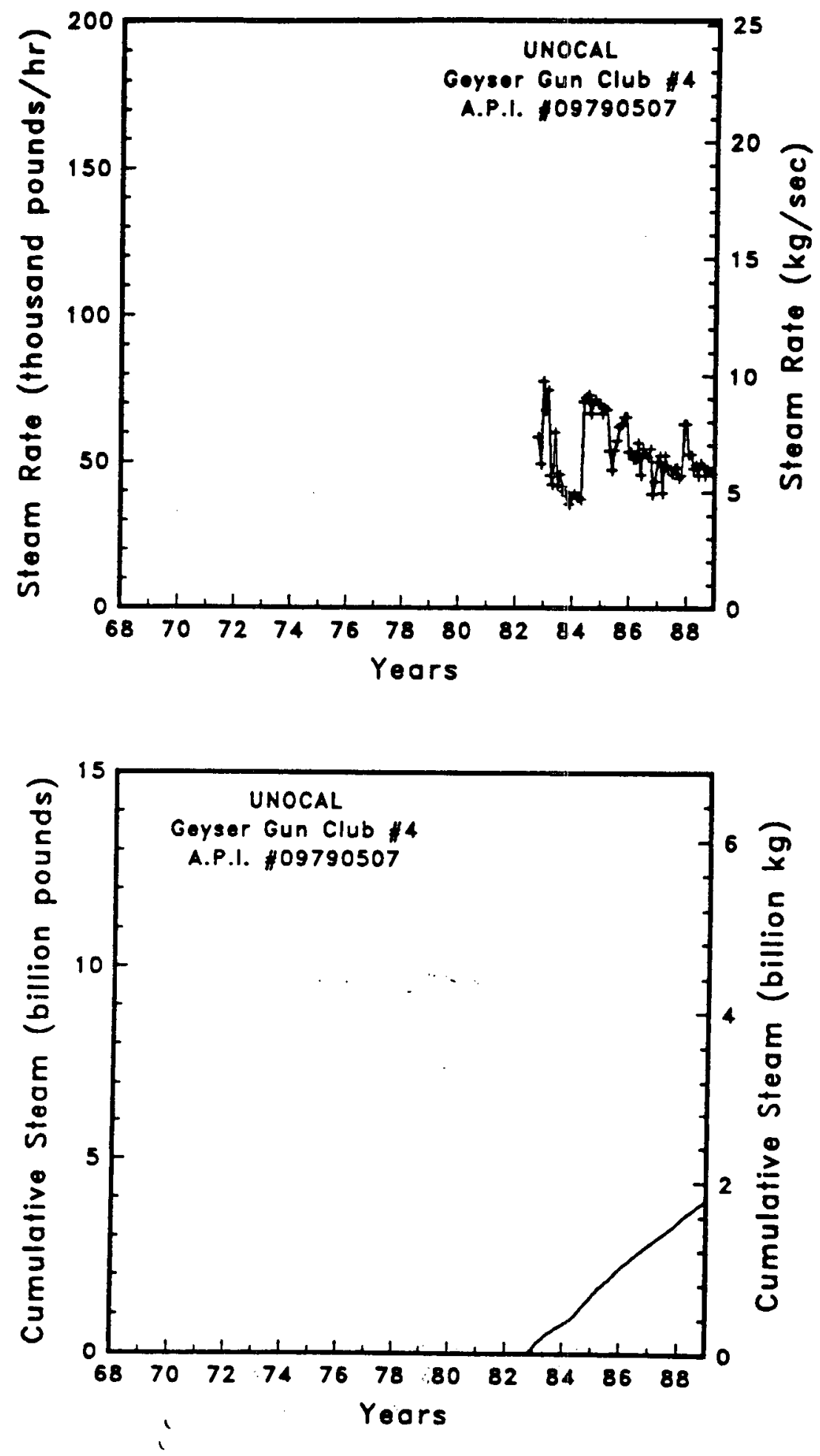

Figure A-101 Steam rate and cumulative mass flow for well Geyser Gun Club \#4 

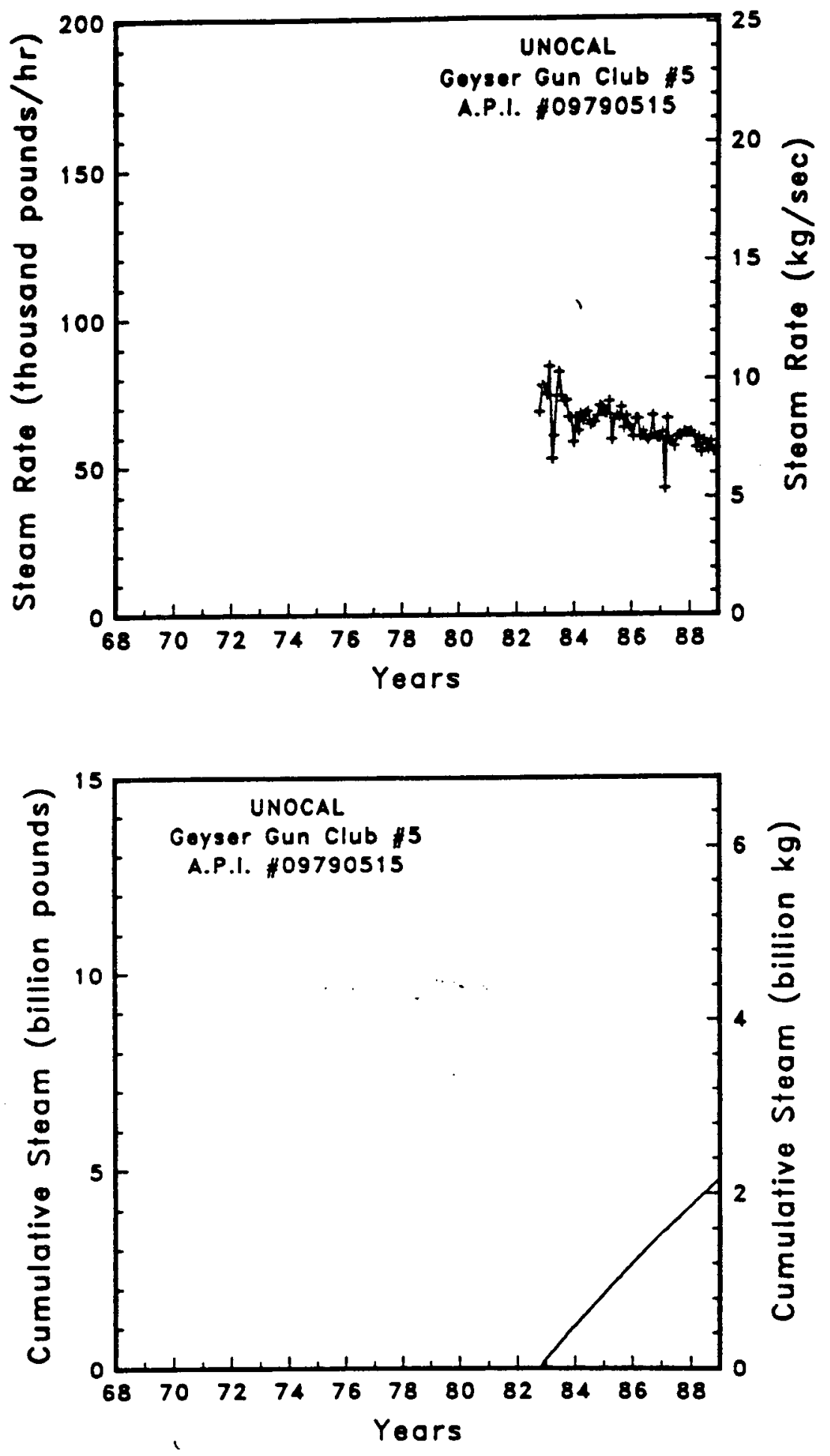

Figure A-102

Steam rate and cumulative moss flow for well Geyser Gun Club \#5 

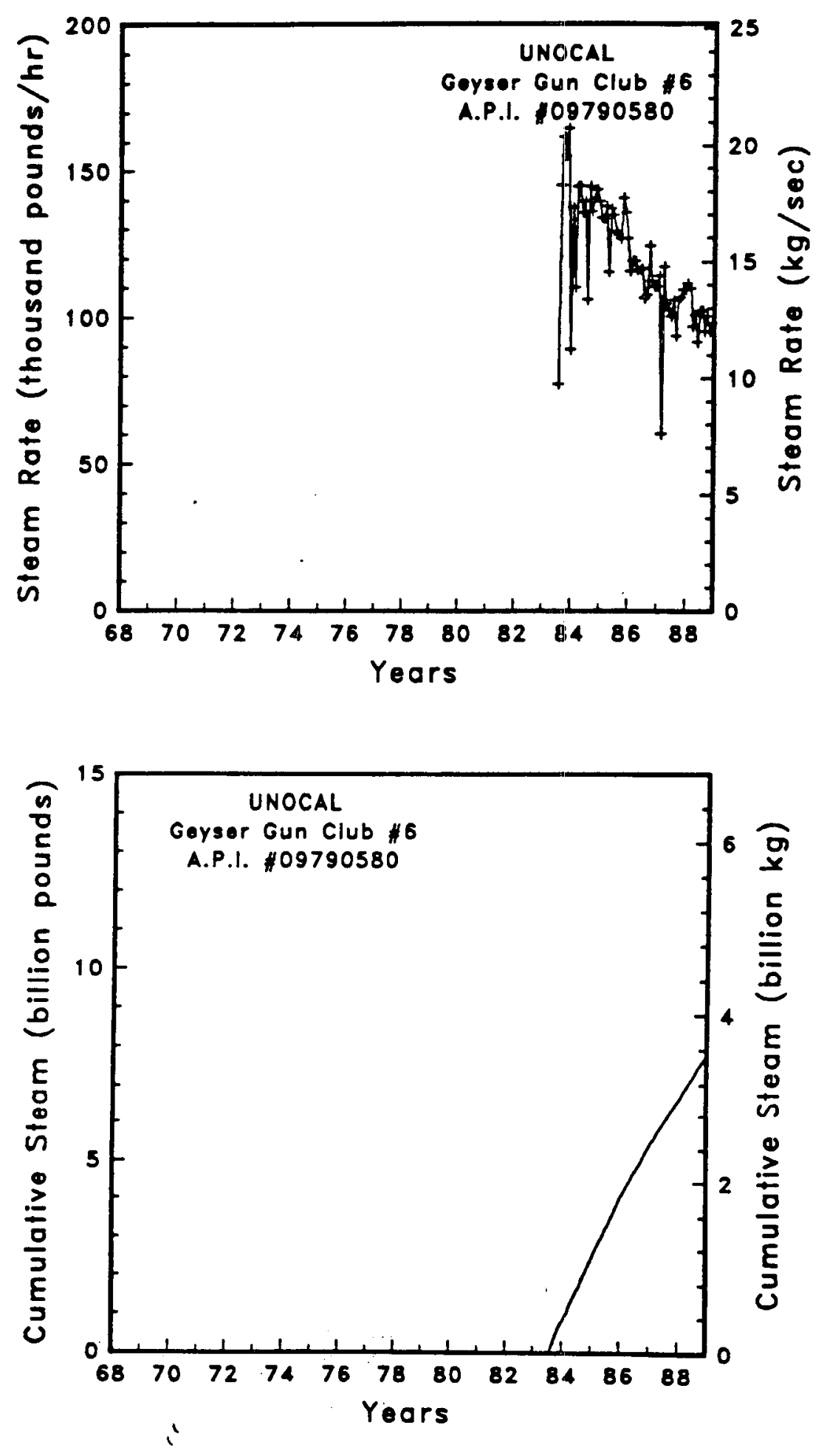

Figure A-103

Steam rote and cumulative mass flow for well Geyser Gun Club \#6 

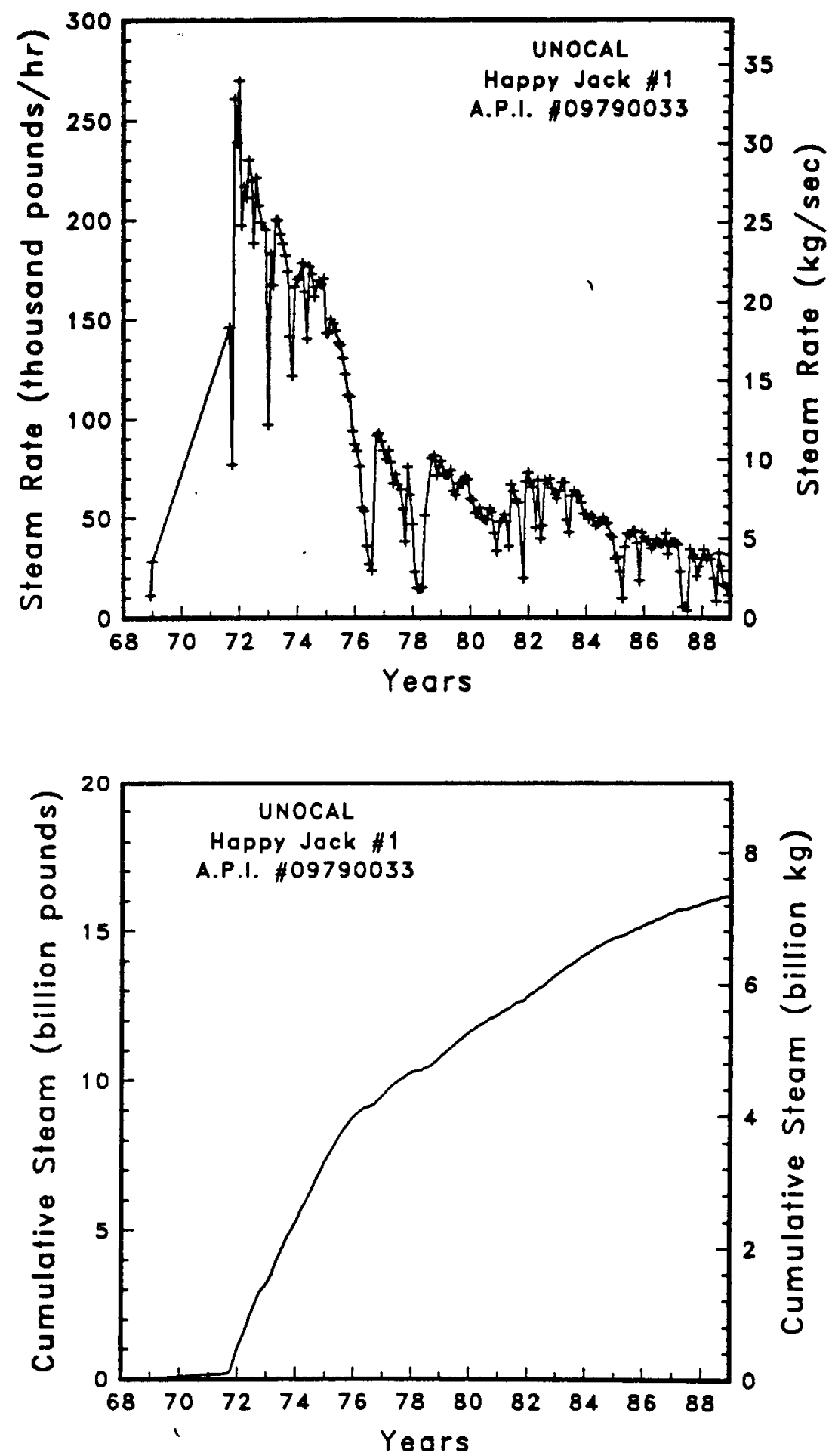

Figure A-104 Steam rate and cumulative mass flow for well Happy Jack \#1 

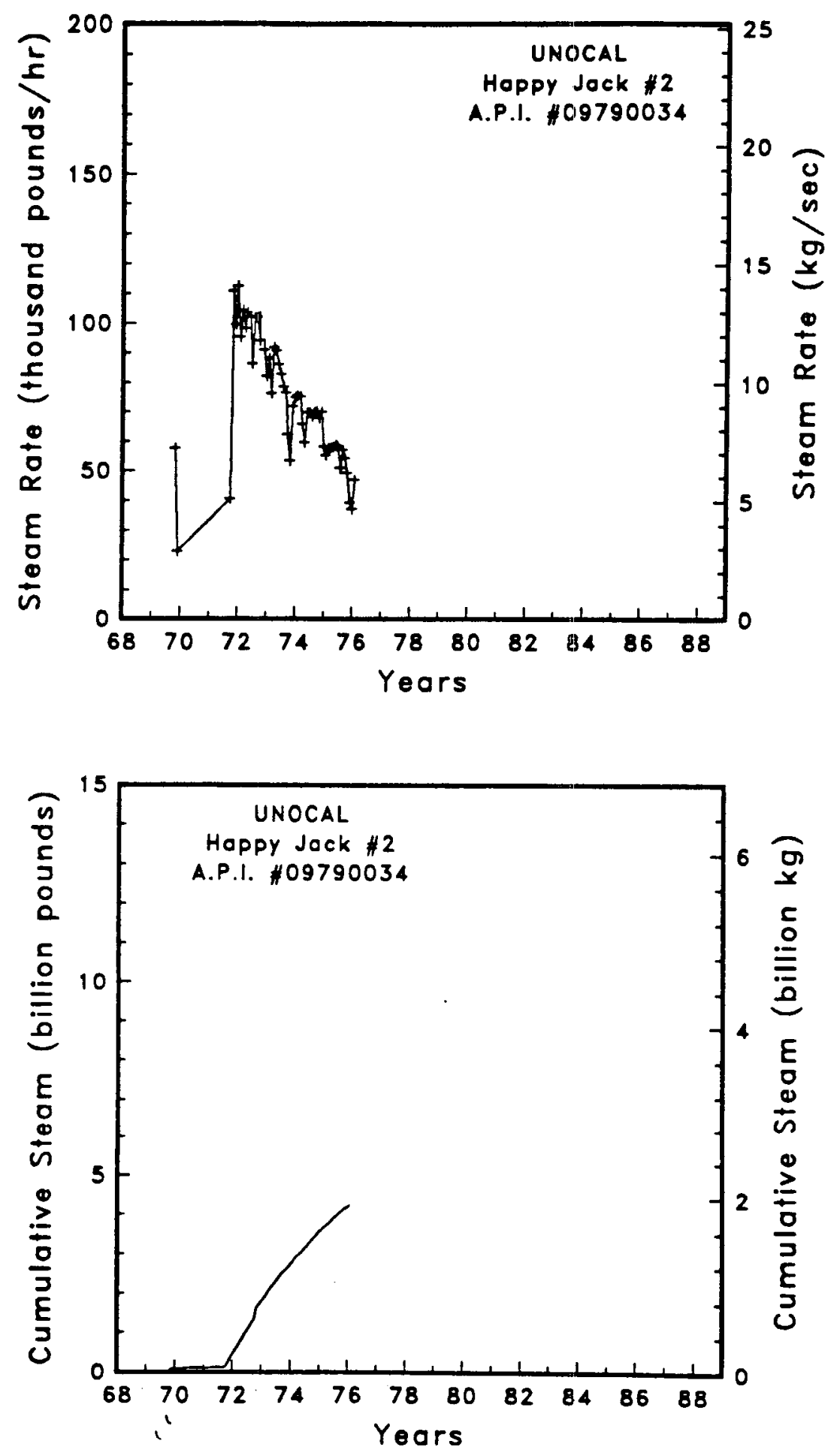

Figure A-105

Steam rate and cumulative mass flow for well Hoppy Jack \#2 

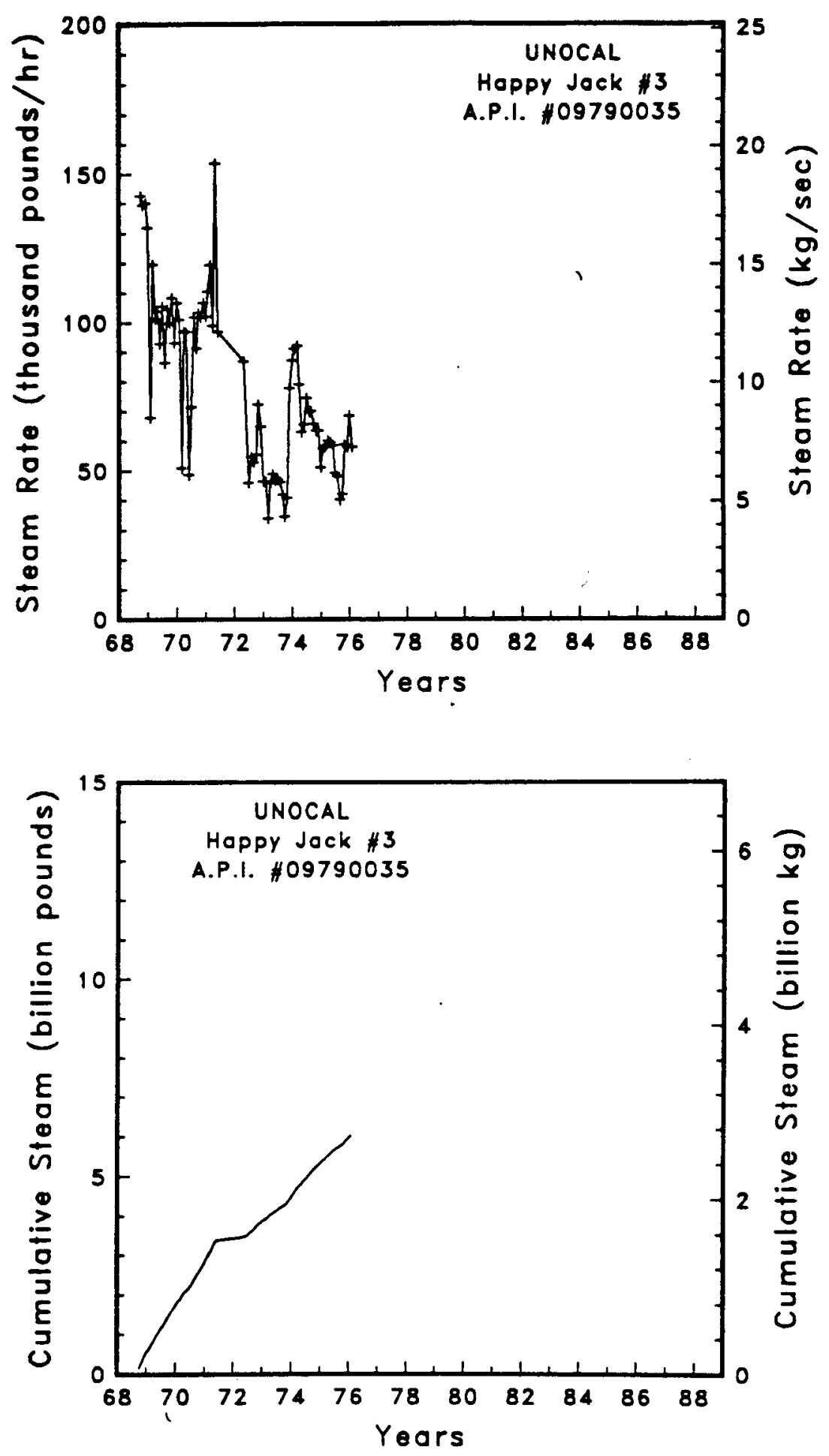

Figure A-106

Steam rate and cumulative mass flow for well Happy Jack \#3 

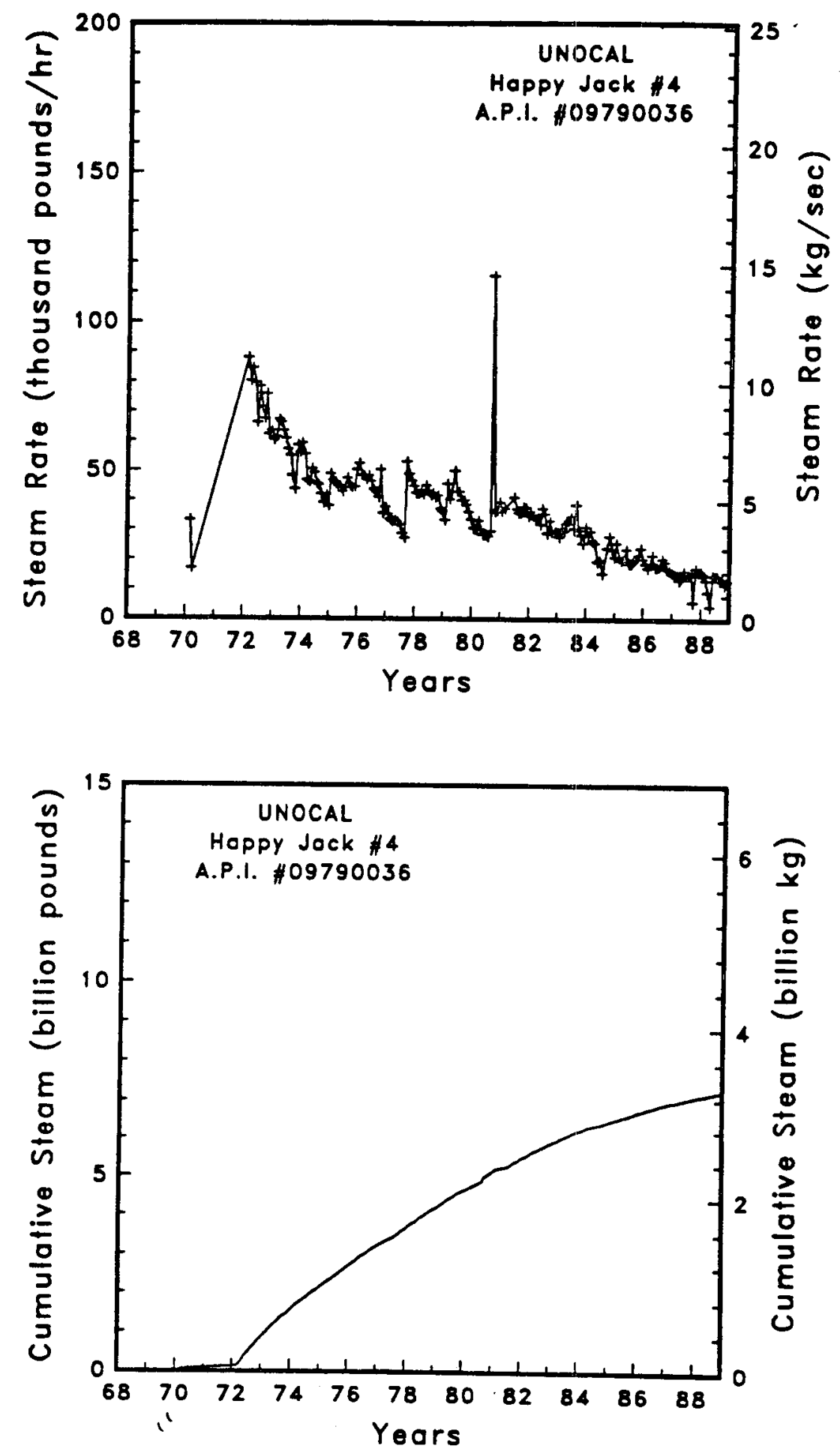

Figure A-107 Steam rate and cumulative mass flow for
well Hoppy Jack \#4 

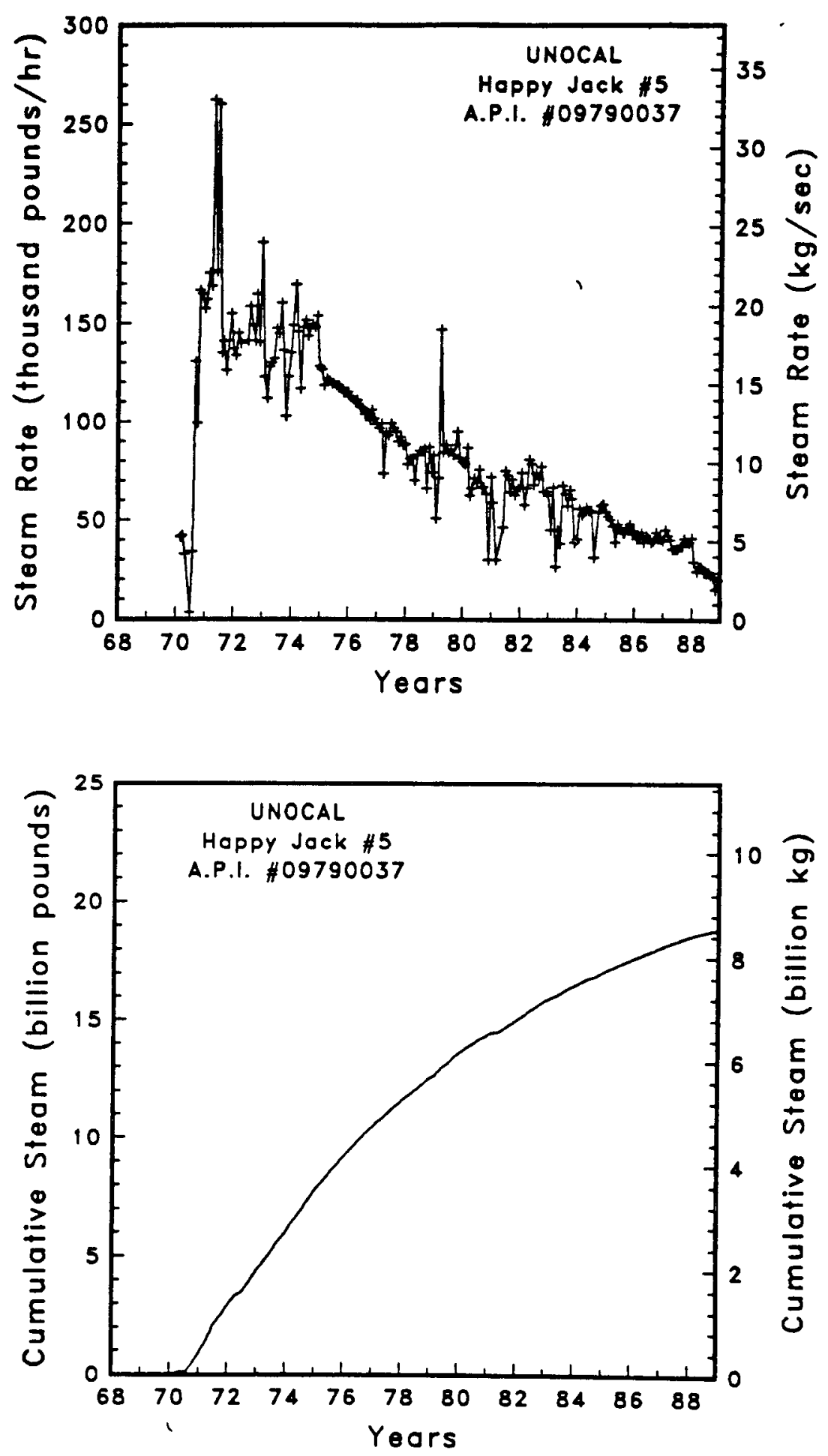

Figure A-108 Steam rate and cumulative mass flow for well Happy Jack \#5 

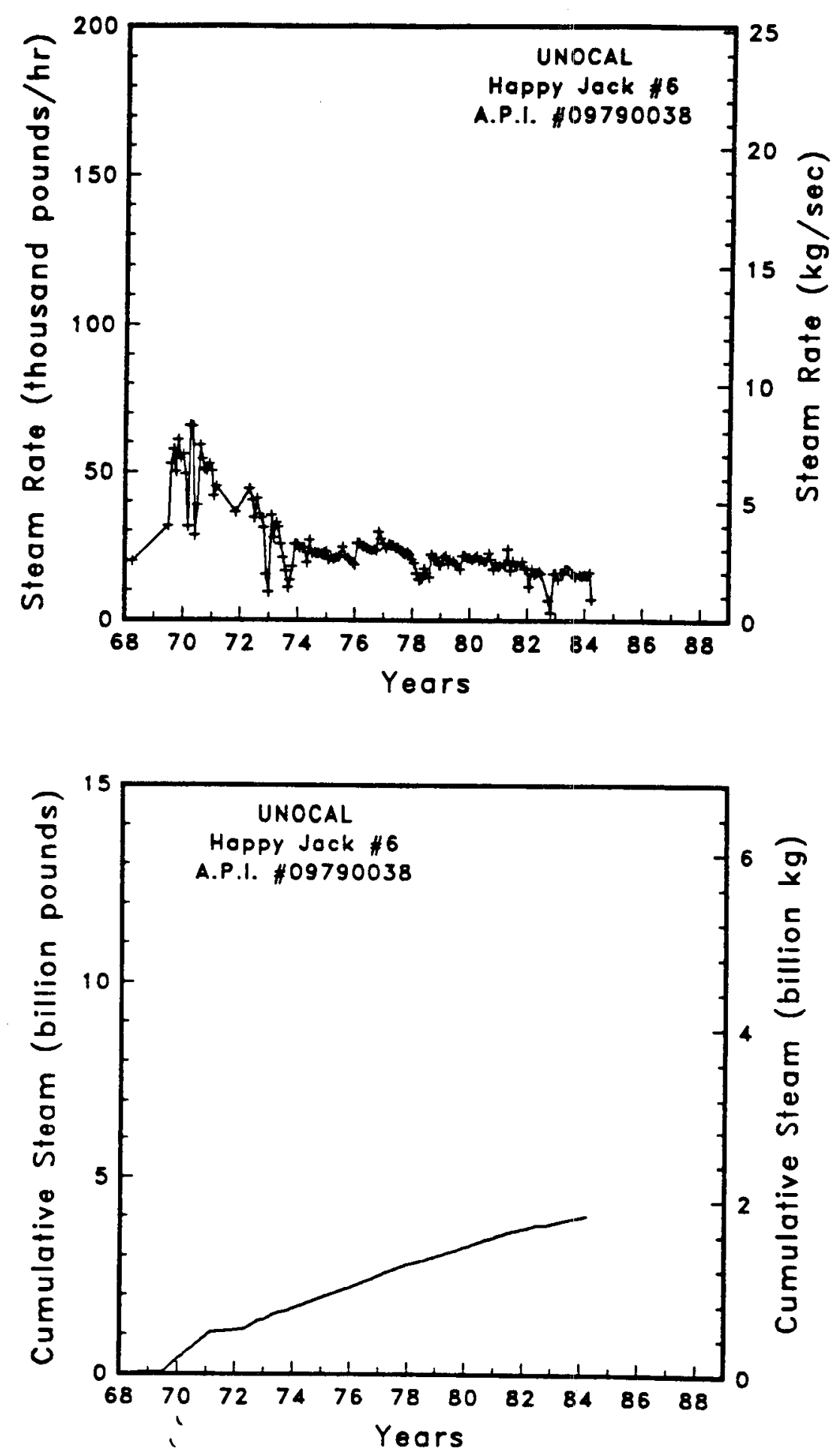

Figure A-109 Steam rate and cumulative mass flow for well Happy Jack \#6 

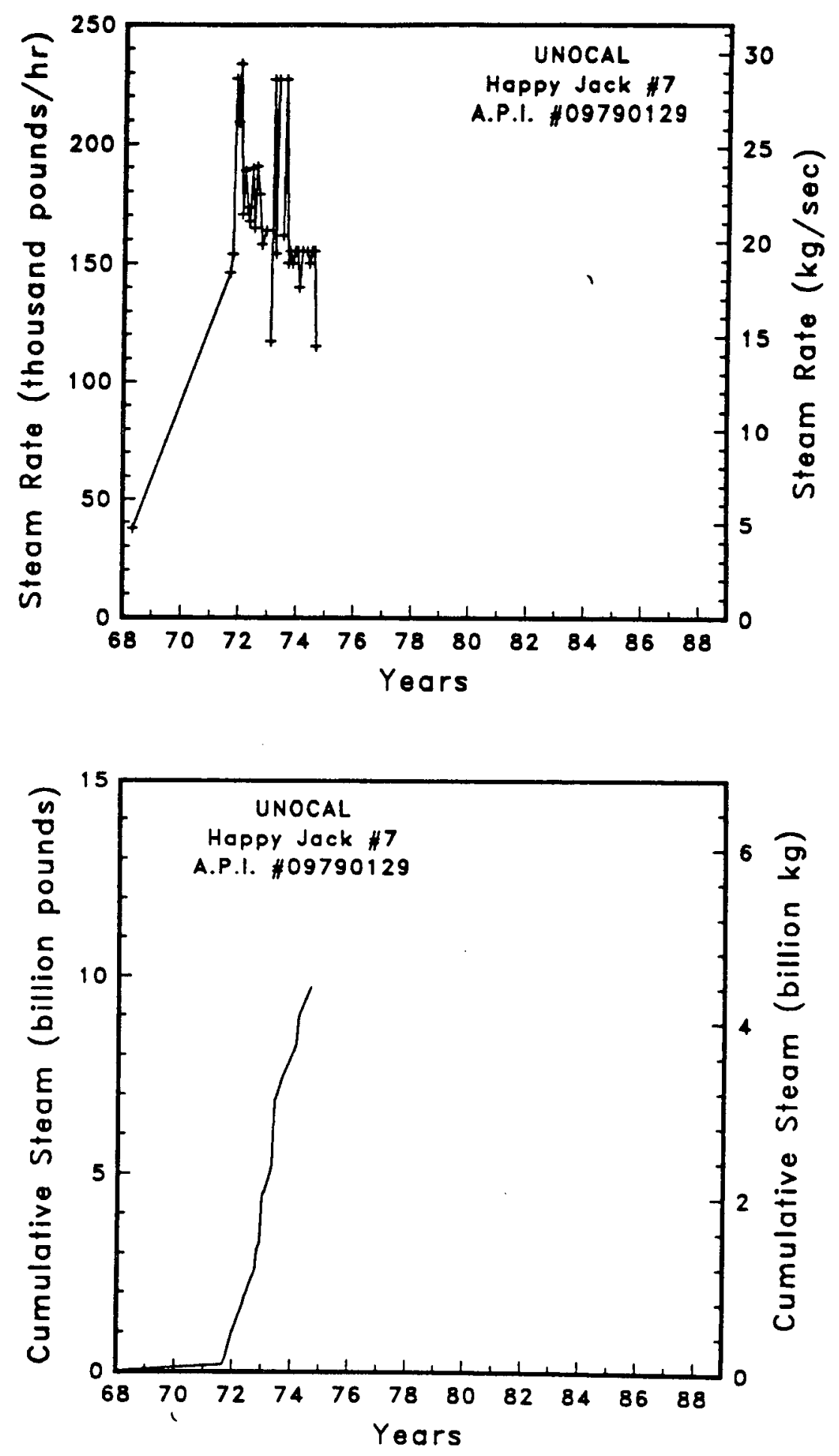

Figure A-110 Steam rate and cumulative mass flow for well Hoppy Jack \#7 

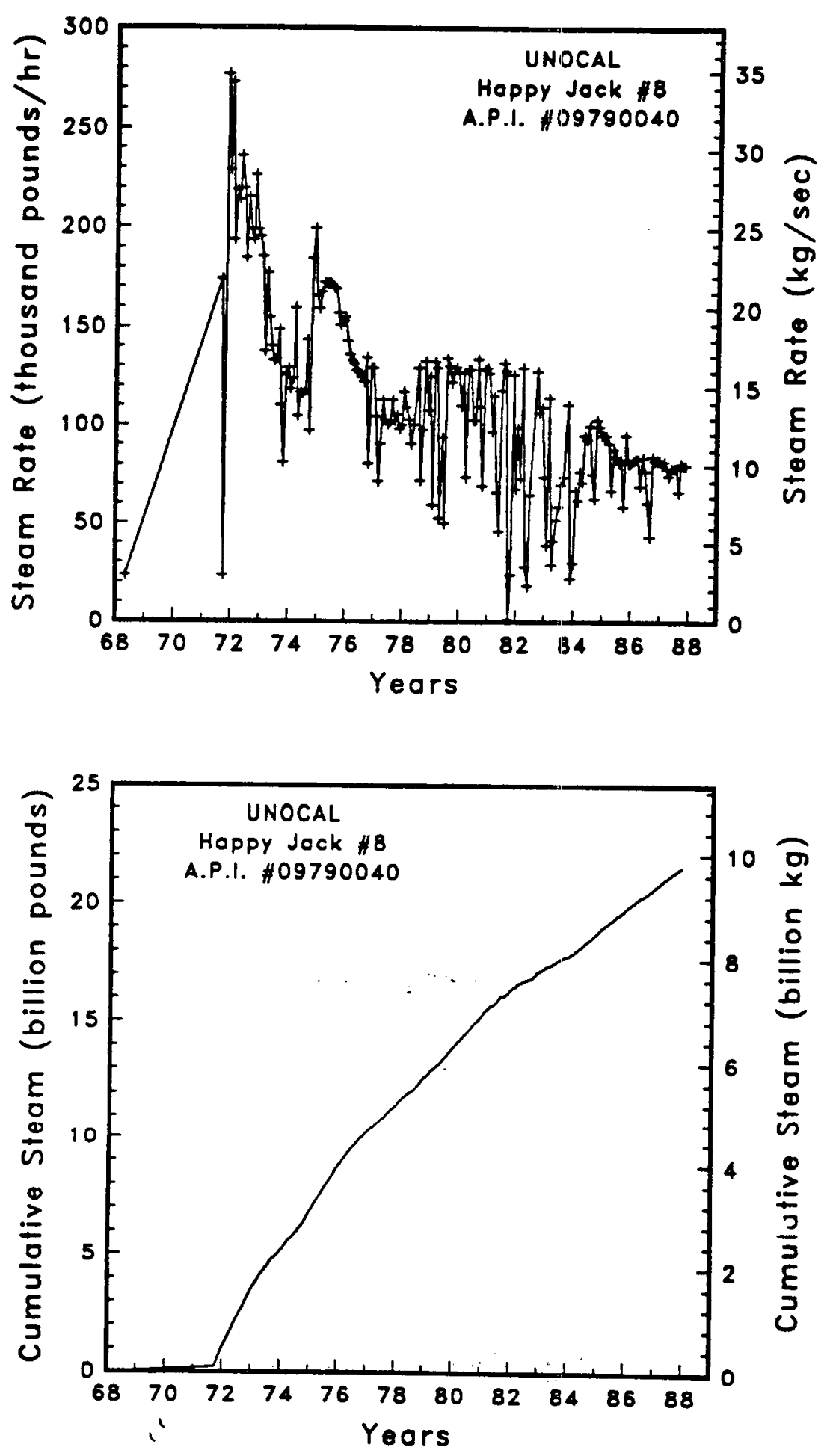

Figure A-111 Steam rate and cumulative mass flow for well Hoppy Jack \#8 

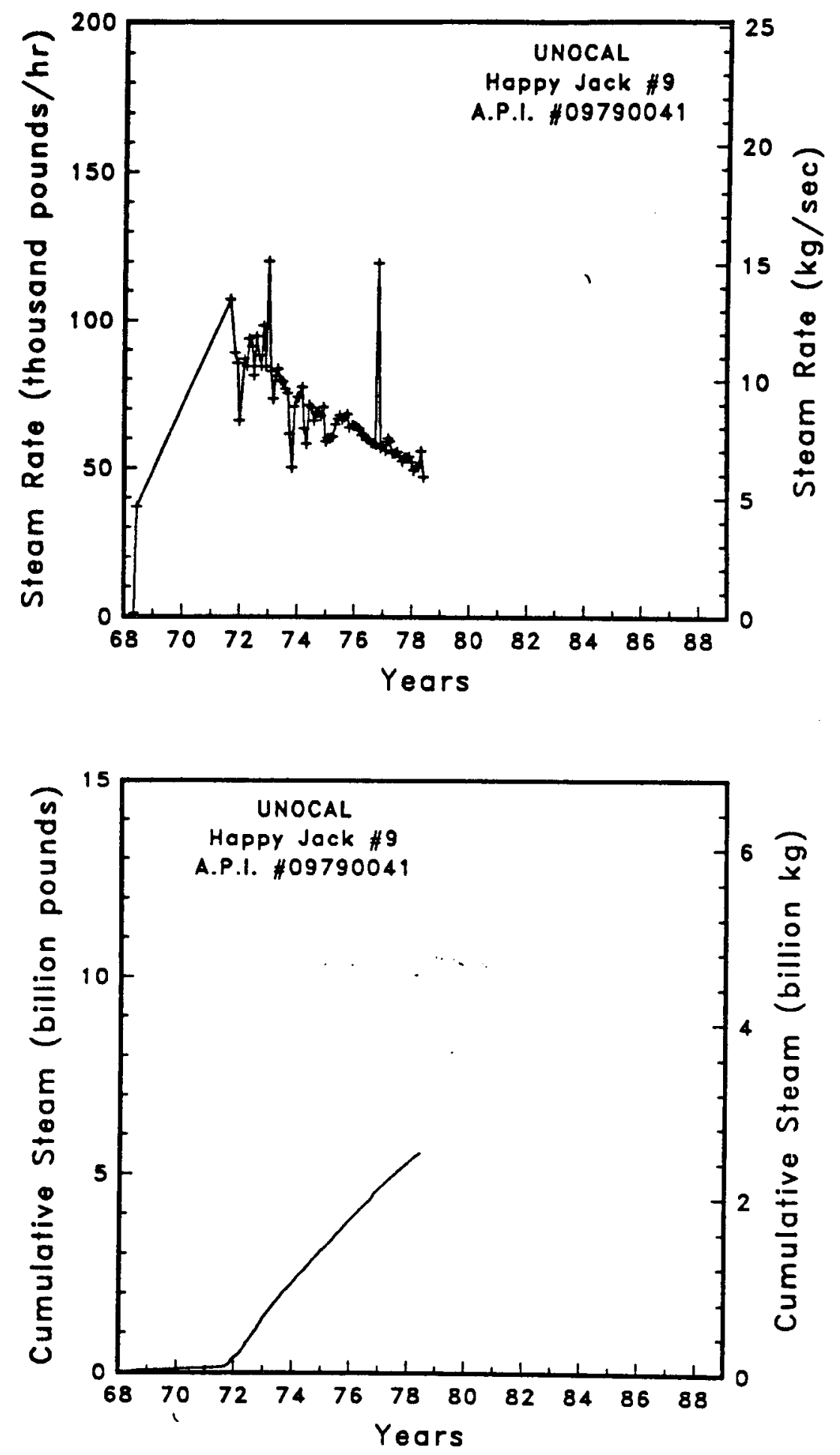

Figure A-112

Steam rate and cumulative mass flow for well Happy Jack \#9 

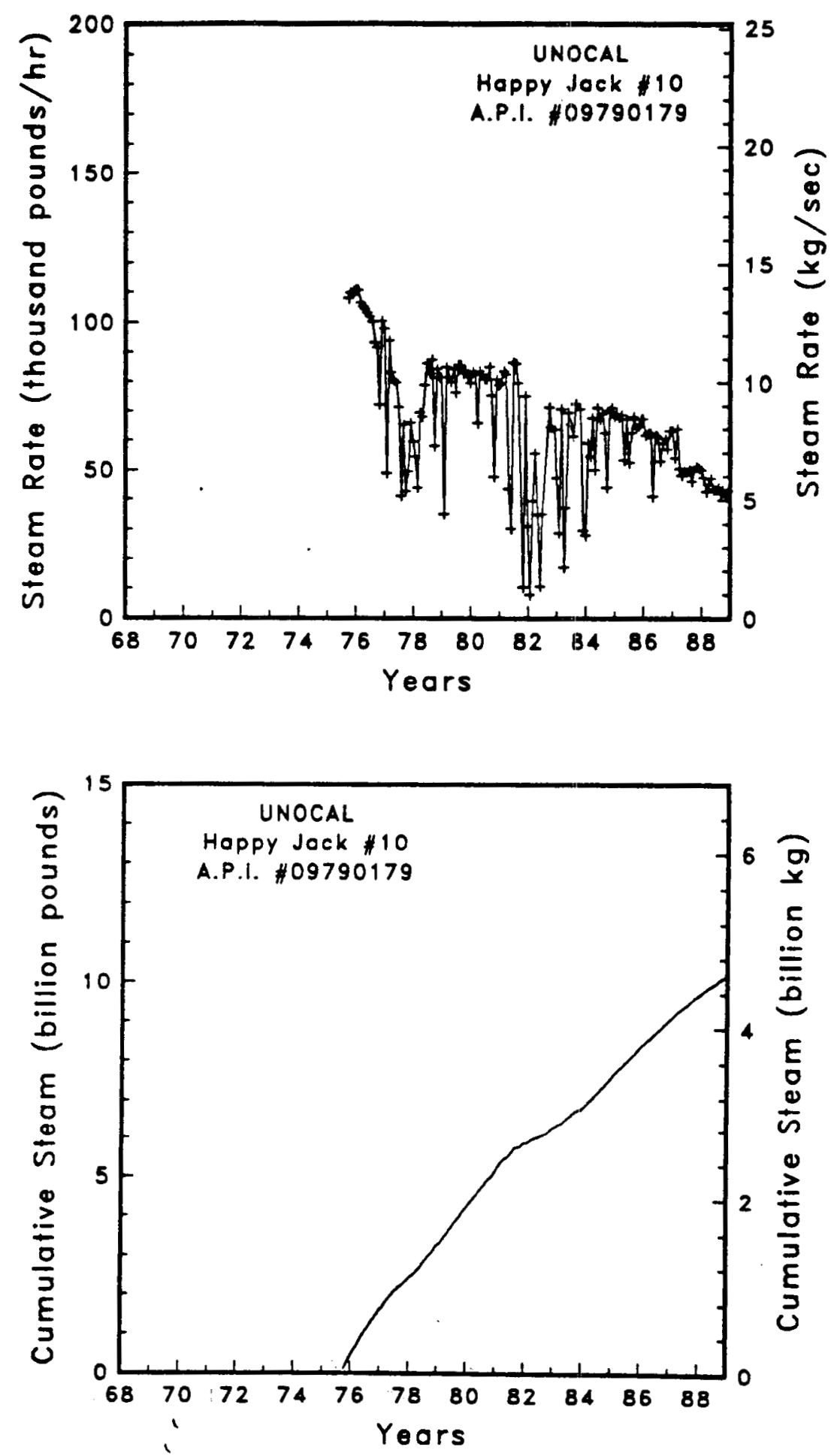

Figure A-113

Steam rote and cumulative mass flow for well Hoppy Jock \#10 

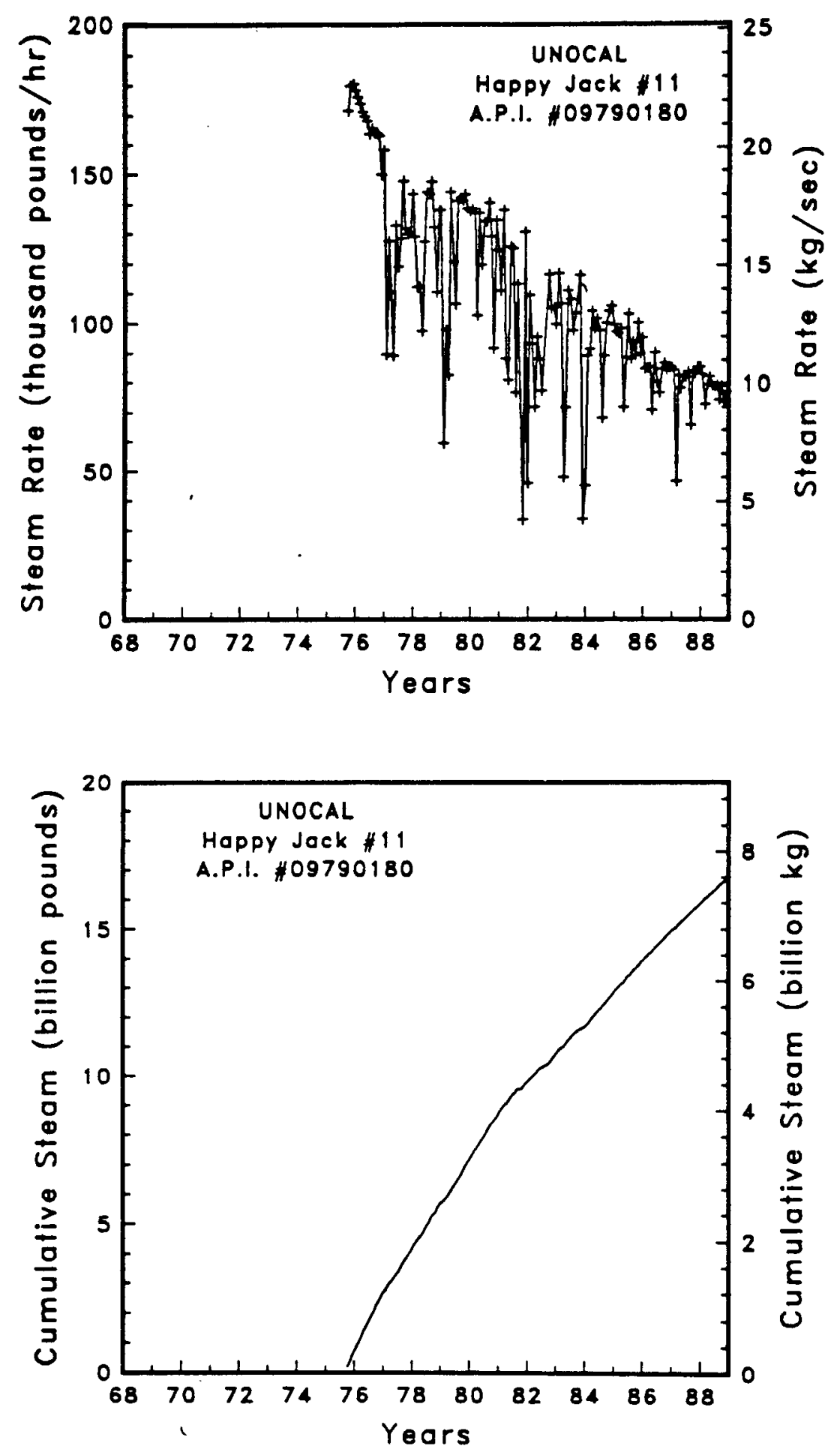

Figure A-114

Steam rate and cumulative mass flow for well Happy Jack \#11 

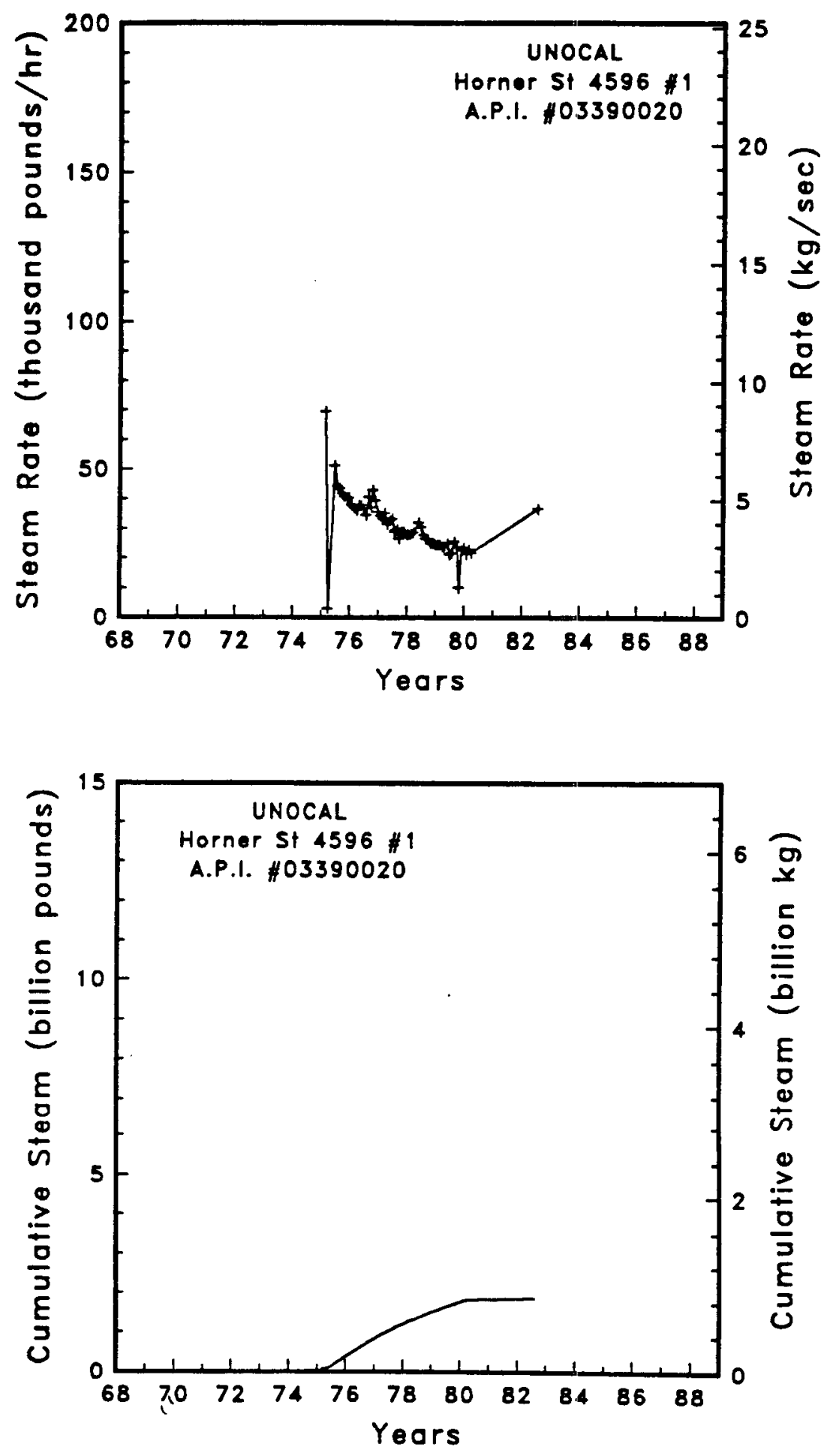

Figure A-115

Steam rate and cumulative mass flow for well Horner St 4596 \#1 

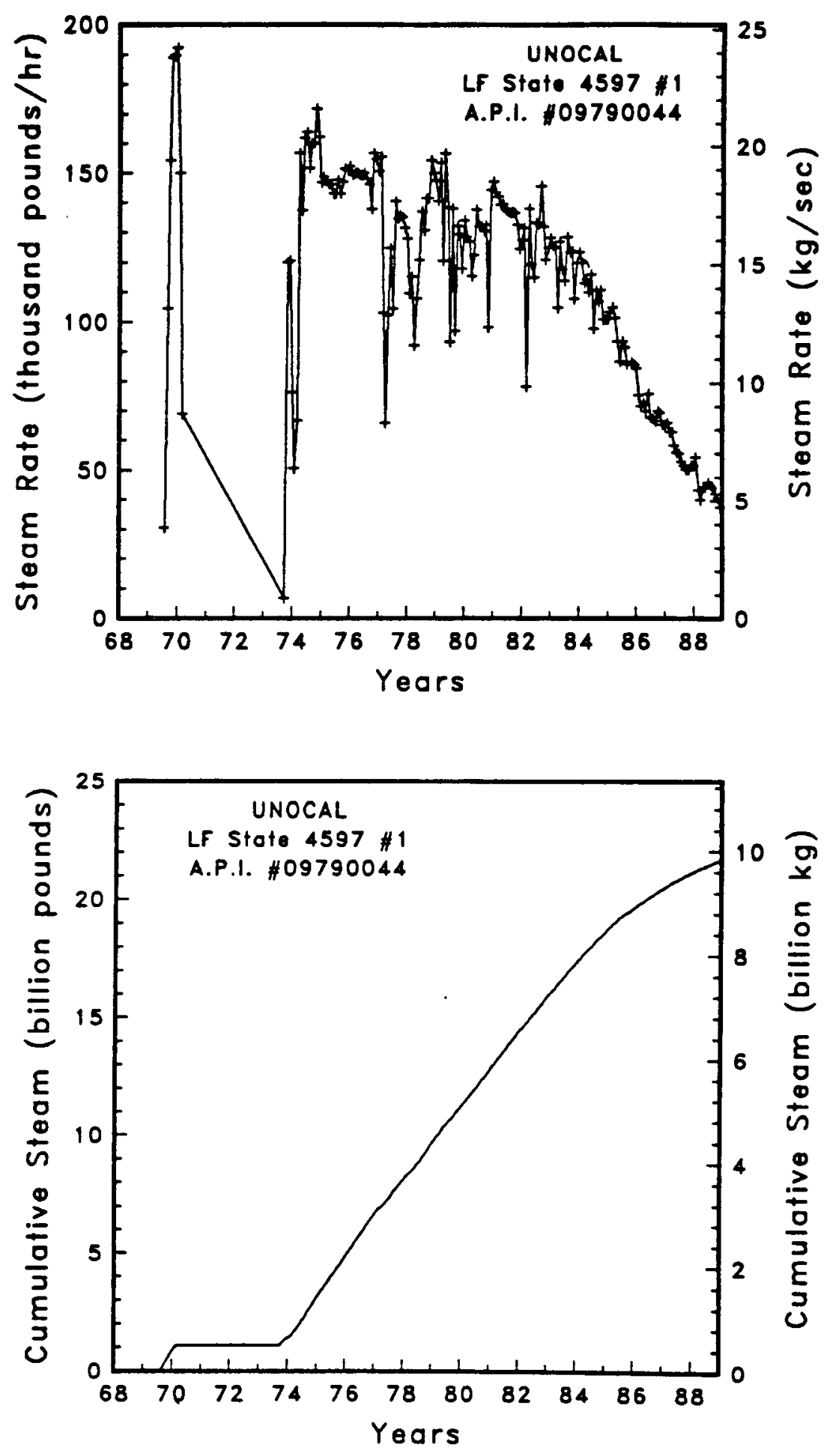

Figure A-116 Steam rate and cumulative mass flow for well LF Stote 4597 \#1 

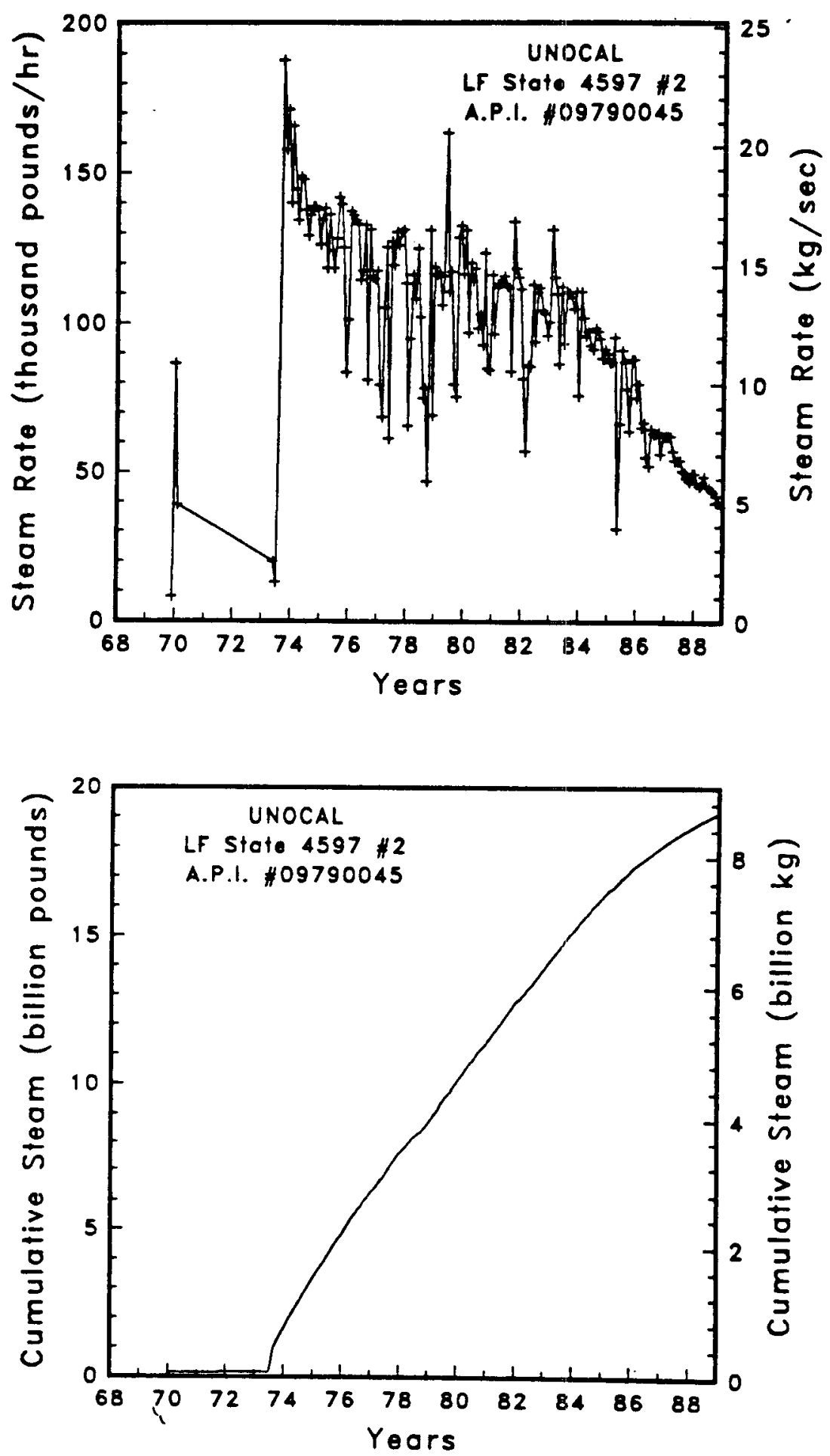

Figure A-117

Steam rate and cumulative mass flow for well LF State 4597 \#2 

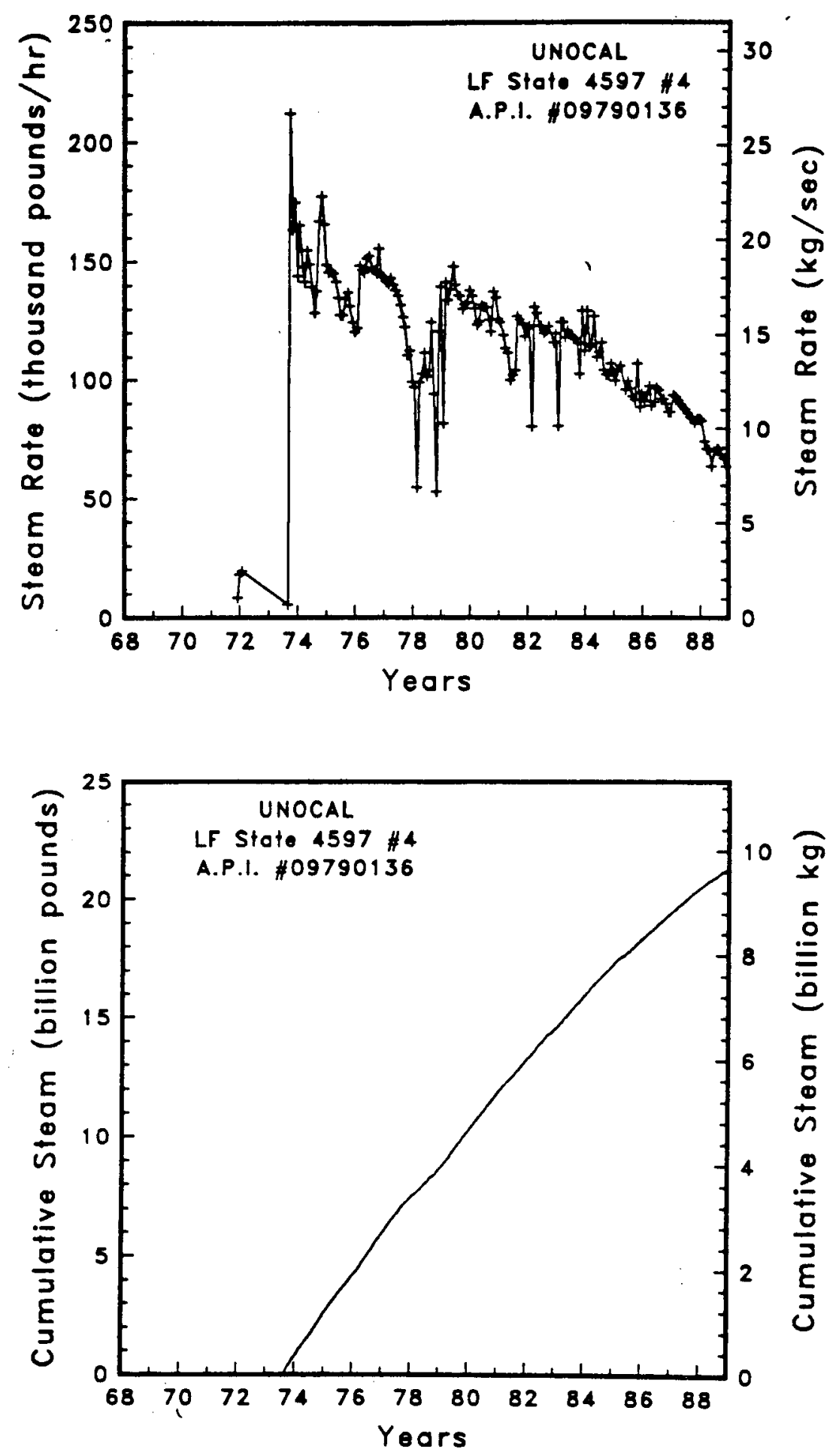

Figure A-118

Steam rate and cumulative mass flow for well LF State 4597 \#4 

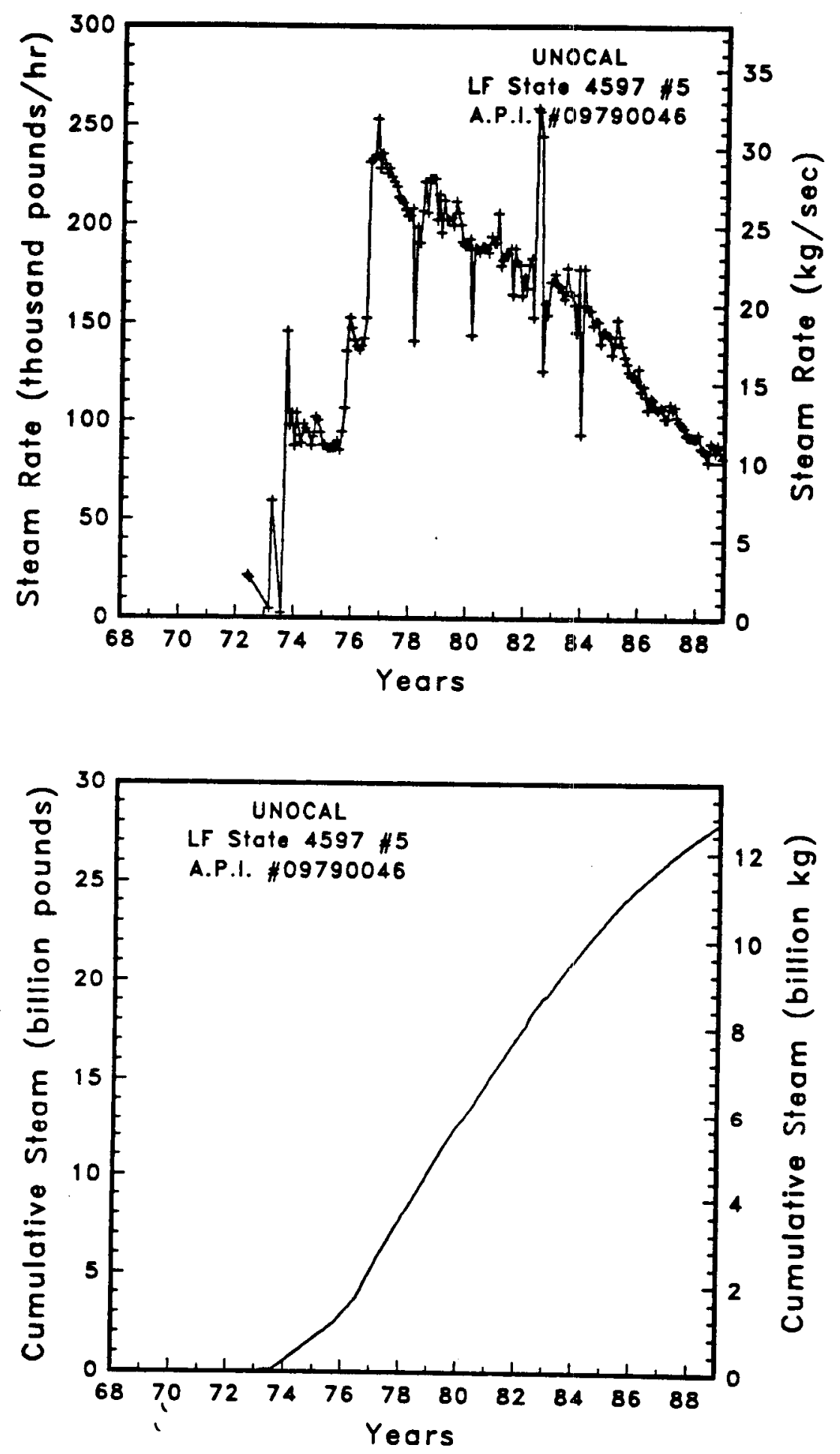

Figure A-119

Steam rate and cumulative mass flow for well LF State 4597 \#5 

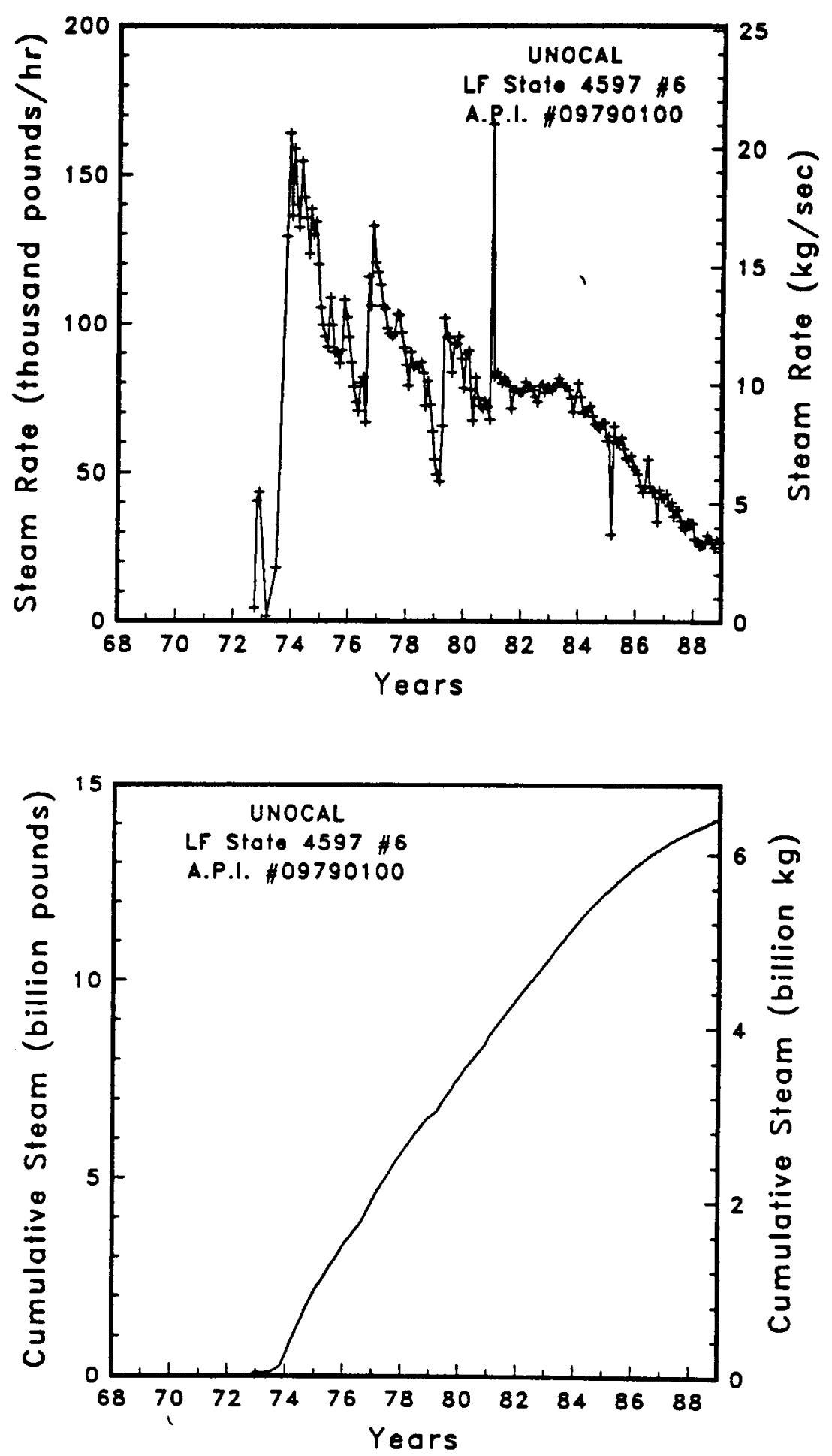

Figure A-120 Steam rate and cumulative mass flow for well LF State 4597 \#6 

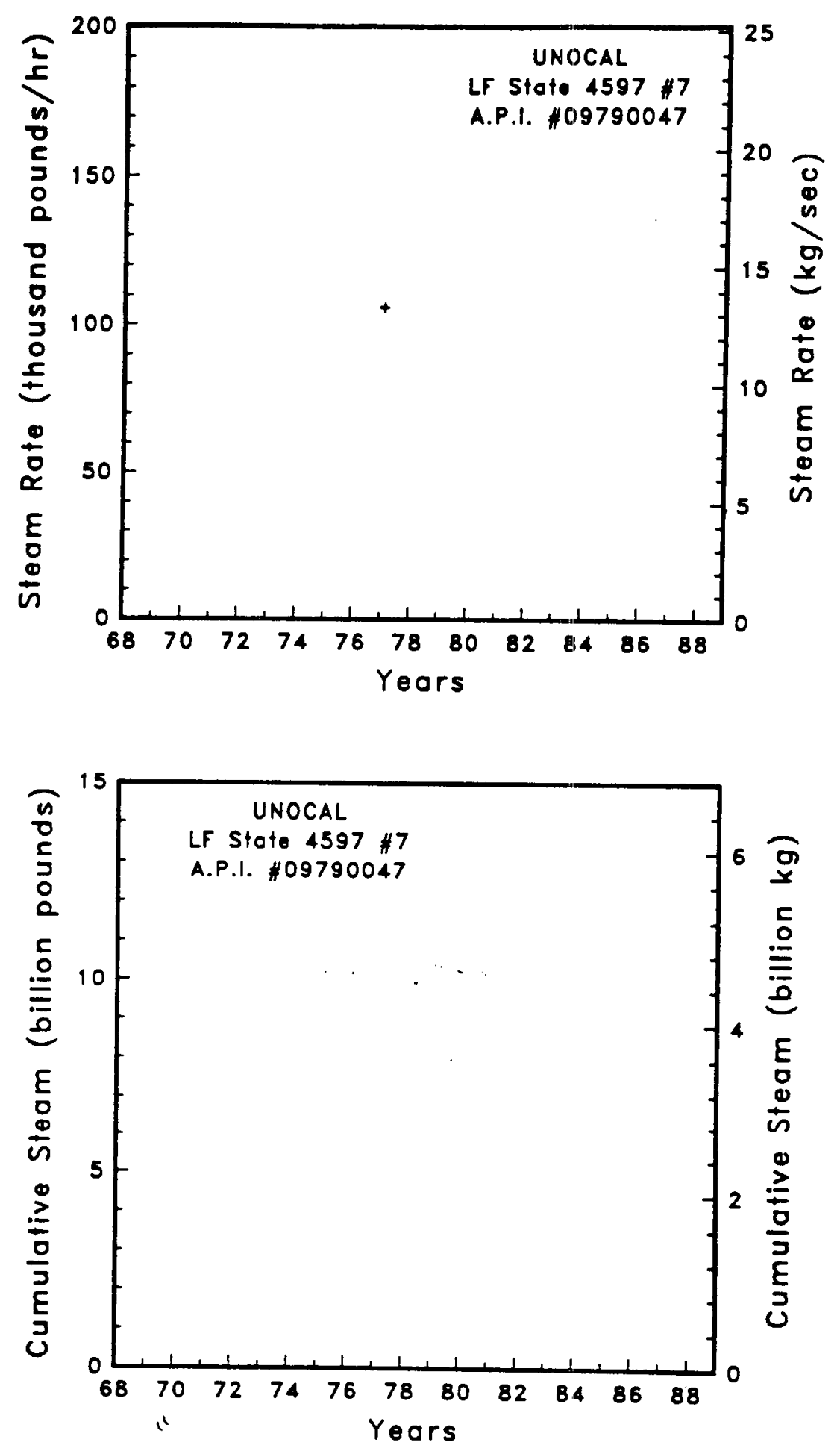

Figure A-121 Steom rate and cumulative mass flow for well LF State 4597 \#7 

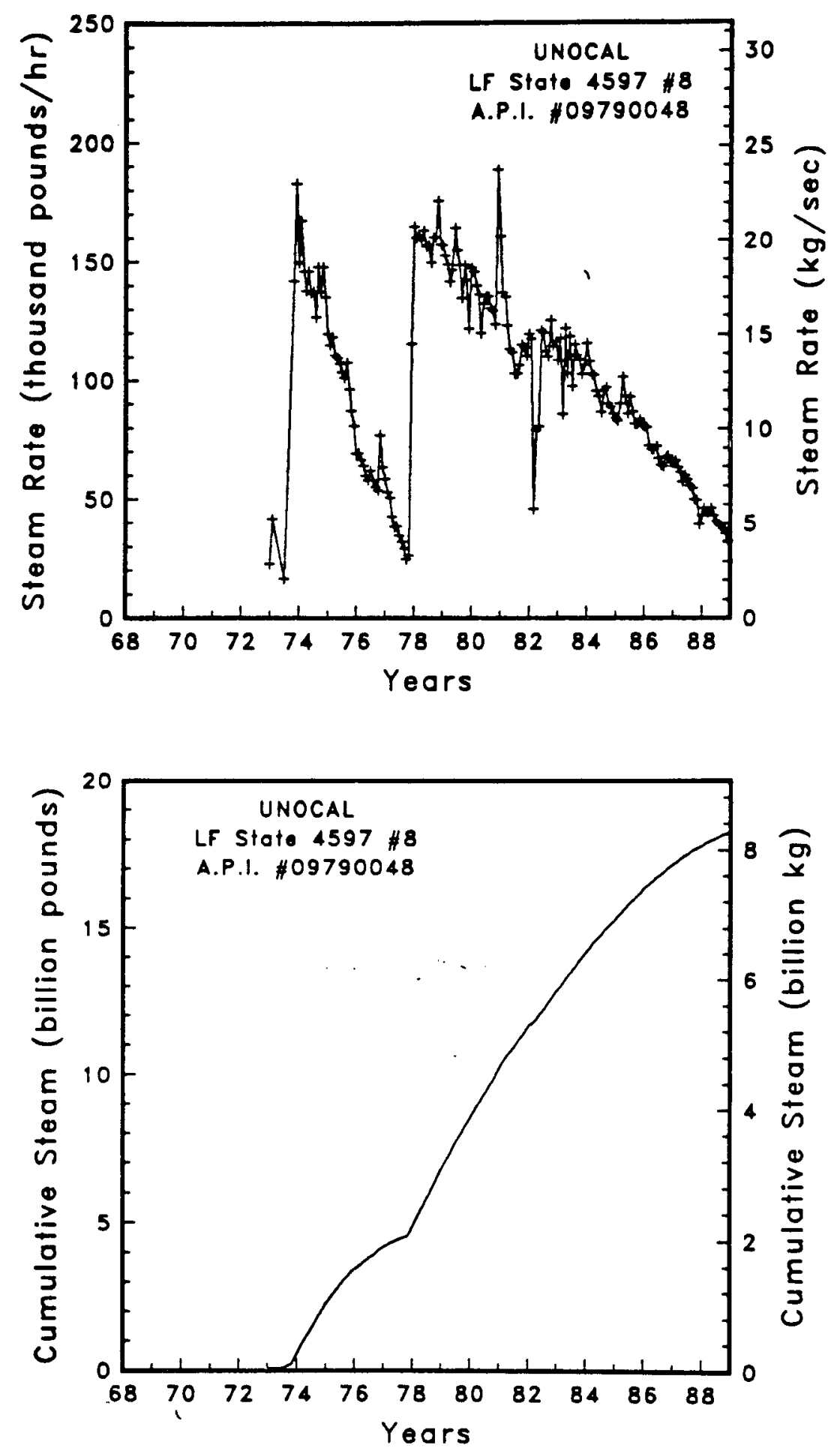

Figure A-122 Steam rate and cumulative mass flow for well LF State $4597 \# 8$ 

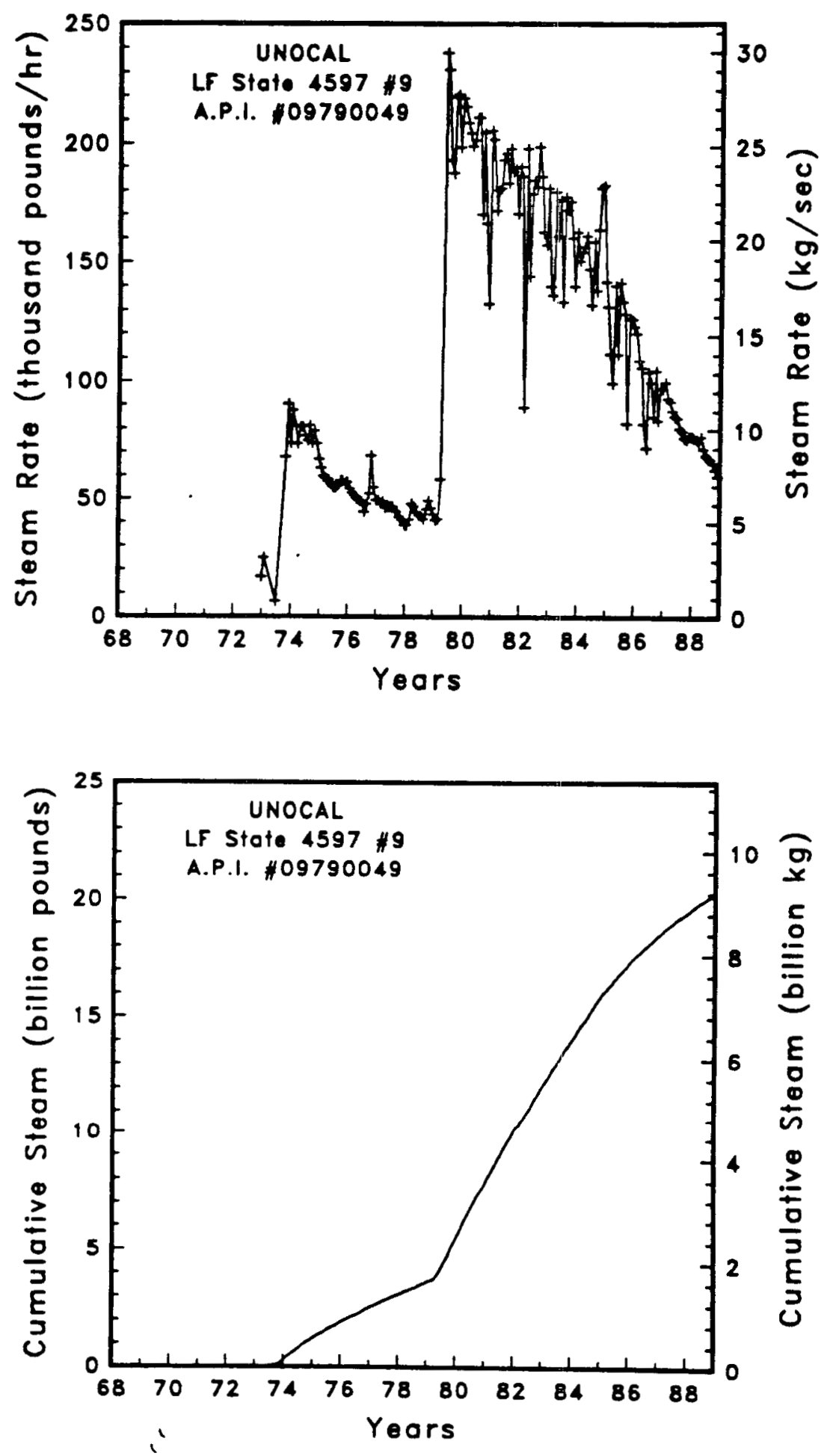

Figure A-123

Steam rate and cumulative mass flow for well LF State 4597 \#9 

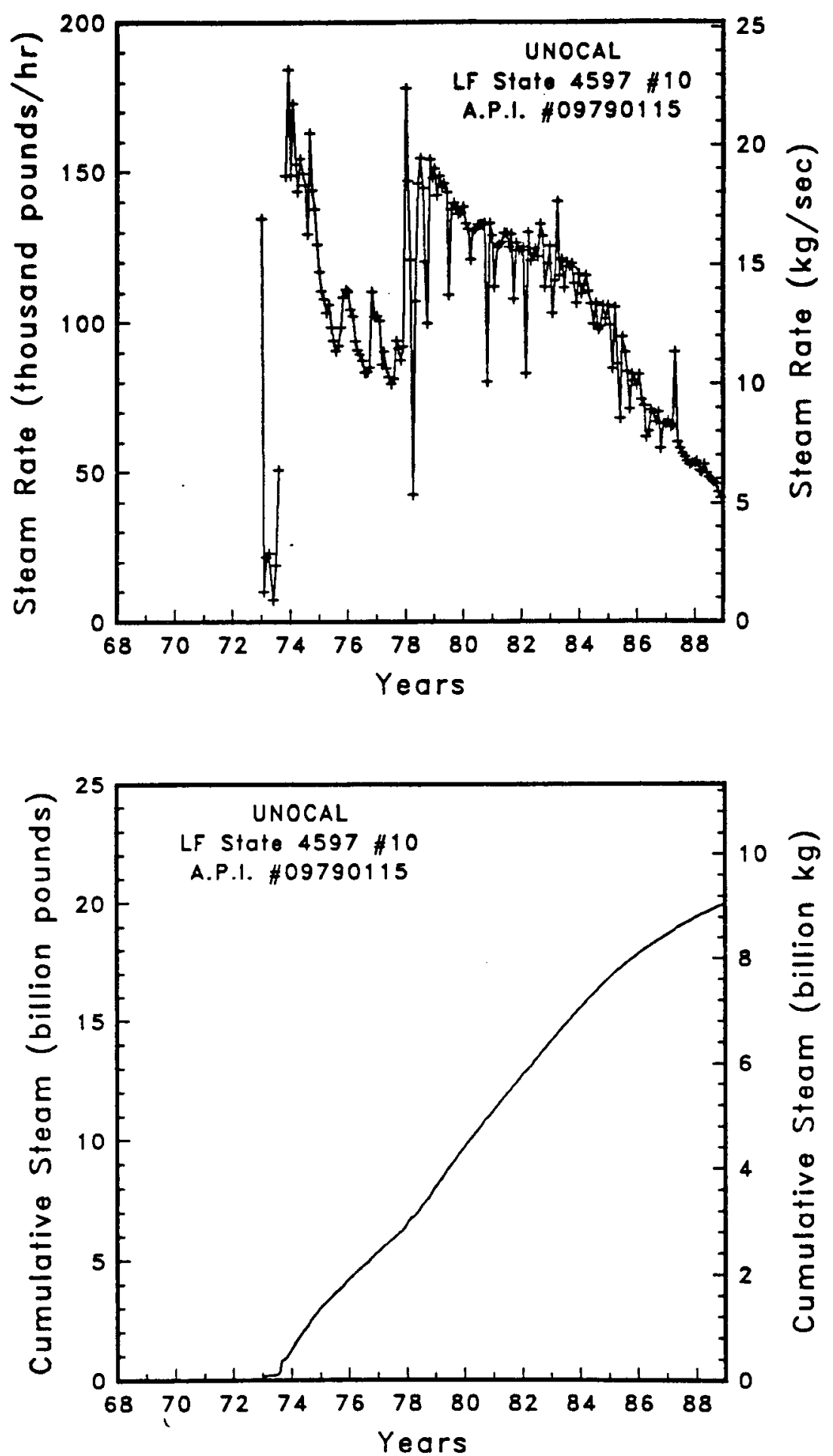

Figure A-124 Steam rate and cumulative mass flow for well LF State 4597 \#10 

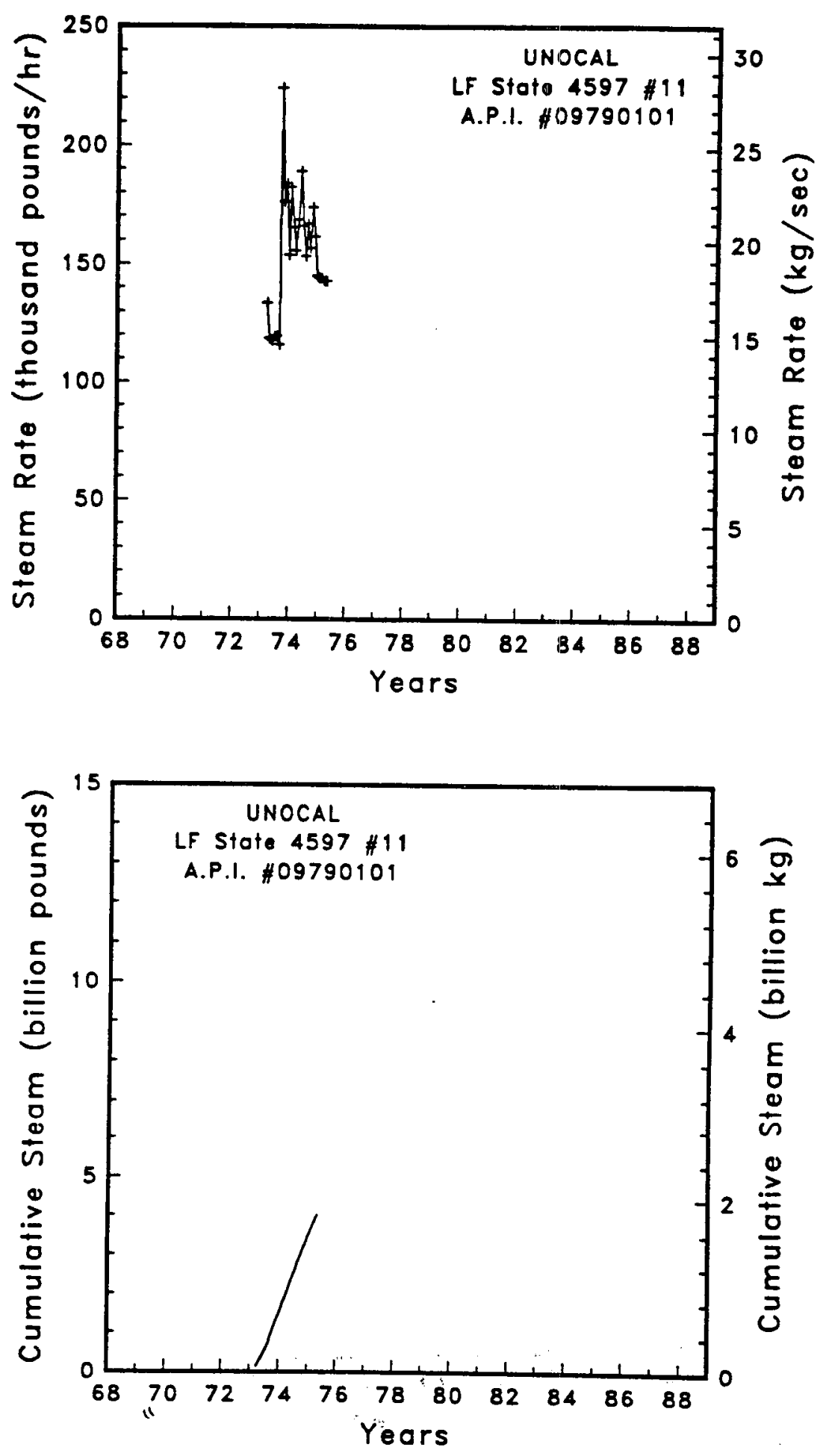

Figure A-125

Steam rate and cumulative mass flow for well LF State 4597 \#11 

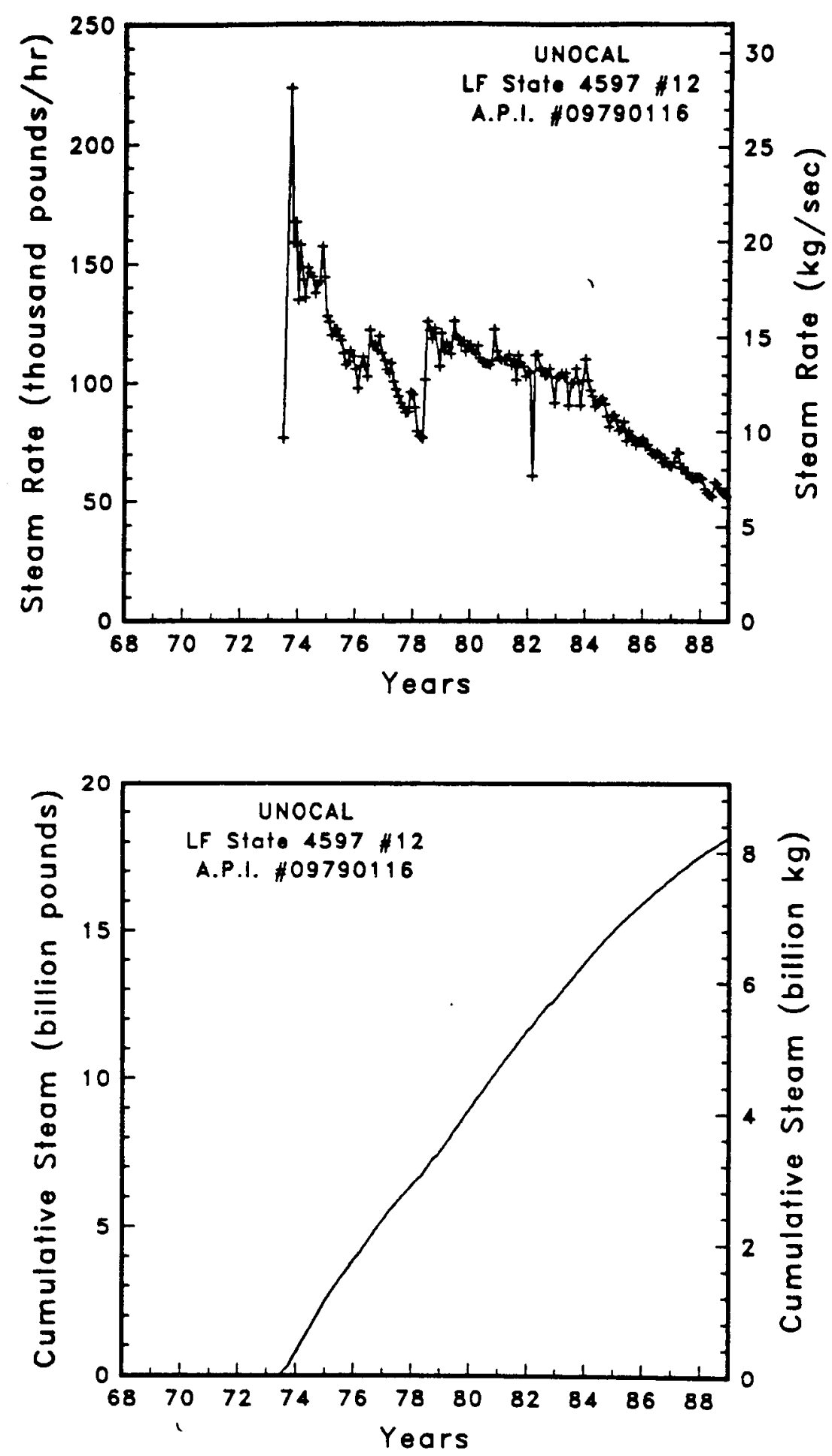

Figure A-126

Steam rate and cumulative mass flow for well LF State 4597 \#12 

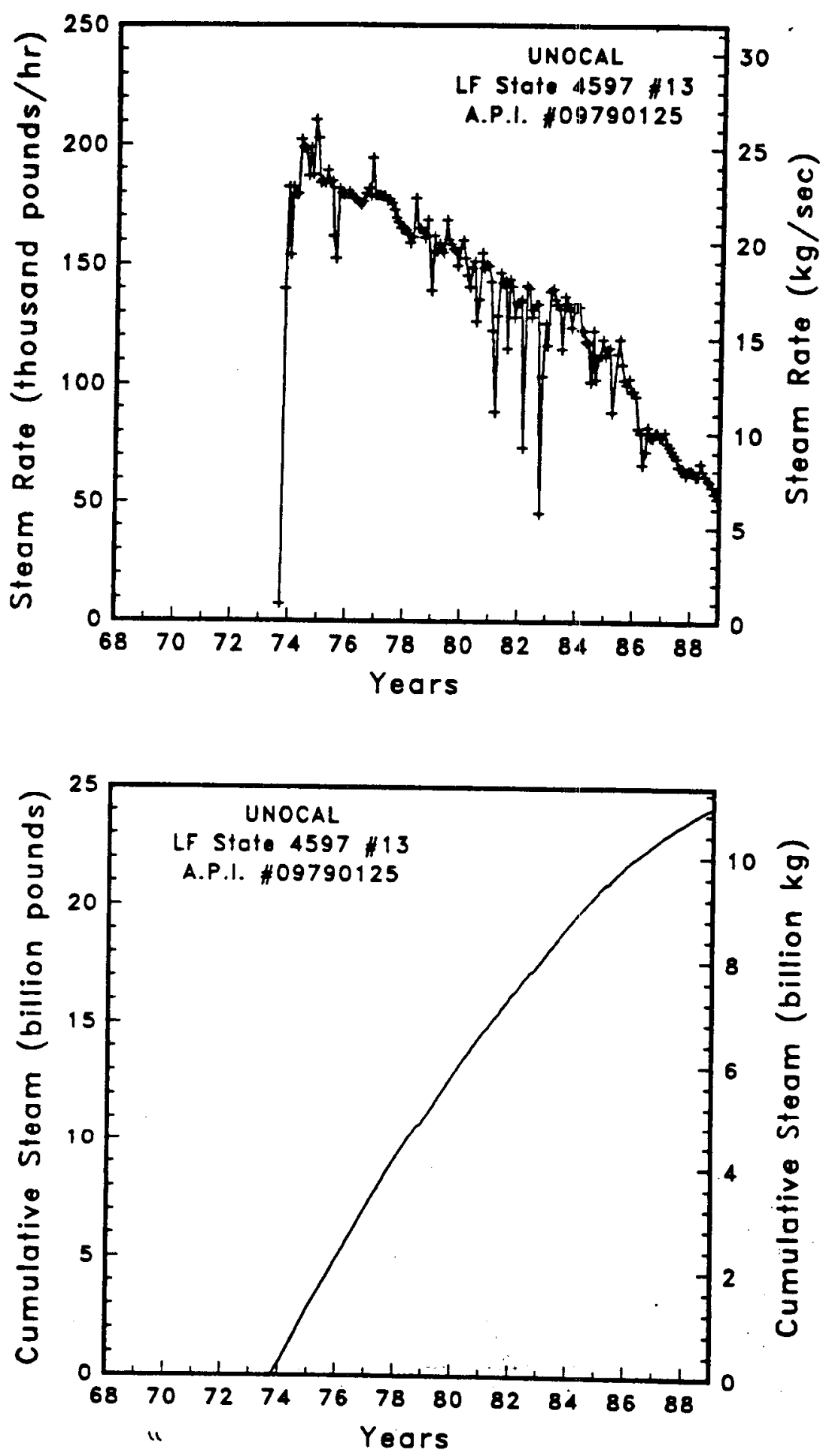

Figure A-127

Steam rate and cumulative mass flow for well LF State $4597 \# 13$ 

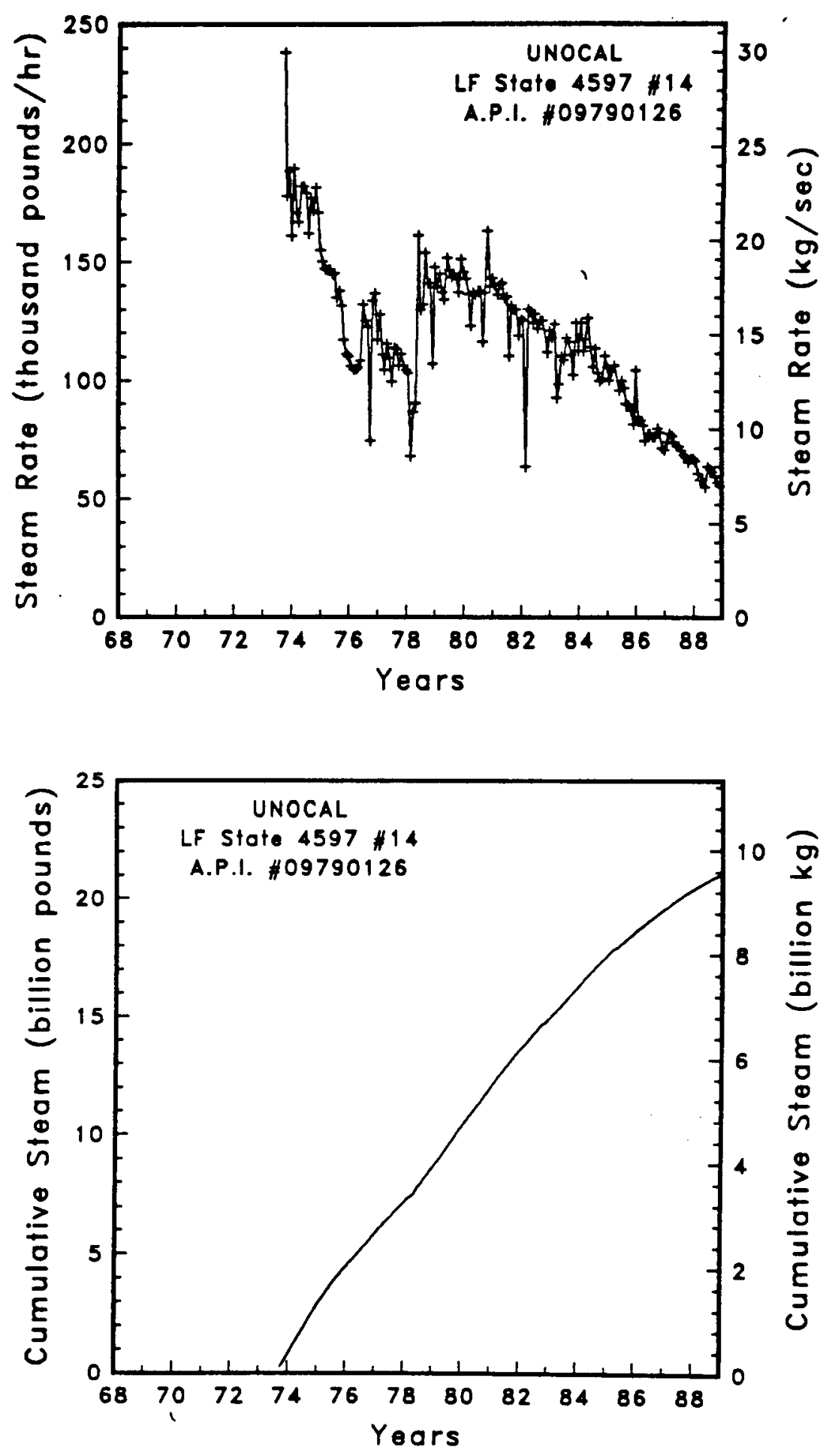

Figure A-128

Steam rate and cumulative mass flow for well LF State 4597 \#14 

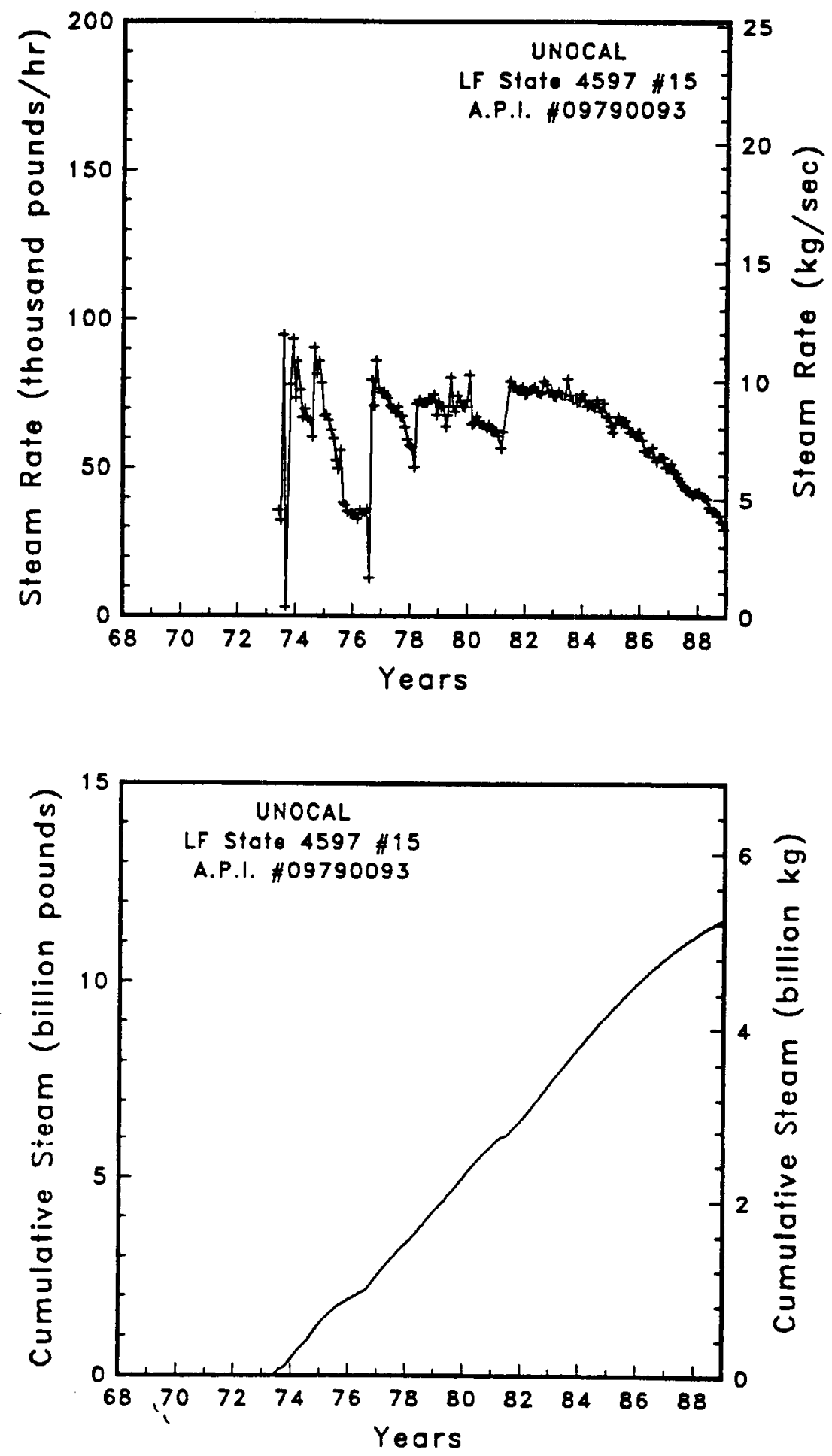

Figure A-129 Steam rate and cumulative mass flow for well LF State 4597 \#15 

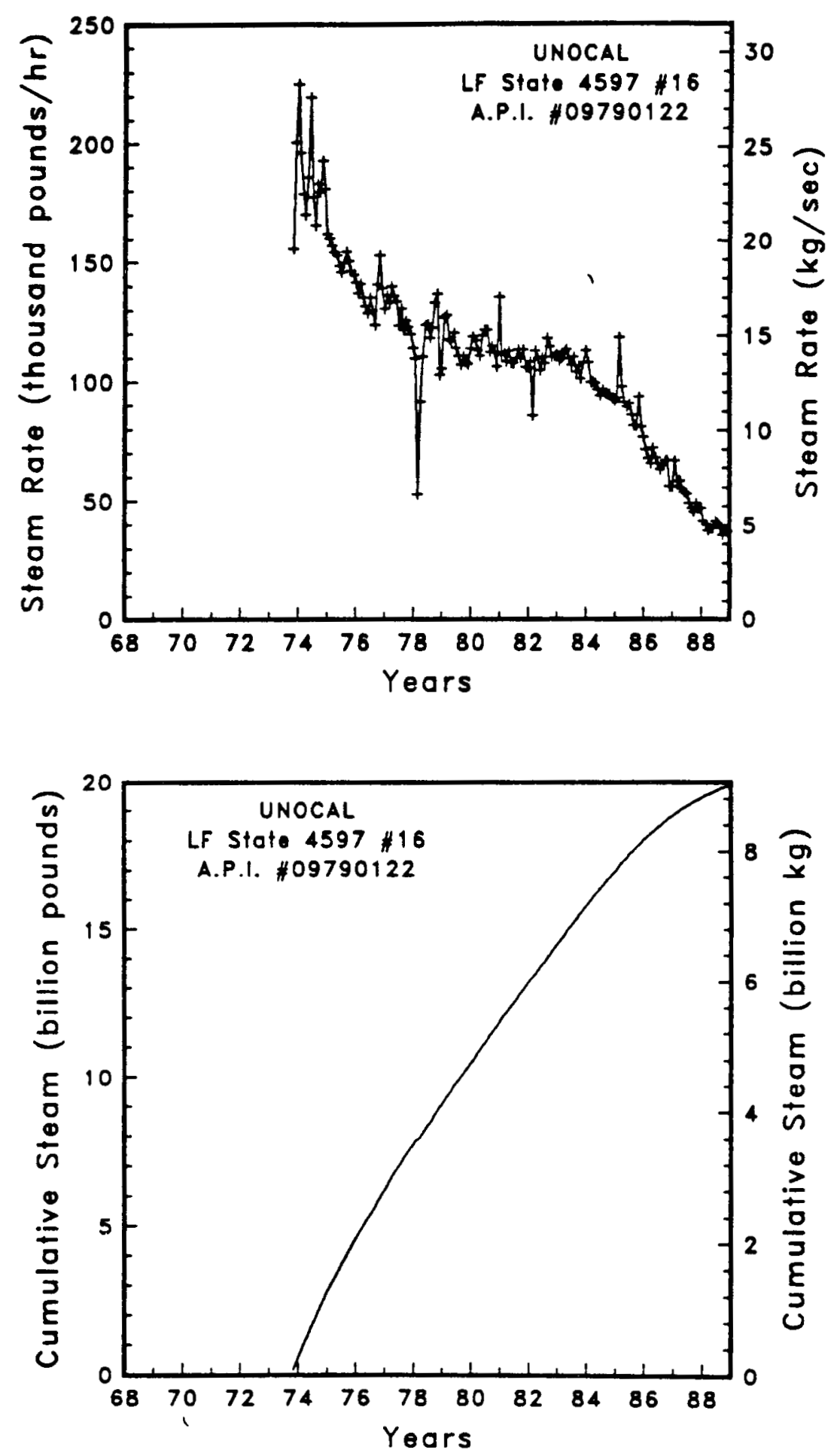

Figure A-130

Steam rate and cumulative mass flow for well LF State 4597 \#16 

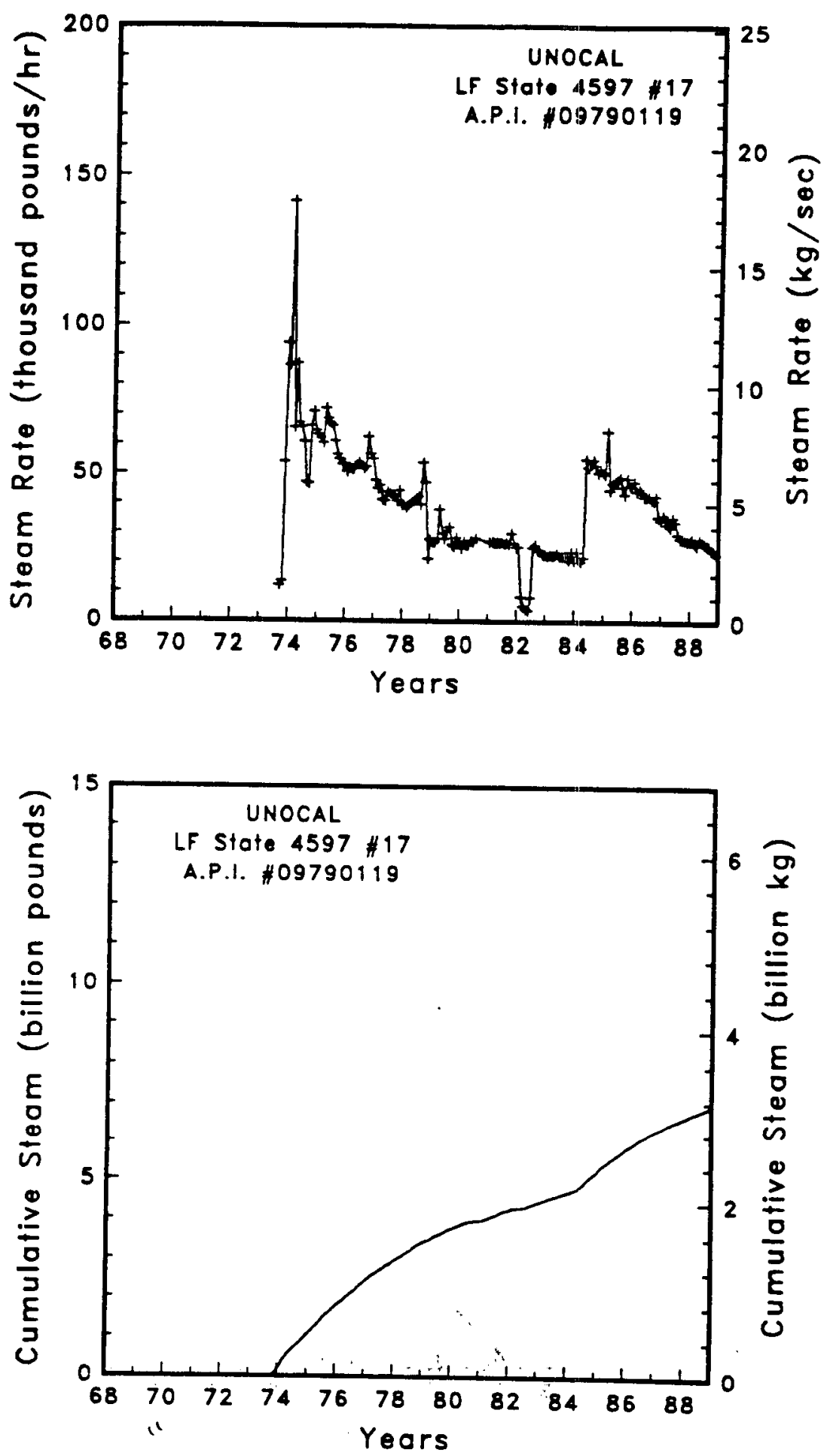

Figure A-131

Steam rate and cumulative mass flow for well LF State 4597 \#17 

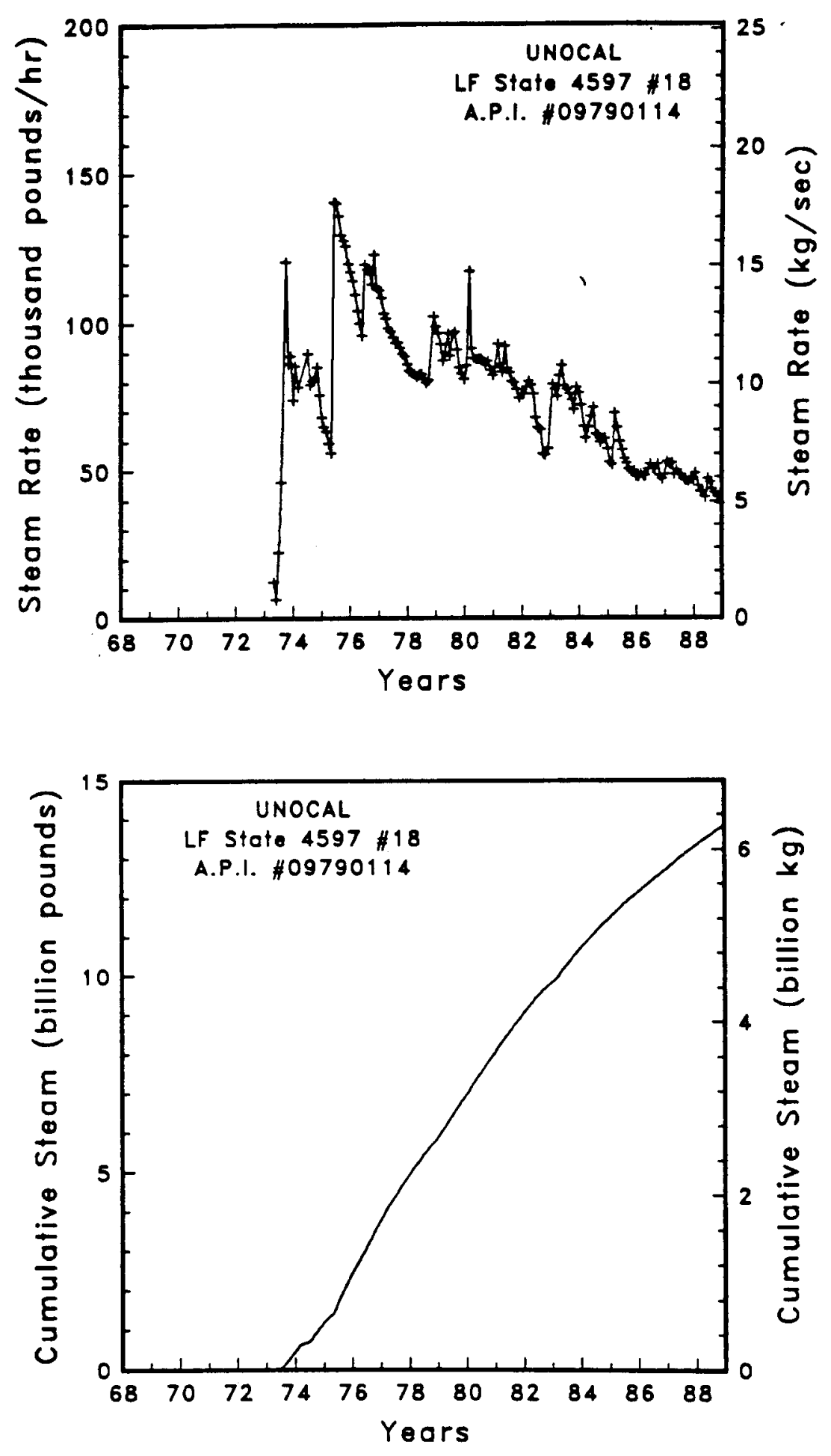

Figure A-132

Steam rate and cumulative mass flow for well LF State 4597 \#18 

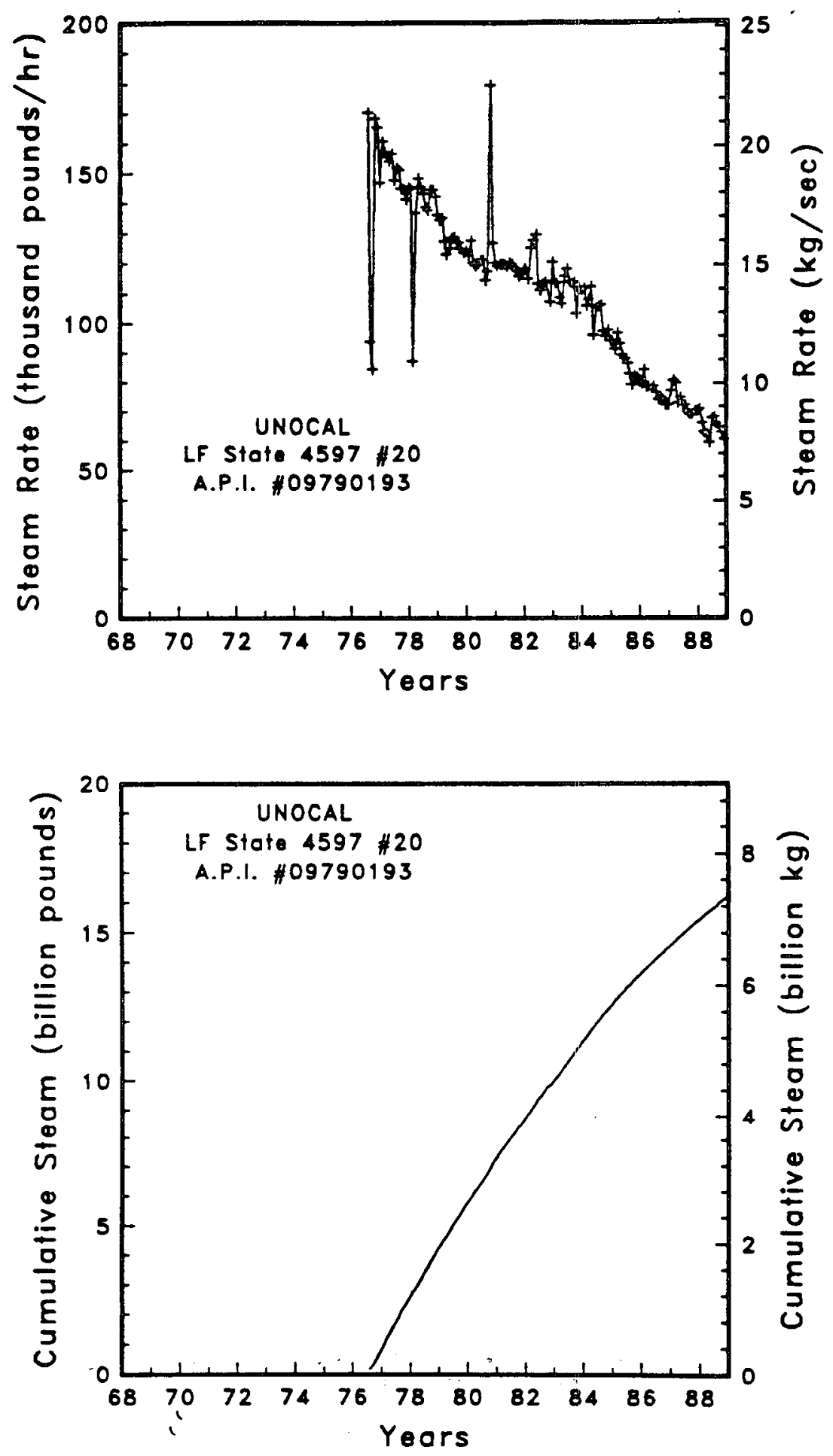

Figure A-133

Steam rate and cumulative mass flow for well LF State 4597 \#20 

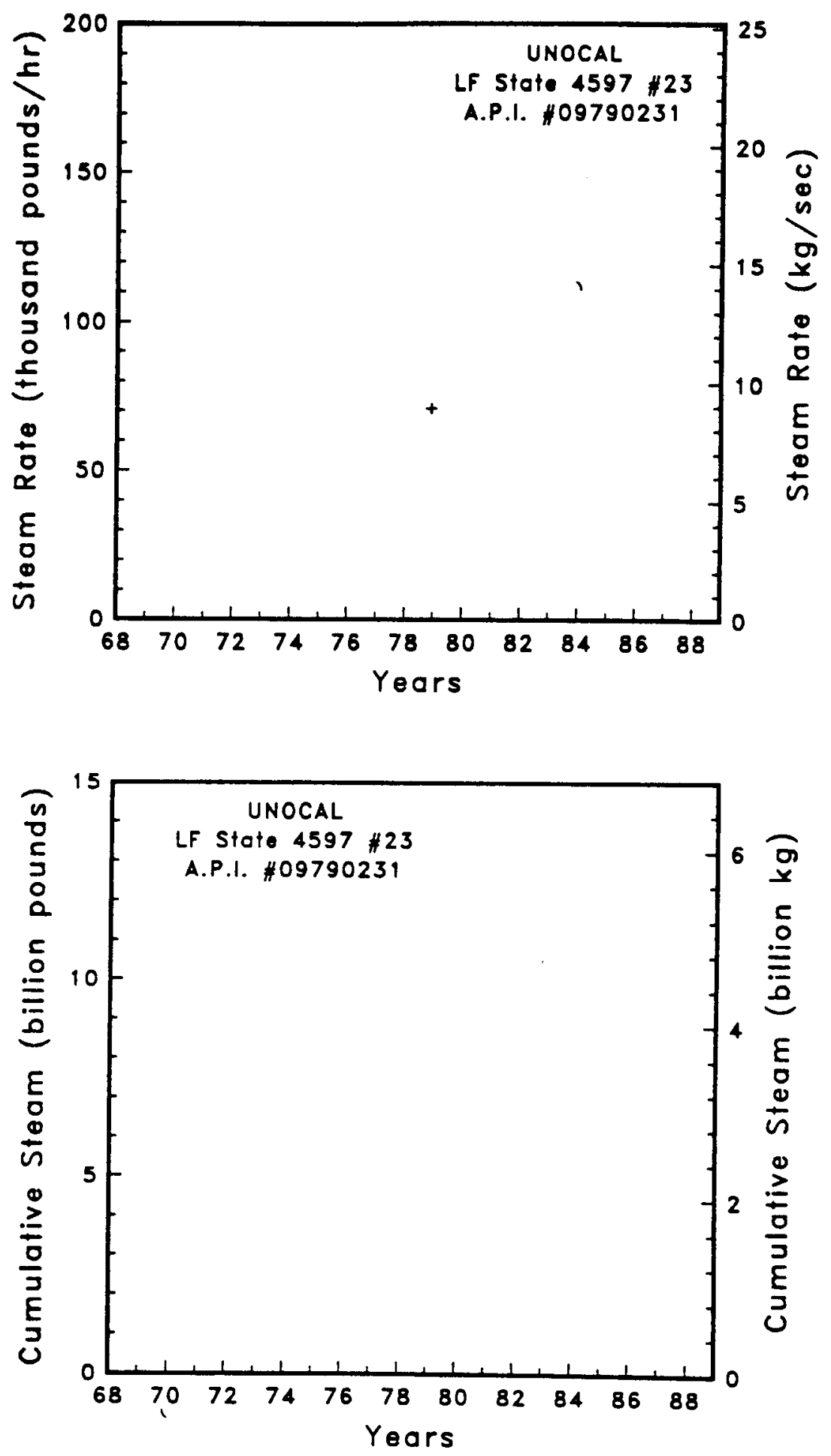

Figure A-134

Steam rate and cumulative mass flow for well LF State 4597 \#23 

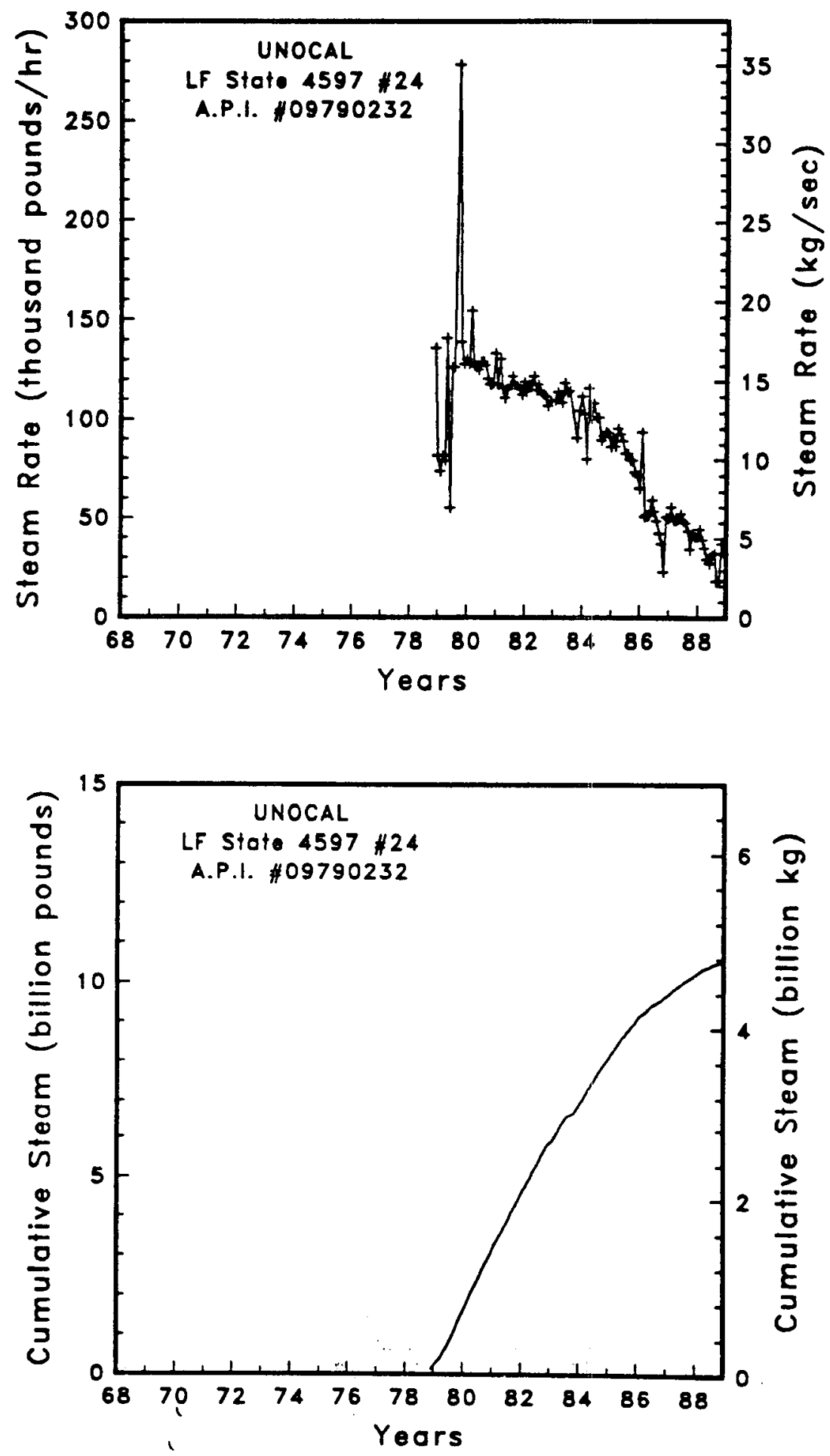

Figure A-135

Steam rate and cumulative mass flow for well LF State $4597 \# 24$ 

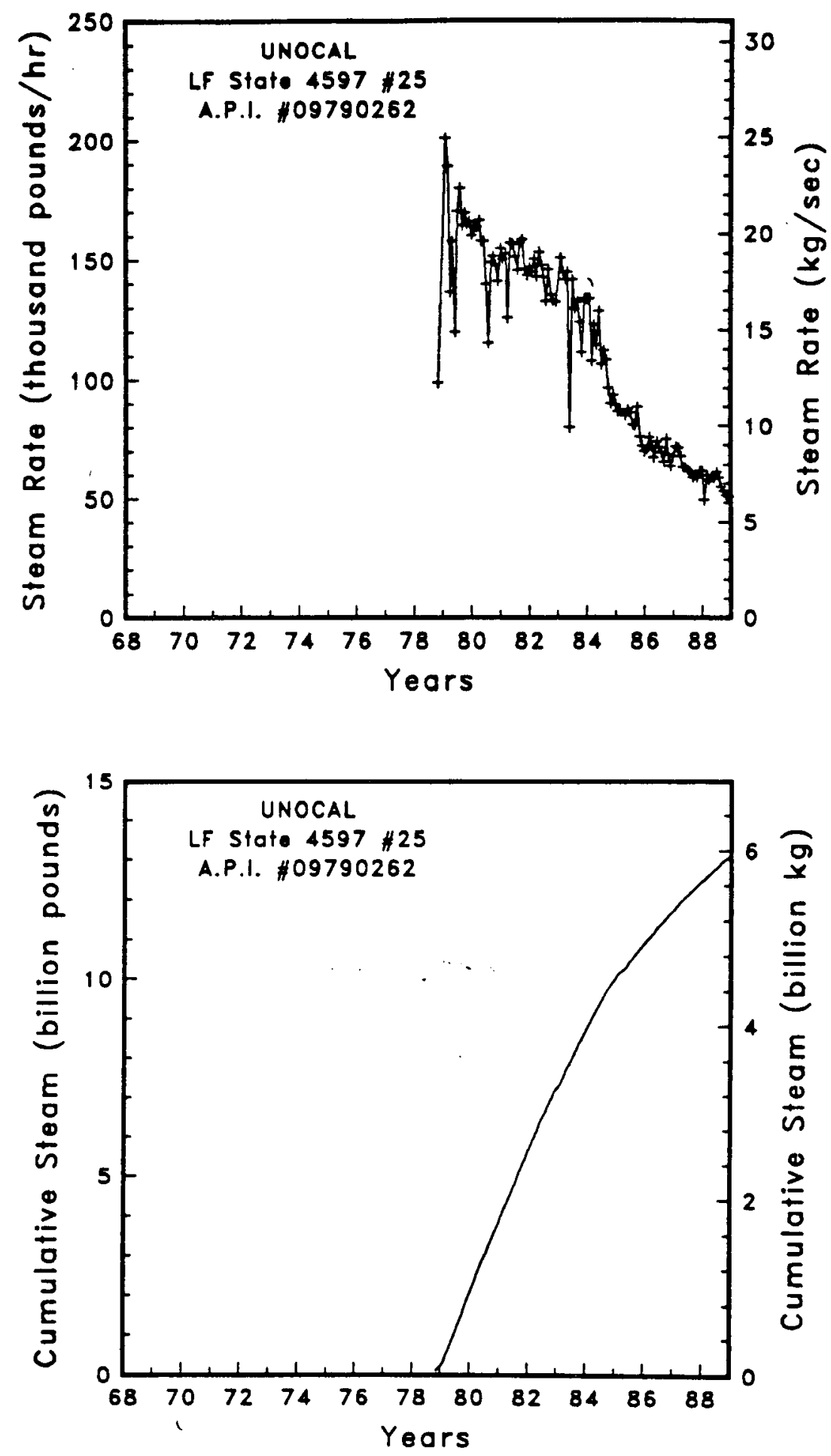

Figure A-136

Steam rate and cumulative mass flow for well LF State 4597 \#25 

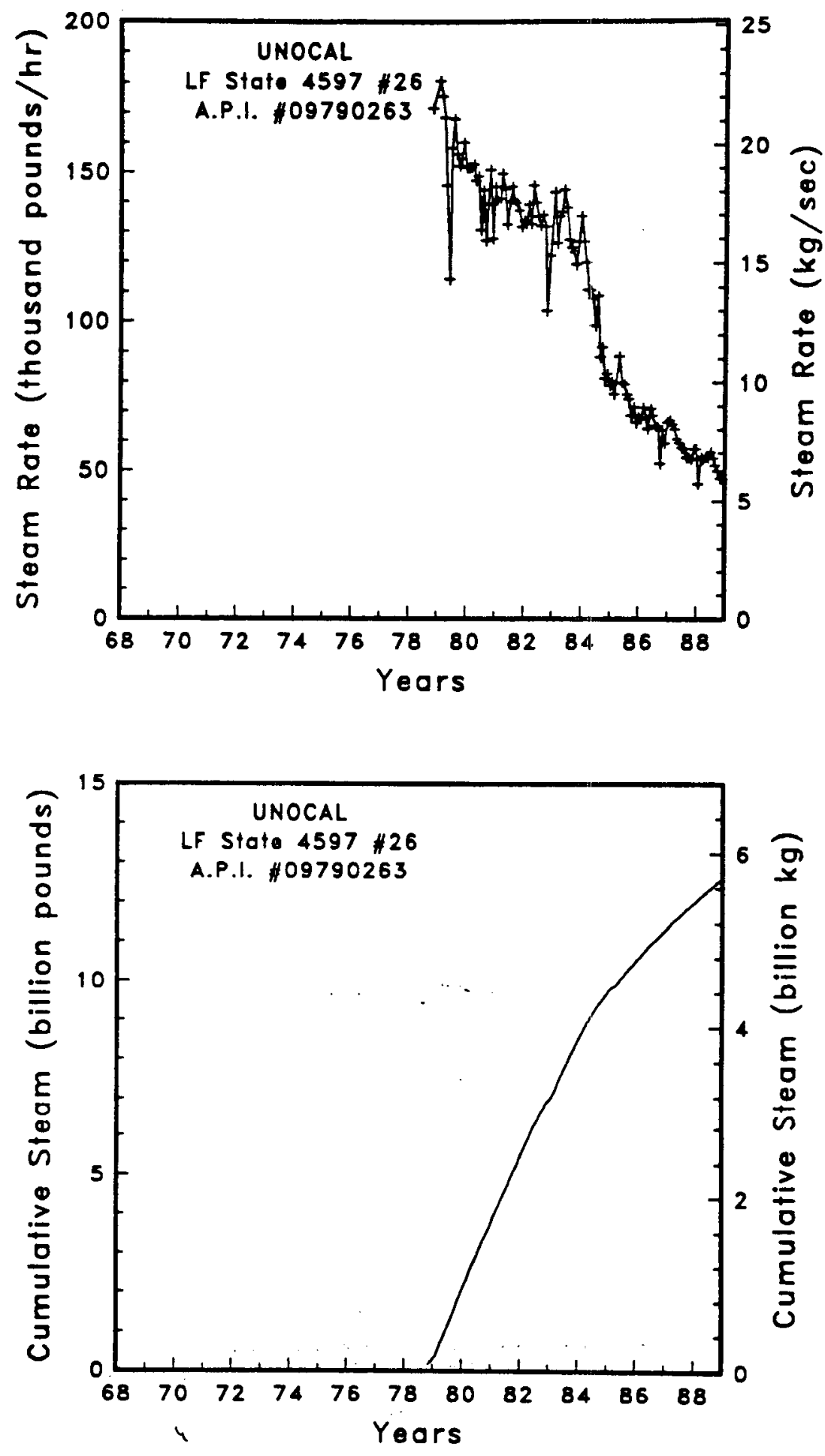

Figure A-137

Steam rate and cumulative mass flow for well LF State 4597 \#26 

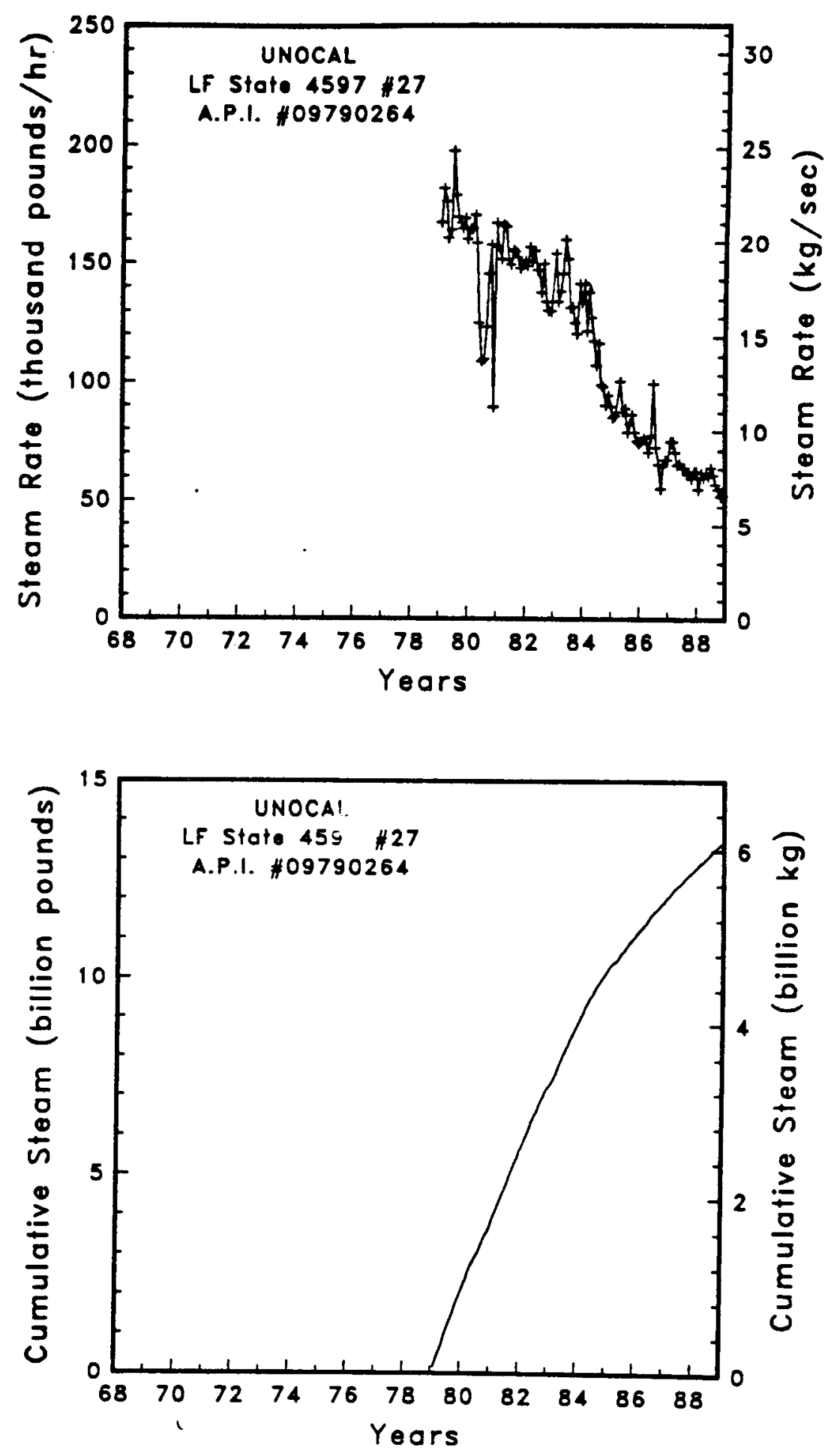

Figure A-138

Steam rate and cumulative mass flow for well LF State 4597 \#27 

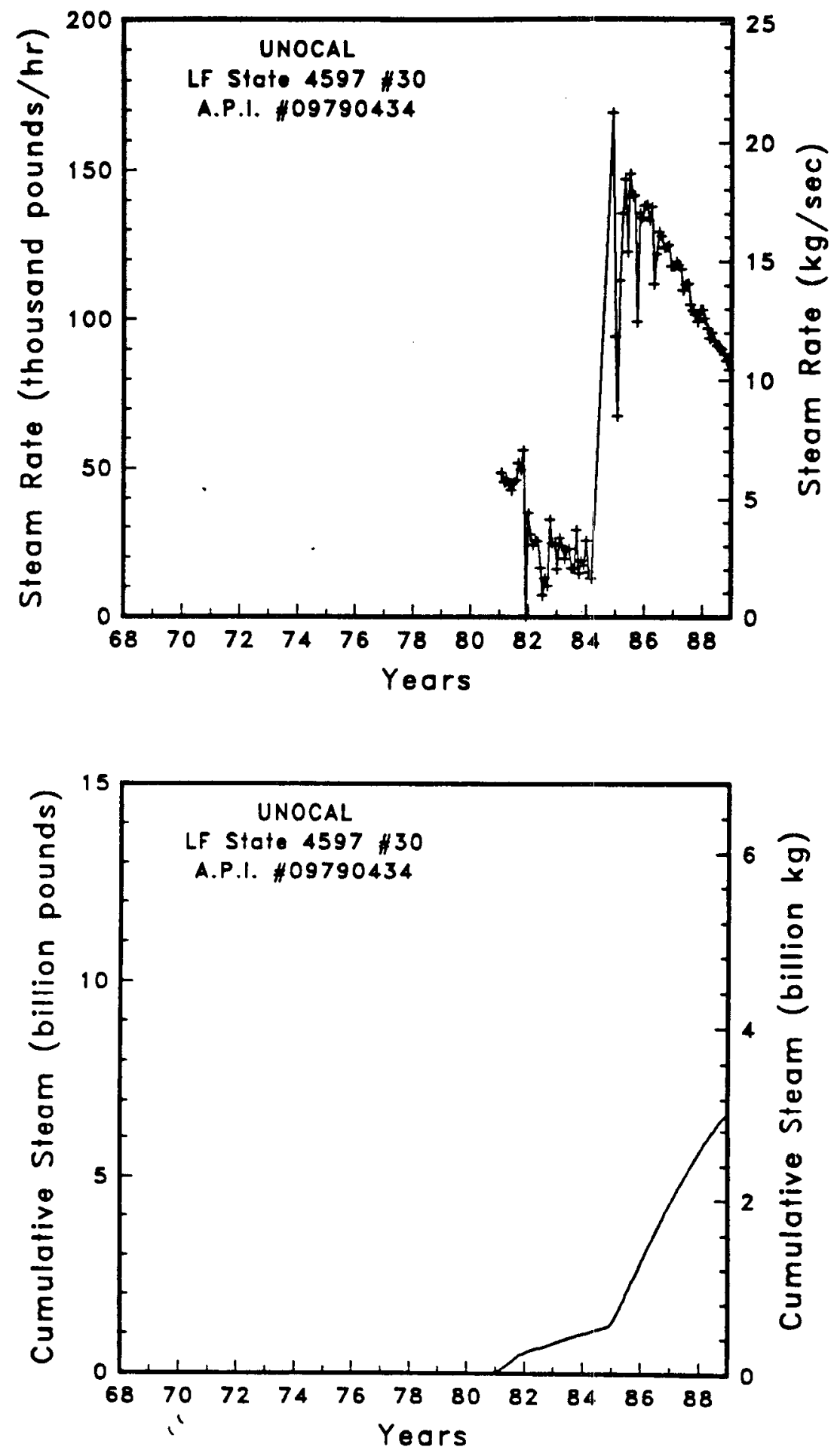

Figure A-139 Steam rate and cumulative mass flow for well LF State 4597 \#30 

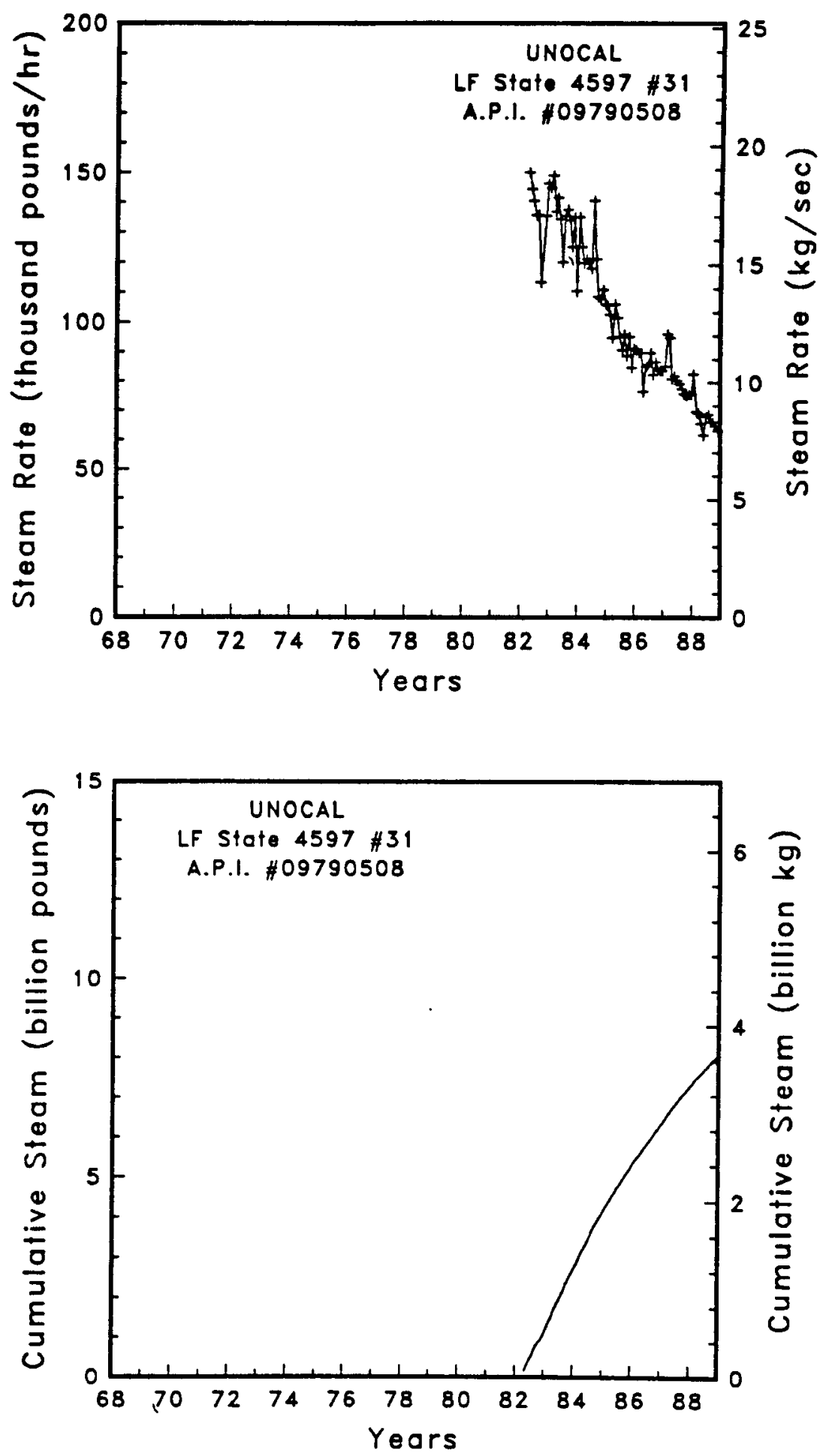

Figure A-140

Steam rate and cumulative mass flow for well LF State 4597 \#31 

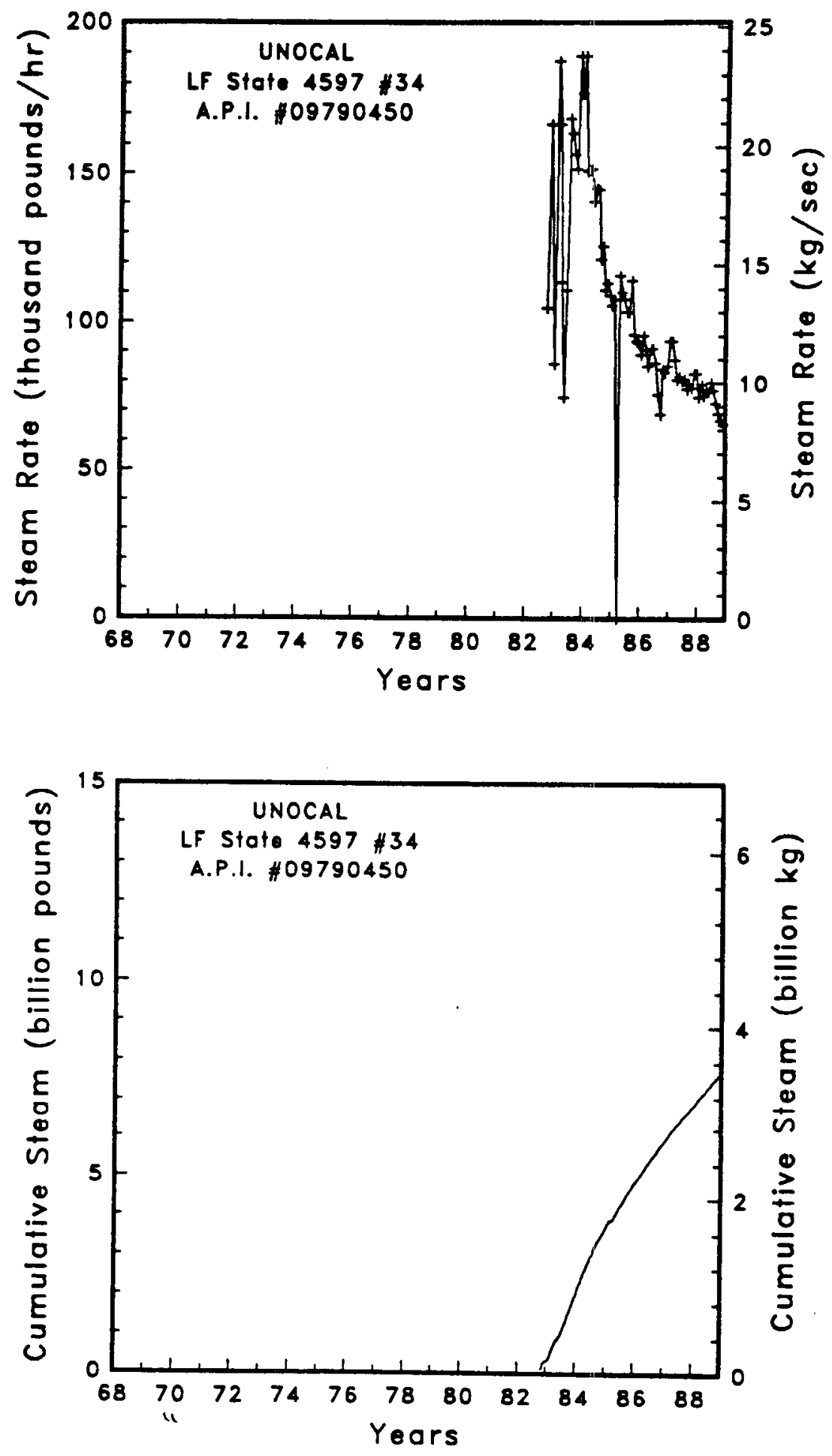

Figure A-141 Steom rate and cumulative mass flow for well LF State 4597 \#34 

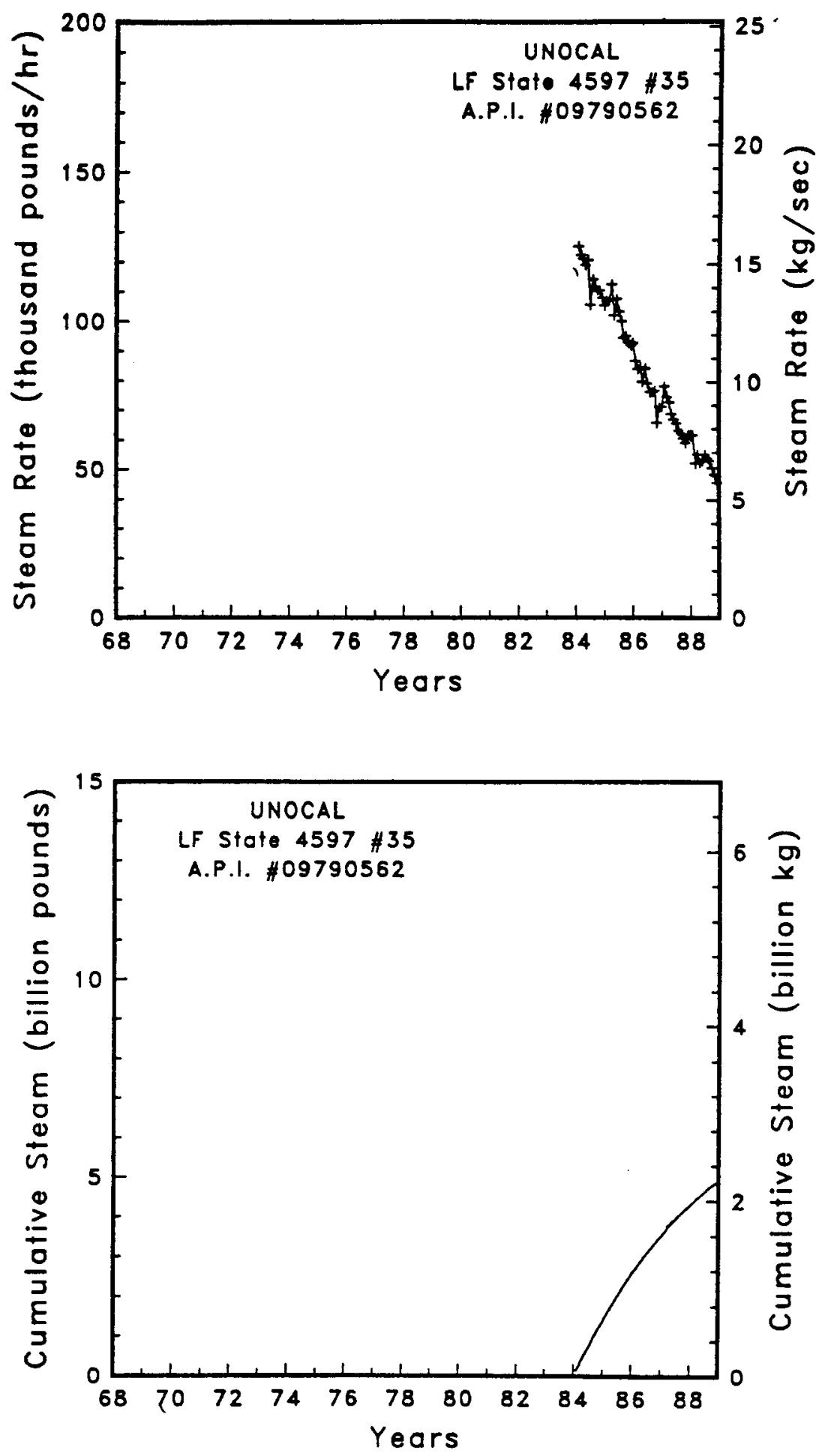

Figure A-142

Steam rate and cumulative mass flow for well LF State 4597 \#35 

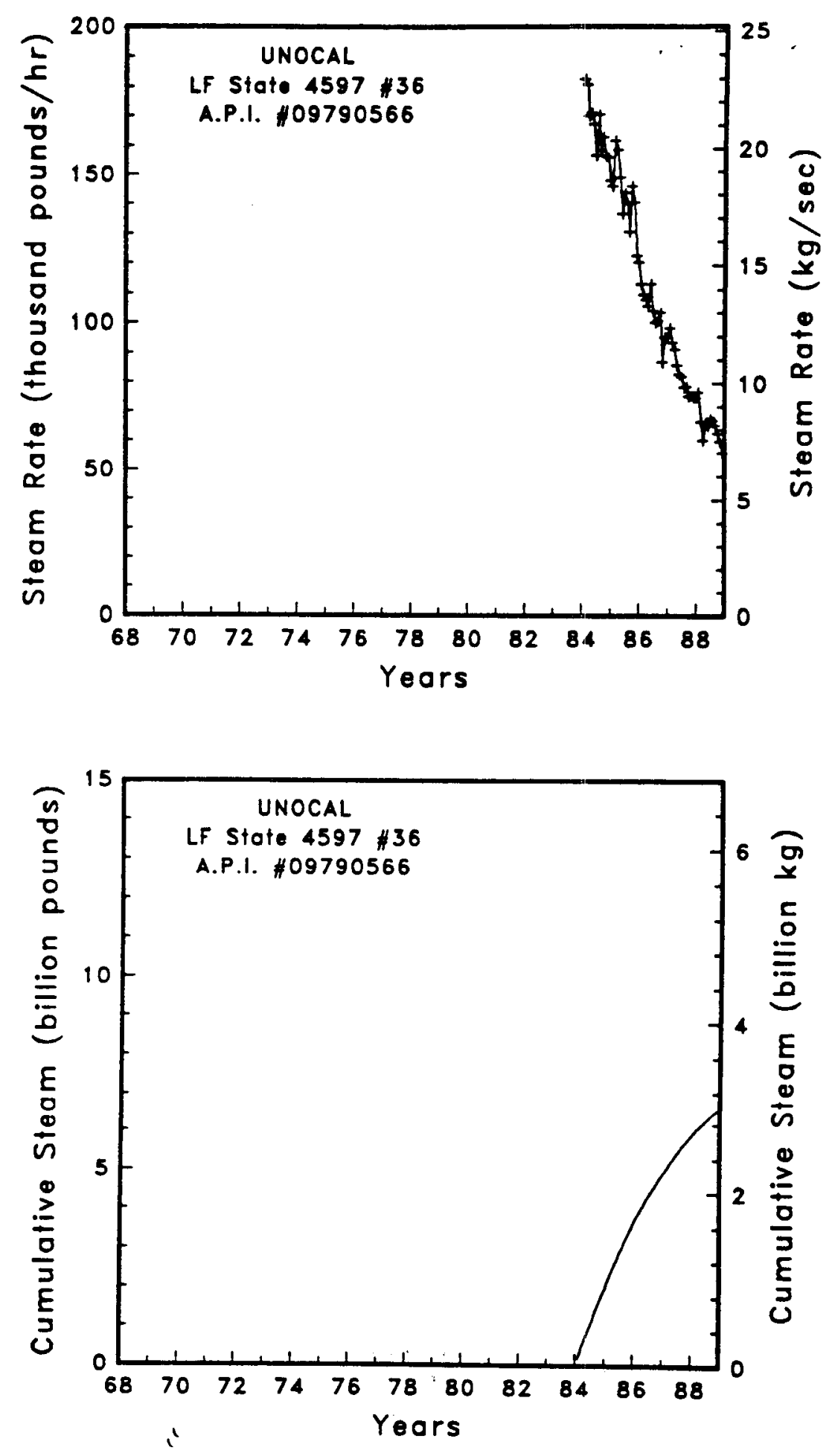

Figure A-143 Steam rate and cumulative mass flow for well LF State 4597 \#36 

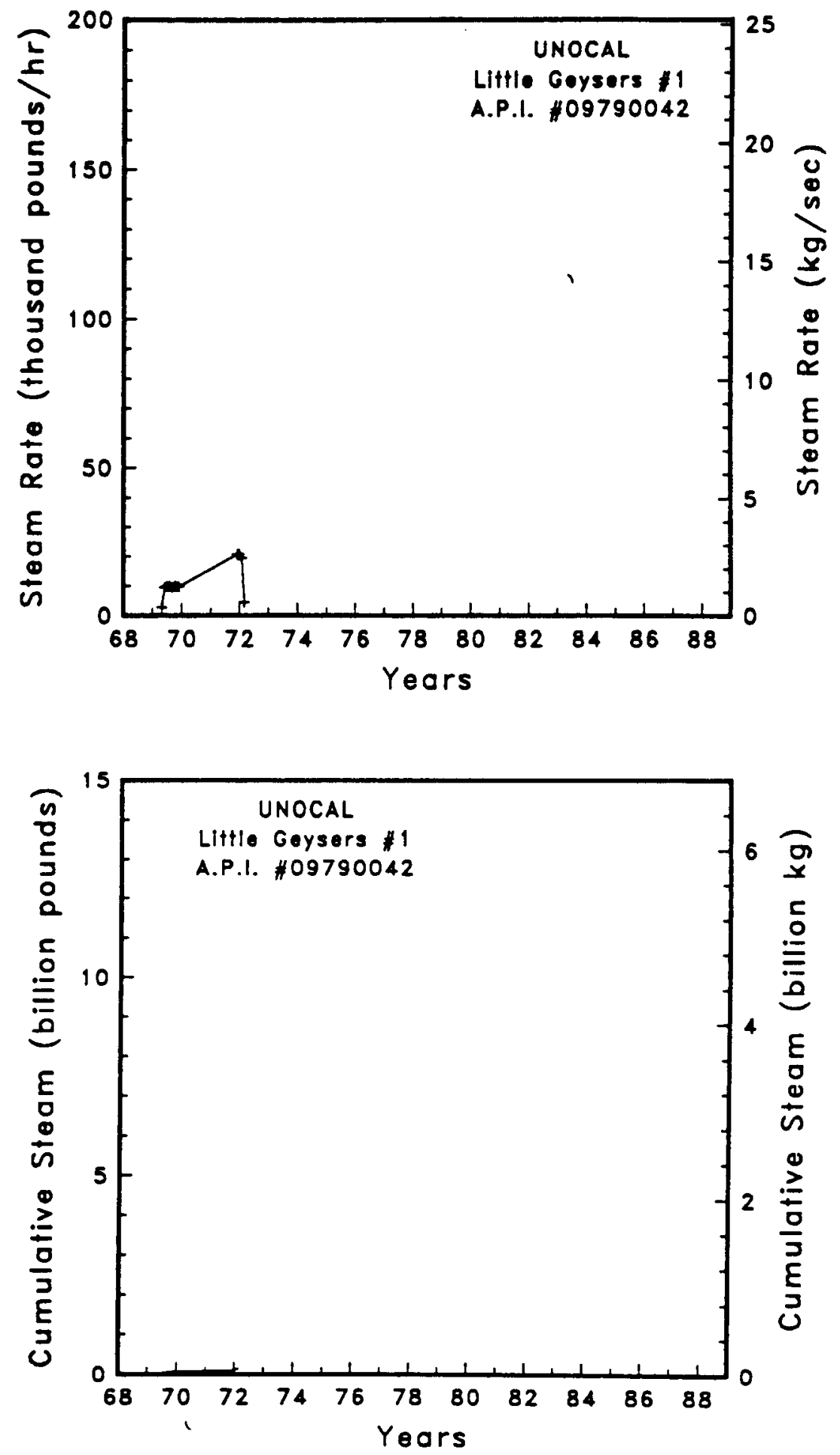

Figure A-144

Steom rate and cumulative mass flow for well Little Geysers \#1 

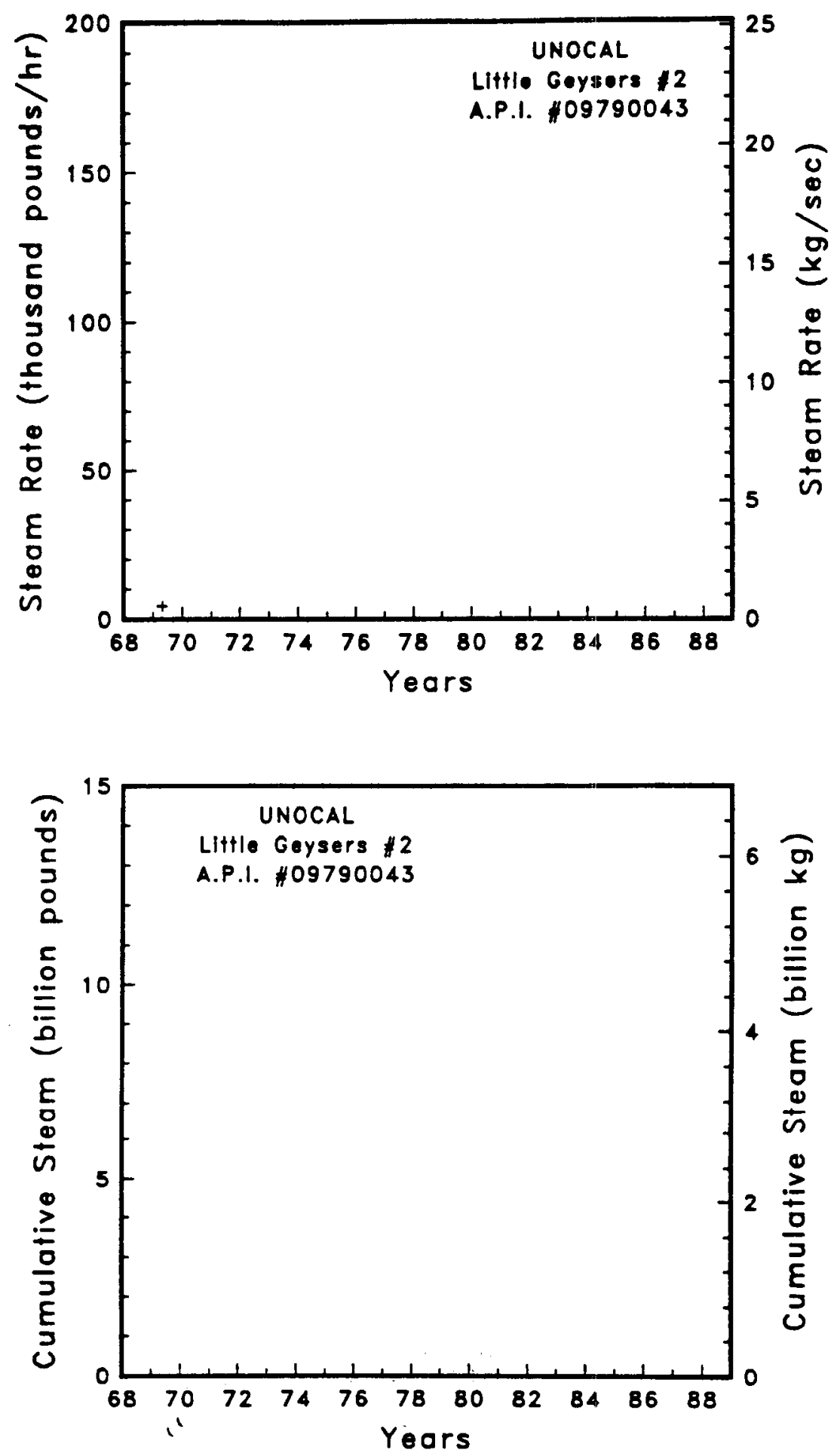

Figure A-145 Steam rate and cumulative mass flow for well Litłle Geysers \#2 

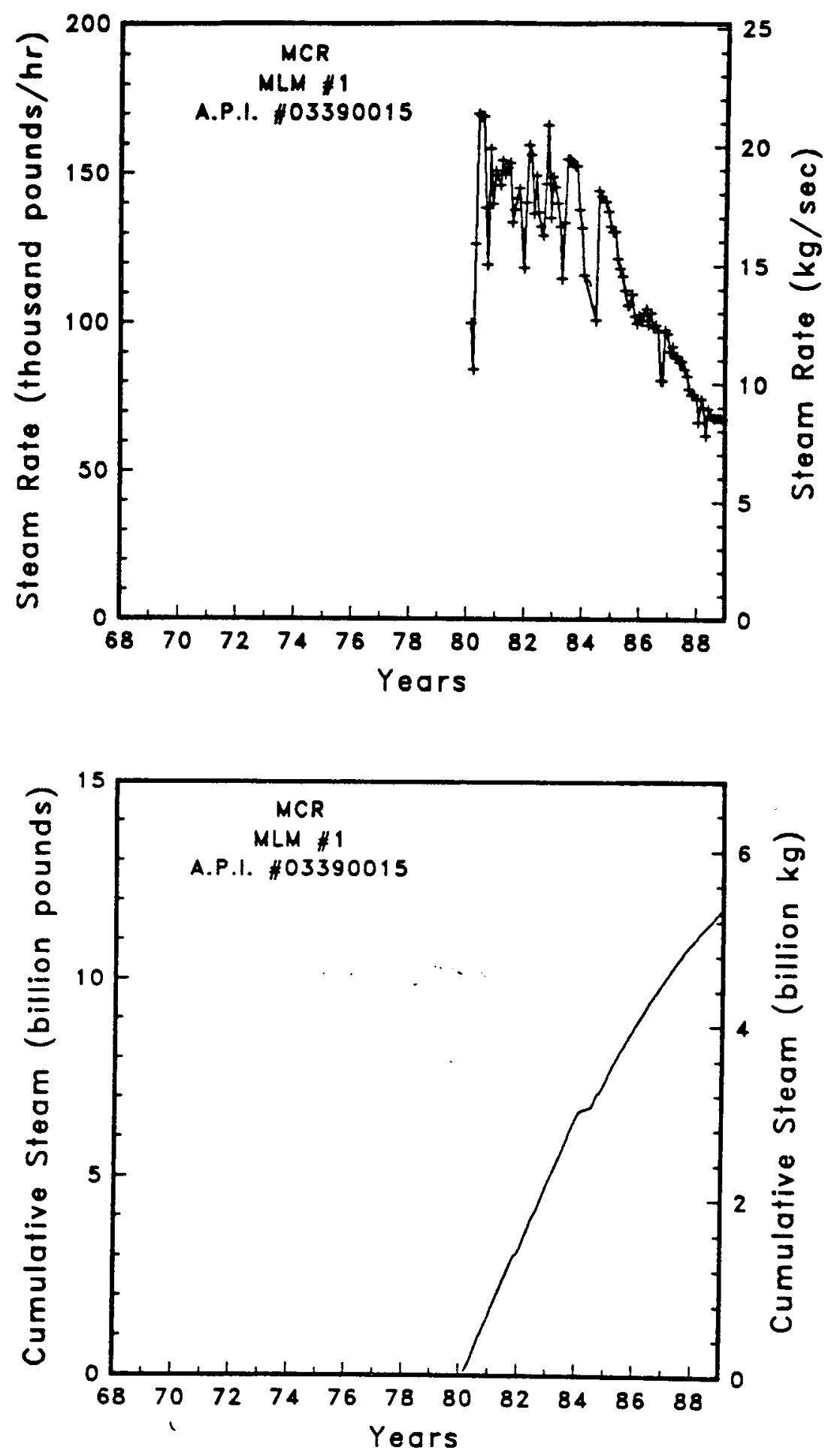

Figure A-146 Steam rate and cumulative mass flow for
well MLM 

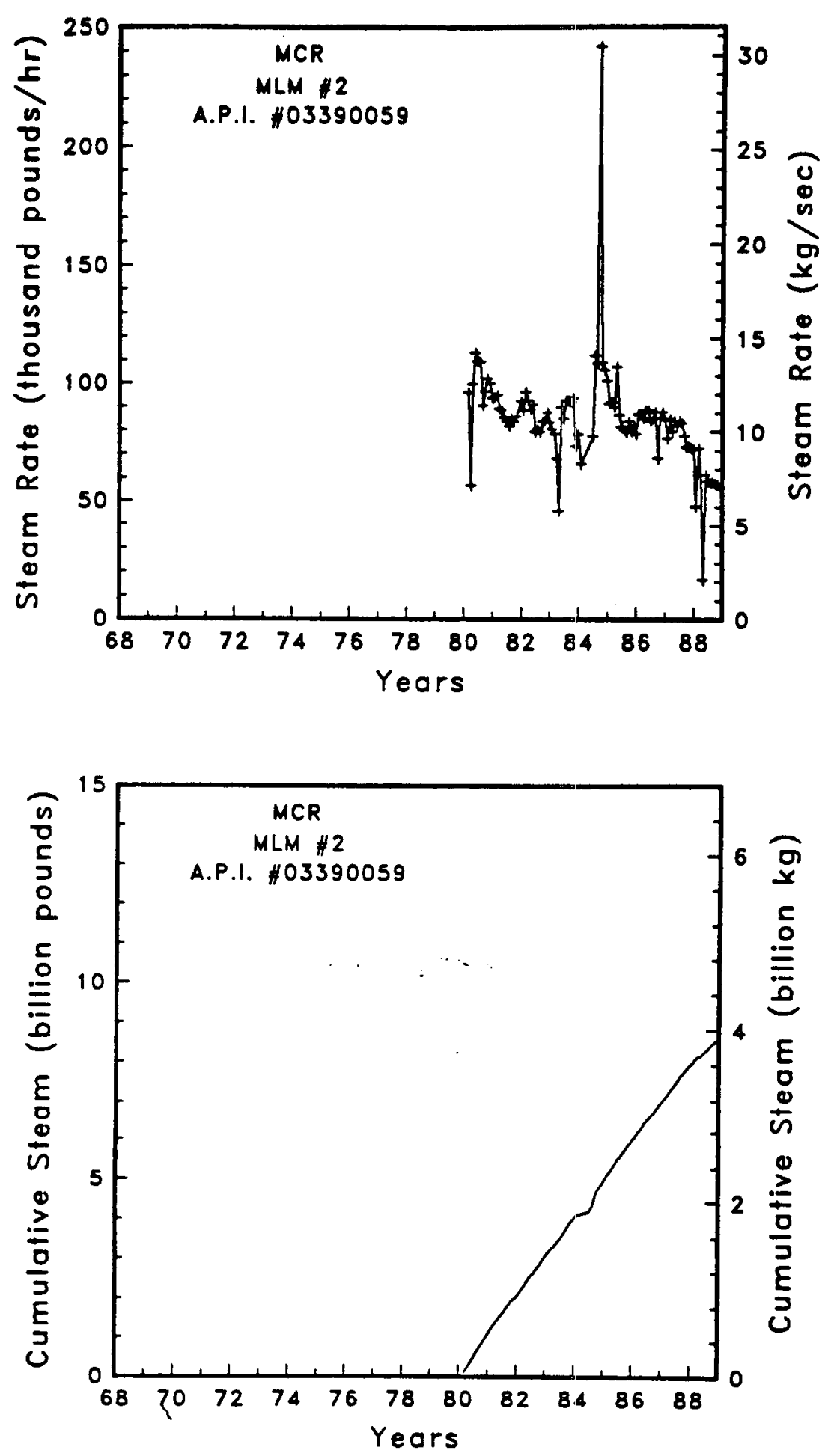

Figure A-147 Steam rate and cumulative mass flow for well MLM \#2 

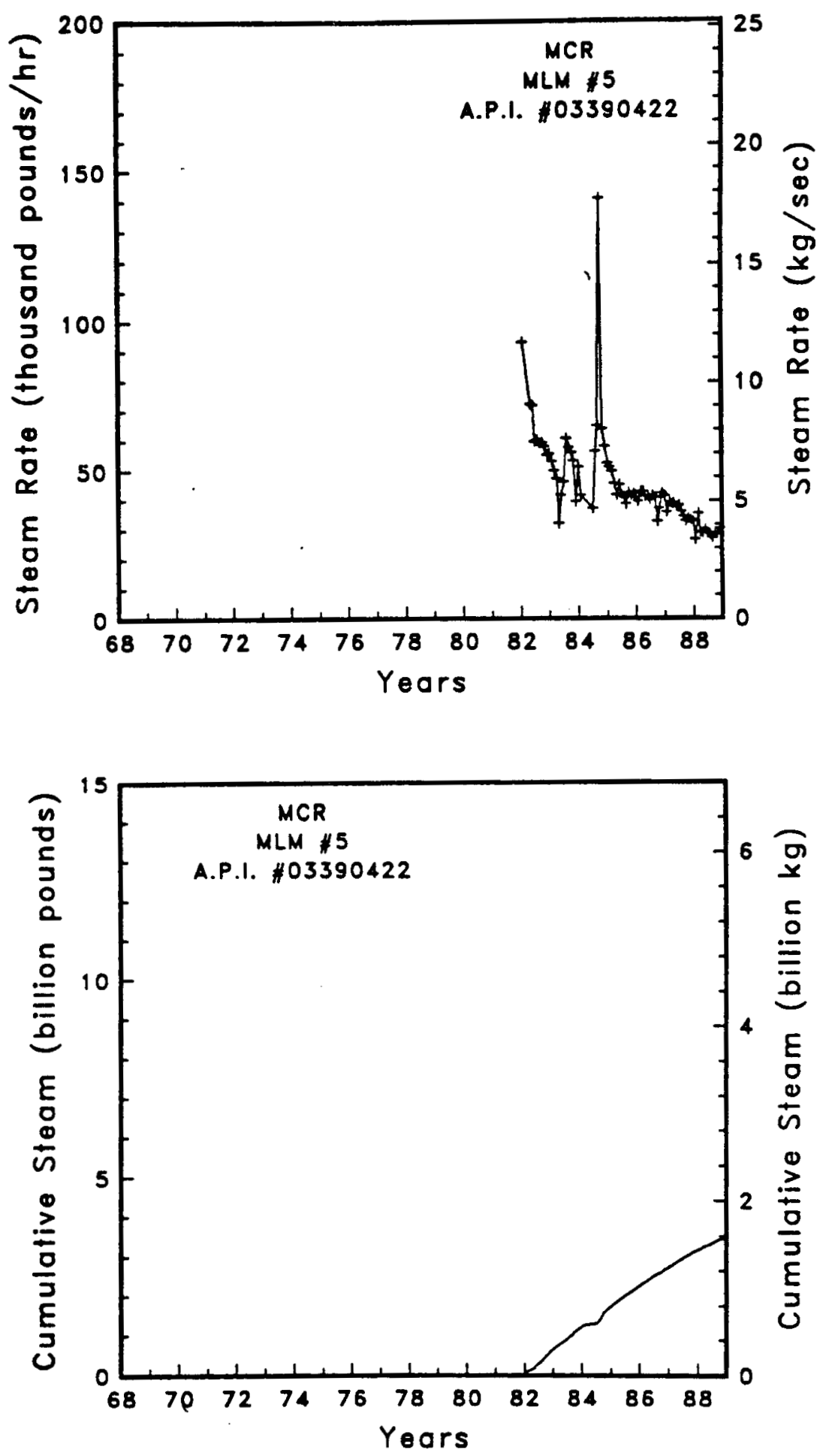

Figure A-148 Steam rate and cumulative mass flow for well MLM \#5 

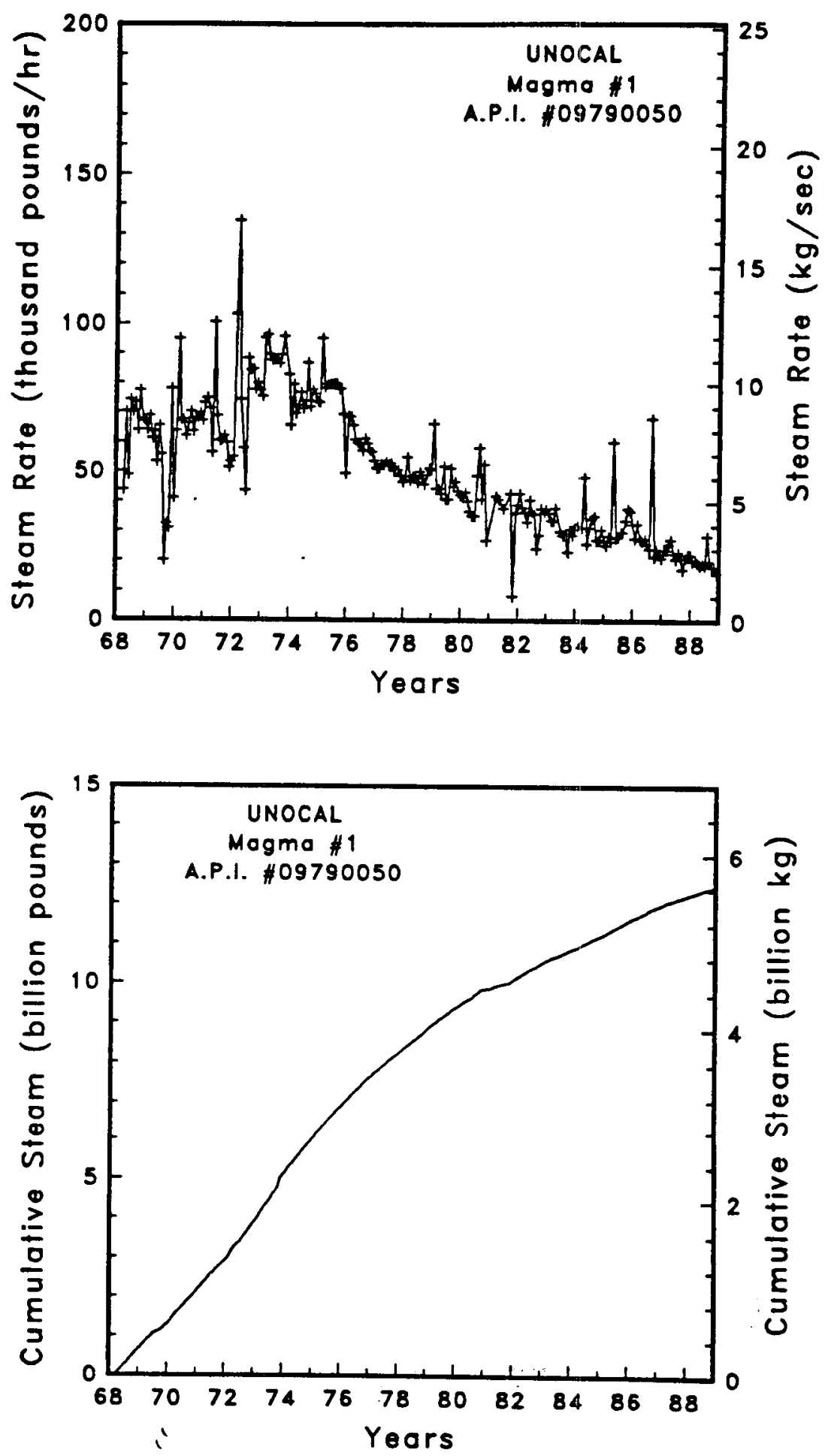

Figure A-149

Steam rate and cumulative mass flow for well Magma \#1 

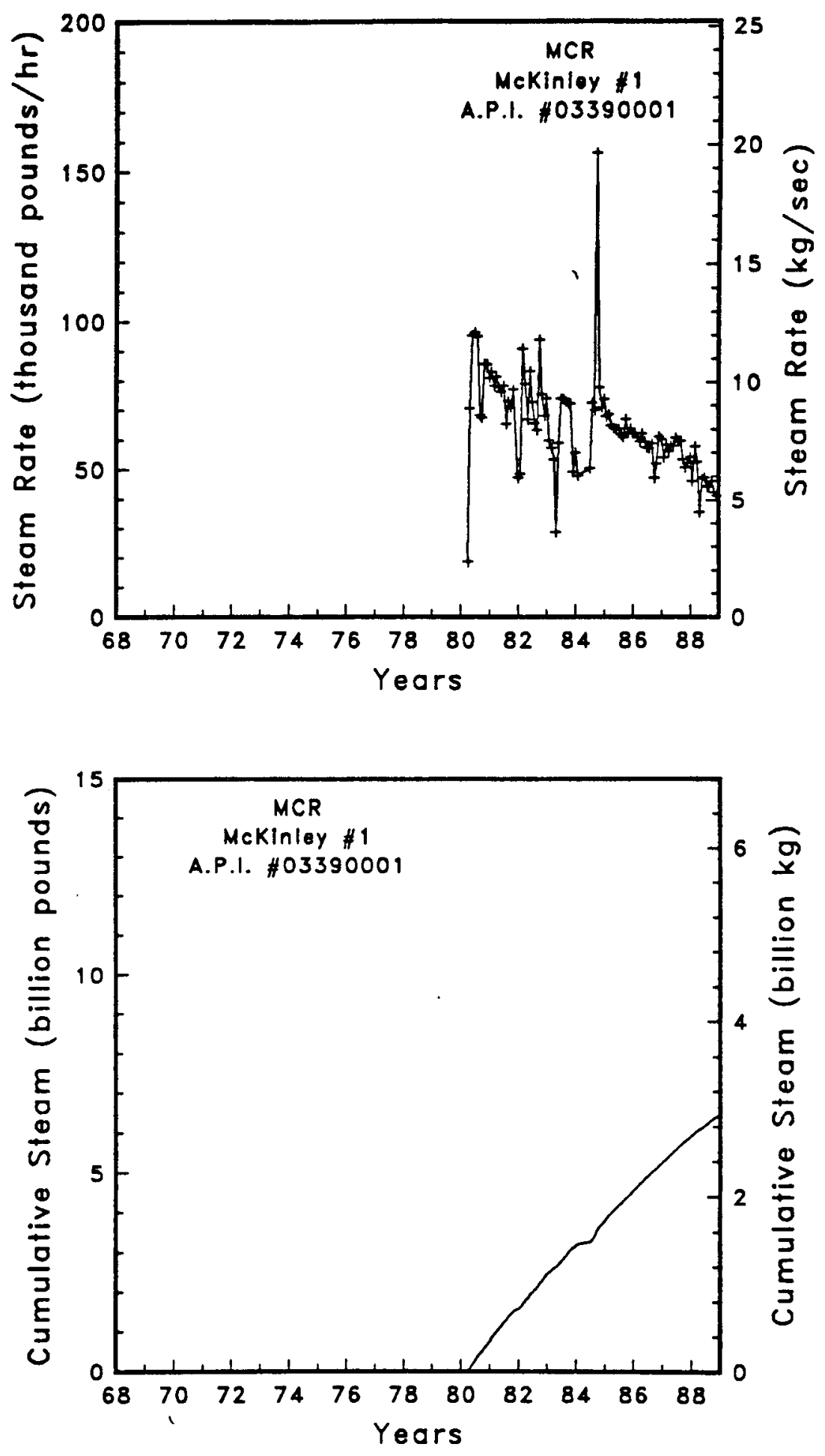

Figure A-150

Steam rate and cumulative mass flow for well McKinley \#1 

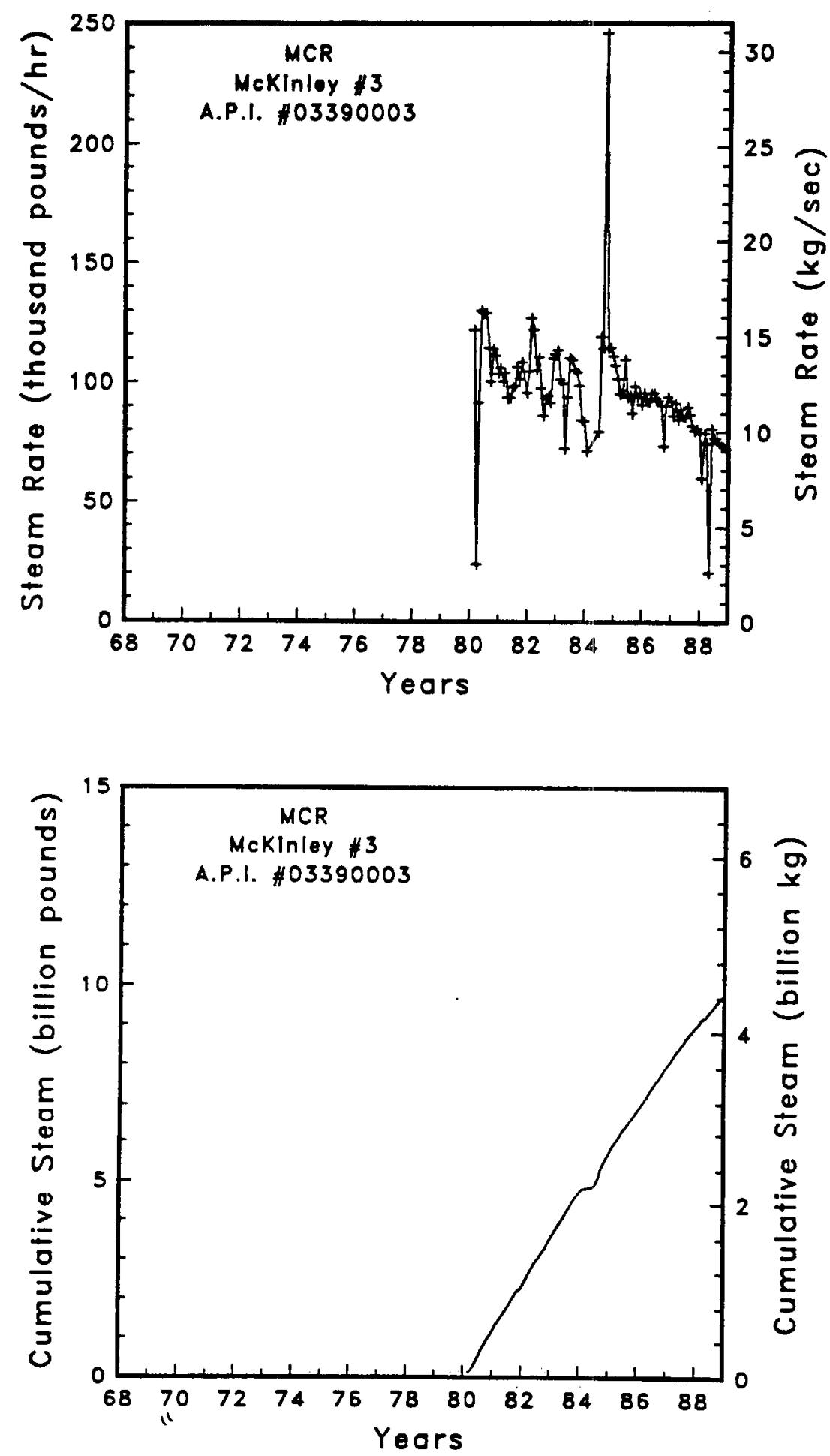

Figure A-151

Steam rate and cumulative mass flow for well Mckinley \#3 

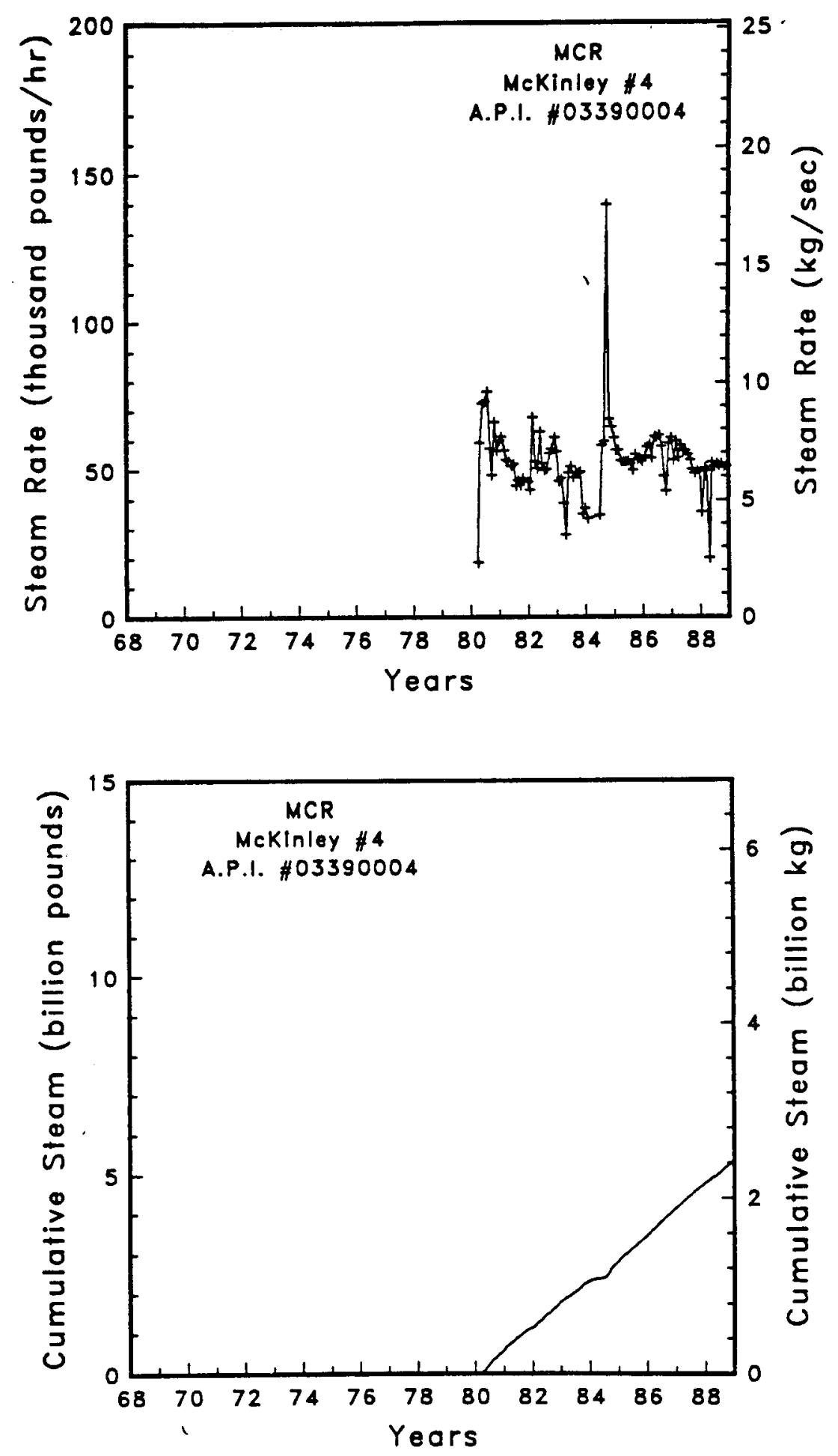

Figure A-152

Steam rate and cumulative mass flow for well McKinley \#4 

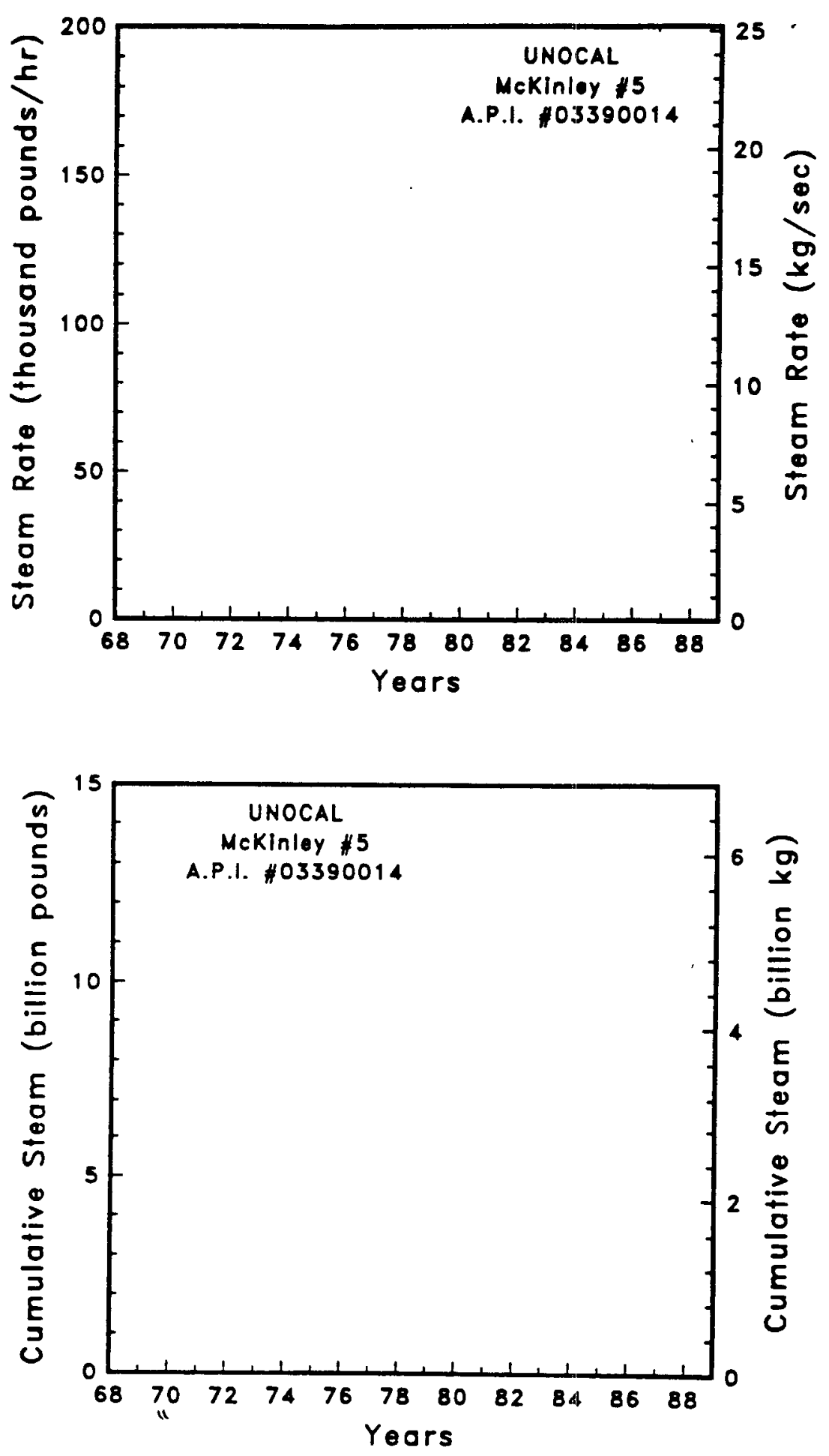

Figure A-153

Steam rate and cumulative mass flow for well McKinley $\# 5$ 

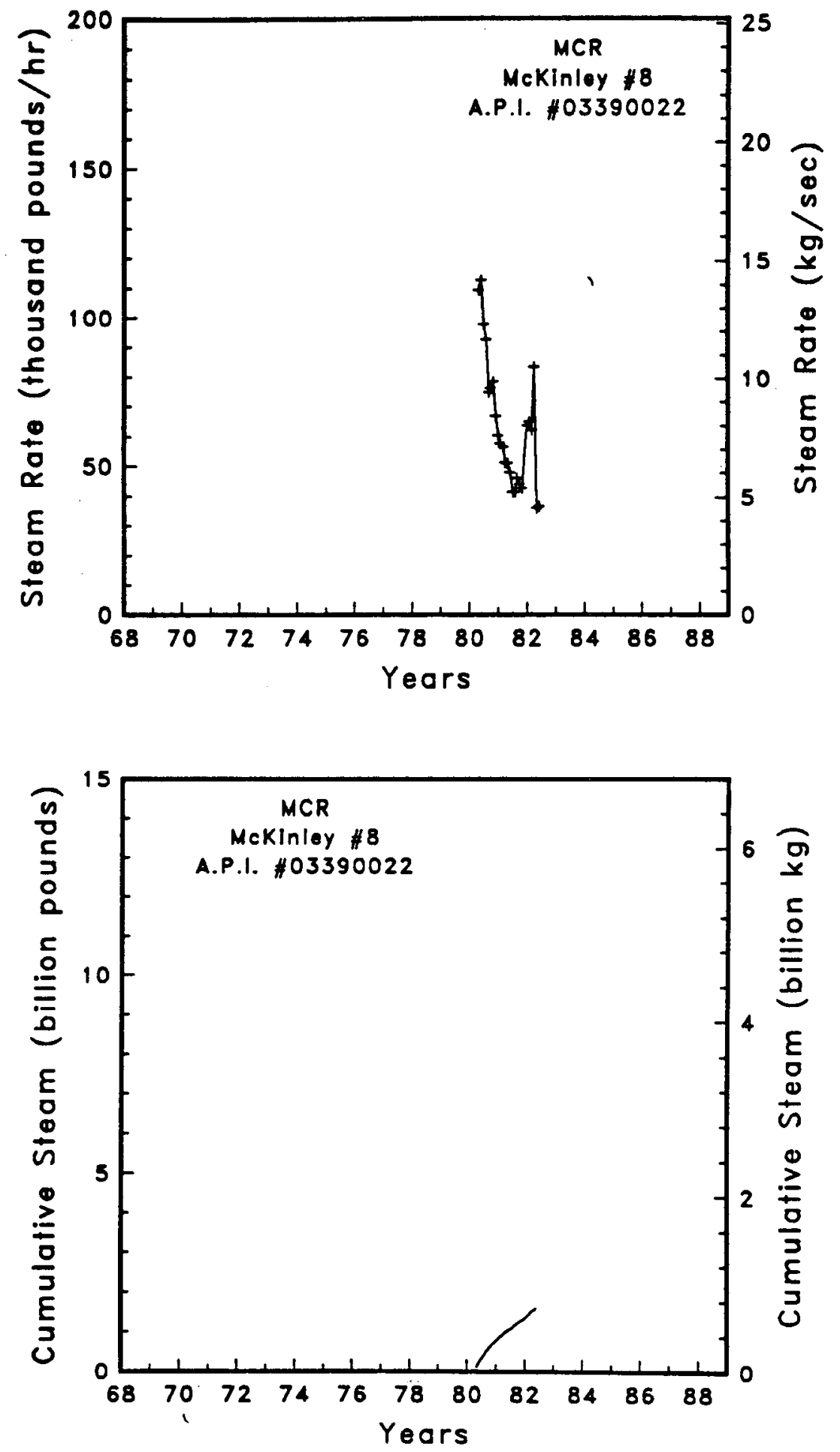

Figure A-154

Steam rate and cumulative mass flow for well McKinley \#8 

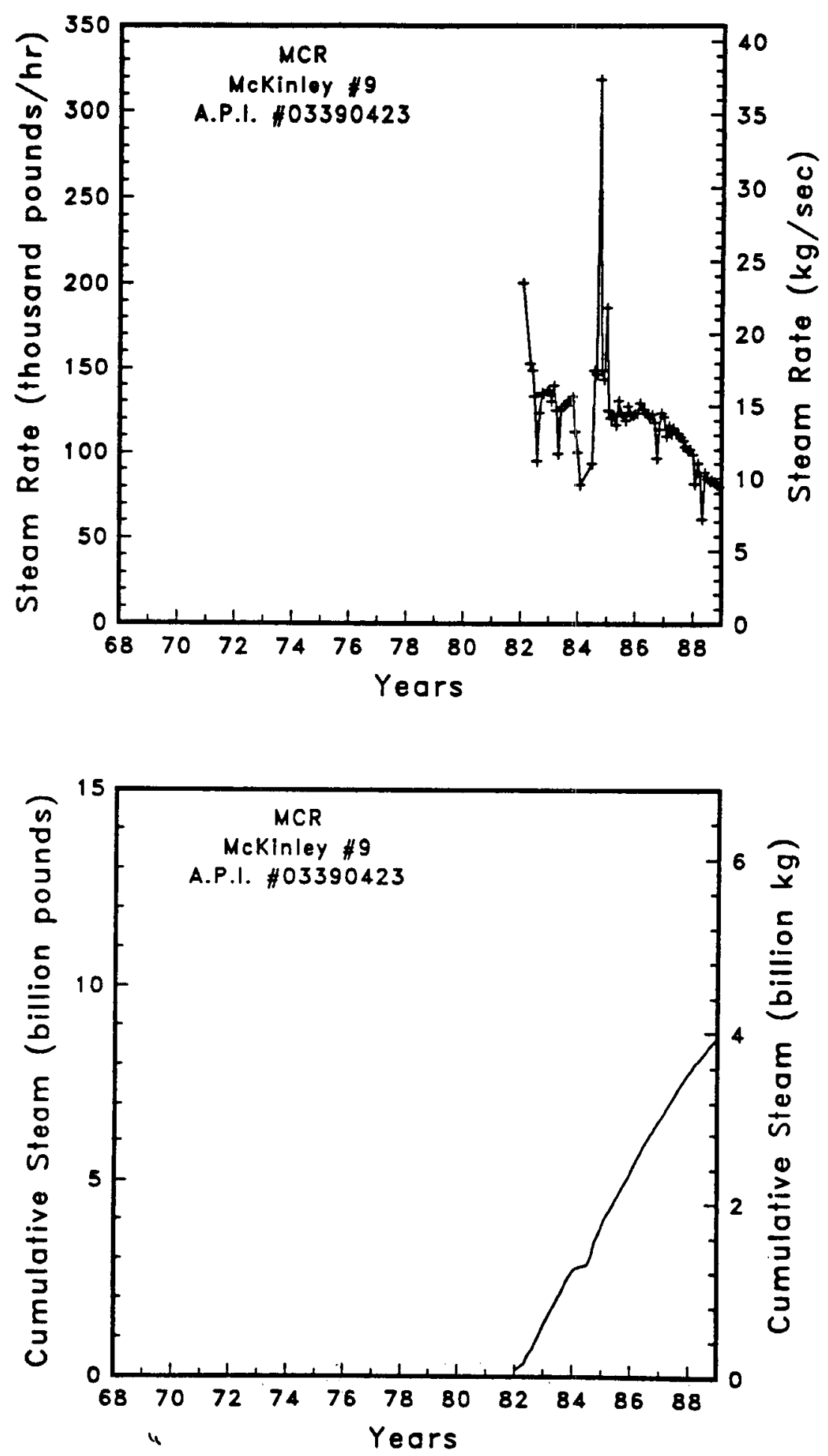

Figure A-155

Steam rate and cumulative mass flow for well McKinley \# 9 

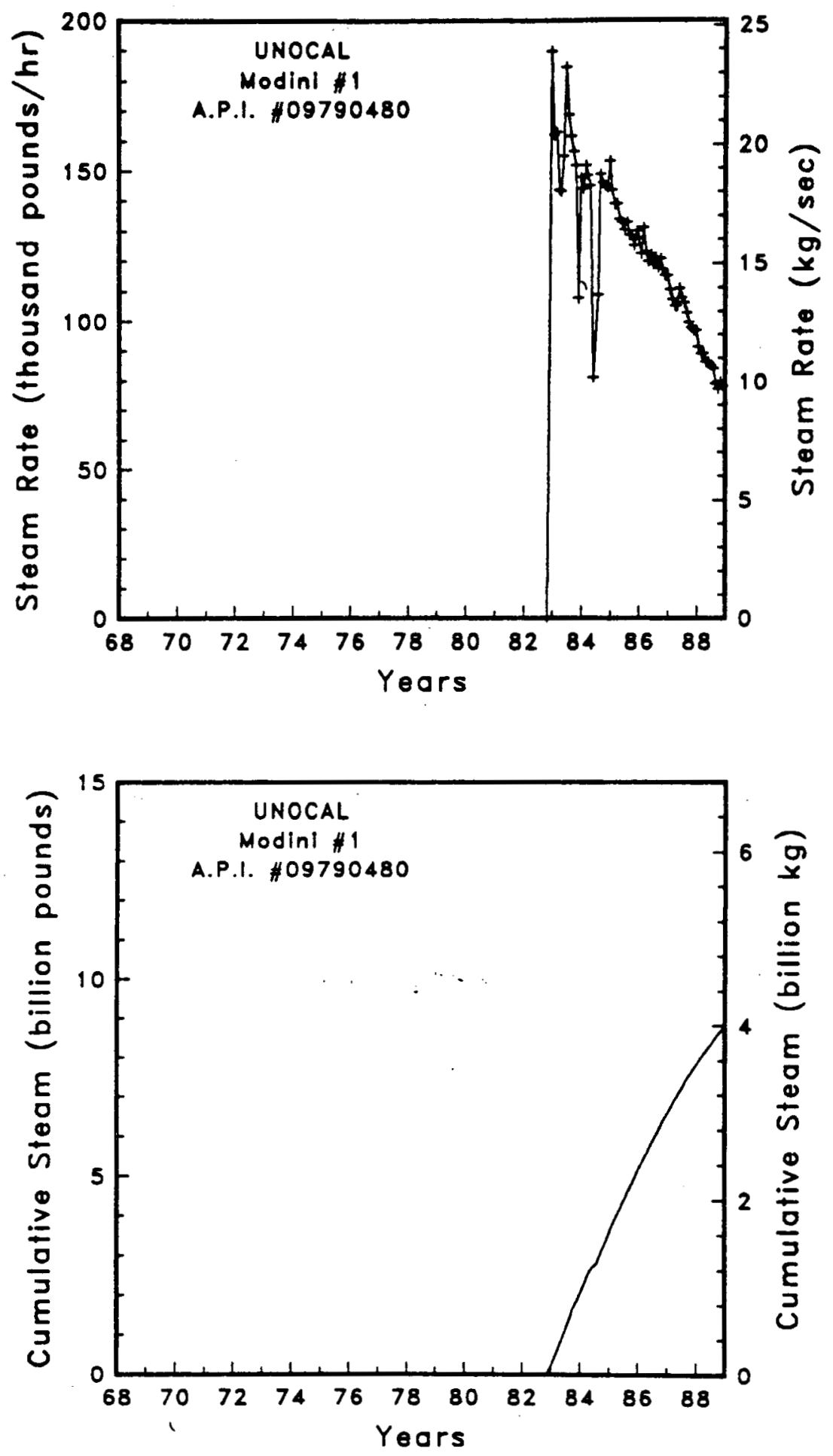

Figure A-156

Steam rate and cumulative mass flow for well Modini \#1 

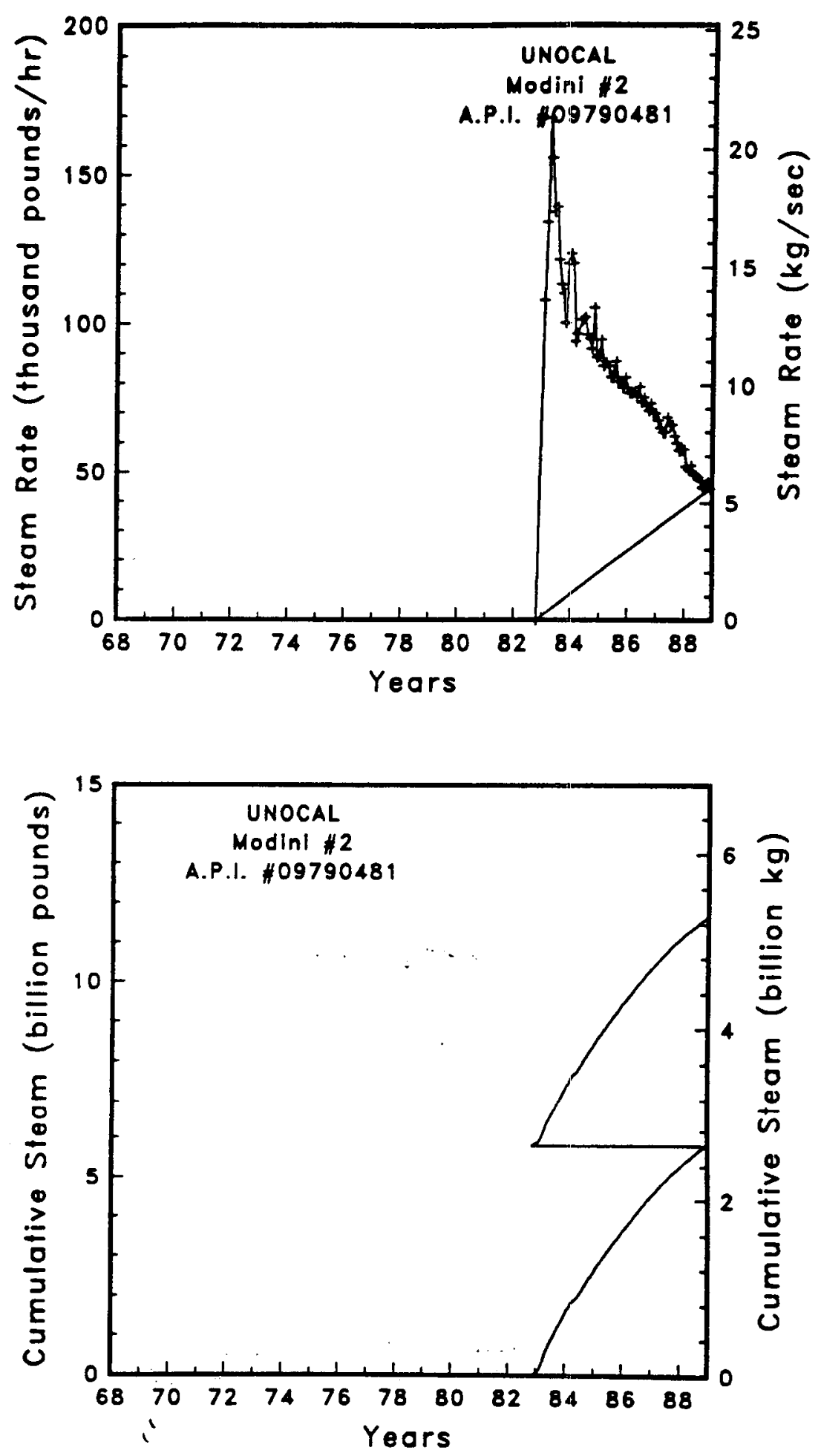

Figure A-157

Steom rate and cumulative mass flow for well Modini \#2 

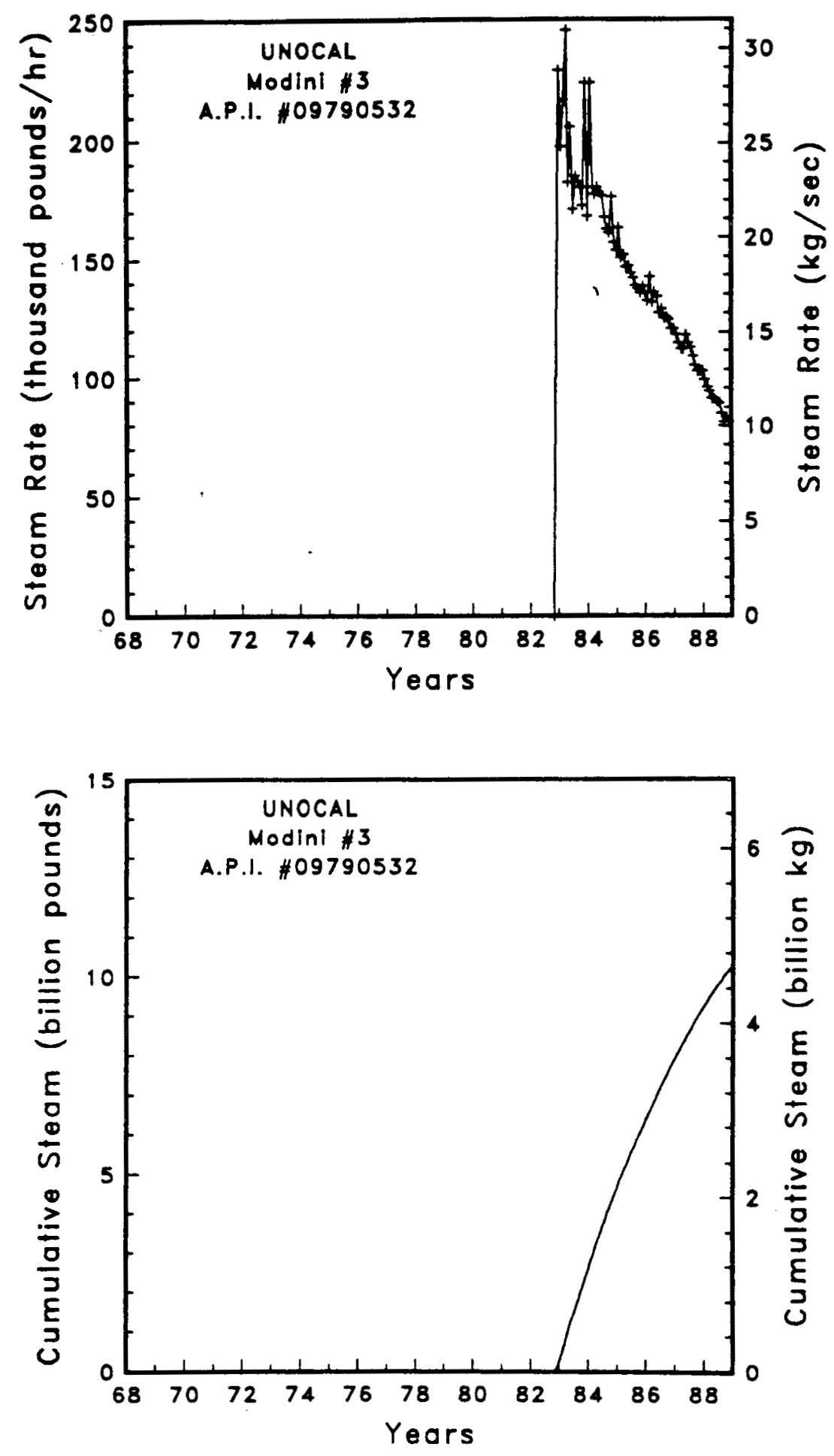

Figure A-158

Steam rate and cumulative mass flow for well Modini \#3 

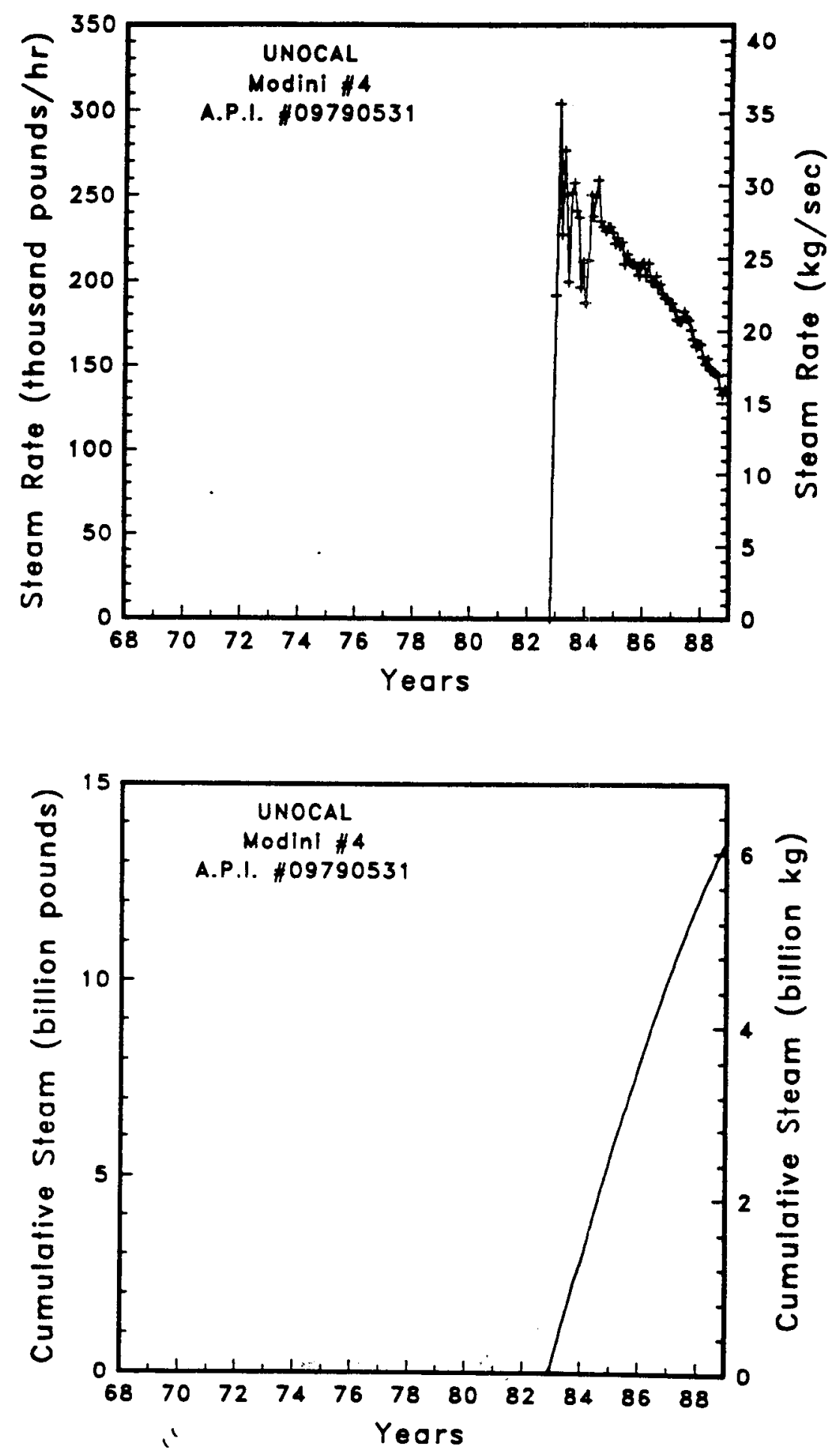

Figure A-159

Steam rate and cumulative mass flow for well Modini \# 4 

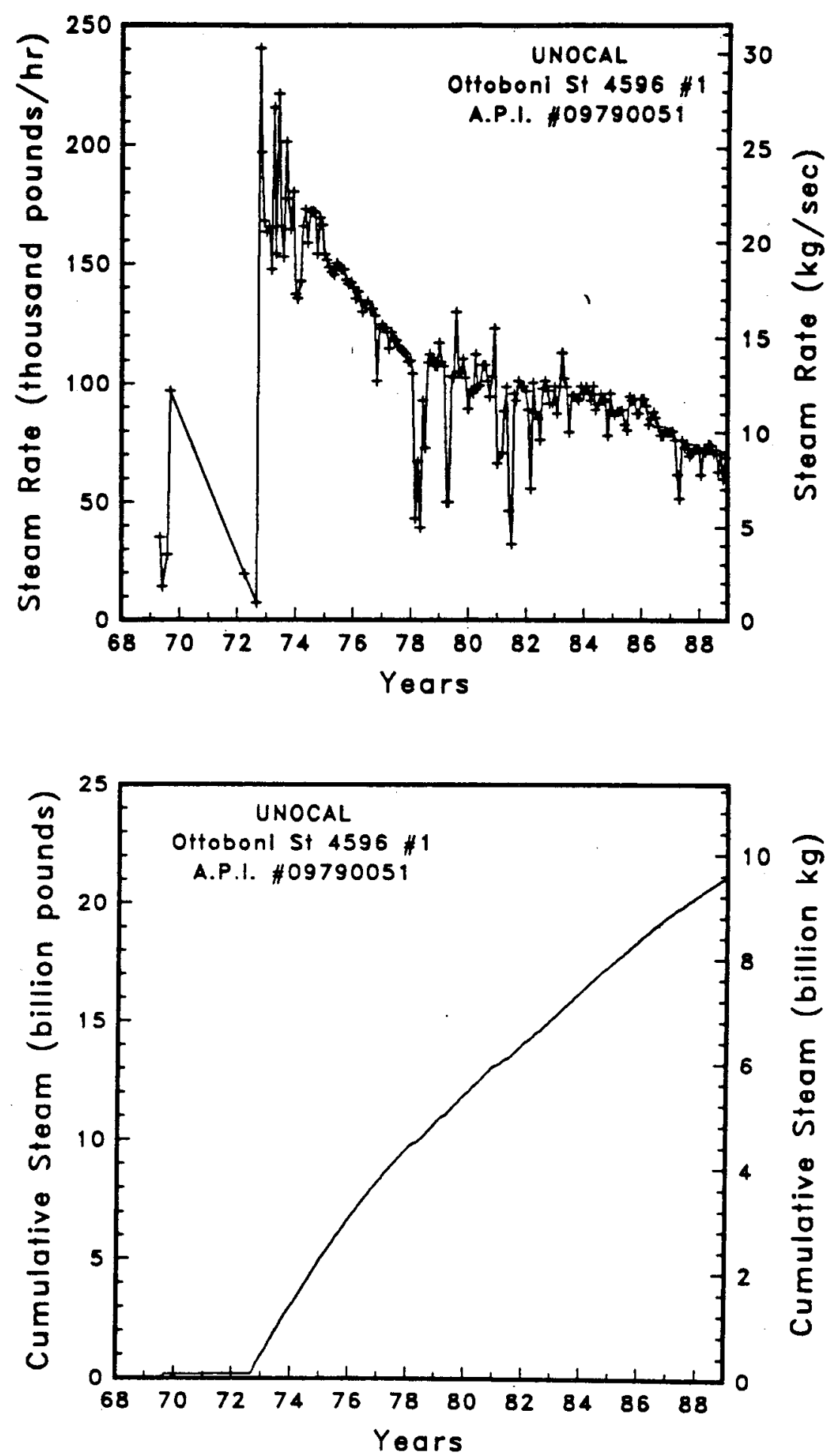

Figure A-160

Steam rate and cumulative mass flow for well Ottoboni St 4596 \#1 

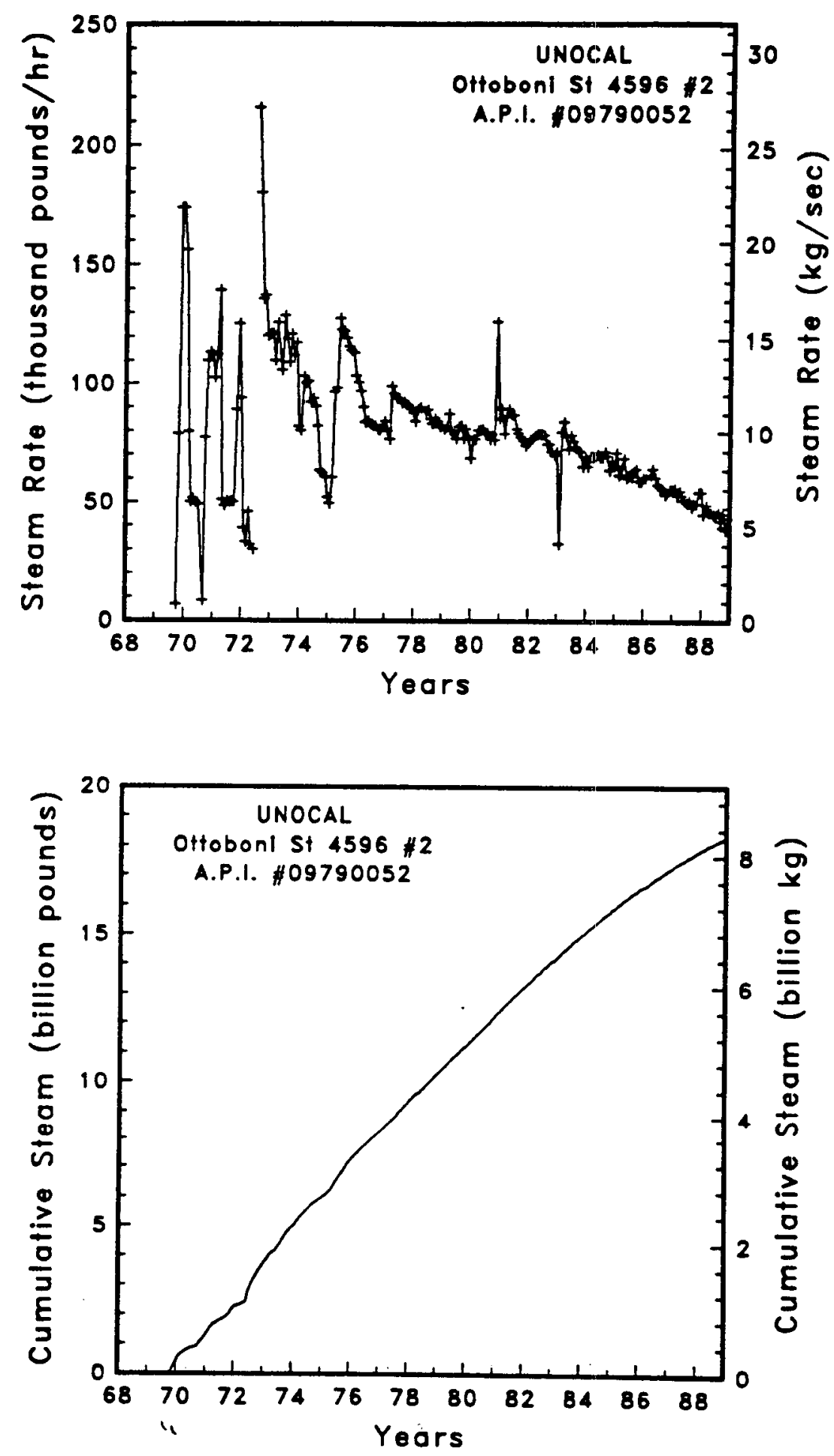

Figure A-161

Steam rate and cumulative mass flow for well Ottoboni St 4596 \#2 

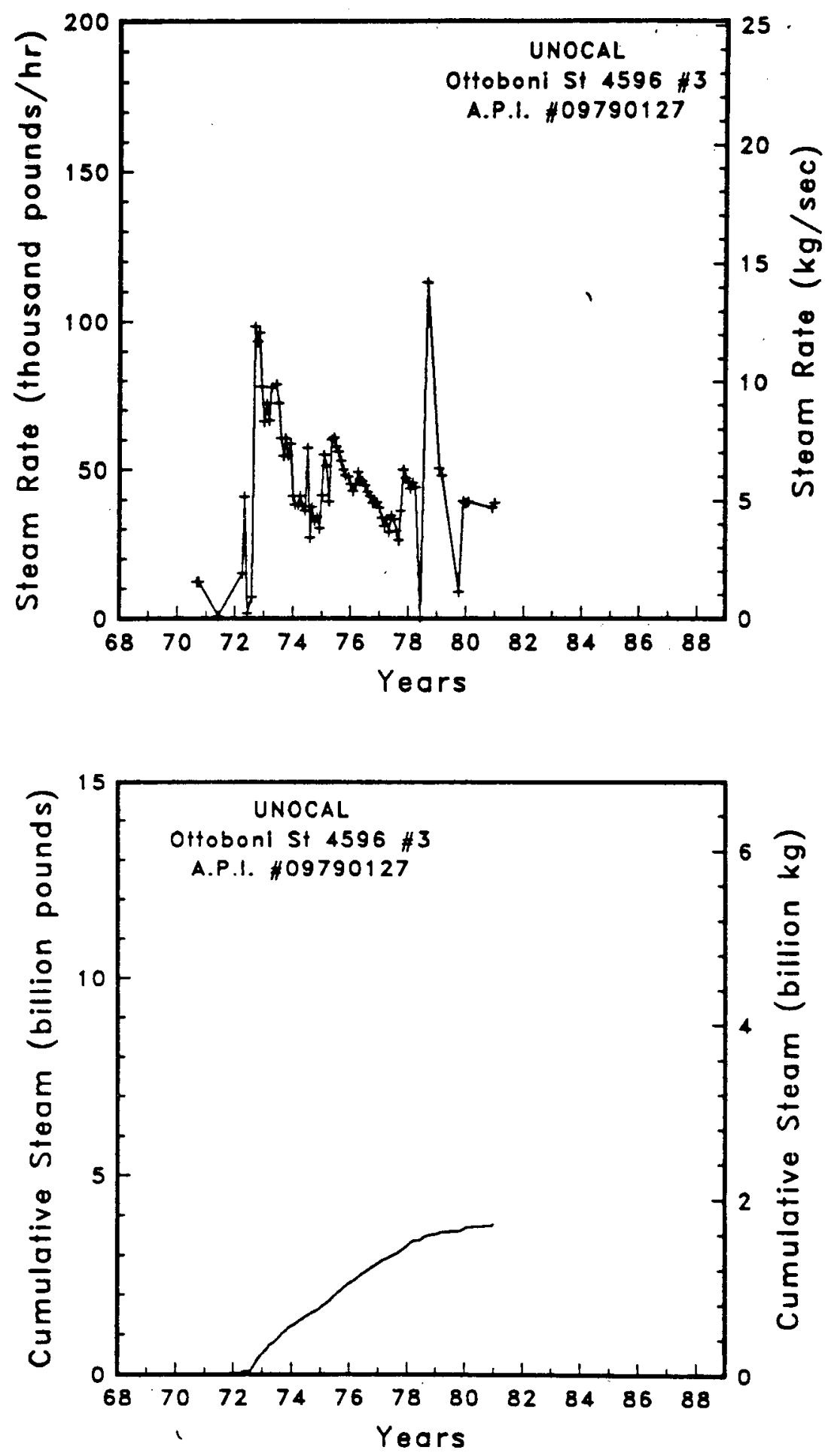

Figure A-162

Steam rate and cumulative mass flow for well Ottoboni St 4596 \#3 

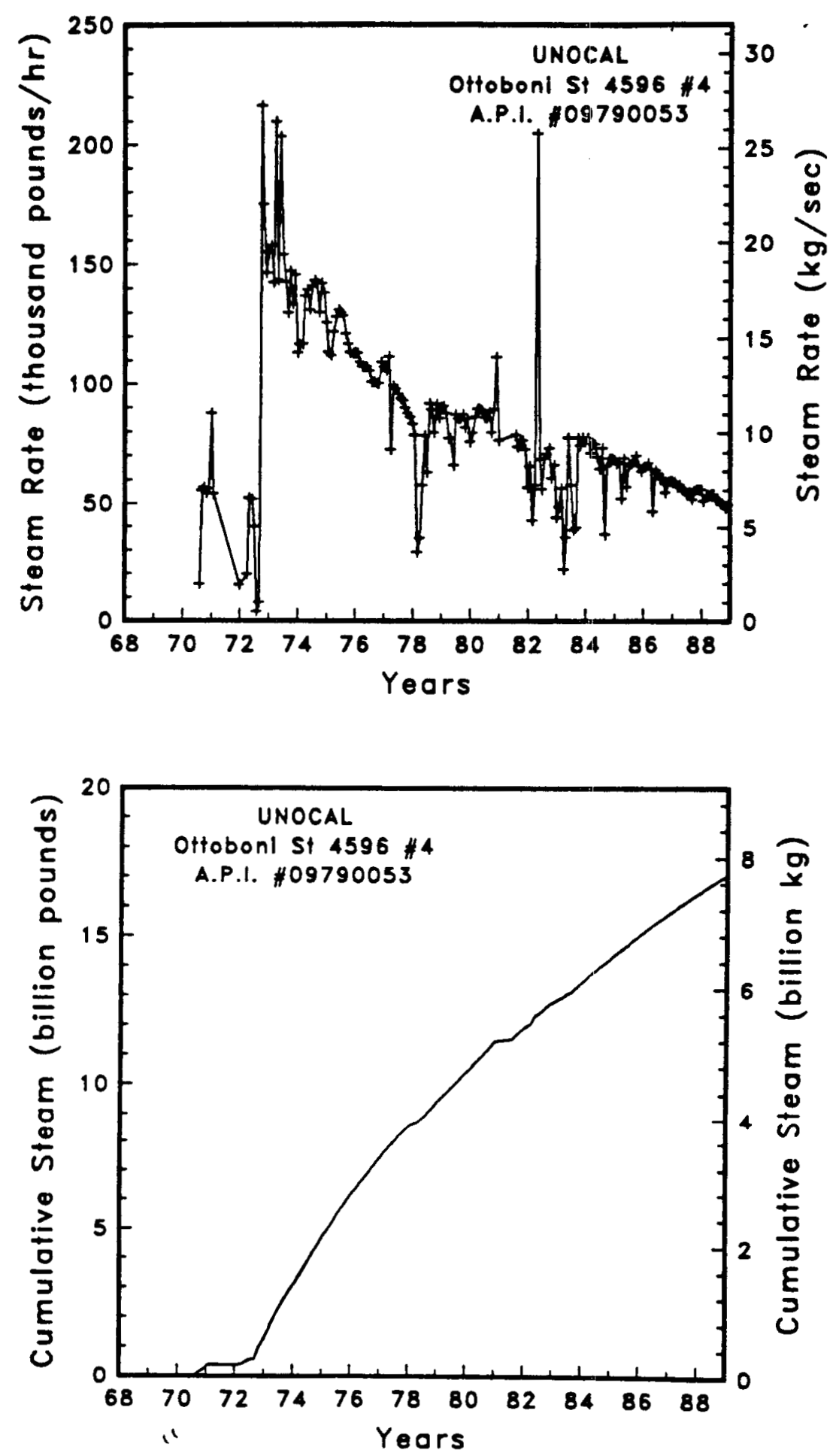

Figure A-163

Steam rate and cumulative mass flow for well Ottoboni St 4596 \# 4 

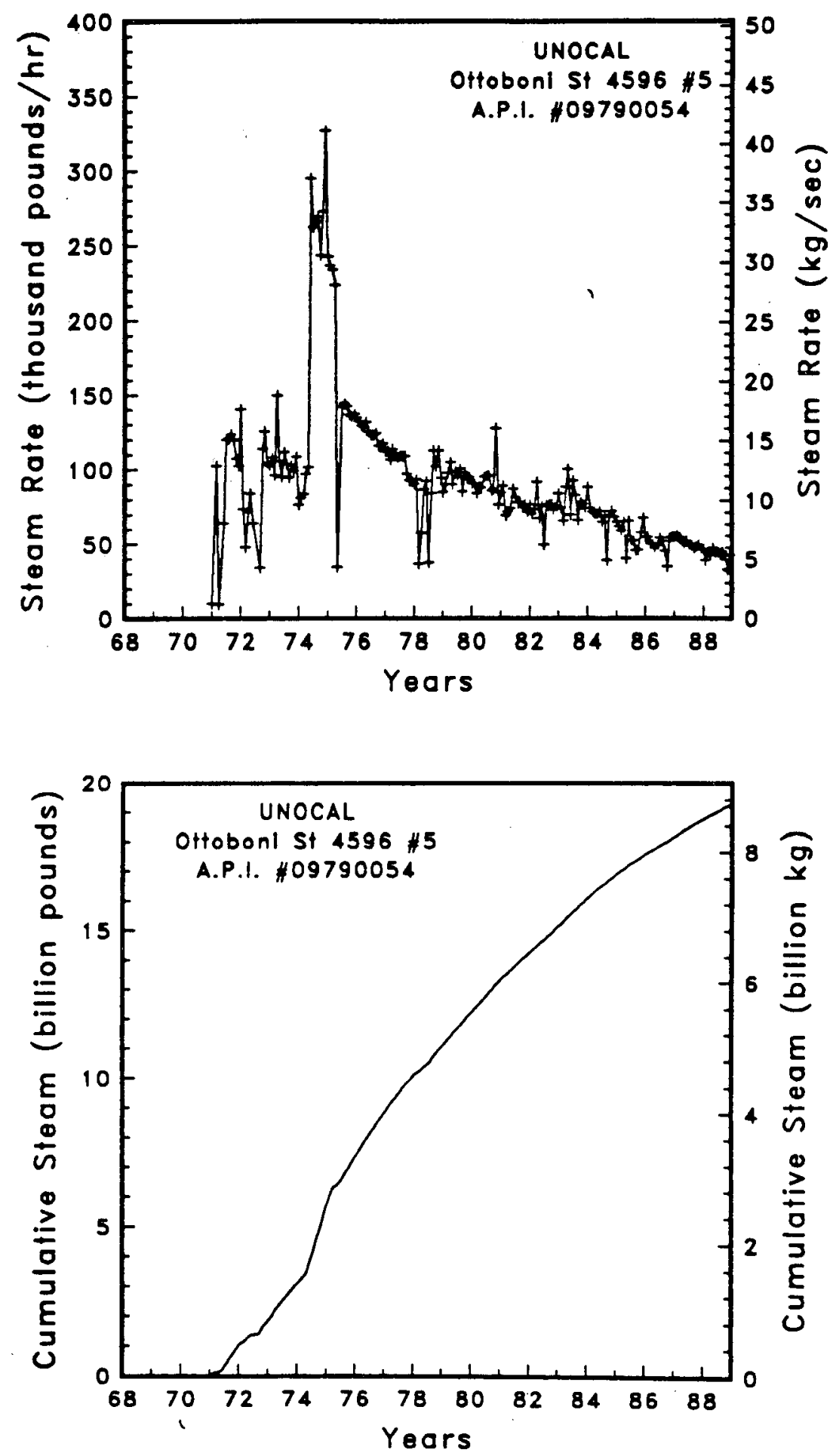

Figure A-164

Steam rate and cumulative mass flow for well Ottoboni St 4596 \#5 

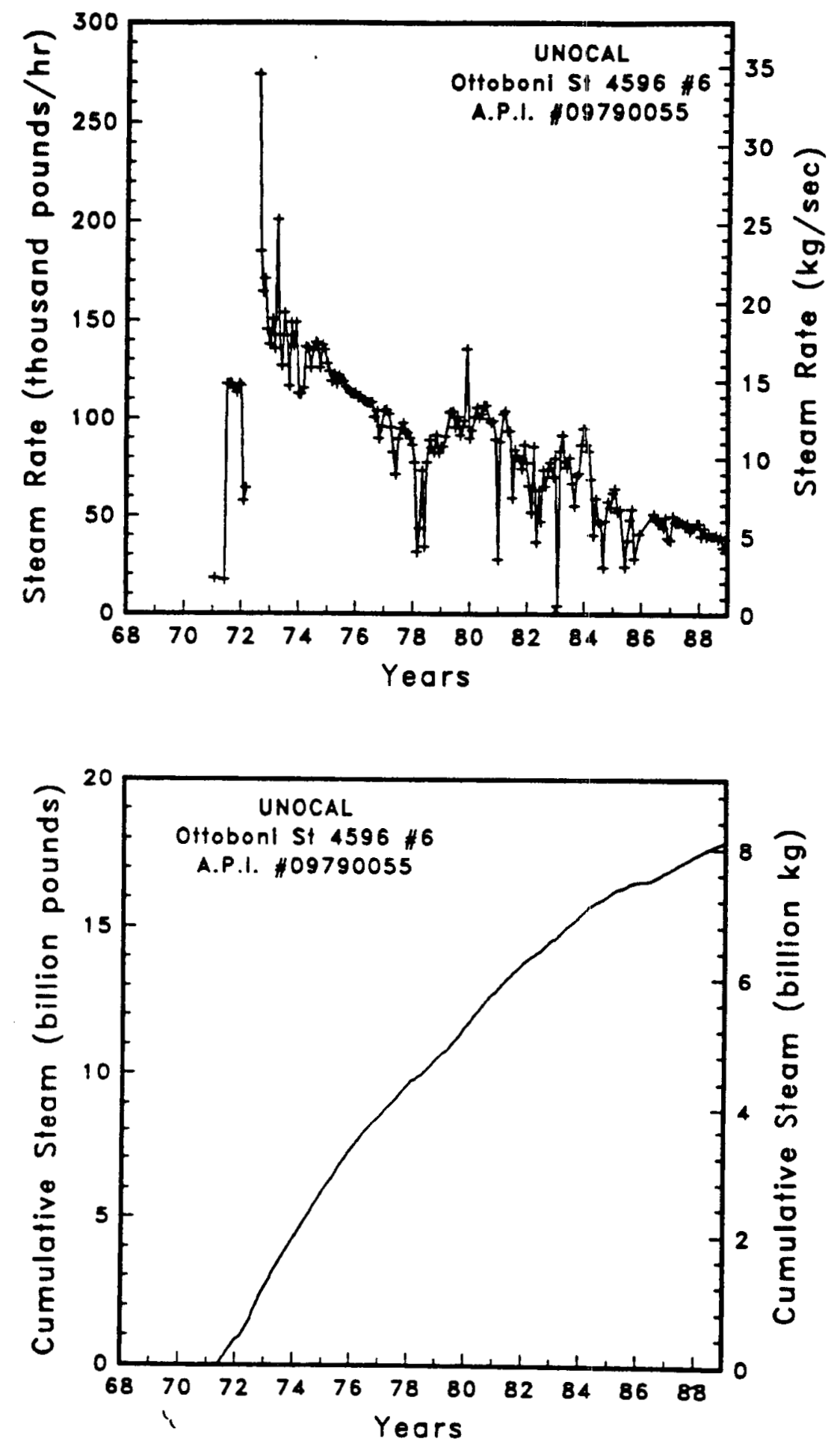

Figure A-165 Steam rate and cumulative mass flow for well Ottoboni St $4596 \# 6$ 

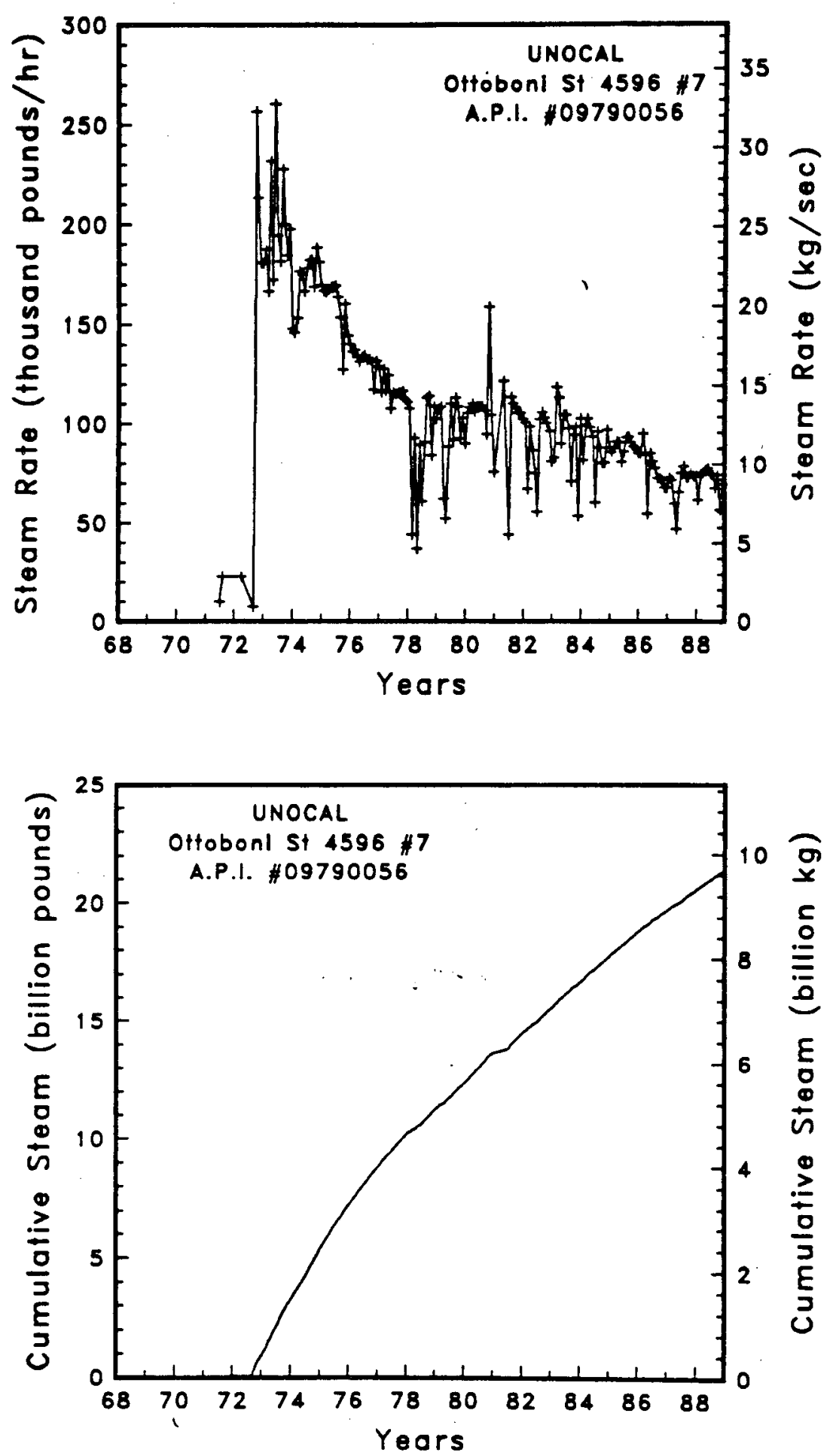

Figure A-166

Steam rate and cumulative mass flow for well Ottoboni St 4596 \# 7 

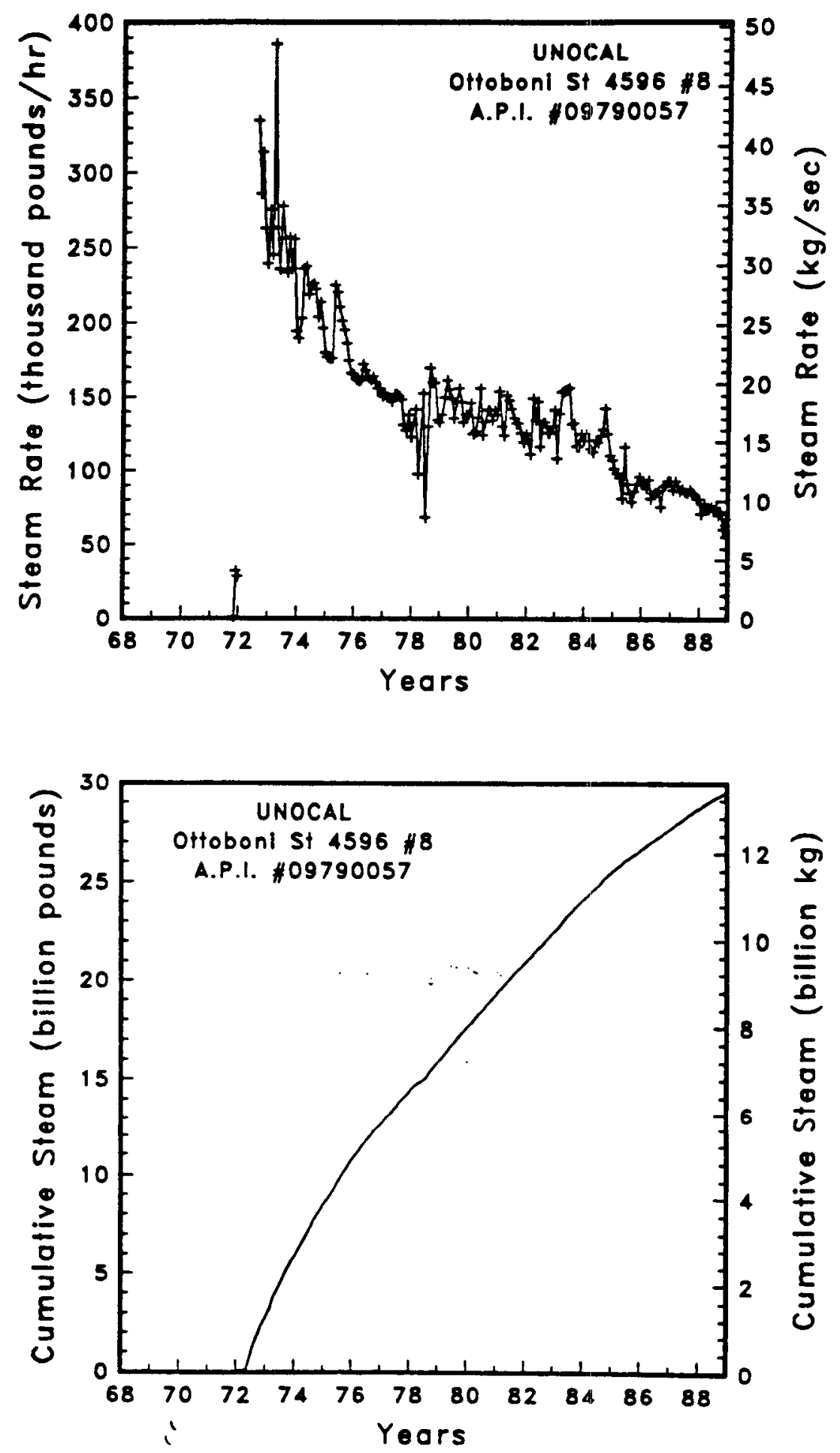

Figure A-167

Steam rate and cumulative mass flow for well Ottoboni St 4596 \#8 

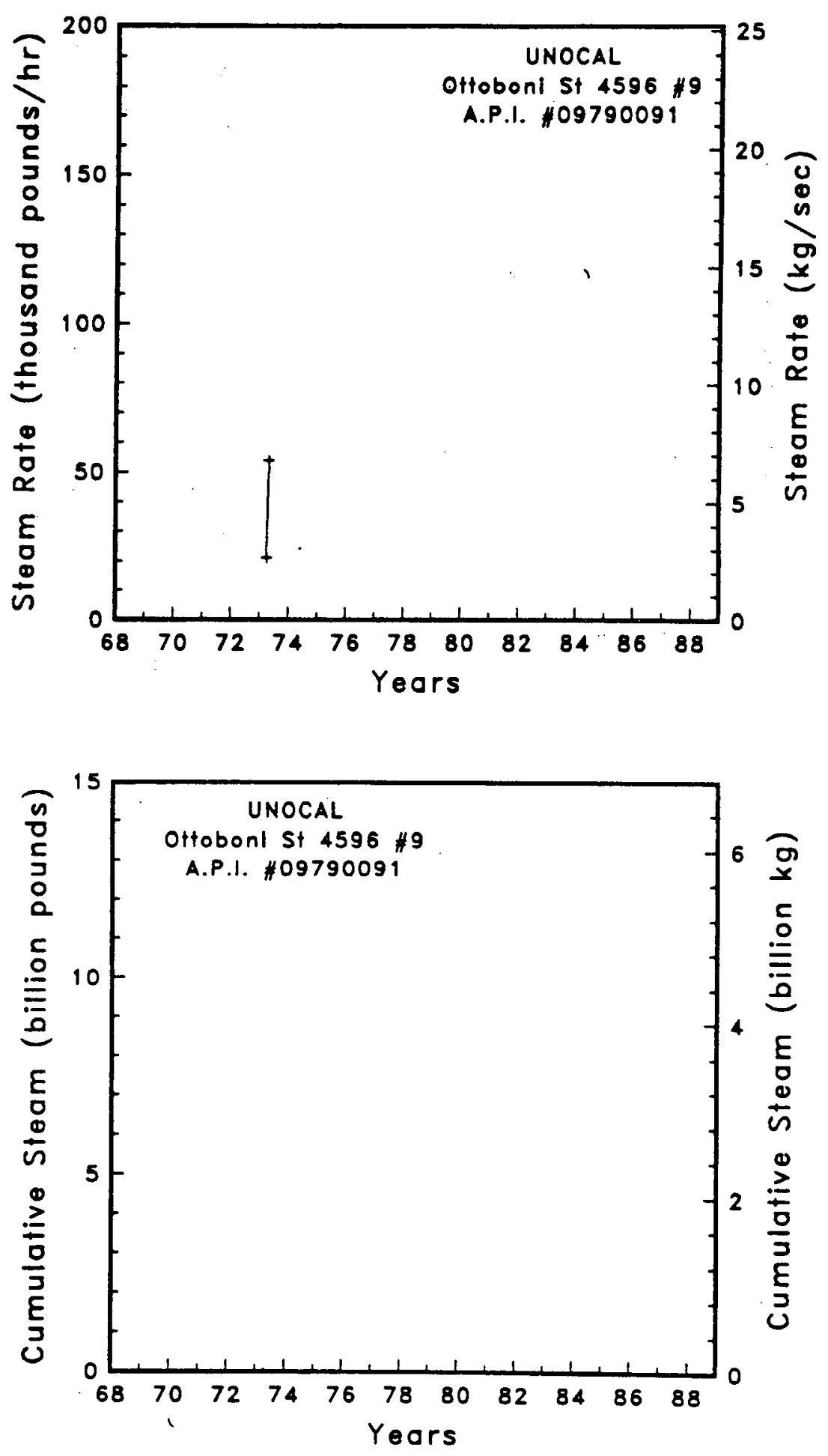

Figure A-168

Steam rate and cumulative mass flow for well Ottoboni St 4596 \#9 

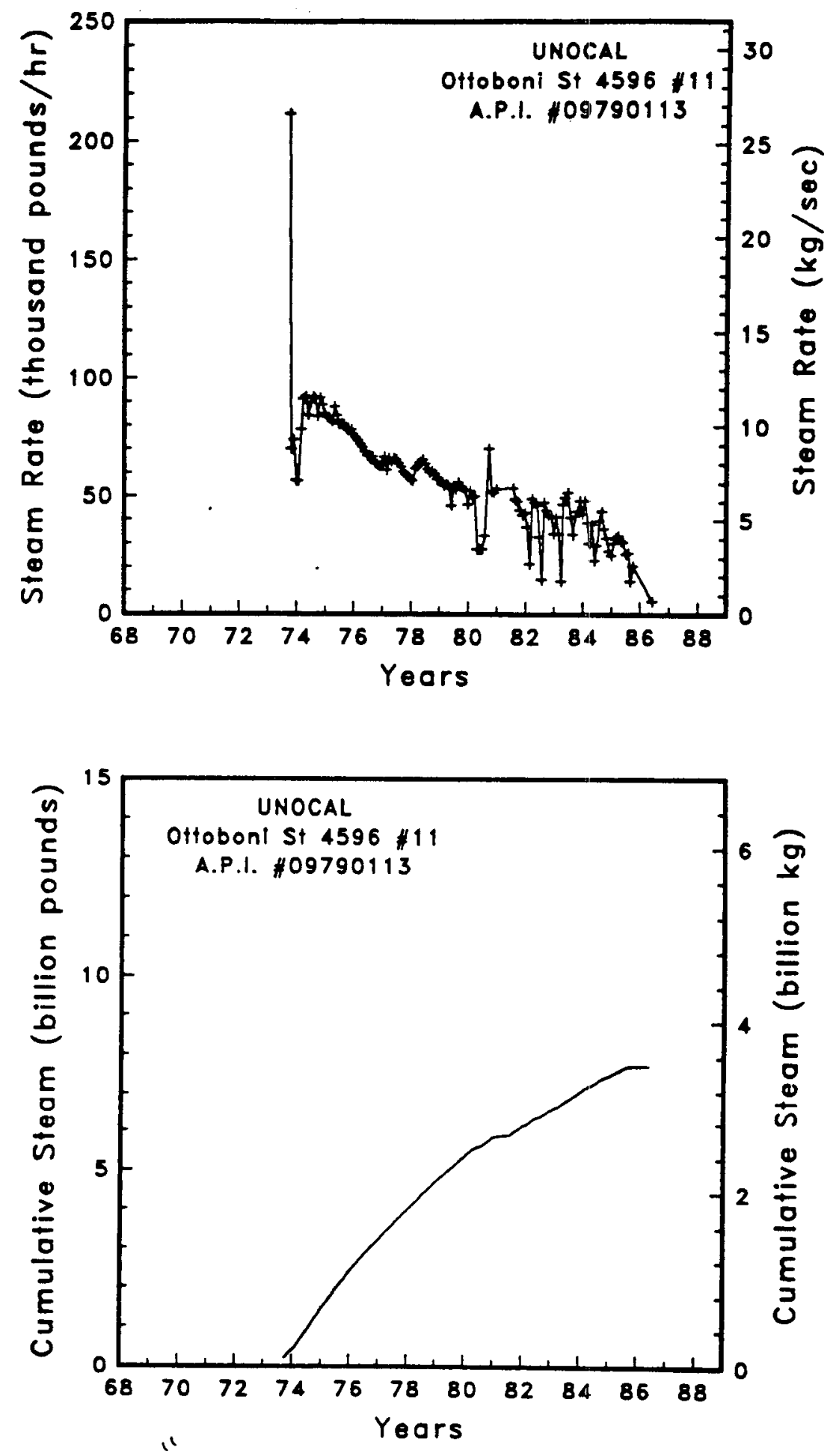

Figure A-169

Steam rate and cumulative mass flow for well Ottoboni St $4596 \# 11$ 

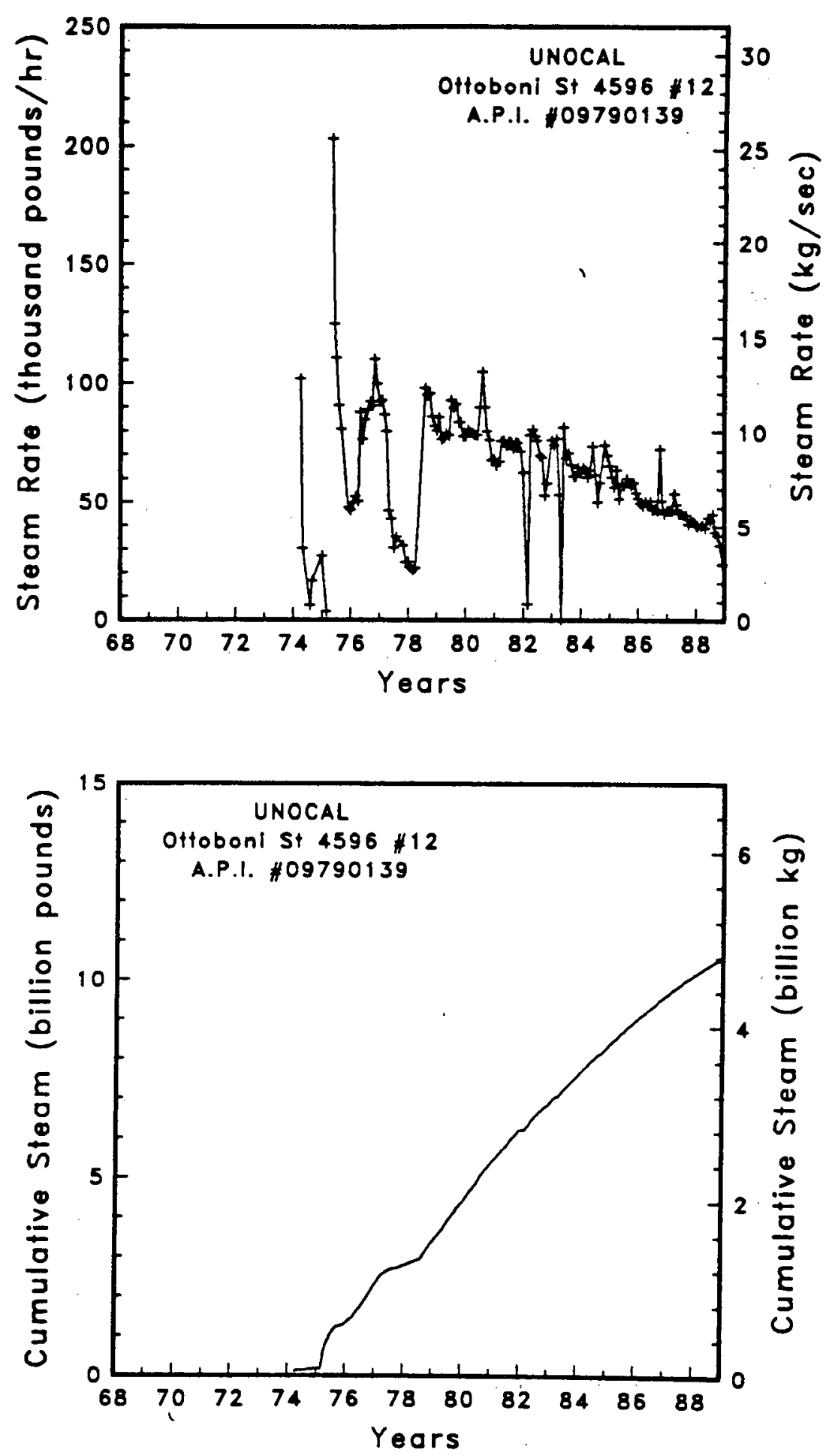

Figure A-170

Steam rate and cumulative mass flow for well Ottoboni St $4596 \# 12$ 

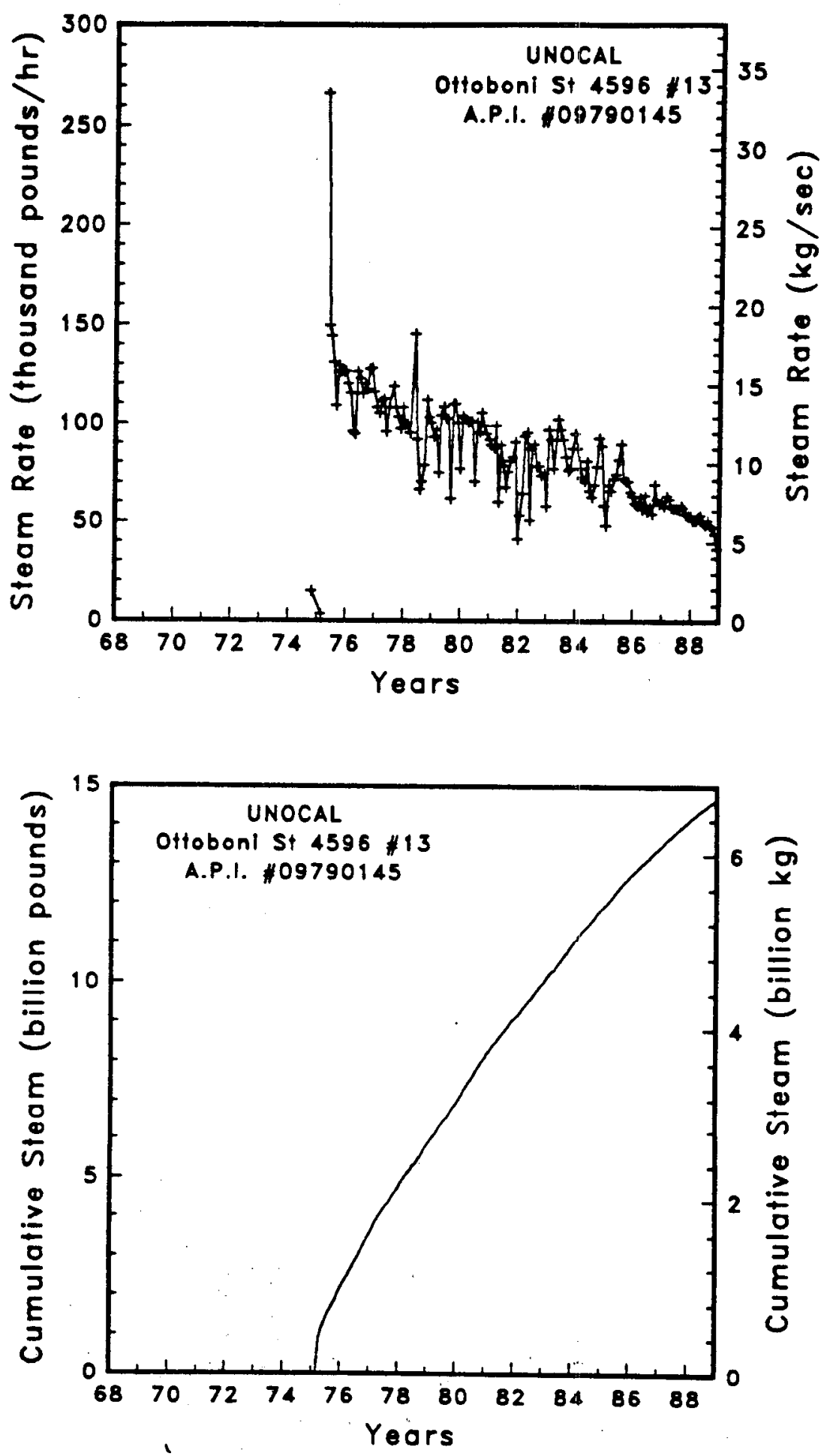

Figure A-171 Steam rate and cumulative mass flow for well Ottoboni St $4596 \# 13$ 

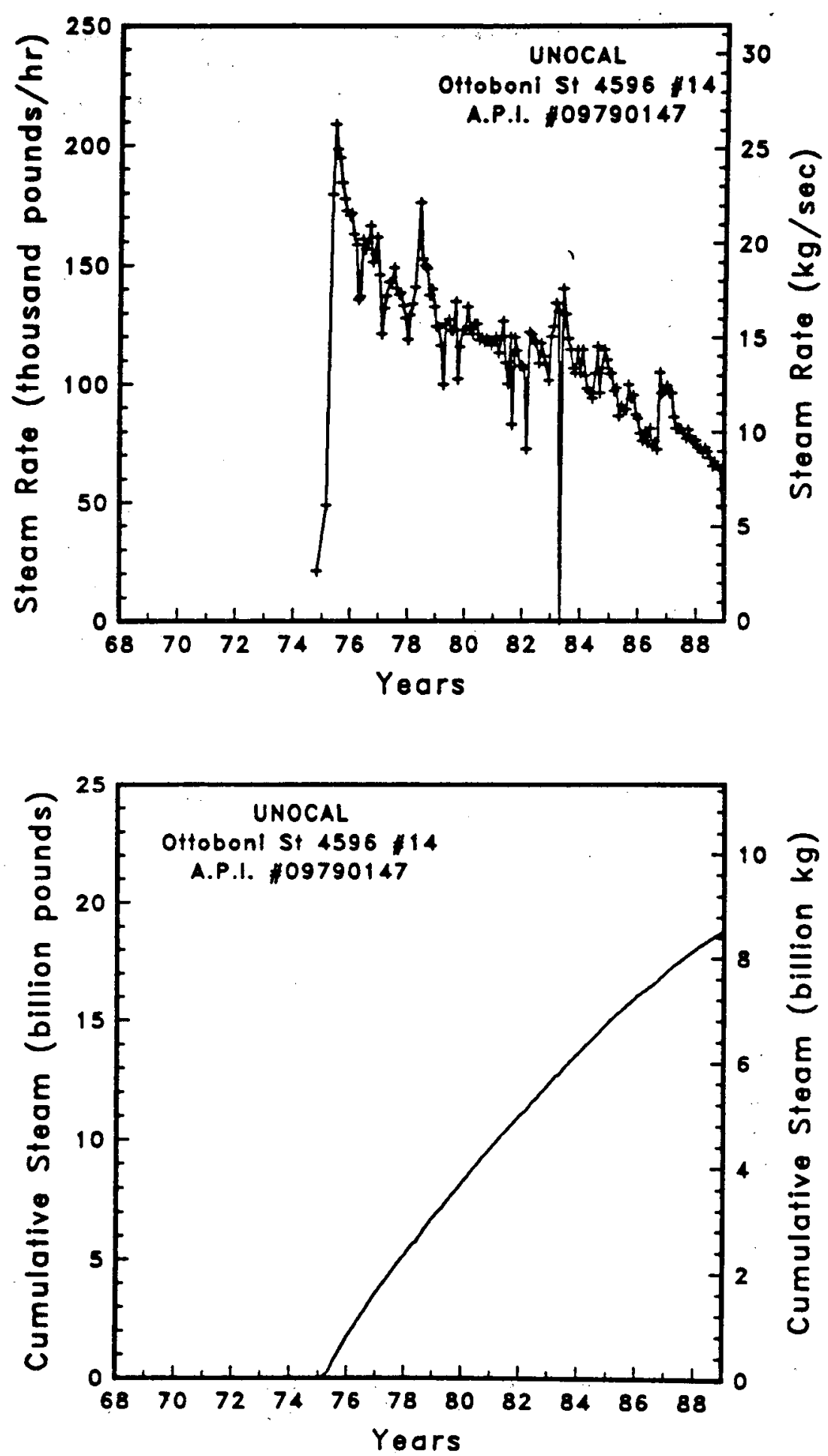

Figure A-172

Steom rate and cumulative mass flow for well Ottoboni St $4596 \# 14$ 

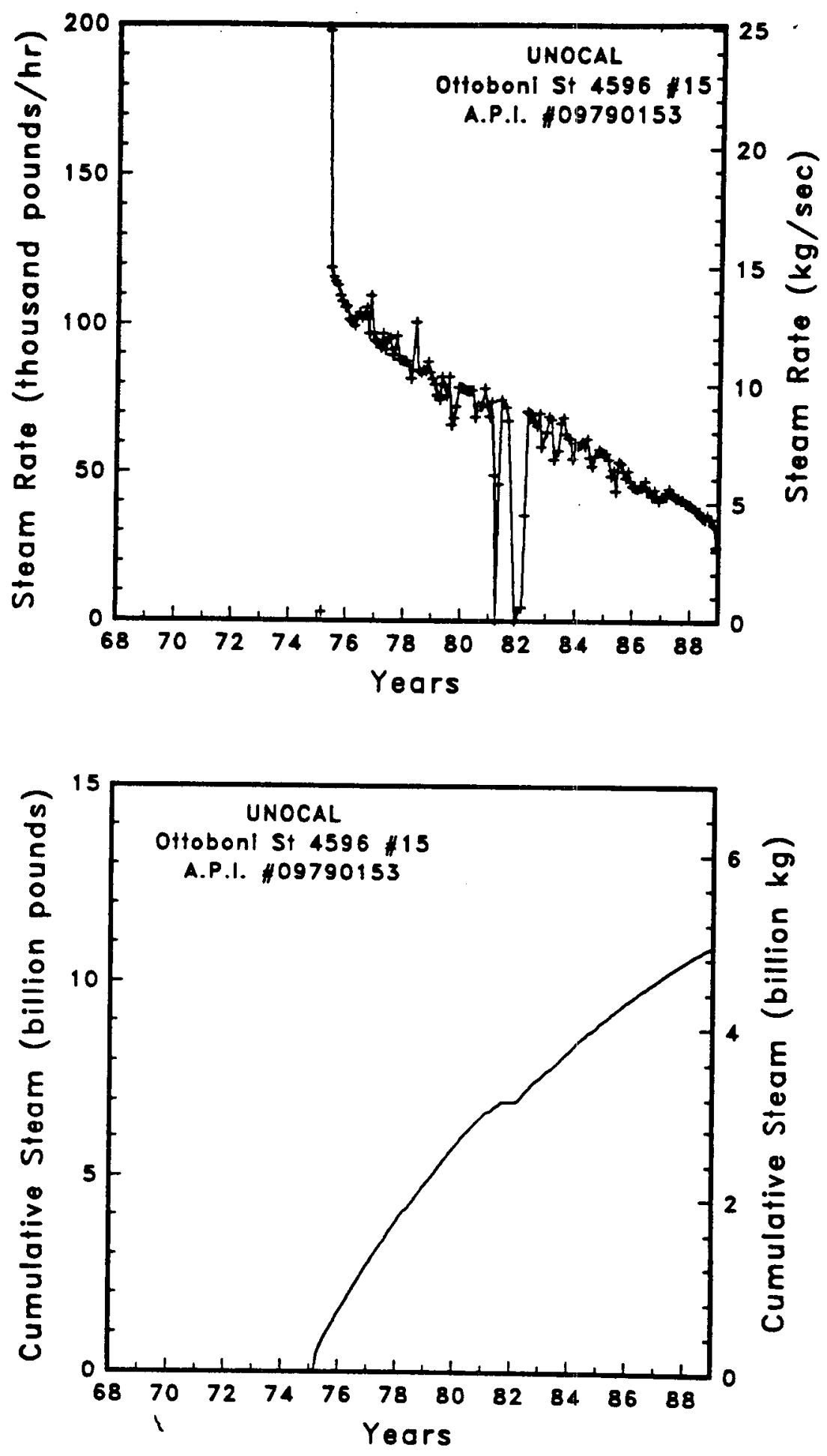

Figure A-173

Steam rate and cumulative mass flow for well Ottoboni St 4596 \#15 

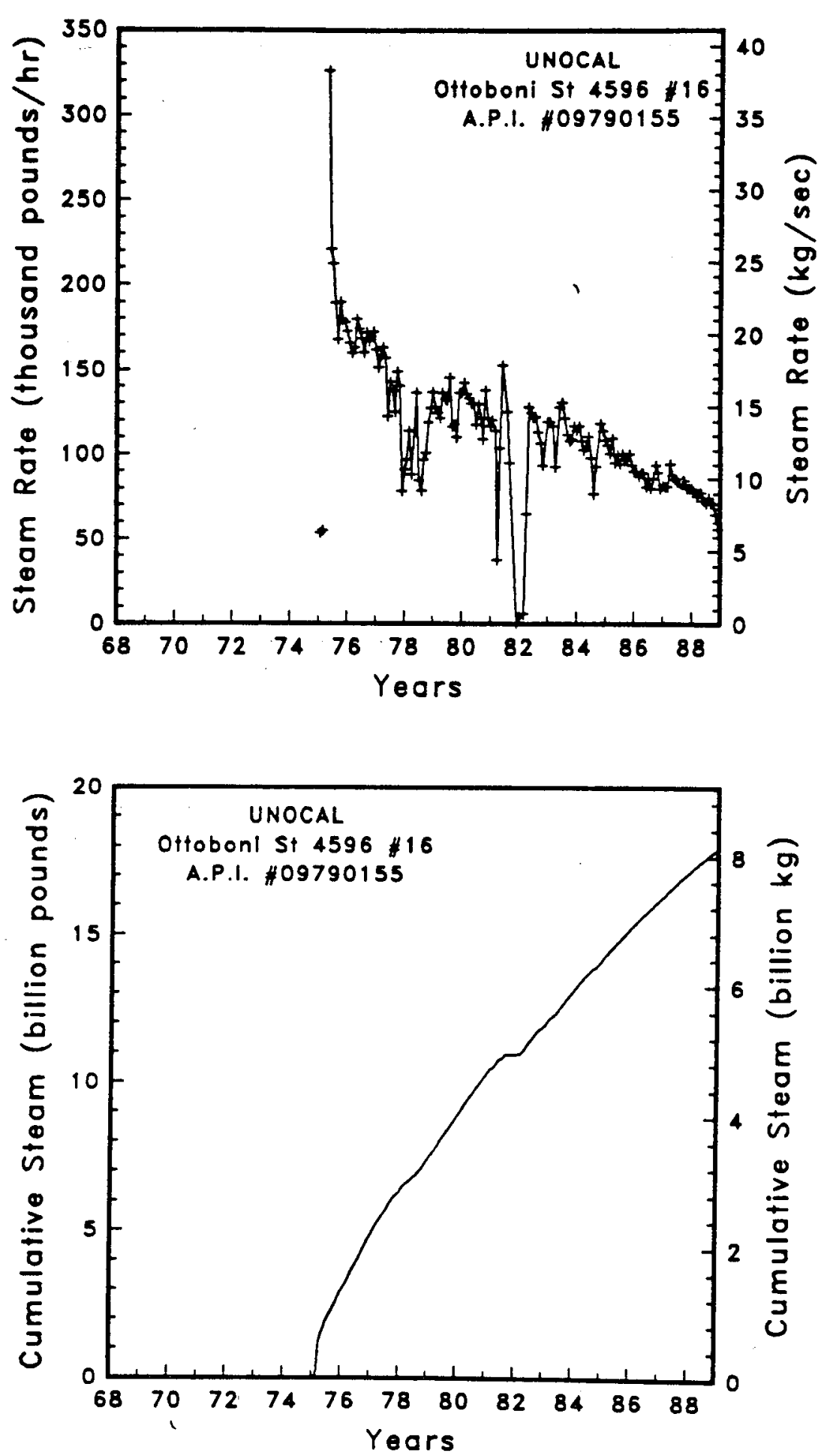

Figure A-174

Steam rate and cumulative mass flow for well Ottoboni St $4596 \# 16$ 

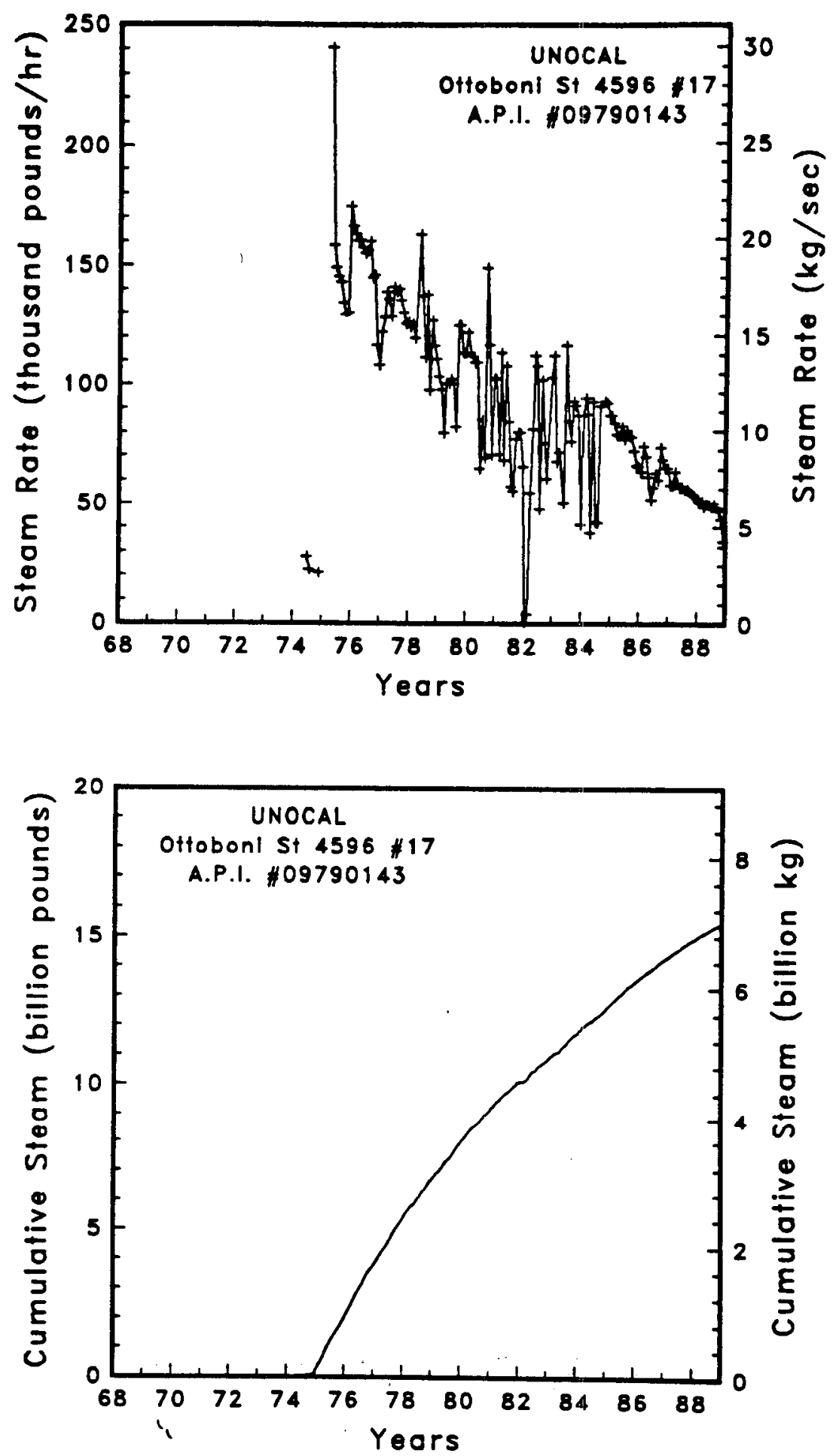

Figure A-175 Steam rate and cumulative mass flow for well Ottoboni St $4596 \# 17$ 

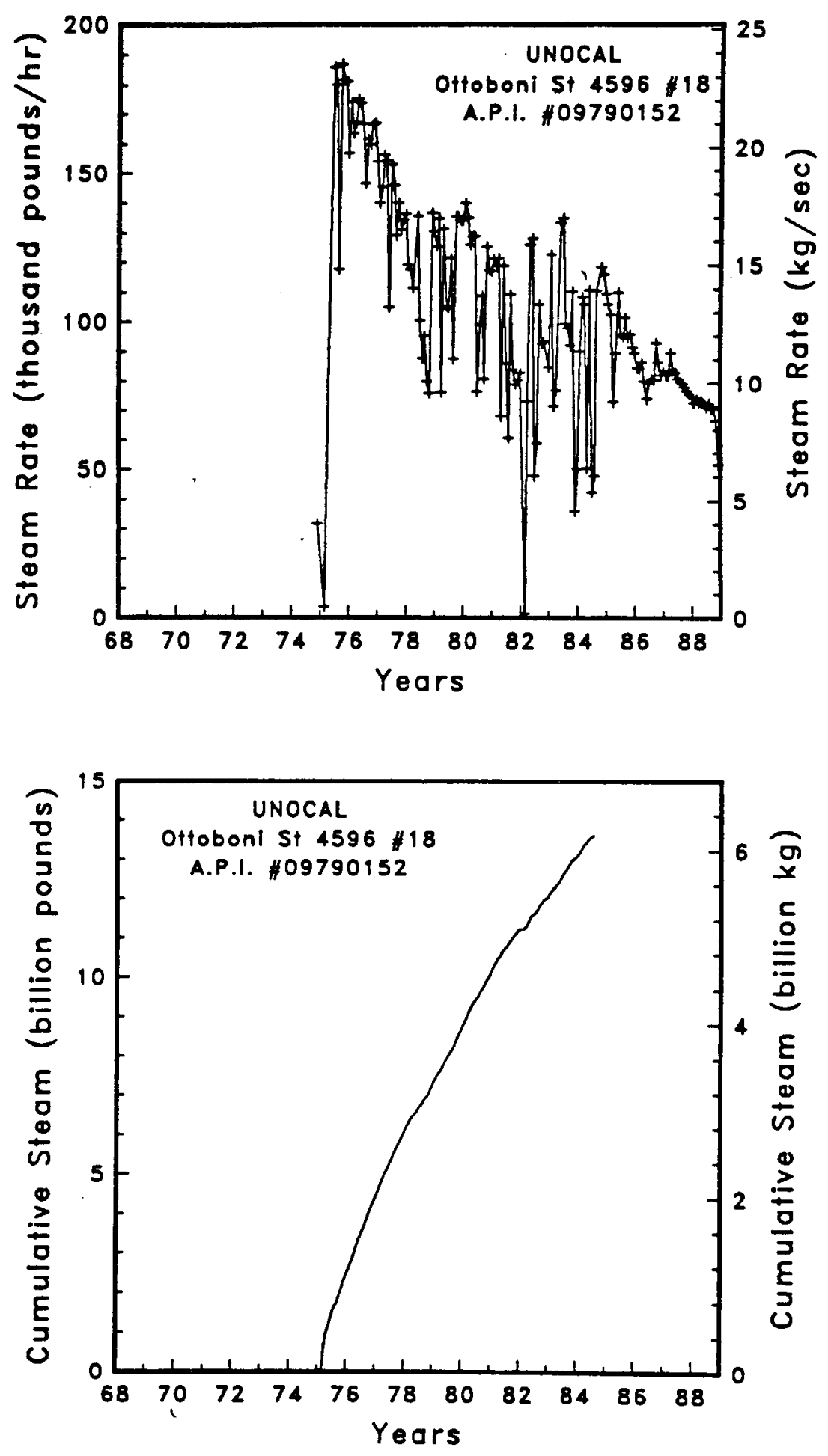

Figure A-176

Steam rate and cumulative mass flow for well Ottoboni St 4596 \#18 

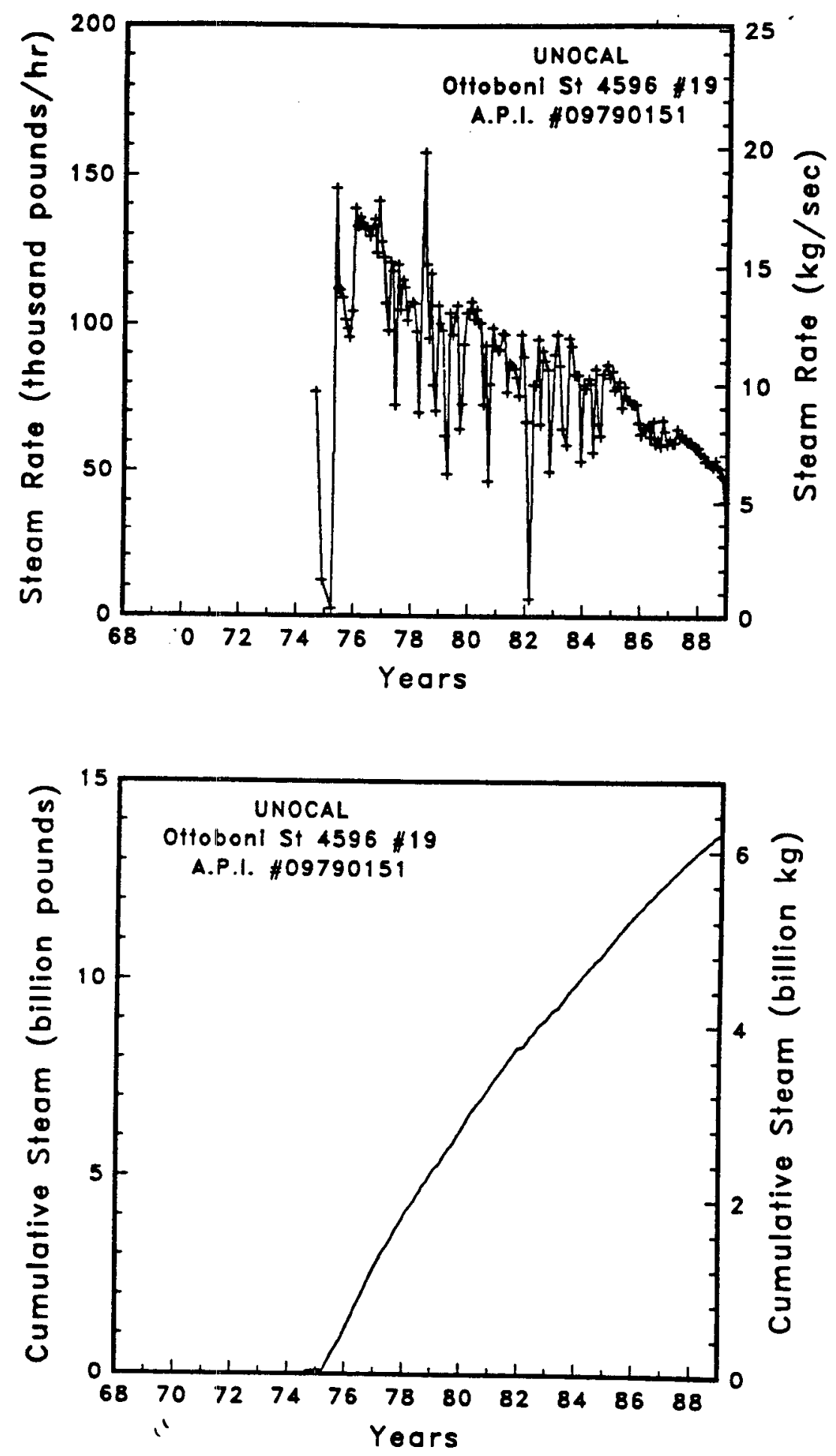

Figure A-177

Steam rate and cumulative mass flow for well Ottoboni St 4596 \#19 

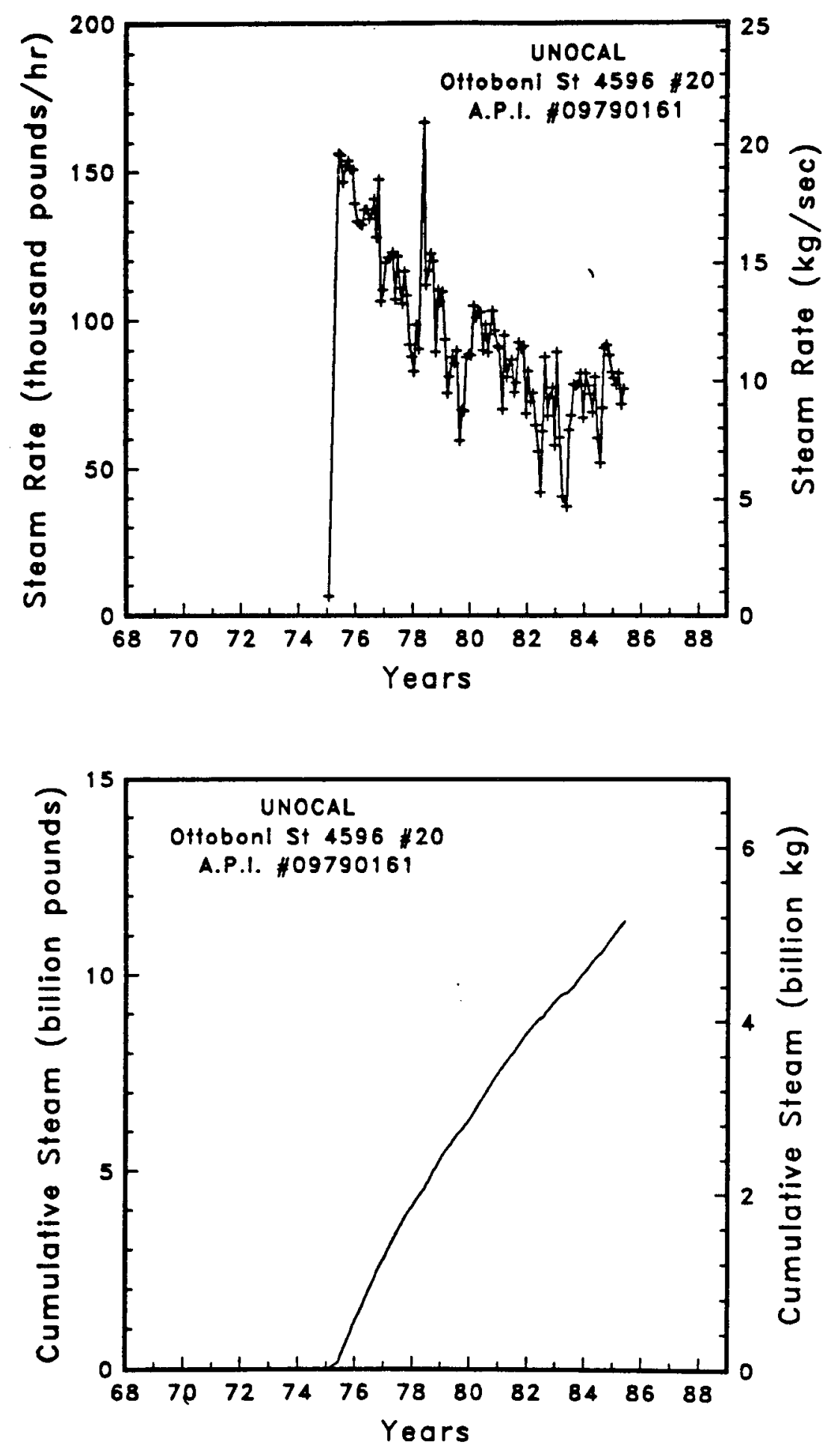

Figure A-178

Steam rate and cumulative mass flow for well Ottoboni St 4596 \#20 

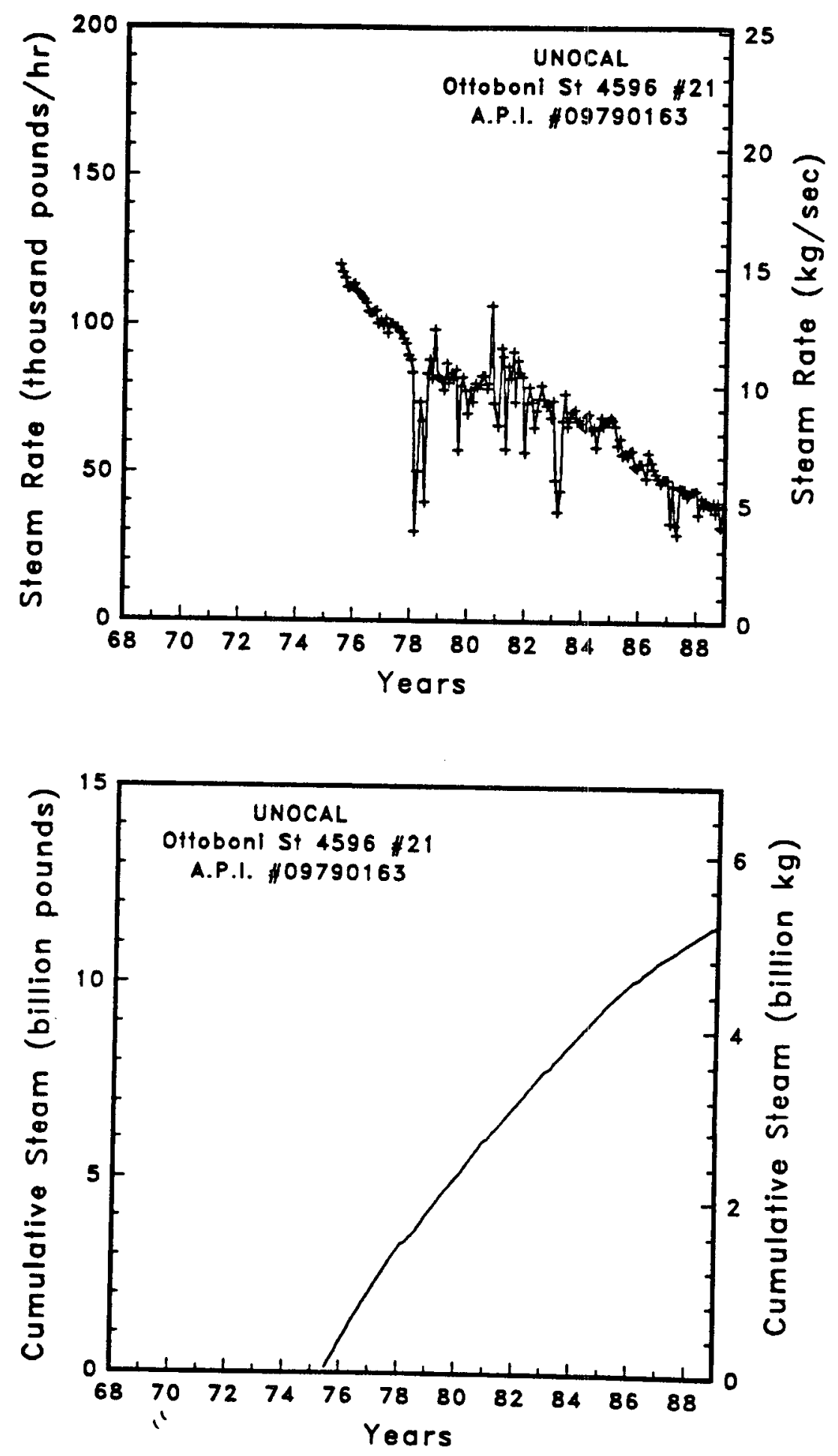

Figure A-179

Steam rate and cumulative mass flow for well Ottoboni St $4596 \# 21$ 

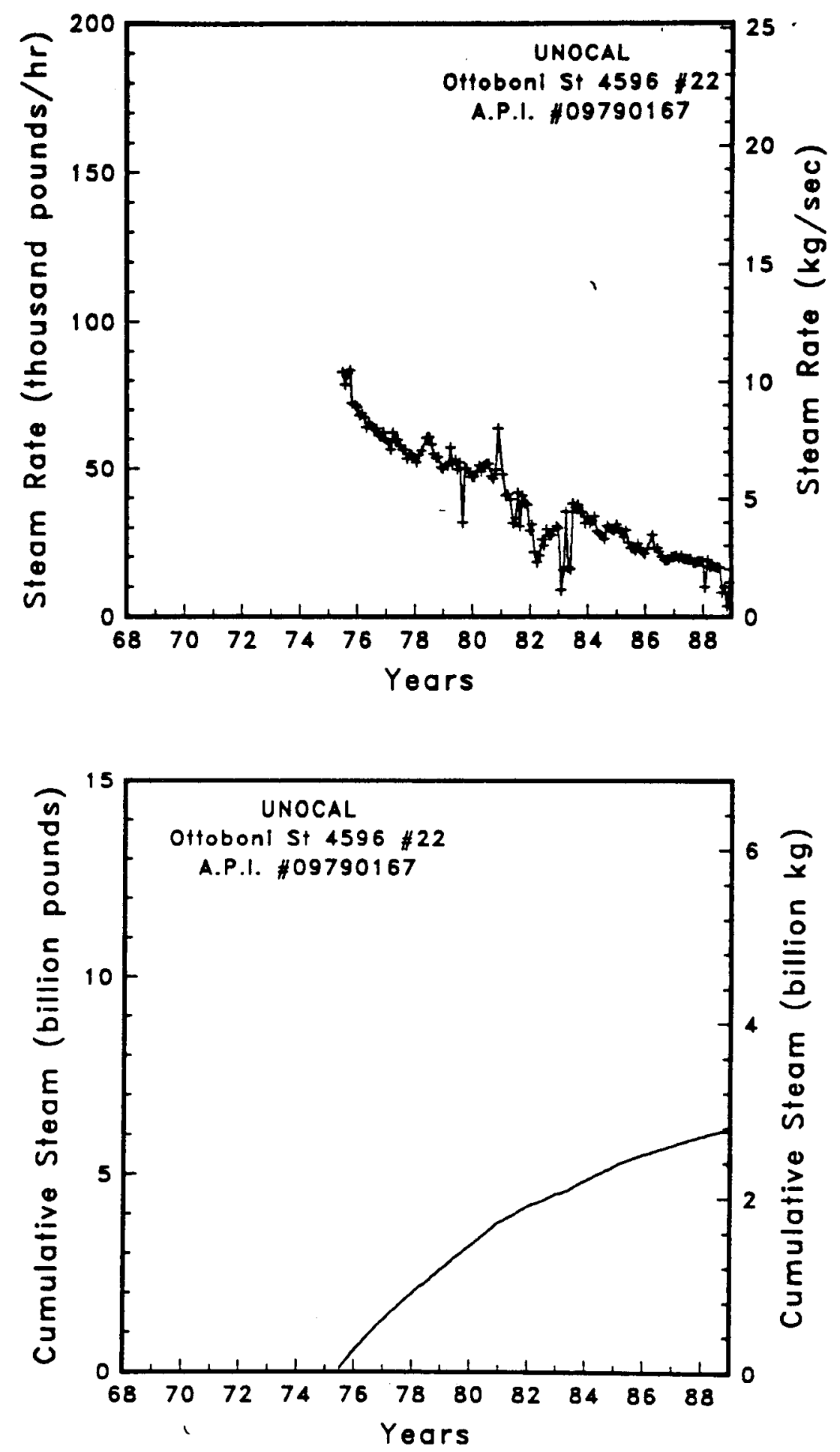

Figure A-180

Steam rate and cumulative mass flow for well Ottoboni St 4596 \#22 

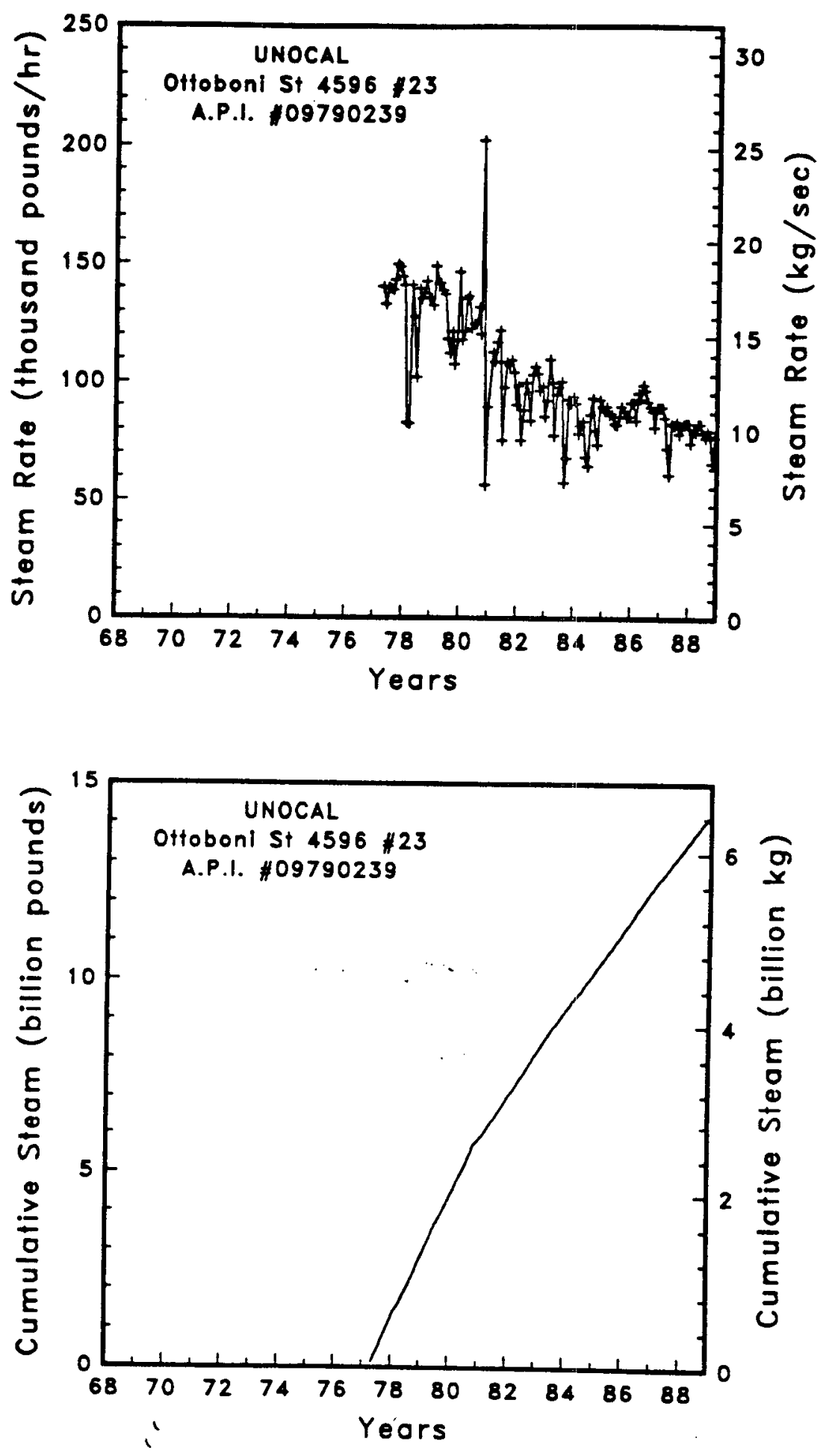

Figure A-181 Steam rate and cumulative mass flow for well Ottoboni St $4596 \# 2.3$ 

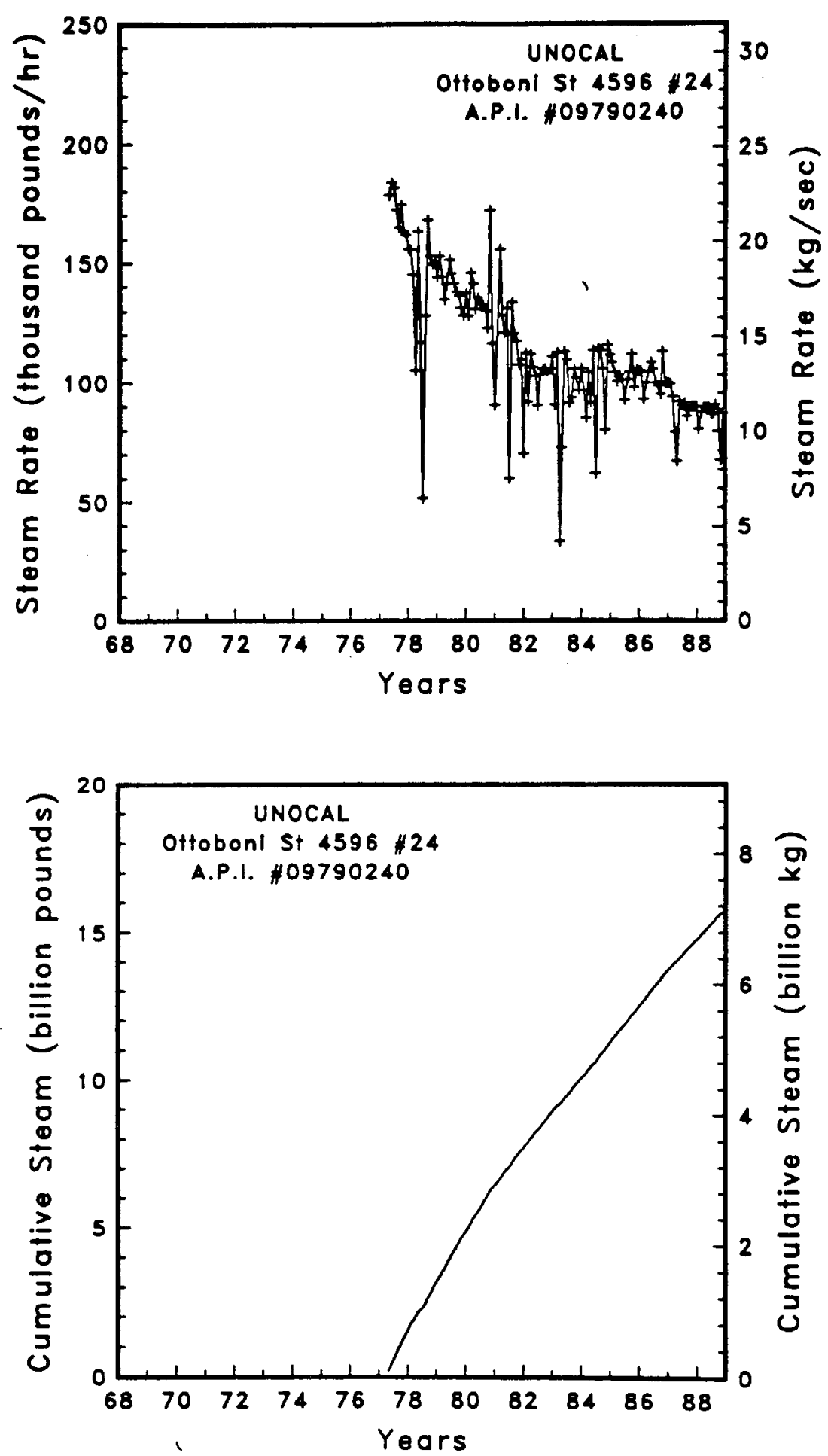

Figure A-182

Steam rate and cumulative mass flow for well Ottoboni St 4596 \#24 

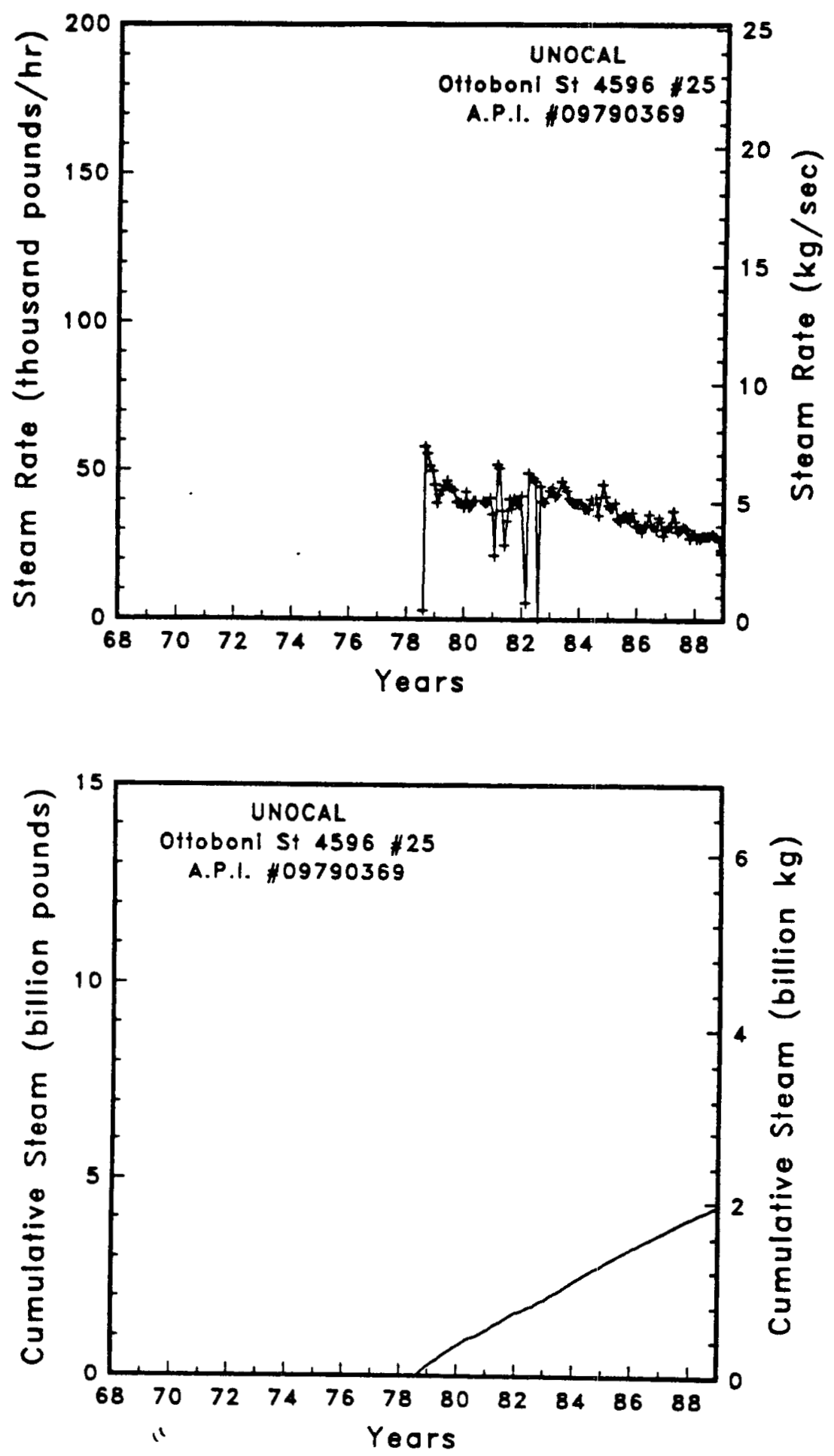

Figure A-183 Steam rate and cumulative mass flow for well Ottoboni St 4596 \#25 

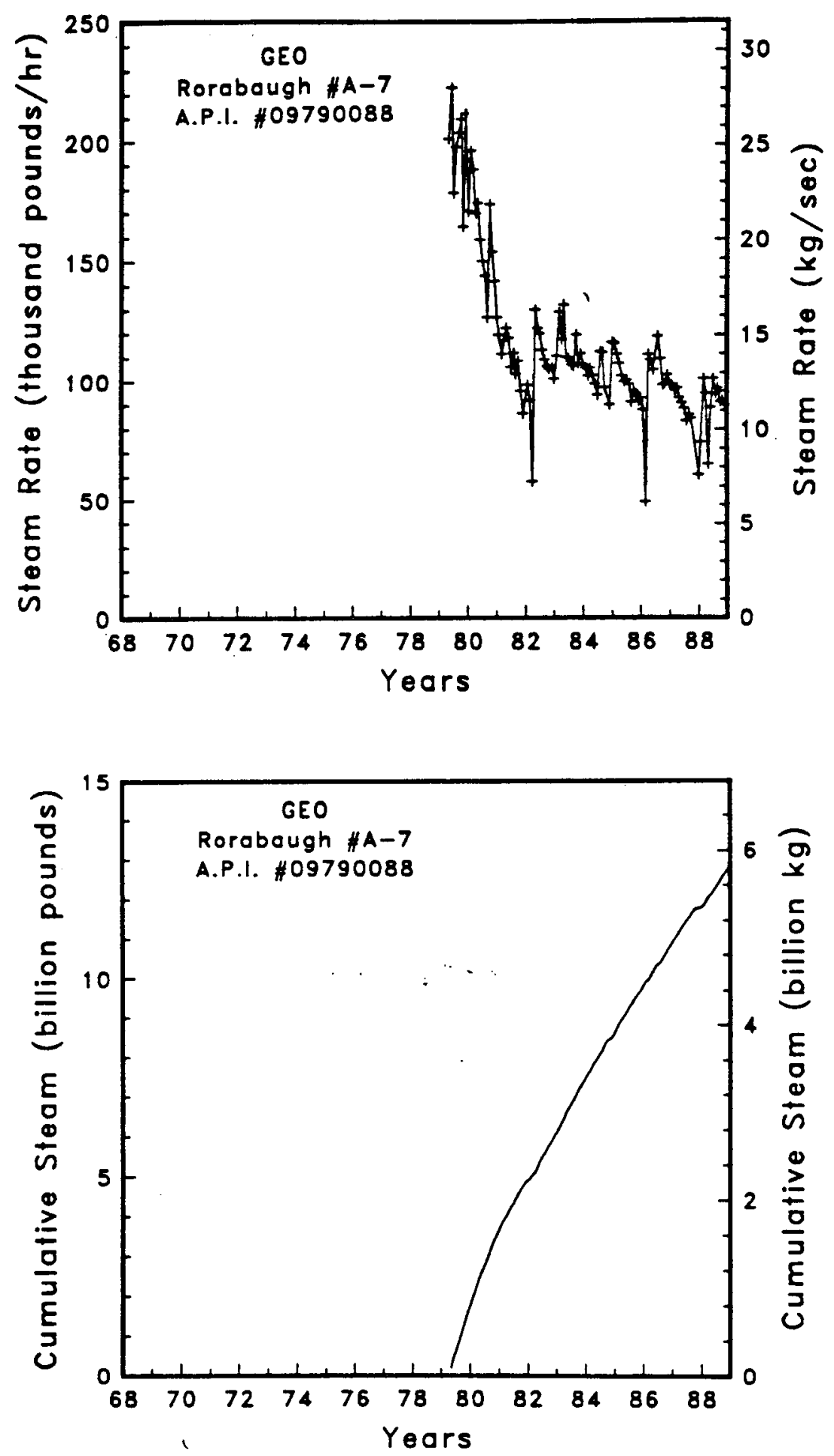

$\begin{array}{ll}\text { Figure A-184 } & \begin{array}{l}\text { Steam rate and cumulative mass flow for } \\ \text { well Rorabaugh \#A-7 }\end{array}\end{array}$ 

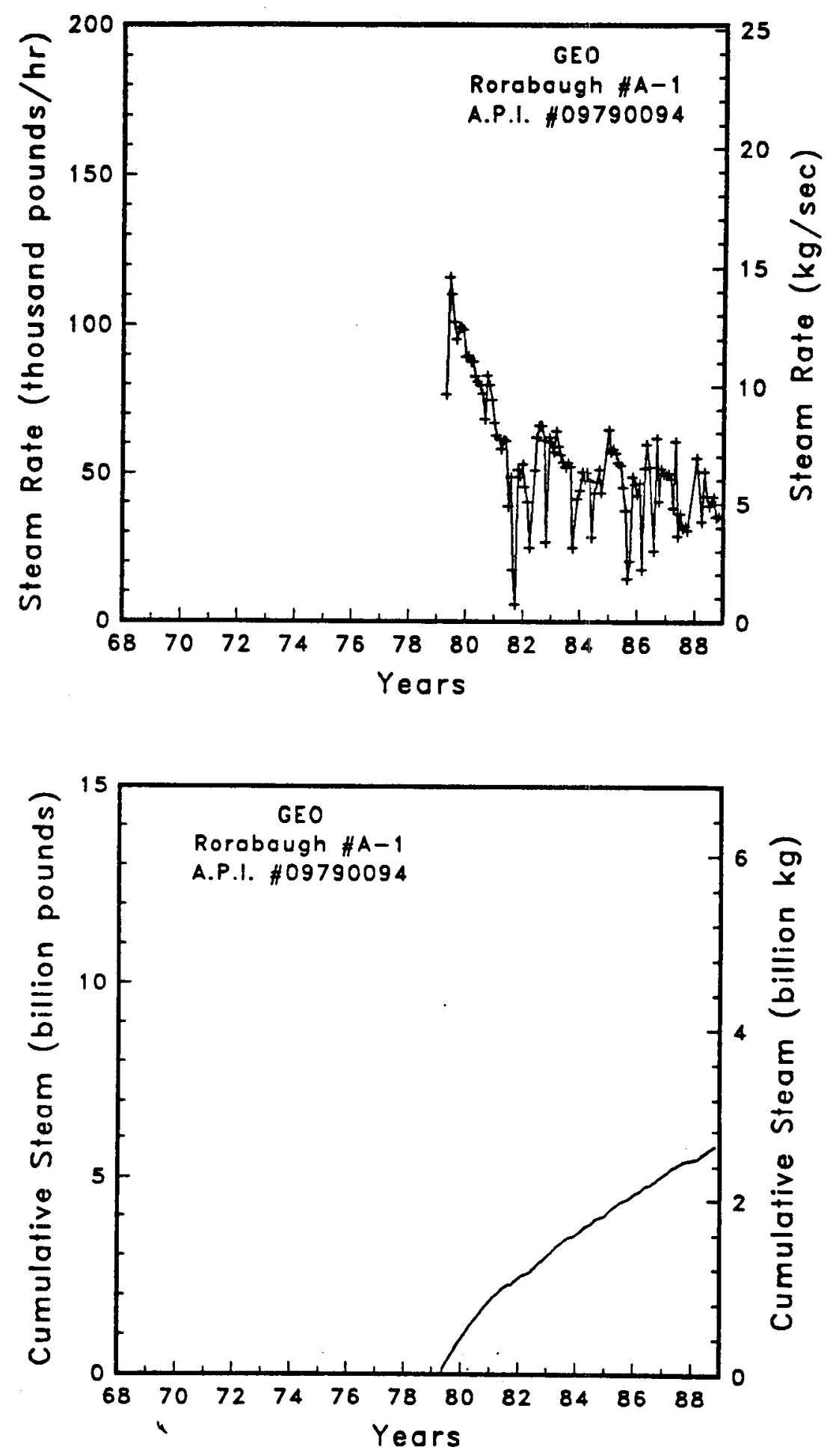

Figure A-185 Steom rate and cumulative mass flow for well Rorabough \#A-1 

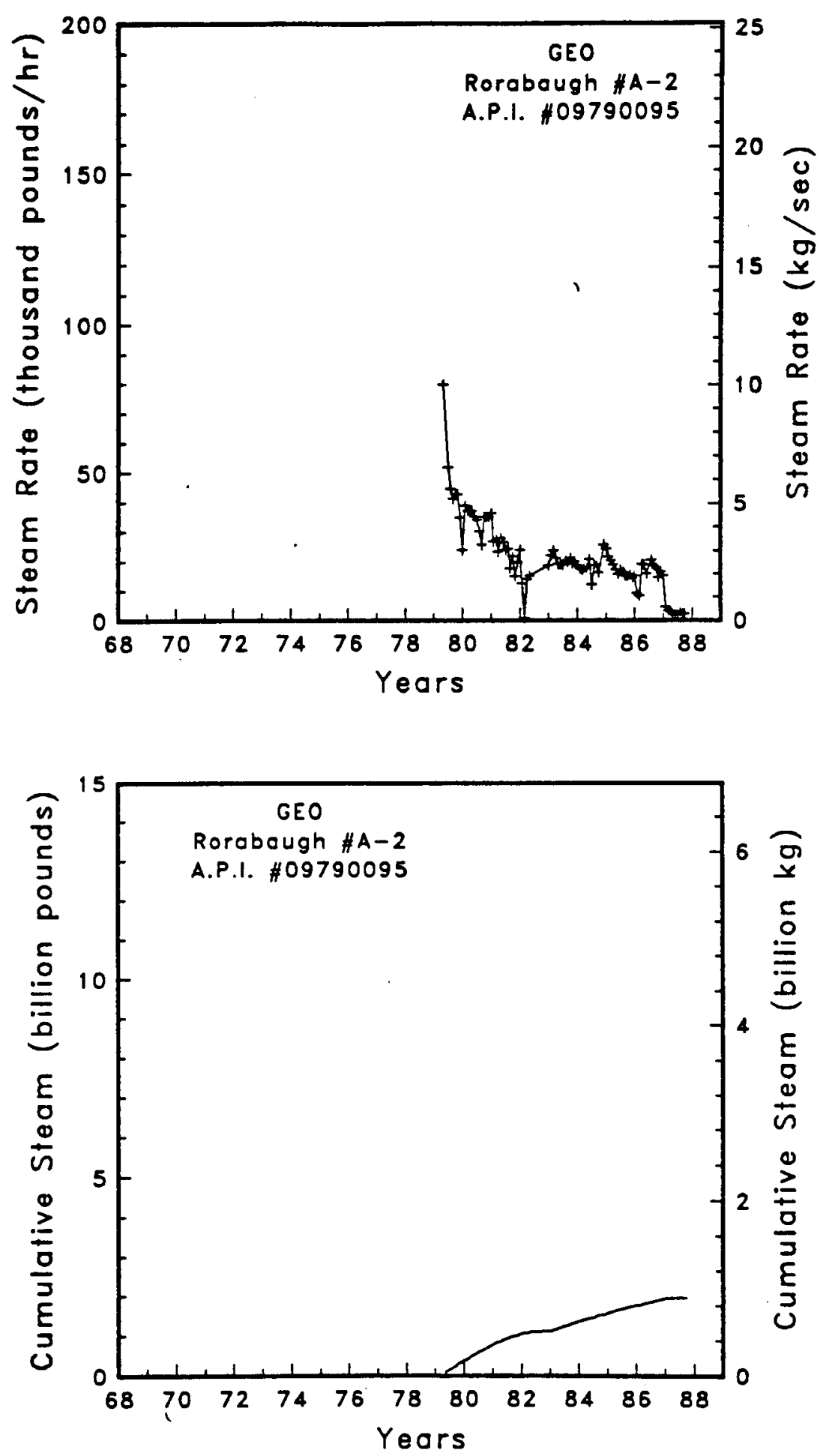

Figure A-186 Steam rate and cumulative mass flow for 

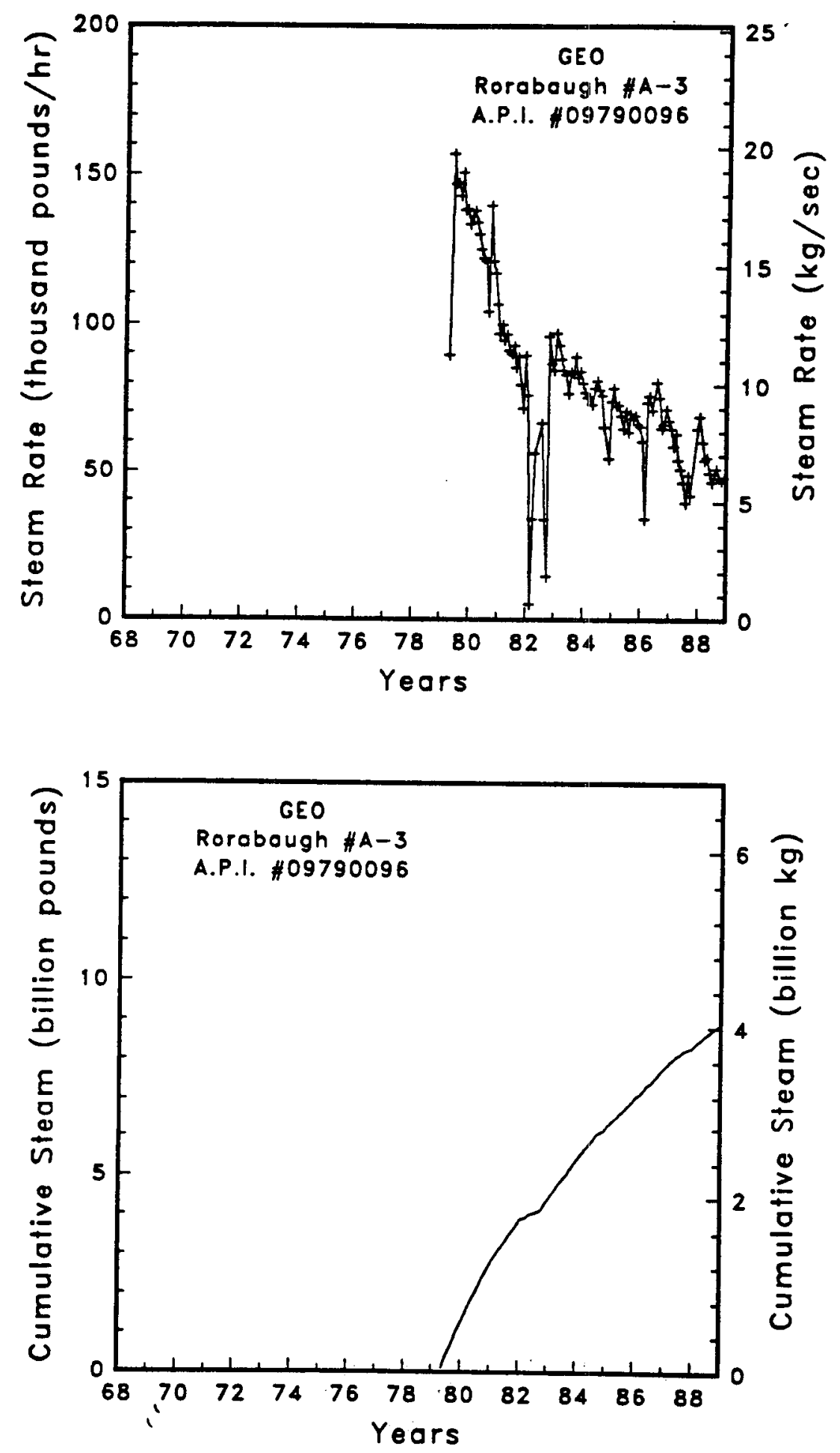

Figure A-187 Steam rate and cumulative mass flow for well Rorabough \#A-3 

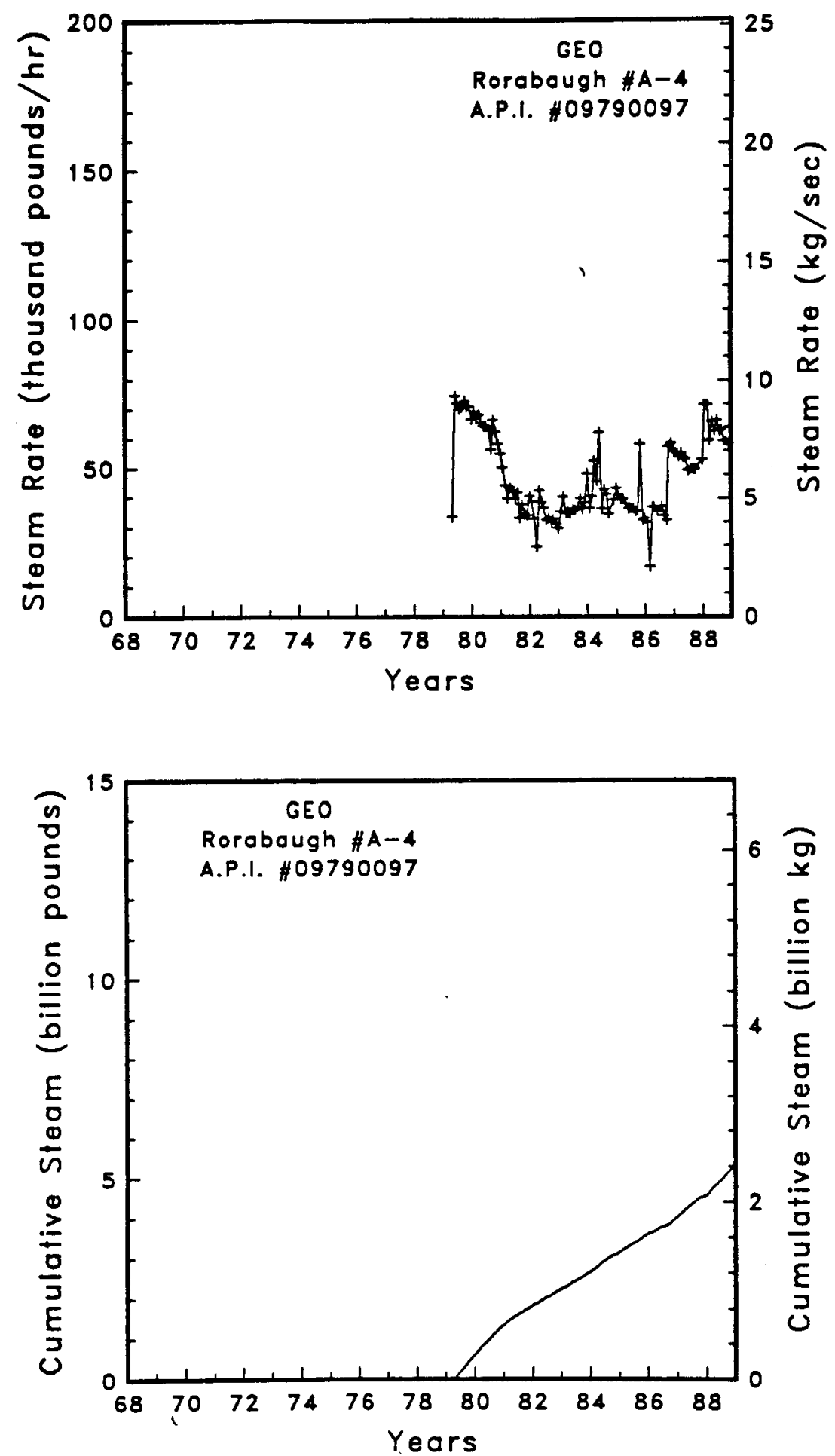

Figure A-188

Steam rate and cumulative mass flow for well Rorabough \#A-4 

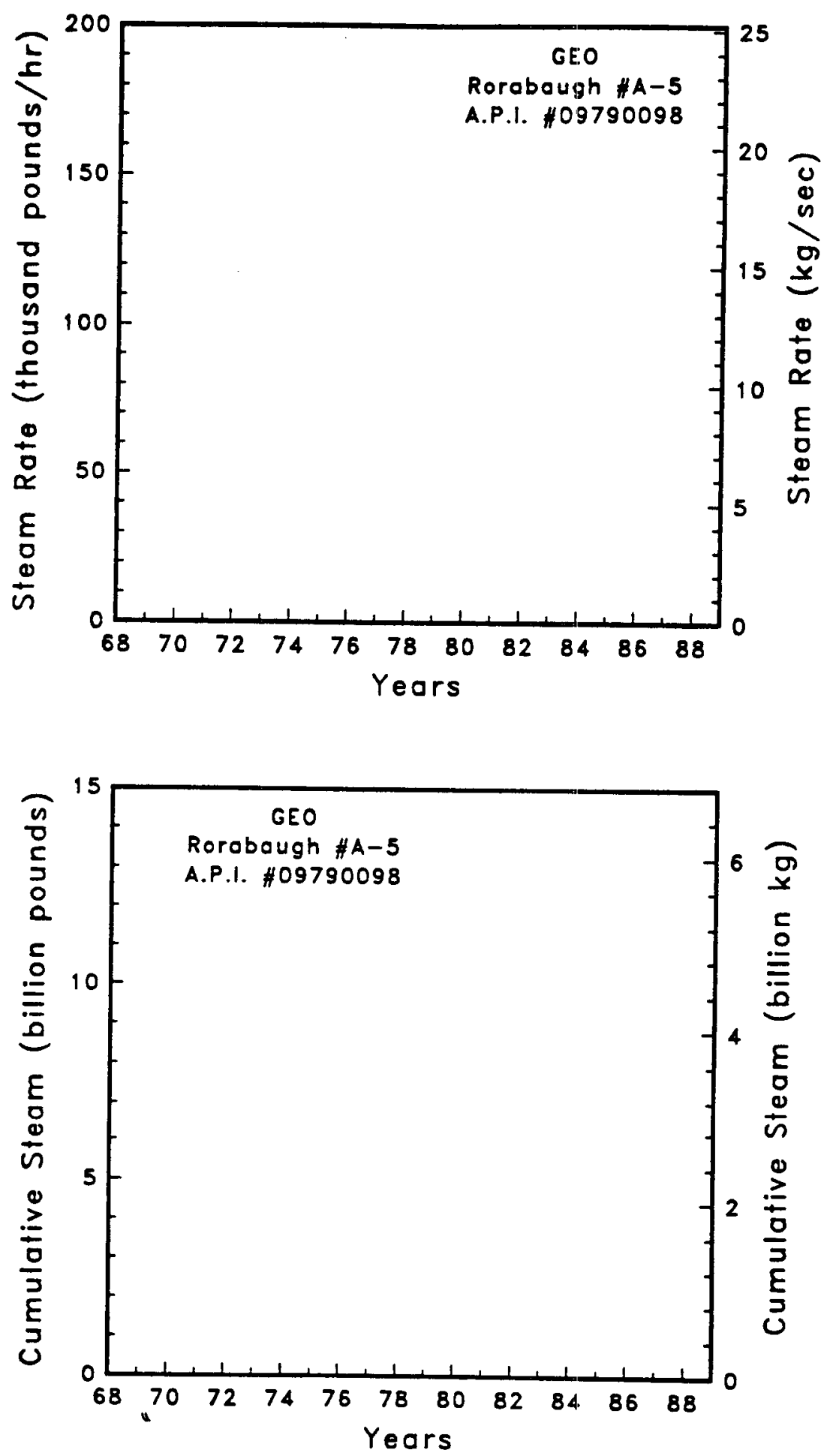

Figure A-189

Steom rate and cumulative mass flow for well Rorabough \#A-5 

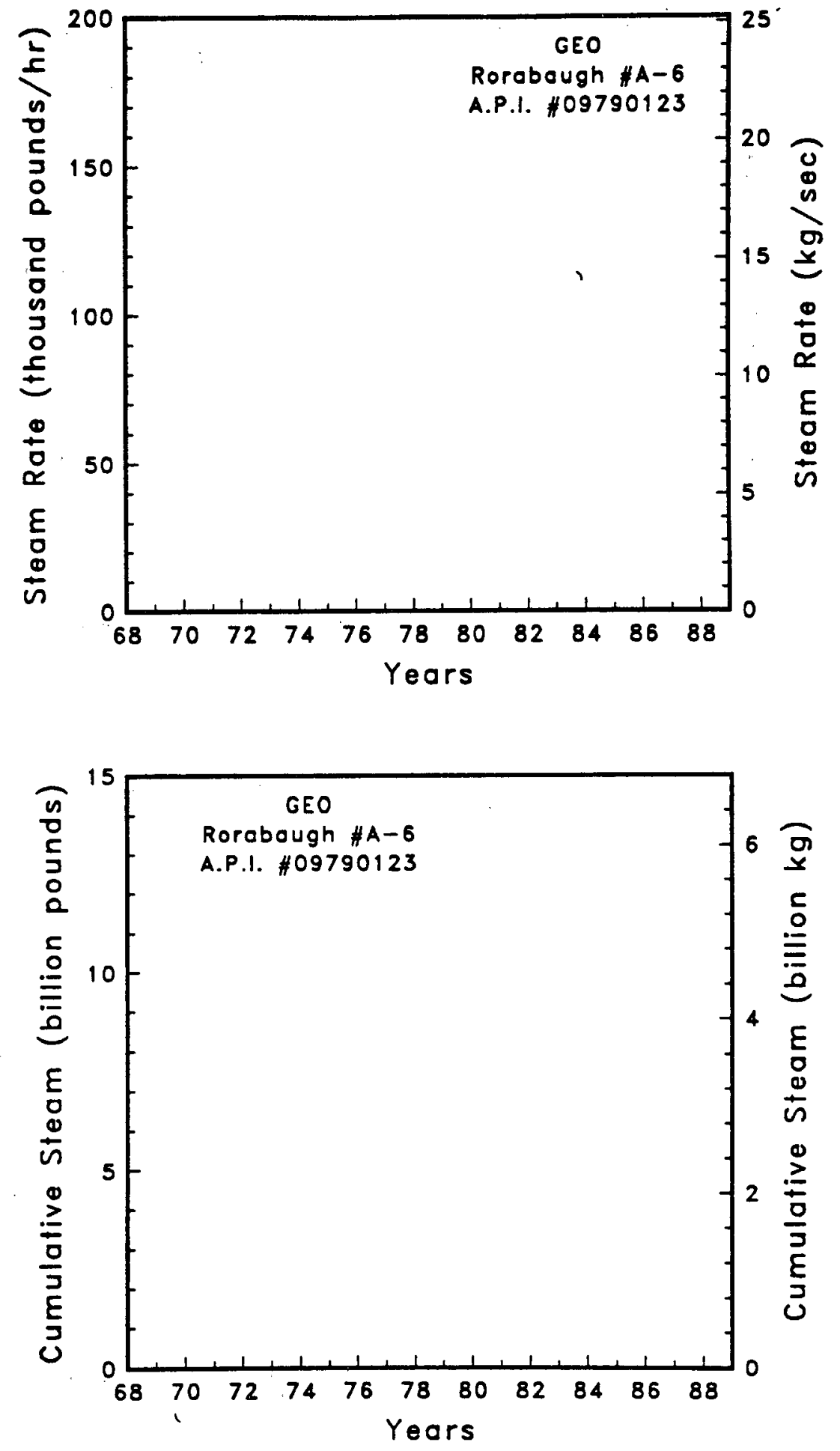

Figure A-190

Steam rate and cumulative mass flow for well Rorabough \#A-6 

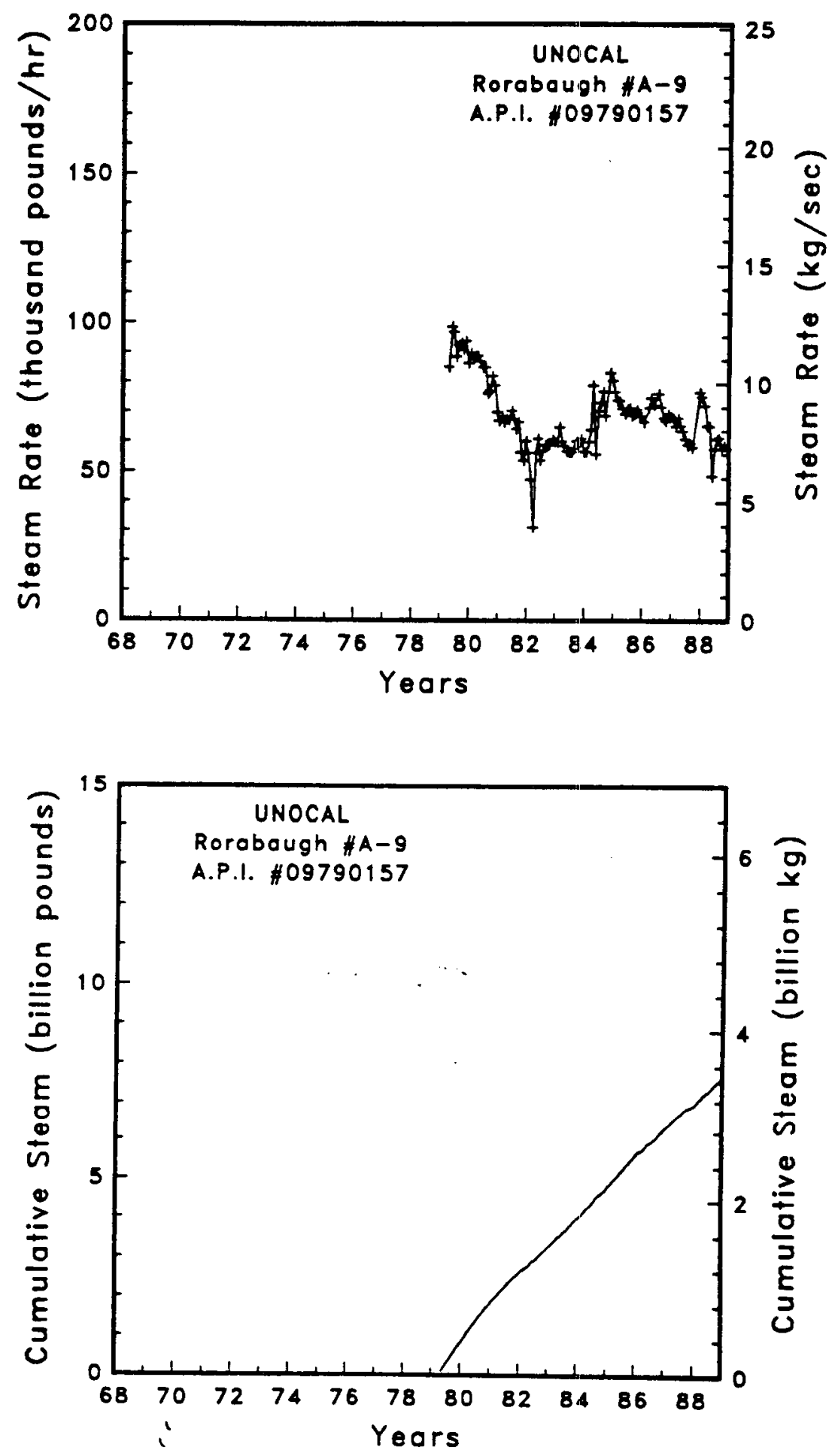

Figure A-191

Steam rate and cumulative mass flow for well Rorabough \#A-9 

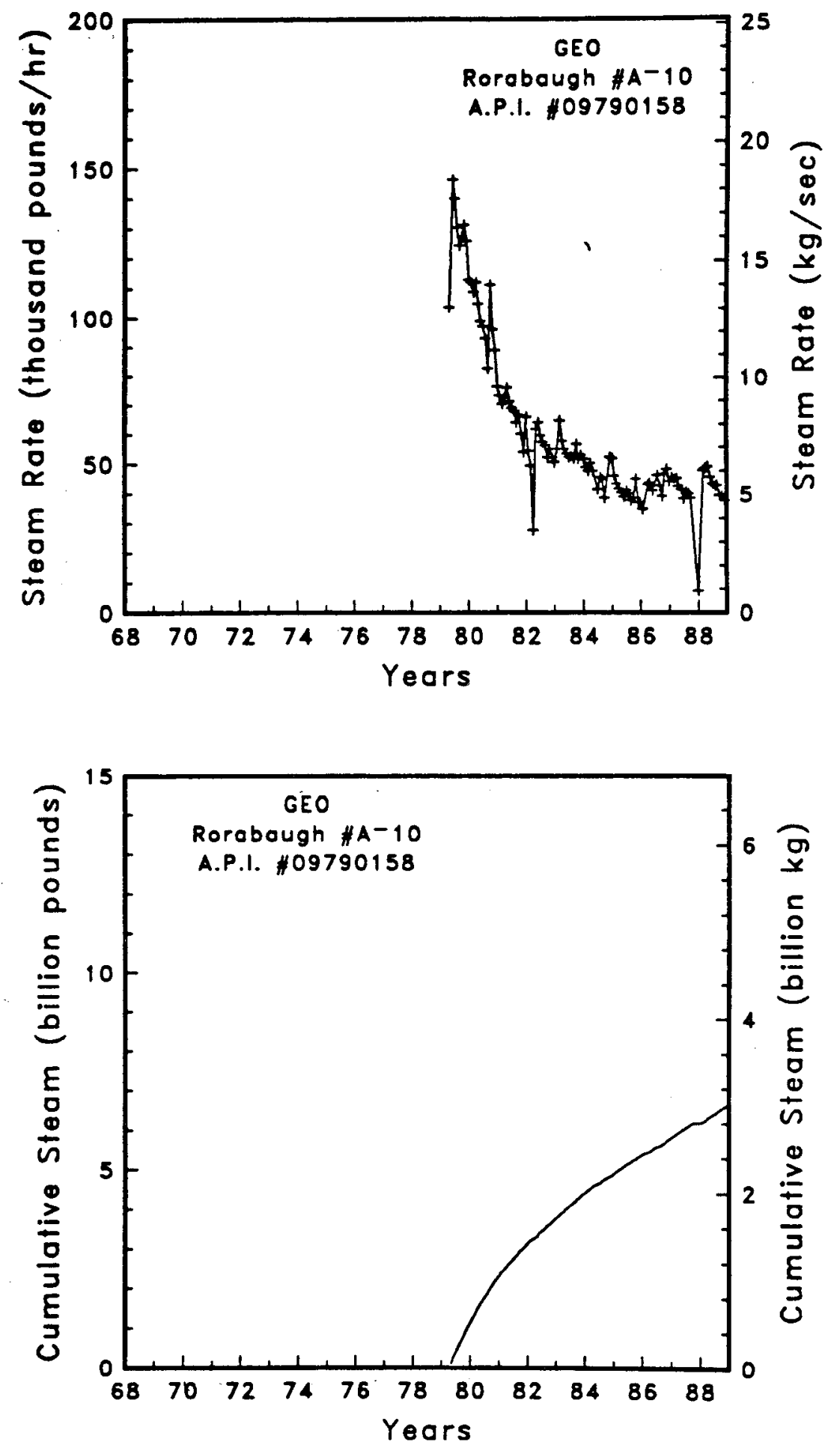

Figure A-192

Steam rate and cumulative mass flow for well Rorabaugh \#A-10 

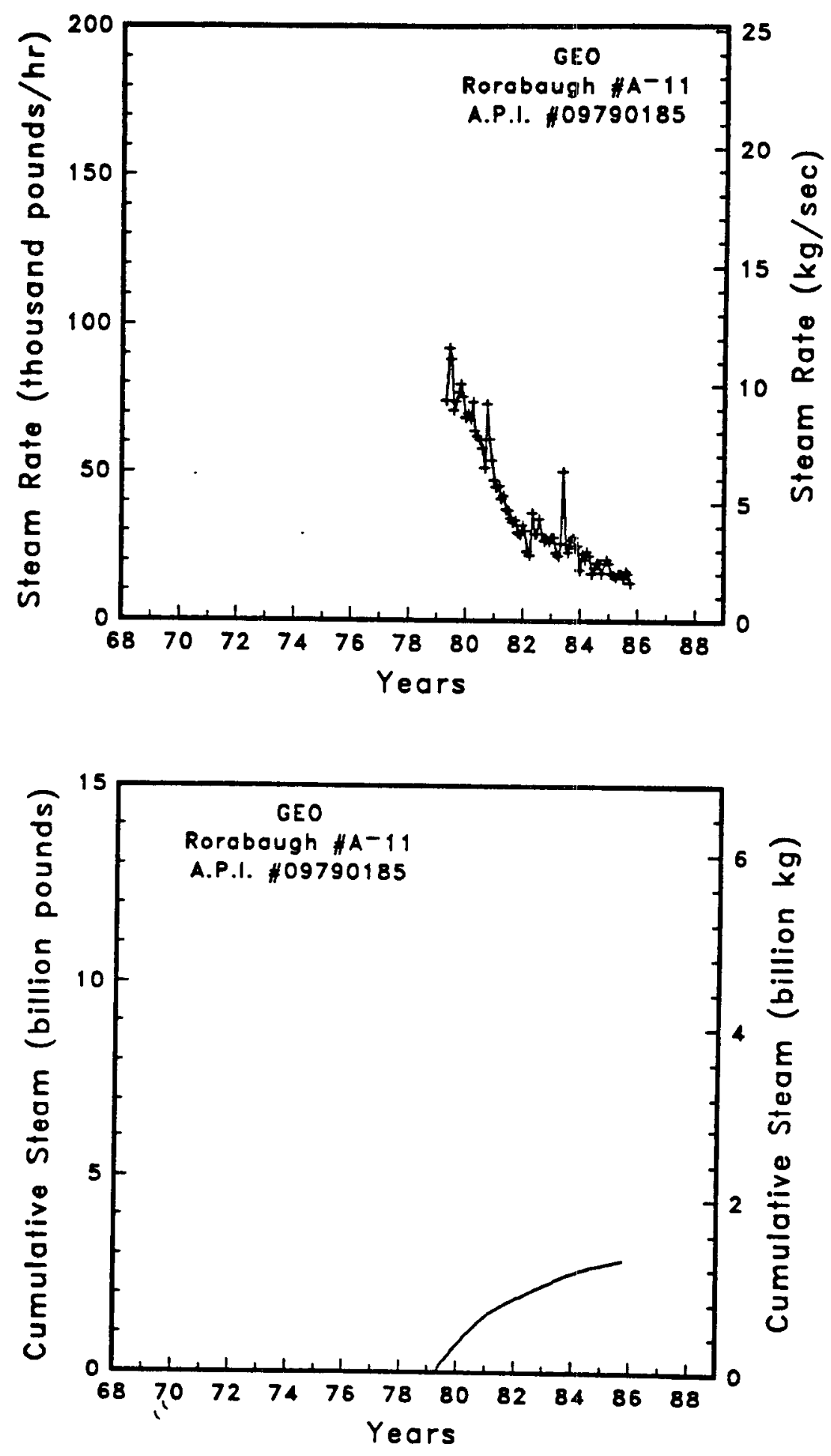

Figure A-193

Steam rote and cumulative mass flow for well Rorabough \#A-11 

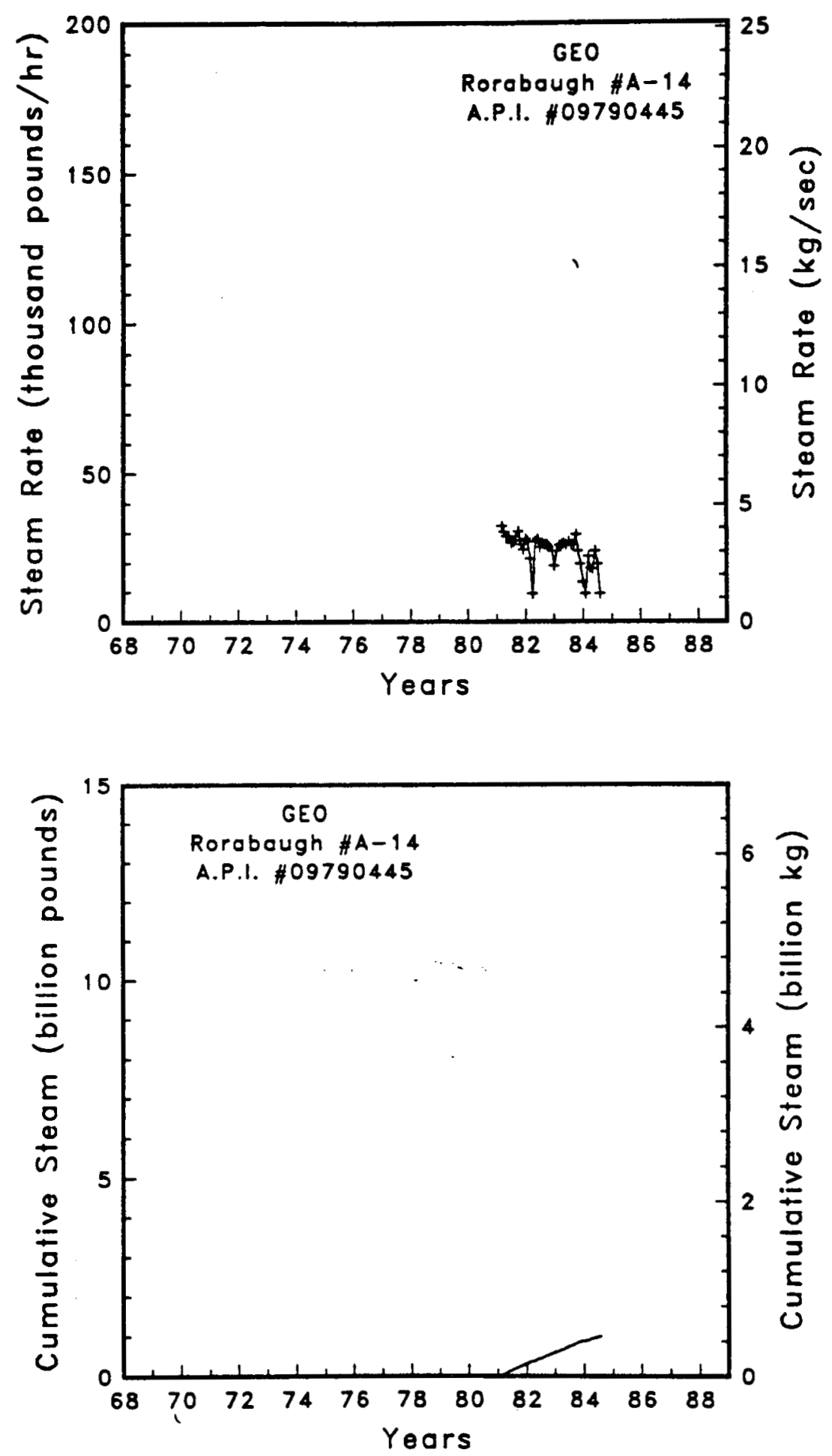

$\begin{array}{ll}\text { Figure A-194 } & \begin{array}{l}\text { Steam rate ond cumulative mass flow for } \\ \text { well Rorabaugh \#A-14 }\end{array}\end{array}$ 

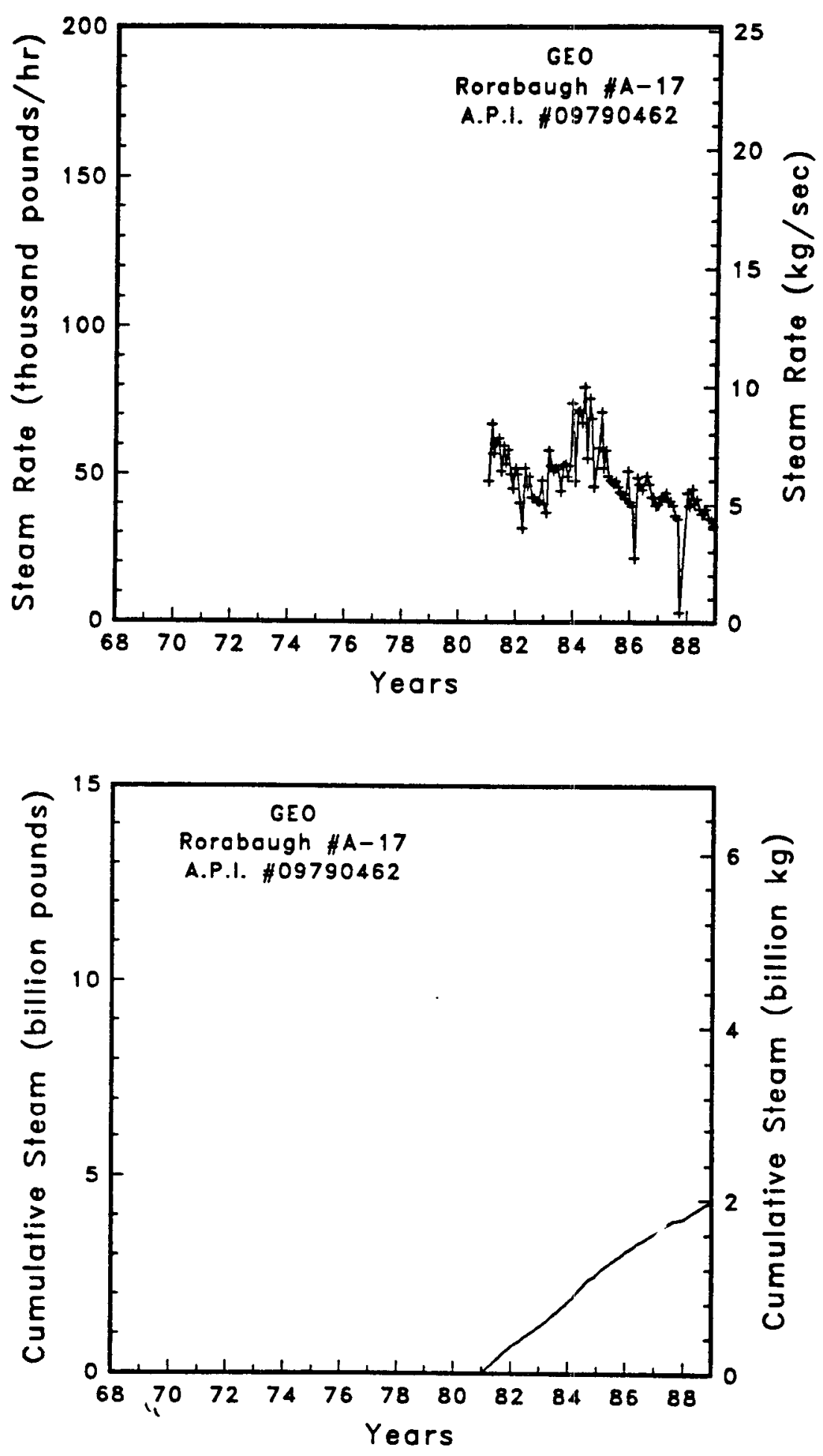

Figure A-195

Steam rate and cumulative mass flow for well Rorabough \#A-17 

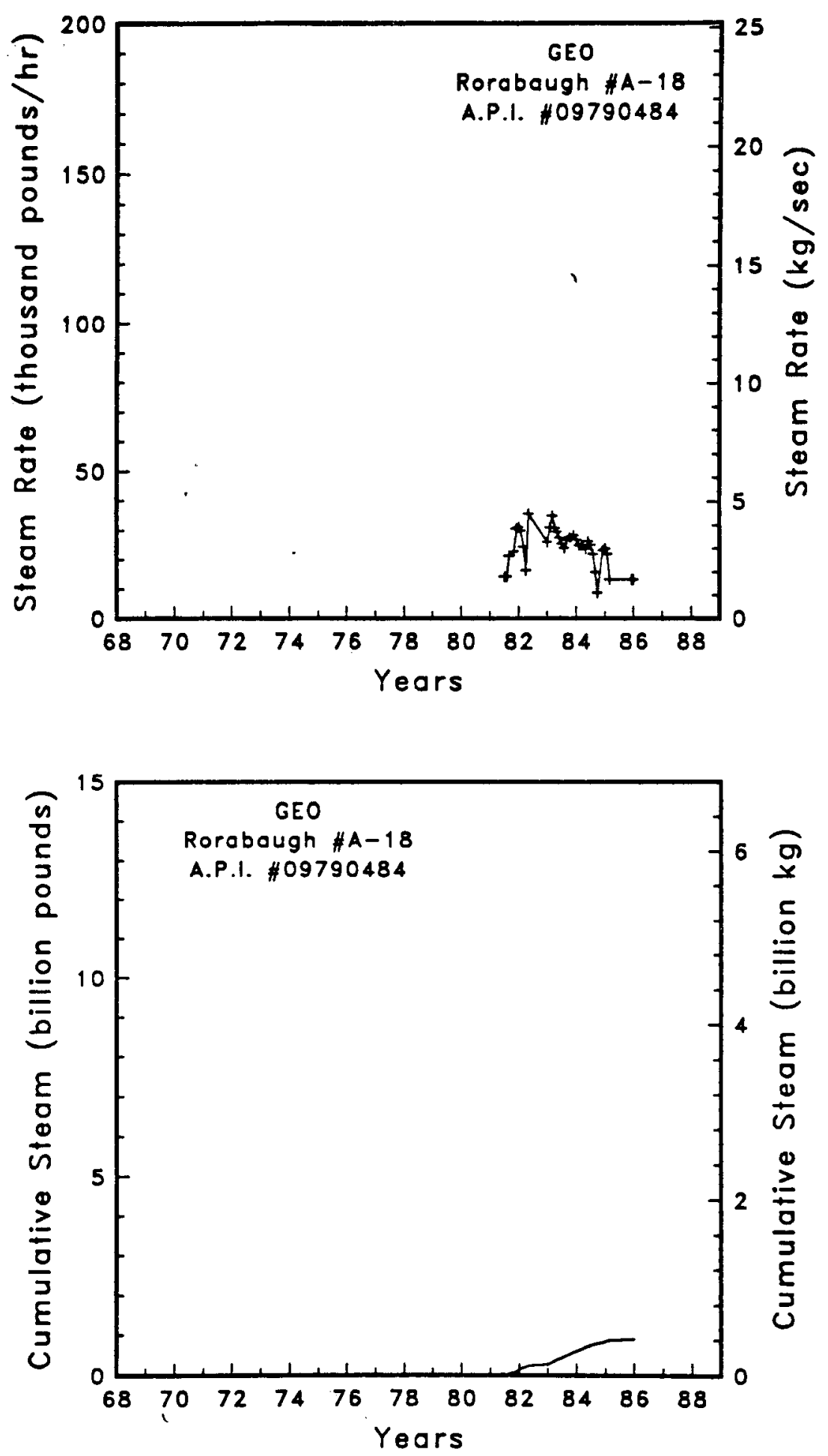

Figure A-196

Steam rate and cumulative mass flow for well Rorabough \#A-18 

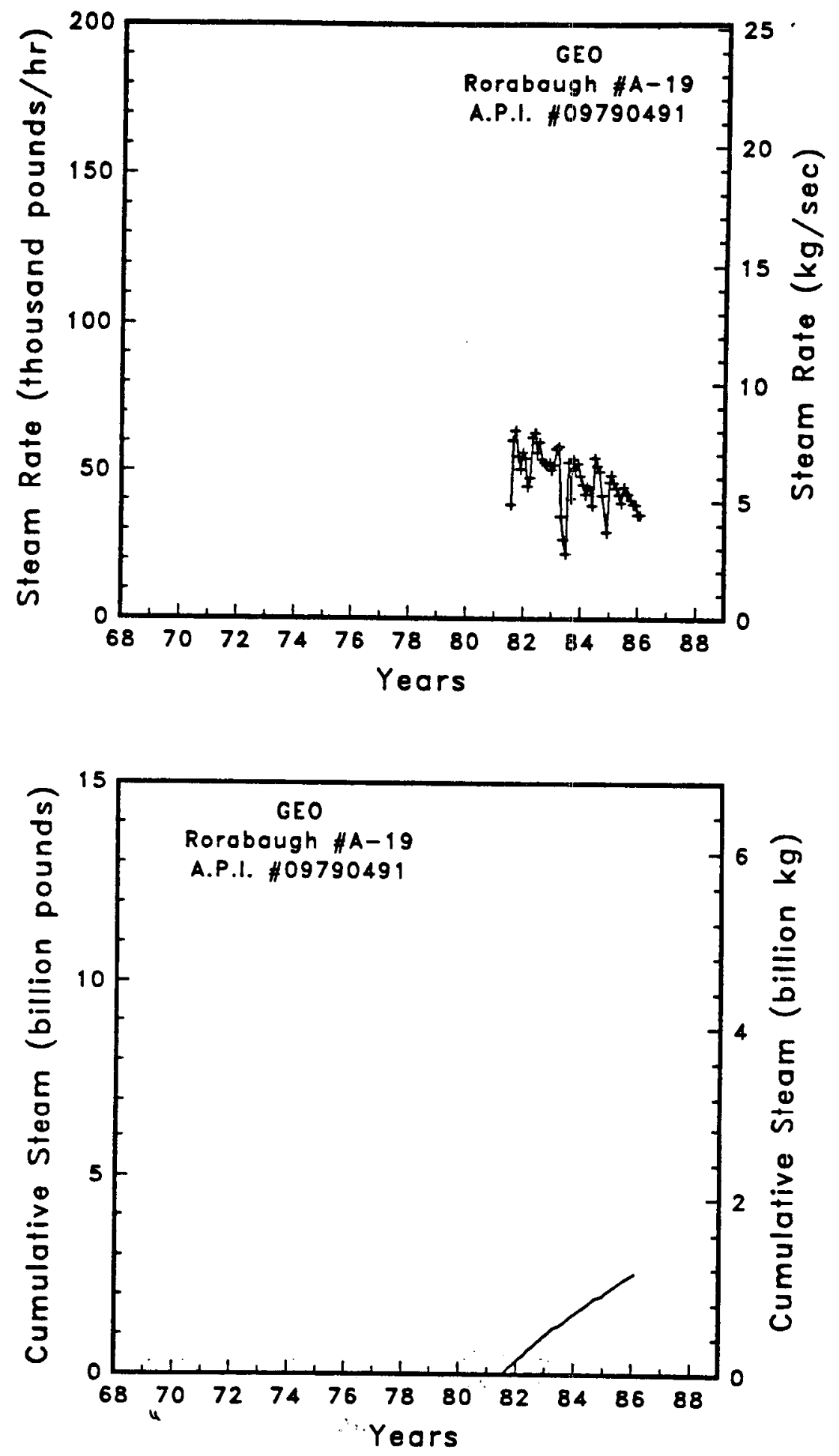

Figure A-197

Steam rate and cumulative mass flow for well Rorabough \#A-19 

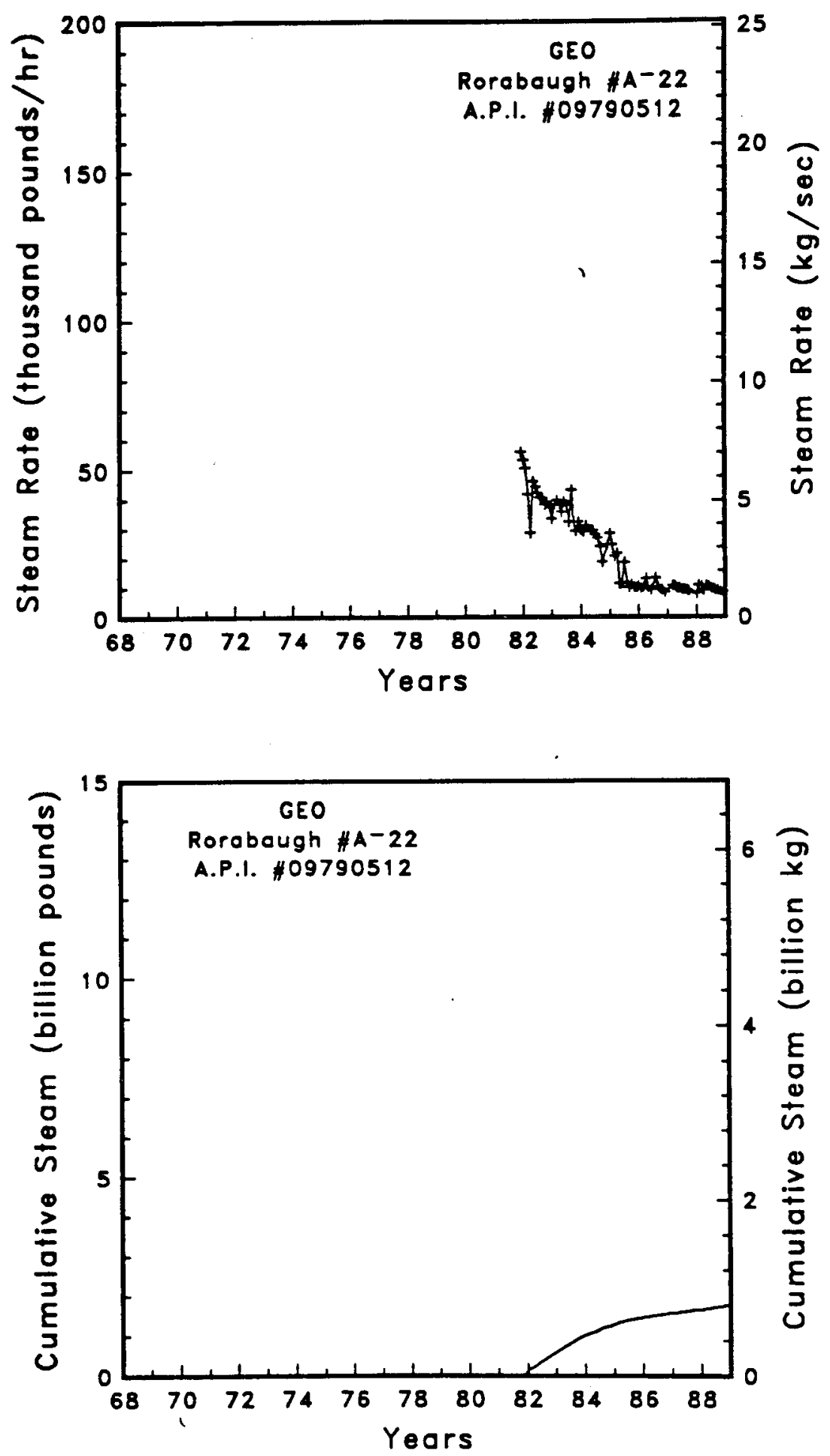

Figure A-198 Steam rate and cumulative mass flow for well Rorabaugh \#A-22 

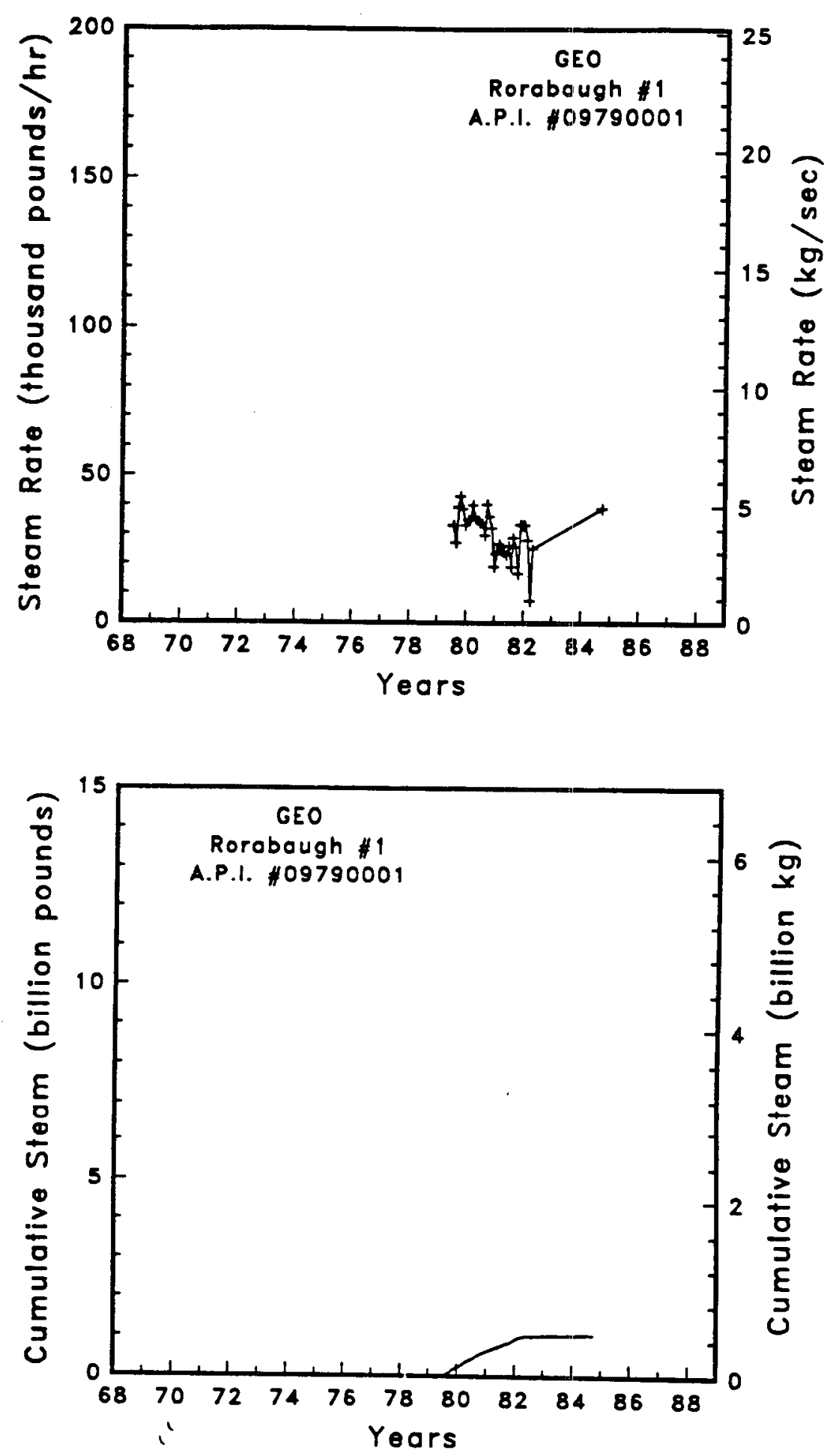

Figure A-199, Steam rate and cumulative mass flow for well Rorabough \#1 

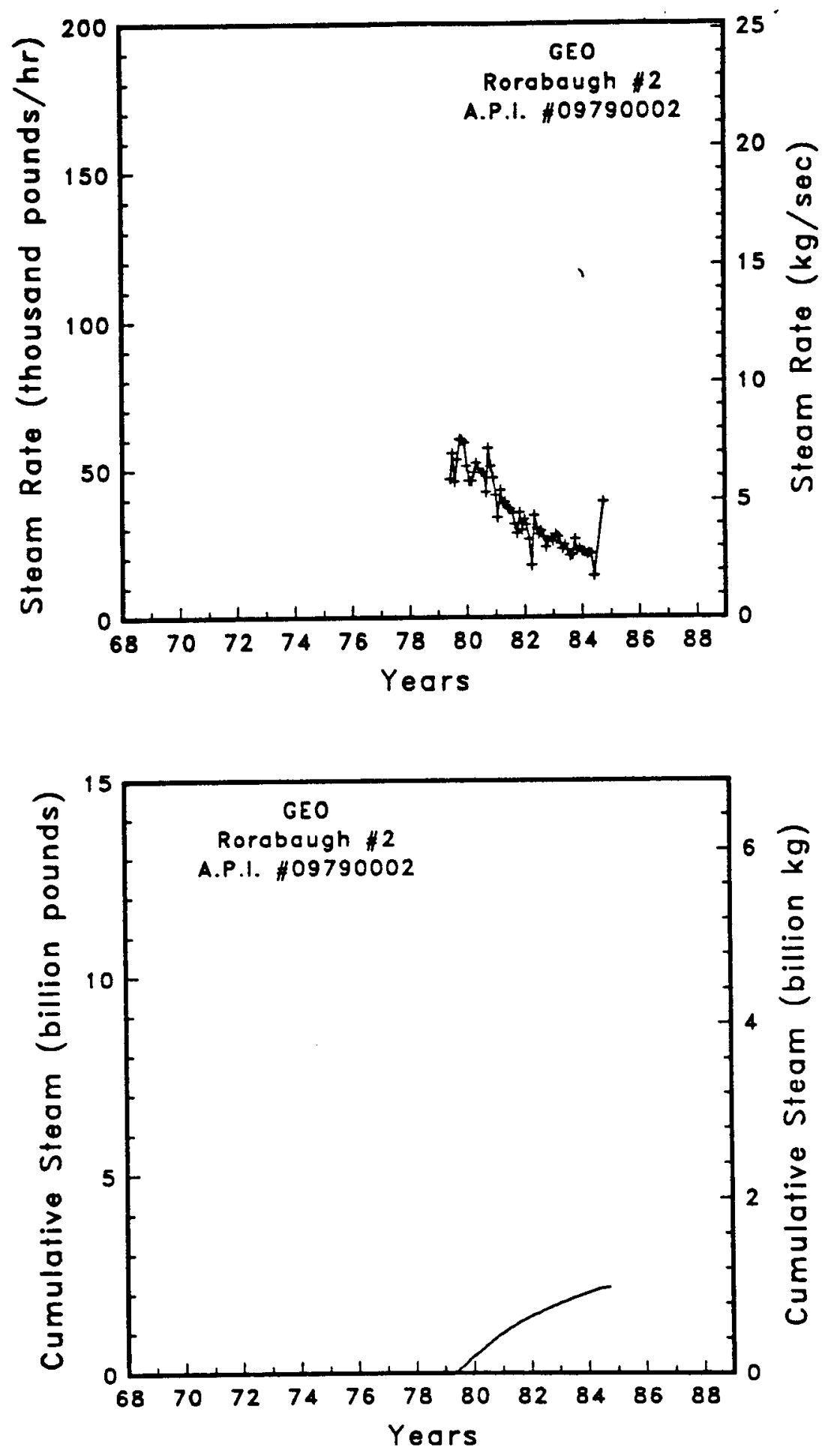

Figure A-200

Steam rate and cumulative mass flow for well Rorabough \#2 

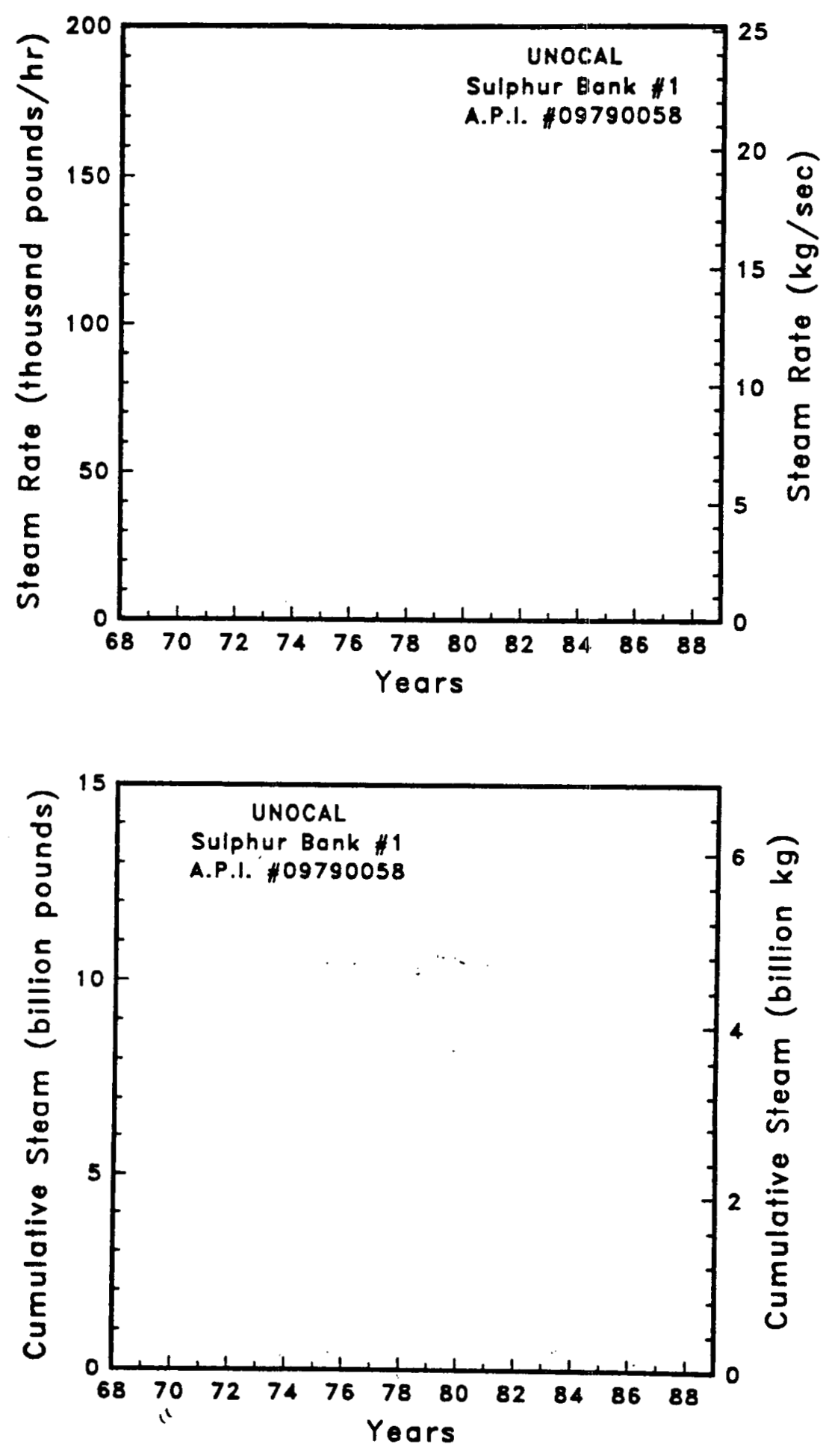

Figure A-201 Steom rate and cumulative mass flow for well Sulphur Bank \#1 

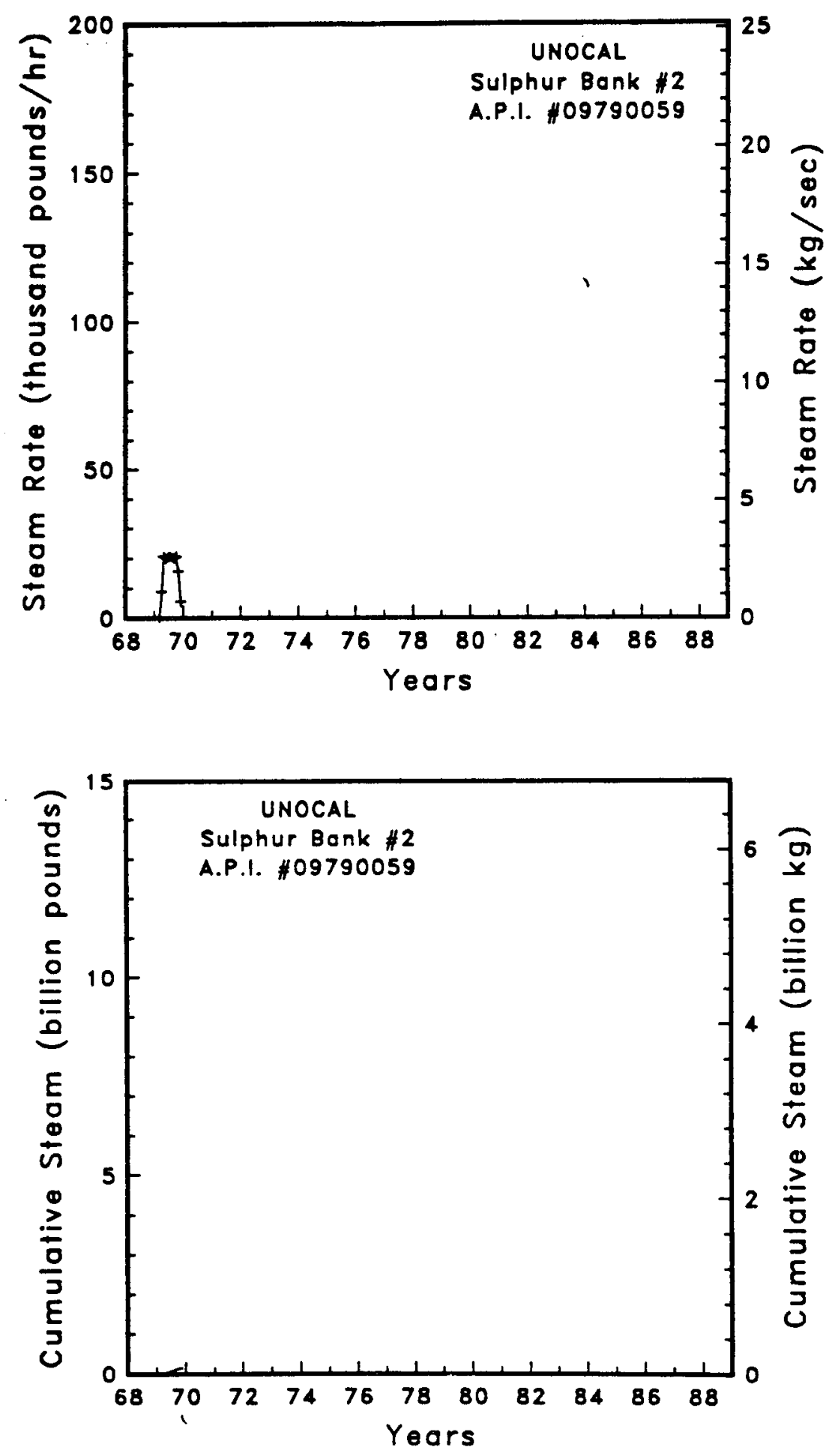

Figure A-202

Steam rate and cumulative mass flow for well Sulphur Bank \#2 

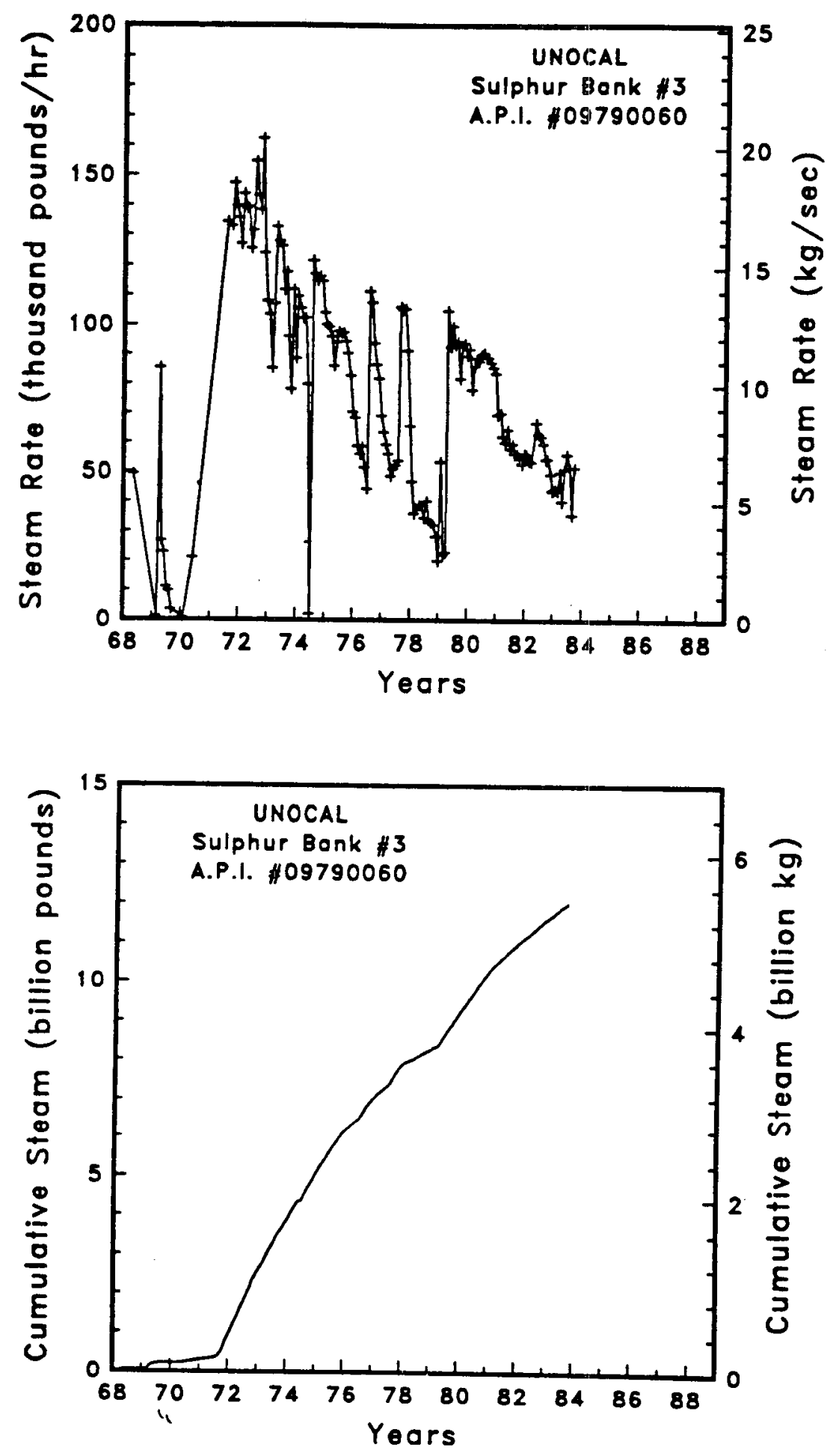

Figure A-203 . Steom rate and cumulative mass flow for well Sulphur Bank \#3 

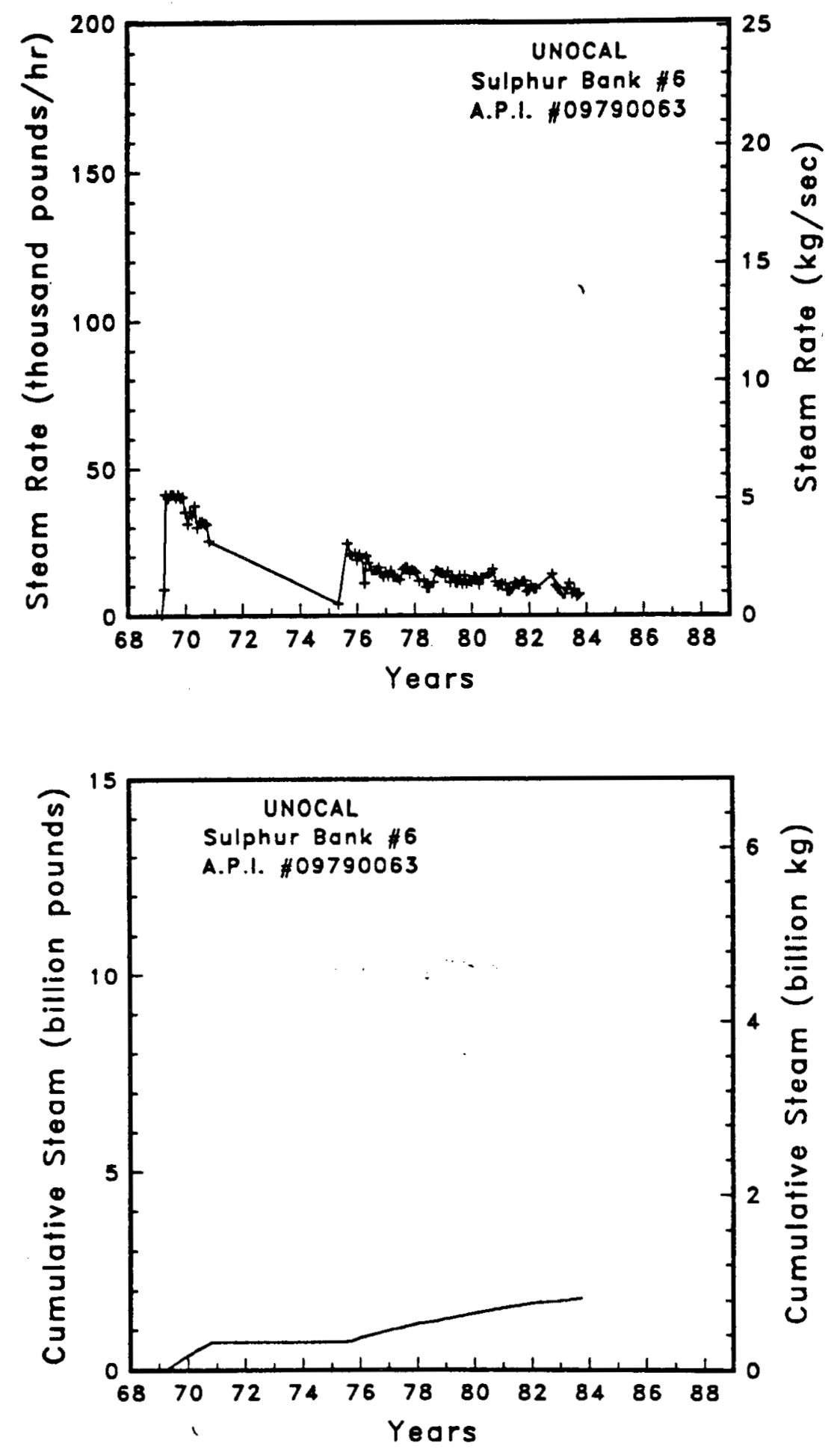

Figure A-204

Steam rate and cumulative mass flow for well Sulphur Bank \#6 

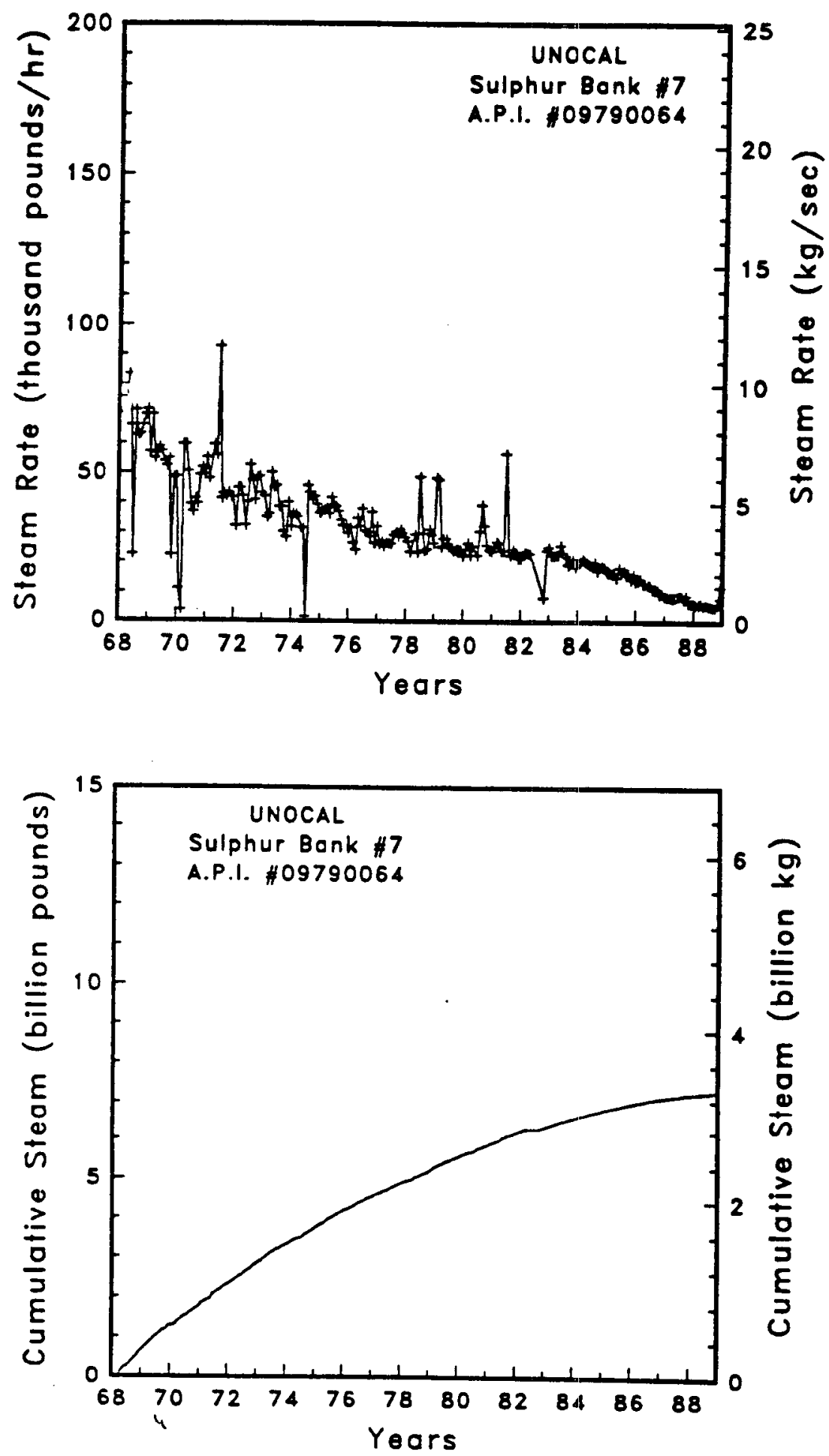

Figure A-205

Steam rate and cumulative mass flow for well Sulphur Bank \#7 

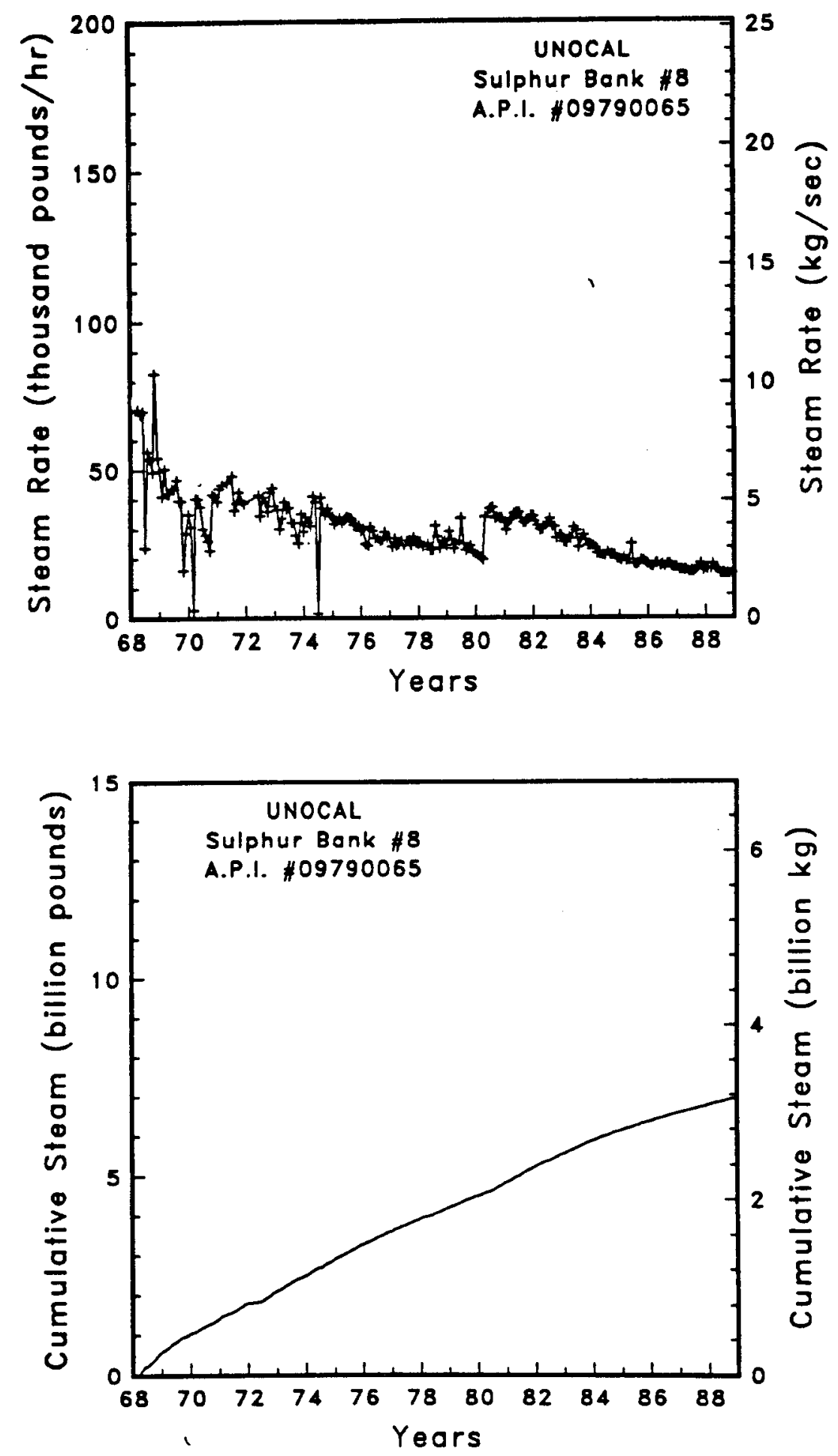

Figure A-206 Steam rate and cumulative mass flow for well Sulphur Bank \#8 

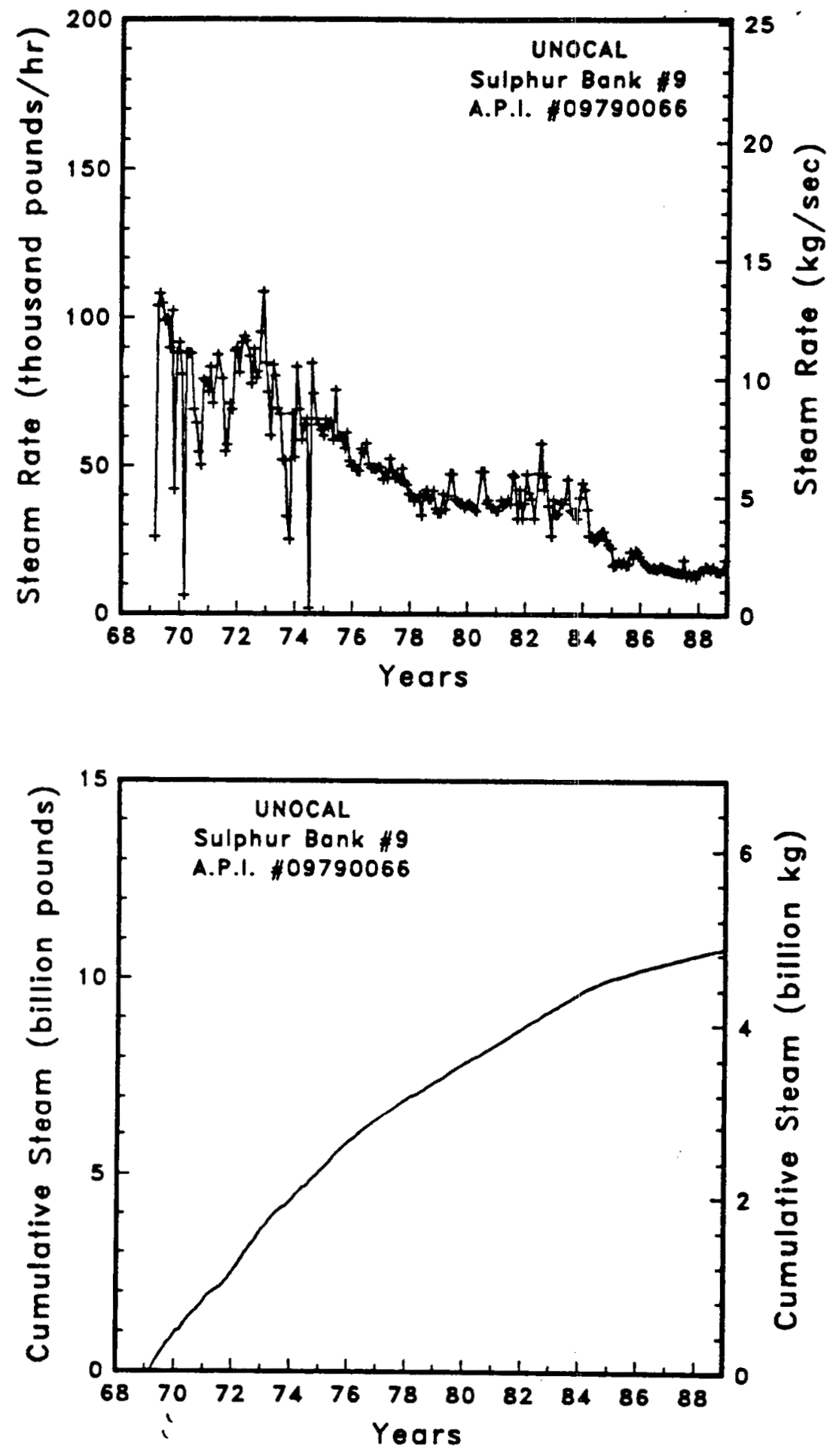

Figure A-207 Steam rate and cumulative mass flow for well Sulphur Bank \#9 

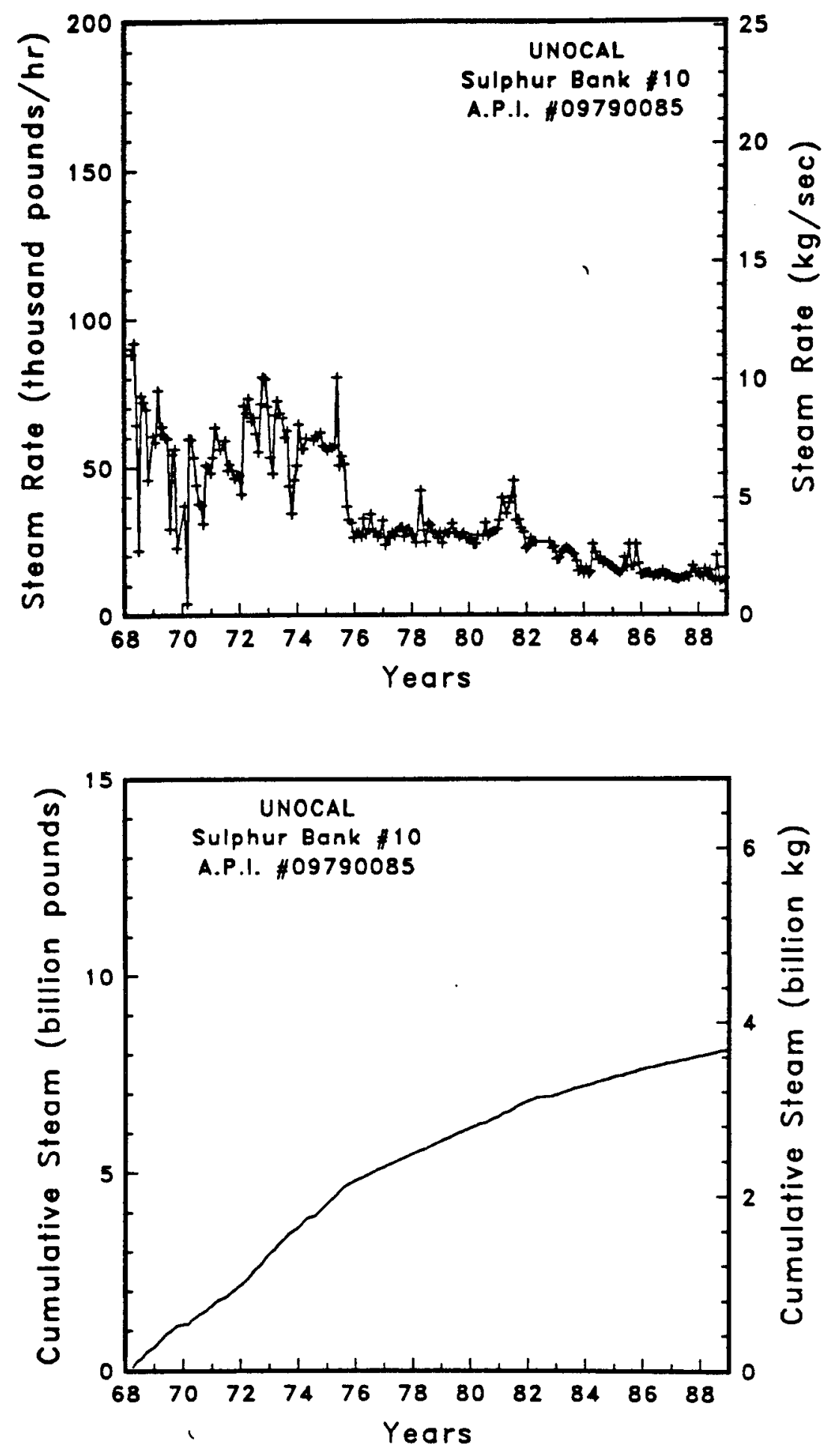

Figure A-208 Steam rate and cumulative mass flow for well Sulphur Bank \#10 

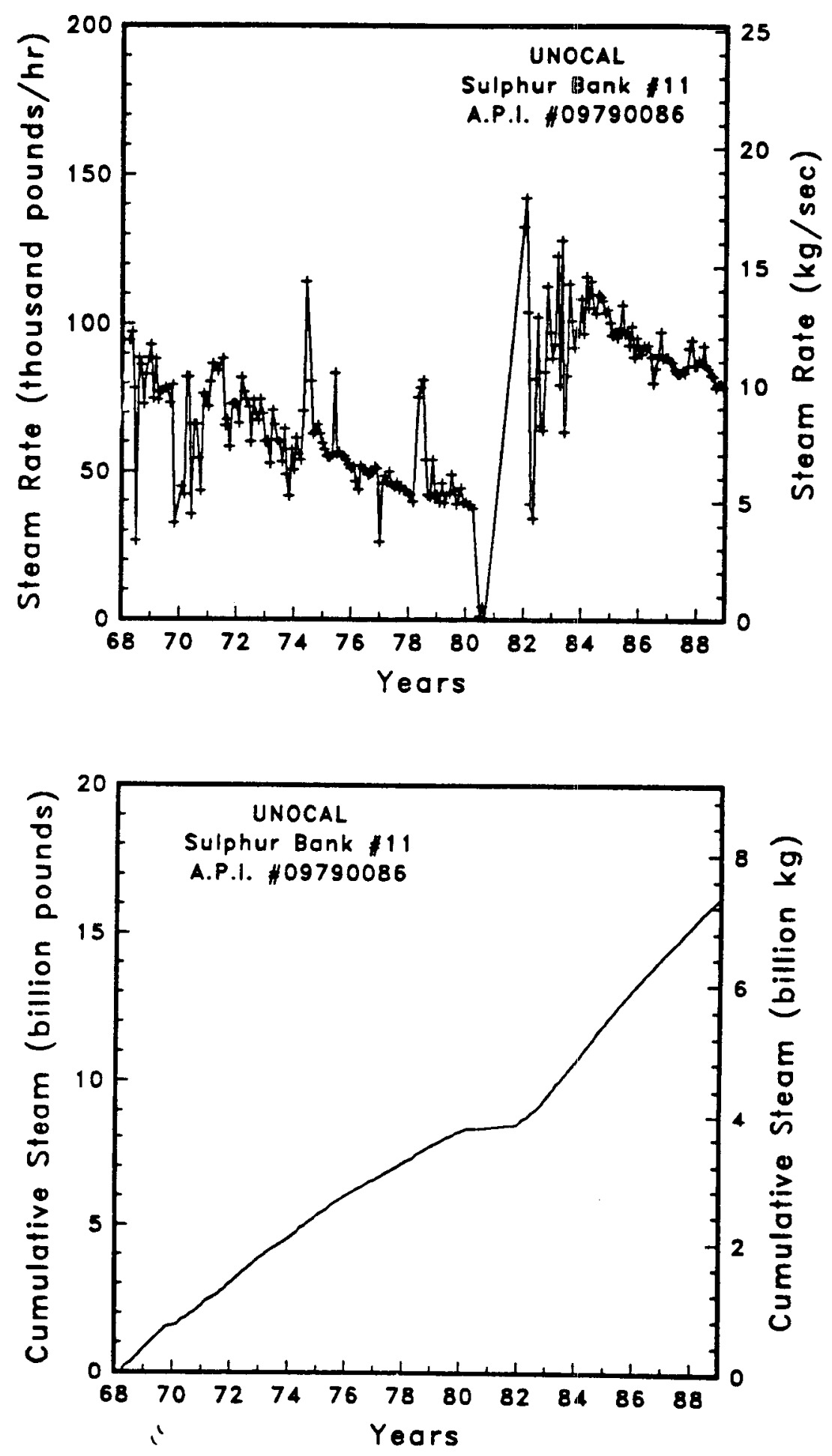

Figure A-209 Steam rate and cumulative mass flow for well Sulphur Bank \#11 

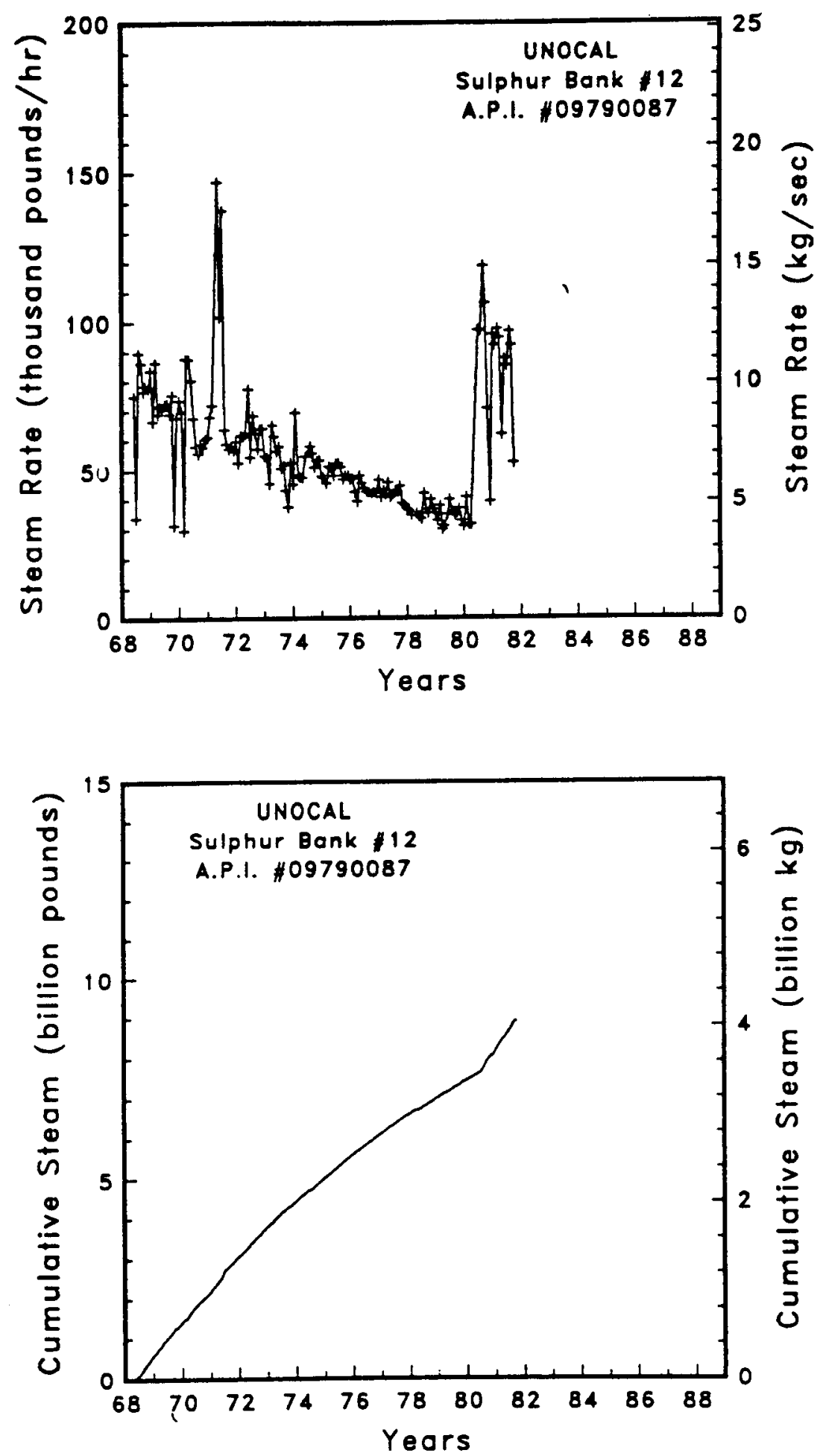

Figure A-210

Steam rate and cumulative mass flow for well Sulphur Bonk \#12 

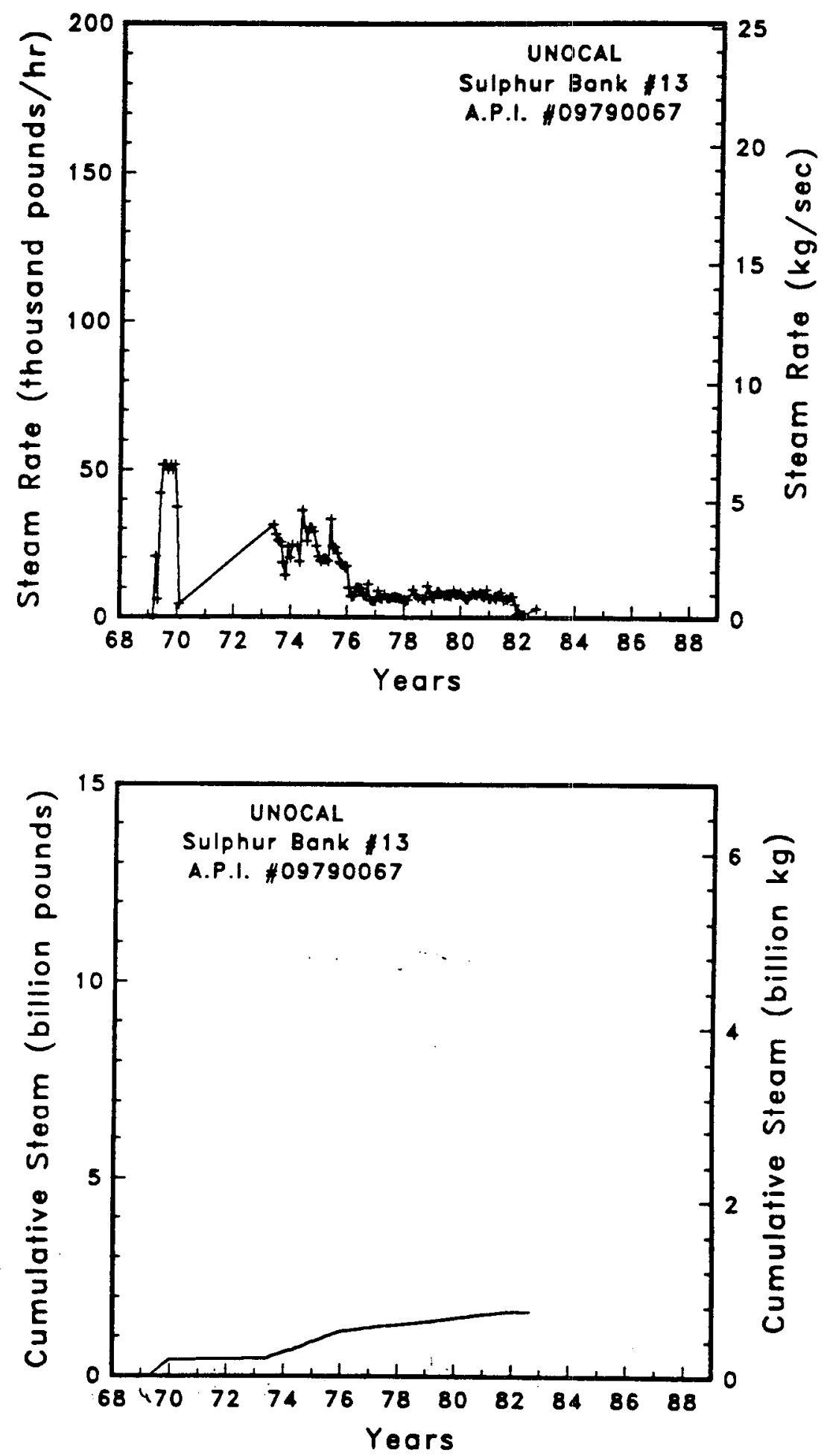

Figure A-211 Steam rate and cumulative mass flow for well Sulphur Bonk \#13 

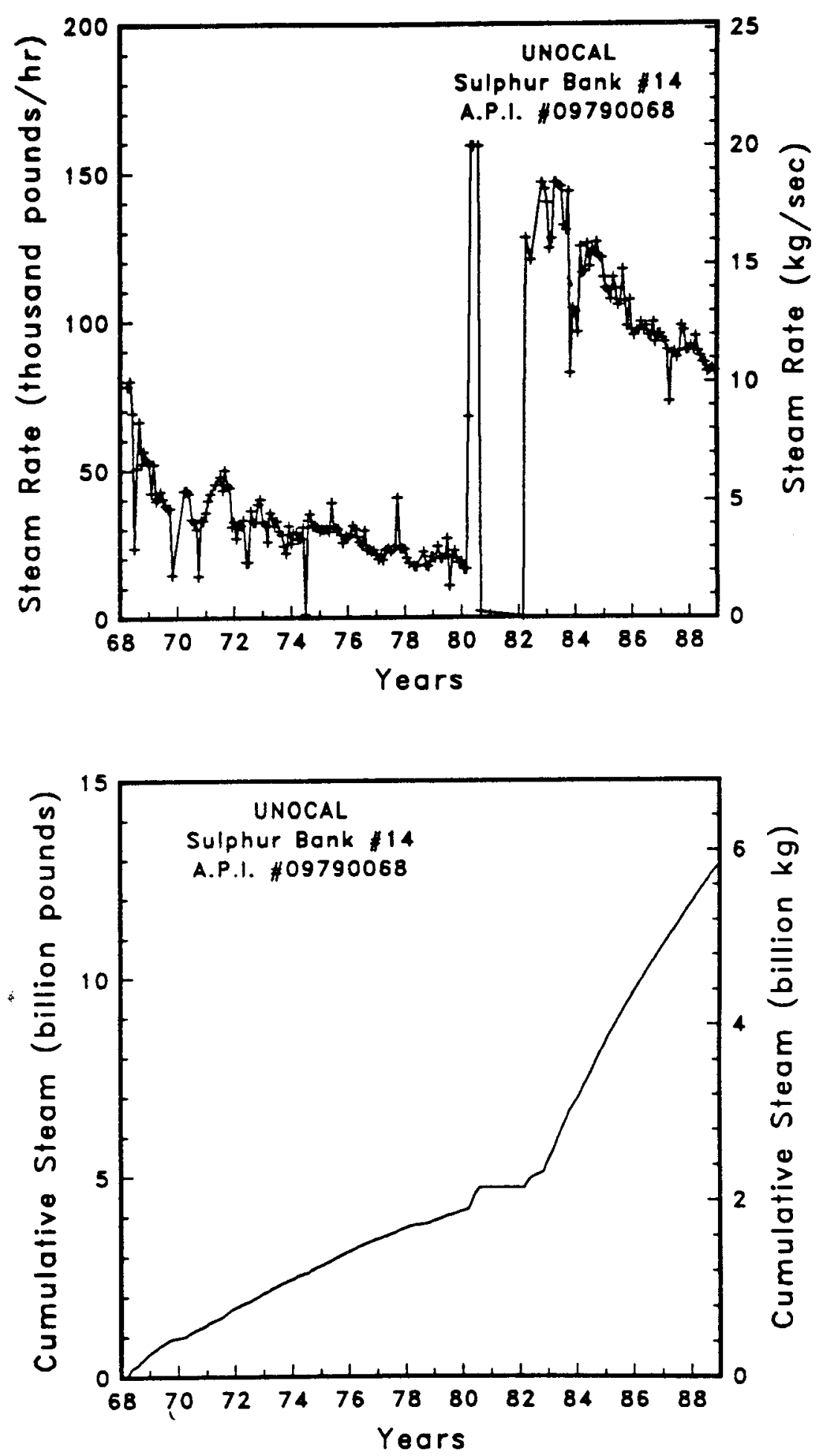

Figure A-212 Steam rate and cumulative mass flow for well Sulphur Bank \#14 

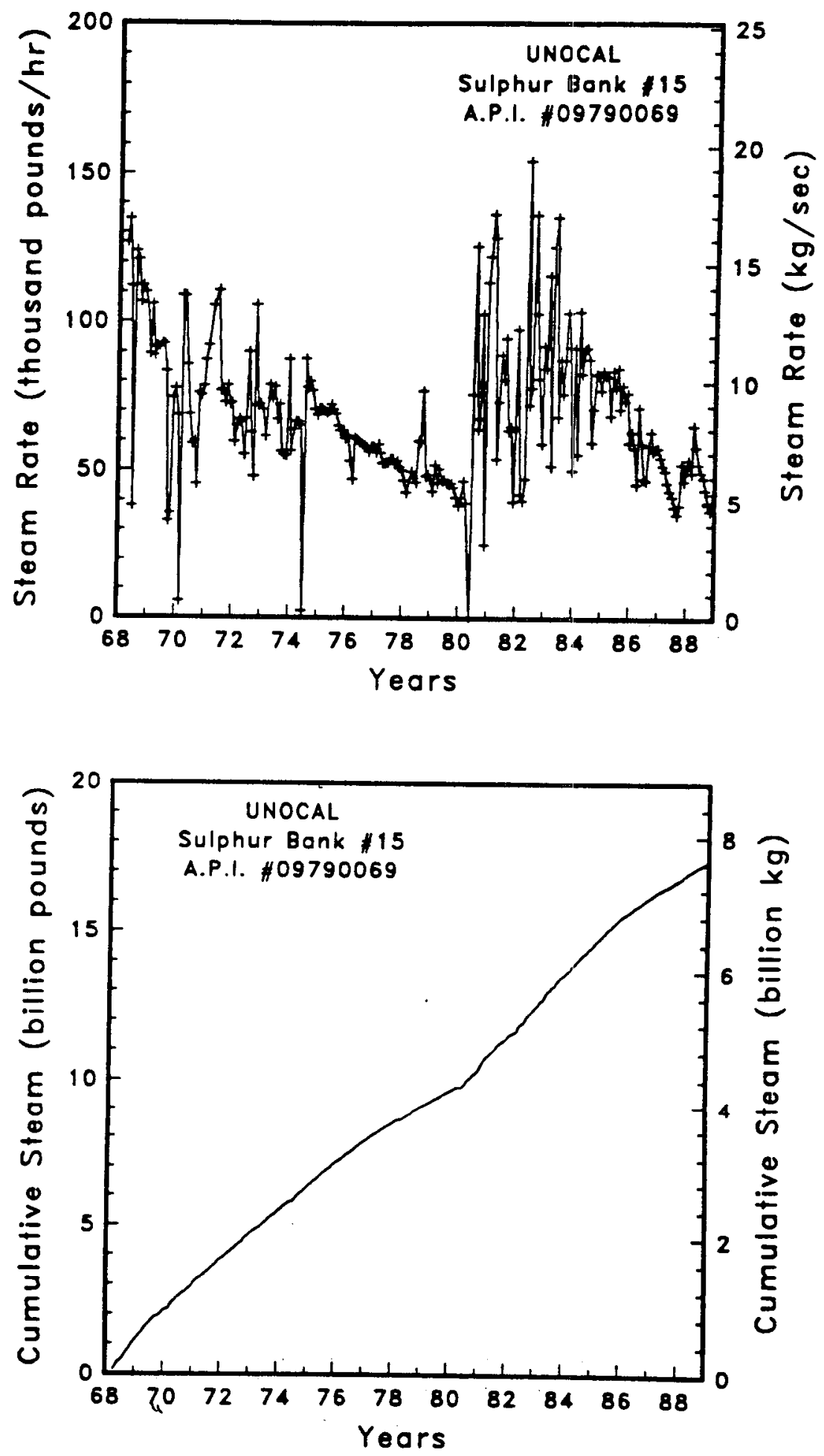

Figure A-213 Steam rate and cumulative mass flow for well Sulphur Bank \#15 

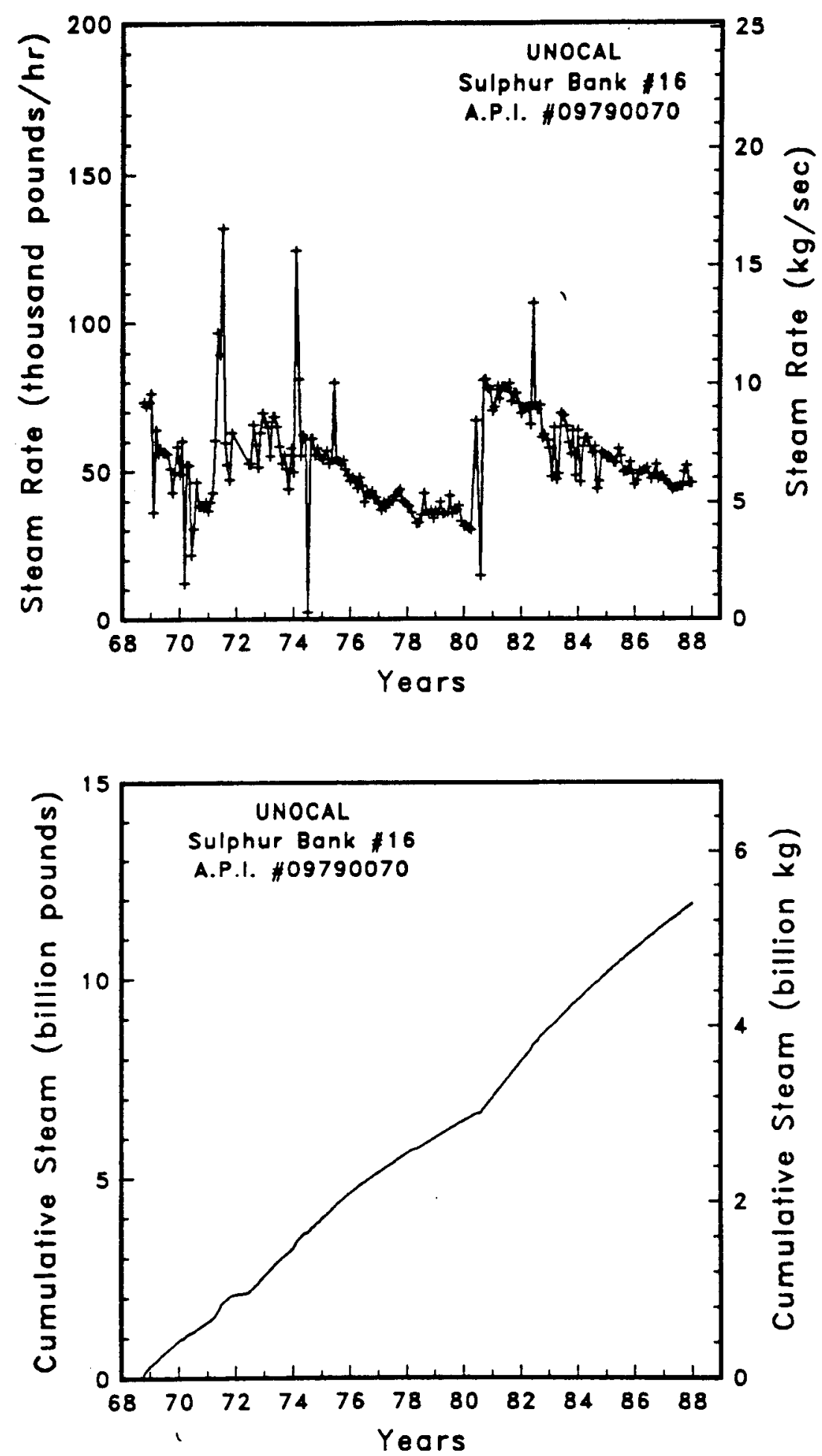

Figure A-214 Steam rate and cumulative mass flow for well Sulphur Bank \#16 

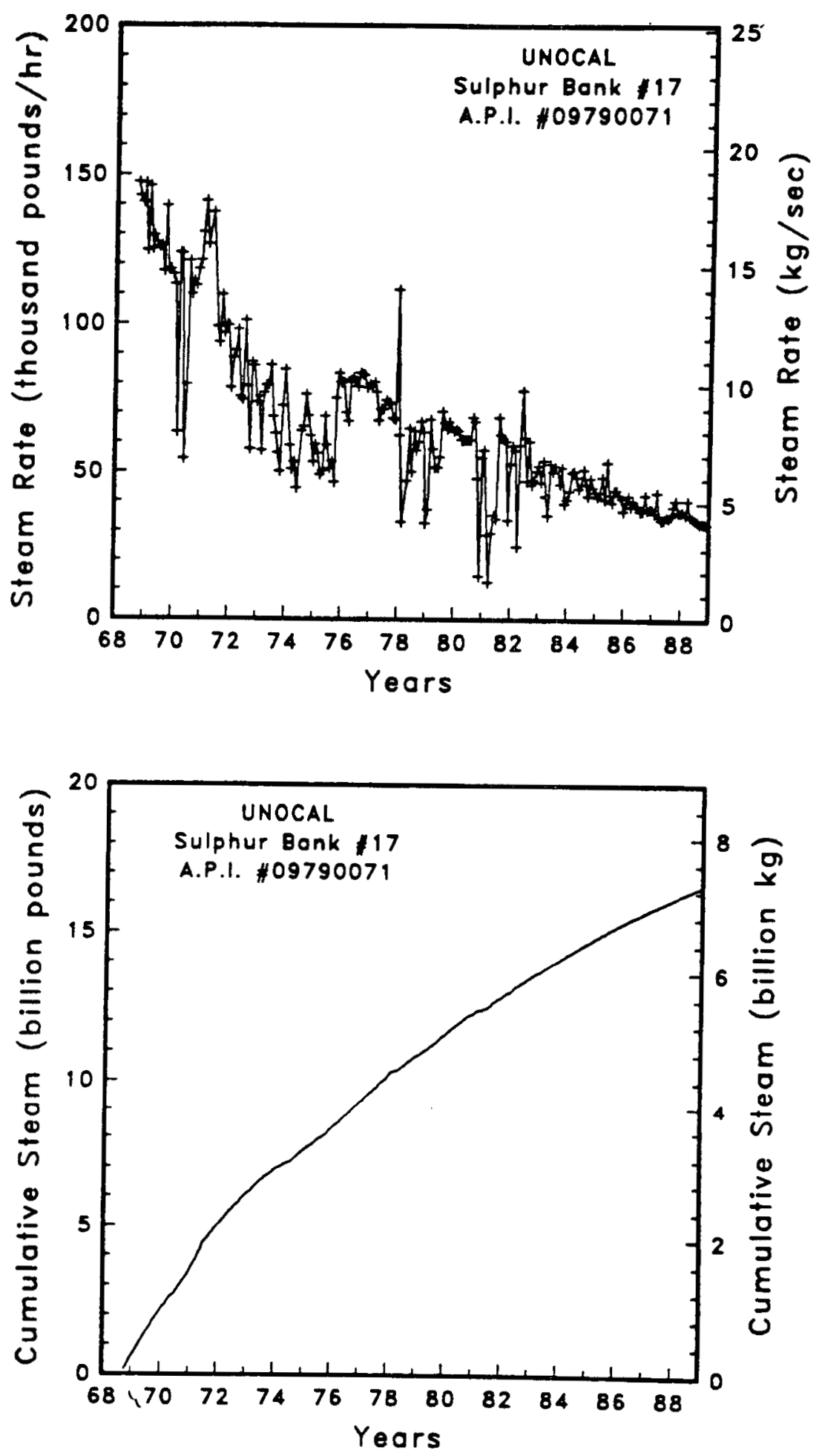

Figure A-215 Steom rate and cumulative mass flow for well Sulphur Bank \#17 

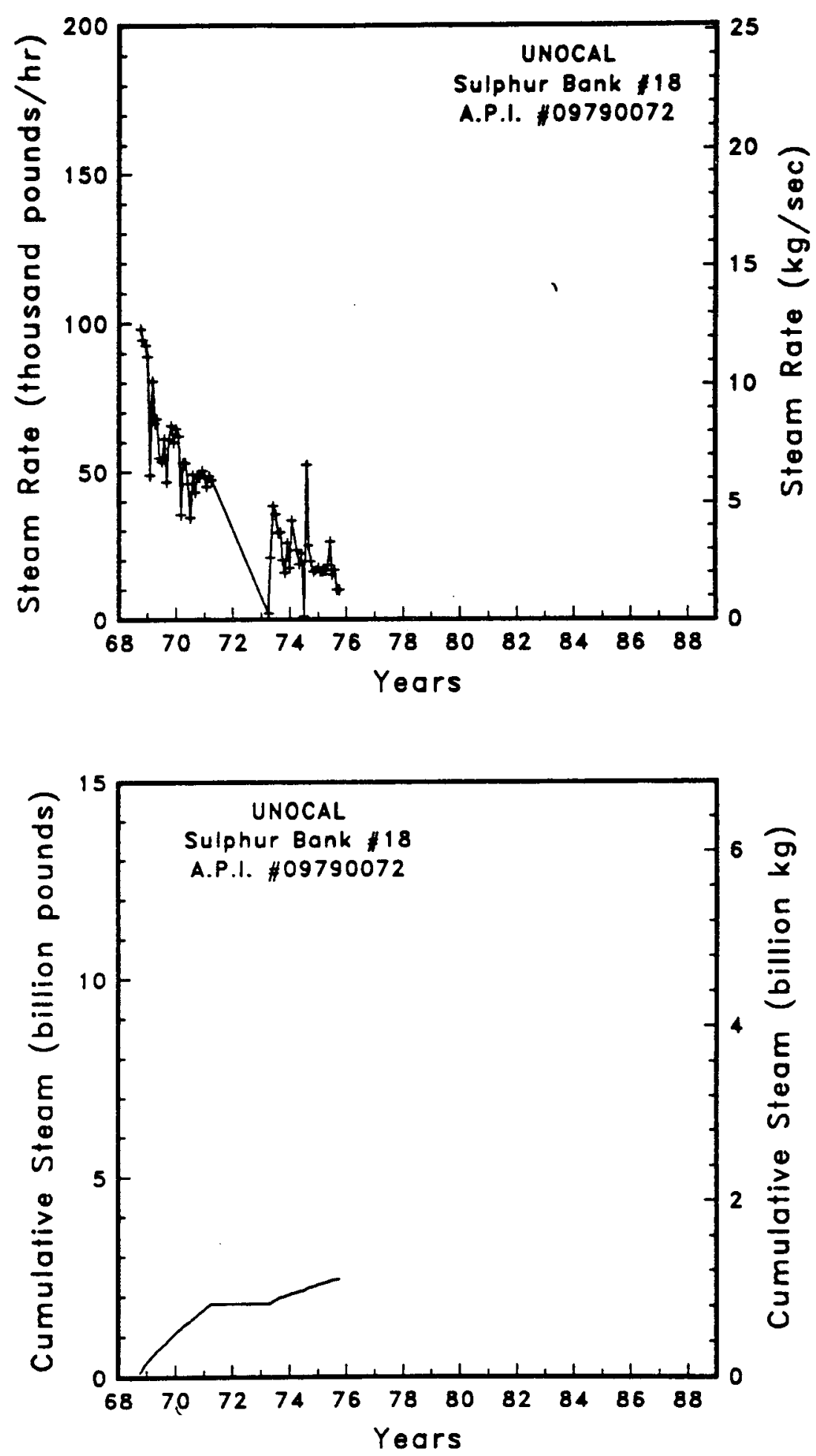

Figure A-216

Steam rate and cumulative mass flow for well Sulphur Bank \#18 

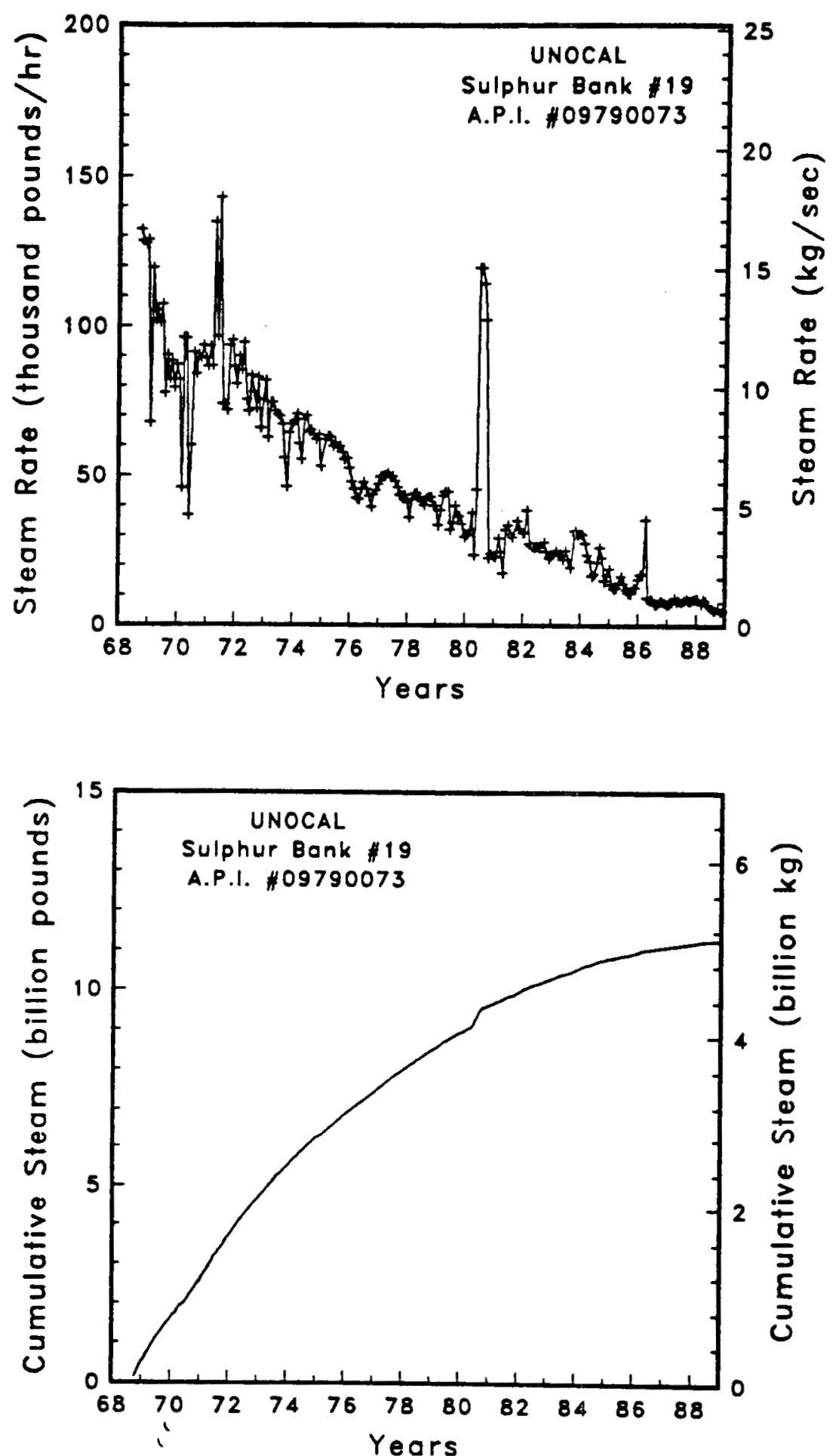

Figure A-217

Steom rate and cumulative mass flow for well Sulphur Bank \#19 

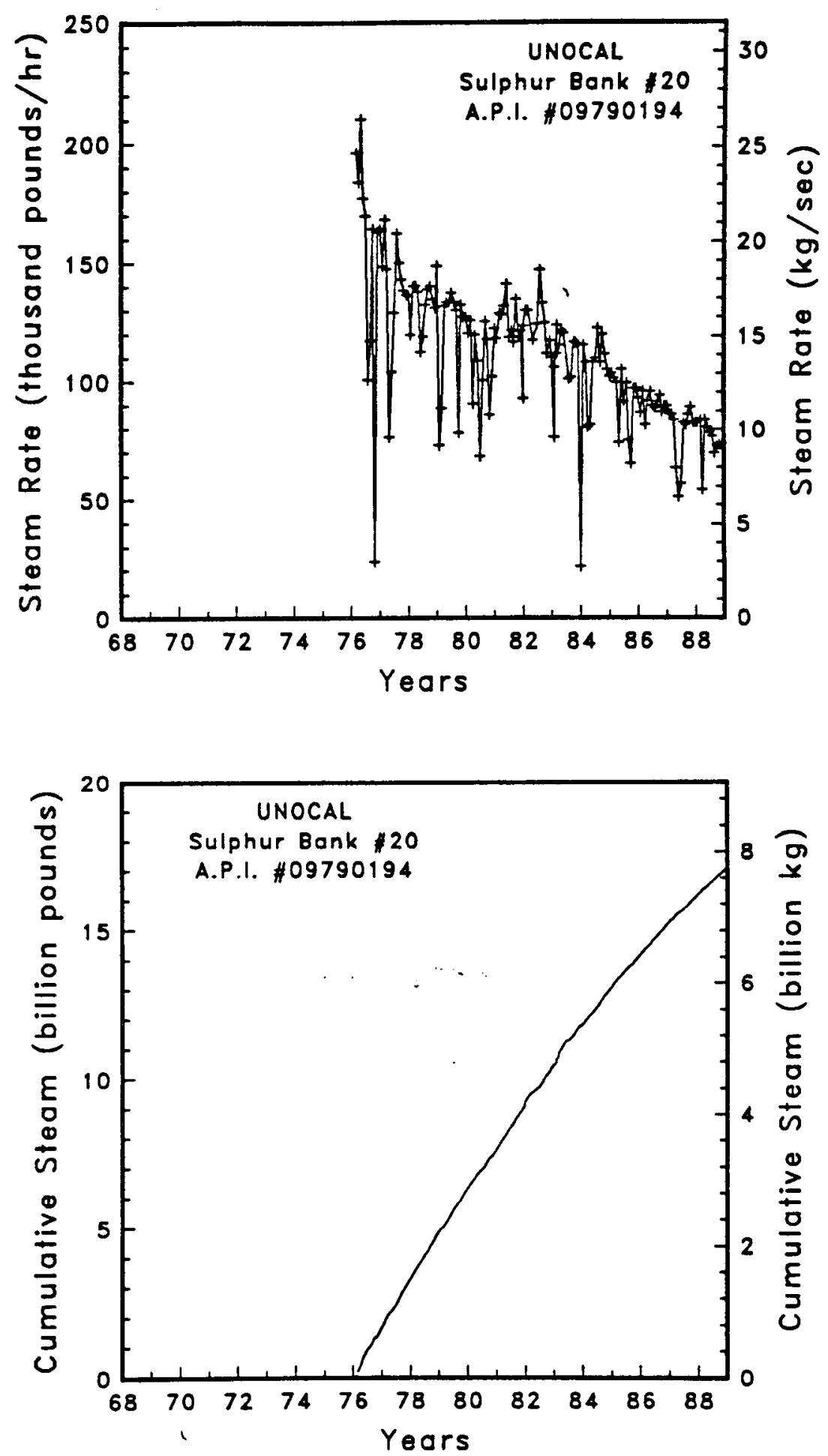

$\begin{array}{ll}\text { Figure A-218 } & \begin{array}{l}\text { Steam rate and cumulative mass flow for } \\ \text { well Sulphur Bank } \# 20\end{array}\end{array}$ 

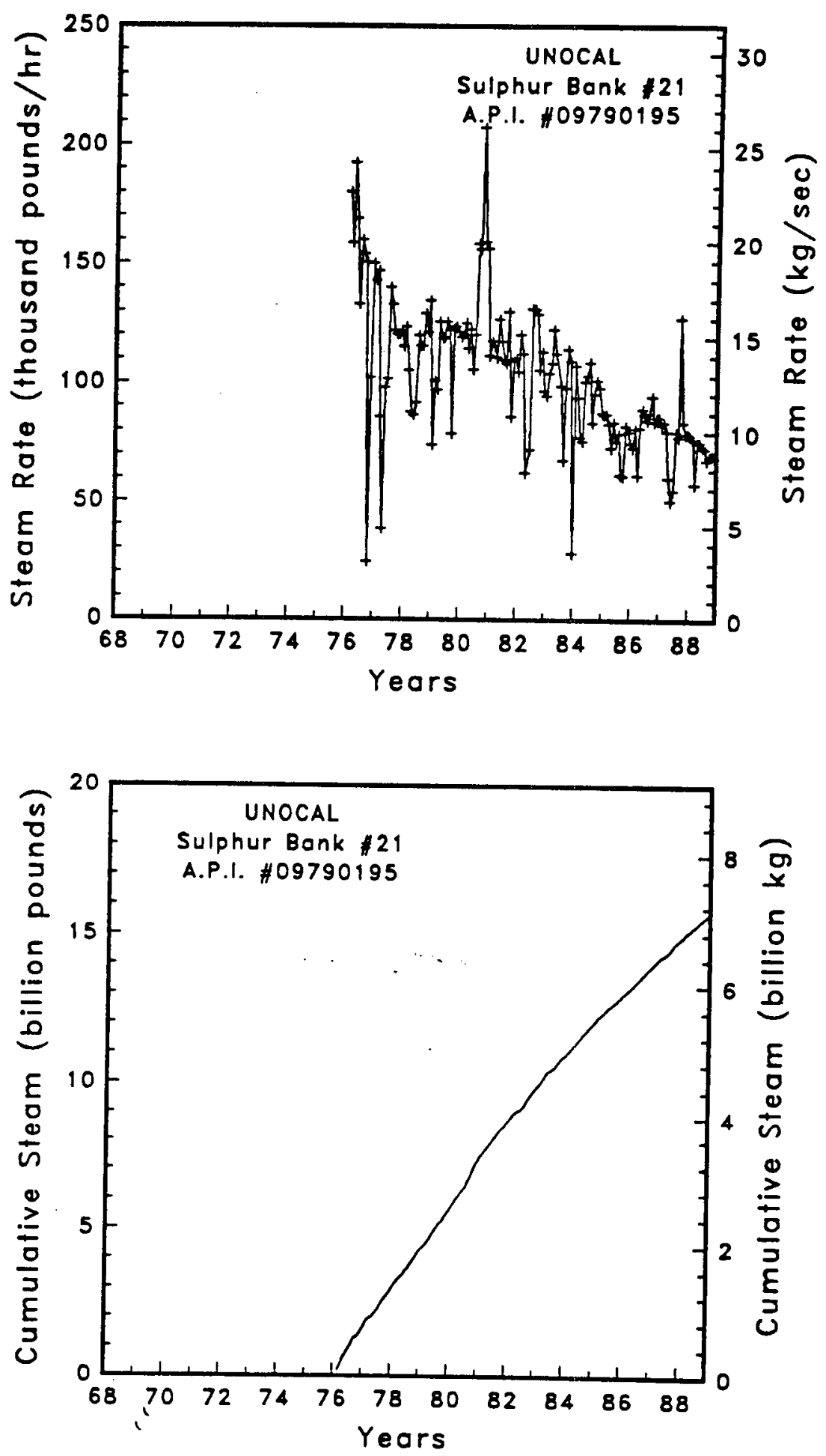

Figure A-219 Steam rate and cumulative mass flow for 

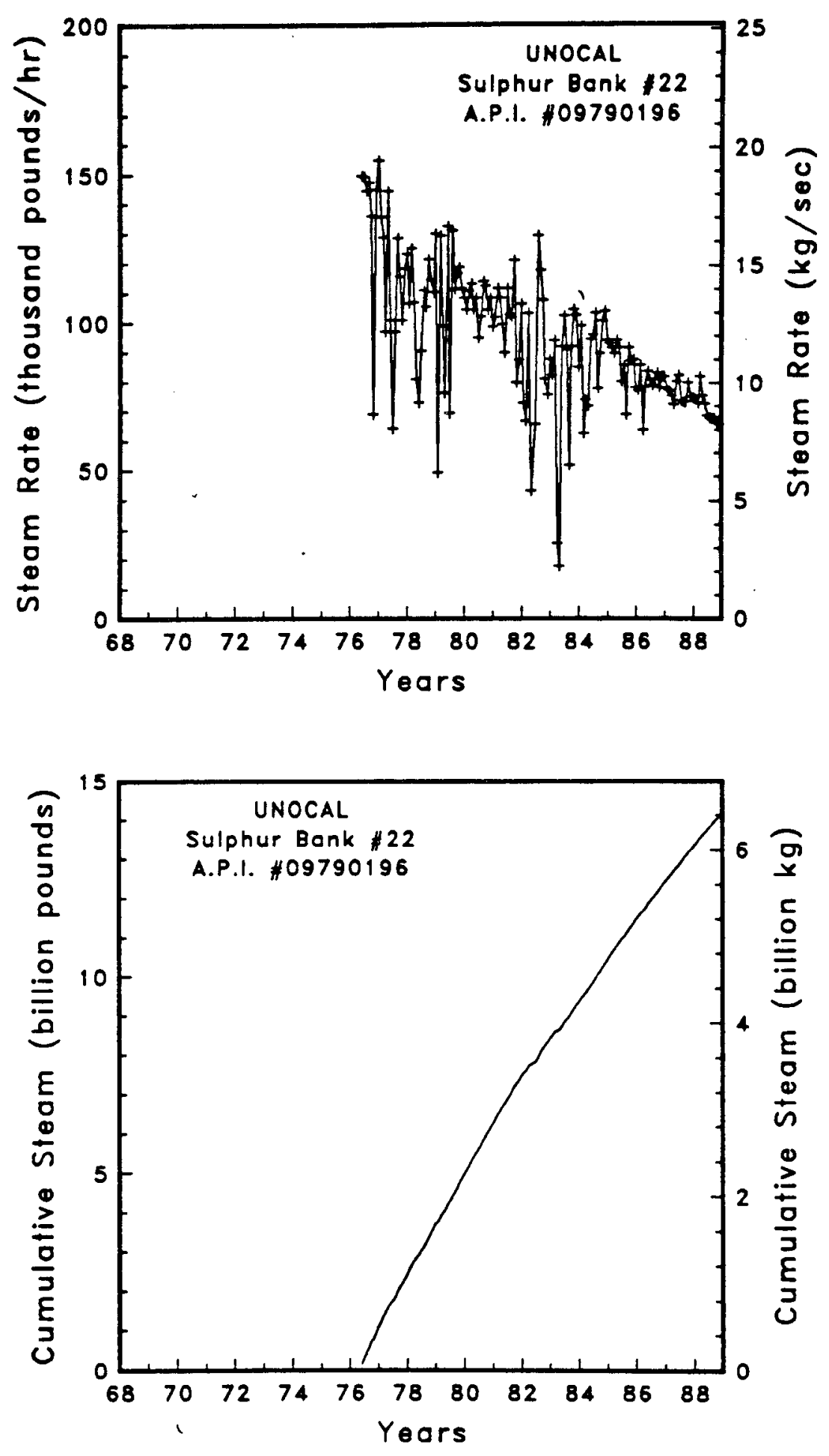

Figure A-220 Steam rate and cumulative mass flow for well Sulphur Bank \#22 

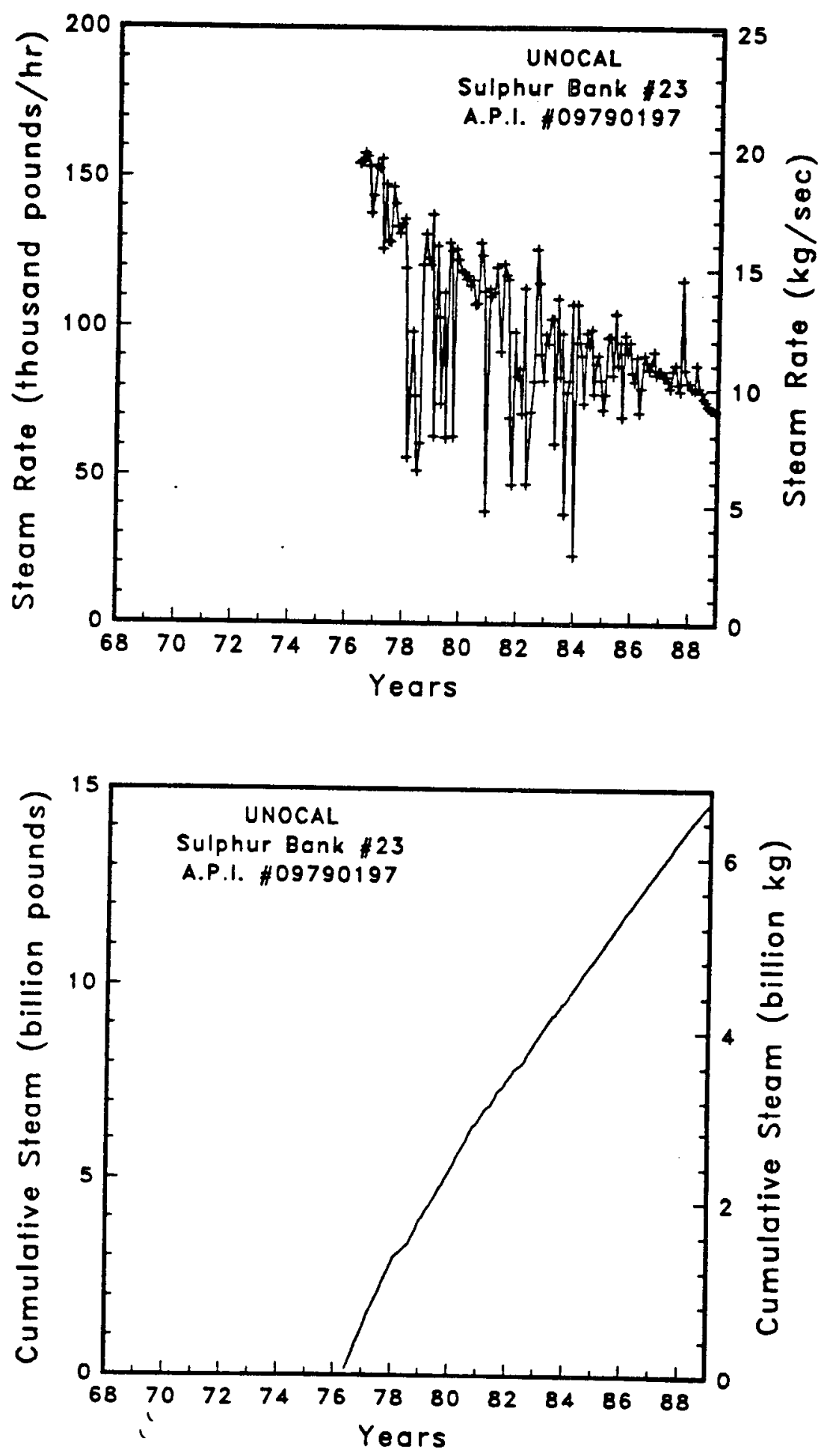

Figure A-221 Steam rate and cumulative mass flow for well Sulphur Bank \#23 

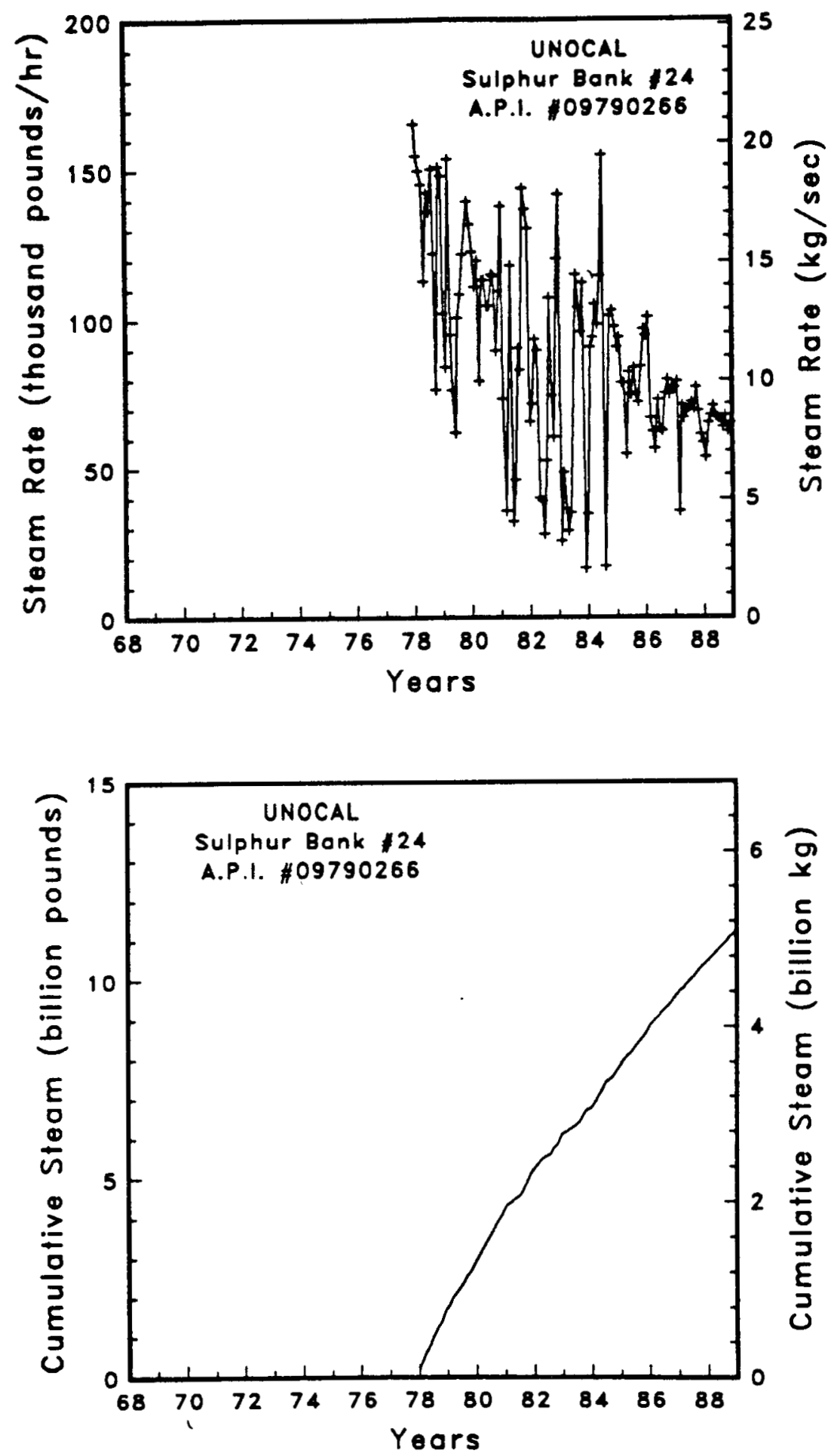

Figure A-222 Steam rate and cumulative mass flow for well Sulphur Bonk \#24 

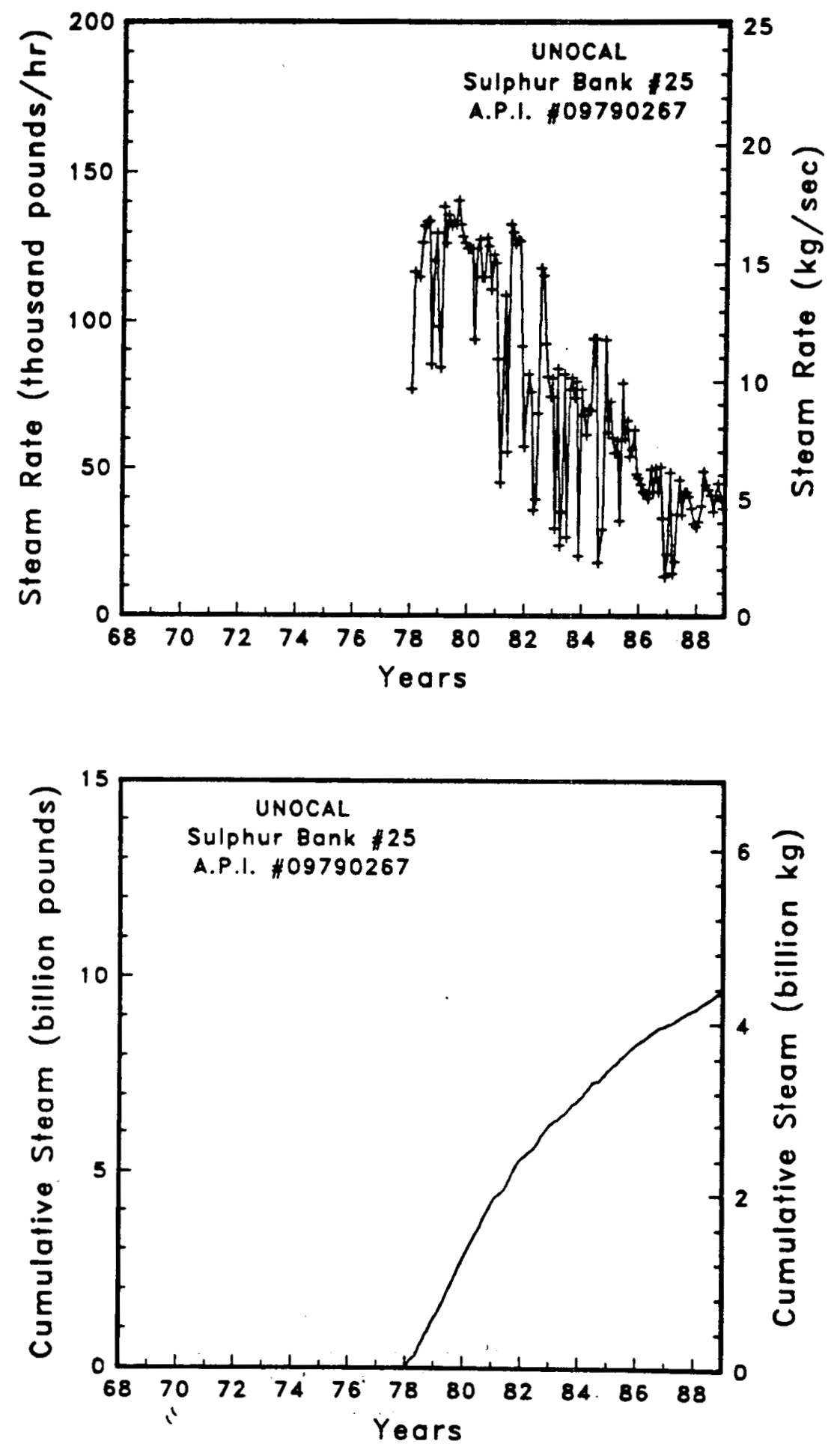

Figure A-223

Steam rate and cumulative mass flow for well Sulphur Bank \#25 

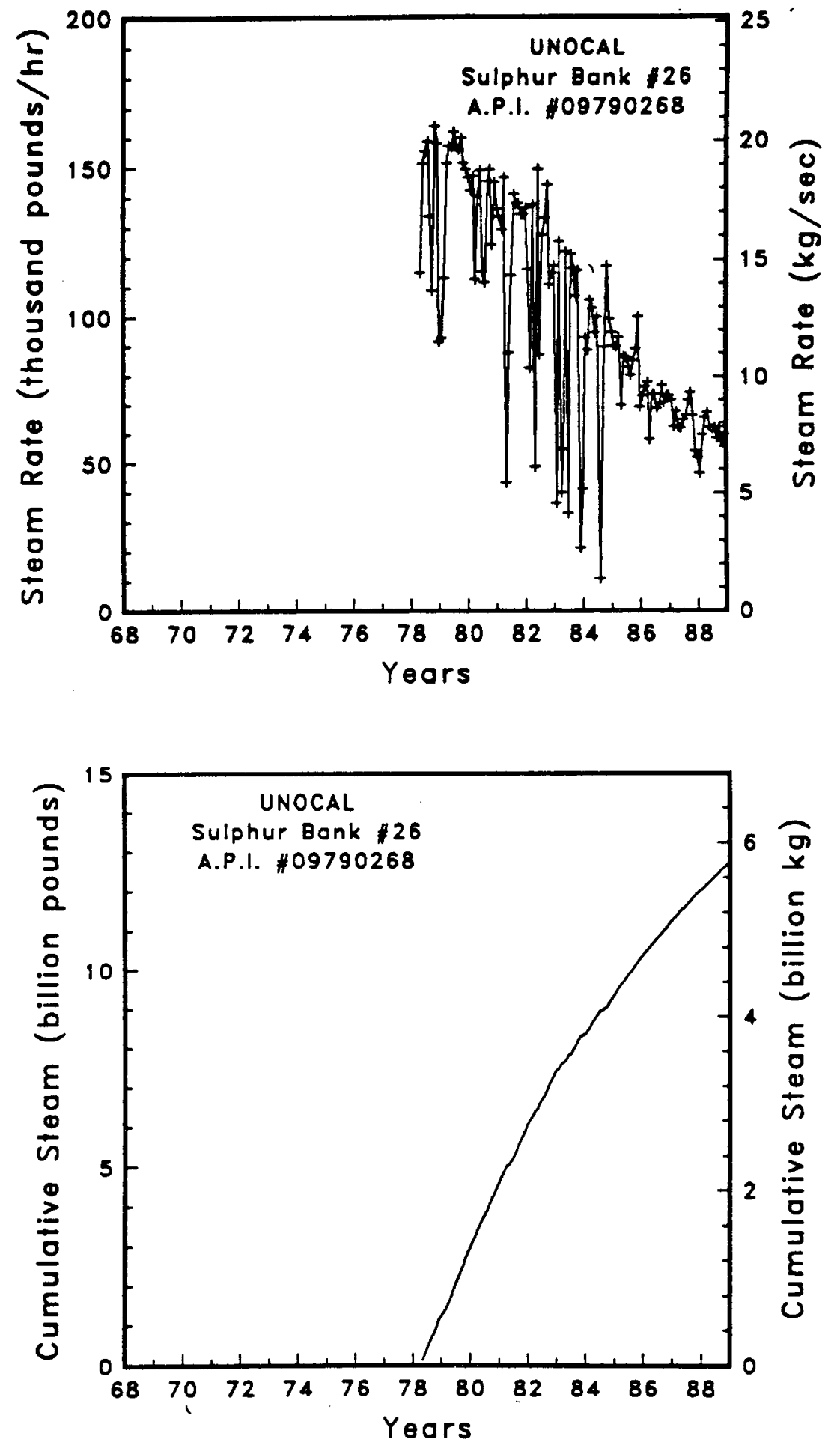

Figure A-224

Steam rate and cumulative mass flow for well Sulphur Bonk \#26 

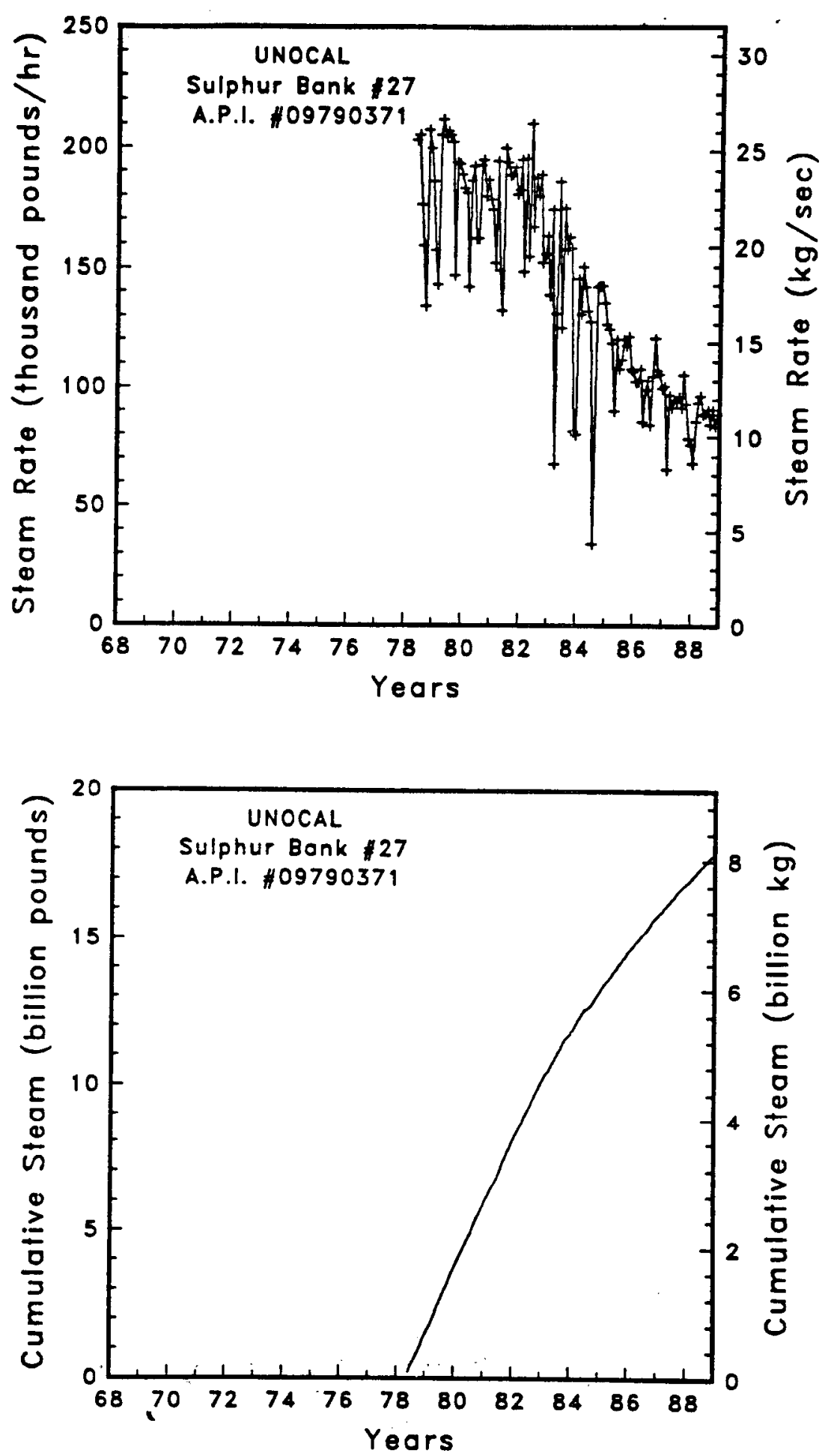

Figure A-225

Steam rate and cumulative mass flow for well Sulphur Bank \#27 

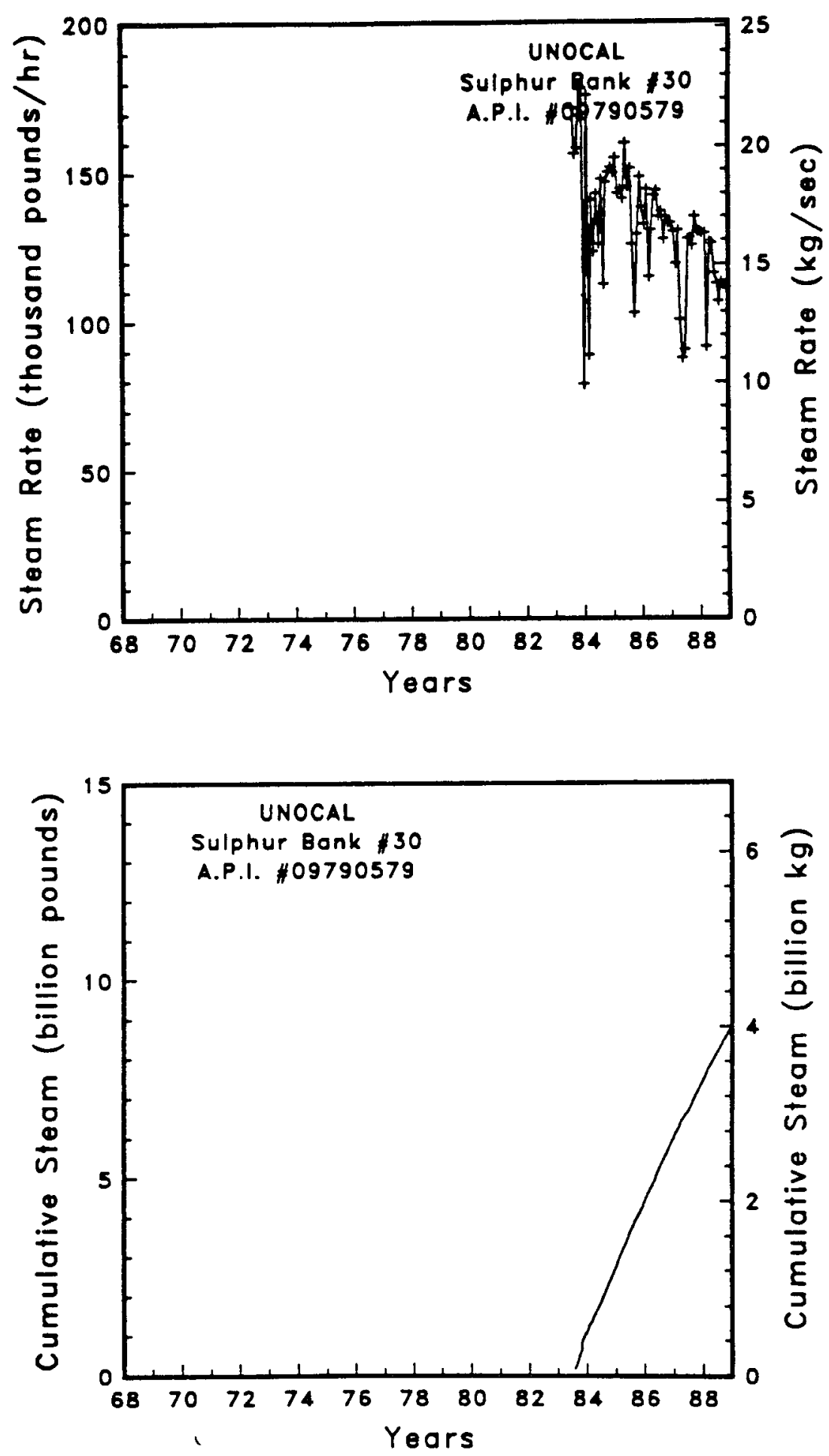

Figure A-226

Steam rate and cumulative mass flow for well Sulphur Bank \#30 

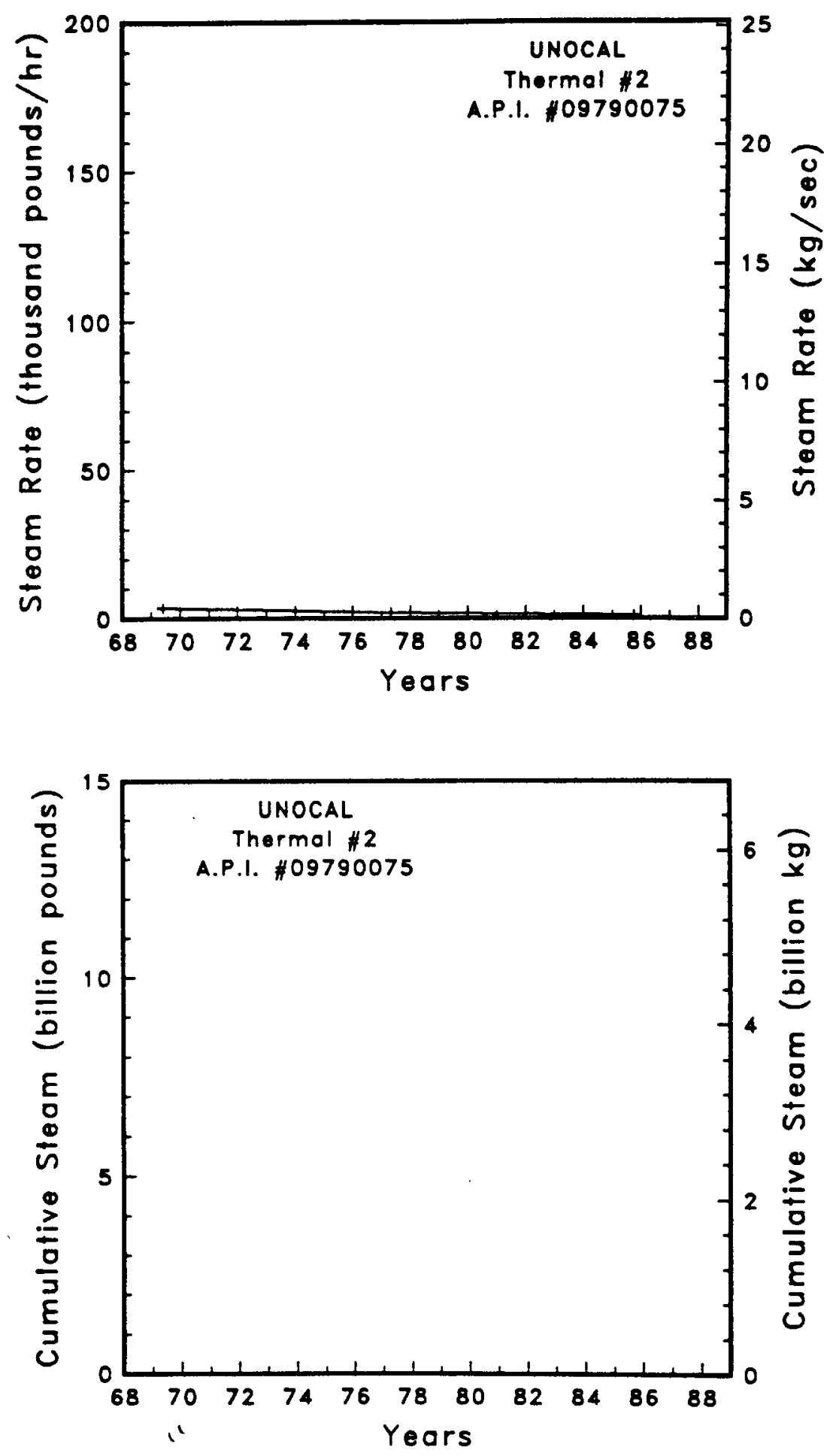

Figure A-227 $\begin{aligned} & \text { Steam rate and cumulative mass flow for } \\ & \text { well Thermol } \# 2\end{aligned}$ 

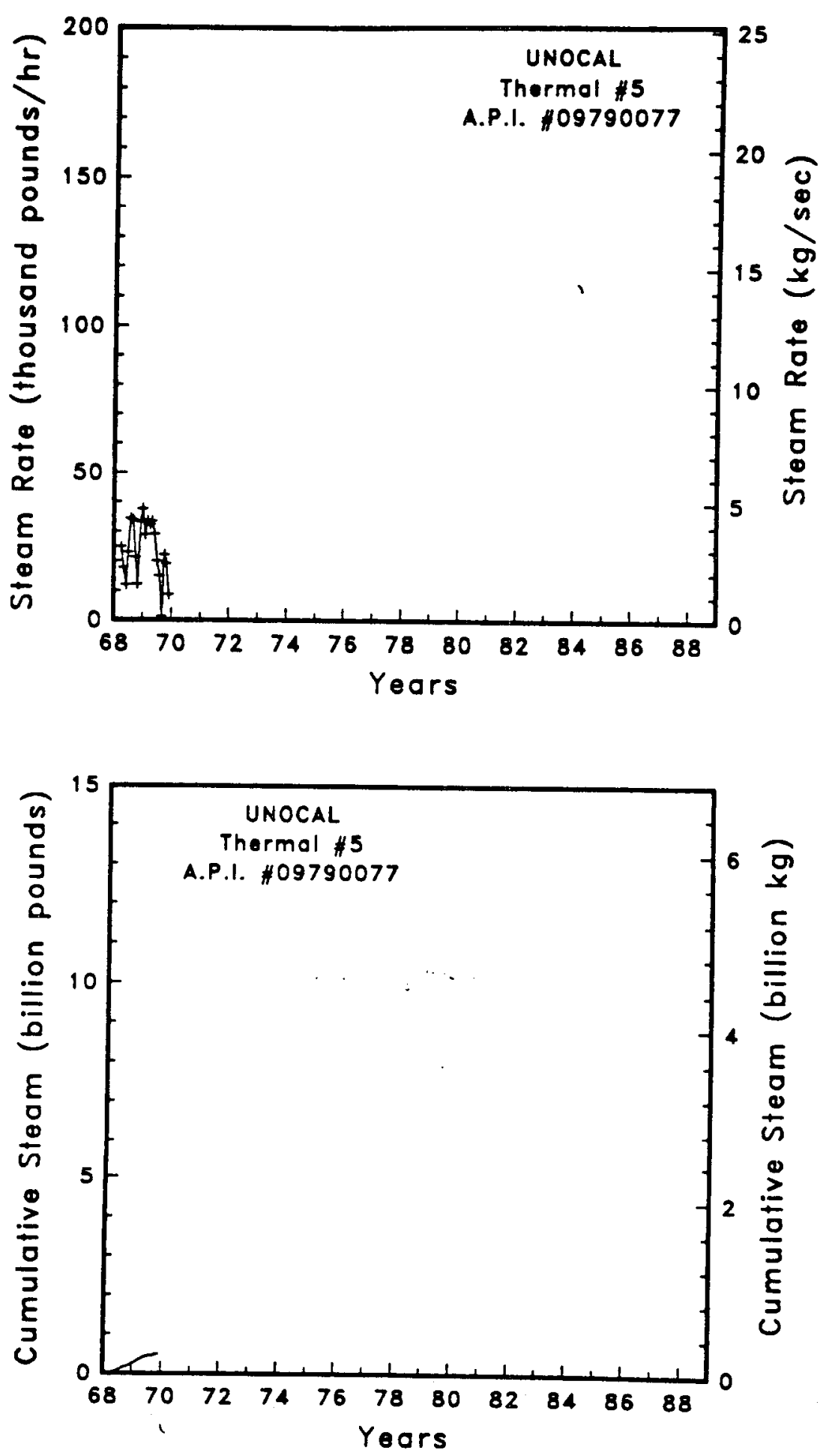

Figure A-228 Steam rate and cumulative mass flow for well Thermal \#5 

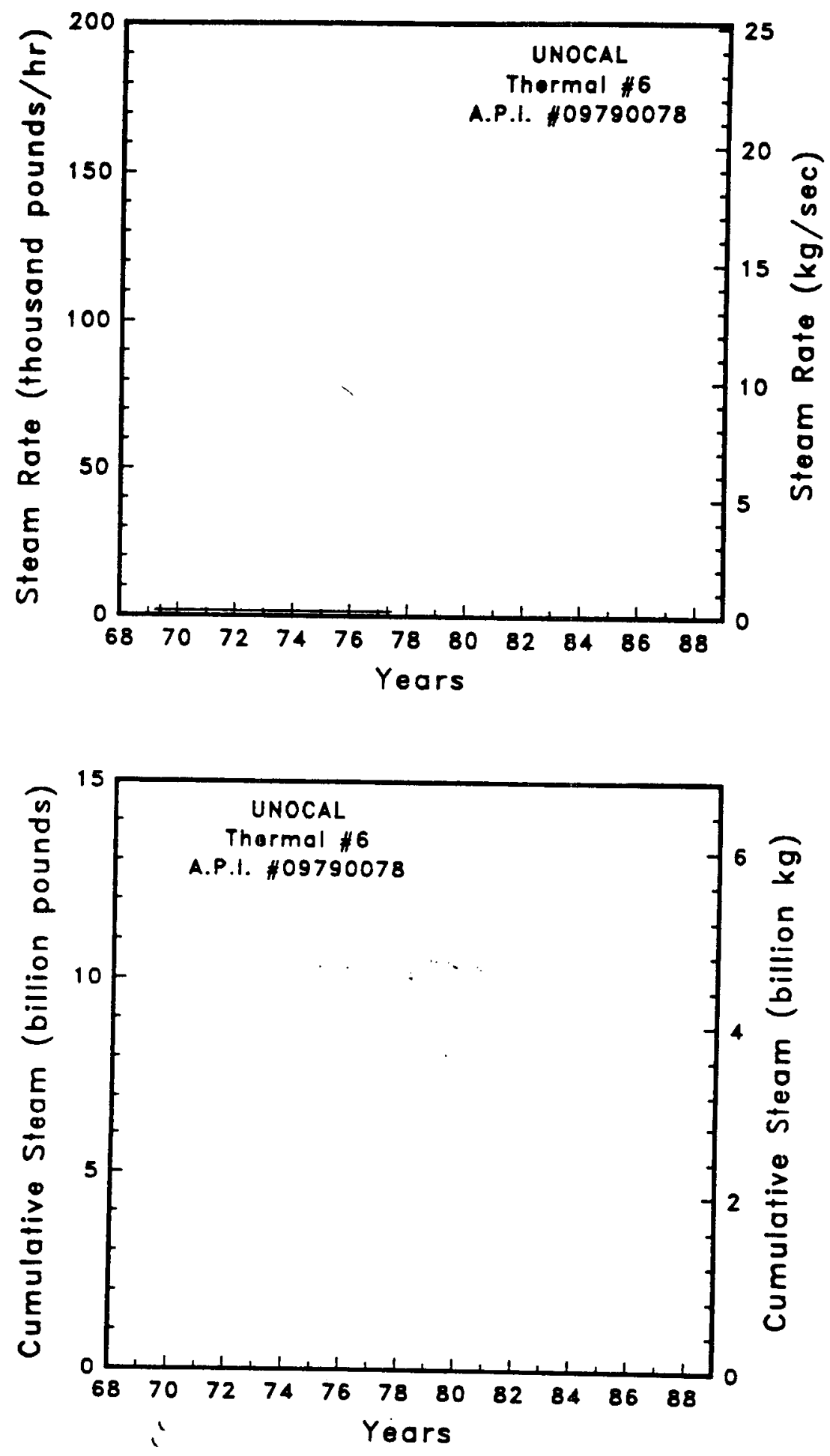

Figure A-229 Steam rate and cumulative mass flow for
well Thermal \#6 

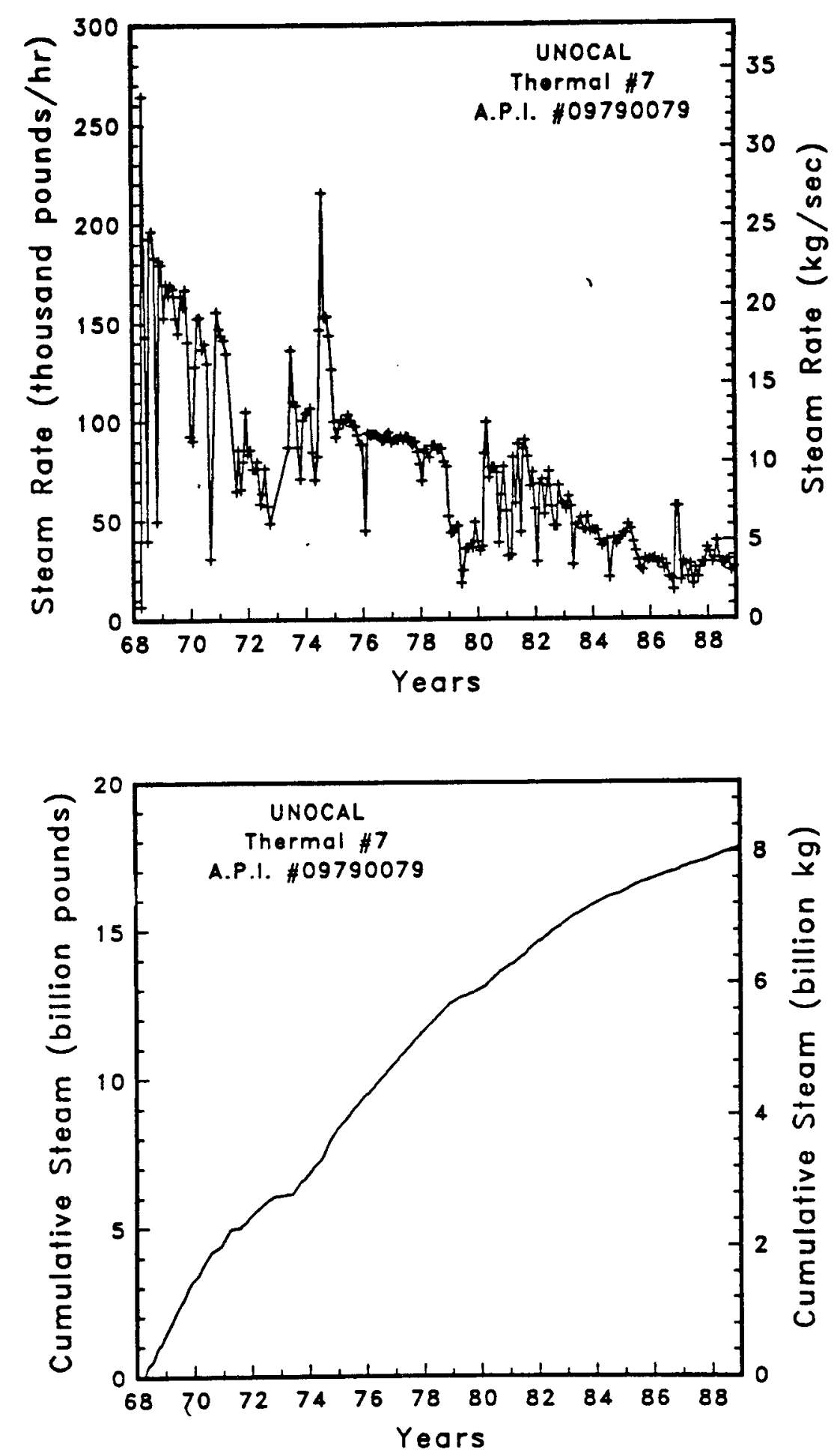

Figure A-230 Steam rate and cumulative mass flow for well Thermal \#7 

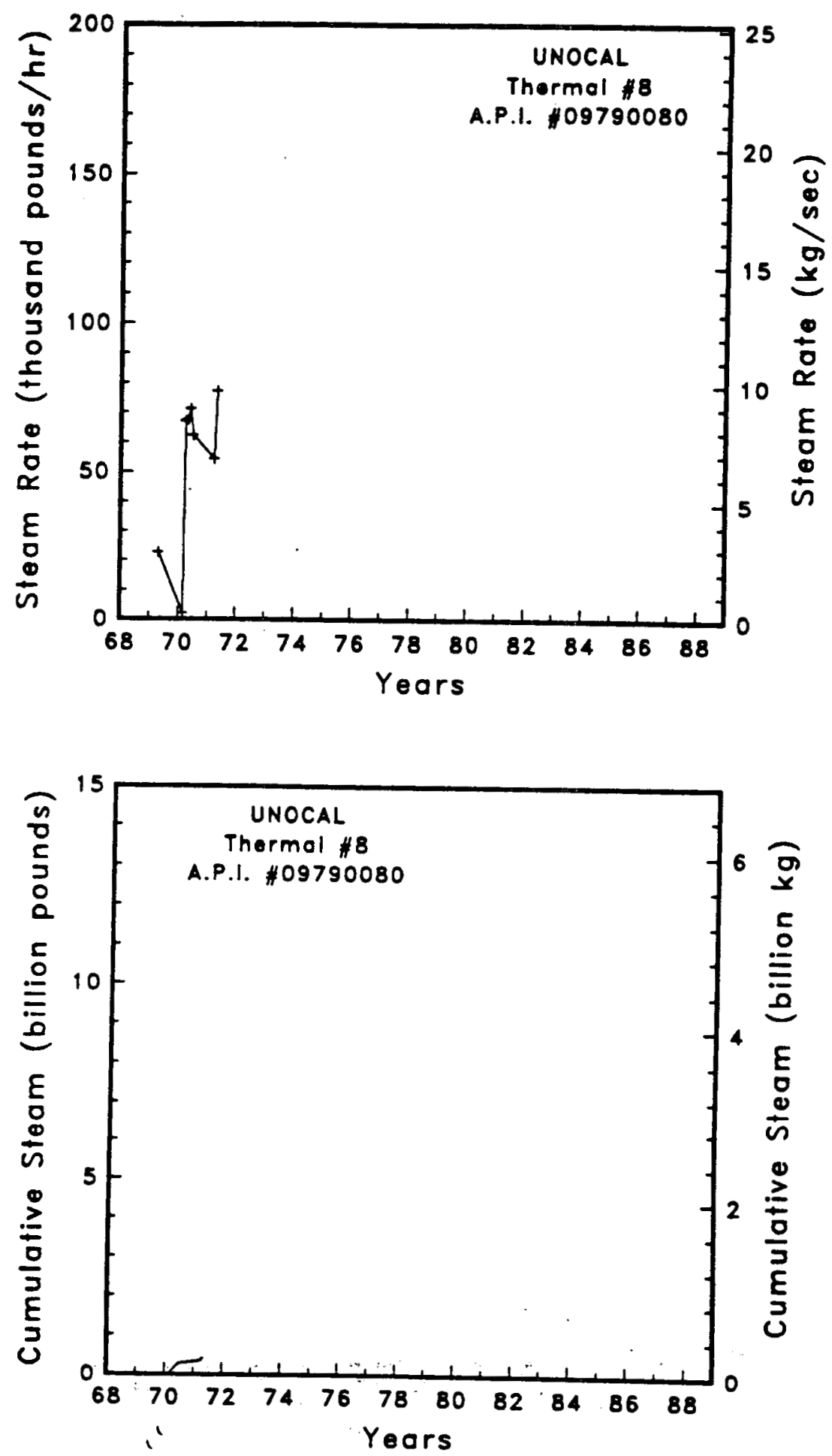

Figure A-231

Steam rate and cumulative mass flow for well Thermal \#8 

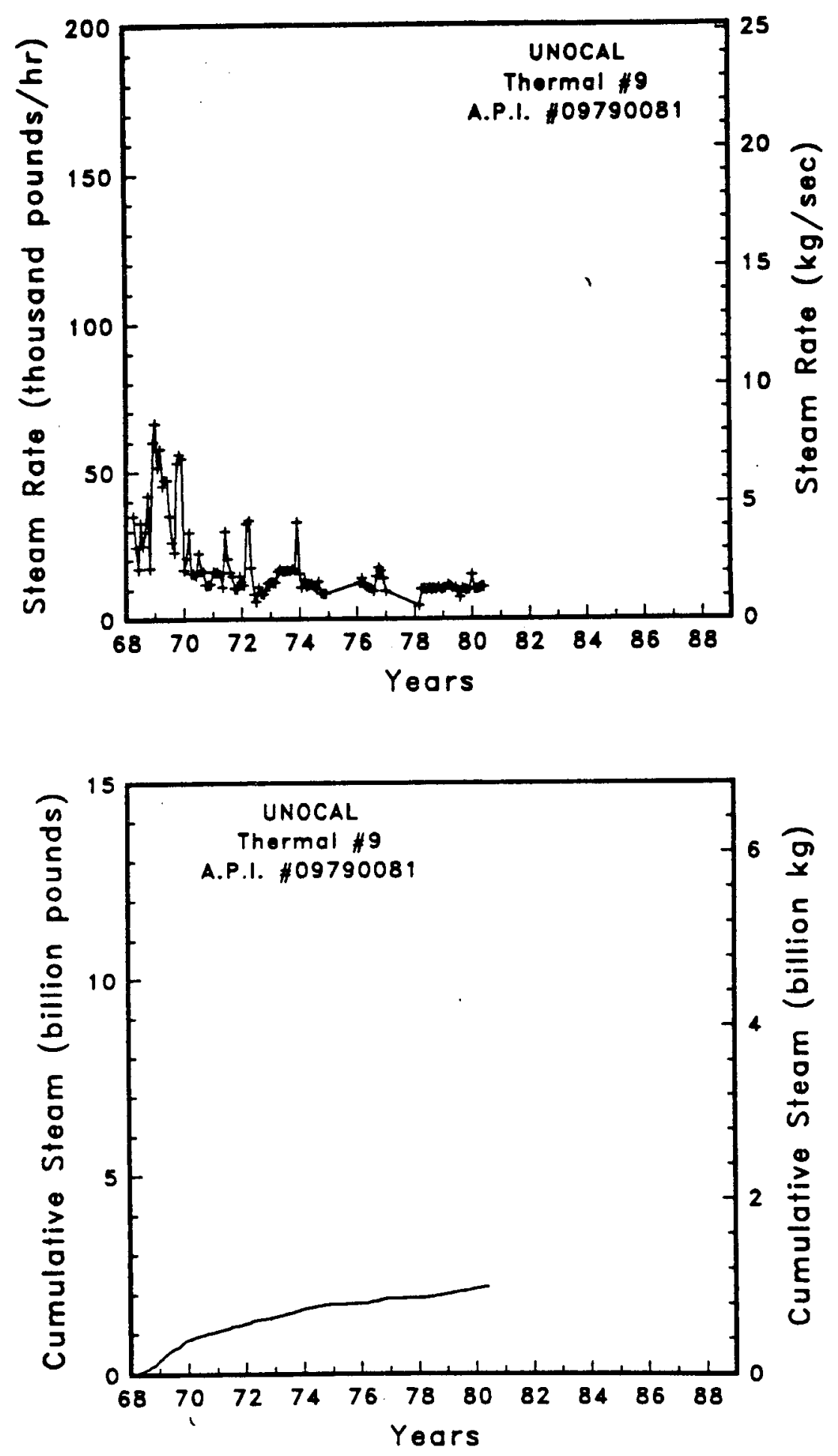

Figure A-232 Steam rate and cumulative mass flow for well Thermal \#9 

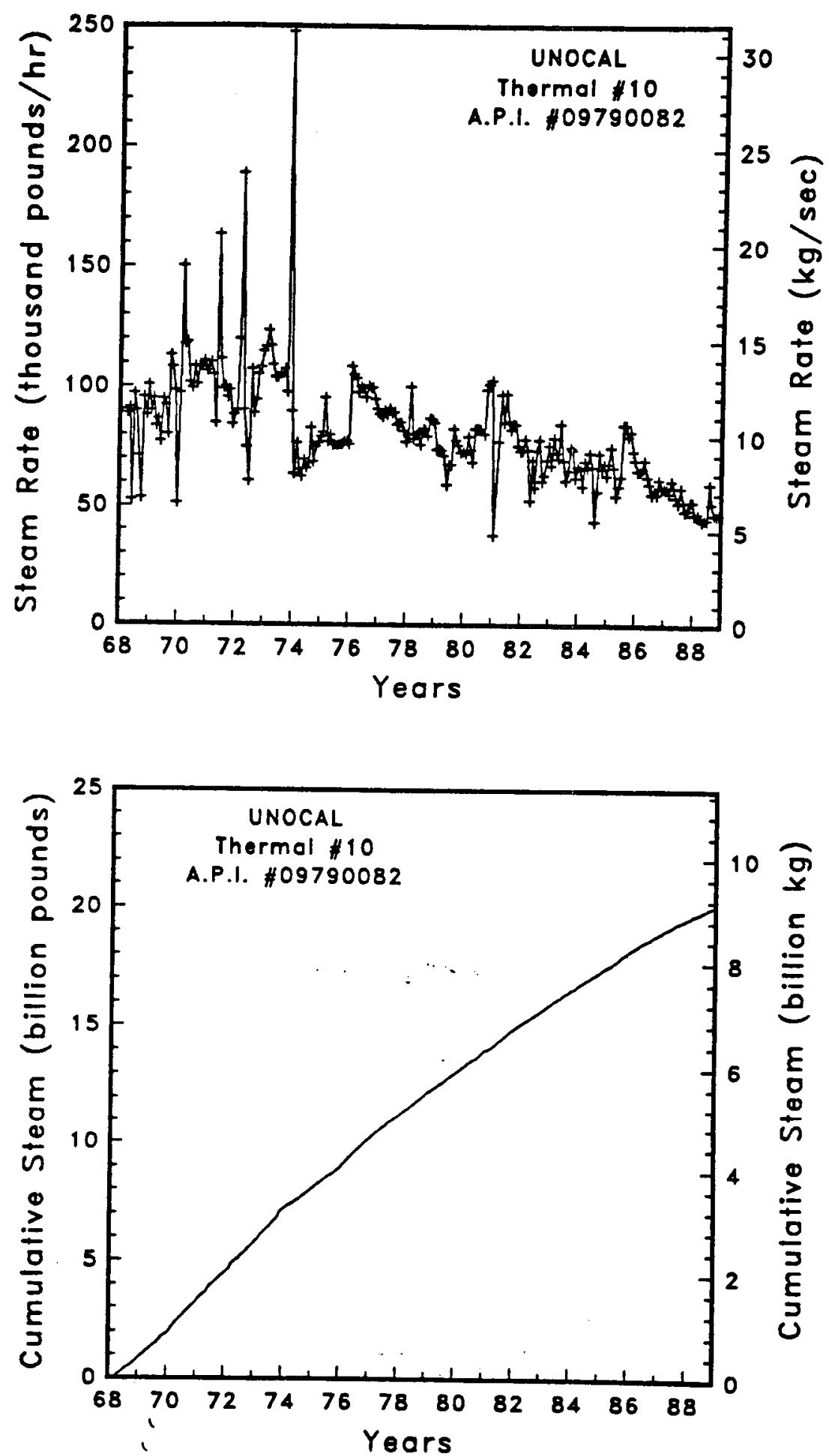

Figure A-233 Steam rate and cumulative mass flow for well Thermal \#10 

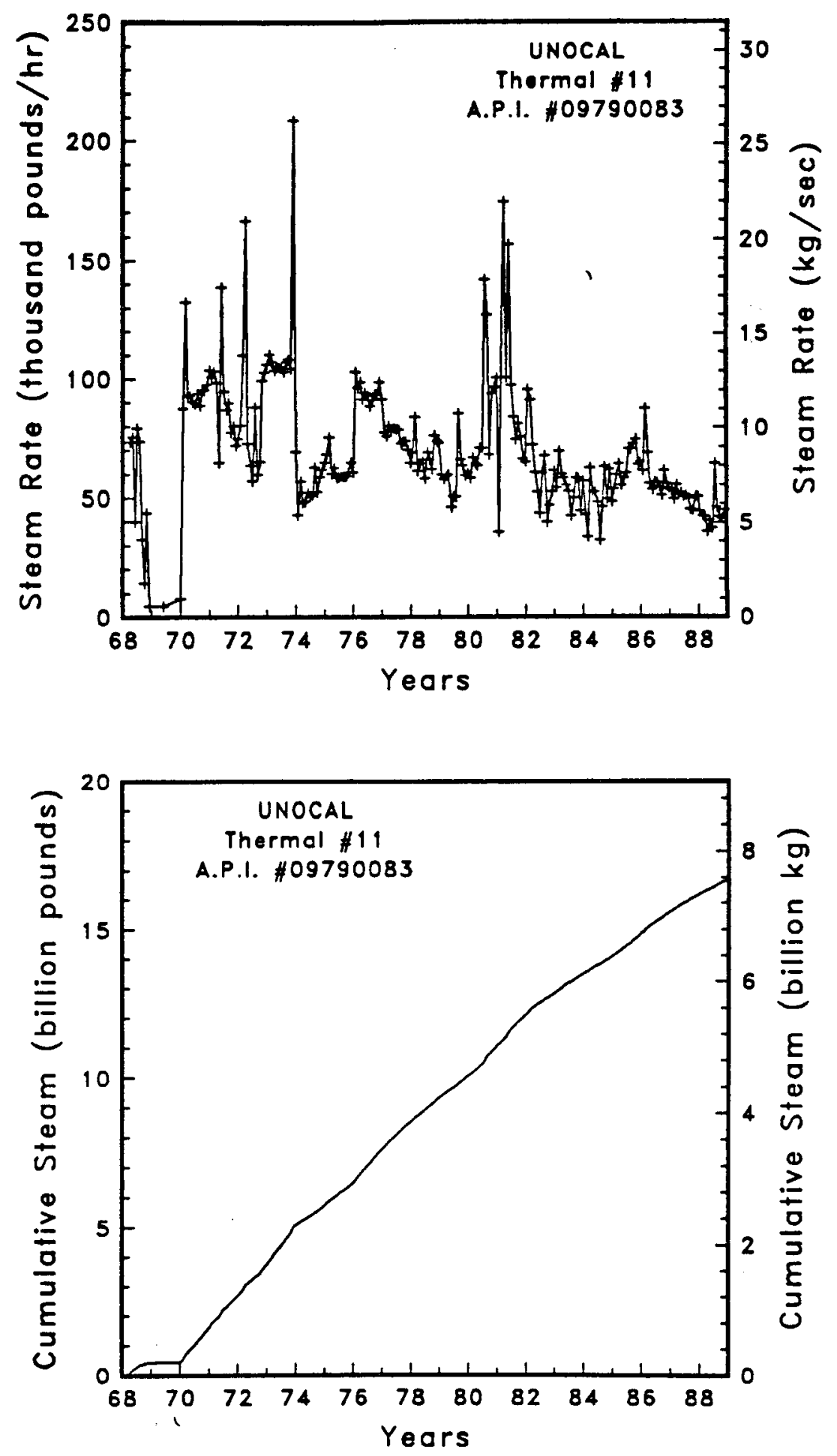

Figure A-234 Steam rate and cumulative mass flow for well Thermal \#11 

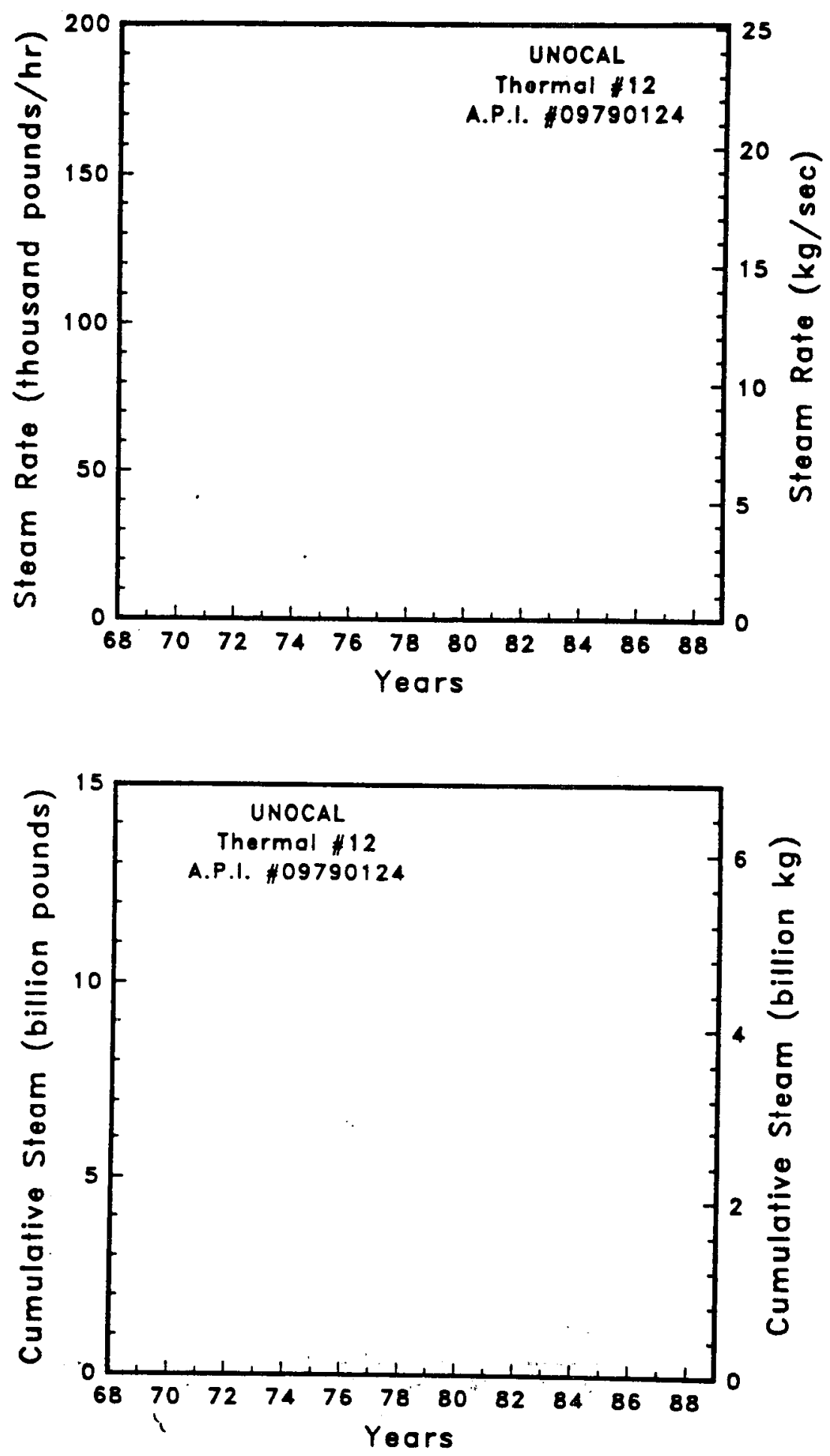
Figure A-235 $\begin{aligned} & \text { Steam rate and cumulative mass flow for } \\ & \text { well Thermol \#12 }\end{aligned}$ 

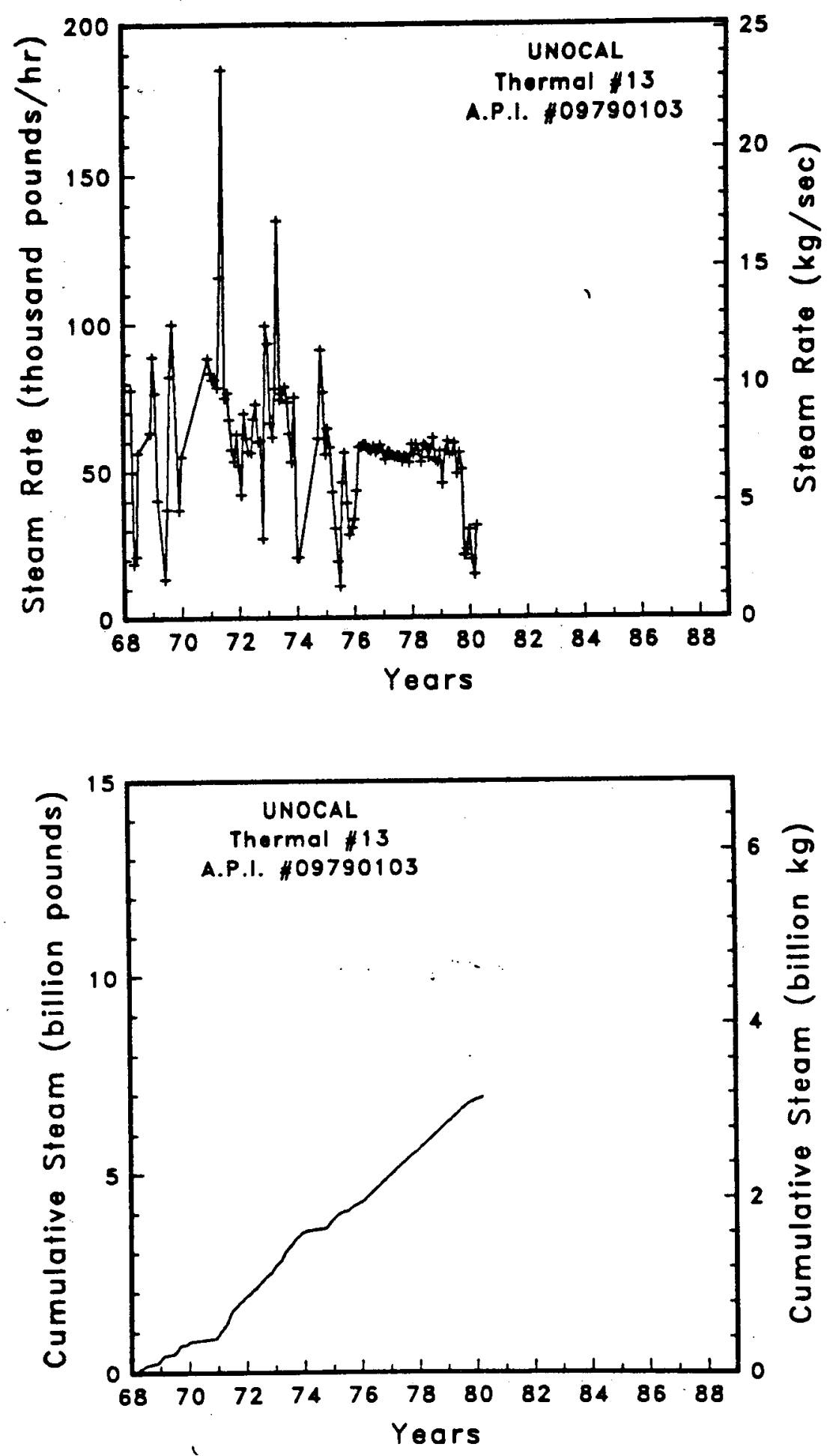
Figure A-236 $\begin{aligned} & \text { Steam rate and cumulative mass flow for } \\ & \text { well Thermal \#13 }\end{aligned}$ 

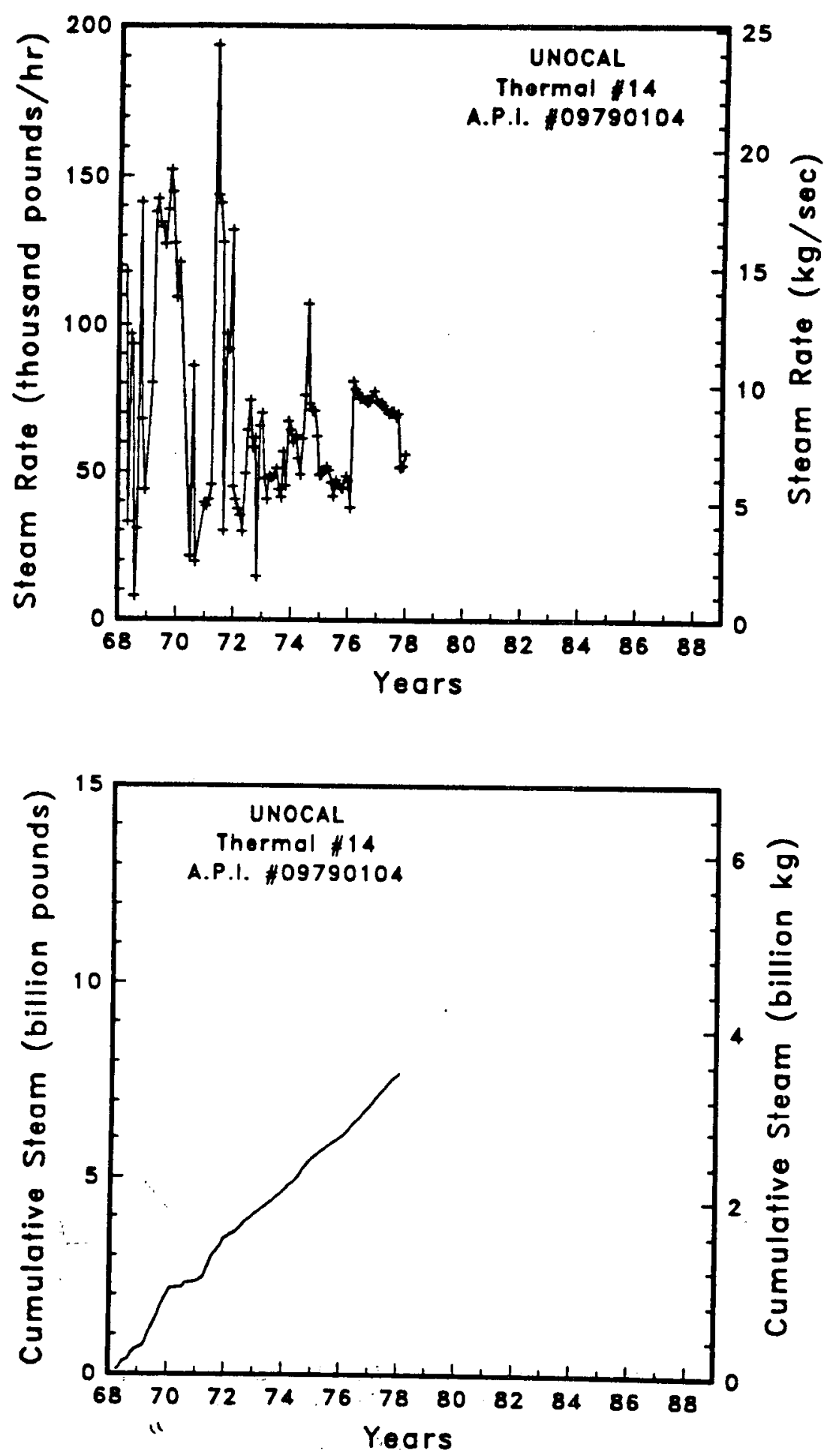

Figure A-237 Steom rate and cumulative mass flow for well Thermol \#14 

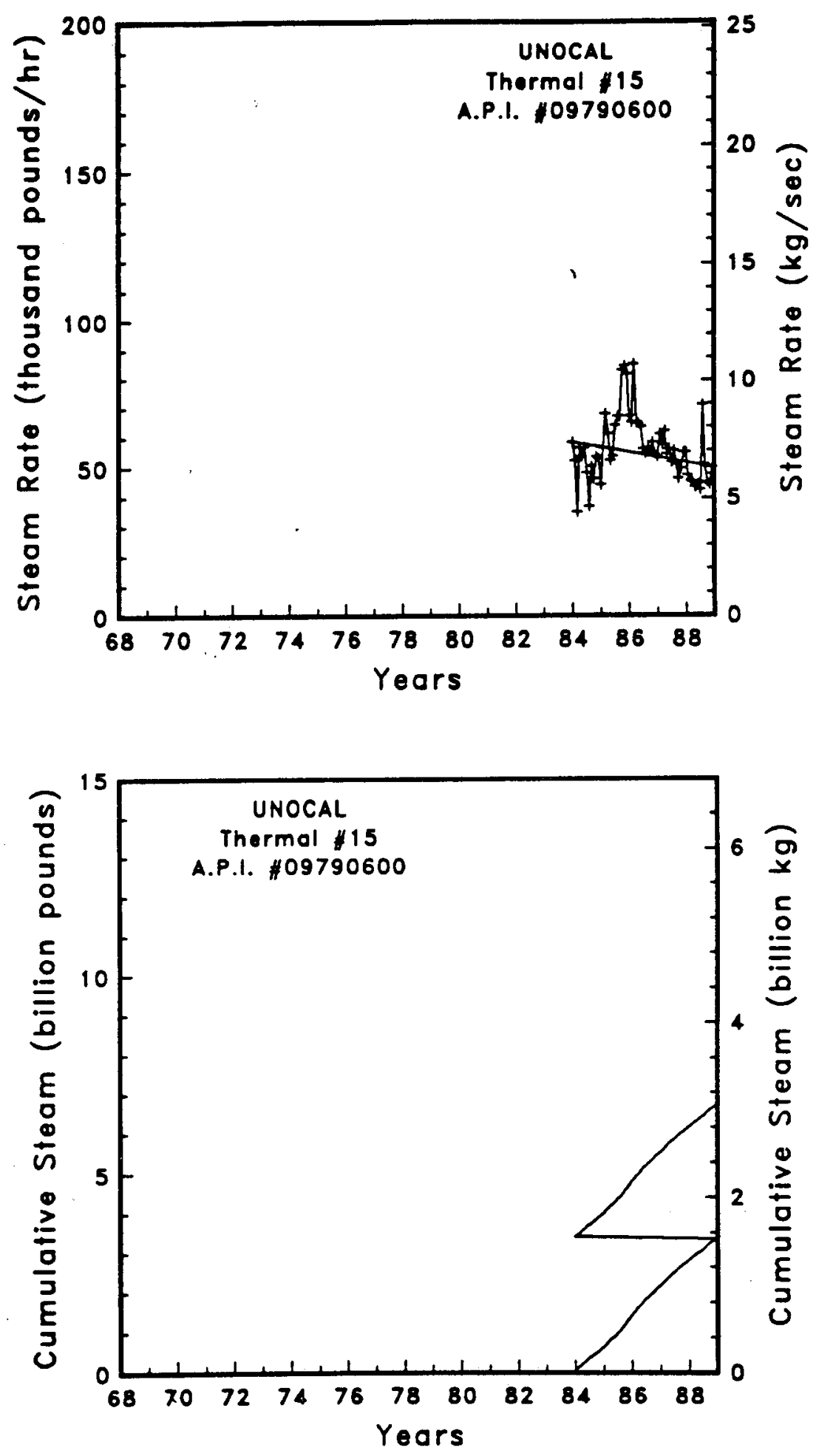

Figure A-238

Steam rate and cumulative mass flow for well Thermal \#15 

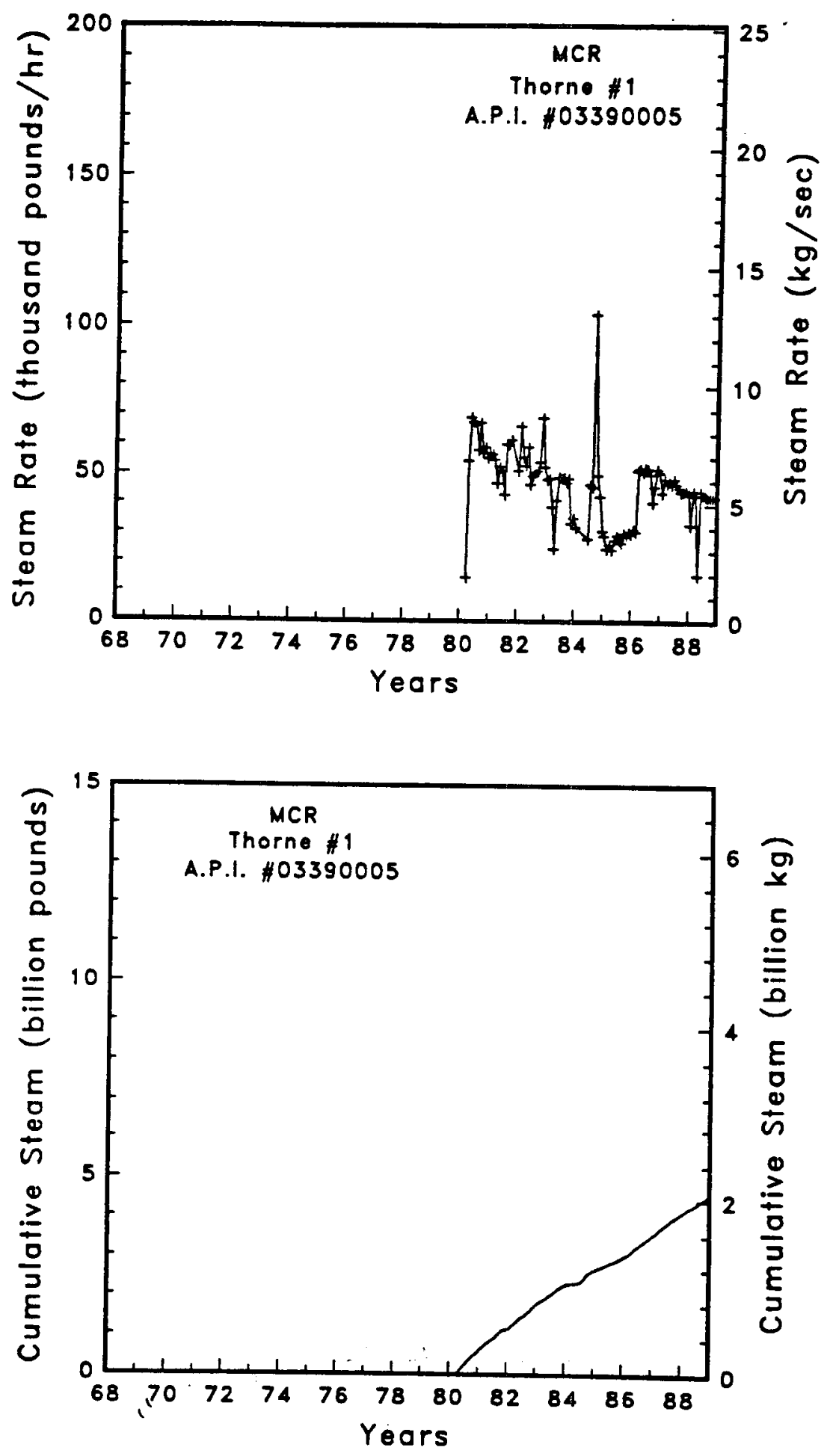

Figure A-239

Steam rate and cumulative mass flow for well Thorne \#1 

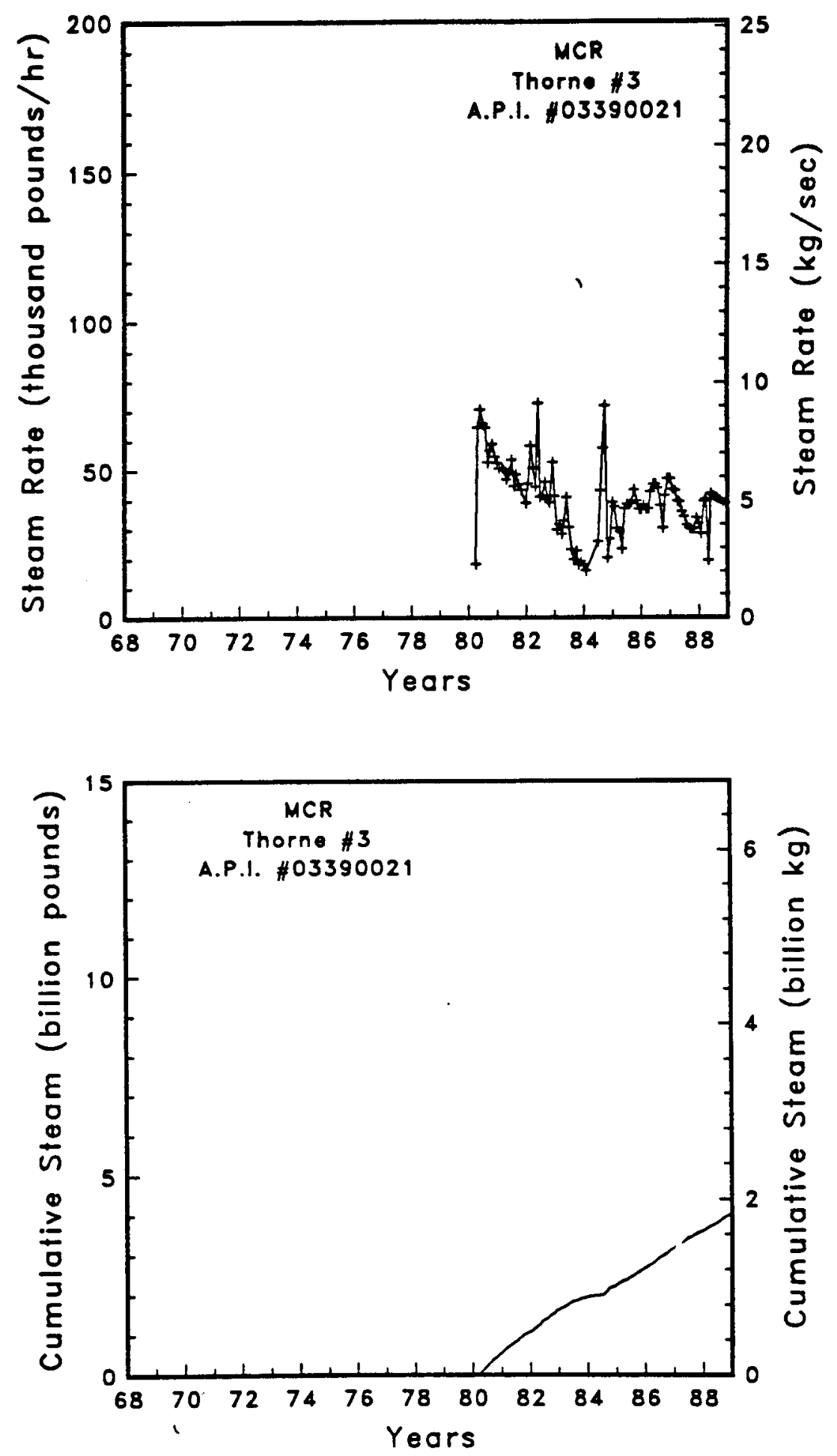

Figure A-240

Steam rate and cumulative mass flow for well Thorne \#3 

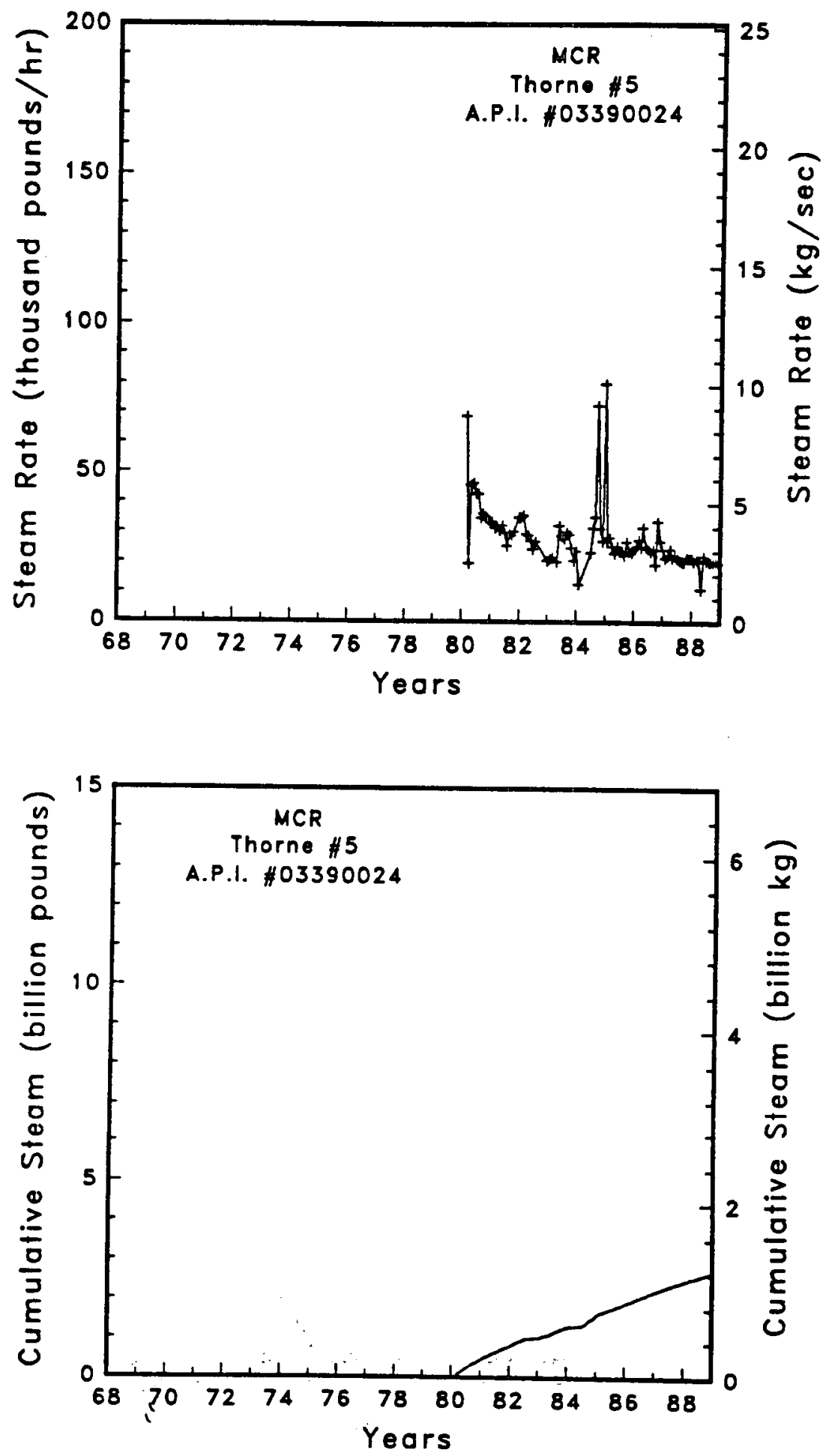

Figure A-241

Steam rate and cumulative mass flow for well Thorne \#5 

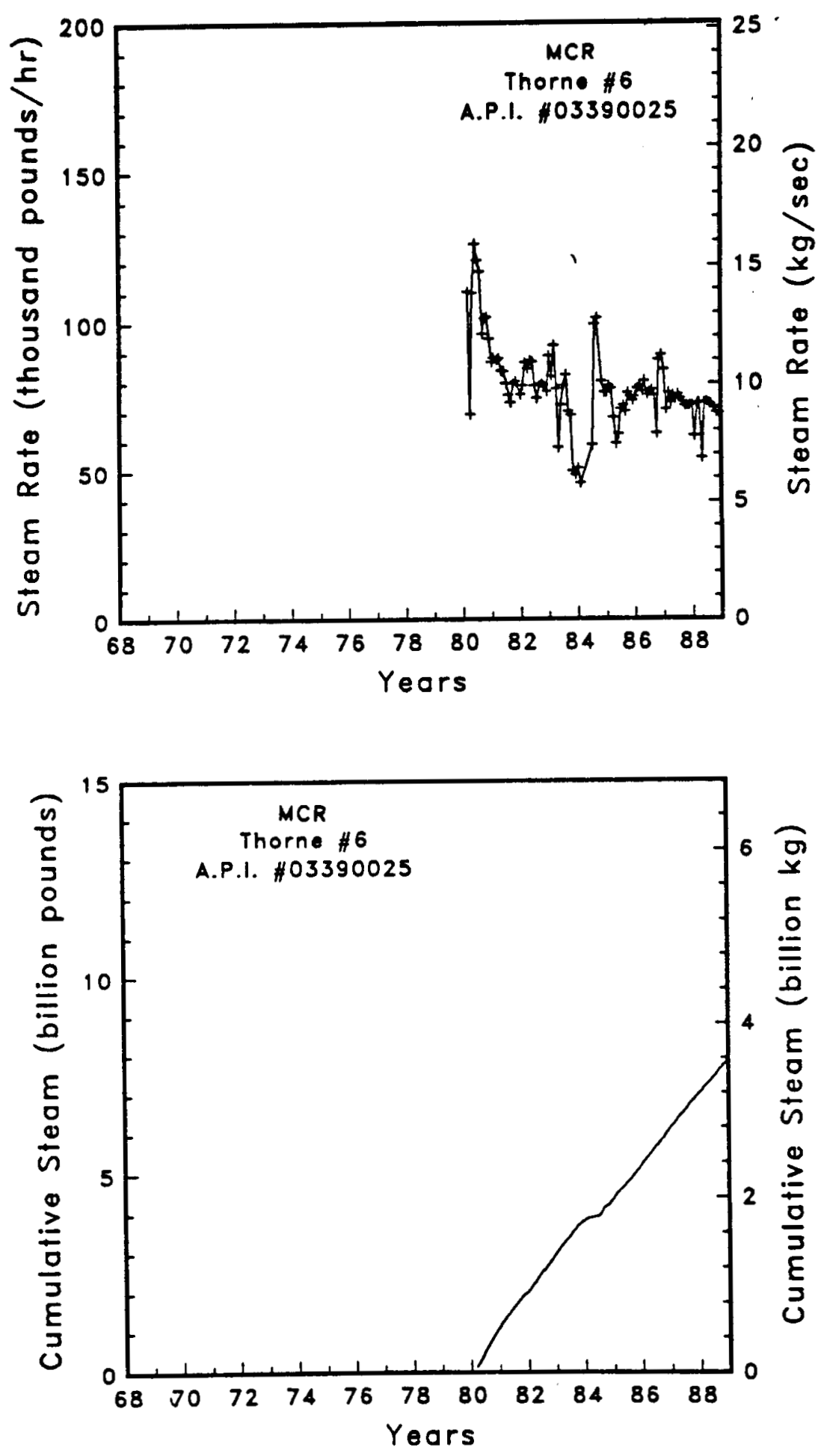

Figure A-242 Steam rate and cumulative mass flow for well Thorne \#6 

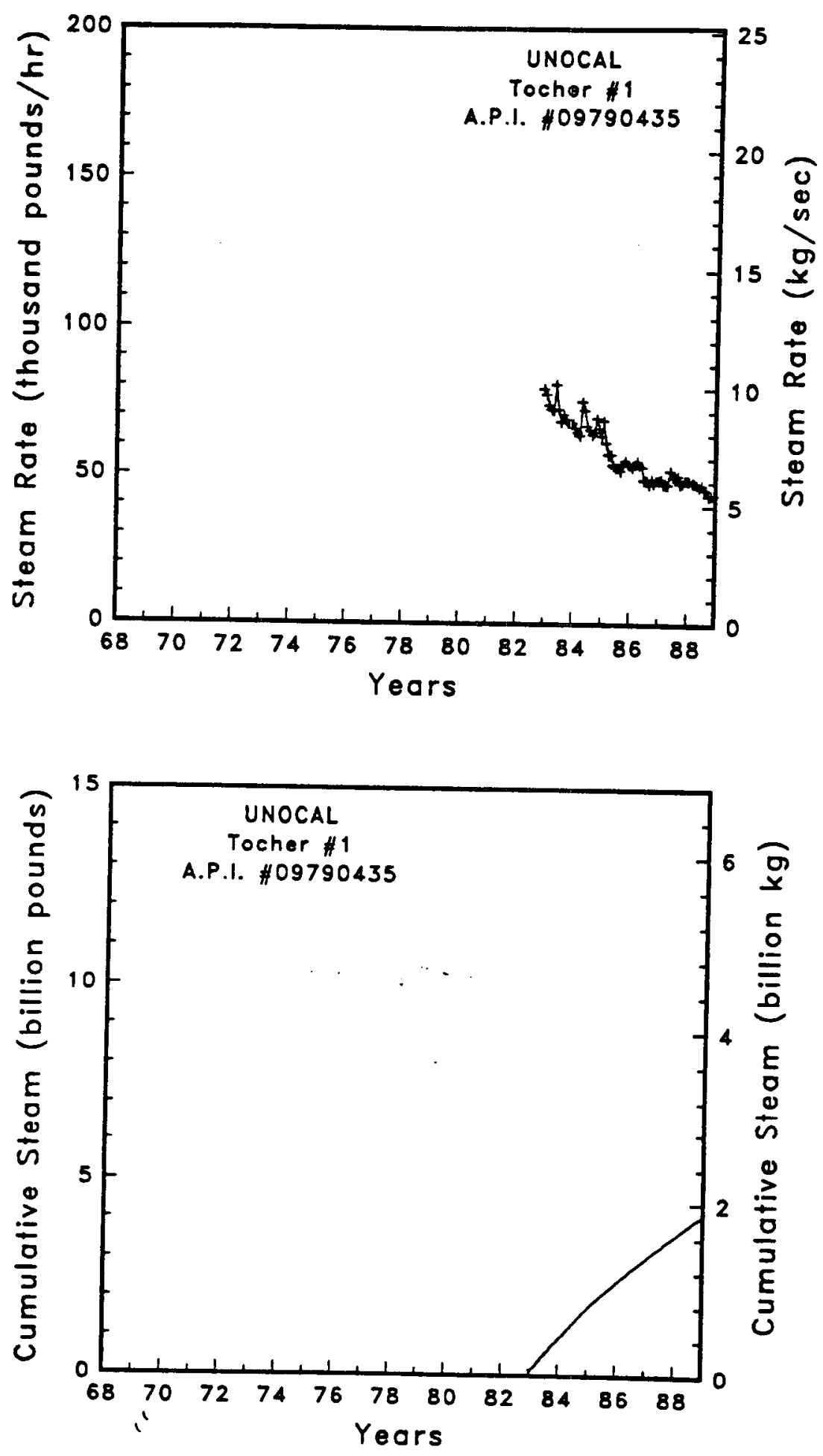
Figure A-243 $\begin{aligned} & \text { Steam rate and cumulative mass flow for } \\ & \text { well Tocher \#1 }\end{aligned}$ 

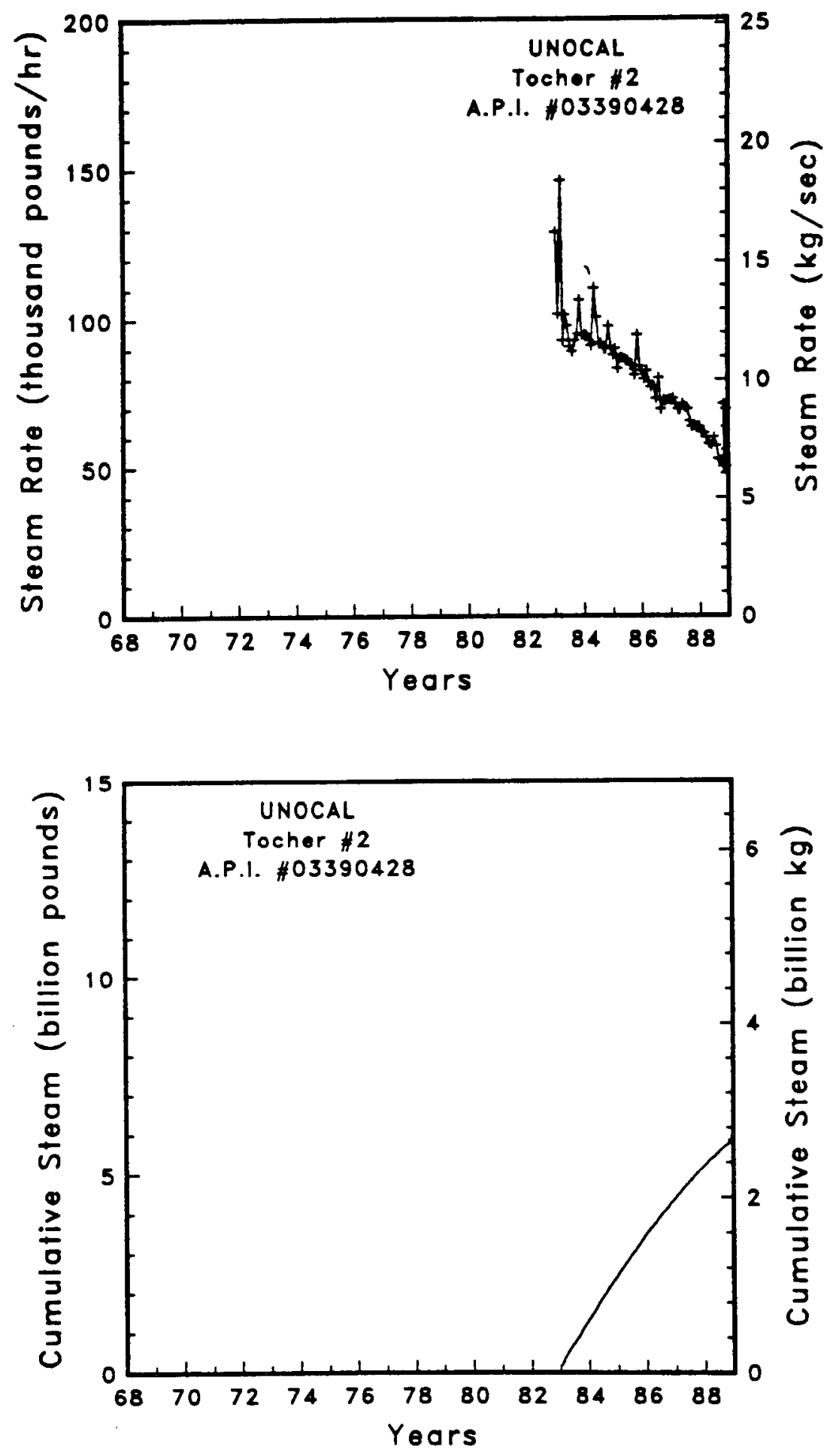

Figure A-244 Steam rate and cumulative mass flow for well Tocher \#2 

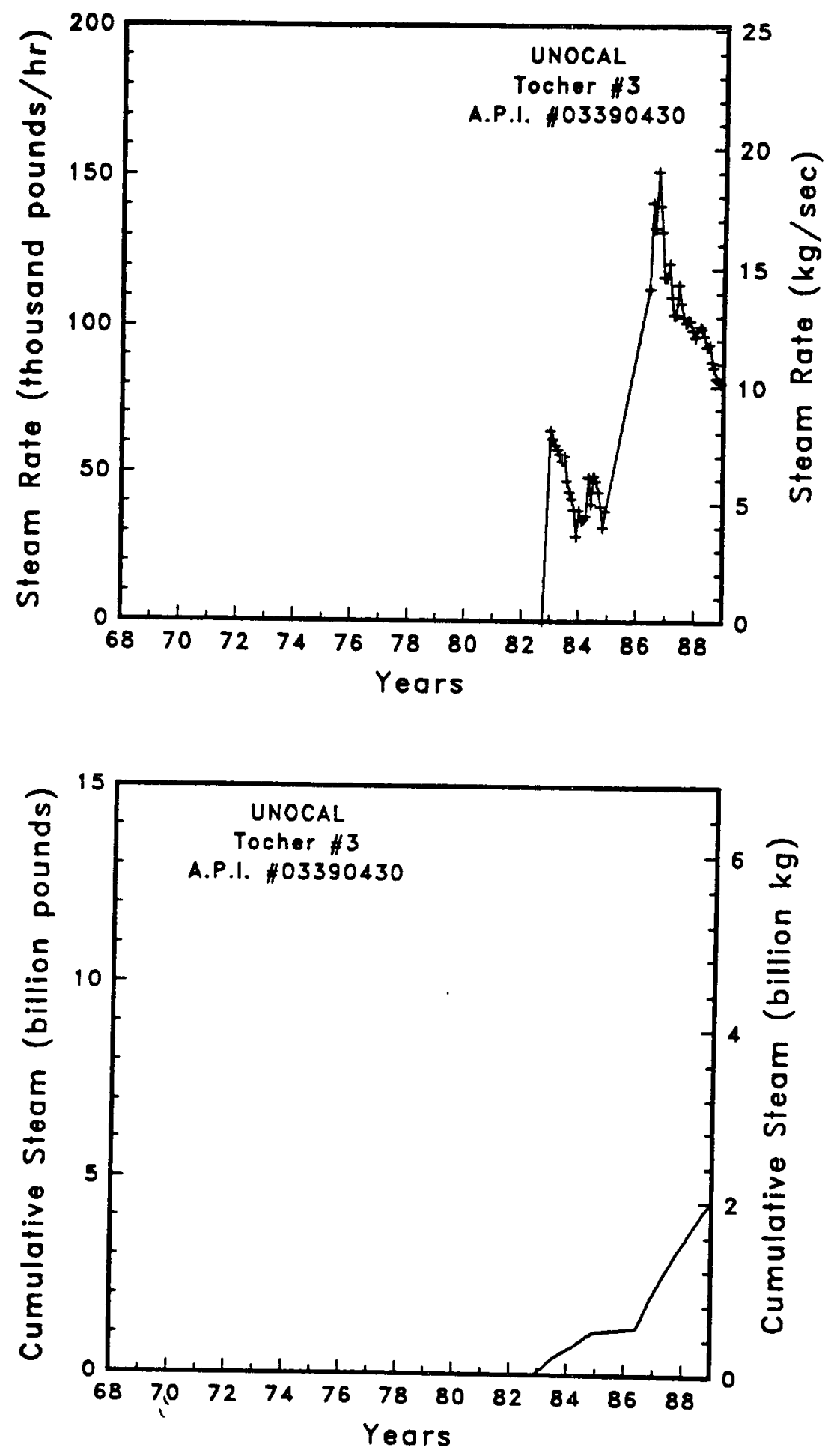

Figure A-245

Steam rate and cumulative mass flow for
well Tocher $\# 3$ 